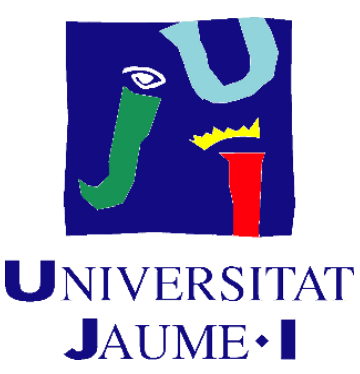

\title{
DEPOSICIÓN DE RECUBRIMIENTOS BIOACTIVOS MEDIANTE PROYECCIÓN TÉRMICA POR PLASMA A PARTIR DE DISTINTOS MATERIALES DE APORTE
}

Tesis doctoral presentada por

Eugeni Cañas Recacha

Directores

Dr. Enrique Sánchez Vilches

Dr. María José Orts Tarí

Castellón de la Plana, Enero 2021 



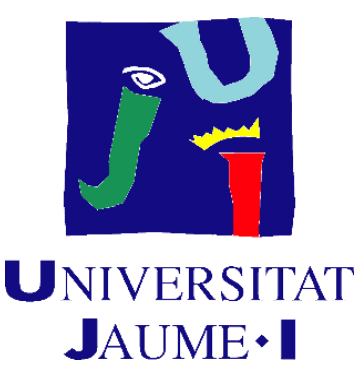

Programa de Doctorado en Tecnologías Industriales y Materiales

Escuela de Doctorado de la Universitat Jaume I

\section{DEPOSICIÓN DE RECUBRIMIENTOS BIOACTIVOS MEDIANTE PROYECCIÓN TÉRMICA POR PLASMA A PARTIR DE DISTINTOS MATERIALES DE APORTE}

Memoria presentada por Eugeni Cañas Recacha para optar al grado de doctor por la Universitat Jaume I

Doctorando:

Eugeni Cañas Recacha

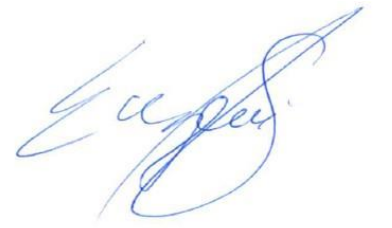

Directores:

Dr. Enrique Sánchez Vilches

Dr. María José Orts Tarí
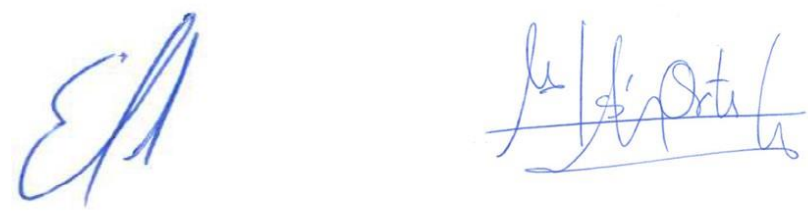

Dr. Enrique Sánchez Vilches, Catedrático de Ingeniería Química en la Universitat Jaume I y Dr. María José Orts Tarí, Profesora Titular de Ingeniería Química en la Universitat Jaume I.

CERTIFICAN: Que Eugeni Cañas Recacha ha realizado bajo su tutela y en el marco del programa de doctorado en Tecnologías Industriales y Materiales de la Universitat Jaume I, el trabajo que bajo el título "Deposición de recubrimientos bioactivos mediante proyección térmica por plasma a partir de distintos materiales de aporte" presenta en este documento y que constituye su tesis para optar al grado de Doctor en Tecnologías Industriales y Materiales.

$Y$ para que conste a los efectos oportunos, firman el presente certificado en Castellón de la Plana, Enero 2021.

\section{Dr. Enrique Sánchez Vilches}

Catedrático de Ingeniería Química

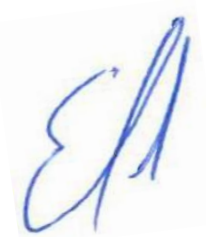

Dr. María José Orts Tarí

Profesora Titular de Ingeniería Química

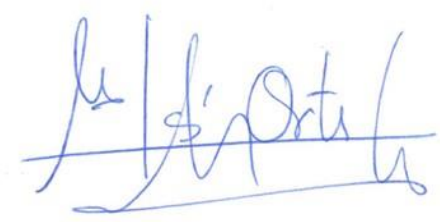





\section{Financiación recibida}

La realización de este trabajo de investigación ha sido posible gracias a la financiación aportada por la Universitat Jaume I (UJI), el Ministerio de Ciencia, Innovación y Universidades, la Sociedad Española de Cerámica y Vidrio (SECV) y The European Virtual Institute on Knowledge-based Multifunctional Materials AISBL (KMM-VIN). A continuación, se procede a detallar toda la financiación recibida.

- Contrato predoctoral de la Universitat Jaume I (Convocatoria 2015, Acción 3.1, ref.: PREDOC/2015/50), en el marco del Programa de soporte a la formación e incorporación de personal investigador de la misma universidad.

- Ayuda para estancia de investigación de la Universitat Jaume I en Institut de Recherche sur les Céramiques (IRCER), Limoges, Francia (Convocatoria 2018, Acción 2, ref.: E-2018-20), en el marco del Programa de movilidad del personal investigador de la misma universidad.

- Ayudas para estancia de investigación de The European Virtual Institute on Knowledge-based Multifunctional Materials AISBL (KMM-VIN) en Institute of Biomaterials (BioMat), Erlangen, Alemania (Convocatorias 2016 y 2018), en el marco de KMM-VIN Research Fellowship programme.

- Asistencia e inscripción a congresos, seminarios y cursos gracias a:

- Proyecto de investigación RECUBIO, "Desarrollo de nuevos recubrimientos bioactivos para prótesis e implantes por proyección térmica de plasma" (Convocatoria 2013, Acción 1.1, ref.: P1-1B2013-69), en el marco del Programa de fomento de proyectos de investigación de la Universitat Jaume I.

- Proyecto de investigación AUTOPLASMA, "Nuevas barreras térmicas con funcionalidad autosellante obtenidas mediante proyección por plasma" (Convocatoria 2015, Programa Estatal de I+D+i Orientada a los Retos de la Sociedad, ref.: MAT201567586-C3-1-R), en el marco del Plan Estatal de Investigación Científica y Técnica y de Innovación 2013-2016 del Ministerio de Ciencia, Innovación y Universidades.

- Proyecto de investigación AEROPLASMA, "Nuevos recubrimientos con propiedades aislantes basados en aerogeles proyectables por plasma" (Convocatoria 2017, Acción 1.1, ref.: UJI-B2017-77), en el marco del Programa de fomento de proyectos de investigación de la Universitat Jaume I. 
- Proyecto de investigación ACCESO, "Piezas y recubrimientos cerámicos avanzados de elevadas prestaciones térmicas y mecánicas a partir de disoluciones y suspensiones precursoras" (Convocatoria 2018, Programa Estatal de I+D+i Orientada a los Retos de la Sociedad, ref.: RTI2018-099033-B-C31), en el marco del Plan Estatal de Investigación Científica y Técnica y de Innovación 2017-2020 del Ministerio de Ciencia, Innovación y Universidades.

- Ayudas dirigidas a estudiantes de la Escuela de Doctorado de la Universitat Jaume I para la realización de actividades formativas (Convocatorias 2016 y 2017).

- Bolsas de viaje de la Sociedad Española de Cerámica y Vidrio (SECV). 


\section{Tesis por compendio de las siguientes publicaciones}

El presente trabajo de tesis doctoral se ha llevado a cabo mediante el compendio de diferentes publicaciones científicas en revistas indexadas de alto índice de impacto. A continuación, se detalla la relación de publicaciones recogidas en este trabajo.

- Autores: Eugeni Cañas, Mónica Vicent, Emilie Bannier, Pablo Carpio, María José Orts, Enrique Sánchez

Título: Effect of particle size on processing of bioactive glass powder for atmospheric plasma spraying

Revista: Journal of the European Ceramic Society

Volumen: $36 \quad$ Páginas: 837-845 Año: 2016

DOI: 10.1016/j.jeurceramsoc.2015.09.039

- Autores: Eugeni Cañas, Mónica Vicent, María José Orts, Rodrigo Moreno, Enrique Sánchez

Título: Bioactive glass suspensions preparation for suspension plasma spraying

Revista: Journal of the European Ceramic Society

Volumen: $36 \quad$ Páginas: 4281-4290 Año: 2016

DOI: 10.1016/j.jeurceramsoc.2016.06.011

- Autores: Eugeni Cañas, Mónica Vicent, María José Orts, Enrique Sánchez

Título: Bioactive glass coatings by suspension plasma spraying from glycolether-based solvent feedstock

Revista: Surface \& Coatings Technology

Volumen: 318 Páginas: 190-197 Año: 2017

DOI: 10.1016/j.surfcoat.2016.12.060

- Autores: Eugeni Cañas, María José Orts, Aldo R. Boccaccini, Enrique Sánchez

Título: Solution Precursor Plasma Spraying (SPPS): A novel and simple process to obtain bioactive glass coatings

Revista: Materials Letters

Volumen: 223 Páginas: 198-202 Año: 2018

DOI: 10.1016/j.matlet.2018.04.031

- Autores: Eugeni Cañas, Vicente Sanz, María José Orts, Enrique Sánchez

Título: Post-deposition heat treatment effect on microstructure of suspension plasma sprayed bioactive glass coatings

Revista: Surface \& Coatings Technology

Volumen: $371 \quad$ Páginas: 136-142

Año: 2019

DOI: 10.1016/j.surfcoat.2018.11.003 
- Autores: Eugeni Cañas, María José Orts, Aldo R. Boccaccini, Enrique Sánchez

Título: Microstructural and in vitro characterization of $45 \mathrm{~S} 5$ bioactive glass coatings deposited by solution precursor plasma spraying (SPPS) Revista: Surface \& Coatings Technology

Volumen: 371 Páginas: 151-160 Año: 2019

DOI: 10.1016/j.surfcoat.2018.12.057

- Autores: Eugeni Cañas, María Díaz, Carmen Alcázar, María José Orts, Rodrigo Moreno, Enrique Sánchez

Título: Comparison of different silica sources in the development of plasma sprayed $45 \mathrm{~S} 5$ bioactive glass coatings

Revista: Journal of Non-Crystalline Solids

Volumen: $544 \quad$ Páginas: 120164

Año: 2020

DOI: 10.1016/j.jnoncrysol.2020.120164

- Autores: Eugeni Cañas, Alina Grünewald, Rainer Detsch, María José Orts, Enrique Sánchez, Aldo R. Boccaccini

Título: In vitro study of bioactive glass coatings obtained by atmospheric plasma spraying

Revista: Boletín de la Sociedad Española de Cerámica y Vidrio

Volumen: - Páginas: - Año: 2020

DOI: 10.1016/j.bsecv.2020.06.004

Además, cabe resaltar que esta tesis dispone de la aceptación de los coautores de las publicaciones que el doctorando presenta como tesis y su renuncia expresa a presentarlas como parte de otra tesis doctoral. 
A mis padres y a Cristina 

AgradeCIMIENTOS 

Si estas leyendo estas palabras significa que un capítulo de mi vida, mi periodo como estudiante de doctorado, llega a su fin. En consecuencia, se deriva el presente trabajo de tesis doctoral, la realización del cual no hubiera sido posible sin la estimable ayuda y colaboración tanto de diferentes entidades como de amigos y compañeros. Por ello, me gustaría dedicarles unas palabras de agradecimiento.

Este trabajo se ha desarrollado mayoritariamente en los laboratorios del Instituto de Tecnología Cerámica (ITC) de la Universitat Jaume I (UJI), institución fruto del convenio entre esta misma universidad y la Asociación de Investigación de las Industrias Cerámicas (AICE). Por tanto, me gustaría agradecer al ITC el haberme facilitado todos los recursos y materiales de los que dispone para llevar a cabo mi formación como doctor.

También a mis directores de tesis el Dr. Enrique Sánchez y la Dr. María José Orts. Agradecerles en primer lugar la oportunidad que me han dado de trabajar con ellos y realizar juntos este trabajo de tesis doctoral, ya que con ellos he aprendido mucho y he crecido como persona. Además, agradecerles todos los consejos que me han dado y su disponibilidad en cualquier momento para ayudarme con cualquier cosa.

A mis compañeros del grupo de investigación en proyección térmica. A Pablo Carpio por ayudarme desde mi llegada al grupo, por compartir conmigo todo su conocimiento sobre proyección térmica y haber estado siempre apoyándome y preocupándose. A Mónica Vicent por toda su ayuda y por sacar siempre tiempo para escuchar mis problemas y revisar mis trabajos, y a Emilie Bannier por sus sugerencias. Tampoco puedo olvidarme de Víctor Carnicer y Fernando Martínez, las últimas incorporaciones al grupo, a los que agradezco toda la ayuda prestada en el laboratorio y buenos momentos.

A la empresa Fritta S.A., por su colaboración en la síntesis del polvo de vidrio bioactivo aportando tanto materiales como infraestructura.

A Hakima Belkadi, Florentina Nita, Davide Borghi y Sergio Gómez, los estudiantes que han trabajado conmigo, no solo por la realización de ensayos y la ayuda prestada en el laboratorio sino también por ayudarme a crecer y mejorar como persona.

A Sonia Sales y Ana López por su apoyo, sus consejos y su gran ayuda tanto en el laboratorio como en la realización de esta memoria.

A los compañeros María José Sánchez, Lola Palacios, Angel de la Dedicación, Paula Agut, Sandra Chamorro y Javier Castellano, Yolanda Bautista y Adriana Belda por abrirme siempre las puertas de su laboratorio, permitiéndome utilizar cualquier recurso que necesitara, y por estar dispuestos a ayudar en todo siempre con una sonrisa. Agradecerles los consejos y buenos momentos en los almuerzos.

También a Magda Lorente y Maricarmen Bordes por estar siempre dispuestas a ayudarme a aclarar cualquier duda o pregunta sobre el funcionamiento de la 
escuela de doctorado y la burocracia relacionada con este trabajo de tesis, además del interés mostrado en este trabajo de tesis. A María José Vicente, Rosa Pérez, Marisa Soriano, Paqui Quereda y Alejandro Saburit agradecerles las materias primas prestadas y toda la ayuda y colaboración en algunos de los ensayos realizados en el laboratorio.

A las compañeras Mํa Pilar Gómez, Julia Toledo, Eulalia Zumaquero, Jessica Gilabert, Eva María Díaz y Fátima Vélez de Guevara, por el interés mostrado en este trabajo, sus consejos y buenos momentos en el despacho. También a Silvia Arrufat y Encarna Blasco, agradecerles todo lo que me han enseñado en cuanto a microscopía y preparación de muestra, y toda la ayuda prestada.

A David Lores, pues su ayuda ha sido vital durante el proceso de montar este documento y cuadrar el formato.

Al Dr. Rodrigo Moreno, la Dr. María Dolores Salvador y la Dr. Amparo Borrell, siempre dispuestos a prestar ayuda y colaborar. Además, agradecerles el apoyo y los buenos momentos en todos los congresos que hemos asistido juntos.

To Prof. Boccaccini and Prof. Ageorges for all their collaboration allowing me to carry out research stays in their institutes and everything they have taught me about biomaterials and plasma spraying.

To Julia, Daniela, Irem, Maria Angela and Maria Laura, my "german family", for all the support given in the lab and the amazing trips. Furthermore, thanks to them my stay in Germany was fantastic.

A Óscar, Germán y Norberto por el trabajo de laboratorio en Limoges y todo lo que me han enseñado.

Finalmente, pero no menos importante, me gustaría agradecer a mis padres todo su apoyo y confianza, el haberme dado la oportunidad de estudiar una carrera, de llegar hasta donde estoy y valorar mi esfuerzo y resultados. Pero, sobre todo, gracias a Cristina pues me embarqué en este proyecto por ella. Gracias por estar siempre a mi lado, por escucharme, darme consejos, siempre animarme a seguir adelante, no dejar que me rinda y hacerme sentir capaz de hacer cualquier cosa.

A todos ellos, incluso aquellos que hayan colaborado y he olvidado mencionar, muchas gracias. 


\section{ÍNDICE}



Resumen

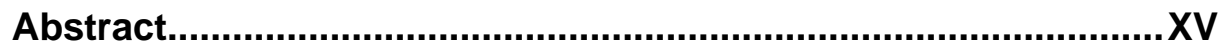

Resum

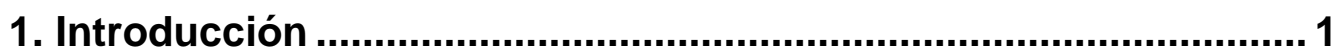

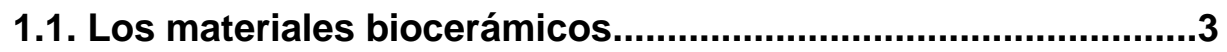

1.1.1. Descripción y alcance ……....................................................... 3

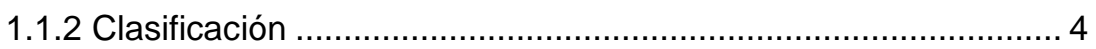

1.1.3. Recubrimientos a partir de materiales biocerámicos ................. 8

1.2. Los vidrios bioactivos............................................................

1.2.1. Descripción y composición ...................................................... 9

1.2.2. Métodos de obtención ......................................................... 10

1.2.3. Propiedades del vidrio bioactivo 45S5 .................................. 12

1.2.4. Reacción con tejidos y fluidos corporales ............................... 14

1.2.5. Composiciones de vidrios bioactivos ...................................... 15

1.2.6. Aplicaciones de los vidrios bioactivos ..................................... 19

1.3. La proyección térmica...........................................................20

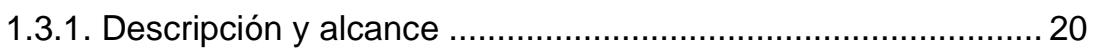

1.3.2. Proyección térmica por plasma atmosférico o APS .................. 26

1.3.3. Parámetros de la técnica de proyección por plasma

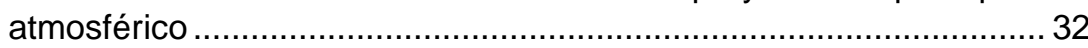

1.4. Proyección térmica por plasma a partir de materiales de aporte

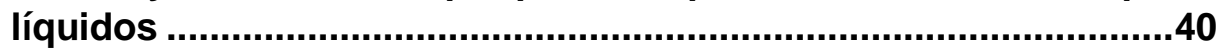

1.4.1. Clasificación y obtención de materiales de aporte líquidos ..... 40

1.4.2. Requisitos y control de los materiales de aporte líquidos ........ 44

1.4.3. Proyección térmica por plasma de materiales de aporte

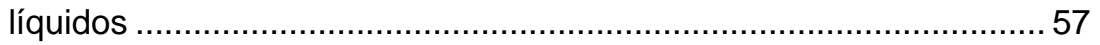

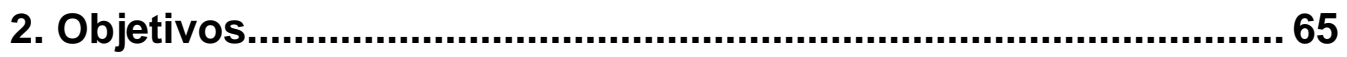

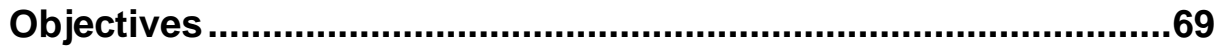

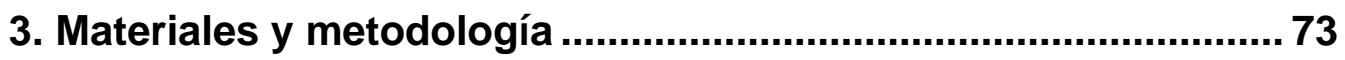

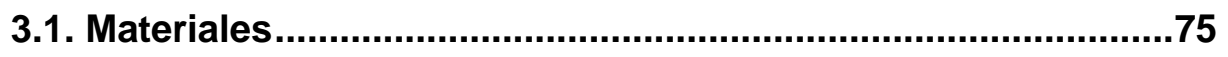

3.1.1. Polvo de vidrio bioactivo 45S5 …......................................... 75

3.1.2. Suspensión de partículas de vidrio bioactivo $45 \mathrm{~S} 5$.................. 88 
3.1.3. Soluciones precursoras de vidrio bioactivo $45 \mathrm{~S} 5$ 94

3.2. Deposición de recubrimientos bioactivos mediante proyección térmica por plasma .......................................................................97

3.2.1. Tipo y adecuación del sustrato ................................................99

3.2.2. Descripción del sistema de proyección utilizado....................... 99

3.2.3. Condiciones de proyección para cada material de aporte ..... 101

3.3. Caracterización de los recubrimientos obtenidos 104

3.3.1. Caracterización microestructural ........................................... 104

3.3.2. Adherencia de los recubrimientos .......................................... 105

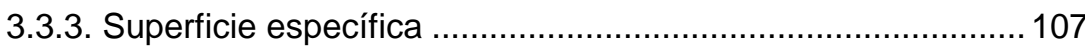

3.3.4. Estudio de la bioactividad................................................... 107

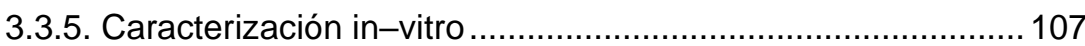

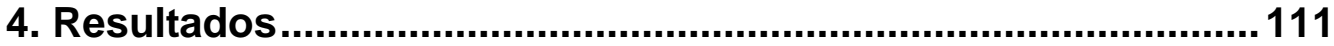

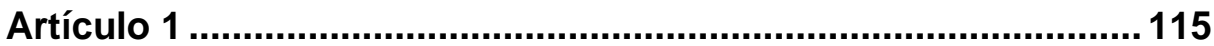

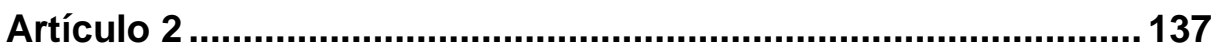

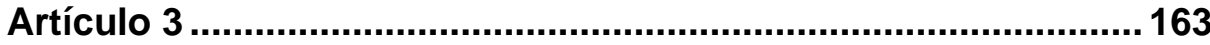

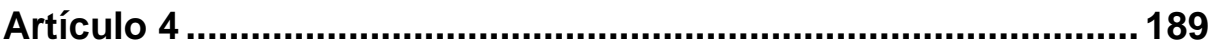

Artículo 5 ...................................................................................... 211

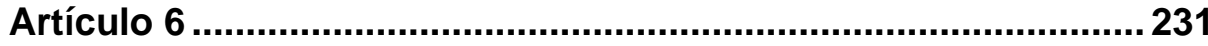

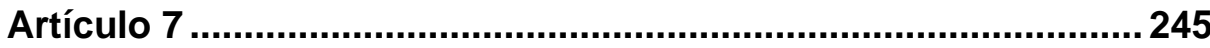

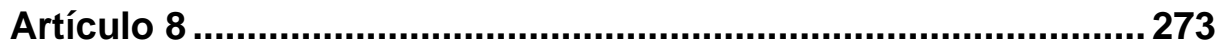

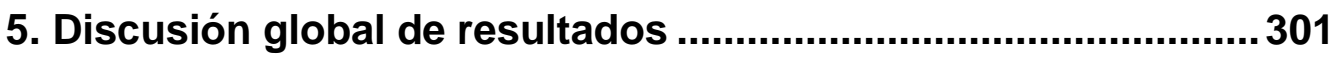

5.1. Adecuación de los polvos de vidrio bioactivo .......................303

5.2. Adecuación de las suspensiones de vidrio bioactivo........... 304

5.3. Adecuación de las soluciones de precursores de vidrio

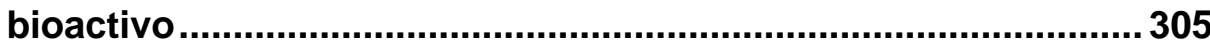

5.4. Efecto del material de aporte en la microestructura resultante 306

5.5. Efecto del material de aporte en las propiedades mecánicas y biológicas del recubrimiento 


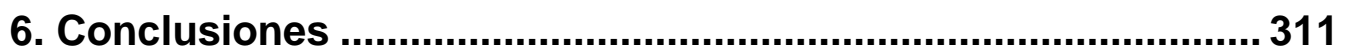

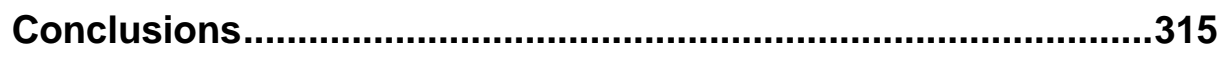

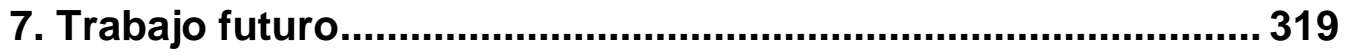

8. Difusión de resultados ............................................................. 323

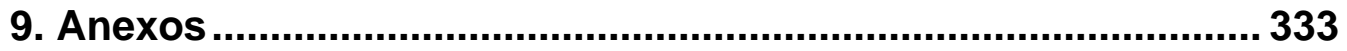

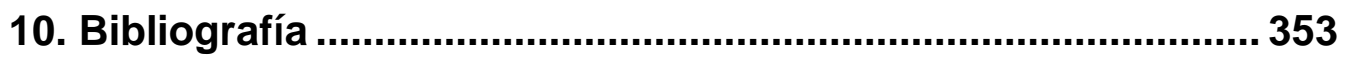



RESUMEN 

Cada vez hay más avances en nuestro entorno que fomentan que la calidad y esperanza de vida aumente. Como consecuencia, la implantación de prótesis metálicas en el cuerpo humano ha aumentado considerablemente. De hecho, hay más de 50 millones de personas en todo el mundo que llevan una prótesis implantada.

Estas prótesis, destinadas a aplicaciones ortopédicas, han ido evolucionando con el tiempo. Inicialmente se fabricaban de acero inoxidable (AISI 304 y AISI 316), más adelante surgieron de aleaciones de cromo-cobalto y, finalmente, se empezó a estudiar el titanio y aleaciones de este elemento como material para elaboración de prótesis. Actualmente, la mayoría de las prótesis implantadas en aplicaciones ortopédicas están compuestas de aleación de titanio de grado 5, también conocida como Ti6Al4V. Una vez implantadas las prótesis, el problema radica en que son inertes, pues no reaccionan o interactúan en gran medida con el entorno biológico. Debido a esto, el cuerpo humano genera un tejido fibroso, encapsulando dichas prótesis y en muchas ocasiones las rechaza. Para paliar este problema, la práctica más común es recubrir estas prótesis con un biomaterial, que es un material adecuado para su empleo e implantación en el cuerpo humano, puesto que puede estar en contacto con tejidos vivos reaccionando positivamente con estos tejidos. De esta forma, se obtiene un composite que combina excelentes propiedades mecánicas (debido al soporte metálico) con excelentes propiedades biológicas (debido al recubrimiento biocompatible).

Desde hace varias décadas, a nivel clínico se están implantando prótesis con un recubrimiento de hidroxiapatita depositado mediante proyección térmica por plasma. Se trata de un material cerámico bioactivo que, debido a su composición similar a la fase mineral del hueso humano, biocompatibilidad y osteoconductividad, es muy utilizado en reparación y reconstrucción de aquellas partes del sistema musculoesquelético dañadas o enfermas. Sin embargo, durante el proceso de proyección por plasma, parte de la hidroxiapatita depositada funde parcial o totalmente, tornándose amorfa o en fases cristalinas distintas. Estas nuevas fases, amorfas y/o cristalinas afectan negativamente a la bioactividad del recubrimiento final. Por ello, recientemente se ha comenzado a estudiar los vidrios bioactivos como sustitutos de la hidroxiapatita en la deposición de estos recubrimientos. Tanto los vidrios bioactivos como la hidroxiapatita son biocompatibles y poseen propiedades mecánicas similares, aunque los vidrios presentan mayor bioactividad que la hidroxiapatita.

En consecuencia, el presente trabajo se enfoca en la deposición de recubrimientos a partir de vidrios bioactivos mediante proyección térmica por plasma. Tras la síntesis de un vidrio bioactivo de composición definida, éste se ha molturado vía seca y se ha tamizado para obtener un material pulverulento con una distribución de tamaños de partícula dada (primer material de aporte para la proyección). Además, parte de este polvo se ha molturado en medio líquido para desarrollar una suspensión estable de partículas de vidrio bioactivo (segundo material de aporte). De forma paralela, en base al método sol-gel 
para la obtención de vidrios, se han seleccionado los precursores necesarios para alcanzar la composición del vidrio sintetizado inicialmente y se han disuelto en medio acuoso para desarrollar una solución de precursores (tercer material de aporte a la proyección).

Los tres materiales de aporte se han depositado mediante proyección térmica por plasma modificando diferentes parámetros relativos tanto al material de aporte y al equipo de proyección, como al estado del sustrato. Los recubrimientos resultantes se han caracterizado microestructural $y$ mecánicamente, y se ha determinado su bioactividad mediante su inmersión en fluido biológico.

Tras el análisis de los recubrimientos obtenidos, se ha observado que la textura y microestructura de éstos depende en gran medida de utilizar un material de aporte pulverulento o un material de aporte líquido (suspensiones y soluciones), y a su vez, estas diferencias microestructurales repercuten en las propiedades mecánicas y biológicas de los recubrimientos resultantes. Asimismo, las condiciones de proyección estudiadas para cada tipo de material también juegan un papel importante en la microestructura obtenida. Sin embargo, a pesar de las diferencias observadas, mediante el uso de los tres materiales de aporte es posible obtener recubrimientos con una buena adherencia al sustrato y una elevada bioactividad. 
ABSTRACT 

Progresses are being made in our environment that encourage quality and life expectancy to increase. As a result, the implantation of metal prostheses in the human body has risen considerably. In fact, there are more than 50 million people around the world who have an implanted prosthesis.

These prostheses, intended for orthopaedic applications, have been evolving over time. Initially, they were made of stainless steel (AISI type 304 and AISI type 316). Then, cobalt-chromium alloys emerged and finally, titanium and its alloys began to be studied for processing prostheses. Nowadays, most implanted prostheses are made of grade 5 titanium alloy, also known as Ti6Al4V. Once implanted, the problem lies in the fact that the prostheses are inert, since they do not react nor interact to a great extent with the biological environment. Consequently, the body generates a fibrous tissue around the prostheses, encapsulating them and often rejecting them. To solve this drawback, the most common solution is to coat the protheses with a biomaterial, a material suitable to be used and implanted inside the human body, since it can be in contact with living tissues positively reacting with them. In this way, a composite is obtained, which combines excellent mechanical and biological properties (due to the metallic substrate and the biocompatible coating respectively).

For several decades, prostheses with a plasma sprayed hydroxyapatite coating have been implanted at clinical level. This is a bioactive ceramic material, widely used in the repair and reconstruction of those parts of the musculoskeletal system that are damaged or diseased due to its composition similar to the mineral phase of the human bone, biocompatibility and osteoconductivity. However, during the coating manufacture, part of the hydroxyapatite partially or totally melts, becoming amorphous or in different crystalline phases. These new, amorphous and/or crystalline phases negatively affect the bioactivity of the final coating. Thus, bioactive glasses have recently started to be studied as substitutes for hydroxyapatite in the deposition of these coatings. Both bioactive glasses and hydroxyapatite are biocompatible and have similar mechanical properties, although the glasses are more bioactive than hydroxyapatite.

Therefore, the present work deals with the manufacture of plasma sprayed coatings from bioactive glasses. After synthesising a bioactive glass with a determined composition, it has been dry-milled and sieved to obtain a powder with a specific particle size distribution (first feedstock). Moreover, some of this powder has been wet-milled to synthesise a stable bioactive glass particle suspension (second feedstock). Parallel to that, based on the sol-gel method for glass synthesis, appropriate precursors have been selected to reach the composition of the synthesised glass before. The precursors have been dissolved in aqueous medium to produce a precursor solution (third feedstock).

The three feedstocks have been deposited by plasma spraying, modifying different spraying parameters relating both to the feedstocks and spraying facility, and to the state of the substrate. The manufactured coatings have been 
microstructural and mechanically characterised, and their bioactivity has been determined by immersion in biological fluid.

After analysing the obtained coatings, it has been observed that their texture and microstructure depend to a large extent on the use of a powder or liquid (suspensions and solutions) feedstock, and in turn, these microstructural differences have an impact on the mechanical and biological properties of the resulting coatings. Similarly, the spraying conditions studied for each type of material also play an important role in the microstructure obtained. However, despite the differences observed, by using all three feedstock materials it is possible to obtain coatings with good adhesion to the substrate and high bioactivity. 


\section{RESUM}



Cada vegada hi ha més avanços en el nostre entorn que fomenten que la qualitat i esperança de vida augmente. Com a conseqüència, la implantació de pròtesis metàl-liques en el cos humà ha augmentat considerablement. De fet, hi ha més de 50 milions de persones a tot el món que porten una pròtesi implantada.

Aquestes pròtesis, destinades a aplicacions ortopèdiques, han anat evolucionant amb el temps. Inicialment es fabricaven d'acer inoxidable (AISI 304 i AISI 316), més endavant van sorgir d'aliatges de crom-cobalt i finalment, es va començar a estudiar el titani i aliatges d'aquest element com a material per a la elaboració de pròtesis. Actualment, la majoria de les pròtesis implantades en aplicacions ortopèdiques estan compostes d'aliatge de titani de grau 5, també coneguda com Ti6Al4V. Una vegada implantades les pròtesis, el problema radica en el fet que són inerts, perquè no reaccionen o interactuen en gran manera amb l'entorn biològic. Per això, el cos humà genera un teixit fibrós, encapsulant aquestes pròtesis i en moltes ocasions les rebutja. Per a pal-liar aquest problema, la pràctica més comuna és recobrir aquestes pròtesis amb un biomaterial, que és un material adequat per al seu ús i implantació en el cos humà, ja que pot estar en contacte amb teixits vius reaccionant positivament amb aquests teixits. D'aquesta forma, s'obté un composite que combina excel-lents propietats mecàniques (a causa del suport metàl-lic) amb excel-lents propietats biològiques (a causa del recobriment biocompatible).

Des de fa diverses dècades, a nivell clínic s'estan implantant pròtesi amb un recobriment de hidroxiapatita depositat mitjançant projecció tèrmica per plasma. Es tracta d'un material ceràmic bioactiu, que a causa de la seua composició similar a la fase mineral de l'os humà, biocompatibilitat i osteoconductivitat, es molt utilitzat en reparació i reconstrucció d'aquelles parts del sistema musculesquelètic danyades o malaltes. No obstant això, durant el procés de projecció per plasma, part de la hidroxiapatita depositada fon parcial o totalment, tornant-se amorfa o en fases cristal-lines diferents. Aquestes noves fases, amorfes i/o cristal-lines afecten negativament la bioactivitat del recobriment final. Per tant, recentment s'ha començat a estudiar els vidres bioactius com a substituts de la hidroxiapatita en la deposició d'aquests recobriments. Tant els vidres bioactius com la hidroxiapatita són biocompatibles i posseeixen propietats mecàniques similars, encara que els vidres presenten major bioactivitat que la hidroxiapatita.

En conseqüència, el present treball s'enfoca en la deposició de recobriments a partir de vidres bioactius mitjançant projecció tèrmica per plasma. Després de la síntesi d'un vidre bioactiu de composició definida, aquest es va moldre via seca i es va tamisar per a obtindre un material pulverulent amb una distribució de grandàries de partícula donada (primer material d'aportació per a la projecció). A més, part d'aquesta pols es va tornar a moldre amb un mig líquid per a desenvolupar una suspensió estable de partícules de vidre bioactiu (segon material d'aportació). De manera paral-lela, sobre la base del mètode sol-gel per a l'obtenció de vidres, es van seleccionar els precursors necessaris per a aconseguir la composició del vidre sintetitzat inicialment i es van dissoldre 
en mig aquós, desenvolupant una solució de precursors (tercer material d'aportació a la projecció).

Els tres materials d'aportació s'han depositat mitjançant projecció tèrmica per plasma modificant diferents paràmetres relatius tant al material d'aportació i a l'equip de projecció, com a l'estat del substrat. Els recobriments resultants s'han caracteritzat microestructural i mecànicament, i s'ha determinat la bioactivitat mitjançant la seua immersió en fluid biològic.

Després de l'anàlisi dels recobriments obtinguts, s'ha observat que la textura i microestructura d'aquests depén en gran manera d'utilitzar un material d'aportació pulverulent o un material d'aportació líquid (suspensions i solucions), i al seu torn, aquestes diferències microestructurals repercuteixen en les propietats mecàniques i biològiques dels recobriments resultants. Així mateix, les condicions de projecció estudiades per a cada tipus de material també juguen un paper important en la microestructura obtinguda. No obstant això, malgrat les diferències observades, mitjançant l'ús dels tres materials d'aportació és possible obtindre recobriments amb una bona adherència al substrat i una elevada bioactivitat. 
1. INTRODUCCIÓN 



\subsection{Los materiales biocerámicos}

\subsubsection{Descripción y alcance}

Los materiales biocerámicos son un conjunto de materiales cerámicos y vidrios pertenecientes a la gran familia de los biomateriales. Se utilizan desde hace mucho tiempo en el cuidado de la salud, por ejemplo, como lentes para gafas, instrumentos quirúrgicos, frascos de cultivo de tejidos o termómetros entre otras aplicaciones [1]. Además, durante las últimas décadas, el empleo de estos materiales ha recibido mucha atención en el campo de la medicina con el fin de reparar y reconstruir aquellas partes del sistema musculoesquelético que se encuentran enfermas o dañadas [1,2]. Estas partes dañadas, no son más que tejido duro como huesos, articulaciones y dientes [2]. Estos materiales no se deben confundir con los materiales biológicos, ya que estos últimos son productos de sistemas biológicos, mientras que los biocerámicos son materiales sintetizados por el hombre que son aceptados por los tejidos vivos [1].

Los materiales biocerámicos utilizados hasta la actualidad presentan unas propiedades químicas excelentes para su empleo en el cuerpo humano [3], y cumplen casi la totalidad de requisitos que ha de presentar un implante, los cuales se listan a continuación [3].

- No presentar toxicidad para el cuerpo.

- Ser estable mecánicamente. No fracturarse o, al menos, no deformar excesivamente.

- Evitar reacciones extrañas hacia el implante por parte del cuerpo humano.

- No estimular el crecimiento de compuestos o la producción de reacciones químicas no deseadas con los fluidos corporales y los tejidos circundantes.

- No presentar corrosión tras la interacción con los fluidos corporales y tejidos circundantes.

- Reabsorberse a una velocidad que pueda ser controlada.

Es de esperar que los materiales biocerámicos no puedan cumplir el segundo requisito ya que son frágiles y poseen bajas propiedades mecánicas. Aun así, el abanico de aplicaciones de estos materiales en el cuerpo humano es muy amplio, tal y como se ilustra en la figura 1.1 [4], abarcando desde reparaciones craneales, pasando por reconstrucción maxilofacial, sustitución de válvulas del corazón hasta reemplazo de articulaciones. 


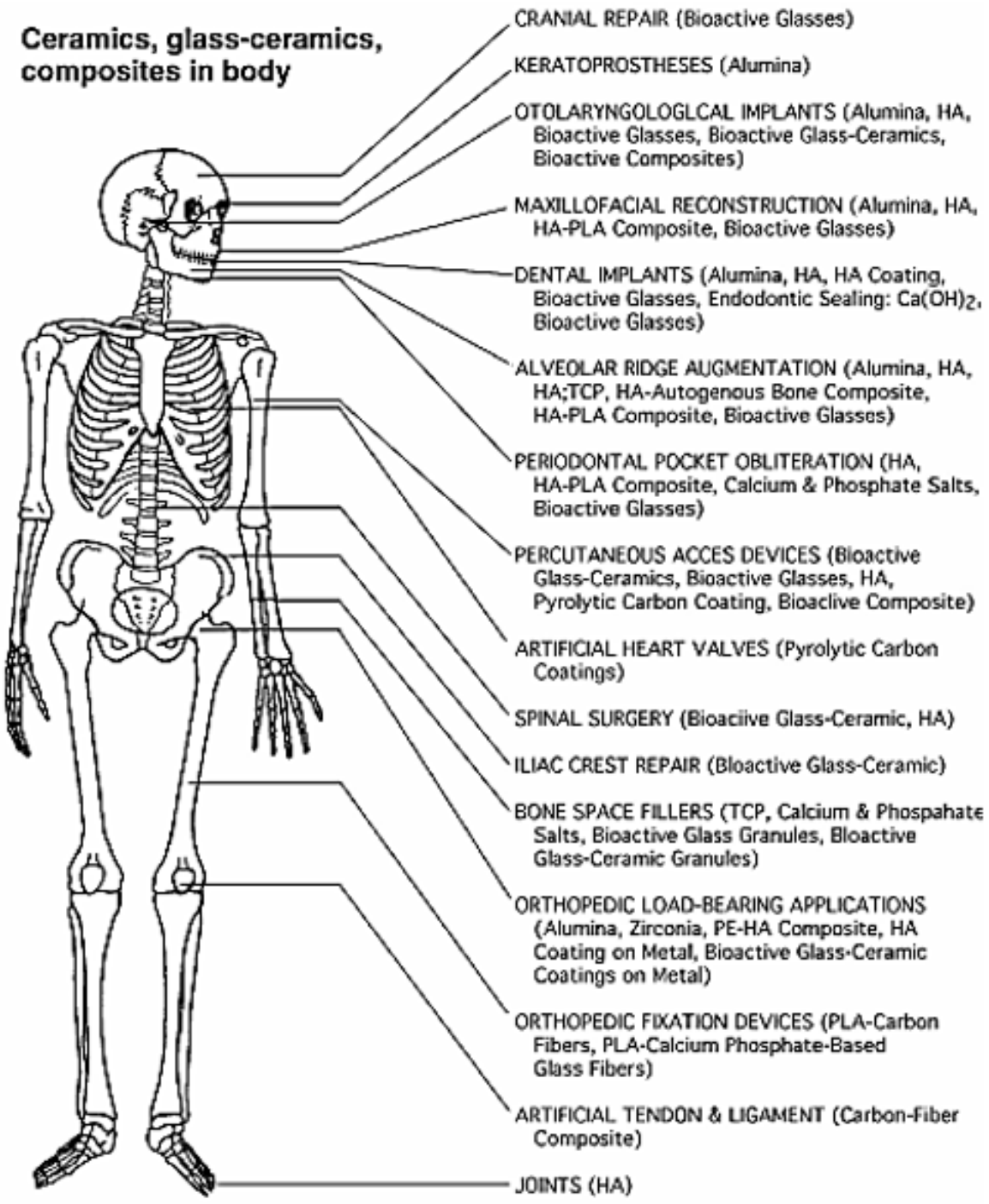

Figura 1.1. Ejemplos de aplicaciones de materiales biocerámicos en el sistema musculoesquelético [4]

\subsubsection{Clasificación}

No todos los materiales biocerámicos se comportan igual una vez implantados en el interior del cuerpo humano. Por tanto, aquellos materiales cerámicos y vidrios aptos para su empleo en el cuerpo humano pueden clasificarse en función del tipo de reacción que generan con el tejido circundante y los fluidos corporales [2,5-7], tal y como se ilustra en la figura 1.2 . 


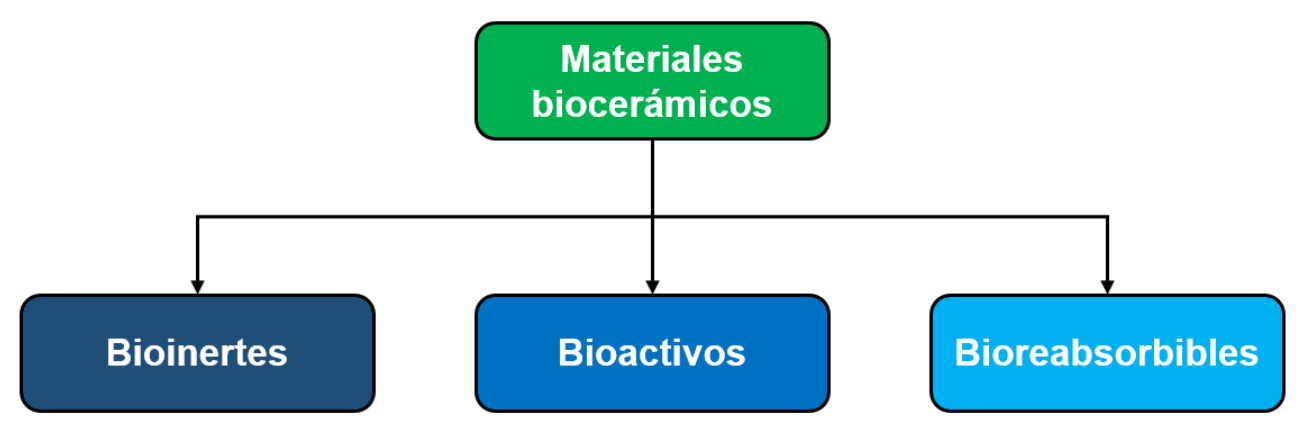

Figura 1.2. Clasificación de los materiales biocerámicos

Como puede apreciarse en la figura 1.3, los materiales bioinertes (no reaccionan con el entorno biológico) apenas tienden a exhibir niveles de bioreactividad hasta aproximadamente 250 años, donde empiezan a mostrar algún signo de reacción [8]. Por ello, surgió una nueva generación de biomateriales cerámicos, es decir, los materiales bioactivos (reaccionan con el entorno biológico) y bioreabsorbibles (reaccionan con el entorno biológico y son asimilados por éste de forma progresiva). La bioreactividad de estos dos nuevos tipos de materiales con los tejidos y fluidos corporales es notablemente superior, siendo los materiales bioreabsorbibles aquellos que presentan mayor bioreactividad [8].

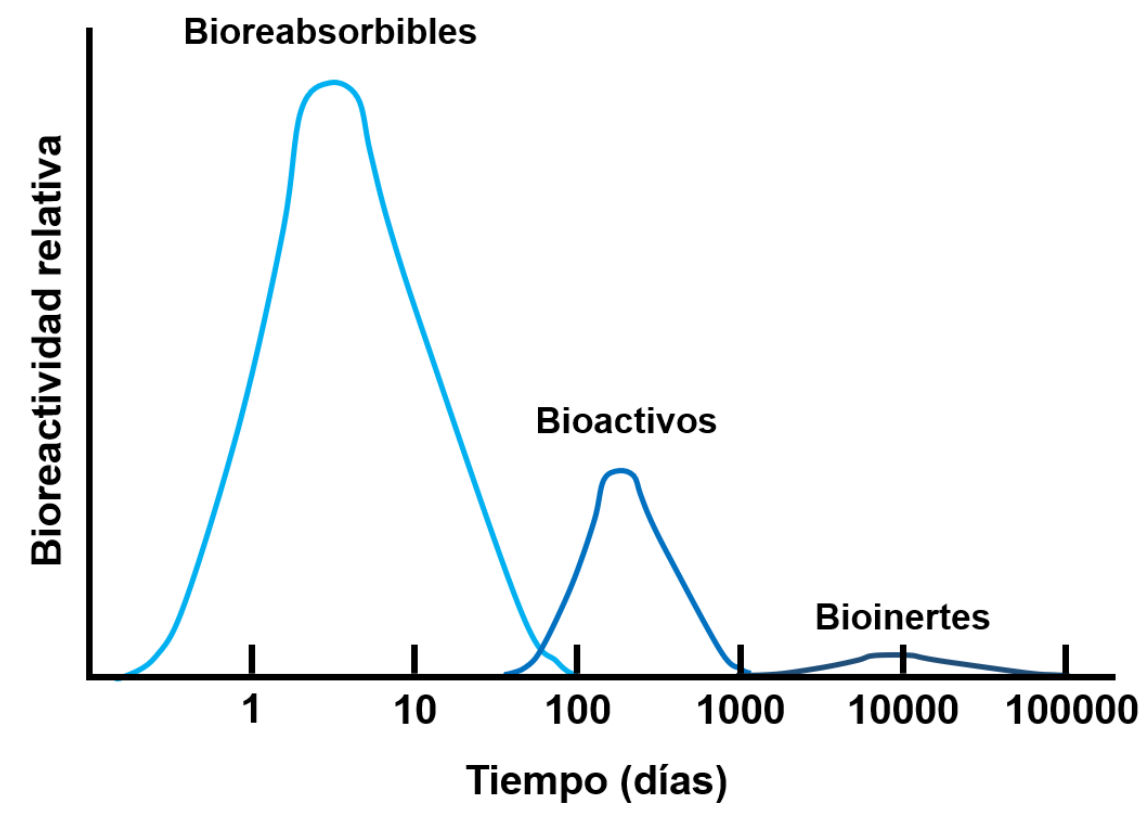

Figura 1.3. Bioreactividad de los diferentes tipos de materiales biocerámicos. Figura adaptada de [8] 


\subsubsection{Materiales bioinertes}

Aunque los materiales pertenecientes a esta clasificación se denominen bioinertes, ningún material es totalmente inerte, sino que siempre provoca una reacción por mínima que sea [6]. Los materiales bioinertes son aquellos que una vez implantados son recubiertos de una capa fibrosa, la cual posee un fino espesor y no está adherida al material implantado, sin reaccionar con los tejidos circundantes [6]. Los materiales biocerámicos más estudiados pertenecientes a esta categoría son la alúmina $\left(\mathrm{Al}_{2} \mathrm{O}_{3}\right)$ y la circona $\left(\mathrm{ZrO}_{2}\right)$.

\section{Alúmina}

La alúmina de elevada pureza $(>99,5 \%$ ) y de gran densidad fue el primer material biocerámico utilizado en el campo de la medicina [9]. Este material es biocompatible debido a sus propiedades químicas y presenta una excelente resistencia a la corrosión y al desgaste [10]. Es por ello por lo que sus mayores aplicaciones son como sustitución de la cabeza en prótesis femorales y en implantes dentales $[10,11]$.

\section{Circona}

La circona fue el segundo material bioinerte utilizado. Presenta características similares a la alúmina en cuanto a su empleo en el cuerpo humano, aunque la alúmina es más dura y, por tanto, más resistente al desgaste. Sin embargo, los puntos favorables de la circona son su elevada resistencia a la fractura y a la flexión y su menor módulo de Young [10]. La circona utilizada en medicina es la tetragonal, siempre estabilizada bien con itrio o bien con magnesio [10,11], siendo la estabilizada con itrio la más utilizada. Las aplicaciones de este material son análogas a las de la alúmina, siendo las más comunes en implantes dentales y en cabezas femorales $[10,11]$.

\subsubsection{Materiales bioactivos}

Los materiales bioinertes no solo producen una escasa reacción en el cuerpo, sino que, además, se ha descubierto que alguno presenta cierta radiación gamma y alfa, siendo esta última peligrosa tras una exposición a largo plazo [10]. Los primeros materiales biocerámicos de la nueva generación que surgió fueron los materiales bioactivos, los cuales una vez implantados, reaccionan con el entorno biológico de tal forma que sobre su superficie se genera una fina capa de hidroxiapatita carbonatada (HCA) [2]. Esta capa de HCA es química y estructuralmente similar a la fase mineral presente en los huesos, por lo que actúa como punto de unión entre el implante y los tejidos circundantes [2,7]. De esta categoría, los materiales más empleados son los fosfatos de calcio (hidroxiapatita), vitrocerámicos y vidrios bioactivos.

\section{Hidroxiapatita}

El término apatita hace referencia a un grupo de fosfatos cálcicos que presentan una estructura muy similar, aunque difieren en composición [10,11]. 
Por un lado, está la hidroxiapatita pura $(\mathrm{HA})$ de composición $\mathrm{Ca}_{10}\left(\mathrm{PO}_{4}\right)_{6}(\mathrm{OH})_{2}$ y una ratio molar $\mathrm{Ca} / \mathrm{P}$ de $1,67[10,11]$. En algunas ocasiones, es posible efectuar sustituciones del $\mathrm{Ca}, \mathrm{PO}_{4}$ y del $\mathrm{OH}$ por diversos elementos tales como $\mathrm{Sr}, \mathrm{Mg}, \mathrm{F}, \mathrm{Cl}$ o $\mathrm{CO}_{3}$ en función de la aplicación final, pues estas sustituciones afectan en gran medida a la estabilidad química del material (solubilidad). Por otro lado, también se emplean las apatitas biológicas, que se obtienen de huesos y dientes animales, que de por sí ya contienen ciertas impurezas a modo de sustitución $\left(\mathrm{CO}_{3}^{2-}, \mathrm{Na}^{+}, \mathrm{Mg}^{2+}\right)[10,11]$.

Debido a que todas estas apatitas presentan una composición muy similar a la fase mineral del hueso humano, son los materiales más empleados desde hace mucho tiempo [10,11]. Las aplicaciones típicas de estos materiales son en reparación y sustitución ósea, en forma de andamio ("scaffold") en regeneración ósea, como agentes de transfección, como portadores de fármacos, como dispositivos percutáneos y a modo de recubrimiento sobre prótesis e implantes dentales (mayor detalle en apartado 1.1.3) [10,11].

\section{Vidrios bioactivos}

Se trata del segundo tipo de material de la categoría de los biocerámicos bioactivos. Al igual que los materiales anteriores, sus propiedades hacen que se utilicen en gran variedad de aplicaciones. Puesto que este tipo de materiales conforman parte del estudio del presente trabajo de tesis doctoral, se detallan con mayor profundidad más adelante (apartado 1.2).

\section{Vitrocerámicos}

Los materiales vitrocerámicos son el tercer tipo de material de los más utilizados en la categoría de materiales bioactivos. Puede decirse que se trata de una variante de los vidrios bioactivos, puesto que para su desarrollo se parte de vidrios con diferente composición los cuales se someten a un tratamiento térmico a elevada temperatura para producir cristalizaciones controladas en el seno de estos materiales vítreos $[10,11]$. El objetivo es lograr un material bioactivo que presente una resistencia mecánica superior a la del hueso cortical, es decir, la zona externa del hueso humano [10,11]. Hay varios ejemplos de este tipo de materiales, como el Ceravital ${ }^{\circledR}$ en el cual cristaliza apatita en una matriz vítrea de $\mathrm{Na}_{2} \mathrm{O}-\mathrm{K}_{2} \mathrm{O}-\mathrm{MgO}-\mathrm{CaO}-\mathrm{SiO}_{2}-\mathrm{P}_{2} \mathrm{O}_{5}$, el vitrocerámico $\mathrm{A} / \mathrm{W}$ en el que cristaliza apatita y wollastonita en una matriz vítrea de $\mathrm{MgO}-\mathrm{CaO}-\mathrm{SiO}_{2}-\mathrm{P}_{2} \mathrm{O}_{5}$, el Bioverit ${ }^{\circledR}$ en el que cristaliza apatita y flogopita en una matriz vítrea de $\mathrm{Na}_{2} \mathrm{O}-\mathrm{MgO}-\mathrm{CaO}-\mathrm{Al}_{2} \mathrm{O}_{3}-\mathrm{SiO}_{2}-\mathrm{P}_{2} \mathrm{O}_{5}-\mathrm{F}$ o el Ilmaplant ${ }^{\circledR}$ en el que cristaliza apatita y wollastonita en una matriz vítrea de $\mathrm{Na}_{2} \mathrm{O}-\mathrm{K}_{2} \mathrm{O}-\mathrm{MgO}-$ $\mathrm{CaO}-\mathrm{SiO}_{2}-\mathrm{P}_{2} \mathrm{O}_{5}-\mathrm{CaF}_{2}$ [10,11]. De entre todo ellos, el más empleado clínicamente es el vitrocerámico A/W [10,11].

Gracias a la gran resistencia mecánica de los vitrocerámicos bioactivos, estos materiales se emplean comúnmente en la espina dorsal a modo de prótesis vertebrales, prótesis de cresta ilíaca de la cadera y en sustitución ósea en zonas donde no puede utilizarse hidroxiapatita $[10,11]$. 
Por otra parte, los biocerámicos bioactivos no solo reaccionan y se enlazan con tejido duro (tejido óseo), sino que algunos de estos materiales también pueden hacerlo con tejidos blandos como es el caso de ciertas composiciones de vidrios bioactivos y el carbón pirolítico [10]. Éste último, se utiliza en reparación y sustitución de las válvulas del corazón a modo de recubrimiento de las paredes de estas válvulas $[3,10]$.

\subsubsection{Materiales bioreabsorbibles}

Por último, están los materiales bioreabsorbibles. Estos materiales no solo reaccionan con el entorno biológico, sino que al hacerlo van degradándose progresivamente y desapareciendo, siendo sustituidos por tejido óseo nuevo natural $[7,9]$. Aunque resultan materiales muy prometedores ya que el resultado final es tejido nuevo en lugar de un elemento externo al cuerpo, hay que ajustar perfectamente la velocidad del proceso de degradación con la velocidad de formación de nuevo tejido [9]. Los materiales bioreabsorbibles más empleados son los fosfatos tricálcicos, más concretamente la familia de fosfatos cálcicos con un ratio molar $\mathrm{Ca} / \mathrm{P}$ alrededor de 1,5. A diferencia de la hidroxiapatita que es bioactiva y estable, la estructura cristalina $\mathrm{Ca}_{3}\left(\mathrm{PO}_{4}\right)_{2}$ de estos compuestos los dota de una solubilidad mayor [10,11]. Hay varias configuraciones cristalográficas, es decir, fosfato tricálcico amorfo (am-TCP), fosfato tricálcico apatítico (ap-TCP), fosfato tricálcico beta $(\beta-\mathrm{TCP})$ y fosfato tricálcico alfa ( $\alpha-$ TCP). El más común o el más utilizado es el $\beta-T C P[10,11]$.

La aplicación más común para estos materiales es su empleo en la sustitución y reparación de defectos óseos a modo de cemento.

\subsubsection{Recubrimientos a partir de materiales biocerámicos}

Tal y como se ha comentado anteriormente, los materiales biocerámicos son frágiles y no poseen buenas propiedades mecánicas. Es por ello que su empleo (aunque amplio como se observa en la figura 1.1) está limitado a aplicaciones que no tengan que soportar altas cargas $[3,4]$. Por este motivo, no es posible implantar una prótesis totalmente conformada a partir de estos materiales. La práctica común es aplicar sobre implantes metálicos un recubrimiento de un material biocerámico bioactivo (típicamente hidroxiapatita), de tal forma que se obtiene un composite que combina excelentes propiedades mecánicas (debido al soporte metálico) con excelente biocompatibilidad (debido al recubrimiento biocerámico) $[3,4,12]$. En la figura 1.4 , se muestran algunos ejemplos de prótesis e implantes recubiertos [13]. 


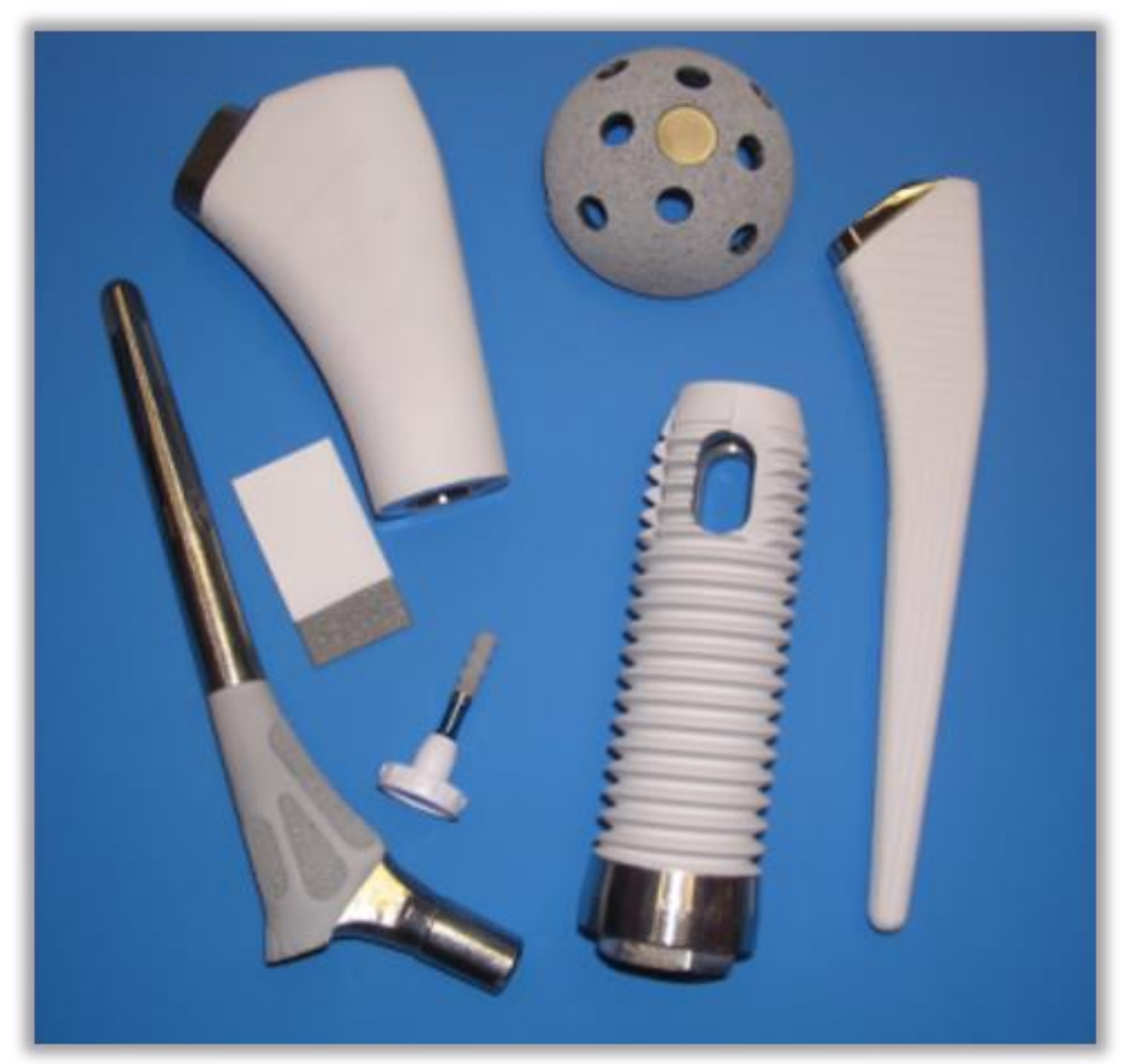

Figura 1.4. Ejemplos de distintas prótesis e implantes metálicos recubiertos con hidroxiapatita [13]

\subsection{Los vidrios bioactivos}

\subsubsection{Descripción y composición}

El término vidrio bioactivo hace referencia al material vítreo que es biocompatible con los tejidos y fluidos corporales a la par que no cancerígeno, no mutagénico y no antigénico [14]. Como se ha comentado anteriormente, los vidrios bioactivos pertenecen a la categoría de materiales biocerámicos bioactivos, pues una vez implantados reaccionan con los fluidos y tejidos circundantes formando sobre su superficie una capa de hidroxiapatita carbonatada (HCA) (son osteoinductivos y osteoconductivos) sobre la cual puede adherirse el tejido óseo (son osteointegrativos).

El primer vidrio de esta categoría es el conocido como biovidrio $45 S 5$ o Bioglass $^{\circledR}$. Este vidrio fue descubierto por el Profesor L.L. Hench en el año 1969 en la Universidad de Florida mediante un proyecto financiado por el ejército de los Estados Unidos, cuyo objetivo era encontrar un sustituto viable a las 
prótesis e implantes metálicos o poliméricos [15]. El profesor Hench le dio el nombre de $45 S 5$ al vidrio basándose en la nomenclatura de éste, pues 45 hace referencia al porcentaje másico de sílice, $\mathrm{S}$ es la inicial del elemento formador principal de red vítrea (sílice) y 5 hace referencia a la ratio $\mathrm{CaO} / \mathrm{P}_{2} \mathrm{O}_{5}[16]$. Se trata de un fosfosilicato sodocálcico cuya estructura está formada mayoritariamente por sílice $\left(\mathrm{SiO}_{2}\right)$, ya que es el óxido formador de red, la cual contiene óxidos de calcio y sodio ( $\mathrm{CaO}$ y $\mathrm{Na}_{2} \mathrm{O}$ respectivamente) que actúan como óxidos modificadores de la red vítrea y pentóxido de fósforo $\left(\mathrm{P}_{2} \mathrm{O}_{5}\right)$ como segundo formador de red $[16,17]$. La composición de este vidrio se detalla en la tabla $1.1[14-17]$.

Tabla 1.1. Composición del vidrio bioactivo 45S5 [14-17]

\begin{tabular}{ccccc}
\hline Composición & $\mathrm{SiO}_{2}$ & $\mathrm{CaO}$ & $\mathrm{Na}_{2} \mathrm{O}$ & $\mathbf{P}_{2} \mathrm{O}_{5}$ \\
\hline $\begin{array}{c}\text { Porcentaje } \\
\text { másico (wt\%) }\end{array}$ & 45,0 & 24,5 & 24,5 & 6,0 \\
$\begin{array}{c}\text { Porcentaje } \\
\text { molar (mol\%) }\end{array}$ & 46,1 & 26,9 & 24,4 & 2,6 \\
\hline
\end{tabular}

En vista a lo anterior, puede decirse que el Bioglass $^{\circledR}$ es un vidrio totalmente diferente a los vidrios usados comúnmente (vidrio plano o vidrio de botella) puesto que contiene más óxidos de calcio y sodio, menos óxido de silicio y contiene, además, óxido de fósforo [17].

\subsubsection{Métodos de obtención}

El Bioglass ${ }^{\circledR}$ se obtiene habitualmente mediante dos métodos diferentes, por fusión y enfriado brusco ("melting and quenching") o por el método sol-gel [1726].

En el primer método, se parte de materias primas de elevada pureza. En función de la composición deseada, se seleccionan las materias primas (típicamente carbonatos, fosfatos y sílice), se mezclan y el producto resultante se lleva a temperaturas del orden de $1300^{\circ} \mathrm{C}$ para asegurar la fusión completa de las materias primas. Para obtener el material vítreo, el fundido resultante se enfría bruscamente en agua (Figura 1.5) dando lugar a partículas gruesas e irregulares de vidrio bioactivo, las cuales se molturan y tamizan al tamaño de partícula deseado. En algunas ocasiones, se desea obtener monolitos o piezas de una geometría determinada. Por ello, el fundido se introduce en un molde de grafito precalentado seguido de un proceso de templado del material resultante para relajar las tensiones $[17,18]$. 


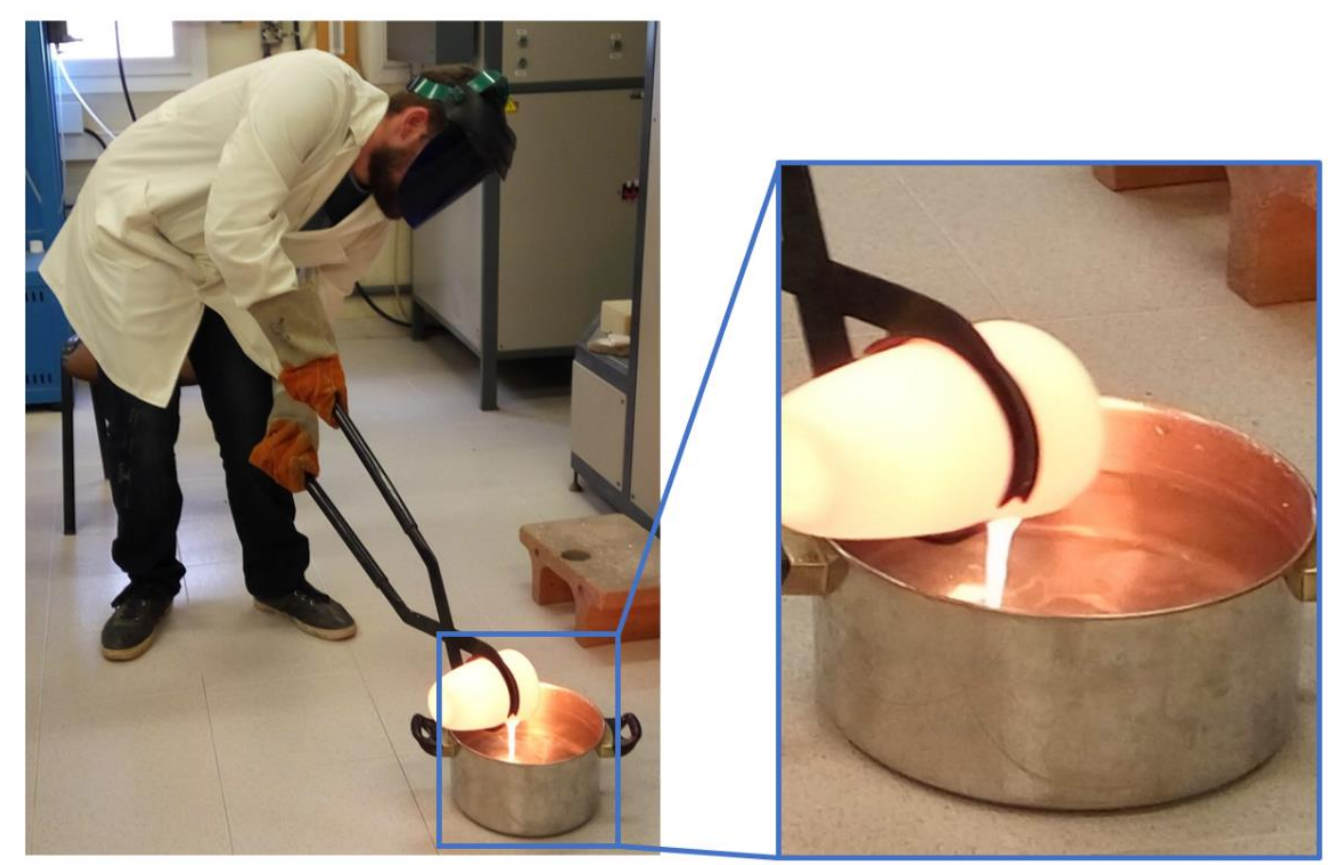

Figura 1.5. Enfriamiento súbito en agua de una mezcla fundida de materias primas para obtener partículas de vidrio

La segunda vía de obtención de estos vidrios es mediante el método sol-gel. En este método, se parte de una serie de precursores, típicamente alcóxidos metálicos y sales inorgánicas (como nitratos y carbonatos), los cuales se mezclan y disuelven en un medio dispersante (acuoso, orgánico o mezclas de éstos). En algunos casos como en el del tetraetilo ortosilicato o TEOS (precursor común para obtener $\mathrm{SiO}_{2}$ ) es necesario acidificar o basificar el medio dispersante para lograr la hidrólisis de este compuesto. Una vez mezclados y disueltos, los materiales pasan por una serie de reacciones hasta formar un sol, en el que las sales se encuentran disueltas y los alcóxidos hidrolizados, y condensan en partículas nanométricas dispersas conocidas como coloides. Cuando se desea obtener un vidrio con una geometría determinada, una vez formado el sol es posible introducirlo en un molde, normalmente de politetrafluoroetileno (PTFE). En cualquier caso, una vez obtenido el sol se producen las etapas de gelificación (formación de cadenas de coloides entrelazadas que atrapan el medio dispersante entre ellas), envejecimiento del gel, secado y estabilización mediante tratamiento térmico para obtener el material vítreo definitivo. Para la síntesis de monolitos de vidrio o estructuras vítreas de una determinada geometría, el proceso de secado será clave para evitar la aparición de grietas en la estructura final. Por ello, este proceso debe llevarse a cabo a velocidades de calentamiento muy pequeñas. Por el contrario, para la obtención de partículas de vidrio, esta etapa no será crítica puesto que la presencia de grietas en la estructura final facilita su posterior molturación [17]. 
Mediante el método sol-gel es posible trabajar a menores temperaturas de sinterización y controlar mejor la composición del material obtenido. Además, los vidrios obtenidos mediante este método presentan una mayor bioactividad debido a su elevada superficie específica, como consecuencia de la elevada micro y meso porosidad de las partículas obtenidas [20,23,25]. Asimismo, esta porosidad permite la obtención de vidrios bioactivos más estables, ya que el contenido en $\mathrm{SiO}_{2}$ puede llegar hasta un $90 \mathrm{~mol} \%$ sin afectar a la bioactividad (conexión de red vítrea o NC, en apartado 1.2.3) puesto que los protones $\left(\mathrm{H}^{+}\right)$ del medio biológico se introducen en estos poros actuando como elementos modificadores de red [17].

Por otro lado, el método de fusión y enfriamiento brusco, aunque solo permite llegar a un porcentaje de sílice del $60 \mathrm{~mol} \%$ para no comprometer la bioactividad del material (contenidos superiores dan lugar a NC elevados), es un proceso más simple y menos costoso que el método sol-gel y los vidrios obtenidos presentan mejores propiedades mecánicas puesto que las partículas están totalmente densificadas [19,21].

\subsubsection{Propiedades del vidrio bioactivo $45 \mathrm{~S} 5$}

En lo relativo a las propiedades del vidrio bioactivo $45 \mathrm{~S} 5$, en la tabla 1.2 se detallan las propiedades físicas y mecánicas correspondientes a este vidrio obtenido por el método de fusión y enfriamiento brusco [17].

Tal y como puede observarse en la tabla, este vidrio posee unas propiedades mecánicas muy pobres, al tratarse de un material rígido (elevado módulo de Young) y frágil (baja resistencia a la tracción y tenacidad) [17], características típicas de un material biocerámico como se ha comentado anteriormente. En el caso de obtención del material por el método sol-gel, como se indica en el apartado anterior, las propiedades mecánicas y físicas son inferiores a las mostradas en la tabla 1.2. En consecuencia, al igual que el resto de biocerámicos, sus aplicaciones se limitan a casos en los que no se requiera soportar elevadas cargas.

Por otro lado, está el comportamiento del vidrio bioactivo $45 S 5$ frente a la temperatura. En ciertas ocasiones es necesario someter los vidrios bioactivos a tratamientos térmicos, como por ejemplo en la consolidación de un "scaffold" (apartado 1.2.6) o en la obtención de un vitrocerámico.

Por ello, resulta interesante conocer cómo se comportan estos vidrios con la temperatura. Se han llevado a cabo numerosos estudios acerca de este comportamiento [26-28]. En todos ellos queda patente como el vidrio empieza a sinterizar a partir de aproximadamente $520-525^{\circ} \mathrm{C}$ (temperatura de transición vítrea) hasta $670 \stackrel{\circ}{\mathrm{C}}$ donde se detiene el proceso de sinterización [17,26-28]. 
Tabla 1.2. Propiedades físicas y mecánicas del vidrio bioactivo 45S5 [17]

\begin{tabular}{lc}
\hline \multicolumn{1}{c}{ Propiedades físicas y mecánicas } & Valor \\
\hline Densidad $\left(\mathrm{kg} / \mathrm{m}^{3}\right)$ & 2700 \\
Coeficiente de expansión térmica $\left({ }^{\circ} \mathrm{C}^{-1}\right)$ & $15,1 \cdot 10^{-6}$ \\
Índice de refracción & 1,6 \\
Resistencia a la tracción $(\mathrm{MPa})$ & 42,0 \\
Módulo de Young $(\mathrm{MPa})$ & 35,0 \\
Módulo de cizalla $(\mathrm{GPa})$ & 30,7 \\
Tenacidad $\left(\mathrm{MPa} \cdot \mathrm{m}^{1 / 2}\right)$ & 0,6 \\
Dureza Vickers $(\mathrm{GPa})$ & 5,8 \\
\hline
\end{tabular}

Esta detención a $670 \stackrel{\circ}{\circ}$ se debe al comienzo de un proceso de cristalización [17,26-28], que aumenta la viscosidad del material e impide el progreso de la densificación. Tras la transición vítrea del material, se produce una separación de fases como consecuencia de la presencia simultánea de dos tipos de iones formadores de red de elevada valencia $\left(\mathrm{Si}^{4+}\right.$ y $\left.\mathrm{P}^{5+}\right)[27,29]$, resultando en una fase rica en silicio y otra rica en fósforo a partir de las cuales cristaliza un silicato de sodio y calcio y un fosfato de calcio y sodio respectivamente. Esta etapa de cristalización tiene lugar hasta aproximadamente $800^{\circ} \mathrm{C}$, puesto que a partir de esta temperatura se reanuda el proceso de sinterización hasta el intervalo de temperaturas comprendido entre 1100 y $1200^{\circ} \mathrm{C}$, donde se produce la fusión total del material [17,26-28]. Es importante conocer este comportamiento a la hora de determinar el ciclo térmico de consolidación del material para su posterior aplicación, puesto que la presencia de fases cristalinas en el vidrio bioactivo provoca un retardo en el inicio de las reacciones entre el material vítreo y los tejidos y fluidos corporales [27].

Por último, puesto que el Bioglass ${ }^{\circledR}$ se encuentra dentro de la categoría de los materiales biocerámicos bioactivos, se espera que reaccione con los tejidos y fluidos corporales circundantes una vez implantado en el cuerpo. Sin embargo, esta capacidad de reaccionar y unirse a los tejidos, también conocida como bioactividad, está influenciada por varios factores. Como se acaba de comentar, la posible presencia de fases cristalinas en el material vítreo, resultantes de algún tratamiento térmico del vidrio previamente a su implantación, provoca el retardo de las correspondientes reacciones entre el material vítreo y el ambiente biológico. Además, la bioactividad está condicionada por la composición del vidrio, y ésta a su vez afecta a la conectividad de la red vítrea [17,30-32].

El caso más común de vidrio bioactivo son los vidrios de sílice. Estos vidrios tienen una estructura formada por tetraedros del elemento formador de red (sílice) dispuestos de forma aleatoria, con los elementos modificadores de red entre los huecos de estos tetraedros [33,34]. Un parámetro muy utilizado para determinar el grado de entrelazamiento y conectividad de estos tetraedros de sílice es la conectividad de la red vítrea (NC) [30-32]. Este parámetro determina el número de oxígenos puente (moléculas de oxígeno que conectan los 
tetraedros de sílice) por tetraedro a partir de la composición del vidrio [17]. Para ello se emplea la siguiente ecuación:

$$
N C=2+\frac{B O-N B O}{G}(\text { ec. } 1.1)
$$

Donde BO hace referencia al número total de oxígenos puente por número de iones de elemento formador de red, NBO hace referencia al número de oxígenos no puente por número de iones de elemento modificador de red y $\mathrm{G}$ hace referencia a la cantidad total de elemento formador de red [17]. Cuanto mayor es el valor de NC menor es la bioactividad del material vítreo ya que éste es más estable frente a la degradación (como se explica en el siguiente apartado, una vez implantado hay cierta degradación del material vítreo).

Finalmente, otro factor que afecta a la bioactividad del material es el método de síntesis del vidrio, que como se ha visto en el apartado anterior, determina la densidad del material (vidrio denso o poroso) afectando a la bioactividad de éste.

\subsubsection{Reacción con tejidos y fluidos corporales}

Como material bioactivo, los vidrios de esta categoría reaccionan con el entorno biológico una vez implantados, desarrollando sobre su superficie una capa de HCA. Para poder desarrollar esta capa, la superficie de los vidrios bioactivos pasa por una serie de cambios físicos y químicos. El mecanismo de generación de esta capa se ilustra en la figura 1.6 [16].

Como puede verse en esta figura, la formación de la capa de HCA se produce mediante cinco etapas consecutivas $[2,9,10,16,17,35]$ :

1) Intercambio de iones entre la superficie del vidrio y el medio biológico. El vidrio cede cationes alcalinos $\left(\mathrm{Ca}^{2+}\right.$ y Na+ $)$ al medio y recibe protones $\left(\mathrm{H}^{+}\right)$de éste, por lo que el $\mathrm{pH}$ del entorno se incrementa.

$$
\mathrm{Si}-\mathrm{O}-\mathrm{Na}^{+}+\mathrm{H}^{+}+\mathrm{OH}^{-} \rightarrow \mathrm{Si}-\mathrm{OH}^{+}+\mathrm{Na}^{+}+\mathrm{OH}^{-} \text {(ec. 1.2) }
$$

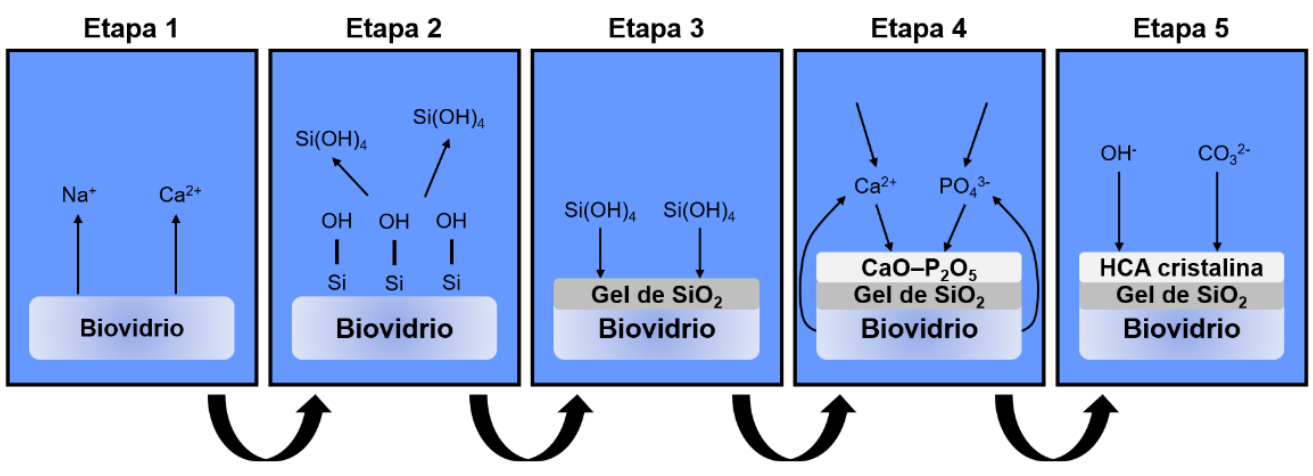

Figura 1.6. Mecanismo de formación de la capa de HCA sobre la superficie de un vidrio bioactivo. Figura adaptada de [16] 
2) Rotura de las estructuras $\mathrm{Si}-\mathrm{O}-\mathrm{Si}$ de la superficie del vidrio y formación de grupos silanol $(\mathrm{Si}-\mathrm{OH})$ sobre esta superficie.

$$
\mathrm{Si}-\mathrm{O}-\mathrm{Si}+\mathrm{H}_{2} \mathrm{O} \rightarrow \mathrm{Si}-\mathrm{OH}+\mathrm{OH}-\mathrm{Si} \text { (ec. 1.3) }
$$

Estos grupos silanol se agrupan en forma de sílice soluble o $\mathrm{Si}(\mathrm{OH})_{4}$, la cual es cedida al medio biológico.

3) Una vez la superficie del vidrio ha intercambiado todos los cationes y cedido los compuestos $\mathrm{Si}(\mathrm{OH})_{4}$, se produce la condensación y polimerización de un gel de $\mathrm{SiO}_{2}$ sobre esta superficie.

$$
\mathrm{SiO}_{3}-\mathrm{OH}+\mathrm{OH}-\mathrm{SiO}_{3} \rightarrow \mathrm{SiO}_{3}-\mathrm{O}-\mathrm{SiO}_{3}+\mathrm{H}_{2} \mathrm{O} \text { (ec. 1.4) }
$$

4) A continuación, se produce una migración de grupos $\mathrm{Ca}^{2+}$ y $\mathrm{PO}_{4}{ }^{3-}$ desde el vidrio hasta la superficie. Estos grupos atraviesan el gel de $\mathrm{SiO}_{2}$ y nuclean sobre su superficie una capa amorfa rica en $\mathrm{CaO}-\mathrm{P}_{2} \mathrm{O}_{5}$. Seguidamente, esta capa crece gracias a la incorporación de más grupos $\mathrm{Ca}^{2+}$ y $\mathrm{PO}_{4}{ }^{3-}$ que precipitan desde el entorno biológico como consecuencia del incremento del $\mathrm{pH}$.

5) Cristalización de la capa de HCA gracias a la migración e incorporación de iones $\mathrm{OH}^{-}$y $\mathrm{CO}_{3}{ }^{2-}$ a la capa rica en $\mathrm{CaO}-\mathrm{P}_{2} \mathrm{O}_{5}$ provenientes del entorno biológico.

De esta forma se desarrolla la capa de HCA sobre la superficie de los vidrios bioactivos tras aproximadamente 10 horas desde el primer contacto con el entorno biológico. A partir de este punto, se propone la siguiente secuencia de etapas acerca de la unión del material bioactivo con el tejido duro circundante $[2,9,10,16,17,35]$ :

6) Adhesión de restos biológicos sobre la capa de HCA.

7) Acción de macrófagos sobre estos restos biólogicos.

8) Unión de células madre óseas a la capa de HCA.

9) Diferenciación de las células madre.

10) Generación de matriz ósea.

11) Cristalización de matriz ósea.

\subsubsection{Composiciones de vidrios bioactivos}

Para la obtención del primer vidrio bioactivo, el profesor Hench se basó en el diagrama ternario $\mathrm{SiO}_{2}-\mathrm{CaO}-\mathrm{Na}_{2} \mathrm{O}$ fijando el contenido en peso de $\mathrm{P}_{2} \mathrm{O}_{5}$ (Figura 1.7) $[2,9,10,14,15,17,35]$. 


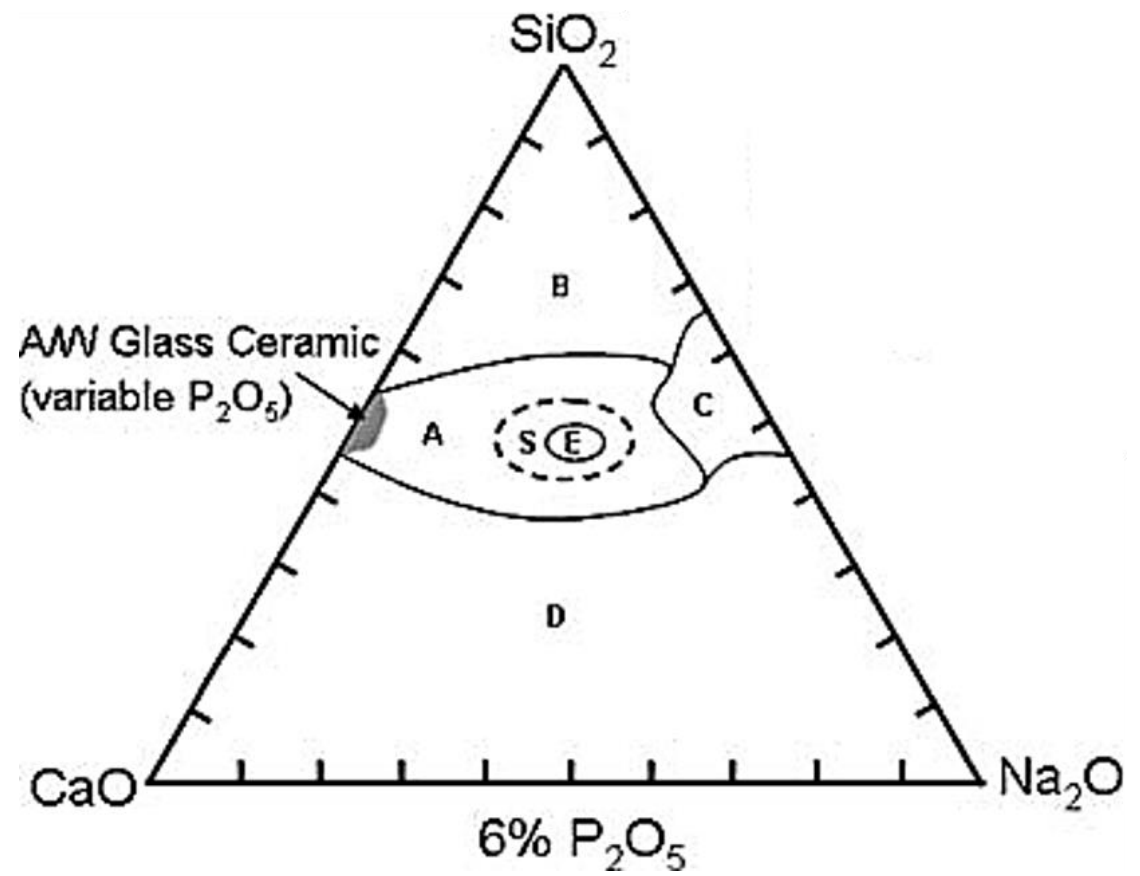

Figura 1.7. Diagrama de fases ternario para el sistema $\mathrm{SiO}_{2}-\mathrm{CaO}-\mathrm{Na}_{2} \mathrm{O}$ con un contenido en peso fijo de $\mathrm{P}_{2} \mathrm{O}_{5}$ del 6 wt\%. Figura adaptada de [2]

Tal y como puede apreciarse en el diagrama anterior, éste se puede dividir en 6 regiones diferentes $[2,9,10,14,15,17,35]$ :

- Región A: Todo vidrio cuya composición se encuentre en esta región se considera bioactivo y tiene la habilidad en mayor o menor medida de enlazarse a tejido óseo, gracias a la proporción de óxidos presente en su composición.

- Región B: Los vidrios cuya composición esté en esta región no tienen la habilidad de enlazarse al tejido óseo puesto que el contenido en sílice es tan elevado que la estructura del vidrio es muy estable y resistente a degradarse (elevado valor de NC) por lo que no tienen lugar los cambios superficiales descritos en el apartado anterior. Estos vidrios se consideran como bioinertes. Este efecto, como se ha comentado en apartados anteriores, puede ser compensado si el vidrio se sintetiza mediante el método sol-gel, dando lugar a un vidrio con capacidad reactiva a pesar de su elevada cantidad de sílice.

- Región C: Los vidrios cuya composición se encuentra en esta región presentan una degradación o disolución extremadamente rápida una vez implantados, debido a la gran cantidad de óxido de sodio presente en su composición. Por ello que se les considera bioreabsorbibles.

- Región D: De igual forma que la región $B$, los materiales en esta región tampoco se enlazan al hueso. Sin en la región $\mathrm{B}$ hay demasiado 
contenido en sílice, en la D la cantidad de sílice (compuesto formador de red vítrea) es tan reducida que no se forma material vítreo y en consecuencia no hay reacción de ningún tipo con el entorno biológico.

- Región E: Es la zona central del diagrama y se corresponde con las composiciones que muestran el mayor nivel de bioactividad. En esta región se encuentra la composición del vidrio bioactivo 45S5, la cual se muestra en la tabla 1.1.

- Región S: Es una región especial dentro de la región A. Los vidrios cuya composición se encuentra en esta región, son capaces de intercambiar rápidamente iones solubles con el entorno biológico, dando lugar a una rápida proliferación de nuevo tejido óseo (osteoproducción). Además, los vidrios de esta región pueden enlazarse con tejido blando (colágeno y la parte inorgánica del hueso).

En vista de lo anterior, es posible trabajar en un rango de composiciones dentro de la región $\mathrm{A}$ ( $\mathrm{y}$ B en el caso de utilizar el método sol-gel) de tal forma que se puede variar la velocidad con la que los vidrios resultantes reaccionan con el entorno biológico sin comprometer su bioactividad.

Por otra parte, a partir del vidrio bioactivo $45 \mathrm{~S} 5$ se han ido desarrollando variantes a lo largo del tiempo modificando ligeramente su composición (sustitución y/o eliminación de óxidos) en función de la aplicación o método de síntesis. Una primera variante, es la introducción de flúor $(F)$ en la composición original (45S5) para obtener una capa de fluorapatita (FAp) en lugar de HCA, ya que ésta ofrece mayor resistencia a ambientes ácidos puesto que es más estable químicamente [33].

Bellucci et al., han desarrollado otra variante de vidrio bioactivo basándose en la composición del 45S5 mediante la sustitución del óxido de sodio por óxido de potasio con el objetivo de reducir la tendencia a la cristalización que presenta el vidrio original y poder sintetizar el material vítreo a temperaturas menores [36-38]. De esta forma, este material resulta prometedor en el desarrollo de "scaffolds" [37,38]. Este nuevo vidrio bioactivo se conoce como BioK y su composición es $45,0 \% \mathrm{SiO}_{2}, 24,5 \% \mathrm{CaO}, 24,5 \% \mathrm{~K}_{2} \mathrm{O}$ y $6,0 \% \mathrm{P}_{2} \mathrm{O}_{5}$.

Otra opción, es la eliminación del óxido de sodio de la composición [39,40], en lugar de sustituirlo por otro óxido como en el caso del vidrio BioK. Este óxido, además de ayudar en la degradación del material vítreo una vez implantado, se emplea para reducir la temperatura de fusión de la mezcla de materias primas en la síntesis del vidrio mediante el método de fusión y enfriamiento brusco. Sin embargo, al obtener este vidrio mediante el método sol-gel, puesto que las temperaturas de trabajo son mucho menores, no es necesario la presencia de $\mathrm{Na}_{2} \mathrm{O}$ para aportar fundencia [41]. Además, la elevada superficie específica resultante de este método también fomenta la degradación del material vítreo [41]. De esta forma, se pasa de un vidrio cuaternario a un vidrio ternario $\left(\mathrm{SiO}_{2}-\mathrm{CaO}-\mathrm{P}_{2} \mathrm{O}_{5}\right)$ [39]. El vidrio ternario más común es el $58 \mathrm{~S}$ cuya composición es $58,0 \% \mathrm{SiO}_{2}, 33,0 \% \mathrm{CaO}$ y $9,0 \% \mathrm{P}_{2} \mathrm{O}_{5}$ (en wt\%) $[20,21,25,40]$. 
En numerosos estudios se ha llevado a cabo la introducción de elementos metálicos en el sistema vítreo (ternario y cuaternario) gracias a la facilidad que ofrece el método sol-gel para modificar la composición final del vidrio. Los elementos metálicos más empleados son zinc $(\mathrm{Zn})$, magnesio $(\mathrm{Mg})$, estroncio $(\mathrm{Sr})$ y boro $(\mathrm{B})$, ya que principalmente tienen un efecto positivo en la actividad de los osteoblastos (mejoran la osteoconductividad) además de fomentar 0 estimular la angiogénesis, es decir, la formación de vasos sanguíneos [23,4247].

Además de los metales anteriores, también es común dopar los vidrios bioactivos con plata $(\mathrm{Ag})$ y cobre $(\mathrm{Cu})$ [48-51]. Al dopar el vidrio con plata, se dota a este material de capacidad biocida sin afectar a su bioactividad $[49,49]$, de tal manera que la plata se intercambia con el entorno biológico eliminando cualquier microorganismo nocivo para el cuerpo humano (bacterias, microbios, células cancerígenas, etc.). En lo referente al cobre, este elemento es esencial para el cuerpo humano a la hora de regenerar y mantener los vasos capilares [50]. Además, se ha comprobado que reduce la temperatura de transición vítrea, por lo que es otro elemento prometedor en la elaboración de "scaffolds" [50].

Por último, están los vidrios de boro y vidrios de fósforo, los cuales se sintetizan usando estos elementos como formadores de red en lugar de emplear silicio [17]. En los vidrios de fósforo, como indica su nombre, el fósforo constituye el elemento formador de red. Si al vidrio de fósforo se le añade óxido de calcio, se puede lograr un vidrio bioactivo con composición similar a la del hueso. Se trata de un vidrio muy soluble en medio biológico, por lo que es un material prometedor para implantes degradables. Además, puede incorporar iones metálicos ( $\mathrm{F}, \mathrm{Zn}, \mathrm{Sr}$, etc.) los cuales son liberados progresivamente conforme se disuelve el material vítreo. Respecto a los vidrios de boro, en este caso es este elemento el que actúa como formador de red. Los vidrios bioactivos de boro también pueden contener iones metálicos en su estructura. Además, reaccionan con el entorno biológico formando también una capa de HCA sobre su superficie. A diferencia de los vidrios de sílice, los vidrios de boro no necesitan formar un gel de boro sobre su superficie para que nuclee la capa $\mathrm{HCA}$, sino que ésta lo hace directamente sobre la superficie del material vítreo conforme se disuelve el boro (igual que el fósforo de los otros vidrios). Ambos tipos de vidrios presentan también aplicaciones en el campo de la medicina como se detalla en [17].

En vista de todo lo anterior, puede afirmarse que actualmente hay una familia creciente de vidrios bioactivos basados en mezclas de óxidos formadores y modificadores de red vítrea, como $\mathrm{SiO}_{2}-\mathrm{CaO}-\mathrm{MgO}-\mathrm{Na}_{2} \mathrm{O}-\mathrm{K}_{2} \mathrm{O}-\mathrm{ZnO}-\mathrm{B}_{2} \mathrm{O}_{5}-$ $\mathrm{P}_{2} \mathrm{O}_{5}-\mathrm{SrO}-\mathrm{Ag}_{2} \mathrm{O}-\mathrm{CuO}$. 


\subsubsection{Aplicaciones de los vidrios bioactivos}

El empleo de los vidrios bioactivos en el ámbito de la medicina está avalado por la agencia de Administración de Alimento y Medicamentos (FDA) de los Estados Unidos [16]. De igual manera que la hidroxiapatita, estos materiales poseen un amplio abanico de aplicaciones [2,4-6,8-11,14-17,41,42,52]. Los vidrios bioactivos se emplean en forma de implantes densos, granular, pulverulenta o conformando "scaffolds" en distintas aplicaciones como cirugía de la oreja, enfermedades periodontales, reparación maxilofacial y aplicaciones ortopédicas. También se emplean en reparación de la médula espinal y vértebras.

Por otra parte, además de las aplicaciones citadas en el párrafo anterior, actualmente se está estudiando el empleo de vidrios bioactivos con tejidos blandos no óseos. Estas aplicaciones se recogen en la tabla $1.3[53,54]$. Finalmente, de igual forma que la hidroxiapatita, los vidrios bioactivos también pueden utilizarse como recubrimientos para prótesis e implantes.

Los recubrimientos de hidroxiapatita depositados mediante proyección por plasma se están empleando con éxito a nivel clínico desde 1980 en aplicaciones dentales y ortopédicas [55]. Sin embargo, el principal inconveniente durante la deposición de la hidroxiapatita mediante proyección térmica por plasma es la descomposición de este material en fosfatos tricálcicos (am-TCP, $\beta-\mathrm{TCP}, \beta-\mathrm{TCP}$, tetracalcio fosfato y óxido de calcio) debido a las temperaturas elevadas del plasma [55,56]. Como resultado se obtiene un recubrimiento que combina fases cristalinas con fases amorfas, lo que reduce su bioactividad. Además, como se ha visto en apartados anteriores, estas fases amorfas tienden a disolverse con facilidad cuando están en contacto con el entorno biológico $[10,11,55]$, provocando roturas e incluso el desprendimiento del recubrimiento.

Tabla 1.3. Aplicaciones de los vidrios bioactivos fuera del sistema óseo [53]

\begin{tabular}{|c|c|}
\hline Aplicación & Implantación a nivel clínico \\
\hline $\begin{array}{c}\text { Cicatrización de heridas } \\
\text { Renaración de nerves }\end{array}$ & Totalmente implantado \\
\hline Ingeniería del tejido muscular & $\begin{array}{l}\text { Todavía no. Estudios in-vitro con } \\
\text { células en proceso. }\end{array}$ \\
\hline Reparación de ligamentos & $\begin{array}{l}\text { Todavía no. Estudios in-vitro con } \\
\text { células en proceso. }\end{array}$ \\
\hline Cornea artificial & $\begin{array}{c}\text { Todavía no. Estudios in-vivo con } \\
\text { animales en proceso. }\end{array}$ \\
\hline Implantes orbitales & Totalmente implantado \\
\hline Implante coclear & Totalmente implantado \\
\hline Tratamiento de cánceres & Totalmente implantado \\
\hline Tratamiento de fibromas uterinos & $\begin{array}{l}\text { Todavía no. Estudios in-vitro con } \\
\text { células en proceso. }\end{array}$ \\
\hline
\end{tabular}


Es por ello por lo que actualmente se está estudiando el empleo de los vidrios bioactivos como sustitutos de la hidroxiapatita en la obtención de recubrimientos mediante proyección térmica por plasma. Ambos materiales pertenecen a la categoría de biocerámicos bioactivos y presentan buena biocompatibilidad y propiedades mecánicas similares [57]. Sin embargo, los vidrios bioactivos presentan mayor índice de bioactividad $[57,58]$ y, durante la deposición mediante proyección térmica, mantienen su carácter amorfo (requisito para su bioactividad como se ha comentado anteriormente) gracias a las elevadas temperaturas y enfriamiento brusco del material depositado [16, 59].

\subsection{La proyección térmica}

\subsubsection{Descripción y alcance}

Se conoce como proyección térmica al grupo o familia de técnicas de obtención de recubrimientos en las cuales materiales metálicos o no metálicos fundidos total o parcialmente se depositan sobre un sustrato previamente dispuesto o preparado para dicho fin [60].

Como puede apreciarse en la figura 1.8 [61], generalmente en cualquier técnica de proyección térmica, un material determinado (bien en forma pulverulenta o en forma de alambre o barra) es sometido a una fuente energética la cual, tras fragmentar el material en pequeñas partículas, transmite a éstas energía calorífica y cinética, de tal manera que el material se transforma en pequeñas gotas en estado fundido o semifundido y son aceleradas hacia el sustrato. Una vez producido el impacto sobre el sustrato, estas gotas se enfrían de forma súbita quedando completamente adheridas al sustrato.

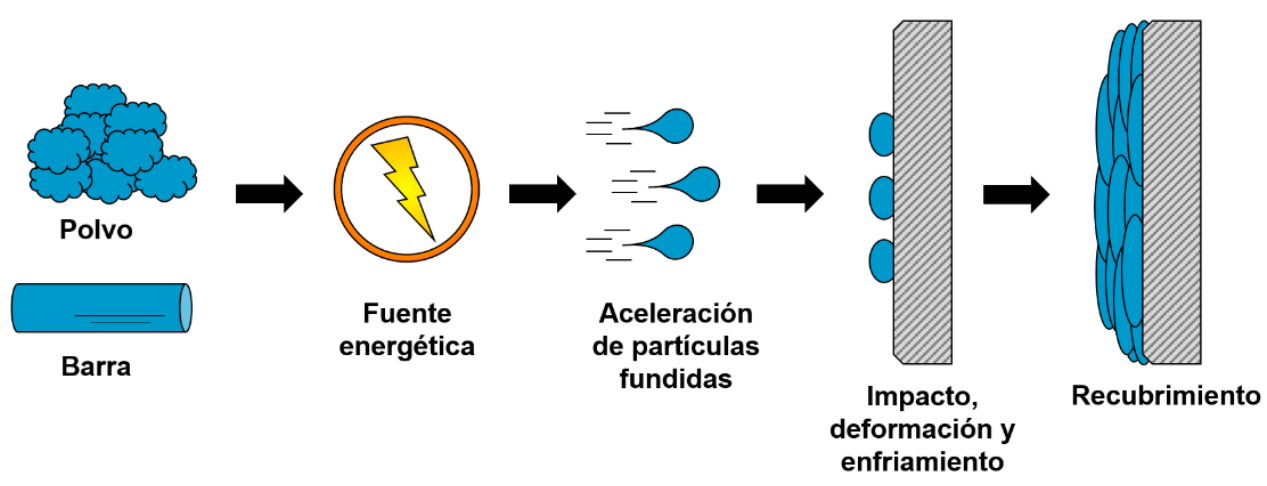

Figura 1.8. Proceso de obtención de un recubrimiento mediante proyección térmica. Figura adaptada de [61]

Al impactar sobre el sustrato, las gotas de material adquieren una morfología más o menos laminar o lenticular denominada "splat", en función de la velocidad de éstas en el momento del impacto y su grado de fusión, adquiriendo 
aproximadamente un diámetro de $150 \mu \mathrm{m}$ y un grosor entre 1 y $20 \mu \mathrm{m}$ [61-64]. A modo de ejemplo, en la figura 1.9 se muestra una ilustración en sección de una serie de "splats" conformando un recubrimiento [64]. Mediante la acumulación de estos "splats" unos sobre otros, se va generando una estructura formada por el material objeto de estudio sobre el sustrato, comúnmente conocida como recubrimiento.

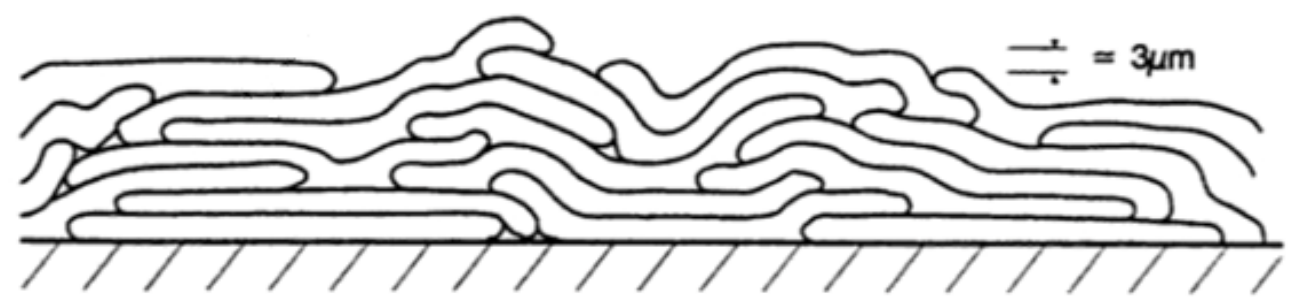

Figura 1.9. Microestructura compuesta por "splats" de un recubrimiento depositado mediante proyección térmica. Figura adaptada de [64]

A la hora de obtener recubrimientos mediante proyección térmica, independientemente de la técnica utilizada, es necesario una serie de etapas, que se describen a continuación.

- Etapa de preparación del sustrato. Como se ha mencionado en la definición de proyección térmica al inicio de este apartado, la deposición del recubrimiento se lleva a cabo sobre un sustrato preparado. Se trata de una etapa muy importante para los procesos de proyección térmica ya que de ella depende en gran medida la adherencia del recubrimiento final. Normalmente, los sustratos utilizados en proyección térmica son de tipo metálico y suelen contener aceites o grasas para protegerlos de la corrosión, algo de óxido o incluso restos de un recubrimiento previo sobre su superficie. Además, no siempre cumplen con las especificaciones de tamaño deseadas para la aplicación final o presentan zonas muy angulosas difíciles de recubrir $[61,62]$. Es por ello que resulta necesario una primera etapa de limpieza y mecanizado de los sustratos. Para desgrasar los sustratos suele emplearse baños de ultrasonidos junto con solventes orgánicos como etanol o vapor de agua a alta presión si el sustrato es de elevadas dimensiones $[61,62,65,66]$. En el caso de restos de anteriores recubrimientos metálicos o cerámicos, se suele sumergir el sustrato en un baño de agentes químicos o someter a un arco eléctrico [62].

Tras la limpieza, es necesario llevar a cabo una activación de la superficie del sustrato, puesto que en proyección térmica la adhesión entre el recubrimiento y el sustrato es de tipo mecánico. Es por ello por lo que esta etapa consiste en dotar la superficie a recubrir de cierta rugosidad, ya que a mayor rugosidad mayor adherencia. Para este fin, el método más utilizado es el de granallado [61,62,65-69], es decir, la proyección de un abrasivo metálico (como acero o hierro fundido [66]) o cerámico (como alúmina, sílice o carburo de silicio [67]) a muy alta velocidad sobre el sustrato. El proceso 
de granallado suele emplearse con sustratos metálicos, y el valor de rugosidad vendrá definido por el tamaño de partícula del abrasivo $[68,69]$. Otra forma de dotar de rugosidad al sustrato es mediante chorreado de agua a alta presión (cuando se trata de sustratos de superaleaciones) o mediante ablación laser [62].

Por otro lado, además de incrementar la rugosidad del sustrato, cuando la composición del recubrimiento difiere mucho de la del sustrato (por ejemplo, deposición de un material cerámico sobre un sustrato metálico) es bastante usual aplicar un recubrimiento intermedio entre el sustrato y el recubrimiento final [70]. Este recubrimiento intermedio se denomina capa de anclaje o "bond coat" (BC) y suele poseer propiedades físicas (coeficiente de expansión térmica) intermedias entre las que posee el sustrato y el recubrimiento final, mejorando así la adhesión de este último y reduciendo las tensiones entre ambos. A modo de ejemplo, Lima et al., depositaron recubrimientos de circona estabilizada con itria (YSZ) sobre sustratos de acero al carbono empleando distintas aleaciones de tipo CoNiCrAIY, NiCoCrAITaY, NiCrAIY y NiCr como capa de anclaje [71], o Kurzweg et al., depositaron recubrimientos de hidroxiapatita sobre sustratos de titanio de grado $\mathrm{V}$ o Ti6AI4V utilizando distintas capas de anclaje (circona estabilizada con óxido de calcio, circona estabilizada con óxido de titanio y óxido de titanio solo) [72]. Además, como se demuestra en estos trabajos, la capa de anclaje puede depositarse mediante la misma técnica de proyección térmica utilizada para depositar el recubrimiento final u otra técnica de la familia de proyección térmica.

- Etapa de proyección o deposición del recubrimiento. Cuando está listo el sustrato, se procede con la deposición del material que constituirá el recubrimiento. La técnica de proyección térmica a emplear dependerá de varios factores como por ejemplo el tipo de material, especificaciones requeridas al recubrimiento final, razones económicas, tamaño y facilidad de manejo del sustrato, etc. [61].

- Etapa de postratamiento del recubrimiento. Una vez obtenido el recubrimiento, puede que no cumpla con las especificaciones necesarias para el fin al cual va destinado. Por ello, durante las últimas décadas es bastante común llevar a cabo un postratamiento del recubrimiento tras su deposición [62]. Los tratamientos más habituales son tratamiento térmico (mediante fuentes electromagnéticas como láser [73] o microondas [74], hornos de alta temperatura [75] o antorcha de proyección por llama [76]), sellado químico [77] o un acabado mediante pulido [78] con el objetivo de densificar el recubrimiento, modificar su grado de cristalinidad y estado de oxidación, reducir en cierto grado su porosidad y modificar su espesor y rugosidad superficial.

Las técnicas que conforman el amplio abanico de la proyección térmica se clasifican en 4 grupos en función de la fuente energética que emplean para fundir, acelerar y depositar el material en cuestión como se ha comentado 
anteriormente. En la figura 1.10 se muestra, a modo de esquema, la clasificación de las técnicas de proyección térmica más empleadas y en la tabla 1.4 se muestran las características generales de estas técnicas. Sin embargo, los datos de la tabla 1.4 no deben considerarse valores definitivos, sino que, para un determinado material, pueden variar debido a diferentes factores como la composición, las propiedades térmicas, físicas o químicas del propio material depositado o los parámetros de proyección utilizados.

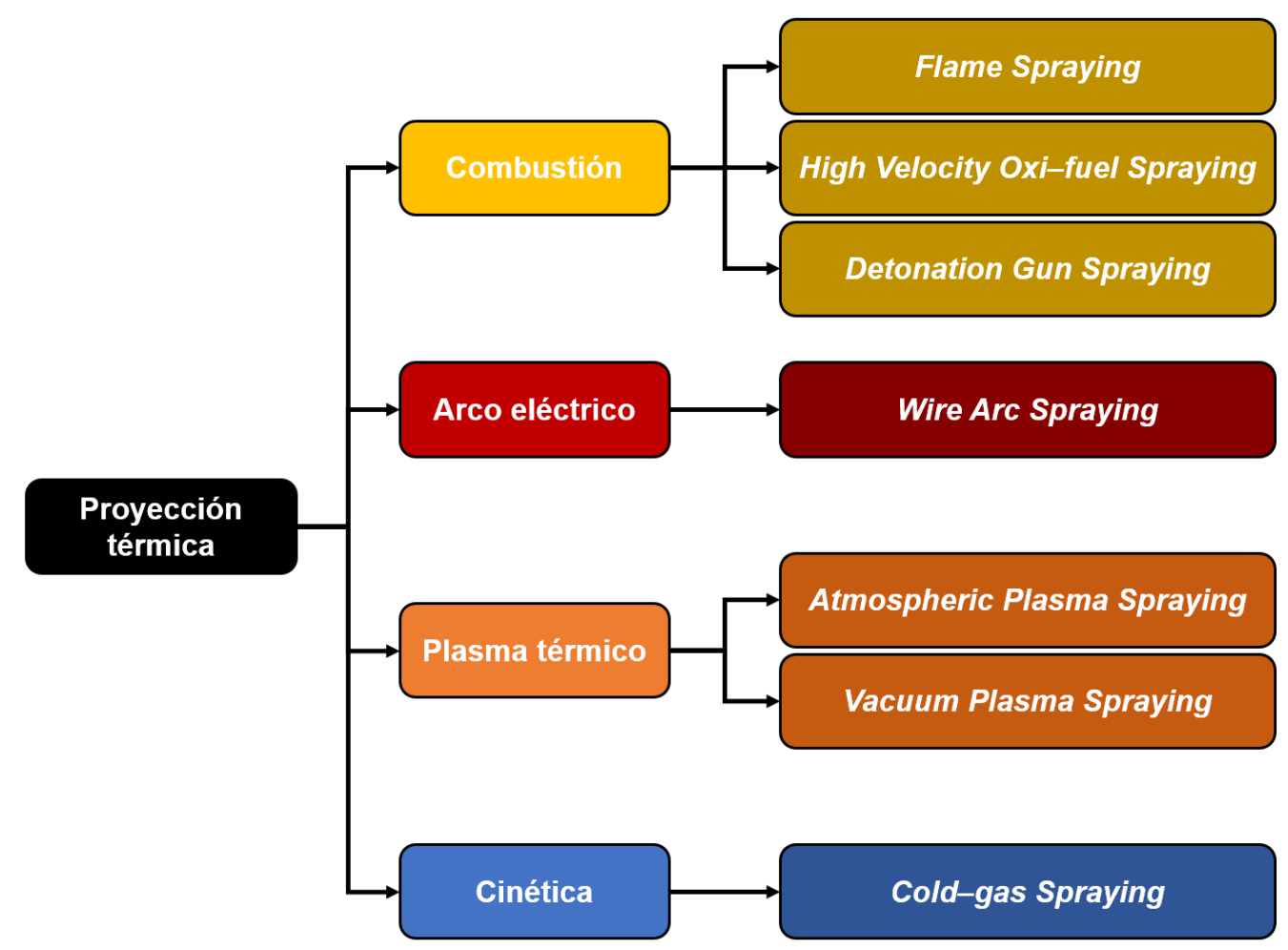

Figura 1.10. Clasificación de diferentes técnicas de proyección térmica en función de la fuente energética que utilizan $[60-63,79]$

El primer grupo de técnicas basan su fuente energética en la combustión. Por un lado, está el caso de la proyección por llama o Flame Spraying (FS) en la que se realiza la combustión de un combustible en oxígeno para generar una llama en la cual se introduce el material pulverulento que funde y es acelerado hacia el sustrato. También se emplea la llama generada en la combustión para fundir una barra del material deseado y mediante una corriente de aire comprimido se pulverizan las gotas de material fundido lanzándolas hacia el sustrato. Por otro lado, están las técnicas de proyección térmica de alta velocidad (High Velocity Oxy-fuel Spraying, HVOF) y por detonación (Detonation Gun Spraying, D-Gun). En HVOF, se introduce una mezcla de gas combustible y oxígeno en una cámara de combustión presurizada de forma continua, en donde se quema alcanzando elevadas temperaturas. 
Tabla 1.4. Características generales de las técnicas de proyección térmica $[60,62]$

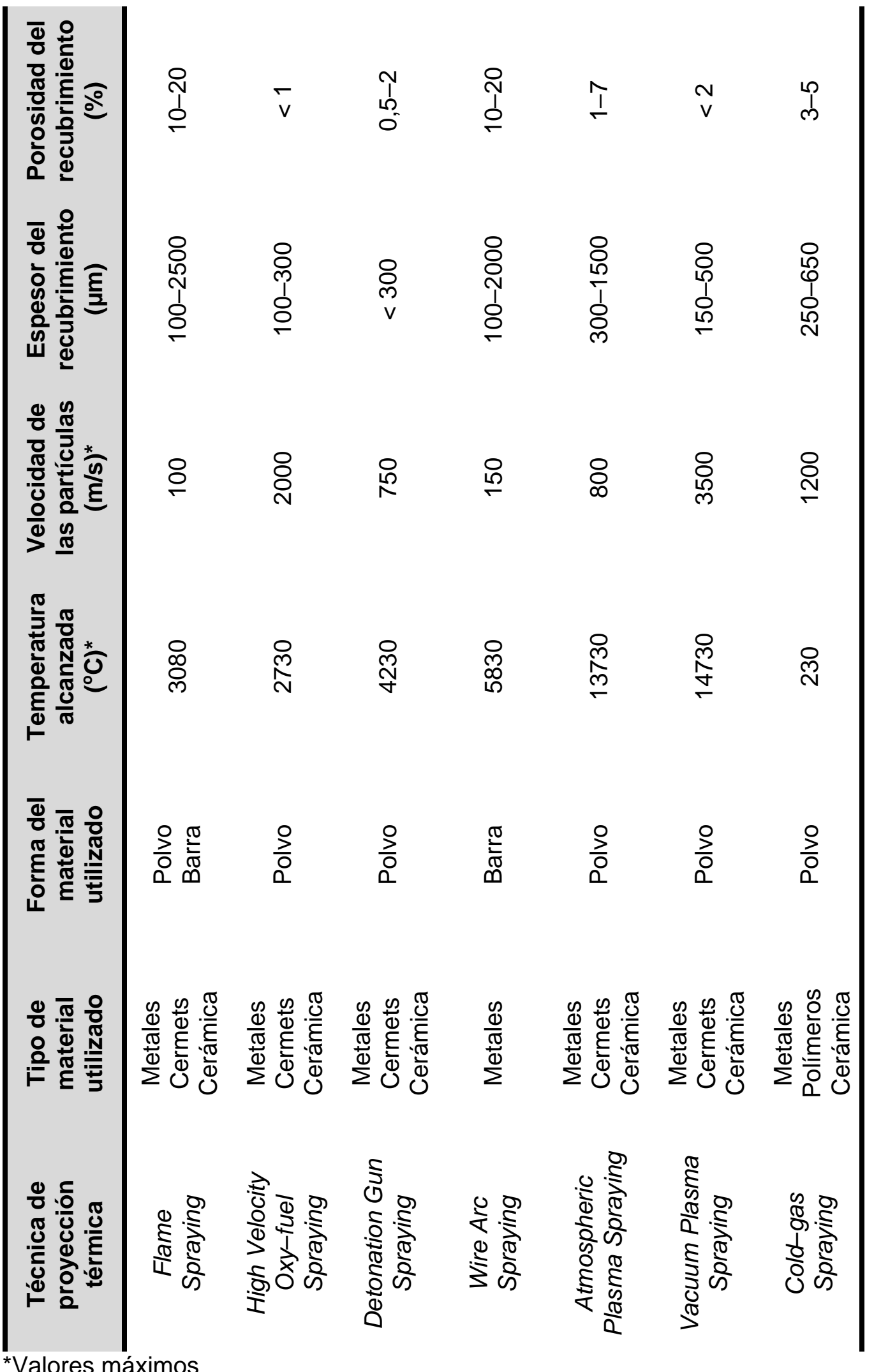


Como resultado se generan unos gases de combustión que, debido a la diferencia de presión, son expulsados de la cámara de combustión y forzados a pasar a través de una boquilla donde alcanzan una elevada velocidad. El material en forma de polvo se introduce en la corriente de gases de combustión procedente de la cámara, donde funde gracias a la elevada temperatura de estos gases por la combustión y se acelera hacia el sustrato por la elevada velocidad de estos gases. La técnica D-Gun es muy similar a la HVOF, salvo que el material se introduce junto con la mezcla de gas combustible y oxígeno a la cámara de combustión, donde se produce una ignición o detonación controlada que funde y proyecta el material. Además, la inyección de material junto con mezcla comburente se lleva a cabo de forma discontinua, introduciendo un gas inerte en la cámara entre inyecciones para reducir el riesgo de explosión.

En el caso del segundo grupo, la fuente energética es un arco eléctrico. Básicamente, en la proyección por arco eléctrico o Wire Arc Spraying (AS), para obtener el recubrimiento deseado se genera un arco eléctrico entre dos barras metálicas de igual o distinta composición y de distinta carga eléctrica, de tal forma que el calentamiento producido por este arco va fundiendo las barras dando lugar a gotas de material fundido y partículas semifundidas, las cuales son arrastradas por un gas de atomización hacia el sustrato.

El siguiente grupo o categoría está compuesto por varias técnicas que utilizan un plasma térmico como fuente de energía. El plasma se genera mediante la ionización de una mezcla gaseosa al pasar a través de un arco eléctrico. Este grupo de técnicas se puede considerar independiente del grupo anterior puesto que, aunque también hay presencia de un arco eléctrico, en este caso el arco solo se emplea para generar el plasma como se ha comentado y no para modificar el estado del material objeto de estudio. En las técnicas de plasma térmico, el material en forma pulverulenta es introducido directamente en el jet o pluma de plasma donde funde y es proyectado hacia el sustrato. La proyección por plasma suele llevarse a cabo a presión atmosférica (Atmospheric Plasma Spraying, APS) o a vacío (Vacuum Plasma Spraying, VPS), aunque recientemente se está empezando a depositar recubrimientos en atmósfera de presión controlada y/o inerte.

Por último, está el grupo formado por la técnica de proyección fría o Cold-gas Spraying (CS). En este grupo, se utiliza energía cinética para la deposición del material objeto de estudio. En un sistema típico de proyección CS, se comprime una corriente gaseosa y posteriormente se calienta a baja temperatura. Esta corriente es forzada a pasar por una boquilla de tipo convergente-divergente DeLaval, y al salir de ésta expande alcanzando velocidades supersónicas. El material, en forma de polvo, se introduce en la corriente gaseosa justo antes de entrar en la boquilla. Una vez introducido en la corriente, en función del punto de fusión del material que se desea depositar, éste fundirá o reblandecerá, y al salir de la boquilla es impulsado hacia el sustrato gracias a la elevada velocidad de la corriente gaseosa. 


\subsubsection{Proyección térmica por plasma atmosférico o APS}

La proyección térmica por plasma atmosférico es una técnica de obtención de recubrimientos que basa su fuente energética en un plasma térmico. El punto fuerte de esta técnica es la elevada temperatura que puede alcanzar (Tabla 1.4) lo que hace posible fundir cualquier material. En la figura 1.11 se muestra un esquema de una antorcha típica de APS [62], junto con una imagen de un juego de electrodos.
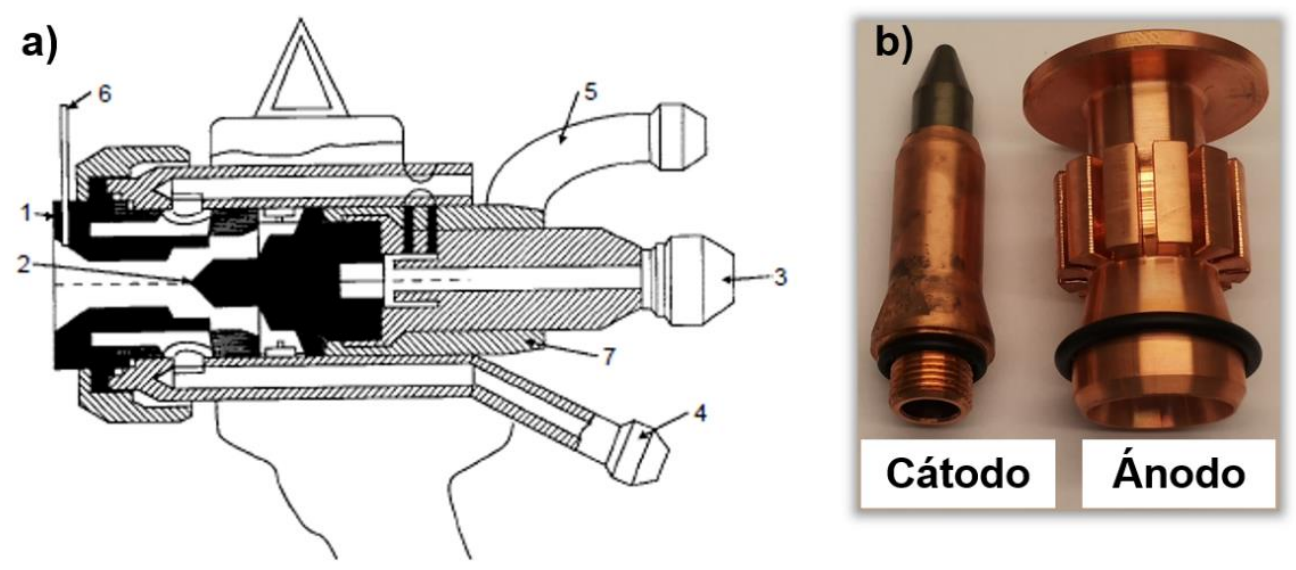

Figura 1.11. Antorcha de plasma de corriente directa (DC) junto con juego de electrodos. a) Esquema de la antorcha [62], b) electrodos

Este tipo de antorcha es conocida como antorcha de proyección por plasma atmosférico de corriente directa (direct current or DC plasma torch) y, como se observa en la figura $1.11 \mathrm{a}$, está compuesta por un juego de electrodos acoplados en el interior de un aislante eléctrico (7), dispuesto a modo de carcasa. En la figura 1.11b se muestra un juego de electrodos, los cuales son un ánodo (1) de geometría circular compuesto totalmente de cobre y un cátodo (2) de geometría longitudinal cuyo cuerpo está formado también por cobre y cuyo extremo final, donde se genera el arco eléctrico, es de tungsteno dopado con torio. Sin embargo, al tratarse el torio de un material radioactivo, recientemente se ha empezado a eliminar este material del cátodo, pasando a ser el extremo final de éste totalmente de tungsteno [80]. Además, esta sustitución no conlleva ningún efecto sobre las propiedades finales de cualquier recubrimiento depositado [80]. La antorcha de plasma lleva instalado un sistema cerrado de refrigeración de los electrodos por agua. Partiendo de un depósito, el agua entra al sistema (4), rodea totalmente al ánodo y sale del sistema (3) para volver al depósito de partida. Es importante mantener la conductividad eléctrica del agua de refrigeración lo más próxima a 0 posible con el fin de evitar pérdidas de potencia del arco eléctrico generado entre los electrodos. Una vez generado el arco eléctrico entre el cátodo y el ánodo, se introducen los gases plasmógenos en la antorcha, siendo el recorrido de estos 
gases de izquierda a derecha de la imagen, entrando al sistema por (5) y saliendo por el extremo izquierdo del ánodo. Al forzar estos gases a pasar a través del arco eléctrico se ionizan generando iones y electrones. A continuación, pasado el arco eléctrico, esta mezcla de iones y electrones sale al exterior por la boquilla del ánodo, recombinándose entre sí, dando como resultado la formación de un plasma térmico (figura 1.12a).

Los gases empleados normalmente para la generación de la pluma de plasma en APS son argón $(\mathrm{Ar})$, helio $(\mathrm{He})$, hidrógeno $\left(\mathrm{H}_{2}\right)$ y nitrógeno $\left(\mathrm{N}_{2}\right)$ y mezclas de éstos [60-62,81-83]. Sin embargo, el empleo de este último gas es mínimo debido a su posible reacción con algunos materiales durante su deposición. El Ar es el gas más utilizado y su función es la de estabilizar el arco eléctrico formado entre los electrodos y aportar energía cinética a las partículas inyectadas $[62,82]$. Se trata de un gas inerte que no reacciona con los materiales inyectados y no es nada agresivo con los componentes de la antorcha y los electrodos. El Ar se emplea por si solo o mezclado con los otros dos gases [81-83]. En cuanto a los otros dos gases, éstos se emplean como gases secundarios y su función es la de mejorar la conducción de energía térmica desde la pluma de plasma hasta las partículas inyectadas gracias a su elevada conductividad térmica (sobre todo el hidrógeno) [61,62,81-83].
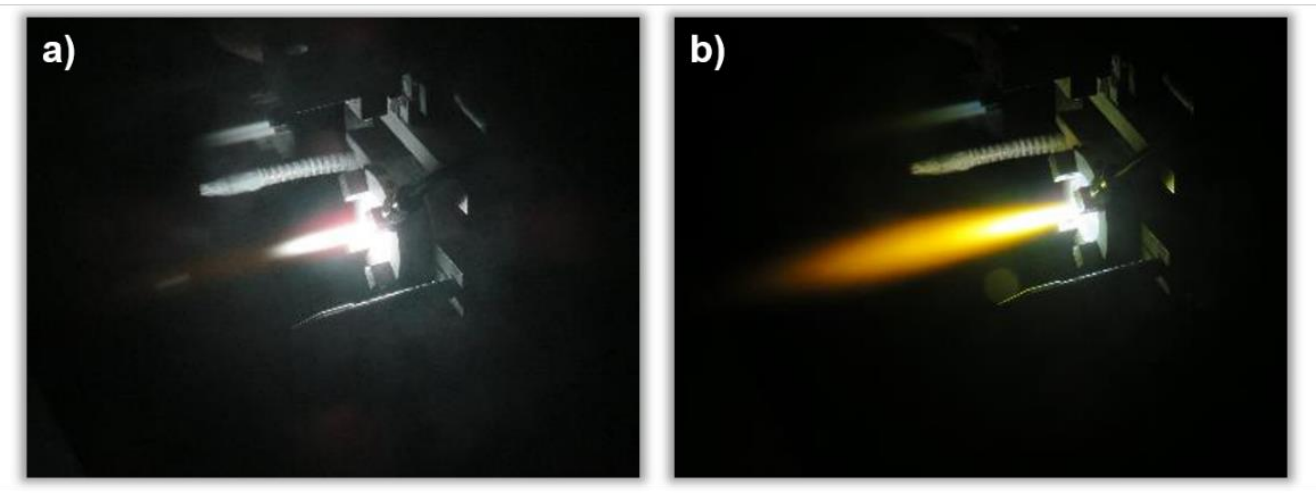

Figura 1.12. Ejemplo de pluma de plasma para una mezcla de gases argón + hidrógeno. a) Solo pluma, b) pluma con inyección de partículas de vidrio

Como ejemplo, en la figura 1.13 se representa la variación de la conductividad térmica de una pluma de plasma de $\mathrm{Ar}$ con diferentes concentraciones de $\mathrm{H}_{2}$ [84]. En esta figura se observa como para una temperatura dada, la conductividad térmica de la pluma aumenta conforme aumenta la concentración de gas secundario $\left(\mathrm{H}_{2}\right)$.

La densidad energética o entalpía de la pluma de plasma generada también depende de la composición de la mezcla gaseosa utilizada [62,84]. De esta forma, en el caso de los gases monoatómicos (argón y helio), al cruzar el arco 


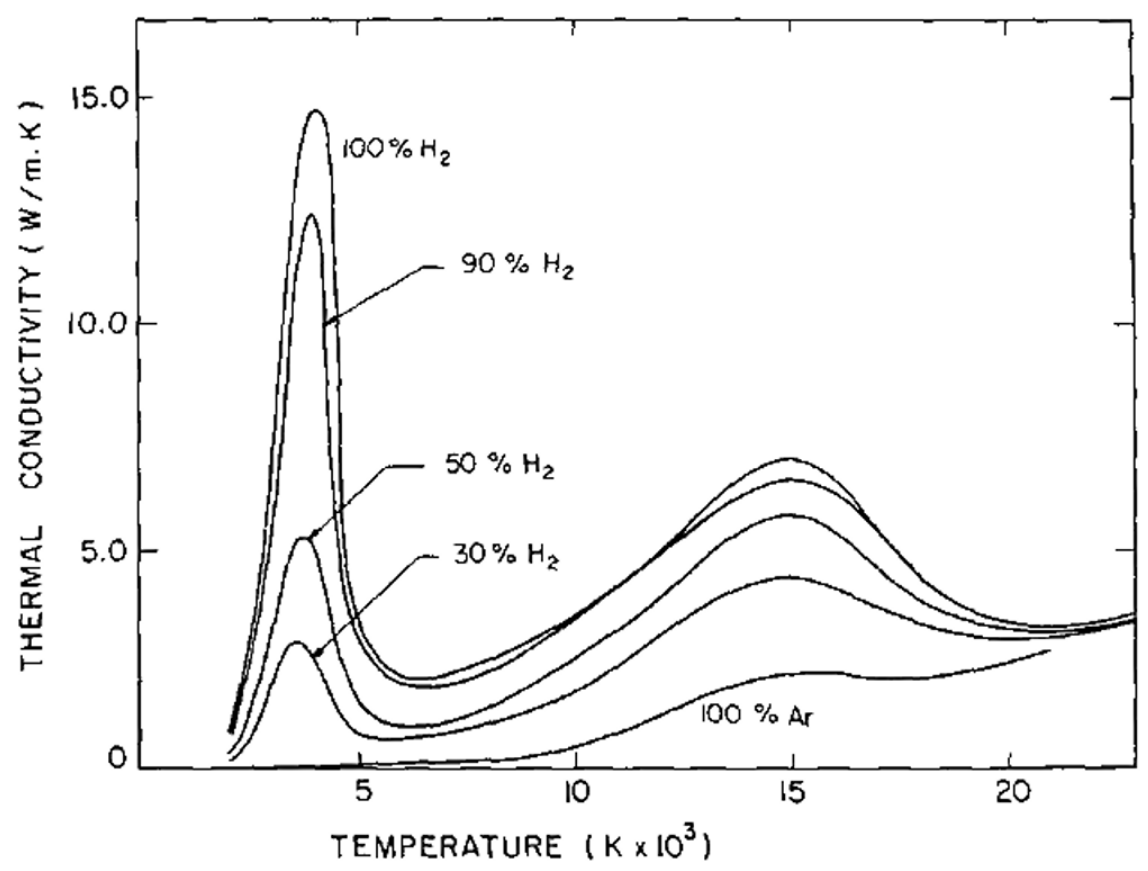

Figura 1.13. Variación de la conductividad térmica en función de la temperatura de una pluma de plasma de argón con diferentes concentraciones de hidrógeno [84]

eléctrico solo experimentan una ionización liberando iones y electrones en base al siguiente esquema de reacción (donde $M$ hace referencia a los gases monoatómicos $\mathrm{Ar}$ y $\mathrm{He}$ ):

$$
M+\text { energía } \rightarrow M^{+}+e^{-} \text {(ec.1.5) }
$$

La densidad energética de estos gases es menor que la de los diatómicos que, previamente a la ionización, se disocian, por lo que al recombinarse los electrones con los iones hay mayor cantidad de éstos (iones y electrones) y se produce una liberación energética mayor. A continuación, se muestran los esquemas de reacción correspondientes a la disociación y ionización de los gases diatómicos $\mathrm{N}_{2}$ y $\mathrm{H}_{2}$ (representados por $\mathrm{D}$ ) y una representación de la densidad energética de cada gas en función de la temperatura (figura 1.14) $[61,83,84]$.

$$
\begin{gathered}
D_{2}+\text { energía } \rightarrow 2 D \text { (ec. 1.6) } \\
2 D+\text { energía } \rightarrow 2 D^{+}+2 e^{-} \text {(ec. 1.7) }
\end{gathered}
$$




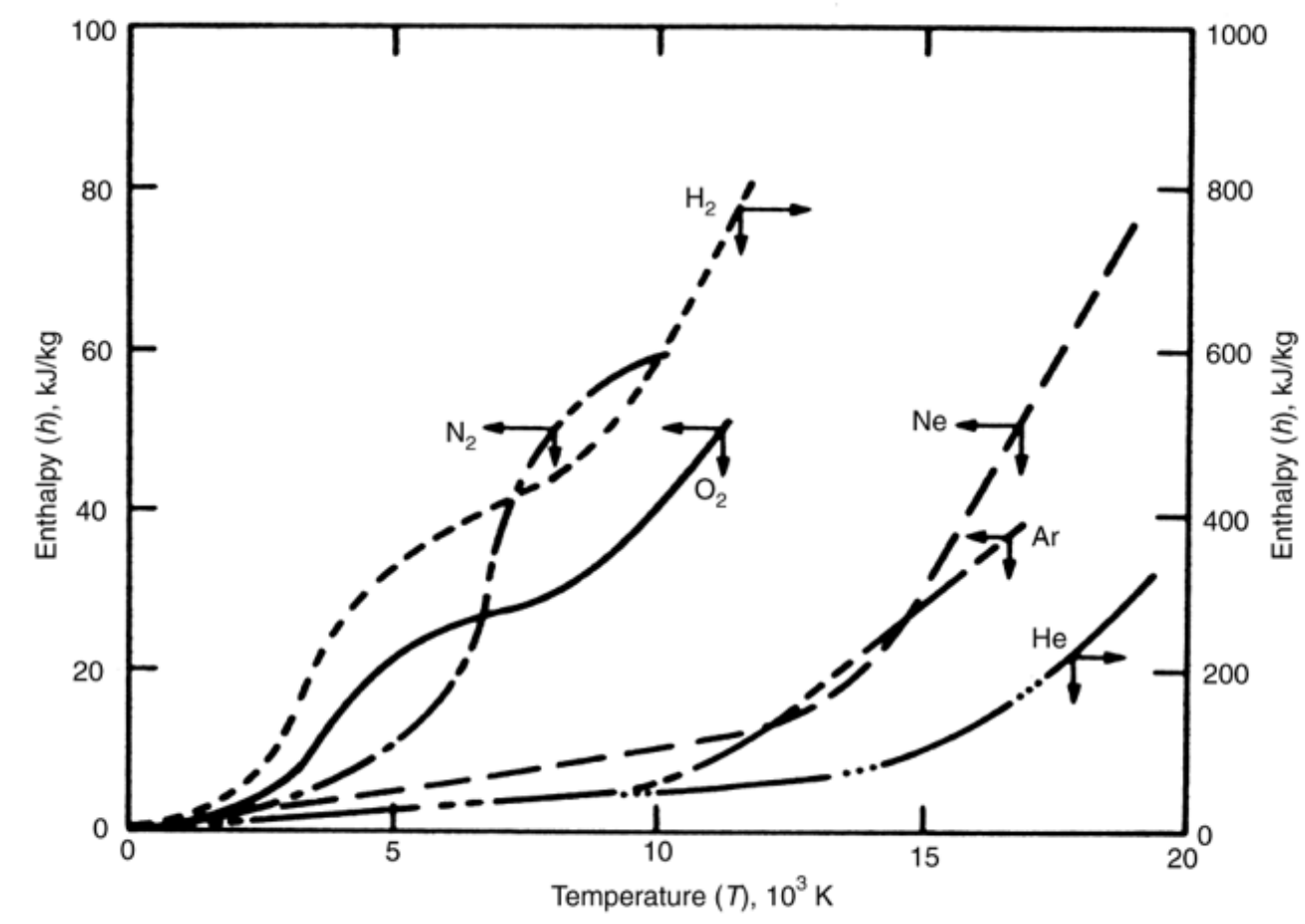

Figura 1.14. Densidad energética en función de la temperatura para los gases plasmógenos $[61,83,84]$

Al observar la figura 1.14, queda patente lo comentado en el párrafo anterior, ya que para una temperatura dada la densidad energética para los gases diatómicos es superior a la de los monoatómicos, sobre todo en el caso del hidrógeno.

Una vez generada la pluma de plasma, es posible inyectar o introducir en la misma el material que se desea depositar (punto 6 en figura 1.11a). Como se ha descrito en la tabla 1.4, los materiales utilizados en APS están en forma pulverulenta. Al introducir el material, la pluma de plasma sufre un cambio de coloración (el nuevo color es función de la composición del material proyectado) y una elongación debido a la nube de partículas incandescentes proyectadas como puede verse en la figura 1.12b. La inyección de las partículas se lleva a cabo mediante transporte neumático empleando uno de los gases utilizado en la generación de la pluma de plasma (normalmente argón). Para tal fin, hay dos tipos diferentes de tolvas o dispositivos de dosificación, los de disco rotatorio y los de lecho fluidizado [85-89]. En la figura 1.15 se muestra un esquema del modo de operación de cada uno de estos dispositivos [85]. Los dispositivos de disco rotatorio (Figura 1.15a) se basan en un principio volumétrico. El polvo contenido en la tolva cae por gravedad a un disco dosificador el cual gira, llevando el polvo desde la tolva al conducto de descarga, donde el gas portador arrastra el polvo hasta la pluma de plasma por transporte neumático tal y como se ha comentado anteriormente. La cantidad de polvo transportado será 
función de la velocidad de rotación del disco, así como de la capacidad volumétrica de éste [85-89]. En cuanto a los dispositivos de lecho fluidizado (Figura 1.15b), parte del gas portador es desviado de la corriente principal, presurizado e introducido, tanto por la parte superior, como por la parte inferior de la tolva que contiene el polvo. De esta forma, se genera una contrapresión en la masa de polvo, dando lugar a la formación de un lecho fluidizado en la tolva. Finalmente, el polvo es arrastrado de este lecho hacia la antorcha de plasma por la corriente principal de gas portador, la cual se introduce de forma perpendicular a la tolva. En este dispositivo, la cantidad de polvo transportado será función de la presión del gas portador, de tal forma que al aumentar este parámetro aumenta el volumen de polvo a transportar [85-89]. Aunque ambos sistemas son fiables y los equipos duraderos a muy largo plazo, el sistema basado en el disco dosificador es más sencillo en diseño, fiable y muy fácil de mantener [89].

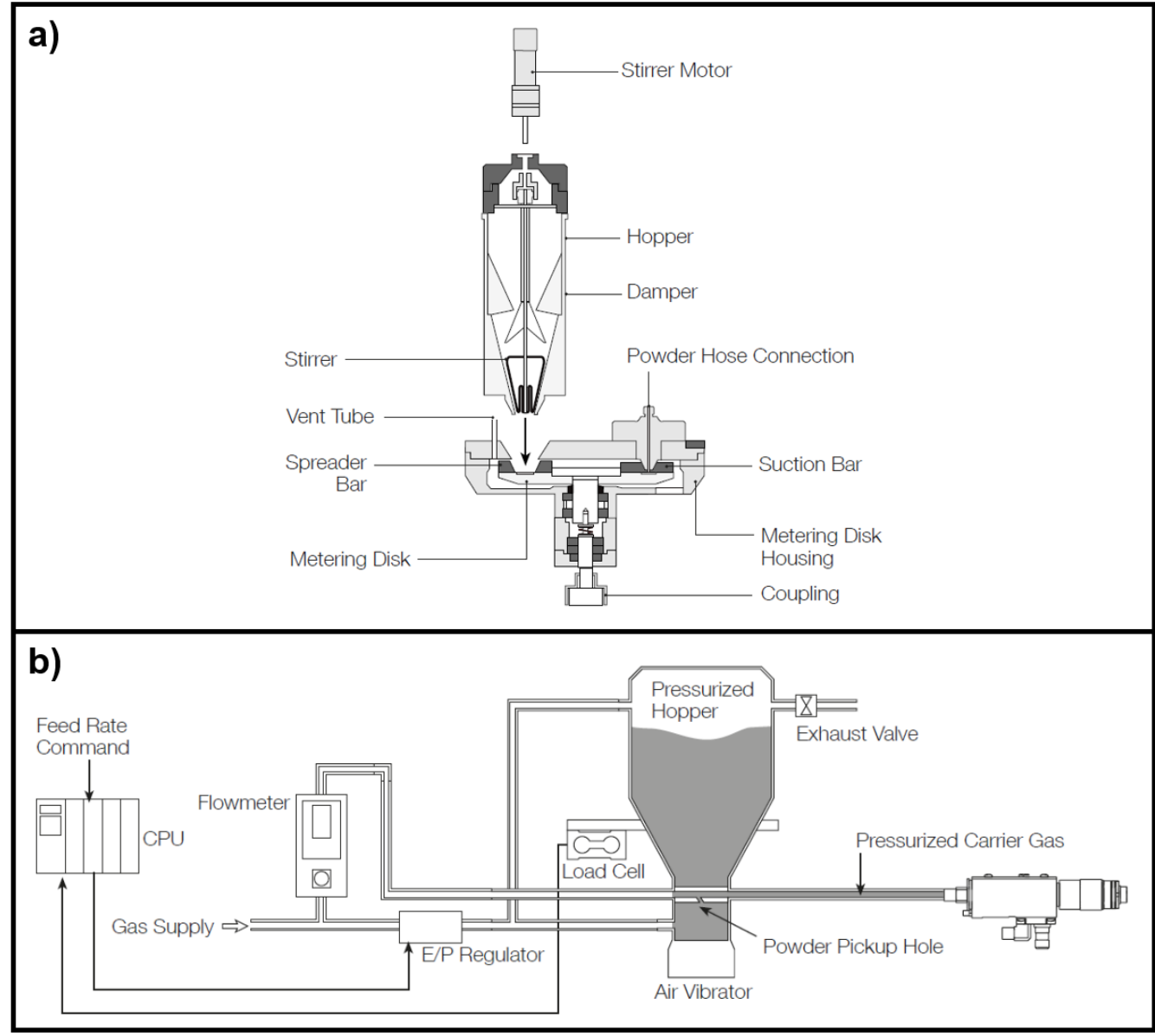

Figura 1.15. Esquemas de operación de los dispositivos dosificadores de polvo utilizados en proyección térmica por plasma. a) Dosificador de disco rotatorio [85], b) dosificador de lecho fluidizado [85]

Desde el desarrollo de la proyección por plasma, este método de deposición se utiliza para obtener recubrimientos a partir de un amplio abanico de materiales. 
A continuación, se detallan los tipos de materiales depositados por APS junto con algunos ejemplos.

- Materiales metálicos como por ejemplo níquel, molibdeno o cobre [9092].

- Aleaciones metálicas tales como Ni20Cr, NiCrSiBC o NiCrSiMoBFeC $[93,94]$.

- Materiales cerámicos como son alúmina, titania, cromia, circona (sola o estabilizada) o hidroxiapatita [95-98].

- Cermets o composites como por ejemplo grafito-Ni o WC-Co $[99,100]$.

- Carburos y boruros como carburo de silicio, boruro de circonio o carburo de cromo (III) $[101,102]$.

Los métodos utilizados para obtener estos materiales en forma de polvo varían en función del material deseado. Los más empleados son la atomización (para metales y aleaciones metálicas), sinterización o fusión (para materiales cerámicos, cermets o composites y carburos y boruros), secado por atomización (para cualquier material), revestimiento físico o químico (para cermets o composites), mecano fusión (para aleaciones metálicas y cermets o composites) y la síntesis por combustión a alta temperatura o SHS (para carburos y boruros) [62]. Como resultado se obtiene un material particulado 0 granulado (en función del método) con un tamaño comprendido entre 10-100 $\mu \mathrm{m}$. Todo material pulverulento desarrollado para su posterior empleo en APS debe cumplir una serie de requisitos [103,104]:

> Presentar una distribución de tamaños de partícula lo más estrecha posible, un tamaño adecuado y una morfología lo más redondeada posible para favorecer la fluidez del material desde la tolva hasta la antorcha de plasma. Las partículas de tamaño inferior a $10 \mu \mathrm{m}$ presentan problemas de fluidez debido a las fuerzas cohesivas que se dan entre partículas.

> Tener una composición controlada, es decir, evitar la presencia de impurezas o contaminaciones ya que éstas pueden afectar negativamente a las propiedades del recubrimiento final. Además, en el caso de composites, se debe asegurar el mezclado íntimo durante el proceso de preparación de los componentes que conformen el material final.

> Por otra parte, en el caso de materiales aglomerados, aunque la morfología de estos polvos es prácticamente esférica, deben presentar densidades superiores a $1700 \mathrm{~kg} / \mathrm{m}^{3}$ y un tamaño de gránulo mayor 0 igual a $20 \mu \mathrm{m}$ para poder ser inyectados sin dificultad en la antorcha de plasma. 


\subsubsection{Parámetros de la técnica de proyección por plasma atmosférico}

A la hora de depositar un recubrimiento mediante proyección térmica por plasma, el caso óptimo o ideal se corresponde con el ilustrado en la figura 1.16, es decir, tras generar la pluma de plasma e inyectar el material, las partículas penetran hasta el corazón o punto central de la pluma donde son calentadas de forma uniforme, alcanzando una temperatura superior a la de fusión y una velocidad suficientemente elevada para impactar y adherirse correctamente al sustrato, formando un recubrimiento denso y homogéneo.

Sin embargo, el proceso APS es muy complejo y la calidad y propiedades finales de los recubrimientos depositados dependen, tanto de la temperatura, como de la velocidad alcanzada por las partículas en el interior de la pluma de plasma, así como del estado del sustrato en el momento de la deposición del material.

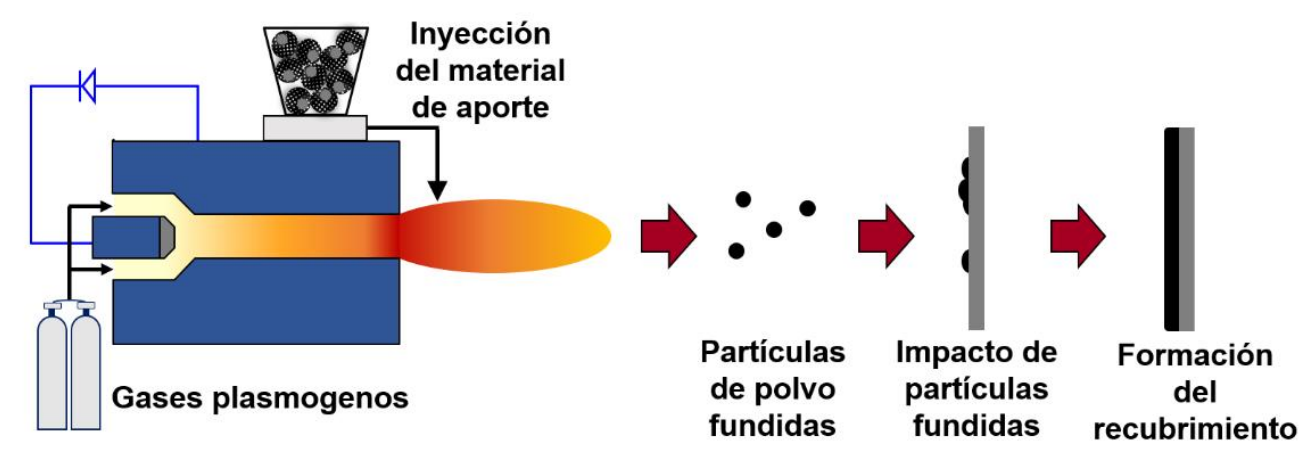

Figura 1.16. Recorrido del polvo desde su inyección hasta la formación del recubrimiento final

A su vez, la temperatura alcanzada, velocidad y estado del sustrato son función de 50-60 parámetros diferentes relativos a la técnica [81], relacionados unos entre otros en menor o mayor medida. De entre todos estos parámetros, los de mayor relevancia se agrupan y se detallan a continuación en tres categorías diferentes, parámetros relacionados con el material y su proceso de inyección, parámetros de la propia antorcha de plasma y parámetros relacionados con el estado del sustrato durante la deposición [61,62,81,84,105-124].

\subsubsection{Parámetros relativos al material depositado}

En lo que concierne al material depositado, los parámetros a tener en cuenta son, por un lado, el tipo de material objeto de estudio y su distribución de tamaños de partícula, ya que los materiales particulados o aglomerados obtenidos por los métodos descritos anteriormente nunca poseen un tamaño 
de partícula constante, sino que éste varía en una distribución más ancha o más estrecha.

Para una misma distribución de tamaños de partícula y una pluma de plasma con condiciones energéticas dadas, la fusión del material objeto de estudio se producirá antes si el material es metálico en lugar de si se utiliza un material cerámico, por lo que el tipo de material será importante a tener en cuenta en la elección de los parámetros de proyección relativos a la pistola de plasma. Por otra parte, para una composición dada, la distribución de tamaños de partícula afectará a la fusión del material. Tal y como describe Fauchais [81], a un material dado con una distribución de tamaños convencional entre 22-45 $\mu \mathrm{m}$ le corresponde una relación entre diámetros de 2, la cual no es elevada. Sin embargo, esta relación de diámetro puede llegar a corresponder a una relación en masa de hasta 8 , por lo que no todas las partículas inyectadas se comportarán igual en el interior de la pluma de plasma desde el punto de vista de la fusión. Mediante APS se deposita diferentes tipos de materiales (como se ha comentado en apartados anteriores), aunque mayoritariamente óxidos cerámicos, con distribuciones de tamaños de partícula variables, cuyos límites inferior y superior se sitúan en 10 y $100 \mu \mathrm{m}$ respectivamente.

Por otro lado, se ha de tener en cuenta el proceso de inyección del material objeto de estudio en el interior de la pluma de plasma. A la hora de inyectar el material, este proceso está fuertemente influenciado por diferentes factores: el tipo de inyección (axial o radial), el caudal de gas portador, el caudal de polvo inyectado y tanto la geometría del inyector como su ángulo y su posición respecto a la pluma de plasma. La inyección del material puede llevarse a cabo de forma axial o radial, y esta última, a su vez, puede ser interna o externa. La inyección axial consiste en introducir el material paralelamente al eje en el cual se genera la pluma de plasma mientras que la radial consiste en introducir el material de forma perpendicular a la pluma de plasma (Figura 1.17).

a)

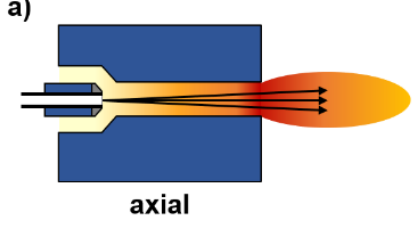

b)

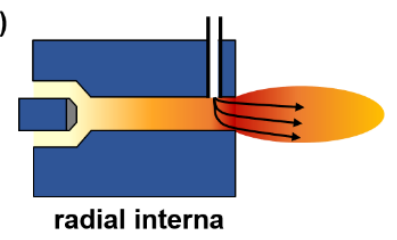

c)

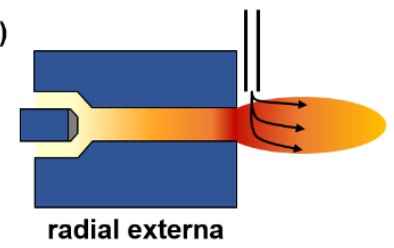

Figura 1.17. Tipos de inyección de polvo en proyección por plasma. Las flechas indican las posibles trayectorias del material una vez inyectado en función del caudal de gas portador. a) Inyección axial, b) inyección radial interna y c) inyección radial externa

En el caso de inyección axial y radial interna (Figuras 1.17a y 1.17b respectivamente), el material se introduce a la corriente gaseosa dentro del ánodo una vez pasado el arco eléctrico, logrando así un calentamiento mayor de todas las partículas, puesto que la recombinación de electrones e iones tiene lugar sobre la superficie de las partículas. Sin embargo, este calentamiento es menor en el caso de la inyección radial debido a que se produce un mayor 
esparcimiento de las partículas en la corriente gaseosa, y por tanto, no todas las partículas siguen la misma trayectoria, mientras que en la inyección axial este esparcimiento o expansión de la nube de partículas es mucho menor, manteniéndose la mayoría de las partículas más concentradas en el eje central de la pluma de plasma. Además, en ambos casos puede producirse una perturbación de la corriente gaseosa, ocasionando una pluma intermitente. En cambio, en el caso de la inyección radial externa (Figura 1.17c), el material se introduce de forma perpendicular aguas abajo desde la boquilla del ánodo donde se genera la pluma de plasma. Puesto que la pluma ya está formada en el punto de inyección, el calentamiento es menor ya que el punto más caliente de la pluma de plasma es el centro de la boquilla del ánodo donde se genera esta pluma. Además, no todas las partículas se calientan por igual debido a diferencias de penetración.

En cuanto al gas portador, éste es el encargado de transportar las partículas de material desde la tolva donde están contenidas hasta la antorcha de proyección e inyectarlas bien en la corriente gaseosa ionizada o bien en la pluma de plasma. Además, este gas debe asegurar la penetración del máximo número de partículas posible en la zona central de la pluma de plasma. Su empleo está justificado en el hecho de que las partículas deben presentar un impulso o energía cinética similar a la de la corriente gaseosa ionizada o la pluma de plasma para poder penetrar en cualquiera de ellos. Es por ello por lo que se utiliza uno de los gases plasmógenos como gas portador (comúnmente argón por su elevada densidad en comparación a los otros gases). El caudal utilizado de este gas portador contribuye en la determinación de la trayectoria de las partículas en el momento de la inyección. De esta forma, para un inyector y tamaño de partícula fijos, caudales muy reducidos de gas portador hacen que las partículas apenas penetren en la pluma (flecha superior en figura 1.17c) mientras que para caudales muy grandes las partículas atraviesan la pluma (flecha inferior en figura 1.17c). El caudal óptimo es aquel para el cual las partículas son capaces de penetrar hasta la zona central de la pluma, es decir, la zona más caliente, y que presenta mayor velocidad (flecha intermedia en figura 1.17c). Este efecto será menos notorio en el caso de utilizar inyección radial interna y axial, puesto que el impulso o energía cinética de la mezcla gaseosa antes de expandir a través de la boquilla del ánodo es inferior al de la pluma de plasma. El caudal de gas portante viene determinado por el diámetro medio de la distribución de tamaños de partícula $\left(d_{50}\right)$, ya que el valor de este caudal es inversamente proporcional al valor del diámetro medio de partícula elevado al cubo, por lo que, independientemente del tipo de inyección, habrá una limitación de tamaños de partícula, ya que cuando el caudal de gas portador es igual o superior al $10 \%$ del caudal total de gases plasmógenos, puede provocar perturbaciones en la pluma de plasma. Además, independientemente del tipo de inyección, siempre se dan variaciones en la trayectoria de algunas partículas en el momento de su inyección debido a colisiones entre estas partículas o entre las partículas y las paredes del inyector. El número de colisiones es mayor cuanto menor es el tamaño medio de partícula y, en consecuencia, mayor el caudal de gas portador. 
Por otro lado, otro factor importante del proceso de inyección del material es su caudal, es decir, la cantidad de material introducido por unidad de tiempo, bien en la pluma de plasma o bien en la corriente gaseosa. Esta cantidad de material afecta al grado de fusión de las partículas y su aceleración, puesto que, aunque la cantidad de material depositado es mayor cuanto mayor es su caudal, la transmisión de energía calorífica y cinética desde la pluma de plasma hacia las partículas es mucho menor. Asimismo, una elevada concentración de partículas también afecta de forma negativa a su penetración en la pluma, ya que la velocidad de las partículas a la salida del inyector disminuye debido al incremento de colisiones entre partículas,

Finalmente, el último factor a considerar es el inyector, el elemento utilizado para introducir el polvo en la pluma o mezcla gaseosa. El diámetro interno del inyector determina también la trayectoria de las partículas. Para un caudal y velocidad de partículas fijados, incrementar el diámetro interno del inyector conlleva a una dispersión excesiva de las partículas, provocando que la mayoría rodee la pluma de plasma en lugar de penetrar en ella. Además, para un caudal fijo de gas portador, el diámetro del inyector afecta a la velocidad de las partículas a la salida del mismo. Por otra parte, en la inyección radial, aunque los dos tipos se suelen llevar a cabo perpendicularmente, es posible modificar el ángulo que forma el inyector con el eje de la pluma de plasma. De esta forma, el material se introduce en contracorriente, bien a la pluma de plasma o a la corriente de gas ionizada. En consecuencia, se incrementa el tiempo de residencia de las partículas en el interior de estas corrientes. Asimismo, para la inyección radial externa, la distancia de la boquilla del inyector respecto a la pluma de plasma también es un parámetro a tener en cuenta, ya que distancias muy cortas dan lugar a un sobrecalentamiento y en consecuencia a la obturación del inyector, si no se funde primero, debido a la formación de una costra de material fundido, mientras que distancias muy largas provocan una dispersión excesiva del polvo, provocando que éste rodee la pluma de plasma y no penetre en ella. Esto último (distancia excesiva) también puede afectar en el caso de inyección radial interna.

Respecto a todos estos factores que influyen en el proceso de inyección del material objeto de estudio, los valores típicos son caudales de gas portador entre 3-10 slpm (litros estándar por minuto), caudales de material entre 50$100 \mathrm{~g} / \mathrm{min}$, ángulos de inyección comprendidos entre 60-90ํㅡㄹ distancias del inyector respecto a la pluma comprendidas entre $2-8 \mathrm{~mm}$ y diámetros de inyector entre 1,5 y $2 \mathrm{~mm}$.

\subsubsection{Parámetros relativos a la pistola o antorcha de plasma}

El siguiente bloque de parámetros se corresponde con los relativos a la propia antorcha de plasma. Este conjunto de parámetros influye en la temperatura y velocidad que presenta la pluma de plasma generada, que nunca son fijos a lo largo y ancho de la pluma, sino que en ésta hay gradientes de velocidad y temperatura, tanto radiales como axiales. En la figura 1.18, se muestra a modo 
de ejemplo los perfiles o gradientes de velocidad (parte superior) y temperatura (parte inferior) típicos de una pluma de plasma generada a partir de una mezcla de gases argón + hidrógeno [62]. Como se observa, el punto donde se genera la pluma de plasma (la boquilla del ánodo) se corresponde con el punto más caliente y de mayor velocidad. A partir de ahí, la pluma va perdiendo temperatura y va decelerando de forma brusca, ya que como puede observarse en la figura, a tan solo $25 \mathrm{~mm}$ aproximadamente respecto el punto caliente en el eje axial, estos valores de temperatura y velocidad caen hasta la mitad de su valor original.

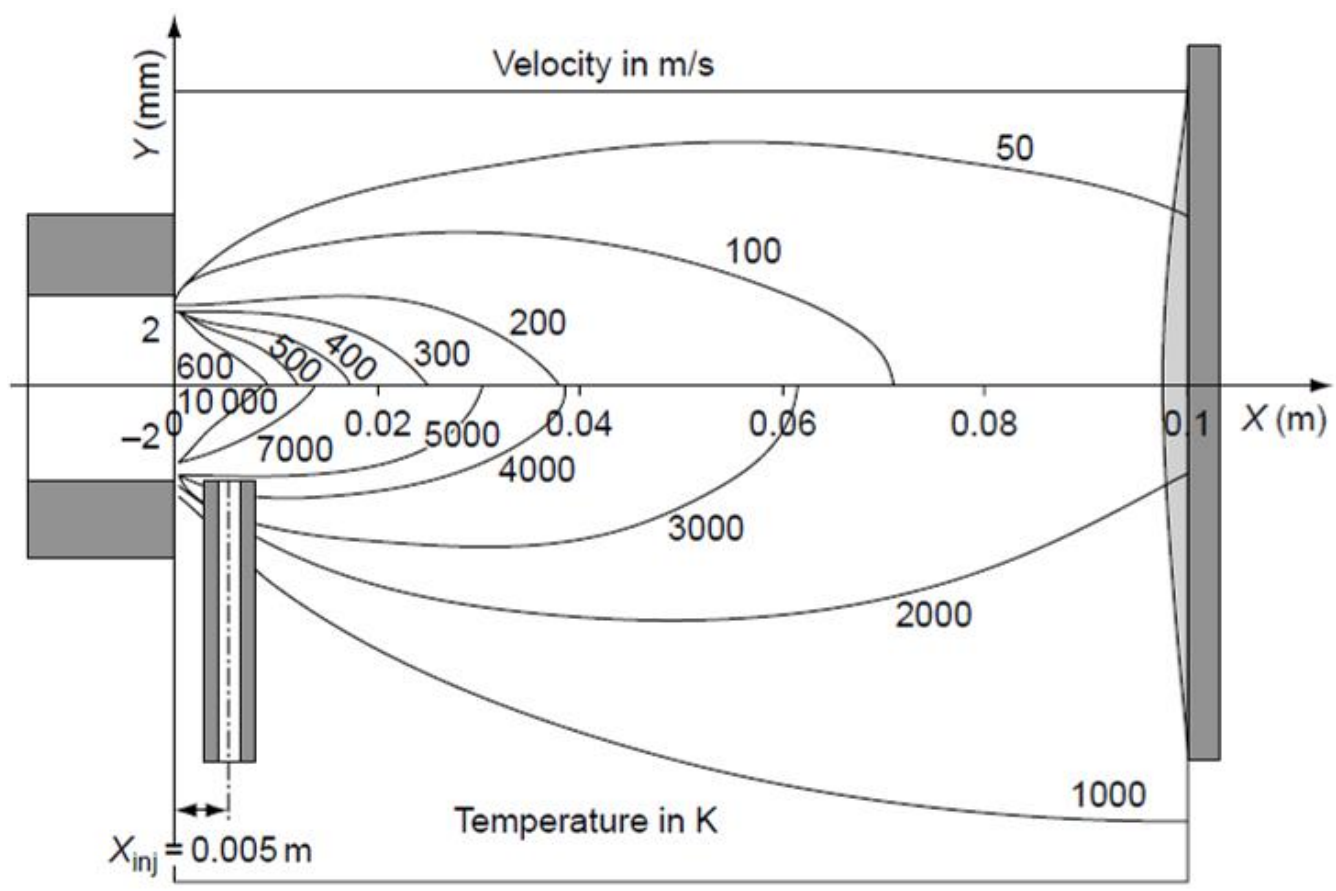

Figura 1.18. Perfiles de temperatura y velocidad de una pluma de plasma para una mezcla de gases argón + hidrógeno [62]

De este bloque, aquellos parámetros más relevantes son la composición, relación y caudal total de gases plasmógenos, la intensidad de corriente y el voltaje del arco eléctrico, la distancia de proyección, la geometría de la boquilla del ánodo y la velocidad lineal y ángulo de la antorcha respecto al sustrato. De las temperaturas y velocidades que se alcanzan en la pluma de plasma, depende la velocidad y temperatura que alcanzan las partículas una vez inyectadas. Es por ello por lo que, en el apartado anterior, se hace énfasis en inyectar las partículas en el punto caliente de la pluma, para que éstas puedan alcanzar la temperatura y velocidad máxima.

Tal y como se ha comentado en apartados anteriores, los gases plasmógenos juegan un papel importante en la generación de la pluma de plasma. Normalmente los plasmas se generan con argón (gas principal) por si solo o con adiciones de helio o hidrógeno (gases secundarios). Como se ha comentado, el nitrógeno apenas se utiliza puesto que reacciona con algunos 
materiales durante la deposición. Los plasmas de argón presentan velocidades muy elevadas y son más fríos en comparación con otros plasmas generados por mezclas de argón con helio o hidrógeno. Mediante la adición de helio, la viscosidad de la mezcla gaseosa aumenta, por lo que el tiempo de residencia de las partículas es mayor. Además, la temperatura que alcanzan estas partículas es mayor debido a la conductividad del helio. Por otra parte, la adición de hidrógeno incrementa en gran medida la energía del plasma como se ha visto en apartados anteriores, debido a la combinación de los procesos de ionización y disociación. Además, la temperatura que alcanzan las partículas también es superior al resto de plasmas debido a la elevada conductividad térmica de este gas, superior incluso a la del helio. Sin embargo, hay un efecto contrapuesto a todo esto, que es el caudal total de gases plasmógenos, ya que conforme aumenta este caudal se obtiene una pluma de mayor velocidad, por lo que el tiempo de residencia de las partículas será menor.

Otros parámetros a tener en cuenta son la intensidad de corriente y el voltaje del arco eléctrico formado entre los electrodos. La intensidad de corriente se controla de forma manual mientras que el voltaje no puede ser controlado directamente, sino que viene definido por la distancia entre los electrodos y el caudal y composición del gas plasmógeno secundario. El voltaje es mayor cuanto mayor es la distancia entre electrodos y mayor caudal de gas secundario (especialmente en el caso de gases diatómicos cono el hidrógeno). Ambos parámetros determinan la potencia de la pluma de plasma generada, ya que esta potencia es el resultado del producto de la intensidad de corriente y el voltaje. Al incrementar la potencia de la pluma aumentan, tanto su temperatura, como su velocidad. En el caso de las partículas inyectadas, la velocidad que alcanzan también es mayor, aunque la temperatura que alcanzan no se incrementa tanto como la velocidad debido al elevado valor de esta variable, la cual reduce el tiempo de residencia de las partículas en la pluma de plasma. Hay que añadir que la potencia real de la pluma de plasma siempre será inferior a la teórica, debido a las pérdidas caloríficas que tienen lugar en la antorcha de plasma a causa de la refrigeración de los electrodos.

En lo referente a la geometría de la boquilla del ánodo, este parámetro básicamente hace referencia al diámetro de esta boquilla, el cual afecta a la velocidad y tamaño de la pluma de plasma. Manteniendo el resto de los parámetros de este bloque fijos, incrementar el diámetro de esta boquilla conlleva una reducción significativa de la velocidad de la pluma de plasma, aunque la pluma obtenida es más robusta ya que el diámetro es mayor y por tanto los gradientes de velocidad están más mitigados. Por otro lado, esta disminución de velocidad de la pluma conlleva un aumento del tiempo de residencia de las partículas, por lo que éstas alcanzan temperaturas mayores.

En cuanto a la distancia de proyección, este parámetro se corresponde con la distancia que hay entre la boquilla del ánodo (punto más caliente de la pluma de plasma) y la superficie del sustrato a recubrir. Este parámetro afecta en gran medida al tiempo de residencia de las partículas en el interior de la pluma, así como al grado de fusión del recubrimiento depositado. A distancias de proyección cortas, el tiempo de residencia es mínimo, aunque esto es 
compensado con un aporte calorífico extra por parte de la antorcha con cada pasada, como consecuencia de esta distancia de proyección corta. Por el contrario, a distancias de proyección elevadas el tiempo de residencia es mucho mayor y apenas hay aporte calorífico desde la pluma al sustrato o recubrimiento ya depositado. Para una serie de parámetros fijos, la distancia de proyección está muy ligada al tamaño medio de la distribución de tamaños de partícula utilizada. Este parámetro se tiene que adaptar en mayor o menor medida al tamaño medio de partícula, puesto que si este tamaño es muy pequeño pero la distancia escogida es elevada, antes de producirse la deposición de la partícula fundida sobre el sustrato ésta puede volver a solidificar y puede que no se adhiera al sustrato. Por el contrario, el empleo de partículas de gran tamaño y distancias de proyección cortas puede provocar que estas partículas no fundan, debido al tiempo de residencia reducido, y por tanto tampoco se adhieran al sustrato.

Por último, está la velocidad lineal y el ángulo de la antorcha de plasma respecto al sustrato. Habitualmente, durante una proyección por plasma, bien los sustratos o bien la antorcha están en movimiento respecto del otro. Se trata de un movimiento de traslación lineal con el fin de evitar el sobrecalentamiento de los sustratos. Cuanto menor es esta velocidad se produce mayor sobrecalentamiento de los sustratos, mientras que a velocidades mayores es posible controlar mejor la temperatura de éstos. Sin embargo, si la velocidad es excesivamente elevada, la inercia del movimiento modificará la trayectoria de las partículas que vuelan en el interior de la pluma hacia el sustrato, provocando una reducción en la eficiencia de deposición puesto que es preferible un impacto de las partículas fundidas perpendicular al sustrato para que la deformación de la gota sea mayor al impactar y se adhiera mejor. En cuanto al ángulo, éste es el formado entre la pistola de plasma y la superficie del sustrato. Típicamente se deposita el material por APS de forma perpendicular al sustrato. Sin embargo, debido a razones externas al equipo (como por ejemplo una geometría compleja del sustrato), la deposición puede llevarse a cabo a ángulos diferentes a 90ㅜ, con la consiguiente pérdida de eficiencia de deposición y adhesión que es mayor cuanto más diferente de $90^{\circ}$ sea el ángulo.

A continuación, en la tabla 1.5 se detallan valores típicos de los parámetros descritos en el presente subapartado. 
Tabla 1.5. Valores típicos de los parámetros relativos a la pistola de plasma

\begin{tabular}{cc}
\hline Parámetro & Valores típicos \\
\hline $\begin{array}{c}\text { Caudal total de gases } \\
\text { plasmógenos } \\
\text { Adiciones de helio } \\
\text { Adiciones de hidrógeno } \\
\text { Intensidad de corriente }\end{array}$ & Hasta un 60 vol.\% \\
Voltaje & Hasta un 20 vol.\% \\
Potencia de la pluma de plasma & $100-700 \mathrm{~A}$ \\
Distancia de proyección & $30-75 \mathrm{~V}$ \\
Diámetro de boquilla de ánodo & Hasta $90 \mathrm{~kW}$ \\
Velocidad lineal de movimiento de \\
la antorcha \\
Ángulo de la antorcha respecto al \\
sustrato
\end{tabular}

\subsubsection{Parámetros relativos al sustrato}

Con el fin de lograr depositar un buen recubrimiento mediante APS, el estado superficial del sustrato utilizado para la deposición también es un factor que tener muy en cuenta, puesto que de ello depende mayoritariamente la adherencia del recubrimiento. Como se ha comentado anteriormente, la adhesión de los recubrimientos obtenidos por APS es de tipo mecánico. Por tanto, es imprescindible dotar de cierta rugosidad a la superficie que se desee recubrir, adaptando siempre esta rugosidad al tamaño de partícula depositado. También se ha comentado que se suele depositar un recubrimiento intermedio con el fin de reducir las diferencias de expansión térmica entre sustrato y recubrimiento y así mejorar la adhesión del recubrimiento final.

Por último, es muy importante controlar la temperatura del sustrato/recubrimiento previamente, durante y tras la deposición del material objeto de estudio con el objetivo de reducir la generación de tensiones. Por ello, los sustratos se suelen precalentar previamente a la deposición del recubrimiento, su temperatura se mantiene lo más constante posible mediante refrigeración durante la deposición, y tras este proceso las muestras se dejan enfriar al ambiente sin forzar su refrigeración. El precalentamiento se lleva a cabo con la misma antorcha de plasma, mientras que la refrigeración de las muestras durante la proyección se lleva a cabo mediante chorros de aire comprimido. Precalentando los sustratos a temperaturas entre $200-300 \stackrel{\circ}{C}$ se 
consiguen "splats" bien definidos de morfología lenticular. De esta forma, evitando la generación excesiva de tensiones entre el recubrimiento y el sustrato (mediante la refrigeración durante la proyección), la adhesión del recubrimiento aumenta puesto que aumentan los puntos de contacto materialsustrato y material-material y se evita la delaminación del recubrimiento debido, bien a un sobrecalentamiento de los sustratos gracias a la refrigeración durante el proceso de deposición, o bien debido a un choque térmico, gracias al enfriamiento controlado tras la deposición.

\subsubsection{Optimización de los parámetros de proyección}

En base a lo expuesto en los últimos subapartados, queda patente el gran número de parámetros que intervienen en la técnica de deposición APS. Es por ello por lo que con vistas a optimizar estos parámetros y obtener recubrimientos con microestructuras y propiedades adecuadas al fin al que van destinados, la práctica más común es variar los parámetros más relevantes en base a un diseño de experimentos y analizar una o distintas propiedades (porosidad, espesor, adherencia, cristalinidad, etc.) de los recubrimientos obtenidos con relación a la aplicación de dicho recubrimiento. En ocasiones, al llevar a cabo el diseño de experimentos también se suele incluir como variables los parámetros clave de un proceso de post tratamiento [125-130]. Con el fin de comprender mejor el efecto de los parámetros de proyección en estos diseños, es habitual utilizar herramientas de monitorización in situ de la temperatura y la velocidad de las partículas durante el vuelo en función de los parámetros utilizados $[131,132]$.

\subsection{Proyección térmica por plasma a partir de materiales de aporte líquidos}

\subsubsection{Clasificación y obtención de materiales de aporte líquidos}

Durante las dos últimas décadas, la tendencia en el ámbito de la proyección térmica es utilizar materiales de tamaño submicrométrico o nanométrico con el objetivo de obtener recubrimientos nanoestructurados con propiedades mejoradas [133]. Sin embargo, como se ha observado en apartados anteriores, los materiales pulverulentos empleados en la obtención de recubrimientos mediante APS presentan una limitación en cuando a tamaño. Al ir a tamaños de partícula demasiado pequeños, además de problemas de fluidez del material, para valores típicos de caudal de gas portador las partículas demasiado pequeñas no penetran en la pluma de plasma y se quedan en la periferia de ésta [81, 116]. Es por ello por lo que, se está produciendo una sustitución progresiva de los materiales de aporte pulverulentos por materiales de aporte líquidos, lo cuales son:

- Suspensiones de partículas: El material sólido pulverulento se dispersa en un medio líquido en lugar de una corriente gaseosa, de tal 
forma que este medio líquido ayuda a las partículas finas a penetrar en el interior de la pluma de plasma.

- Soluciones de precursores químicos: Precursores de la composición deseada se disuelven en un medio líquido, de tal forma que este medio penetra totalmente en la pluma dando como resultado la formación del material en el interior de ésta.

Las suspensiones empleadas en proyección térmica por plasma pueden prepararse mediante dos rutas diferentes como se muestra en la figura 1.19. Por un lado, el material objeto de estudio en forma pulverulenta se puede dispersar directamente en un medio líquido, mientras que, por otro lado, la suspensión puede obtenerse como resultado de un proceso de molienda mediante vía húmeda [134]. Independientemente de la ruta escogida, como medio dispersante se utiliza agua destilada, orgánicos como por ejemplo etanol o isopropanol, o mezclas de estos compuestos [134]. El empleo de líquidos orgánicos conlleva un aumento significativo de la temperatura de la pluma de plasma cuando éstos se evaporan. Sin embargo, a la hora de escoger el disolvente orgánico se debe tener en cuenta que no todos los compuestos orgánicos sirven para su uso en proyección por plasma, ya que han de cumplir unos requisitos en cuanto a límites de explosividad o inflamabilidad. Por el contrario, el empleo de agua destilada como disolvente no supone ningún riesgo ni durante el manejo de la suspensión ni durante su almacenamiento, aunque el aspecto negativo de este medio dispersante es que al evaporarse en la pluma de plasma la enfría, reduciendo la temperatura superficial de las partículas [135].

La cantidad o proporción de sólido dispersado en un volumen dado de suspensión se conoce como contenido en sólidos. Este contenido en sólidos puede expresarse en porcentaje en peso (wt\%) o porcentaje volumétrico (vol.\%) y, aunque esta proporción puede ser variable, está limitada a un valor máximo que viene marcado por la viscosidad final de la suspensión, tal y como se detalla en el siguiente subapartado.

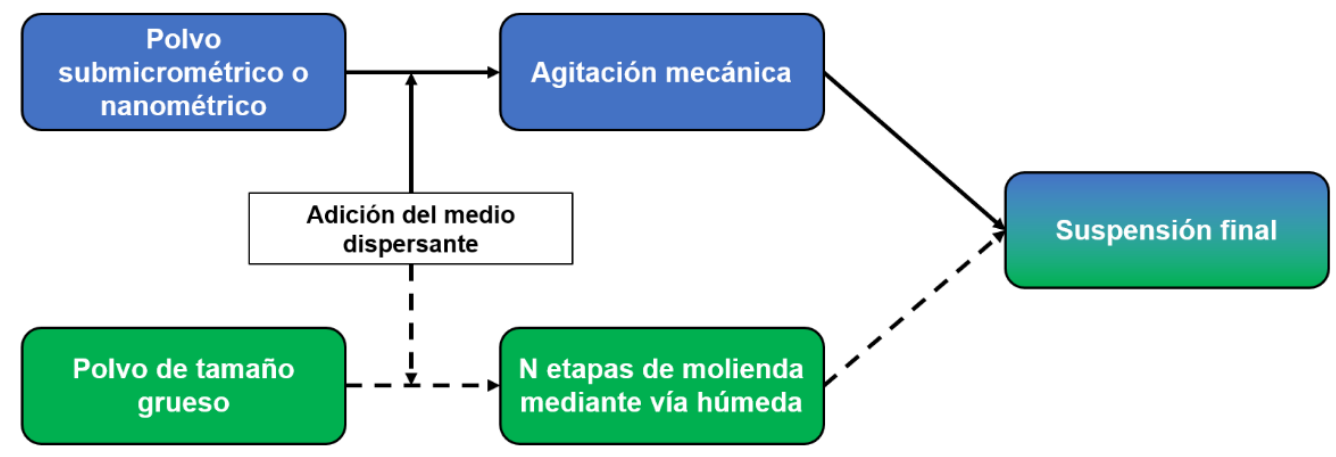

Figura 1.19. Diferentes rutas para obtener suspensiones de partículas para su empleo como material de aporte en proyección por plasma 
La preparación de la suspensión por dispersión directa (agitación mecánica) es la ruta más común, y en ella se utiliza polvos comerciales con un tamaño de partícula nanométrico o submicrométrico. Como se ha comentado, una vez escogido el medio dispersante, se prepara la suspensión adicionando directamente el polvo fino a este medio y agitando mecánicamente la mezcla. Debido al pequeño tamaño de partícula, la adición debe llevarse a cabo de forma progresiva con el fin de evitar la formación prematura de aglomerados de partículas los cuales afectan negativamente a la estabilidad de la suspensión resultante.

Otra forma de obtener suspensiones, como se muestra en la figura 1.19, es a partir de un material pulverulento con un tamaño de partícula grueso. En este caso, para obtener la suspensión deseada, el polvo se somete a una o varias etapas de molienda hasta alcanzar el tamaño de partícula requerido. Esta etapa o etapas de molienda se llevan a cabo vía húmeda, es decir, el material pulverulento se introduce en el dispositivo de molienda junto con el medio dispersante. Comúnmente se utilizan molinos de atrición para reducir el tamaño de partícula [136,137], aunque hay ocasiones en que el tamaño de partícula es excesivamente grueso y se requieren tiempos de molienda muy elevados para reducir el tamaño a valores deseados. Por ello, algunos investigadores llevan a cabo una primera etapa de molienda en molino planetario previamente a la molienda en molino de atrición [138]. Para un material determinado con una distribución de tamaños dada, el rendimiento del proceso de molienda es función del tiempo de molienda y del tipo de molino (planetario o de atrición), y según este último factor, también afecta el tipo, tamaño y cantidad del elemento de molienda (típicamente bolas) así como la velocidad de molienda a la que se somete el material [139].

Respecto a las soluciones de precursores químicos, la preparación de estos materiales de aporte se lleva a cabo mediante la disolución en medio acuoso u orgánico (etanol, acetona, etc.) de determinadas sales inorgánicas y alcóxidos metálicos que actúan como precursores de los elementos de la composición deseada, como en un proceso sol-gel, pero sin llevar a cabo las etapas de gelificación, envejecimiento, secado y tratamiento térmico [134,140]. El efecto de los medios dispersantes empleado en la elaboración de las soluciones es análogo al caso de las suspensiones. El proceso de obtención de este tipo de material de aporte es más sencillo que en el caso de suspensiones o incluso polvos. Además, permite trabajar con materiales de aporte de mayor pureza, ya que evita la introducción de contaminantes (provenientes por ejemplo de etapas de molienda en el caso de suspensiones o fusiones/sinterizaciones en el caso de procesos de síntesis de materiales pulverulentos) en el material final y facilita en gran medida la modificación de la composición del material de aporte resultante. A diferencia de las suspensiones, puesto que en las soluciones no hay presencia de partículas sólidas, la cantidad o proporción de precursor o precursores disueltos en el medio tiende a expresarse en molaridad (M; moles de precursor/litro total de disolución). Sin embargo, algunos investigadores expresan las concentraciones de precursores en porcentajes en peso o volumétricos. 
De igual forma que en la deposición de polvos, se pueden obtener recubrimientos de muchos tipos de materiales a partir de suspensiones de partículas y soluciones de precursores. Sin embargo, son los materiales cerámicos los que se depositan mayoritariamente [140]. En las tablas 1.6 y 1.7 se muestran diferentes ejemplos de suspensiones y soluciones de precursores depositadas mediante proyección por plasma [134,140].

Tabla 1.6. Ejemplos de suspensiones de partículas depositadas mediante proyección térmica por plasma $[134,140]$

\begin{tabular}{cccc}
\hline Recubrimiento & $\begin{array}{c}\text { Tamaño medio } \\
\text { de partícula (nm) }\end{array}$ & $\begin{array}{c}\text { Medio } \\
\text { dispersante }\end{array}$ & $\begin{array}{c}\text { Contenido en } \\
\text { sólidos }\end{array}$ \\
\hline $\mathrm{TiO}_{2}$ & 330 & Agua destilada & $4-10 \mathrm{wt} \%$ \\
$\mathrm{LaMnO}_{3}$ & 1000 & Etanol & $80 \mathrm{wt} \%$ \\
$8 \mathrm{YSZ}$ & 1500 & Agua destilada & $24 \mathrm{wt} \%$ \\
$8 \mathrm{YSZ}+50 \mathrm{wt} \%$ & $600-1500$ & Agua destilada & $20 \mathrm{wt} \%$ \\
$\begin{array}{c}\mathrm{NiO} \\
\mathrm{ZrO} \\
\mathrm{Y}_{2} \mathrm{O}_{3} \mathrm{wt} \%\end{array}$ & 100 & $\begin{array}{c}\text { Acetato de } \\
\text { n-butilo }\end{array}$ & $2 \mathrm{vol} \%$ \\
$\mathrm{Al}_{2} \mathrm{O}_{3}$ & 400 & Agua destilada & $10 \mathrm{wt} \%$ \\
$\mathrm{HA}$ & 1470 & Agua destilada & $10 \mathrm{wt} \%$ \\
\hline
\end{tabular}

Tabla 1.7. Ejemplos de soluciones de precursores depositadas mediante proyección térmica por plasma $[134,140]$

\begin{tabular}{|c|c|c|c|}
\hline Recubrimiento & Precursor & $\begin{array}{c}\text { Medio } \\
\text { dispersante }\end{array}$ & $\begin{array}{c}\text { Concentración } \\
\text { total }\end{array}$ \\
\hline $\mathrm{TiO}_{2}$ & $\mathrm{Ti}\left(\mathrm{OC}_{4} \mathrm{H}_{9}\right)_{4}$ & Etanol & - \\
\hline $\begin{array}{c}8 Y S Z+40 w t \% \\
\mathrm{NiO}\end{array}$ & $\begin{array}{c}\mathrm{ZrOCl}_{2} \cdot \mathrm{H}_{2} \mathrm{O}+ \\
\mathrm{Y}\left(\mathrm{NO}_{3}\right)_{3} \cdot 6 \mathrm{H}_{2} \mathrm{O}+ \\
\mathrm{Ni}\left(\mathrm{NO}_{3}\right)_{3} \cdot 6 \mathrm{H}_{2} \mathrm{O}\end{array}$ & Agua destilada & - \\
\hline $\mathrm{La}_{1-x} \mathrm{Sr}_{x} \mathrm{MnO}_{3}$ & $\begin{array}{c}\mathrm{La}\left(\mathrm{NO}_{3}\right)_{3} \cdot 6 \mathrm{H}_{2} \mathrm{O}+ \\
\mathrm{Sr}\left(\mathrm{NO}_{3}\right)_{3}+ \\
\mathrm{Mn}\left(\mathrm{NO}_{3}\right)_{3} \cdot 4 \mathrm{H}_{2} \mathrm{O}\end{array}$ & Agua destilada & $1 \mathrm{M}$ \\
\hline $\mathrm{CeO}_{2}$ & $\mathrm{Ce}\left(\mathrm{NO}_{3}\right)_{3}$ & - & $0,1 \mathrm{M}$ \\
\hline $\mathrm{MnO}$ & $\mathrm{Mn}\left(\mathrm{NO}_{3}\right)_{2}$ & Isopropanol & $1 \mathrm{M}$ \\
\hline $\mathrm{Al}_{2} \mathrm{O}_{3}$ & $\mathrm{Al}\left(\mathrm{NO}_{3}\right)_{3}$ & Isopropanol & $0,4 \mathrm{M}$ \\
\hline $\mathrm{Y}_{3} \mathrm{Al}_{5} \mathrm{O}_{12}$ & $\begin{array}{l}\mathrm{AlO}(\mathrm{OH})_{+}+ \\
\mathrm{Y}\left(\mathrm{NO}_{3}\right)_{3}\end{array}$ & Agua destilada & - \\
\hline
\end{tabular}




\subsubsection{Requisitos y control de los materiales de aporte líquidos}

Las propiedades físicas y químicas de los materiales de aporte líquido tienen mayor influencia que las de los materiales pulverulentos en la inyección y penetración de estos materiales en la pluma de plasma, y en consecuencia, afectan en gran medida a las características y propiedades finales de los recubrimientos obtenidos. Por lo tanto, los materiales de aporte líquidos deben prepararse y estabilizarse adecuadamente de tal forma que cumplan los siguientes requisitos [133-135, 140]:

- Una viscosidad baja para facilitar, tanto el transporte desde el depósito de almacenamiento hasta la pluma de plasma, como la inyección en dicha pluma.

- Elevada estabilidad tanto física como química con el fin de prevenir la modificación de las propiedades de estos materiales líquidos con el tiempo y evitar la obturación del inyector.

Por otra parte, además de los requisitos mencionados, hay una serie de parámetros que también deben controlarse siempre con el fin de poder garantizar la reproducibilidad de los recubrimientos obtenidos. Estos parámetros son densidad, concentración, pH, distribución de tamaños de partícula o velocidad de sedimentación de partículas.

\subsubsection{Viscosidad y comportamiento de los materiales de aporte líquidos}

El primer requisito de cualquier material de aporte líquido utilizado en proyección térmica por plasma es mantener una viscosidad lo más baja posible durante el transporte desde la tolva a la pluma de plasma y su inyección.

La viscosidad está influenciada por diversos factores como la temperatura, la presión o la acción de campos eléctricos o electromagnéticos [141]. Sin embargo, es la velocidad de cizalla la variable de mayor influencia sobre la viscosidad desde el punto de vista reológico [141], siendo este último parámetro la velocidad a la que se deforma un material y fluye cuando está sometido a un esfuerzo de cizalladura.

Puesto que, tanto las suspensiones de partículas como las soluciones de precursores, se encuentran sometidos a diferentes esfuerzos y velocidades de cizalla durante el proceso de transporte e inyección, resulta muy interesante no solo determinar un valor puntual de viscosidad del material objeto de estudio, sino que es conveniente estudiar cómo evoluciona su viscosidad durante los procesos de transporte e inyección, o, lo que es lo mismo, estudiar su comportamiento bajo diferentes condiciones de cizalla. Para ello se realizan estudios reológicos mediante el empleo de un reómetro. Los reómetros más empleados son los de tipo rotacional puesto que proporcionan una información más completa al permitir trabajar a gradientes de velocidad definidos, haciendo posible la interpretación de distintos fenómenos que puedan ocurrir en relación 
al comportamiento del material objeto de estudio [142]. En la figura 1.20 se muestra un ejemplo de este tipo de reómetros, compuesto básicamente por un vaso de medición que contiene la muestra objeto de estudio y un elemento de medida (cuya geometría es variable) acoplado a un rotor [143].

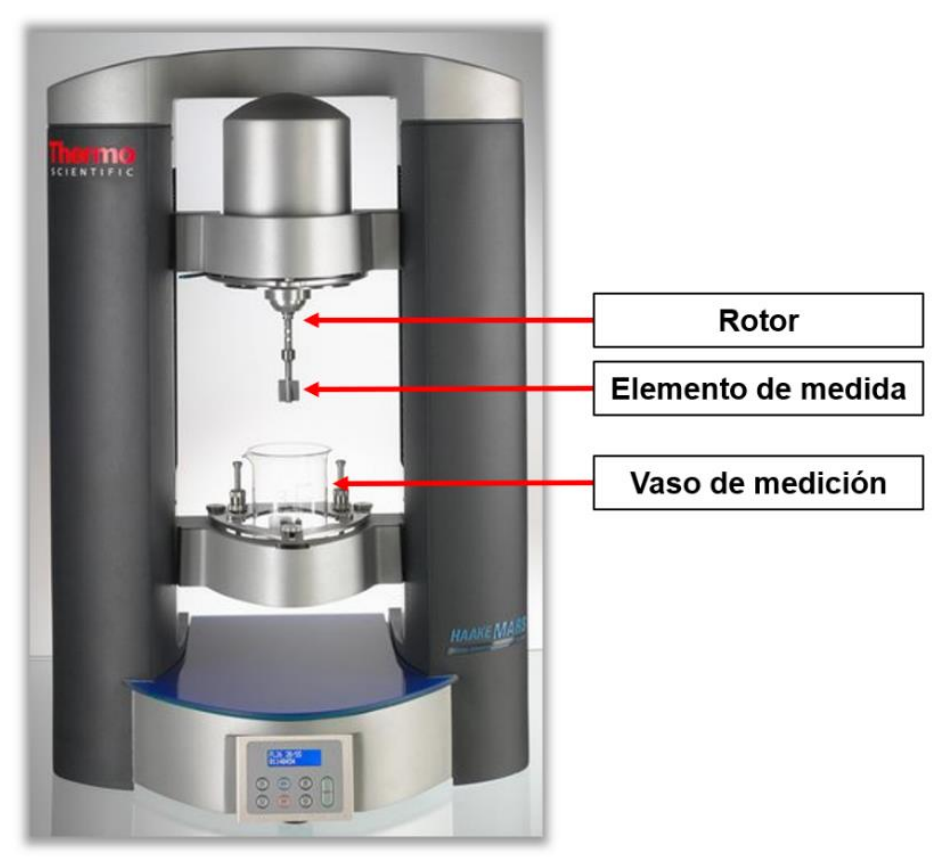

Figura 1.20. Ejemplo de reómetro rotacional. El reómetro mostrado en la figura se corresponde con el HAAKE ${ }^{\circledR}$ MARS $^{\circledR}$ de ThermoFisher Scientific [143]

En un estudio o ensayo reológico típico, se introduce la muestra líquida en el vaso de medición y se sumerge el elemento de medida en la muestra objeto de estudio. Una vez hecho esto, se aplica una velocidad de cizalla al rotor, de tal forma que el elemento de medida empieza a girar provocando el impulso o movimiento de la muestra entre las superficies del mismo elemento y el vaso de medición en un régimen de flujo laminar. La velocidad de cizalla aplicada se va incrementando gradualmente hasta un valor máximo, registrando para cada velocidad el esfuerzo de cizalla correspondiente que padece el material estudiado. Una vez alcanzado el valor máximo de velocidad de cizalla, ésta comienza a reducirse también de forma gradual hasta un valor nulo. De esta forma, asumiendo un flujo homogéneo y que la velocidad de cizalla es la misma en cualquier zona de la muestra, es posible obtener a partir del equipo, mediante las constantes características del elemento de medida, la relación entre la viscosidad del material estudiado con la velocidad y el esfuerzo de cizalla $[135,141,142]$. La interpretación de los resultados suele hacerse de forma gráfica mediante dos tipos de representaciones como se muestra en la figura 1.21 [141]. Por un lado, está la denominada curva de flujo del material (Figura 1.21a), en la que se representa el esfuerzo de cizalla en función de la velocidad de cizalla aplicada y donde los valores de viscosidad se obtienen 
como el cociente entre cada par de valores esfuerzo de cizalla-velocidad de cizalla. Por otra parte, otra forma de interpretar los resultados obtenidos es mediante la curva de viscosidad, en la cual se representa directamente este parámetro en función de la velocidad de cizalla.
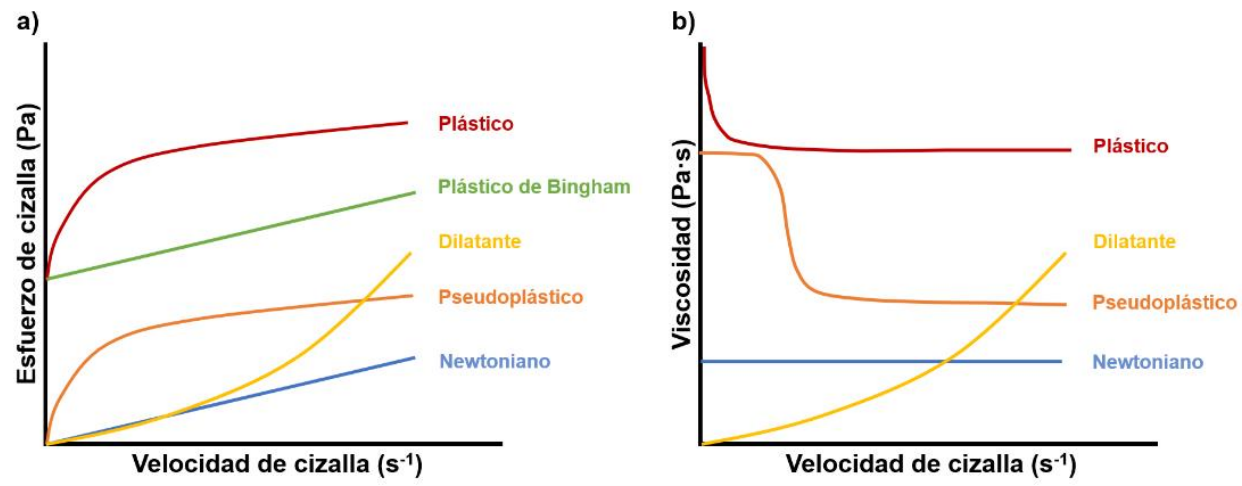

Figura 1.21. Curvas de flujo (a) y curvas de viscosidad (b) correspondientes a los distintos comportamientos que pueden presentar los materiales líquidos. Figura adaptada de [141]

Como puede apreciarse en la figura 1.21, hay varios tipos de curvas de flujo, así como distintas curvas de viscosidad, dependiendo de la relación entre la viscosidad y la velocidad de cizalla [135,141,142]. El caso ideal son los materiales que poseen un comportamiento Newtoniano, tales como el agua o el aceite. Las soluciones de precursores también suelen mostrar este tipo de comportamiento, puesto que no contienen partículas que puedan oponer resistencia al flujo. Este tipo de materiales cumplen la ley de Newton (ecuación 1.8), la cual establece una proporcionalidad directa entre el esfuerzo de cizalla $(\sigma)$ y la velocidad de cizalla $(\gamma)$ (Figura 1.21a), siendo su viscosidad $(\eta)$ constante frente a la velocidad de cizalla (Figura 1.21b).

$$
\sigma=\eta \cdot \dot{\gamma}(\text { ec. 1.8) }
$$

Sin embargo, el caso más común es que la viscosidad de los materiales líquidos varíe en gran medida con la velocidad de cizalla, por lo que el comportamiento de estos materiales se desvía de la linealidad establecida por el modelo de Newton. Estos materiales son conocidos como fluidos no Newtonianos, los cuales a su vez pueden presentar dos tipos de comportamiento diferente conforme se incrementa la velocidad de cizalla [141]. Las suspensiones de partículas suelen mostrar un comportamiento no Newtoniano. Si al incrementar la velocidad de cizalla la viscosidad del material disminuye, se dice que el material posee un comportamiento fluidificante 0 pseudoplástico. Se trata, además del Newtoniano, de un comportamiento preferible para proyección por plasma ya que, aunque en reposo el material pueda presentar una viscosidad alta, durante el transporte e inyección, la cizalla es elevada, por lo que se espera que el material reduzca su viscosidad y fluya sin dificultad. Como se aprecia en la figura 1.21, las curvas de flujo y viscosidad presentan una primera región Newtoniana a bajas cizalla, una región intermedia 
en la que la viscosidad disminuye hasta un valor mínimo, y una tercera región también Newtoniana en la que la viscosidad alcanzada en la segunda región se mantiene constante. Por el contrario, puede darse casos en los que un aumento en la velocidad de cizalla produzca cambios en la estructura del material estudiado de tal forma que la viscosidad de este material aumente $y$, en consecuencia, oponga una mayor resistencia al flujo. En este caso, se dice que el material posee un comportamiento espesante o dilatante. Como se aprecia en la figura 1.21, en regiones de baja cizalla, la viscosidad de estos materiales es mínima, pero al aumentar la cizalla, la viscosidad tiene a incrementarse hasta valores muy elevados. En proyección por plasma, también resulta interesante conocer el comportamiento de los materiales a muy alta cizalla (momento de la inyección en la pluma), pero este tipo de reómetros están limitados a velocidades de cizalla 1000-1050 s $\mathrm{s}^{-1}$, muy inferiores a las que tienen lugar en la boquilla del inyector. Por ello, se suele extrapolar el comportamiento de los materiales líquidos mediante el empleo de modelos matemáticos. En el caso del comportamiento Newtoniano se emplea el modelo de Newton, mientras que para los fluidos no Newtonianos se suele emplear los modelos de Cross o Carreau (ecuaciones 1.9 y 1.10 respectivamente) [135,141,142], los cuales con el fin de poder modelizar la forma cuadrática de las curvas de flujo y viscosidad incluyen hasta cuatro nuevos parámetros independientes que son la viscosidad correspondiente a velocidad de cizalla cero $\left(\eta_{0}\right)$, la viscosidad correspondiente a velocidad infinita $\left(\eta_{\infty}\right)$, el parámetro $\mathrm{K}$ (dimensiones de tiempo) y el parámetro $\mathrm{m}$ (adimensional) [141]. Estos dos últimos parámetros han sido determinados mediante ajustes experimentales.

$$
\begin{gathered}
\frac{\eta_{o}-\eta}{\eta-\eta_{\infty}}=\frac{1}{\left(1+(K \dot{\gamma})^{m}\right)}(\text { ec. 1.9) } \\
\frac{\eta-\eta_{\infty}}{\eta_{o}-\eta_{\infty}}=\frac{1}{\left(1+(K \dot{\gamma})^{2}\right)^{m_{1 / 2}}}(\text { ec. 1.10) }
\end{gathered}
$$

En ocasiones, los materiales líquidos también pueden presentar un comportamiento plástico, lo que significa que es necesario superar un valor umbral de esfuerzo de cizalla para que el material empiece a fluir. Esto se observa en la figura 1.21a donde las curvas de flujo correspondientes a materiales con comportamiento plástico o plástico de Bingham no empiezan en el origen de coordenadas, sino que empiezan a partir del valor umbral de esfuerzo de cizalla.

Otra variable a tener en cuenta en el estudio reológico de los materiales de aporte líquidos es el efecto del tiempo sobre el comportamiento de flujo de estos materiales. Como se ha comentado anteriormente, durante el estudio reológico, el material se somete a una serie de velocidades de cizalla que aumentan progresivamente hasta un valor máximo, para luego reducir estas velocidades de forma progresiva hasta un valor nulo. Tras alcanzar este valor máximo y empezar a reducir la velocidad de cizalla, el material empieza a recuperar su estructura original [141]. Por ello, si al reducir la velocidad de cizalla se produce una disminución de la viscosidad con el tiempo durante el 
proceso de recuperación de la estructura original del material, este fenómeno se conoce como tixotropía. Por el contrario, si en el mismo proceso la viscosidad aumenta con el tiempo el fenómeno se denomina reopexia. Estos fenómenos de tixotropía y reopexia suelen asociarse a comportamientos pseudoplásticos y dilatantes respectivamente, y se trata de procesos no deseados en proyección por plasma, ya que modifican la estructura inicial del material objeto de estudio. A modo de ejemplo, se ilustra el efecto de estos fenómenos sobre las curvas de flujo de un material determinado en la figura 1.22 [135]. En ambos casos, se observa la formación de un ciclo de histéresis debido a cada fenómeno descrito.
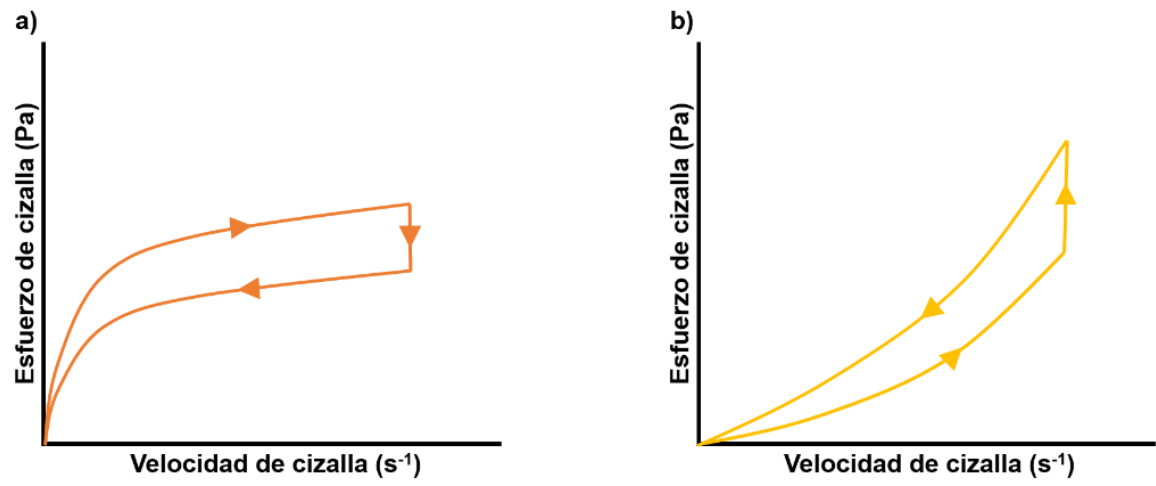

Figura 1.22. Curvas de flujo de un determinado material a) tixotrópico y b) reopéxico. En ambos casos las flechas indican el sentido del esfuerzo de cizalla conforme se incrementa la velocidad de cizalla hasta un valor máximo para posteriormente disminuirla. Figura adaptada de [135]

En el caso de las suspensiones de partículas, su viscosidad también está afectada por el contenido en sólidos, la distribución de tamaños de partícula y la morfología de las partículas [135,141,142]. Este efecto no es tan notable si se trabaja con suspensiones diluidas, pero sí cuando se quiere trabajar con suspensiones concentradas.

El modelo matemático más utilizado para relacionar la viscosidad de la suspensión con el contenido en sólidos es el modelo de Krieger-Dougherty (ecuación 1.11) donde $\eta$ es la viscosidad de la suspensión (Pa.s), $\eta_{s}$ es la viscosidad del medio dispersante (Pa.s), $\phi$ es la fracción de empaquetamiento o fracción volumétrica de sólidos, $\phi_{\mathrm{m}}$ es la fracción de empaquetamiento o fracción volumétrica de sólidos máxima y $[\eta]$ es la viscosidad intrínseca $[135,141,142]$.

$$
\eta=\eta_{s} \cdot\left(1-\frac{\phi}{\phi_{m}}\right)^{-[\eta] \cdot \phi_{m}}(\text { ec. 1.11) }
$$

Conforme se incrementa el contenido en sólidos de la suspensión, las partículas van aproximándose poco a poco unas a otras y empaquetándose de tal forma que aumentan las interacciones entre ellas, a la par que aumenta la 
viscosidad de la suspensión de forma exponencial. Al continuar incrementando el contenido en sólidos se llega a un punto donde todas las partículas estarán en contacto unas con otras formando una estructura. El contenido en sólidos para el cual se produce esta estructura define la fracción de empaquetamiento máximo, a partir del cual el valor de la viscosidad se dispara y tiende asintóticamente a infinito [135,141]. Para ejemplificar lo explicado, en la figura 1.23 se representa el resultado de aplicar el modelo de Krieger-Dougherty a una mezcla de $\mathrm{Al}_{2} \mathrm{O}_{3}$ (con un tamaño medio de partícula de $0,35 \mu \mathrm{m}$ ) con $\mathrm{TiO}_{2}$ (con un tamaño medio de partícula de 0,04 $\mu \mathrm{m}$ ) [144].

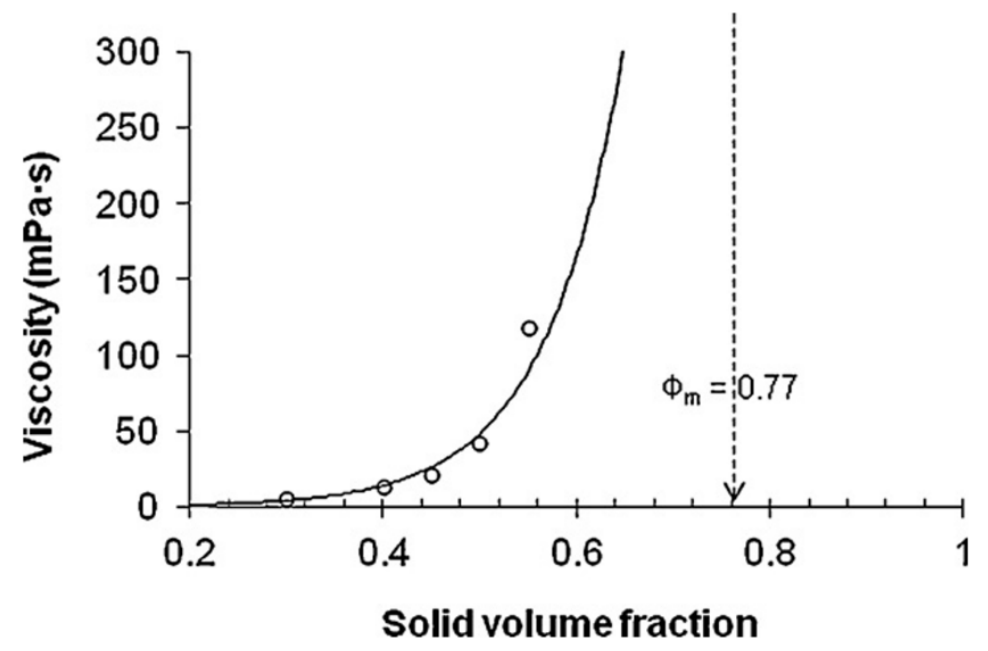

Figura 1.23. Aplicación del modelo de Krieger-Dougherty para una suspensión bimodal de partículas de $\mathrm{Al}_{2} \mathrm{O}_{3}+\mathrm{TiO}_{2}[144]$

Como se ha representado en la figura, el contenido en sólidos volumétrico máximo admitido por este sistema es del $77 \%$, valor a partir del cual la suspensión empieza a comportarse como un sólido [144]. Hay que añadir que se trata de un contenido volumétrico más elevado que los valores típicos (63$70 \%$ ). Esto es debido al empleo de una distribución de tamaños de partícula bimodal como se explica más adelante.

La fracción máxima de empaquetamiento, que define el contenido máximo de sólidos de la suspensión de trabajo, no solo depende del tipo de empaquetamiento (cúbico simple, cúbico centrado en el cuerpo, etc.) sino que también depende de la esfericidad y distribución de tamaños de las partículas [135,141]. Cuanto más se ensancha la distribución de tamaños, mayor es la densidad de empaquetamiento, puesto que las partículas de menor tamaño se sitúan entre los huecos de las partículas de mayor tamaño. Por el contrario, cuanto más se aleja la forma de las partículas de la esfericidad, la densidad de empaquetamiento es menor, pues hay menor superficie de contacto y mayores huecos entre partículas. Además, el grado de esfericidad de las partículas también afecta a la viscosidad intrínseca, parámetro presente en el modelo de Krieger-Dougherty. La viscosidad intrínseca es un parámetro que se utiliza 
para cuantificar el efecto o contribución de un material sólido a la viscosidad de una suspensión. Como se acaba de comentar, está influenciado por la morfología de las partículas, de tal forma que adopta un valor de 2,5 cuando las partículas son totalmente esféricas. Cuando la morfología de la partícula empieza a alejarse de la esfericidad, se recurre a ecuaciones empíricas para cada posible morfología. Por ejemplo, en el caso de láminas o varillas, sus relaciones empíricas se muestran en las ecuaciones 1.12 y 1.13 respectivamente.

$$
\begin{gathered}
{[\eta]_{\text {lámina }}=\frac{3 \cdot(\text { factor de forma })}{10}(\text { ec. } 1.12)} \\
{[\eta]_{\text {varilla }}=\frac{7 \cdot(\text { factor de forma })^{5 / 3}}{100}(\text { ec. } 1.13)}
\end{gathered}
$$

Por último, comentar el efecto de la distribución de tamaños de partícula. El modelo expuesto anteriormente (Krieger-Dougherty), solo es válido para distribuciones monomodales. En el caso de distribuciones de partícula bimodales, la fracción de empaquetamiento máxima es mayor que en una distribución monomodal, debido a que las partículas más pequeñas se sitúan entre los huecos de las partículas más grandes como se ha comentado en el párrafo anterior. En el caso de una suspensión con una distribución de tamaños de partícula bimodal, en lugar del modelo de Krieger-Dougherty se suele utilizar el modelo de Farris (ecuación 1.14) [145]. En este modelo, basado en el de Krieger-Dougherty, se trata la distribución bimodal como varias monomodales, relacionando la viscosidad de la suspensión con las relaciones viscosidad-fracción volumétrica de cada componente de la distribución bimodal $[135,141]$.

$$
\eta=\eta_{s} \cdot \prod_{i=1}^{n}\left(1-\frac{\phi_{i}}{\phi_{m i}}\right)^{-[\eta] \phi_{m i}}(\text { ec. } 1.14)
$$

A modo de ejemplo, en la figura 1.24 se muestra el efecto de una distribución de tamaños de partícula bimodal en la viscosidad de una suspensión en función de la fracción volumétrica de partículas gruesas [145].

En esa figura, se observa como aumentar el contenido en sólidos total conlleva un incremento significativo de la viscosidad de la suspensión. A pesar de este aumento de viscosidad, queda patente el efecto positivo de la distribución bimodal, pues en todas las curvas de contenidos en sólidos totales elevados hay presencia de un mínimo en viscosidad, siendo este valor inferior al correspondiente al $100 \%$ de partículas gruesas o finas. 


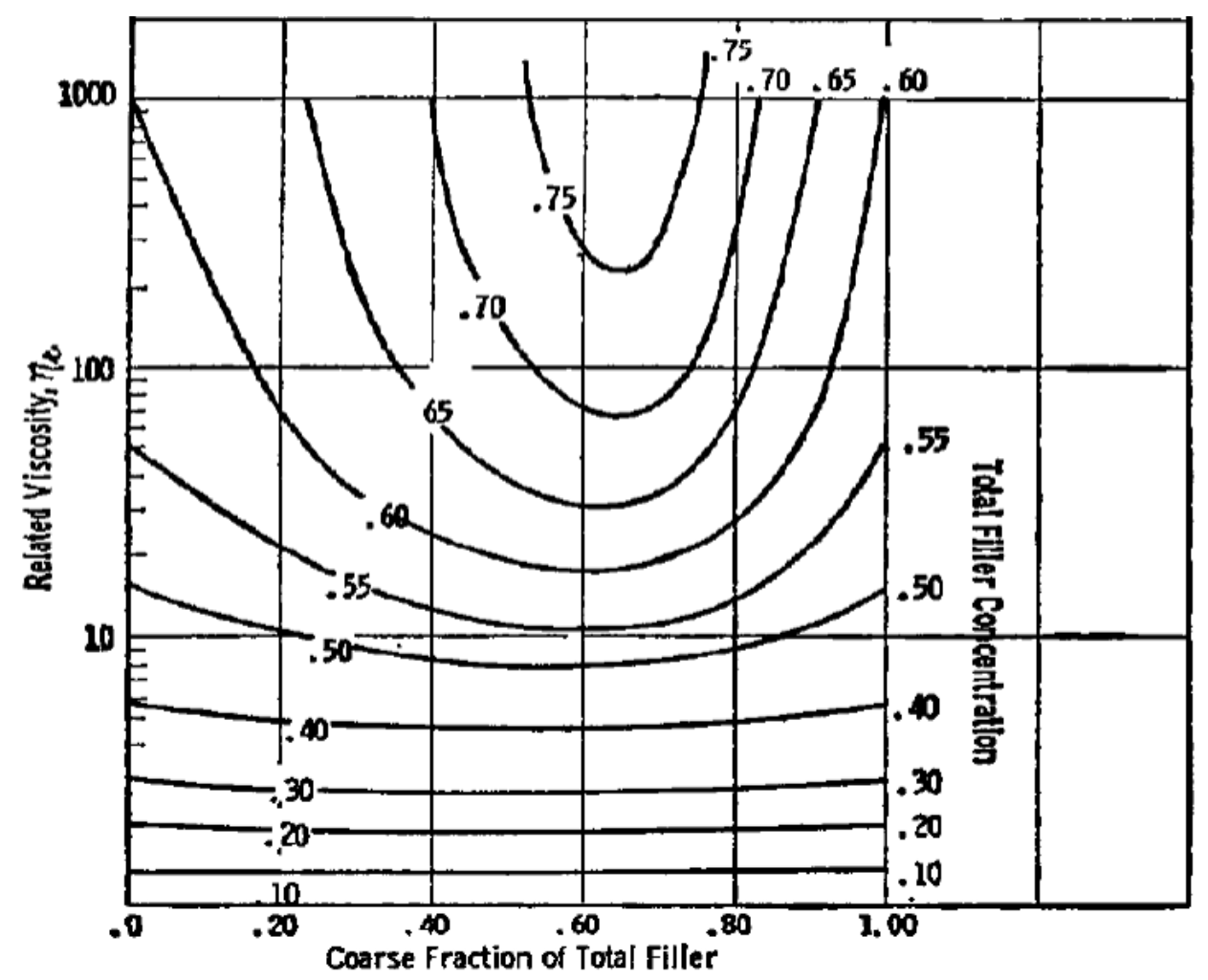

Figura 1.24. Efecto de una distribución de tamaños de partícula bimodal sobre la viscosidad de la suspensión en función de la fracción volumétrica de partículas gruesas [145]

Finalmente, en el caso de soluciones de precursores, puesto que no contienen partículas sólidas, la única propiedad intrínseca de este tipo de material de aporte que afecta a su viscosidad es la concentración de precursores. Según la ley de mezclas, a mayor concentración de precursores, mayor viscosidad del material.

\subsubsection{Estabilidad de los materiales de aporte líquidos.}

Otro de los requisitos de los materiales de aporte líquidos es presentar una elevada estabilidad física y química.

Para las suspensiones de partículas, una buena estabilidad es imperativa con el fin de evitar la coagulación de las partículas, dando lugar a aglomerados que pueden permanecer en la microestructura del recubrimiento final afectando negativamente a sus propiedades, o pueden sedimentar en las conducciones durante el transporte de la suspensión hasta la antorcha, llegando incluso a obturar el inyector.

Como se ha comentado en apartados anteriores, la proyección por plasma a partir de materiales de aporte líquidos se suele utilizar mayoritariamente en la 
deposición de óxidos cerámicos. Al dispersar las partículas de estos materiales en un medio polar, tienen lugar dos efectos. Por un lado, la superficie de las partículas se hidrata, pasando a ser anfótera, y al estar sujeta a reacciones ácido-base como las indicadas en las ecuaciones 1.15 y 1.16 , los protones y los iones hidroxilo se adsorben sobre esta superficie hidratada.

$$
\begin{gathered}
\mathrm{MOH}+\mathrm{H}^{+} \rightarrow \mathrm{MOH}_{2}^{+} \text {(ec. 1.15) } \\
\mathrm{MOH}+\mathrm{OH}^{-} \rightarrow \mathrm{MO}^{-}+\mathrm{H}_{2} \mathrm{O} \text { (ec. 1.16) }
\end{gathered}
$$

La cantidad de aniones o protones adsorbidos sobre las partículas depende del $\mathrm{pH}$ del medio y determina la densidad o potencial de carga superficial de estas partículas. Por tanto, tal y como se muestra en la figura 1.25a [141], a pH básicos predomina la adsorción de iones hidroxilo, por lo que la carga final de la superficie de la partícula será muy negativa. Este proceso también tiene lugar a pH ácidos, donde predomina la adsorción de protones y, por tanto, la carga superficial es muy positiva. Sin embargo, hay un valor de $\mathrm{pH}$ para el cual la adsorción de aniones y protones se lleva a cabo por igual, por lo que las cargas negativas y positivas de la superficie de la partícula se contrarrestan dando lugar a una carga superficial final nula. Este valor de $\mathrm{pH}$ define lo que se conoce como punto de carga cero (ZPC).

El otro efecto que tiene lugar es la atracción/repulsión de las partículas. Al dispersar partículas sólidas en un medio líquido, éstas nunca permanecen en reposo, sino que están en continuo movimiento de forma aleatoria en el seno del fluido a causa del movimiento Browniano (movimiento causado por colisiones entre las partículas sólidas y las moléculas del medio fluido) [135,140,141]. Debido a este movimiento las partículas se acercan unas a otras. En este caso, si las fuerzas de atracción son superiores a las de repulsión las partículas se coagulan formando aglomerados. Las fuerzas de atracción típicas que afectan a las partículas en una suspensión son fuerzas de van der Waals, más concretamente fuerzas de dispersión de London, provocadas por la aparición de dipolos instantáneos entre partículas [135,140,141]. Estas fuerzas son superiores a las de repulsión cuando la carga superficial de las partículas no es suficientemente elevada (en valor absoluto) para contrarrestar el efecto de atracción, es decir, en el punto de carga cero (ZPC) y valores de $\mathrm{pH}$ próximos al ZPC (zona delimitada en la figura 1.25a). Esta desestabilización afecta negativamente a la viscosidad de la suspensión como se aprecia en la figura 1.25b [141]. 
a)

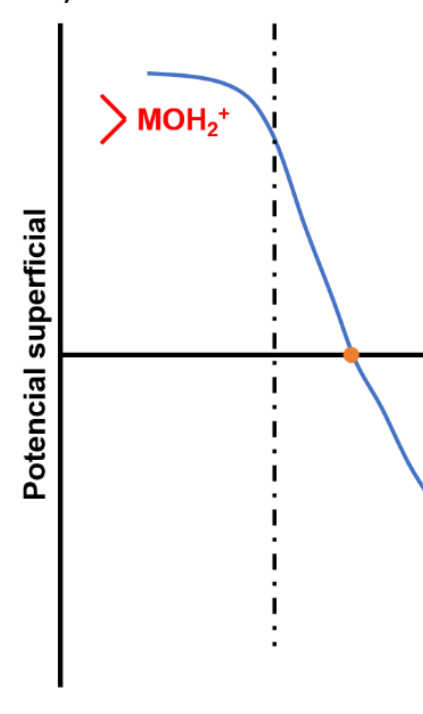

b)

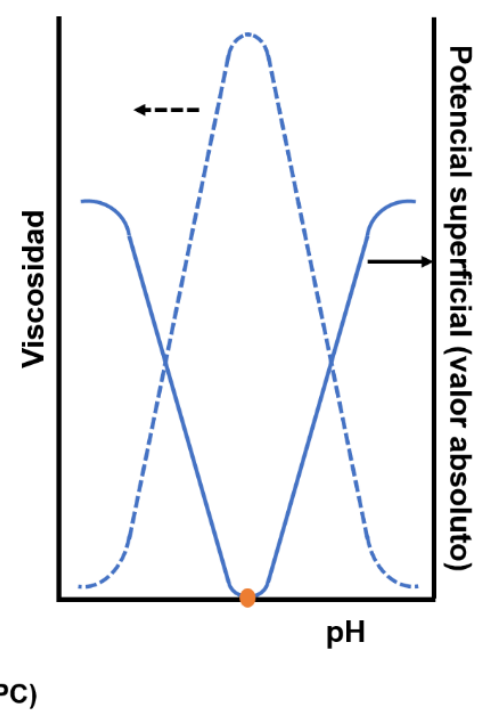

Figura 1.25. Efecto del pH sobre el potencial superficial de partícula (a), viscosidad y potencial superficial de partícula en función del pH para una suspensión de un material determinado (b). Figura adaptada de [141]

En base a lo expuesto, queda patente cómo la estabilidad de una suspensión de partículas está fuertemente afectada por ambas fuerzas (atracción y repulsión). Puesto que las fuerzas de dispersión de London siempre están presentes y no pueden evitarse, se debe fomentar la superioridad de las fuerzas repulsivas frente a las atractivas con el fin de obtener una suspensión estable. Este objetivo se logra mediante la adición de agentes defloculantes, los cuales pueden ser de dos tipos, electrostáticos o poliméricos.

Los agentes defloculantes electrostáticos suelen ser ácidos y bases fuertes (como $\mathrm{HCl} \circ \mathrm{NaOH}$ ) y electrolitos (como hidróxidos de $\mathrm{NH}_{4}{ }^{+}$o sales de $\mathrm{Na}^{+}$) [135]. Una vez adicionados los defloculantes electrostáticos, éstos se disocian formando iones de carga positiva e iones de carga negativa. Puesto que las partículas dispersadas en el medio líquido presentan una superficie cargada, como se ha comentado anteriormente, los iones del mismo signo (coiones) son repelidos mientras que los iones de carga contraria (contraiones) se adhieren a la superficie de la partícula, de tal forma que se desarrolla una doble capa eléctrica sobre la superficie de cada partícula [140,141]. Esta doble capa está compuesta por dos zonas diferentes, una primera monocapa de contraiones adsorbidos sobre la superficie de la partícula denominada capa de Stern y una segunda zona denominada capa difusa compuesta por una nube de contraiones y coiones (Figura 1.26) [141]. 


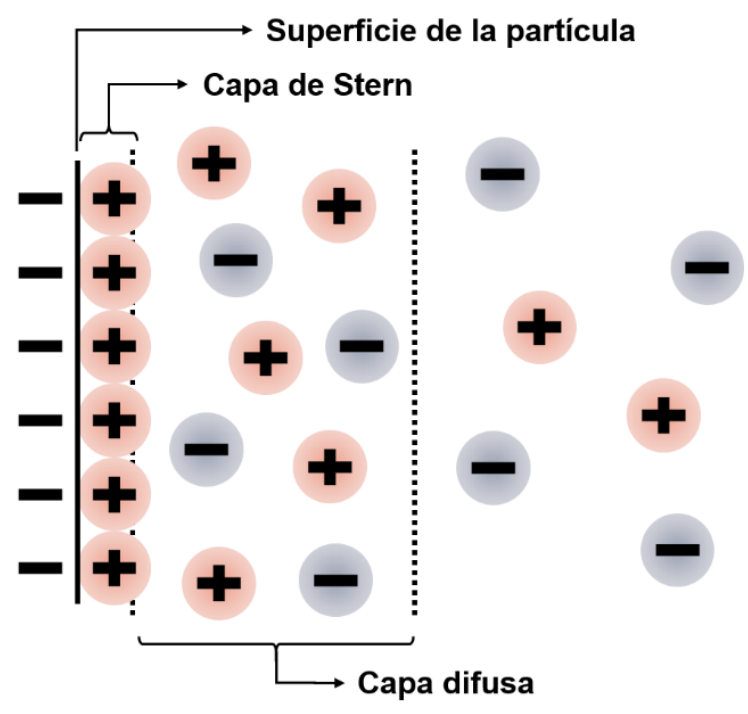

Figura 1.26. Estructura de la doble capa eléctrica. Figura adaptada de [141]

Cuando una partícula se mueve en el seno de un fluido líquido la capa de Stern y un fragmento de la capa difusa se desplazan con la partícula de tal forma que se produce una cizalla entre la capa de Stern y la difusa. El potencial de carga

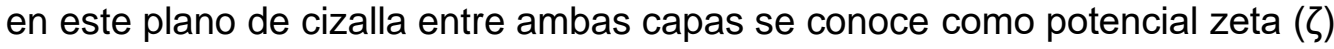
y es el responsable de la repulsión entre partículas [141]. En ocasiones hay un valor del pH para el que el potencial zeta vale cero, el cual se conoce como punto isoeléctrico. En ausencia de contraiones adsorbidos, el potencial zeta coincide con el potencial superficial de la partícula y el punto isoeléctrico con el PZC [141].

La estabilización electrostática se basa en la teoría Derjaguin-Landau VerweyOverbeek (DLVO), mediante la cual es posible predecir la estabilidad de una suspensión asumiendo que el potencial total de interacción $\left(\mathrm{V}_{\mathrm{T}}\right)$ entre partículas es el conjunto o suma de todas las fuerzas de repulsión $\left(\mathrm{V}_{\mathrm{E}}\right)$, debido al solapamiento entre dos dobles capas de partículas diferentes junto con las de atracción $\left(\mathrm{V}_{\mathrm{A}}\right)$ debido a las fuerzas de van der Waals [140,141]. Esta teoría propone fomentar las fuerzas de repulsión frente a las de atracción de tal forma que se genere una barrera de potencial que impida que las partículas se aproximen, como se ilustra en la figura 1.27a. En la figura, se aprecia cómo, para un rango de distancias entre partículas, la curva $\mathrm{V}_{\mathrm{T}}$ presenta un pico convexo en la zona de repulsión el cual actúa de barrera electrostática que dificulta la aproximación entre partículas. A la izquierda de este pico se da un mínimo primario (zona de atracción) y a la derecha de éste un mínimo secundario (zona de atracción). Si la barrera de potencial no es suficiente para repeler las partículas, estás se sitúan en el mínimo primario, de tal forma que se produce una coagulación de las mismas. En cambio, en el caso opuesto, las partículas se sitúan en el mínimo secundario donde no llegan a entrar en 
contacto directo entre ellas, y son fácilmente redispersables mediante agitación mecánica. En algunas ocasiones, esta barrera es tal que no llega a formarse mínimo secundario.
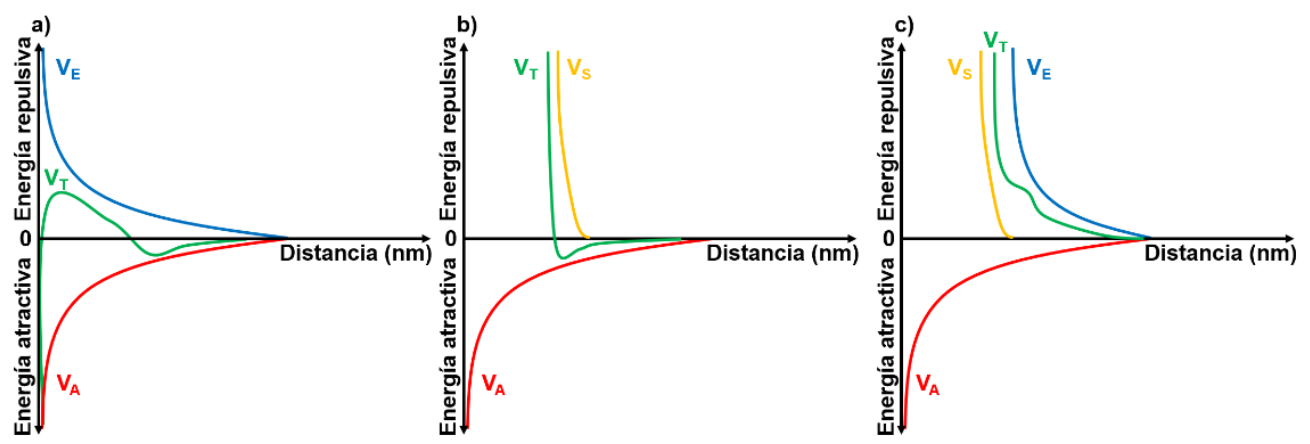

Figura 1.27. Curvas de potencial de interacción entre partículas en función de la distancia entre partículas para repulsión electrostática (a), repulsión estérica (b) y repulsión electroestérica (c)

Respecto a los agentes defloculantes poliméricos, éstos pueden ser copolímeros (como butiral de polivinilo o poliisobutileno), polímeros cargados (ácido poliacrílico o polimetilmetacrilato) y alcóxidos (como tetraetilo ortosilicato o metiltrietoxisilano) [135]. Una vez adicionados estos agentes, pueden estabilizar la suspensión mediante tres mecanismos diferentes [140,141]:

- Estabilización por depleción (Figura 1.28a). En este mecanismo los agentes poliméricos están dispersos por el medio líquido situados entre partículas. Cuando dos partículas se aproximan, la distancia se reduce de tal forma que los polímeros son expulsados de los espacios entre partículas. Al desplazarse estos polímeros, se produce un efecto osmótico en el medio dispersante el cual fluye desde el hueco entre partículas hacia afuera para diluir la concentración de polímero.

- Estabilización estérica (Figura 1.28b). Un agente polimérico se ancla mediante uno de sus extremos a la superficie de la partícula mientras que el extremo libre se elonga hacia el medio dispersante. De esta manera, cuando dos partículas se aproximan hasta una distancia inferior a la elongación del agente polimérico, se produce una compresión de la capa de polímero, a partir de la cual esta capa genera una repulsión elástica.

En ambos casos, la componente de repulsión es puramente elástica, ya que no hay actuación de cargas en ningún caso como en la estabilización electrostática. El último mecanismo de estabilización polimérica es:

- Estabilización electroestérica (Figura 1.28c). Este mecanismos de estabilización genera la repulsión entre partículas combinando una componente elástica (estabilización estérica) con una componente 
eléctrica (repulsión electrostática). Para ello se emplean polímeros cargados conocidos como polielectrolitos. Aunque en la figura 1.28c se ha ilustrado un polielectrolito con carga negativa, esto es a modo de ejemplo pues algunos polielectrolitos pueden presentar carga positiva una vez anclado a la superficie de la partícula. Este mecanismo es el que mejor resultado aporta, puesto que a distancias grandes opera la componente electrostática, y si ésta no fuera suficiente, a distancias cortas es apoyada por la componente elástica de tal forma que se favorece la estabilización [141].

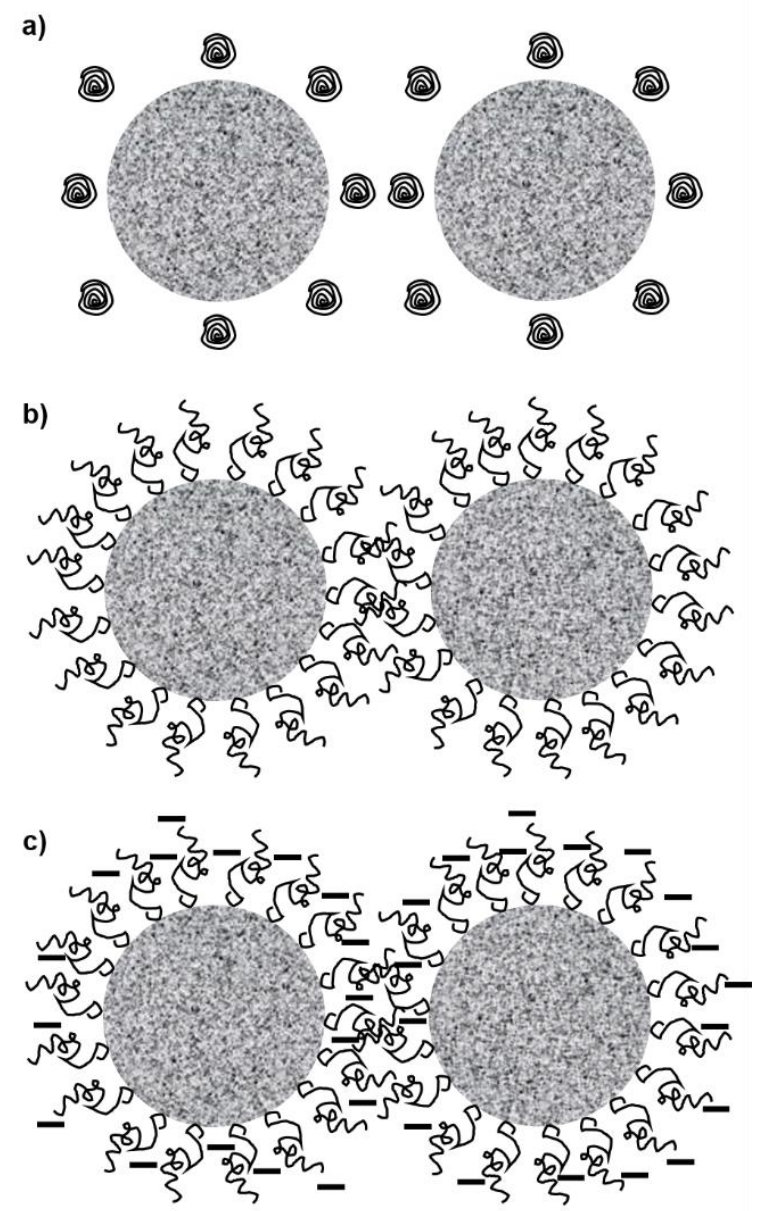

Figura 1.28. Mecanismos de estabilización polimérica. Estabilización por depleción (a), estabilización estérica (b) y estabilización electroestérica. Figura adaptada de [140,141]

A diferencia de la estabilización elestrostática, la estérica (o electroestérica) se basa en la teoría Hesselink, Vrij y Overbeek (HVO), ya que la teoría DLVO no puede predecir la estabilidad a distancias cortas [141]. Las curvas de potencial de interacción total resultante de la estabilización estérica y por depleción se muestran en la figura 1.27b mientras que la curva correspondiente a la estabilización electroestérica se muestra en la figura 1.27c. La teoría HVO 
también busca la generación de un potencial total de barrera que impida la atracción de las partículas. Sin embargo, a diferencia con la teoría DLVO, la HVO no presenta mínimo primario debido al predominio de la componente elástica a distancias cortas (cercanas a la de contacto entre partículas) [141]. Aunque si puede darse la presencia de un mínimo secundario (Figura 1.27b) donde las partículas floculen. En estas curvas, queda patente el efecto positivo de la estabilización electroestérica puesto que, debido a la combinación de ambas componentes (eléctrica y elástica) la curva de potencial de interacción total se encuentra en la zona de repulsión para cualquier rango de distancia entre partículas.

Finalmente, en cualquier tipo de estabilización (electrostática o polimérica), la elección y cantidad del agente desfloculante se lleva a cabo mediante la determinación del potencial zeta junto con estudios reológicos [135].

En cuanto a las soluciones de precursores, son sistemas más sencillos puesto que no contienen partículas sólidas. Sin embargo, también pueden desestabilizarse. La elección de los precursores, así como su concentración en la solución es clave, de tal forma que el precursor escogido y/o la cantidad adicionada a la disolución conlleve una descomposición total de este precursor en la pluma de plasma dando lugar a la formación del material deseado para conformar el recubrimiento. Por otra parte, el precursor escogido, como es el caso del tetraetilo ortosilicato (TEOS) empleado como fuente de sílice $\left(\mathrm{SiO}_{2}\right)$, puede desestabilizarse bajo determinadas condiciones de $\mathrm{pH}$ y temperatura, dando lugar a un proceso de gelificación con la consecuente formación de una estructura sólida.

\subsubsection{Proyección térmica por plasma de materiales de aporte líquidos}

A la hora de depositar los materiales líquidos, puesto que el sistema utilizado es el mismo que en el caso de polvos, los parámetros relativos tanto al equipo como al estado del sustrato descritos en apartados anteriores no varían y su efecto es el mismo. Las principales diferencias entre depositar un material sólido y uno líquido radican obviamente en el tipo y características del material depositado y en la forma de transportar e inyectar este material a la pluma de plasma.

El transporte e inyección de ambos tipos de materiales líquidos se lleva a cabo de la misma forma. Puesto que tanto en el caso de la suspensión como en el caso de la solución ya hay presencia de un medio fluido (dispersante líquido) no es necesario emplear un gas portador para transportar estos materiales hasta la pluma de plasma. Para transportar estos materiales líquidos, la práctica más común es emplear bien una bomba (peristáltica o de pistón) o un sistema neumático presurizado $[134,140,146]$. En el caso de emplear una bomba, el caudal de material se controla mediante la velocidad de rotación de los elementos mecánicos de dicha bomba, mientras que, en el caso del sistema 
neumático, al usar un gas para presurizar el sistema (típicamente aire) es la presión de este gas la que controla el caudal de material líquido [134,140,146]. Mediante el empleo de una bomba se controla mejor la velocidad y el caudal de inyección de material. Sin embargo, este dispositivo a menudo genera inyecciones intermitentes. Por el contrario, el sistema neumático es más simple $y$, aunque fluctuaciones en la presión conlleven pequeñas variaciones en el caudal de material inyectado, genera una inyección continua.

En cualquiera de los casos anteriores (bomba o presurización), la inyección del material puede llevarse a cabo de forma axial o radial (ésta, a su vez, puede ser interna o externa) como en el caso de los materiales pulverulentos. El sistema de inyección del material de aporte líquido en la pluma de plasma puede ser de forma mecánica (como corriente líquida continua) o un atomizador [134,140,146-150].

En lo referente a la atomización, el sistema de atomización coaxial es el más común o empleado [147]. En este sistema, el material líquido es introducido en el atomizador y mediante una corriente gaseosa (típicamente argón) se fragmenta la corriente líquida en pequeñas gotas, las cuales son introducidas en la pluma de plasma [147]. El grado de fragmentación del material líquido depende de su viscosidad y tensión superficial [148].

El sistema de inyección mecánico consiste básicamente en forzar el paso del material líquido a través de una boquilla de un determinado diámetro [147,148]. Los diámetros típicos varían entre 0,05 y $0,3 \mathrm{~mm}[147,148]$ y, una vez pasado el líquido por la boquilla, se genera una corriente continua de líquido cuyo diámetro es entre 1,2 y 1,5 veces superior al diámetro de la boquilla, en función de la presión de la corriente líquida que llega a la boquilla y la geometría de ésta $[147,148]$.

La microestructura de los recubrimientos obtenidos mediante la deposición de líquidos depende en gran medida de cómo se inyecta el material en la pluma de plasma (tipo y sistema de inyección) [149], pues la inyección afecta a la trayectoria y calentamiento del material inyectado [146]. Como se acaba de comentar, la inyección puede ser radial (externa o interna) o axial y, a su vez, el sistema de inyección puede ser un sistema mecánico o un atomizador. Al utilizar un atomizador, independientemente del tipo de inyección (axial o radial), normalmente se obtienen recubrimientos compuestos por finos gránulos redondeados sinterizados unos con otros. Este caso también es común en el proceso de inyección mecánica radial externa. Sin embargo, cuando se emplea inyección interna mediante sistema mecánico la microestructura obtenida generalmente es diferente. Al emplear inyección axial, se obtienen recubrimientos con gránulos de mayor tamaño, pero más fundidos y cohesionados entre ellos. En el caso de utilizar inyección radial interna, la microestructura resultante es intermedia entre la correspondiente a inyección axial e inyección radial externa (ambos casos mediante sistema de inyección mecánico). En este caso se obtiene lo que se conoce como la microestructura de dos zonas, es decir el recubrimiento está formado por gránulos totalmente 
fundidos que componen zonas densas y partículas sólidas muy finas las cuales llegan al sustrato resolidificadas [149].

Por último, añadir que, una vez inyectados los materiales de aporte líquidos, aunque el proceso de inyección de ambos es similar, los procesos que tienen lugar en el interior de la pluma de plasma difieren de un material a otro.

\subsubsection{Proyección térmica de suspensiones por plasma o SPS}

En proyección térmica por plasma a partir de suspensiones, no solo debe fundirse el material sólido antes de depositarlo como en el caso de proyección APS, sino que previamente hay que evaporar el medio dispersante. Es por ello que se producen más fenómenos en el interior de la pluma de plasma como se ilustra en la figura 1.29 [146].

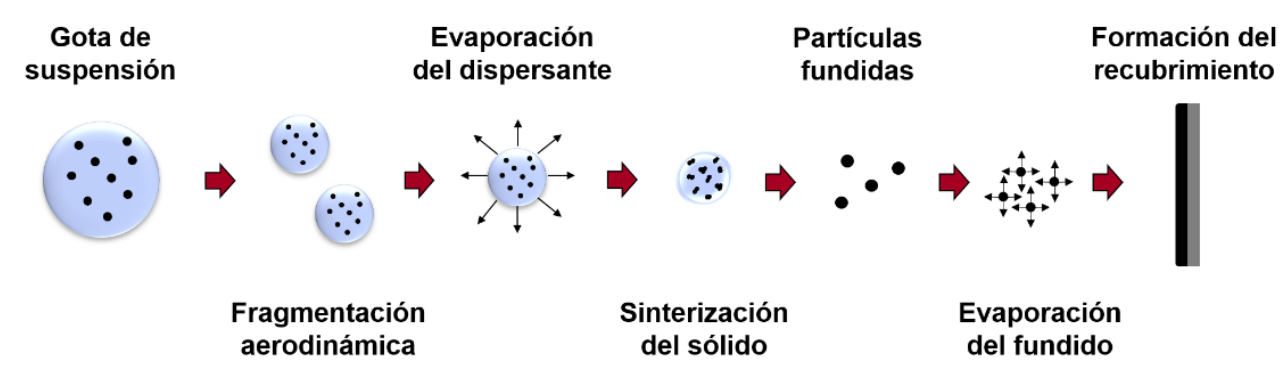

Figura 1.29, Fenómenos desarrollados en una gota de suspensión durante su vuelo a través de la pluma de plasma. Figura adaptada de [146]

La figura anterior, se corresponde con el caso típico. Al inyectar la suspensión, independientemente del sistema utilizado (mecánico o atomización), tanto para la corriente continua de suspensión como para las gotas atomizadas, se produce una rotura en pequeñas gotas de suspensión. Este fenómeno de rotura es conocido como fragmentación aerodinámica y es debido a una cizalla producida sobre la suspensión debido a la inercia de la pluma de plasma. El tamaño de las gotas está influenciado por la viscosidad de la suspensión y la tensión superficial del medio dispersante, de igual forma que en el caso del sistema de inyección por atomización. Inmediatamente tras la fragmentación, el medio dispersante comienza a evaporar rápidamente. Ambos procesos (fragmentación y evaporación) tienen lugar antes de que el material alcance una distancia entre 10 y $15 \mathrm{~mm}$ aguas abajo desde el punto de inyección. A partir de este punto, la mayoría de las partículas finas contenidas en las gotas de suspensión, comienzan a sinterizar de forma instantánea formando gránulos que funden e impactan contra el sustrato para formar el recubrimiento. Como puede apreciarse en la figura 1.29, hay ocasiones en que previamente al impacto de los gránulos fundidos, la capa superficial del fundido puede evaporar debido al pequeño tamaño de estos gránulos $[133,134,140,146-150]$. 
Sin embargo, pueden darse casos diferentes al ideal detallado anteriormente. Tal y como se ha comentado en apartados anteriores, la pluma de plasma no tiene un valor de temperatura homogéneo y constante a lo largo de su longitud y amplitud, sino que tiene importantes gradientes de temperatura. Por un lado, si la inyección de la suspensión no se lleva a cabo correctamente (en inyección radial) y la suspensión no penetra totalmente hasta el eje central de la pluma (zona más caliente), parte del material permanece en la periferia del plasma (en zonas menos calientes) donde el medio dispersante evapora, pero las partículas no funden o lo hacen parcialmente [148]. Por otra parte, independientemente del tipo de inyección (axial o radial), aunque la penetración de la suspensión sea máxima, debido a la termoforesis, las partículas muy finas que alcanzan la parte central son repelidas hasta la periferia de la pluma. Puesto que estas partículas han podido fundir, este fundido se enfría en la periferia, dando lugar a resolidificados que se incrustan en el recubrimiento.

En cualquiera de los dos casos, se introducen partículas sólidas al recubrimiento, las cuales pueden generar defectos y afectan a la cohesión del recubrimiento.

\subsubsection{Proyección térmica de soluciones de precursores por plasma 0 SPPS}

En el caso de la deposición de soluciones de precursores, los procesos que tienen lugar en la pluma de plasma son aún más complejos que en el caso de las suspensiones ya que hay que formar el material a depositar en la propia pluma. En la figura 1.30, se ilustra el proceso típico [152,153], aunque la técnica es más novedosa que las anteriores y los procesos que tienen lugar dentro de la pluma de plasma no han sido estudiados en profundidad y no están del todo claros [154].

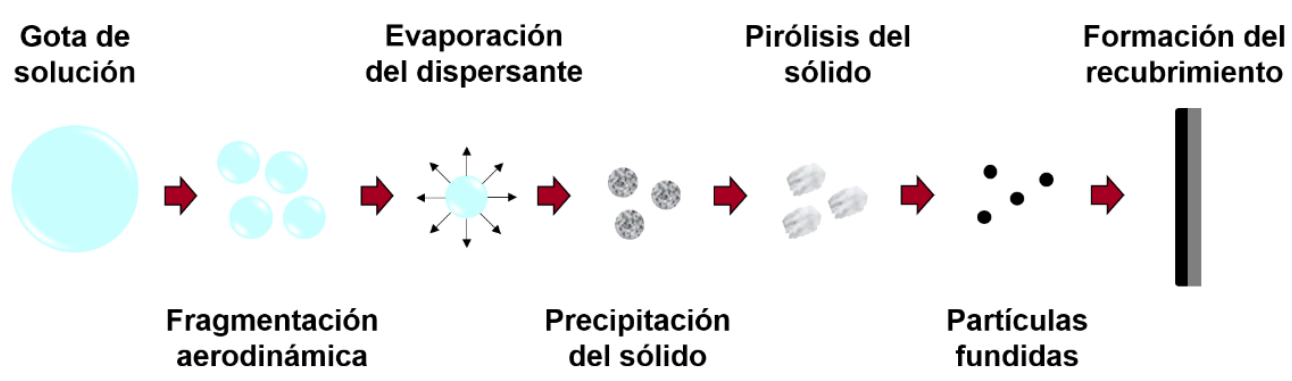

Figura 1.30. Fenómenos desarrollados en una gota de solución durante su vuelo a través de la pluma de plasma. Figura adaptada de $[152,153]$

Al inyectar la solución, de igual forma que en el caso anterior, las primeras etapas, que se dan en microsegundos, son de fragmentación y evaporación del medio dispersante. A continuación, se produce la precipitación del sólido en la gota conforme se evapora el medio dispersante. En gotas muy pequeñas, esta 
precipitación es total en todo el volumen de la gota, mientras que, en gotas grandes, primero precipita una costra de material en la superficie de la gota que va avanzando hacia el centro de la gota. En ciertas ocasiones, la presión del líquido en el interior de la gota conlleva la ruptura de la costra inicial y el proceso vuelve a empezar de nuevo en la gota resultante. A continuación, se produce una pirólisis del sólido precipitado y una sinterización de las partículas formadas en pequeños gránulos, los cuales funden e impactan contra el sustrato [147,148,151-155].

De igual forma que en la deposición de suspensiones, no siempre se cumplen la totalidad de los procesos descritos anteriormente debido a diversas razones, por lo que el material puede llegar al sustrato en diferentes estados [152-155]. Debido a una incorrecta o insuficiente inyección de la solución en la pluma de plasma, parte del material inyectado viaja por las zonas frías de la pluma, donde experimenta diferentes grados de vaporización del medio dispersante. Como resultado, se obtiene partículas de gel o partículas huecas resultantes de la precipitación de un costra de sólido, conteniendo solución en su interior [152155]. Asimismo, debido a la inyección, pueden incluso llegar gotas de solución al sustrato sin haber experimentado ninguno de los procesos comentados anteriormente [154]. Por otra parte, debido a una distancia de proyección excesivamente larga, las partículas fundidas pueden resolidifcar en pequeñas esferas cristalinas que apenas se adhieren sobre el sustrato [154].

De esta forma, también se introducen elementos en el recubrimiento final que pueden generar defectos y afectan a la cohesión del recubrimiento, como en la deposición de suspensiones.

\subsubsection{Consideraciones respecto a los recubrimientos obtenidos}

Aunque se ha comentado que el efecto de los parámetros relativos al equipo es el mismo, se ha de tener en cuenta que, a la hora de depositar materiales líquidos (sobre todo en el caso de suspensiones), es imprescindible trabajar a distancias de proyección menores que en el caso de la deposición de polvos, ya que el tamaño de partícula es muy inferior, por lo que a grandes distancias puede darse el caso de volatilización del material fundido previamente al impacto sobre el sustrato [151].

Por otro lado, para que los materiales líquidos puedan penetrar en la antorcha de plasma, la presión dinámica del material de aporte líquido debe ser igual o superior a la presión dinámica de la pluma de plasma, por ello, se deberá cumplir la siguiente relación [75,81,87-91]:

$$
\rho_{l} v_{l}^{2} \geq \rho_{p} v_{p}^{2} \text { (ec. 1.17) }
$$

Donde $\rho$ es la densidad $\left(\mathrm{kg} / \mathrm{m}^{3}\right)$ y $v$ es velocidad $(\mathrm{m} / \mathrm{s})$, y los prefijos / y $p$ hacen referencia al material líquido y la pluma de plasma respectivamente. 
Además, aunque la microestructura obtenida de la deposición de líquidos presenta mejores propiedades, como se ha comentado en apartados anteriores, la eficiencia de deposición respecto a la deposición de polvo es menor debido, por un lado, a que parte de la energía de la pluma de plasma se consume en el proceso de evaporación del medio dispersante y, por otro, a la limitación en el contenido en sólidos de las suspensiones o en la concentración de las soluciones [151]. Asimismo, debido al efecto Knudsen, las partículas reciben menos energía e inercia por parte de la pluma de plasma por su pequeño tamaño [140,148].

Mediante la deposición de materiales de aporte líquidos, no solo se obtienen recubrimientos con microestructuras densas o porosas como en el caso de proyección a partir de polvos, sino que también es posible obtener microestructuras columnares [146,150]. A menor tensión superficial del medio dispersante, mayor es la fragmentación aerodinámica y más pequeño el tamaño de las gotas resultantes (conteniendo menos material cada gota). Por ello, los gránulos sinterizados y fundidos durante el proceso de deposición también serán muy pequeños. Este reducido tamaño, conlleva a que, en el momento del impacto de estos gránulos sobre el sustrato, predominen las fuerzas de arrastre sobre las gravitacionales, de forma que el impacto no se produce de forma perpendicular al sustrato, sino que la corriente gaseosa resultante de la pluma de plasma arrastra los gránulos de forma paralela al sustrato y éstos impactan sobre las asperezas del mismo [156].

Por último, independientemente de si se utilizan suspensiones de partículas o suspensiones de precursores, para unas condiciones de proyección determinadas resulta interesante estudiar el efecto del medio líquido en las propiedades termodinámicas de la pluma de plasma encargadas de la transferencia de calor (conductividad térmica) y energía cinética (viscosidad) a las partículas durante su vuelo $[157,158]$. Asumiendo despreciables el calentamiento de las partículas por radiación desde la pluma de plasma y el enfriamiento radiante de las mismas, y que las partículas presentan una única temperatura, la expresión que describe la transferencia de calor desde la pluma de plasma a las partículas es la siguiente:

$$
\pi d_{p}^{2} h\left(T_{g}-T_{p}\right)=\frac{1}{6} \pi \rho_{p} c_{p} d_{p}^{3} \frac{d T_{p}}{d t}(\text { ec. 1.18) }
$$

donde $d_{p}$ es el diámetro de la partícula $(m)$, h es el coeficiente de transmisión de calor por convección $\left(\mathrm{W} / \mathrm{m}^{2} \cdot \mathrm{K}\right), \mathrm{T}_{\mathrm{g}}$ es la temperatura del plasma $(\mathrm{K}), \mathrm{T}_{\mathrm{p}}$ es la temperatura de la partícula $(K), \rho_{p}$ es la densidad de la partícula $\left(\mathrm{kg} / \mathrm{m}^{3}\right)$ y $\mathrm{c}_{\mathrm{p}}$ es el calor específico de la partícula $(\mathrm{J} / \mathrm{kg} \cdot \mathrm{K})$. Considerando las suposiciones realizadas por el profesor Pawlowski [62], la ecuación 1.18 puede escribirse como sigue:

$$
A H F=\frac{L\left(T_{g}-300\right)^{2}{\overline{\lambda_{g}}}^{2}}{\overline{\eta_{g}} v_{g}}=\frac{H_{m}^{2} d_{p}^{2} \overline{\rho_{p}}}{16}=D M F(\text { ec. 1.19) }
$$


donde $L$ es la longitud de la zona de alta temperatura del plasma $(m), \lambda_{g}$ es la conductividad térmica media del plasma $(\mathrm{W} / \mathrm{m} \cdot \mathrm{K}), \eta_{\mathrm{g}}$ es la viscosidad dinámica media del plasma $(\mathrm{kg} / \mathrm{m} \cdot \mathrm{s}), \mathrm{v}_{\mathrm{g}}$ es la velocidad del plasma de la zona de alta temperatura $(\mathrm{m} / \mathrm{s})$ y $\mathrm{H}_{\mathrm{m}}$ es la entalpía de fusión de partículas $(\mathrm{J} / \mathrm{kg})$.

En la ecuación 1.19, el lado izquierdo contiene todas las variables relacionadas con la antorcha de plasma y sus propiedades termodinámicas, siendo este lado conocido como "ability of heating factor" (AHF), mientras que el lado derecho contiene todas las variables relacionadas con las partículas y se conoce como "difficulty of melting degree" (DMF). Por lo tanto, una partícula con un diámetro $d_{p}$ inyectada en el punto más caliente de la antorcha de plasma fundirá completamente siempre y cuando AHF > DMF.

Una vez inyectado un material de aporte líquido en la antorcha de plasma, el medio líquido se evapora, por lo que el gas formado pasa a formar parte de la mezcla gaseosa de la pluma de plasma. En consecuencia, las propiedades termodinámicas iniciales se modifican. Con el fin de cuantificar el efecto del medio líquido sobre estas propiedades, el profesor Pawlowski propuso calcular un valor modificado del parámetro AHF, derivado del lado izquierdo de la ecuación 1.19 teniendo únicamente en cuenta la conductividad térmica media y la viscosidad media de la pluma de plasma $[157,158]$.

$$
\frac{1}{\left(T_{g}-300\right)} \sqrt{\frac{A H F v_{g}}{L}}=A H F_{m}=\frac{\overline{\lambda_{g}}}{\sqrt{\bar{\eta}_{g}}}(\text { ec. 1.20) }
$$





\section{OBJetivos}



El principal objetivo de este trabajo de tesis es obtener y comparar recubrimientos de vidrio bioactivo mediante proyección térmica por plasma a partir de tres materiales de aporte diferentes: polvo, suspensión de partículas y solución de precursores químicos. Se pretende estudiar el efecto de cada tipo de material de aporte a la antorcha de proyección sobre la microestructura resultante de los recubrimientos de vidrio bioactivo obtenidos $y$, en consecuencia, el efecto de dichos materiales de aporte sobre las diferentes propiedades de estos recubrimientos (adherencia, bioactividad, presencia de fases cristalinas, etc.).

Con el fin de poder lograr el objetivo principal planteado, primero es necesario alcanzar una serie de objetivos específicos, los cuales se detallan a continuación:

- Selección de la composición de vidrio bioactivo a estudiar.

- Síntesis de polvo de vidrio bioactivo adecuado para su empleo en proyección térmica. Se debe obtener un material pulverulento que presente un tamaño de partícula micrométrico con una densidad adecuada y una excelente fluidez para poder transportarlo desde la tolva e inyectarlo en la pluma de plasma.

- Preparación y adecuación de suspensiones de vidrio bioactivo. A partir del polvo obtenido y tras la selección de un medio de suspensión adecuado, se debe reducir el tamaño de partícula del polvo y preparar suspensiones con una viscosidad mínima y elevada estabilidad, tanto física como química, para su correcto transporte e inyección en la pluma de plasma.

- Preparación y adecuación de soluciones precursoras de vidrio bioactivo. Tras la selección de los precursores (alcóxidos y sales) y el medio disolvente más adecuados, se debe preparar soluciones precursoras con baja viscosidad y elevada estabilidad química (de igual forma que en el objetivo anterior) para su correcto transporte e inyección en la pluma de plasma, que permitan sintetizar la composición de vidrio bioactivo deseada en el interior de esta pluma.

- Deposición de los recubrimientos. Selección de los distintos parámetros de proyección (caudales de gases plasmógenos, distancia de proyección, presencia o no de capa de anclaje, etc.) en función del tipo de material de aporte depositado, y deposición de los distintos recubrimientos.

- $\quad$ Caracterización a distintos niveles de los recubrimientos obtenidos. Estudio de la influencia de los diferentes materiales de aporte sobre los recubrimientos obtenidos mediante análisis microestructural, fases cristalinas, adherencia, bioactividad, etc. 



\section{OBJECTIVES}



The main goal of the present work is to obtain and compare plasma sprayed bioactive glass coatings from three different feedstocks: powder, particle suspension and precursor solution. The idea is to study the effect of each feedstock on the resulting bioactive glass coatings' microstructure, and therefore, the effect of each feedstock on the different properties of these coatings (adhesion, bioactivity, coating's crystallinity, etc.).

To achieve the main objective, it is first necessary to accomplish a series of specific objectives, which are detailed below:

- Selection of the working glass composition.

- Synthesis of bioactive glass powder suitable to be used as feedstock in thermal spraying. A powder feedstock with micrometric particle size, suitable density and excellent flowability must be obtained to transport it from the hopper and inject it into the plasma plume.

- Synthesis and stabilisation of bioactive glass particle suspension. After selecting a suitable suspension medium, the particle size of the powder obtained above must be reduced to produce suspensions with low viscosity and high stability over time, both physically and chemically, for correct transport and injection into the plasma plume.

- Synthesis and stabilisation of bioactive glass precursor solutions. After selecting the appropriate precursors (alkoxides and salts) and solvent, precursor solutions with low viscosity and high chemical stability over time (as in the previous objective), for its correct transport and injection into the plasma plume, must be obtained to develop the desired glass composition inside the plasma plume.

- Manufacture of the coatings. Selection of the different spraying parameters (plasma gases flow rate, spraying distance, presence of bond coating, etc.) depending on the type of feedstock employed, and deposition of the different coatings.

- Characterisation at different levels of the obtained coatings. Study of the effect of the different feedstocks on the obtained coatings by microstructural analysis, crystalline phases, adherence, bioactivity, etc. 



\section{MATERIALES Y METODOLOGÍA}





\subsection{Materiales}

La obtención de los recubrimientos bioactivos mediante proyección térmica por plasma atmosférico se ha llevado a cabo a partir de tres materiales de aporte diferentes (polvo, suspensión de partículas y solución de precursores químicos) tal y como se ha comentado en secciones anteriores. El vidrio objeto de estudio escogido es el vidrio bioactivo 45S5, cuya composición viene definida en el capítulo 1. Introducción. En base a esta composición, se han sintetizado y caracterizado los tres materiales de aporte tal y como se detalla en los siguientes apartados.

\subsubsection{Polvo de vidrio bioactivo $45 \mathrm{~S} 5$}

El primer material de aporte sintetizado en este trabajo de tesis es el polvo de vidrio bioactivo 45S5. Para ello se ha utilizado el método de fusión y enfriado brusco ("melting and quenching"). Con el fin de obtener una gran cantidad de este material de forma rápida, es necesario realizar este proceso de forma continua. Por ello, se ha llevado a cabo una colaboración con la empresa Fritta S.L., la cual ha facilitado acceso a materias primas y un horno tubular rotatorio a escala piloto similar al mostrado en la figura 3.1a.

En primer lugar, se preparó una mezcla de cuarzo $\left(\mathrm{SiO}_{2}\right)$, fosfato de calcio $\left(\mathrm{Ca}_{3}\left(\mathrm{PO}_{4}\right)_{2}\right)$, carbonato de sodio $\left(\mathrm{Na}_{2} \mathrm{CO}_{3}\right)$ y carbonato de calcio $\left(\mathrm{CaCO}_{3}\right)$ de elevada pureza. La mezcla resultante se introdujo de forma continua en el horno rotatorio llevándola hasta una temperatura máxima de $1450{ }^{\circ} \mathrm{C}$, y el fundido resultante se enfrió bruscamente mediante vertido en agua, obteniendo así una frita (Figura $3.1 \mathrm{~b}$ ), partículas de vidrio de forma irregular y tamaño grueso.
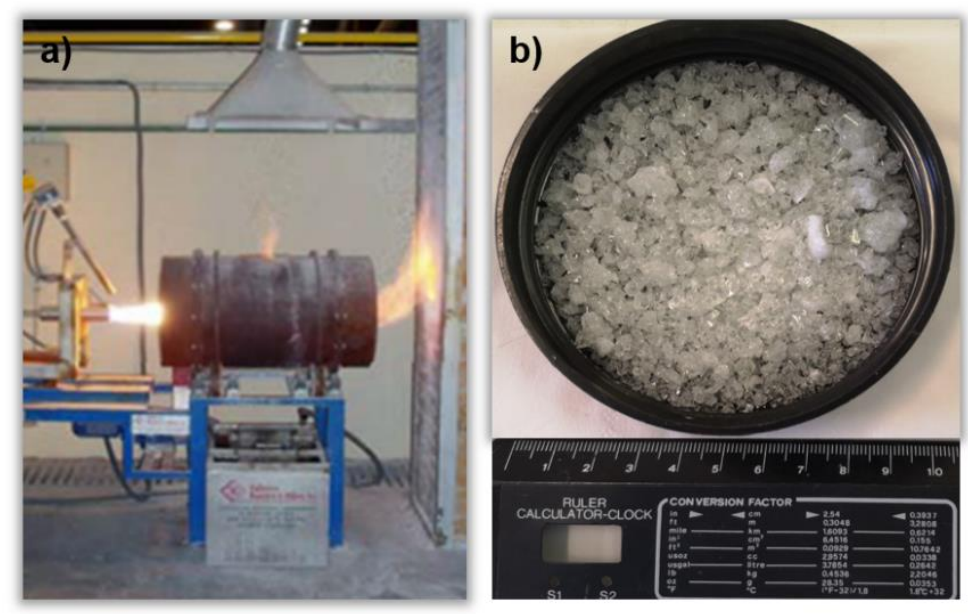

Figura 3.1. Ejemplo de horno tubular rotatorio junto con imagen de la frita resultante tras el enfriamiento brusco. a) Horno tubular rotatorio, b) Partículas de frita 
A continuación, con el objetivo de adecuar el tamaño de partícula de la frita para su uso en proyección térmica por plasma, ésta se ha molturado vía seca en molino de martillos (SK 100, Retsch, Alemania) y el polvo resultante ha sido clasificado vía seca en diferentes fracciones granulométricas mediante batería de tamices. El proceso de clasificación se ha llevado a cabo en un vibrotamiz (AS 200 DIGIT, Retsch, Alemania) durante 5 minutos, con condiciones fijas de vibrado, y tamices con luz de malla de $700,400,200,150,100$ y $63 \mu \mathrm{m}$. En la tabla 3.1 se detallan las distintas fracciones granulométricas obtenidas.

Tabla 3.1. Fracciones granulométricas de polvo de vidrio bioactivo $45 \mathrm{S5}$

\begin{tabular}{cccccc}
\hline Referencia & BGGS & BGGS1 & BGGS2 & BGGS3 & BGGS4 \\
\hline $\begin{array}{c}\text { Distribución de } \\
\text { tamaños de } \\
\text { partícula }(\mu \mathrm{m})\end{array}$ & $700-200$ & $400-200$ & $200-100$ & $150-63$ & $<63$ \\
\hline
\end{tabular}

Asimismo, debido al reducido tamaño e irregularidad de las partículas de la fracción BGGS4, fue necesario mezclarla con un fluidificante con el fin de conseguir la fluidez necesaria para poder transportar e inyectar esta fracción de partículas de vidrio desde la tolva a la antorcha de plasma. Como agente fluidificante se ha utilizado una sílice pirogénica hidrófoba (Aerosil R812, Evonik Industries, Alemania) con un tamaño medio de partícula de $7 \cdot 10^{-3} \mu \mathrm{m}$ y una superficie específica de $260 \pm 30 \mathrm{~m}^{2} / \mathrm{g}$. La elección de este material se llevó a cabo en base a experiencia previa en el uso de fluidificantes y en el hecho de que no introduce ningún compuesto nuevo en la composición final del vidrio. Ambos materiales (fracción BGGS4 y fluidificante) se mezclaron vía seca mediante un molino de cuchillas de fabricación propia. Tras varios ensayos fue posible comprobar que los mejores resultados se obtenían para un tiempo de mezclado de 5 minutos y un porcentaje másico de fluidificante de $1 \%$ en peso respecto a la masa total de polvo de vidrio bioactivo.

\subsubsection{Composición química}

La determinación de la composición química de la frita se ha realizado mediante espectrometría de fluorescencia de rayos $X(F R X)$ con un espectrómetro (AXIOS, PANalytical, Paises Bajos) como el mostrado en la figura 3.2. Se trata de una técnica que permite llevar a cabo un análisis cualitativo y cuantitativo de los elementos químicos presentes en un determinado material. 


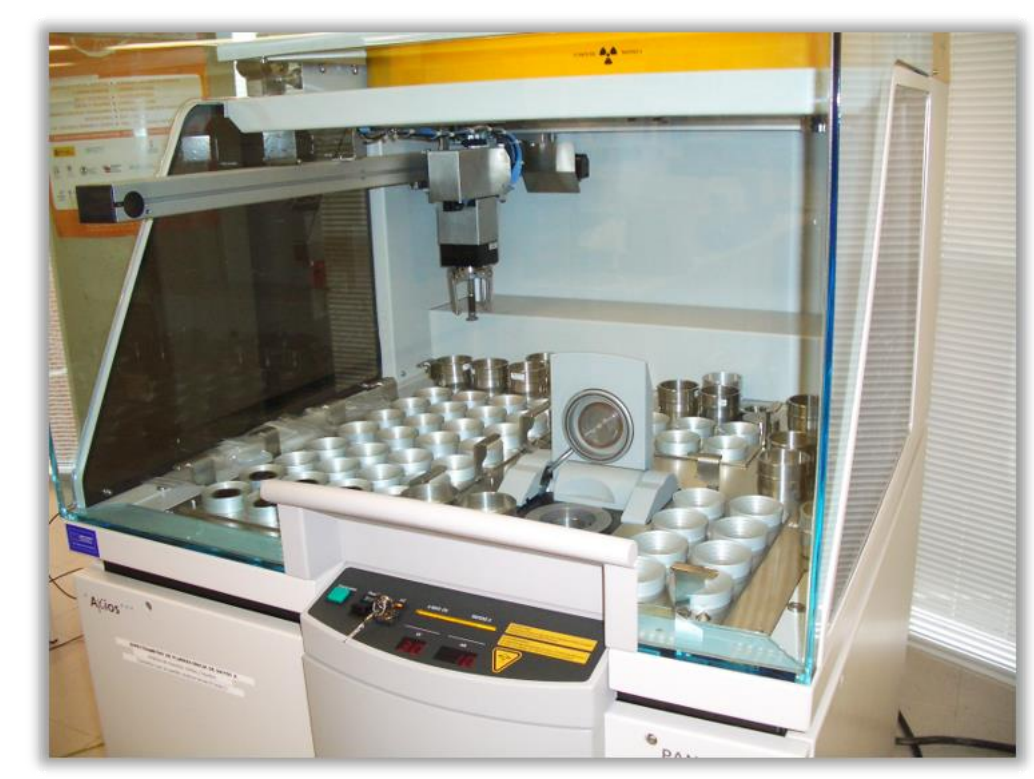

Figura 3.2. Equipo de fluorescencia de rayos X AXIOS. Fuente: Fondo documental de AICE

El método consiste en generar un haz de rayos $X$ (radiación primaria) con el que irradiar la muestra objeto de estudio hasta provocar que cada elemento químico presente en la muestra se excite. Como consecuencia de esta excitación, cada elemento emite rayos $X$ en todas direcciones (radiación secundaria) con una longitud de onda característica de cada uno y distinta intensidad. Mediante un sistema móvil compuesto por dos colimadores, un cristal y un detector es posible captar, clasificar y contar todas las longitudes de onda de la radiación secundaria emitida por los distintos elementos, y así conocer qué elementos forman parte de la muestra y en qué proporción se encuentran [159].

Para determinar la composición de la frita, previamente al ensayo de fluorescencia, el material se secó en estufa a $100^{\circ} \mathrm{C}$, se molturó vía seca y se fundió en una perladora (PERL'X 3, PANalytical, Paises Bajos). La perla resultante se analizó en el espectrómetro descrito utilizando un tubo de $\mathrm{Rh}$ como fuente de radiación primaria, $4 \mathrm{~kW}$ de potencia y patrones certificados para asegurar la trazabilidad de las medidas.

\subsubsection{Morfología de las partículas de vidrio}

Mediante microscopía electrónica de barrido es posible observar la morfología y analizar la composición de cualquier material objeto de estudio, escaneando la superficie del mismo con un haz de electrones. En el microscopio electrónico de barrido los electrones se generan en el cañón de electrones (que puede ser un emisor termoiónico o una fuente de emisión de campo) y se someten a un determinado voltaje, que los acelera. El haz es canalizado hacia la superficie 
objeto de estudio a través de una columna a vacío y, al incidir sobre la muestra, los electrones del haz (electrones primarios) generan distintas señales que, recogidas por los diferentes detectores, suministran información sobre la morfología y composición de la muestra. El haz de electrones se desplaza por la superficie de la muestra y las imágenes que se obtienen, son el resultado de la variación en la intensidad de la señal captada por el detector en cada punto (píxel) a medida que el haz de electrones se va desplazando por el área escaneada [160]. De entre las diferentes señales generadas, las más o utilizadas son:

$>$ Electrones retrodispersados. Cuando los electrones primarios colisionan con los núcleos atómicos pueden experimentar variaciones en su trayectoria y volver a salir de la muestra. Estos electrones que salen de la muestra son de alta energía y se denominan electrones retrodispersados. Si el peso atómico de la muestra es bajo, la probabilidad de que se produzca una retrodispersión es menor que si el peso atómico de la muestra es elevado, por lo que principalmente aportan información sobre la composición. En las imágenes de electrones retrodispersados, las zonas más brillantes (blancas) son aquellas en las que la emisión de electrones retrodispersados es mayor y corresponden a zonas con elementos más pesados y las zonas más oscuras corresponden a zonas con elementos ligeros. En las muestras pulidas, la señal de electrones retrodispersados permite visualizar zonas con diferente composición. Sin embargo, si la muestra es rugosa los electrones retrodispersados pueden ser absorbidos, por lo que la emisión de éstos dependerá también de la topografía de la muestra, con lo que la información que se obtiene es una mezcla de composición y topografía.

$>$ Electrones secundarios. Los electrones del haz pueden interaccionar con los de la muestra y expulsarlos de ésta. Si la interacción es con un electrón débilmente enlazado, éste sale de la muestra con una energía de unos pocos eV. Debido a su baja energía los electrones secundarios que salen de la muestra solo se detectan si proceden de las inmediaciones de la superficie. Por este motivo, son sensibles a la topografía de la muestra. Los electrones secundarios no proporcionan información sobre la composición de la muestra, sino únicamente sobre su topografía.

> Rayos X característicos. Cuando un haz de electrones con una energía superior a la crítica de ionización que corresponde a los electrones de los átomos que constituyen la muestra, incide sobre la superficie de un sólido, se produce, entre otros fenómenos, la expulsión de electrones de las capas internas, creándose huecos. Estos huecos se llenan con electrones de capas más externas, produciéndose una liberación de energía que puede ser en forma de rayos $X$ característicos. La detección de los rayos $X$ se hace mediante espectrómetros de 
dispersión de longitudes de onda y de dispersión de energías, obteniéndose la composición de la muestra.

Por ello, la morfología de las partículas de vidrio para todas las fracciones granulométricas obtenidas (incluyendo la BGGS4 con fluidificante) se ha observado mediante microscopía electrónica de barrido (FEG-ESEM) empleando un microscopio (QUANTA 200F, FEI Company, USA) como el mostrado en la siguiente figura.

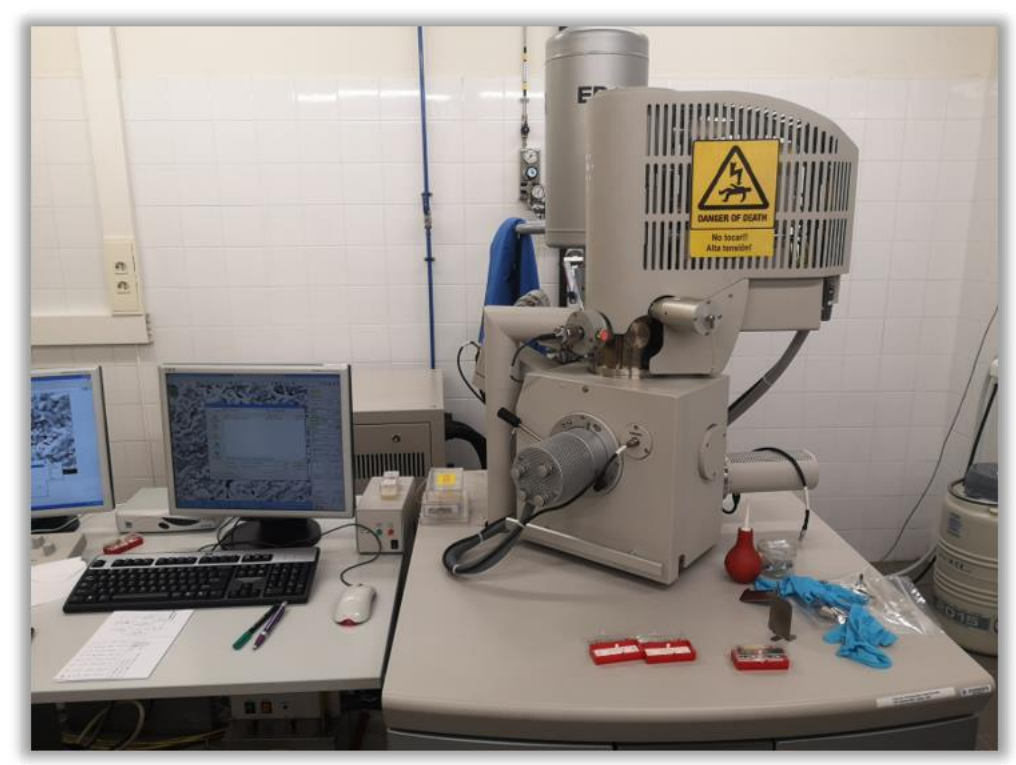

Figura 3.3. Microscopio electrónico de barrido QUANTA 200F. Fuente: Fondo documental de AICE

Para la observación de las distintas fracciones de polvo, éstas se han colocado sobre un adhesivo de carbono en un portamuestras metálico. A continuación, se han tomado micrografías a diferentes aumentos utilizando la señal de electrones retrodispersados y un voltaje de $20 \mathrm{kV}$.

\subsubsection{Identificación de fases cristalinas}

Se ha analizado la posible presencia de fases cristalinas en las diferentes fracciones granulométricas mediante difracción de rayos $X(D R X)$ utilizando un difractómetro (Advance diffractometer, Bruker Theta-Theta, Alemania) como el mostrado en la figura 3.4.

La determinación de fases cristalinas mediante DRX consiste en generar un haz de rayos $X$ de longitud de onda conocida (radiación primaria) y hacerlo incidir sobre la muestra objeto de estudio. El haz de rayos $X$ incidente se difracta desde el material objeto de estudio, reflejándose con ángulos característicos de los planos de los cristales y es recogido por el detector, 
obteniéndose el correspondiente difractograma, a partir del cual es posible identificar las fases presentes utilizando las fichas del International Centre for Diffraction Data (ICDD) para fases cristalinas puras (Powder Diffraction File, PDF-4 2018) [161,162].

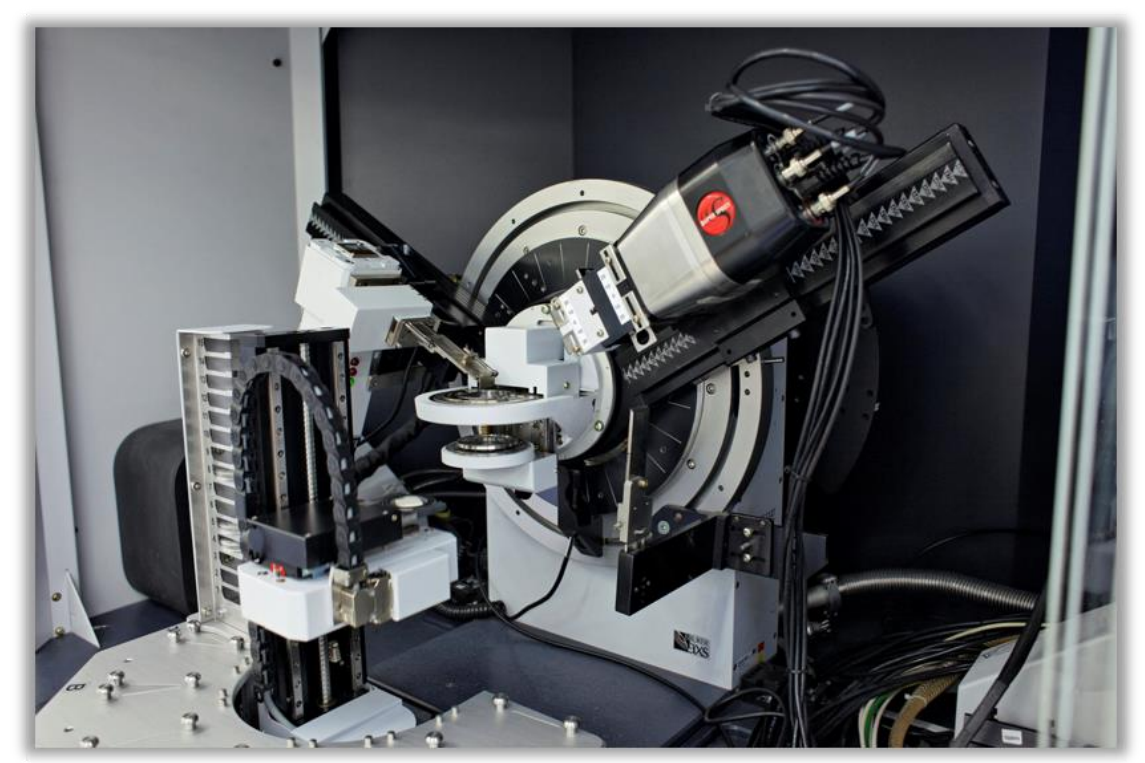

Figura 3.4. Difractómetro de rayos X Advance diffractometer. Fuente: Fondo documental de AICE

Para determinar la presencia de fases cristalinas en las fracciones de polvo obtenidas en este trabajo de tesis, se ha utilizado un tubo de rayos $\mathrm{X}$ de $\mathrm{Cu} \mathrm{Ka}$ con una longitud de onda $(\lambda)$ de 1,54183 $\AA$. El tubo opera a un voltaje de $30 \mathrm{kV}$ y una intensidad $40 \mathrm{~mA}$, y el intervalo $2 \theta$ analizado está comprendido entre $5 \mathrm{y}$ $90^{\circ}$ con un tamaño de paso de $0,02^{\circ}$ y una constante de tiempo de $0,5 \mathrm{~s} /$ paso.

\subsubsection{Determinación de la fluidez de las distintas fracciones}

Uno de los requisitos de los materiales de aporte pulverulentos utilizados en proyección térmica por plasma es presentar una buena fluidez. Por ello, para cada una de las fracciones de polvo obtenidas se ha estudiado esta propiedad por medio del Índice de Hausner (HR) y el ángulo de reposo estático $\left(\alpha_{M}\right)$.

Por un lado, el Índice de Hausner es el cociente entre la densidad aparente de un lecho de polvo vibrado o consolidado y la densidad aparente del mismo lecho sin consolidar según la ecuación 3.1.

$$
H R=\frac{\rho_{c}}{\rho_{o}}(\text { ec. 3.1) }
$$

Donde $\rho_{c}$ es la densidad del lecho consolidado $\left(\mathrm{kg} / \mathrm{m}^{3}\right)$ y $\rho_{o}$ es la densidad del lecho sin consolidar $\left(\mathrm{kg} / \mathrm{m}^{3}\right)$. Se trata de un método muy simple para estudiar 
la fluidez de polvos, por lo que su empleo es bastante común en la caracterización de materiales pulverulentos para proyección térmica por plasma [65,163]. En base a este método, es posible clasificar el grado de fluidez del material objeto de estudio según a la siguiente tabla [164,165].

Tabla 3.2. Clasificación de un material pulverulento en función del Índice de Hausner $[164,165]$

\begin{tabular}{cc}
\hline Índice de Hausner (HR) & Comportamiento del material \\
\hline$<1,25$ & Material con fluidez elevada \\
$1,25-1,40$ & Material con cierta cohesión \\
$>1,40$ & Material muy cohesivo \\
\hline
\end{tabular}

Con el fin de determinar el HR, para cada fracción de polvo de vidrio bioactivo se ha vertido el material en una probeta graduada hasta que rebosaba y se ha enrasado con ayuda de una espátula de laboratorio. Seguidamente, se ha pesado la probeta enrasada y se ha calculado la densidad del lecho sin consolidar como el cociente entre la masa de material y el volumen total rellenado. A continuación, se ha consolidado el lecho mediante vibración durante 2 minutos, empleando condiciones fijas de vibrado. Con el nuevo volumen del lecho, y tras pesar de nuevo la probeta con material, se ha obtenido la densidad del lecho consolidado. Con ambas densidades, aplicando la ecuación 3.1 se ha obtenido el HR para cada fracción de polvo de vidrio bioactivo. Todos los ensayos se han llevado a cabo tras secar totalmente el polvo en estufa a $110^{\circ} \mathrm{C}$ y enfriarlo en desecador.

Por otra parte, el ángulo de reposo se puede definir como el ángulo formado entre la pendiente de un lecho de polvo vertido sobre una superficie y la superficie horizontal sobre la que se vierte (Figura 3.5a).
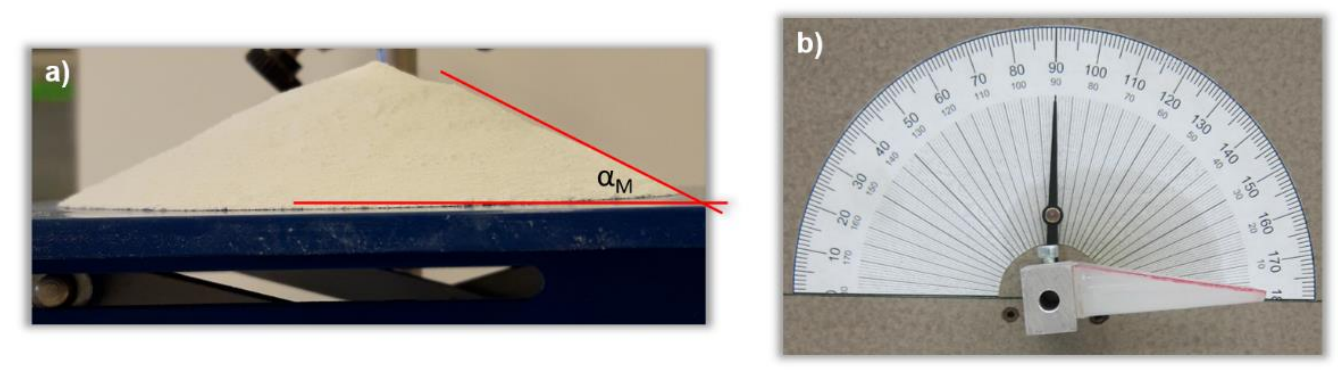

Figura 3.5. a) Ejemplo medida de ángulo de reposo, b) Dispositivo de fabricación propia utilizado en la determinación del ángulo de reposo

Se trata de un método utilizado a nivel industrial, el cual también permite clasificar el comportamiento al flujo de un material pulverulento (Tabla 3.3) [165]. 
Tabla 3.3. Clasificación de un material pulverulento en función del ángulo de reposo [165]

\begin{tabular}{cc}
\hline Ángulo de reposo estático $\left(\alpha_{\mathrm{M}}\right)$ & Comportamiento del material \\
\hline$<30^{\circ}$ & Material con fluidez elevada \\
$30^{\circ}-45^{\circ}$ & Material con cierta cohesión \\
$45^{\circ}-55^{\circ}$ & Material cohesivo \\
$>55^{\circ}$ & Material muy cohesivo \\
\hline
\end{tabular}

En este trabajo, la determinación del ángulo de reposo de los distintos polvos estudiados se ha llevado a cabo con un dispositivo de fabricación propia, ilustrado en la figura 3.5b. En ella se aprecia un portamuestras cóncavo, donde se aloja el polvo objeto de estudio, el cual está acoplado a una aguja que marca una serie de ángulos. Una vez vertido y enrasado el polvo en el interior del portamuestras, éste empieza a girar lentamente a velocidad constante hasta que el polvo cae. Una vez ha caído todo el polvo contenido en el portamuestras, se ha leído el valor del ángulo de reposo indicado por la aguja.

Tanto la obtención del HR como el $\alpha_{M}$ se ha llevado a cabo tras secar totalmente el polvo en estufa a $110^{\circ} \mathrm{C}$ y enfriarlo en desecador.

\subsubsection{Efecto de la humedad sobre la fluidez de las distintas fracciones de polvo}

El vidrio bioactivo estudiado en este trabajo de tesis es un material muy higroscópico [166]. Por ello, de forma complementaria a los ensayos del apartado anterior, también se ha estudiado el efecto de la humedad en la fluidez del material. Este estudio se ha llevado a cabo con las dos fracciones de polvo más finas (BGGS3 y BGGS4 con y sin fluidificante) mediante una cámara climática (WK3, Weiss Umwelttechnik, Alemania), equipo que permite simular distintas condiciones de humedad y temperatura. Puesto que estas fracciones poseen mayor superficie específica, es de esperar que se adsorba más cantidad de agua sobre su superficie que las otras fracciones de polvo.

De igual forma que en el apartado anterior, ambas fracciones de polvo se han secado totalmente en estufa a $110^{\circ} \mathrm{C}$ y se han enfriado en desecador. Una vez secas y frías, se han pesado e introducido en la cámara climática durante 24 horas a $20 \stackrel{\circ}{\circ}$ y $60 \%$ de humedad relativa. Este tiempo de ensayo se ha escogido para asegurar que el material adsorbe la máxima cantidad de humedad alcanzándose el equilibrio. Por otra parte, las condiciones de humedad relativa y temperatura ensayadas son las típicas en el laboratorio de proyección por plasma medidas con la ayuda de un higrómetro. Una vez transcurridas las 24 horas, se ha vuelto a pesar el material para conocer la cantidad de agua adsorbida por diferencia de peso, y se ha vuelto a determinar tanto el HR como el $\alpha_{M}$.

Asimismo, siguiendo el mismo procedimiento, para la fracción BGGS4 (con y sin fluidificante) se ha realizado un seguimiento durante las primeras 8 horas 
de ensayo, determinando la cantidad de agua adsorbida y el $\alpha_{M}$ en cada alícuota a distintos tiempos.

\subsubsection{Comportamiento de las fracciones de polvo con la temperatura}

El comportamiento de las diferentes fracciones con la temperatura se estudió mediante dos métodos, análisis térmico diferencial y termogravimétrico (ATD/TG) y microscopio de calefacción.

Por un lado, el análisis térmico diferencial y termogravimétrico (ATD/TG) permite conocer si se producen transformaciones en el material objeto de estudio debidas a un intercambio energético (absorción o emisión de calor) cuando éste es sometido a un ciclo térmico. Estas transformaciones se registran como cambios energéticos tanto endotérmicos como exotérmicos. Además, también aporta información respecto a la pérdida o ganancia de peso del material estudiado como consecuencia de estas transformaciones. La técnica consiste en someter a tratamiento térmico el material objeto de estudio, y registrar en continuo, tanto el peso, como el incremento de temperatura entre la superficie de la muestra y la superficie de una muestra de referencia previamente ensayada [142,167].

El análisis térmico diferencial y termogravimétrico se ha llevado a cabo con las fracciones BGGS y BGGS3. Las dos muestras de polvo se han secado en estufa a $110^{\circ} \mathrm{C}$, enfriado en desecador y sometidas a un tratamiento térmico desde temperatura ambiente hasta $1200^{\circ} \mathrm{C}$ a una velocidad de calentamiento de $10^{\circ} \mathrm{C} / \mathrm{min}$. El ensayo se ha llevado a cabo en un analizador térmico diferencial (TGA/SDTA 851e, Mettler Toledo, Suiza) como se muestra en la figura 3.6a, utilizando atmosfera de aire y crisol de platino.
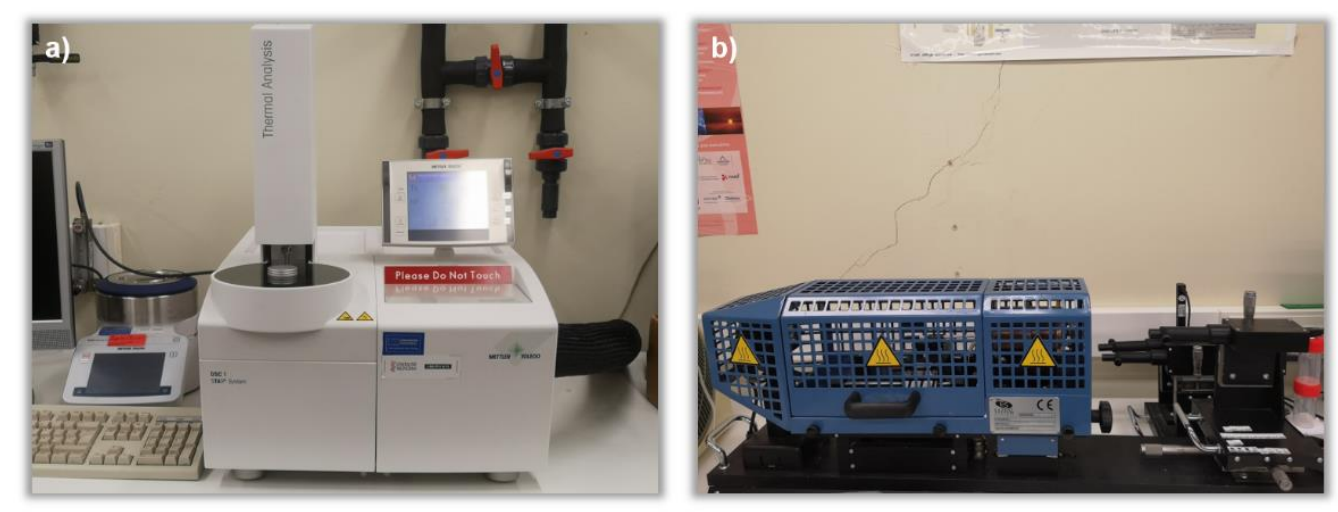

Figura 3.6. a) Analizador diferencial térmico TGA/SDTA 851e, b) Microscopio de calefacción Misura 3. Fuente: Fondo documental de AICE

Por otra parte, el microscopio de calefacción permite la visualización del comportamiento de una muestra cuando es sometida a un tratamiento térmico. Tras conformar una probeta de pequeño tamaño de dimensiones conocidas, 
ésta se somete a un ciclo de calentamiento y se va registrando la silueta de la probeta durante el tratamiento térmico. Una vez finalizado el ensayo, al tratar las imágenes obtenidas en un software de análisis de imagen, es posible determinar, tanto la curva de contracción-temperatura del material, como sus temperaturas características [168]. Estas temperaturas se detallan a continuación:

$>$ Temperatura de inicio de contracción $\left(\mathrm{T}_{\mathrm{FS}}\right)$. Temperatura a la que es detectable la sinterización de la probeta. Además, el área de la silueta de la probeta es un $99 \%$ del área inicial.

$>$ Temperatura de final de contracción ( $\left.\mathrm{T}_{\mathrm{MS}}\right)$. Temperatura a la que la probeta deja de contraer.

$>$ Temperatura de reblandecimiento $\left(\mathrm{T}_{\mathrm{SP}}\right)$. Temperatura a la que los bordes de la probeta se redondean.

$>$ Temperatura de esfera $\left(T_{B}\right)$. Temperatura a la que la probeta adopta una geometría similar a una esfera.

$>$ Temperatura de media esfera $\left(\mathrm{T}_{\mathrm{HB}}\right)$. Temperatura a la que la probeta adopta una geometría similar a una semiesfera.

$>$ Temperatura de fusión ( $\left.T_{F P}\right)$. Temperatura a la que la probeta funde y adopta una geometría similar a un casquete esférico.

Para cada fracción granulométrica se ha conformado por prensado una probeta cilíndrica de $3 \mathrm{~mm}$ de altura y $3 \mathrm{~mm}$ de diámetro. Las distintas probetas han sido sometidas a un tratamiento térmico en atmósfera de aire desde temperatura ambiente hasta $1250{ }^{\circ} \mathrm{C}$ a una velocidad de calentamiento de 25 ○C/min en microscopio de calefacción (Mlsura 3, Expert System Solutions, Italia). El equipo utilizado se muestra en la figura 3.6b. La imágenes obtenidas se han tratado con el software de análisis de imagen Microlmage.

\subsubsection{Superficie específica}

Una de las propiedades que más influyen sobre la bioactividad es la superficie específica. Por ello, también se ha determinado esta propiedad para el caso de la fracción de polvo más fina (BGGS4).

La superficie específica se ha determinado mediante el método Brunauer, Emmeth y Teller o método BET [169]. Este método se basa en el fenómeno de adsorción de un determinado gas sobre la superficie del material a estudiar. Al poner en contacto el material deseado (adsorbente) con un gas (adsorbato) a una temperatura y presión de vapor relativa determinadas, el sólido retiene una cierta cantidad de gas en su superficie una vez alcanzado el equilibrio entre fases (gas y sólido) [169]. La representación de la cantidad de gas adsorbido a temperatura constante frente a la presión del gas se denomina isoterma de 
adsorción. Ajustando los valores de gas adsorbido a cada presión al modelo BET [169], se obtiene la cantidad de gas adsorbido que conforma una monocapa de gas sobre el sólido $\left(\mathrm{n}_{\mathrm{m}}\right)$, a partir de la cual es posible determinar la superficie específica mediante la siguiente expresión:

$$
S_{B E T}=n_{m} \cdot a_{g a s} \cdot N_{A}(\text { ec 3.2) }
$$

Donde $S_{B E T}$ es la superficie específica del material a estudiar $\left(\mathrm{m}^{2} / \mathrm{g}\right), \mathrm{n}_{\mathrm{m}}$ es la capacidad de la monocapa (moles adsorbato/g adsorbente) o cantidad de adsorbato que puede formar una capa monomolecular completamente llena en la superficie de $1 \mathrm{~g}$ de sólido adsorbente, $\mathrm{a}_{\mathrm{gas}}$ es el área media ocupada por una molécula de adsorbato ( $\mathrm{m}^{2} /$ molécula de adsorbato) y $\mathrm{N}_{\mathrm{A}}$ es el número de Avogadro (moléculas de adsorbato/mol de adsorbato).

En el caso de la fracción BGGS4, se ha determinado la isoterma de adsorción a la temperatura del nitrógeno líquido $\left(-196{ }^{\circ} \mathrm{C}\right)$ por un método volumétrico estático utilizando nitrógeno como adsorbato $\left(\mathrm{a}_{\text {gas }}=1,62 \cdot 10^{-19} \mathrm{~m}^{2}\right)$. El ensayo se ha llevado a cabo mediante un analizador de superficie específica (TriStar 3000, Micrometrics, USA) de acuerdo con la norma ISO 9277:2010. En la figura 3.7 se puede ver el equipo utilizado.

Previamente a la realización del ensayo, el material se ha secado en estufa a $110^{\circ} \mathrm{C}$. Una vez introducida la muestra en el analizador, ésta se ha sometido a desgasificación con corriente de nitrógeno a $150 \stackrel{\circ}{\circ}$ antes de la determinación de la isoterma.

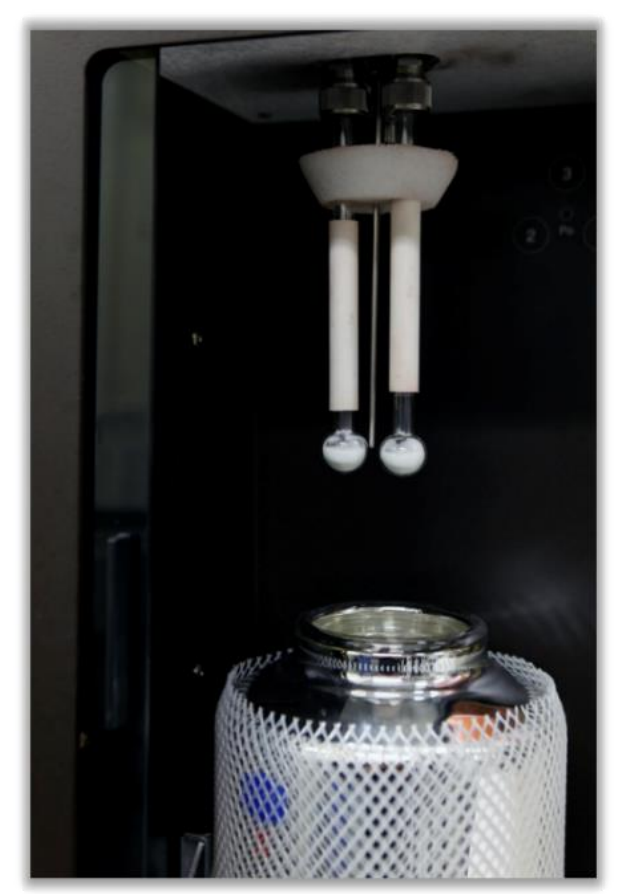

Figura 3.7. Analizador de superficie específica TriStar 3000. Fuente: Fondo documental de AICE 


\subsubsection{Bioactividad del material}

La última propiedad caracterizada del polvo de vidrio bioactivo sintetizado es su bioactividad. Esta propiedad se ha estudiado mediante la monitorización del desarrollo de la capa de HCA sobre la superficie de las partículas de vidrio tras su inmersión en fluido biológico simulado (SBF) siguiendo un protocolo estándar [170]. Esta propiedad se ha determinado para la fracción de polvo más fina (BGGS4).

En primer lugar, se ha preparado el SBF según el procedimiento descrito por el profesor Kokubo [171]. Para ello, tomando como base la obtención de 1000 $\mathrm{cm}^{3}$ de SBF, se ha introducido $700 \mathrm{~cm}^{3}$ de agua en un recipiente de plástico y el conjunto se ha calentado hasta $36,5 \pm 0,5^{\circ} \mathrm{C}$ en un baño de agua provisto de agitador. El montaje utilizado se ilustra en la figura 3.8.

Una vez alcanzada la temperatura deseada, se ha adicionado los diferentes reactivos necesarios. En la tabla 3.4 se muestra estos reactivos junto con el orden de adición, la cantidad adicionada y el grado de pureza de cada uno [171].

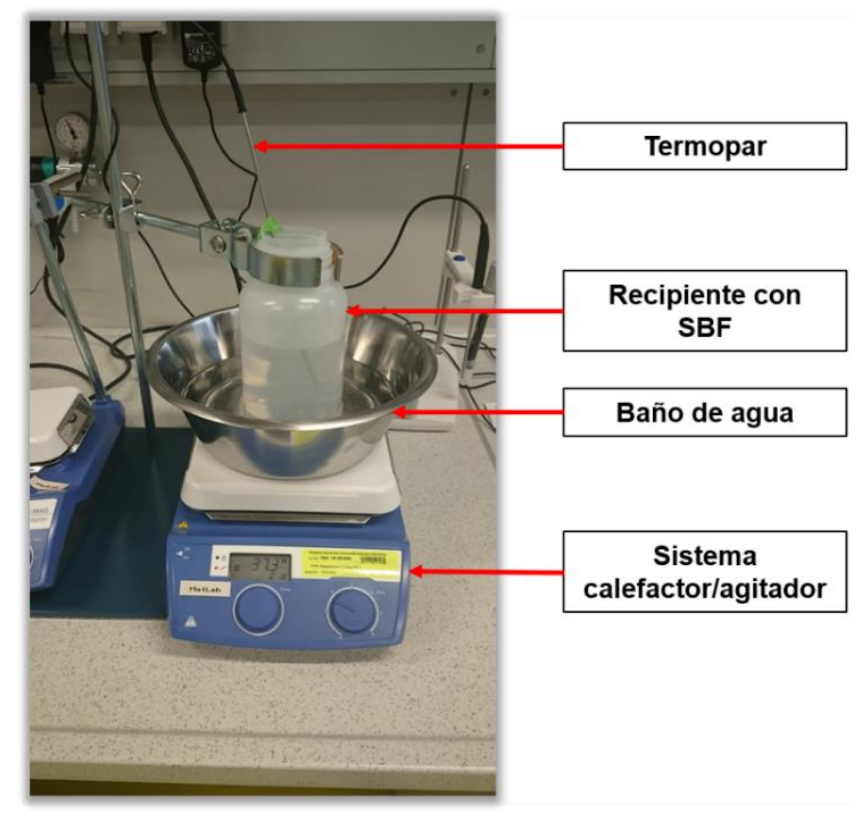

Figura 3.8. Montaje experimental para la preparación del SBF

El procedimiento seguido ha consistido en adicionar los reactivos muy poco a poco en el orden indicado, añadiéndolos uno a uno hasta su completa disolución. Tras incorporar los 8 primeros reactivos, se ha medido el pH de la mezcla para asegurar que esté en un valor de 2,00 $\pm 1,00$. A continuación se ha añadido el último reactivo muy poco a poco, volviéndose a medir el pH para comprobar que esté en un valor de 7,40 $\pm 0,01$. Finalmente, el SBF se deja enfriar hasta temperatura ambiente. En ese momento, se añade agua destilada 
hasta lograr un volumen total de $1000 \mathrm{~cm}^{3}$ de $S B F$ y se conserva en refrigerador a 5-10 $\stackrel{\circ}{C}$ hasta su utilización.

Tabla 3.4. Orden, cantidad adicionada y pureza de los diferentes reactivos utilizados en la preparación del SBF

\begin{tabular}{|c|c|c|c|c|}
\hline \multirow{2}{*}{ Orden } & \multirow{2}{*}{ Reactivo } & \multicolumn{2}{|c|}{ Cantidad a adicionar } & \multirow{2}{*}{$\begin{array}{c}\text { Grado de } \\
\text { pureza (\%) }\end{array}$} \\
\hline & & $\mathrm{g} / \mathrm{cm}^{3}$ SBF $10^{3}$ & $\mathrm{~cm}^{3} / \mathrm{cm}^{3}$ SBF $10^{3}$ & \\
\hline 10 & $\mathrm{NaCl}$ & 8,0756 & - & 99,5 \\
\hline $2^{\circ}$ & $\mathrm{NaHCO}_{3}$ & 0,3532 & - & 99,5 \\
\hline $3^{\circ}$ & $\mathrm{KCl}$ & 0,2250 & - & 99,5 \\
\hline $4^{\circ}$ & $\mathrm{K}_{2} \mathrm{HPO}_{4} \cdot 3 \mathrm{H}_{2} \mathrm{O}$ & 0,2310 & - & 99,0 \\
\hline $5^{\circ}$ & $\mathrm{MgCl}_{2} \cdot 6 \mathrm{H}_{2} \mathrm{O}$ & 0,3033 & - & 98,0 \\
\hline $6^{\circ}$ & $\mathrm{HCl} 1 \mathrm{M}$ & - & 39 & - \\
\hline $7^{\circ}$ & $\mathrm{CaCl}_{2} \cdot 2 \mathrm{H}_{2} \mathrm{O}$ & 0,3638 & - & 95,0 \\
\hline 80 & $\mathrm{Na}_{2} \mathrm{SO}_{4}$ & 0,0716 & - & 99.0 \\
\hline 90 & Tris & 6,0568 & - & 99.0 \\
\hline
\end{tabular}

Una vez preparado el SBF, se ha llevado a cabo la inmersión del polvo introduciéndolo en recipientes de plástico según la relación $1,5 \cdot 10^{-3} \mathrm{~g}$ de polvo por $\mathrm{cm}^{3}$ de SBF [170]. Seguidamente, estos recipientes se han incubado en baño de agua a $36,5 \pm 0,5^{\circ} \mathrm{C}$ durante 1 hora, $1,2,5$ y 7 días. Para cada tiempo se han incubado tres alícuotas de polvo diferentes. Además, también se han incubado recipientes conteniendo solo SBF a modo de control.

Una vez transcurrido el tiempo de incubación, se ha determinado el pH del SBF y se ha retirado el polvo con la ayuda de un pequeño tamiz. A continuación, el polvo resultante se ha lavado con agua destilada para interrumpir la reacción con el SBF y se ha secado en estufa a $110^{\circ} \mathrm{C}$ para su posterior caracterización.

En primer lugar, se ha observado la morfología de la capa de HCA desarrollada mediante FEG-ESEM. Esta observación se ha realizado de forma análoga al apartado 3.1.1.2. Morfología de las partículas de vidrio, salvo por el uso de la señal de electrones secundarios con el fin de poder apreciar la superficie con mayor detalle. Además, el voltaje utilizado ha sido de $10 \mathrm{kV}$ y previamente a la observación, el material se ha recubierto con una fina capa de carbono mediante evaporación y deposición a vacío.

Asimismo, aprovechando la radiación $\mathrm{X}$ característica de cada elemento resultante de la incidencia del haz de electrones (apartado 3.1.1.2. Morfología de las partículas de vidrio), se ha determinado la composición elemental de la capa de HCA mediante un sistema de microanálisis por dispersión de energías de rayos $X$ (Genesis 7000 SUTW, EDAX, USA) integrado en el microscopio electrónico de barrido. Este análisis se ha llevado a cabo en las mismas condiciones a las cuales se ha tomado las micrografías, salvo por el voltaje, que se ha incrementado a $20 \mathrm{kV}$.

Finalmente, la presencia de HCA se ha corroborado mediante DRX y espectroscopía de infrarrojos por transformada de Fourier (FTIR). El análisis 
por DRX se ha realizado de forma análoga al apartado 3.1.1.3 Identificación de fases cristalinas, para un intervalo $2 \theta$ comprendido entre $10^{\circ}$ y $80^{\circ}$.

Respecto al análisis por FTIR, éste se emplea para identificar los grupos funcionales que conforman cualquier material (sólido, líquido o gas). Al irradiar la muestra objetivo con un haz de radiación infrarroja, parte es transmitida a través del material, pero otra parte es absorbida por los enlaces entre moléculas, lo que provoca la vibración de estos enlaces. Mediante un detector es posible medir la intensidad de la radiación infrarroja tras pasar por el material a estudiar. A partir de esta intensidad se obtiene un espectro infrarrojo, una representación de la intensidad de radiación infrarroja (bien transmitida o bien absorbida por el material) en función del número de onda, es decir, número de veces que vibra una onda en una unidad de distancia [172].

Tras la inmersión del polvo en SBF, el análisis por FTIR se he llevado a cabo para un intervalo de número de onda entre $1500 \mathrm{~cm}^{-1}$ y $500 \mathrm{~cm}^{-1}$ con una resolución espectral de $2 \mathrm{~cm}^{-1}$. Los espectros se han realizado en modo absorbancia, y previamente a cada ensayo se ha medido el fondo para eliminar el efecto del aire y el vapor de agua.

\subsubsection{Suspensión de partículas de vidrio bioactivo $45 \mathrm{~S} 5$}

El siguiente material de aporte sintetizado es la suspensión de partículas de vidrio bioactivo. Su síntesis se ha llevado a cabo por molienda vía húmeda en molino de atrición según se indica en el capítulo 1. Introducción (1.4.1. Clasificación y obtención de materiales de aporte líquido), utilizando la fracción granulométrica BGGS4, que es la fracción de polvo sintetizada de menor tamaño, y un medio de suspensión orgánico, puesto que este tipo de vidrio reacciona con el agua liberando cationes y modificando su estructura [173]. Comúnmente, en proyección térmica de suspensiones el medio de suspensión orgánico por excelencia es el etanol. Sin embargo, en este trabajo se ha utilizado dipropilenglicol metil éter (Dowanol DPM, Dow Chemicals, USA).

A pesar de que ambos orgánicos poseen propiedades físicas similares (Tabla 3.5), la elección de Dowanol se debe a que posee mayor punto de inflamabilidad que el etanol, por lo que la preparación, manipulación y almacenamiento de suspensiones empleando este medio orgánico es más seguro. Además, es muy utilizado en la preparación de tintas cerámicas en el ámbito de la impresión digital. 
Tabla 3.5. Propiedades del etanol y Dowanol DPM

\begin{tabular}{|c|c|c|c|c|c|c|c|}
\hline $\begin{array}{c}\text { Medio } \\
\text { orgánico }\end{array}$ & $\mathbf{M}_{\mathrm{w}}{ }^{\mathrm{a}}$ & $\rho^{b}$ & $\eta^{c}$ & $Y^{d}$ & $\mathbf{P}_{\mathrm{v}}{ }^{\mathrm{e}}$ & $\Delta H_{v}{ }^{f}$ & $T_{i}{ }^{g}$ \\
\hline $\begin{array}{c}\text { Etanol } \\
\text { Dowanol DPM }\end{array}$ & $\begin{array}{c}46,1 \\
148 ?\end{array}$ & $\begin{array}{l}790,0 \\
9480\end{array}$ & $\begin{array}{l}1,2 \\
37\end{array}$ & $\begin{array}{l}25,1 \\
28,8\end{array}$ & 59,0 & 0,93 & 20,0 \\
\hline $\begin{array}{l}\text { a Peso molecular } \\
\text { b Densidad (kg/m } \\
\text { b Viscosidad (Pa.s } \\
\text { d Tensión superfic } \\
\text { e Presión de vapor } \\
\text { d Entalpía de evap } \\
\text { ' Punto de inflama }\end{array}$ & $\begin{array}{l}\mathrm{g} / \mathrm{kmol}) \\
\text { medida } \\
10^{3} \mathrm{me} \\
\mathrm{l}(\mathrm{N} / \mathrm{m}) \cdot \\
(\mathrm{mm} \mathrm{Hg} \\
\text { ración (. } \\
\text { ilidad ( }\end{array}$ & $\begin{array}{l}25^{\circ} \mathrm{C} \\
\text { da a } 25^{\circ} \\
b^{3} \text { medid } \\
\text { medida a } \\
\mathrm{kg}) \cdot 10^{-6}\end{array}$ & $\begin{array}{l}25 \stackrel{\circ}{\circ} \mathrm{C} \\
\stackrel{\circ}{ } \mathrm{C}\end{array}$ & & & & \\
\hline
\end{tabular}

Debido al tamaño de partícula de la fracción BGGS4, fue necesaria una primera etapa de molienda en molino planetario para adecuar el tamaño de partícula para el molino de atrición [138]. El proceso de molienda se ha llevado a cabo a 260 rpm, utilizando un molino planetario (Pulversitte 5, Fritsch $\mathrm{GmbH}$, Alemania) como el mostrado en la figura 3.9 a en cuyo interior se han introducido jarras de alúmina de $400 \mathrm{~cm}^{3}$ de capacidad conteniendo el polvo de vidrio, el medio orgánico y bolas de alúmina de diferentes tamaños. La carga de bolas, polvo de vidrio y orgánico se detalla en la tabla 3.6.

Tabla 3.6. Carga de bolas, medio orgánico y polvo de vidrio bioactivo por jarra de molienda

\begin{tabular}{cc}
\hline Material & Cantidad $(\mathbf{g})$ \\
\hline Bolas de $20 \mathrm{~mm}$ de diámetro & 255 \\
Bolas de $5 \mathrm{~mm}$ de diámetro & 163 \\
Polvo de vidrio bioactivo & 80 \\
Dowanol DPM & 37 \\
\hline
\end{tabular}
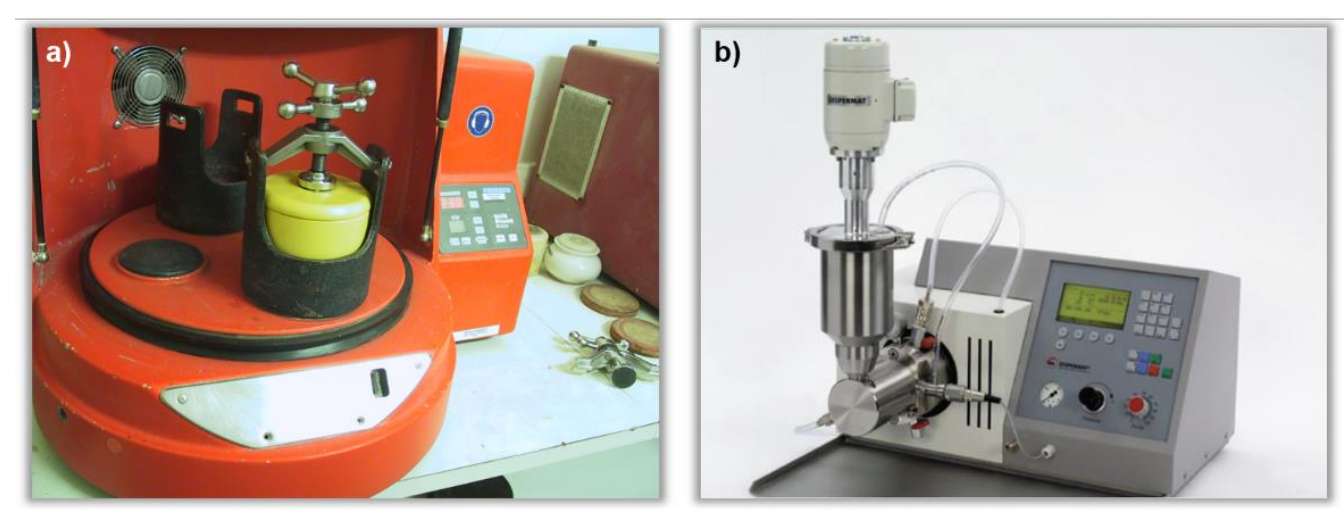

Figura 3.9. a) Molino planetario Pulverisette 5, b) Molino de atrición Dispermat SL. Fuente: Fondo documental de AICE 
Una vez finalizada la molienda y recogida la suspensión, se limpia el interior de la jarra y las bolas con el mismo medio orgánico, mezclando el producto resultante de la limpieza con la suspensión para reducir el contenido en sólidos a un valor del 10 vol.\%. La determinación del tiempo de molienda necesario en el molino planetario para alcanzar la mínima distribución de tamaños de partícula se ha efectuado mediante sedimentación. Se han ensayado diferentes tiempos de molienda, tomando una alícuota de suspensión para cada tiempo e introduciéndola en una probeta graduada durante una hora. Transcurrido ese tiempo, se ha medido el volumen de material sólido sedimentado a partir de la altura de la interfase entre líquido clarificado y suspensión sedimentada. Esta altura es mayor cuanto menor es el tamaño de partícula, ya que la velocidad de sedimentación del material disminuye. Una vez alcanzado el tamaño mínimo, esta altura de la interfase del material sedimentado se mantiene constante, a pesar de aumentar el tiempo de molienda.

Una vez conocido el tiempo óptimo de molienda, se ha determinado tanto la densidad de la suspensión resultante como la distribución de tamaños de partícula mediante difracción de láser (apartado 3.1.2.1. Distribución de tamaños de partícula).

A partir de la suspensión obtenida tras la primera etapa de molienda (BG-Pul) se ha procedido a determinar el tipo y cantidad de dispersante para estabilizarla y evitar la formación de aglomerados y sedimentación de las partículas. Esta elección se ha llevado a cabo en base a los resultados de un estudio reológico y de sedimentación (apartado 3.1.2.3. Estudio reológico y de la sedimentación). Se han probado diferentes cantidades de varios dispersantes en base a trabajos previos sobre estabilización de suspensiónes no acuosas [174], los cuales se detallan a continuación:

$>$ Emphos PS21A (Witco Chemical, USA). Se trata de una combinación de monoésteres y diésteres con una longitud de cadena de carbono de 15-25 unidades. De ahora en adelante denominada Pho.

> Hypermer KD7 (Croma, Reino Unido). Se trata de un compuesto polimérico aniónico. De ahora en adelante denominada KD7.

$>$ Glyceryl Trioleate (Fluka, Alemania). Se trata de un triglicérido con tres unidades de ácido graso insaturado, más concretamente ácido oleico. De ahora en adelante denominada como Triol.

$>$ Disperbyk 190 (Byk, Alemania). Se trata de una solución de un copolímero en bloque de elevado peso molecular. De ahora en adelante denominada D190.

Una vez obtenida una suspensión estable y con una distribución de tamaño de partícula adecuada, se llevó a cabo la siguiente etapa de molienda vía húmeda. Este proceso se efectuó en un molino de atrición (Dispermat SL, VMAGetzmann $\mathrm{GmbH}$, Alemania), figura 3.9b, usando bolas de circona de 0,8 mm de diámetro. 
En esta etapa también es necesario determinar el tiempo óptimo de molienda para el cual ya no es posible reducir más el tamaño de las partículas. Sin embargo, esta determinación no es posible hacerla por sedimentación como en la etapa anterior de molienda. Debido al reducido tamaño de partícula y la presencia de dispersante, se necesitan tiempos muy largos para apreciar diferencias en sedimentación. Por ello, durante el proceso de molienda, se han ido extrayendo pequeñas alícuotas de suspensión para distintos tiempos y se ha ido obteniendo la distribución de tamaños de partícula mediante difracción de láser. Una vez determinado el tiempo óptimo, la suspensión resultante (denominada BG-Att) se ha caracterizado de igual manera que la suspensión obtenida tras la primera etapa (densidad de la suspensión, morfología de las partículas mediante MEB, viscosidad mediante estudio reológico y estudio de la sedimentación).

\subsubsection{Distribución de tamaños de partícula}

La determinación de las distintas distribuciones de tamaños de partícula de las suspensiones del apartado anterior se ha llevado a cabo mediante difracción láser en medio líquido utilizando el Dowanol.

Esta técnica se basa en forzar el paso de una suspensión de partículas muy diluida a través de un haz de luz láser monocromático, de tal forma que el patrón de luz difractado por las partículas es medido por una serie de detectores situados en diferentes ángulos [175]. Estos detectores transforman la señal medida (llevan a cabo una deconvolución de la señal) en una distribución del tamaño de las partículas mediante el uso de una matriz basada en un modelo teórico. Esta matriz contiene las señales calculadas por todos los detectores por unidad de volumen de partículas. Los modelos teóricos más empleados son Fraunhofer y Mie. A diferencia del modelo de Fraunhofer, para utilizar el de Mie se requiere conocer la parte real e imaginaria del índice de refracción. Siempre se supone que las partículas son esféricas. En el caso de partículas no esféricas, la distribución de tamaños de partícula se obtiene en base a los diámetros equivalentes de las partículas, el cual depende de la orientación de éstas.

Para este ensayo se ha utilizado un difractómetro láser (Mastersizer 2000, Malvern Instruments, Reino Unido) como el mostrado en la figura 3.10. 


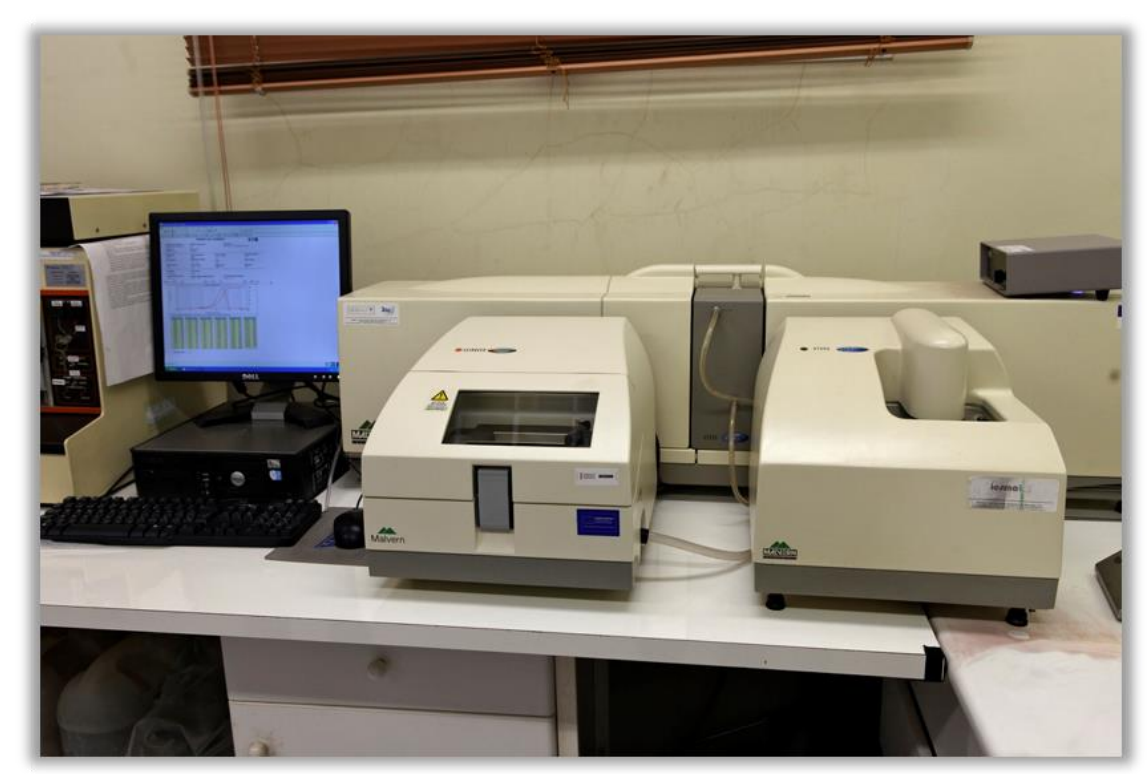

Figura 3.10. Difractómetro láser Mastersizer 2000. Fuente: Fondo documental de AICE

La determinación de todas las distribuciones de tamaño de partícula se ha realizado mediante el modelo teórico de Mie, para un índice de refracción de 1,423 para el Dowanol y un índice de refracción de 1,520 para el vidrio bioactivo.

\subsubsection{Morfología de las partículas}

Tal y como se ha indicado en apartados anteriores, la morfología de las partículas de vidrio de las dos suspensiones obtenidas se ha observado mediante microscopía electrónica de barrido (FEG-ESEM).

Para la observación, primero se ha secado en estufa a $373 \mathrm{~K}$ una pequeña alícuota de cada suspensión para eliminar el medio líquido, y las partículas secas se han colocado sobre un adhesivo de carbono en un portamuestras metálico. A continuación, se han tomado micrografías a diferentes aumentos utilizando la señal de electrones retrodispersados y un voltaje de $20 \mathrm{kV}$.

\subsubsection{Estudio reológico y de la sedimentación}

Para determinar el efecto de los distintos dispersantes y para comprobar que las suspensiones son estables frente al tiempo y poseen una viscosidad mínima que les permita ser usadas en proyección por plasma, se ha llevado a cabo un estudio reológico y de sedimentación.

Por un lado, el estudio reológico se ha llevado a cabo a temperatura ambiente empleando un reómetro rotacional (Haake RS50, ThermoFisher Scientific, 
Alemania) muy similar al mostrado en la figura 1.20. Todos los ensayos se realizaron utilizando un sistema doble-cono y placa como elemento de medida y controlando la velocidad de cizalla. De esta forma, una vez sumergido el elemento de medida en el material, se ha incrementado la velocidad de cizalla desde 0 hasta $1000 \mathrm{~s}^{-1}$ a una velocidad constante de $200 \mathrm{~s}^{-1} / \mathrm{min}$, se ha mantenido esta velocidad a $1000 \mathrm{~s}^{-1}$ durante 1 minuto y finalmente se ha reducido la velocidad de cizalla desde 1000 hasta $0 \mathrm{~s}^{-1}$ a una velocidad constante de $200 \mathrm{~s}^{-1} / \mathrm{min}$. Durante todo el proceso se ha registrado los valores de esfuerzo de cizalla y viscosidad en función de la velocidad de cizalla.

Además, los valores de viscosidad obtenidos en función de la velocidad de cizalla para la suspensión ya estabilizada resultante de la segunda etapa de molienda se han ajustado al modelo de Cross con el fin de extrapolar el comportamiento de la suspensión a distintos puntos del sistema de alimentación de líquidos a la antorcha de plasma y conocer la viscosidad real de esta suspensión a muy altos valores de velocidad de cizalla (interior del inyector). Este modelo ya ha sido descrito en el capítulo 1. Introducción (1.4.2.1. Viscosidad y comportamiento de los materiales de aporte líquidos).

Por otro lado, el estudio de la sedimentación se ha llevado a cabo mediante un equipo de dispersión múltiple de la luz (TurbiScan Classic MA2000, Formulaction, Francia) como el mostrado en la figura 3.11. Mediante este equipo, se fuerza a pasar un haz de luz a través de la suspensión objeto de estudio, registrando tanto la luz reflejada por las partículas como la luz transmitida a través del medio líquido en función del tiempo [176]. De esta forma, en función del porcentaje de luz reflejada o transmitida a lo alto de la celda que contiene la muestra problema, es posible estimar si se está produciendo sedimentación en la muestra problema y comparar entre distintas muestras cuales sedimentan más rápido.

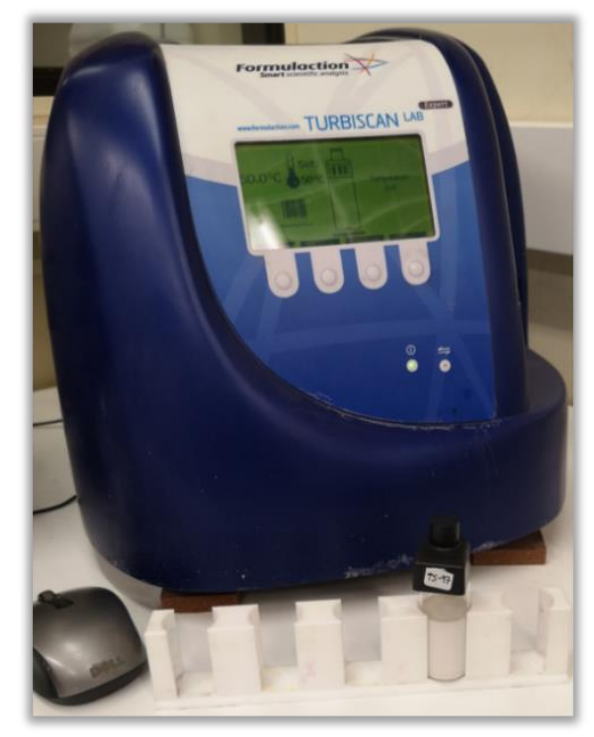

Figura 3.11. Equipo de dispersión múltiple de la luz TurbiScan 
Los ensayos de sedimentación se han llevado a cabo para distintos intervalos de tiempo. En el caso de la suspensiones con diferentes contenidos en dispersante, estos ensayos se han llevado a cabo durante 60 minutos, realizando medidas cada 5 minutos. En el caso de la suspensión ya estabilizada resultante de la segunda etapa de molienda, este ensayo se ha llevado a cabo durante 24 horas, realizando medidas cada 3 horas.

\subsubsection{Comportamiento de la suspensión con la temperatura}

Debido a que se ha reducido aún más el tamaño de partícula del polvo de vidrio bioactivo, resulta interesante estudiar el comportamiento de la nueva distribución de tamaños de partícula con la temperatura. Este estudio se ha llevado a cabo mediante microscopio de calefacción de igual forma que en apartados anteriores.

A partir del polvo obtenido tras secar una alícuota de suspensión, se ha conformado por prensado una probeta cilíndrica de $3 \mathrm{~mm}$ de altura y $3 \mathrm{~mm}$ de diámetro, la cual ha sido sometida a un tratamiento térmico, a una velocidad de calentamiento de $25^{\circ} \mathrm{C} / \mathrm{min}$, desde temperatura ambiente hasta $1250 \stackrel{\circ}{\circ} \mathrm{C}$ en atmósfera de aire.

\subsubsection{Efecto del medio líquido en las propiedades de la antorcha de plasma}

Como se ha comentado en el capítulo 1. Introducción (1.4.3.3. Consideraciones respecto a los recubrimientos obtenidos), al utilizar suspensiones de partículas o soluciones precursoras, el medio líquido afecta a las propiedades de la antorcha de plasma.

En este trabajo, puesto que se han preparado suspensiones utilizando un medio líquido orgánico diferente al empleado comúnmente (etanol), para las condiciones de proyección utilizadas en la deposición de estas suspensiones se ha calculado los parámetros $\mathrm{AHF}_{\mathrm{m}}$ y AHF de la antorcha de plasma, y el DMF según las ecuaciones 1.19 y 1.20. Estos parámetros se han determinado para la antorcha de plasma antes y durante la inyección de la suspensión (evaporación del Dowanol). Para determinar el valor de las variables de estas ecuaciones se han empleado los softwares gratuitos Jet\&Poudres y T\&TWinner $[177,178]$.

\subsubsection{Soluciones precursoras de vidrio bioactivo $45 \mathrm{~S} 5$}

El tercer material de aporte sintetizado en este trabajo es la solución de precursores. Este material de aporte se ha preparado en base acuosa con una concentración de precursores $4 \mathrm{M}$. La elección de los diferentes precursores para alcanzar la composición del vidrio bioactivo $45 S 5$ se ha llevado a cabo en 
base a bibliografía acerca de la síntesis de este vidrio por el método sol-gel [179-181]. Los precursores seleccionados se detallan a continuación:

$>$ Ortosilicato de tetraetilo o TEOS $\left(\mathrm{C}_{8} \mathrm{H}_{20} \mathrm{O}_{4} \mathrm{Si}\right.$ para síntesis, Merck, Alemania) como precursor del $\mathrm{SiO}_{2}$.

$>$ Fosfato de trietilo o TEP $\left(\mathrm{C}_{6} \mathrm{H}_{15} \mathrm{O}_{4} \mathrm{P}\right.$ para síntesis, Merck, Alemania) como precursor del $\mathrm{P}_{2} \mathrm{O}_{5}$.

$>$ Nitrato de calcio tetrahidratado $\left(\mathrm{Ca}\left(\mathrm{NO}_{3}\right)_{2} \cdot 4 \mathrm{H}_{2} \mathrm{O}>99 \%\right.$, VWR Chemical, USA) como precursor del $\mathrm{CaO}$.

$>$ Nitrato de sodio $\left(\mathrm{NaNO}_{3}>99 \%\right.$, Sigma-Aldrich, USA) como precursor del $\mathrm{Na}_{2} \mathrm{O}$.

Puesto que los dos primeros reactivos no son miscibles en agua, es necesario añadir un catalizador a la solución con el fin de hidrolizar estos compuestos. De entre los catalizadores posibles, el ácido nítrico es el más utilizado. Una elevada cantidad de catalizador acelera drásticamente la velocidad de gelificación de la solución, aunque también conlleva la formación de partículas de vidrio de menor tamaño. Por ello, en este trabajo de tesis se han preparado soluciones de precursores con concentraciones de ácido nítrico $\left(\mathrm{HNO}_{3}\right.$ Tritripur, Merck, Alemania) $1 \mathrm{M}, 0,5 \mathrm{M}$ y 0,2M.

En primer lugar, para cada una de las concentraciones de ácido nítrico, se prepara una disolución de agua destilada y la cantidad necesaria de ácido para cada una de las concentraciones. A continuación, se ha mantenido la solución ácida en agitación magnética a 500 rpm y se ha adicionado el TEOS muy lentamente. Una vez añadido todo el TEOS, la mezcla resultante se ha mantenido en agitación magnética durante un mínimo de 30 minutos hasta conseguir una solución totalmente transparente. Seguidamente, se ha añadido el TEP de forma idéntica al TEOS, volviendo a dejar la mezcla en agitación a $500 \mathrm{rpm}$ durante 30 minutos. Finalmente, se ha añadido el nitrato de calcio y se ha dejado la solución en agitación a 700 rpm durante 60 minutos, tras lo cual, se ha adicionado el nitrato de sodio volviendo a dejar la mezcla en agitación a $700 \mathrm{rpm}$ durante otros 60 minutos. A modo de comparación, se ha preparado una solución siguiendo el mismo procedimiento, pero sin añadir catalizador.

Todas las soluciones preparadas contienen la misma cantidad de agua destilada, y la cantidad de TEOS que se ha añadido es aquella que conlleva una relación molar agua destilada TEOS de 18. La cantidad del resto de precursores se ha determinado por estequiometría a partir de la composición del vidrio bioactivo $45 S 5$ y la cantidad de TEOS adicionada. Una vez finalizada la preparación, cada solución se ha mantenido a una temperatura de $5 \stackrel{\circ}{\mathrm{C}}$ en un recipiente sellado hasta su utilización. 


\subsubsection{Composición química}

Para cada una de las soluciones obtenidas, se ha determinado la composición química mediante FRX siguiendo el mismo procedimiento descrito en apartados anteriores para los polvos de vidrio bioactivo.

La única diferencia es que, previamente a la obtención de la perla para realizar el análisis, se ha secado una alícuota de cada solución en estufa a $100{ }^{\circ} \mathrm{C}$ y el material resultante se ha calcinado en horno eléctrico a $700 \stackrel{\circ}{ } \mathrm{C}$.

\subsubsection{Comportamiento de las soluciones con la temperatura}

Se ha estudiado el comportamiento con la temperatura de las soluciones preparadas para comprender los diferentes procesos físicos y químicos que puede experimentar el material de aporte durante el proceso de proyección.

Este estudio se ha llevado a cabo mediante ATD-TG, introduciendo directamente una muestra de cada solución en el analizador térmico diferencial. Para cada ensayo, se han utilizado los mismos parámetros que para los polvos de vidrio bioactivo.

\subsubsection{Estudio reológico}

Se ha llevado a cabo un estudio reológico de todas las soluciones de precursores sintetizadas para determinar su viscosidad. Asimismo, puesto que la ruta de síntesis de estos materiales se ha realizado en base a un proceso sol-gel, la presencia de catalizador conlleva la gelificación (incremento brusco de la viscosidad) de la solución, por lo que es necesario estudiar la estabilidad de estos materiales con el tiempo.

Por ello, desde la síntesis de cada solución, se han obtenido curvas de viscosidad a diferentes tiempos siguiendo el mismo procedimiento descrito en apartados anteriores (3.1.2.3. Estudio reológico y de la sedimentación). A partir de cada curva, se ha extraído el valor de viscosidad correspondiente a la máxima velocidad de cizalla y se ha representado frente al tiempo, determinando así el tiempo exacto a partir del cual la solución pasa a ser un gel y su viscosidad tiende a infinito (comportamiento de material sólido).

\subsubsection{Introducción de partículas coloidales}

En el capítulo 1. Introducción (1.4.3.2. Proyección térmica de soluciones de precursores por plasma o SPPS), se ha comentado que los procesos que tienen lugar en la pluma de plasma al inyectar soluciones de precursores son muy complejos, ya que durante la evaporación del medio líquido debe formarse el material sólido y posteriormente debe fundirse antes de impactar. Para intentar simplificar estos procesos que tiene lugar en el interior de la pluma de 
plasma, además de las soluciones de precursores descritas en apartados anteriores, se han sintetizado materiales de aporte líquidos en los que el TEOS (precursor de $\mathrm{SiO}_{2}$, formador principal de la red vítrea) ha sido sustituido parcial $(50 \%)$ o totalmente $(100 \%)$ por partículas coloidales de $\mathrm{SiO}_{2}$. Se ha mantenido tanto la composición del vidrio bioactivo 45S5, como el procedimiento de síntesis. Se han sintetizado materiales de aporte líquidos en base acuosa, con una concentración $4 \mathrm{M}$ de precursores y $0,2 \mathrm{M}$ de ácido nítrico. La única diferencia es que las partículas coloidales han sido el último componente añadido en lugar del primer componente como en el caso del TEOS.

Como fuente de partículas coloidales de $\mathrm{SiO}_{2}$, se han utilizado dos suspensiones comerciales:

> Levasil CT17 PDL (AkzoNobel, USA) suspensión de $\mathrm{SiO}_{2}$ coloidal en base acuosa, con un contenido en sólidos del $30 \%$ en peso, estabilizada a pH 3.

$>$ Ludox TM-40 (Sigma-Aldrich, USA) suspensión de $\mathrm{SiO}_{2}$ coloidal en base acuosa, con un contenido en sólidos del $40 \%$ en peso, estabilizada a $\mathrm{pH} 9$.

La caracterización de estos nuevos materiales líquidos se ha realizado de forma análoga a las soluciones originales, es decir, determinación de la composición química mediante FRX y estudio reológico. Sin embargo, al introducir partículas sólidas en estos nuevos materiales, además del estudio reológico se han realizado dos procesos adicionales de caracterización con el fin de estudiar la estabilidad con el tiempo de estos materiales. Por un lado, se ha determinado el potencial zeta en función del $\mathrm{pH}$ para cada una de las suspensiones desde $\mathrm{pH} 2$ hasta $\mathrm{pH}$ 10. Para ello, se han diluido diferentes alícuotas de cada suspensión en una solución acuosa $0,01 \mathrm{M}$ de cloruro potásico $(\mathrm{KCl})$, y se ha ajustado el $\mathrm{pH}$ de cada alícuota diluida mediante ácido clorhídrico $(\mathrm{HCl})$ e hidróxido potásico $(\mathrm{KOH})$. Una vez ajustados los $\mathrm{pH}$ de cada alícuota, se ha medido el potencial zeta mediante un equipo de dispersión dinámica de la luz (Zetasizer NanoZS, Malvern Instruments, Reino Unido). Por otro lado, se han realizado estudios de sedimentación mediante el equipo de dispersión múltiple de la luz (TurbiScan), tomando medidas cada minuto durante una hora de ensayo.

\subsection{Deposición de recubrimientos bioactivos mediante proyección térmica por plasma}

\subsubsection{Tipo y adecuación del sustrato}

Todos los recubrimientos se han depositado sobre el mismo tipo de sustrato. Como sustrato se ha utilizado discos de acero inoxidable AISI 304, con un diámetro de $25 \mathrm{~mm}$ y $10 \mathrm{~mm}$ de espesor. A continuación, se detalla la composición y propiedades de los sustratos utilizados. 
Tabla 3.7. Propiedades del sustrato utilizado

\begin{tabular}{cccc}
\hline $\mathbf{M E}^{\mathbf{a}}$ & $\mathbf{a}^{\mathbf{b}}$ & $\boldsymbol{\lambda}^{\mathbf{c}}$ & $\mathbf{T}_{\mathbf{f}}{ }^{\mathbf{d}}$ \\
\hline 20 & 17 & 16 & 1400 \\
\hline
\end{tabular}

a Módulo de elasticidad (GPa)

${ }^{b}$ Coeficiente de dilatación térmica $\left({ }^{\circ} \mathrm{C}^{-1}\right)$

${ }^{c}$ Conductividad térmica $(\mathrm{W} / \mathrm{m} \cdot \mathrm{K})$

d Temperatura de fusión $\left({ }^{\circ} \mathrm{C}\right)$

Tabla 3.8. Composición del sustrato utilizado

\begin{tabular}{cc}
\hline Elemento químico & Porcentaje en peso (\%) \\
\hline Carbono $(\mathrm{C})$ & $<0,08$ \\
Manganeso $(\mathrm{Mn})$ & $<2,00$ \\
Silicio $(\mathrm{Si})$ & $<1,00$ \\
Cromo $(\mathrm{Cr})$ & $18,00-19,00$ \\
Níquel $(\mathrm{Ni})$ & $8,00-10,50$ \\
Fósforo $(\mathrm{P})$ & $<0,05$ \\
Azufre $(\mathrm{S})$ & $<0,03$ \\
\hline
\end{tabular}

En primer lugar, se han limpiado todos los sustratos mediante etanol en baño de ultrasonidos. A continuación, se ha tratado los sustratos para dotarlos de cierta rugosidad mediante una granalladora (MAB-6, MAB Industrial S.A., España) como la ilustrada en la figura 3.12.
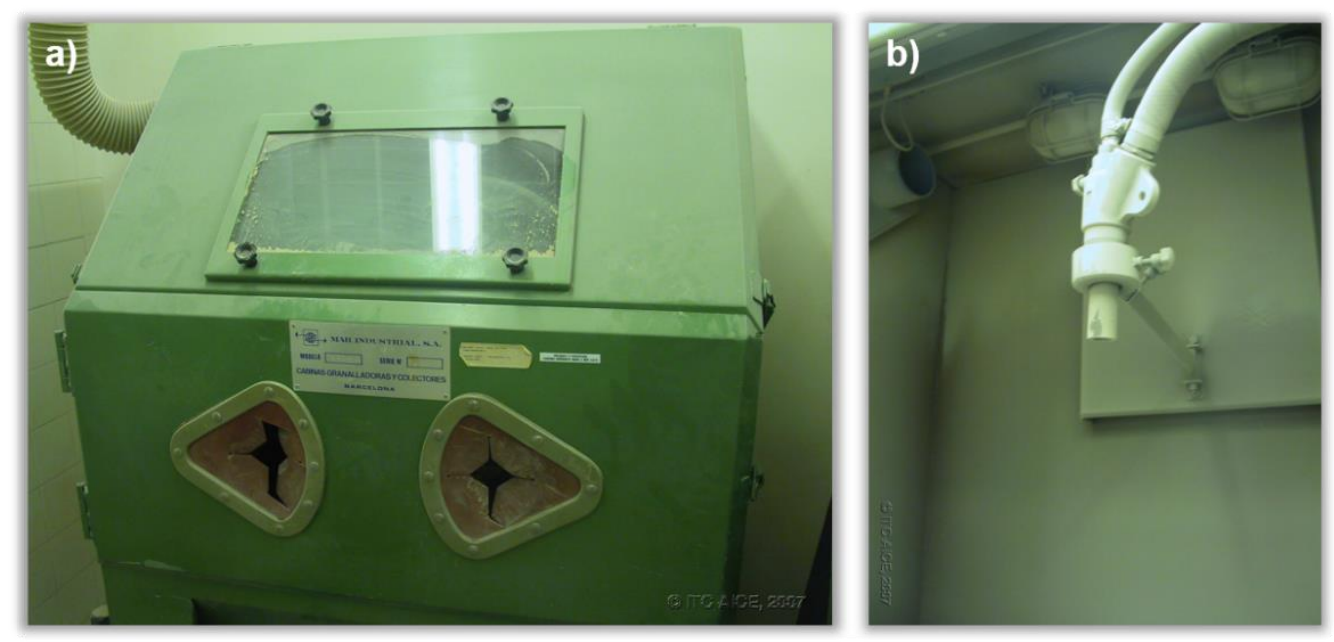

Figura 3.12. a) Granalladora MAB-6, b) Boquilla de salida del abrasivo

El proceso consiste en situar el sustrato en el interior de la granalladora, a una altura fija, debajo de una boquilla desde la cual se rocía la cara deseada del sustrato con las partículas de abrasivo a una presión determinada (en este caso 4,2 bar). Como abrasivo se ha utilizado corindón marrón comercial (Metcolite 
VF, Oerlikon Metco, Suiza) con una distribución de tamaños de partícula comprendida entre 170 y $600 \mu \mathrm{m}$. La composición química del abrasivo se detalla en la tabla 3.9. Tanto el tipo de abrasivo, como la presión de trabajo, se han seleccionado de un estudio realizado en trabajos anteriores.

Tabla 3.9. Composición química del abrasivo utilizado (Metcolite VF)

\begin{tabular}{cc}
\hline Compuesto químico & Porcentaje en peso (\%) \\
\hline Alúmina $\left(\mathrm{Al}_{2} \mathrm{O}_{3}\right)$ & 94,0 \\
Titania $\left(\mathrm{TiO}_{2}\right)$ & 3,5 \\
Otros óxidos & 2,5 \\
\hline
\end{tabular}

Independientemente del material de aporte, todos los sustratos se han granallado hasta un valor de rugosidad superficial de $R_{a}=2,2 \pm 0.1 \mu \mathrm{m}$.

Finalmente, se ha limpiado de nuevo los sustratos mediante etanol en baño de ultrasonidos para retirar cualquier impureza o resto de abrasivo resultante del proceso de granallado.

\subsubsection{Descripción del sistema de proyección utilizado}

El sistema utilizado para depositar todos los recubrimientos es una cabina de proyección cerrada, dotada con un sistema de extracción de aire que recoge todo el material que no se deposita y los vapores resultantes de la evaporación de éste, y lo lleva a un hidrociclón. En el interior de esta cabina, se encuentra una antorcha de plasma monocátodo (F4-MB, Oerlikon Metco, Suiza) acoplada a un robot industrial (IRB 1400, ABB, Suiza) capaz de moverse en los ejes x,y,z. Este sistema se ilustra en la figura 3.13.
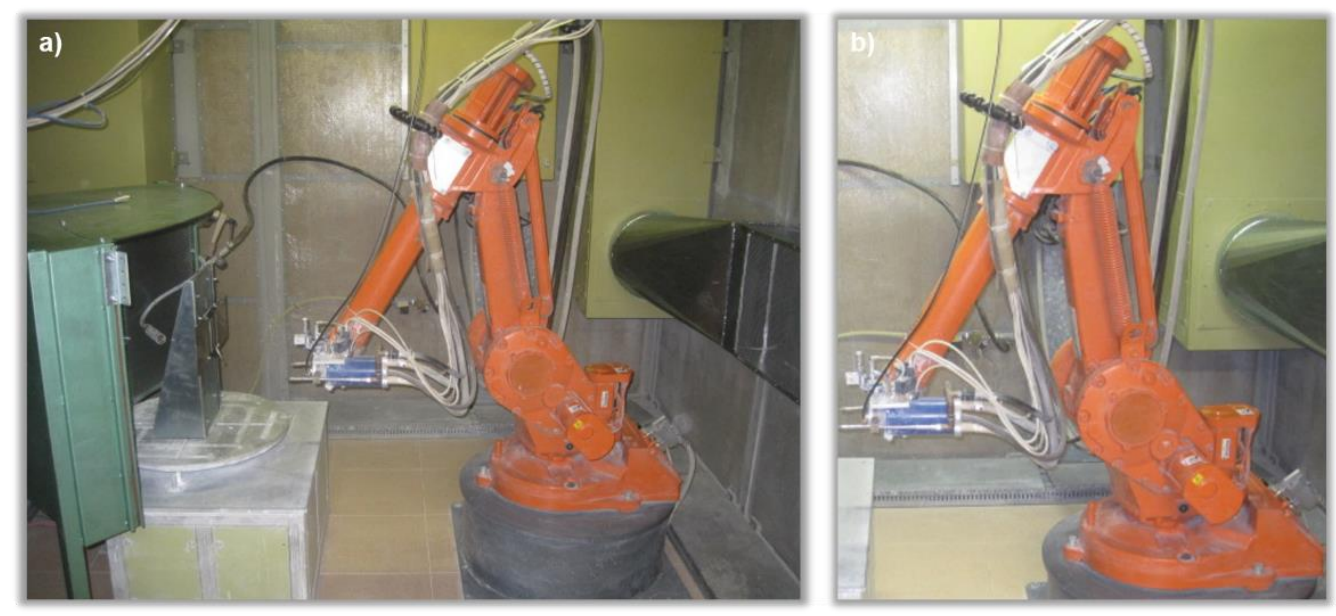

Figura 3.13. a) Interior de la cabina de proyección, b) Antorcha de plasma F4-MB acoplada al robot IRB 1400

Tal y como se ha comentado, se trata de una antorcha monocátodo compuesta únicamente por un ánodo y un cátodo, y un sistema cerrado de agua de 
refrigeración para enfriar estos electrodos. Respecto a los gases plasmógenos, la antorcha está conectada a un caudalímetro de argón (gas plasmógeno principal) y uno de hidrógeno (gas plasmógeno secundario).

En el exterior de la cabina, se encuentran los dispositivos de dosificación de material, tanto para materiales pulverulentos, como para materiales líquidos. En el caso de materiales pulverulentos se ha utilizado un dispositivo comercial de disco rotatorio (Twin 120A, Oerlikon Metco, Suiza) descrito en el capítulo 1. Introducción (1.3.2. Proyección térmica por plasma atmosférico o APS), el cual utiliza argón como gas portador del polvo. Para los materiales de aporte líquidos se ha utilizado un sistema neumático presurizado de fabricación propia diseñado en el Instituto de Tecnología Cerámica. El dispositivo está compuesto básicamente por dos depósitos presurizados, cada uno provisto de un sistema de agitación mecánica, en los cuales se introduce el material líquido a depositar, y un sistema de inyección mecánica con boquillas intercambiables de distinto diámetro. El funcionamiento básico de este tipo de dispositivo está explicado en el capítulo 1. Introducción (1.4.3. Proyección térmica por plasma de materiales de aporte líquidos).

Por último, el portamuestras utilizado para sostener los sustratos durante el proceso de proyección también varía en función del material de aporte. Para la deposición de materiales de aporte pulverulentos se ha utilizado un portamuestras estático tal y como se muestra en la figura 3.14a. Los sustratos se anclan entre una chapa fija y varias chapas móviles, con la cara que se desea recubrir perpendicular a la antorcha de plasma. El ciclo de proyección (también conocido como pasada) seguido por la antorcha se detalla en la figura $3.14 \mathrm{~b}$, donde se puede apreciar que la antorcha se ha desplazado, desde el punto inicial del ciclo hasta el punto final, movida por el robot en dos direcciones (eje z y eje y). Además, durante este ciclo de proyección, los sustratos se han refrigerado mediante chorros de aire comprimido, uno situado detrás del portamuestras refrigerando la parte trasera de la placa donde se anclan los sustratos, y dos acoplados a cada extremo de la antorcha de plasma refrigerando directamente la superficie recubierta.

Para la deposición de materiales de aporte líquidos, se ha utilizado un portamuestras rotacional (Figura 3.14c), donde los sustratos están girando de forma continua. El cambio de portamuestras es debido a la necesidad de una mejor refrigeración de los sustratos, puesto que, durante la proyección de materiales líquidos, al utilizar distancias de proyección más cortas, éstos reciben mayor cantidad de energía calorífica de la pluma de plasma. En este portamuestras, la cara de los sustratos que se desea recubrir también se encuentra perpendicular a la antorcha. Sin embargo, la fijación de los sustratos es diferente puesto que éstos están introducidos en orificios independientes y anclados mediante un tornillo. El ciclo o pasada de la antorcha de plasma únicamente se realiza en una dirección (eje y) como se aprecia en la figura $3.14 \mathrm{~d}$, debido a la rotación de las muestras no es necesario mover la antorcha en el eje $z$ para recubrir toda la cara del sustrato. En este portamuestras, los 
sustratos también están refrigerados por jets de aire comprimido como en el portamuestras para materiales pulverulentos.
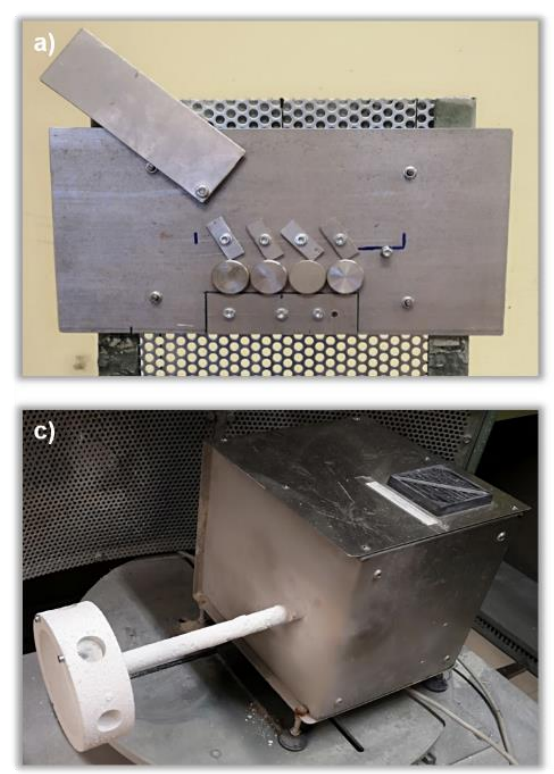

b)

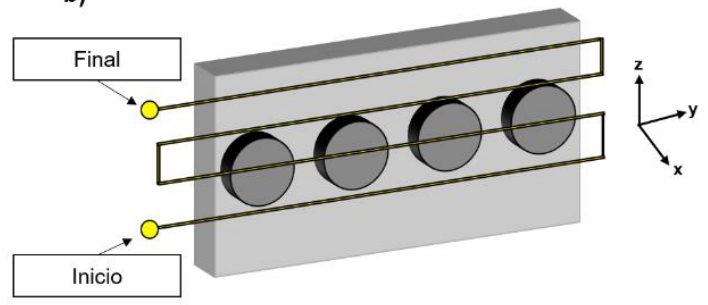

d)

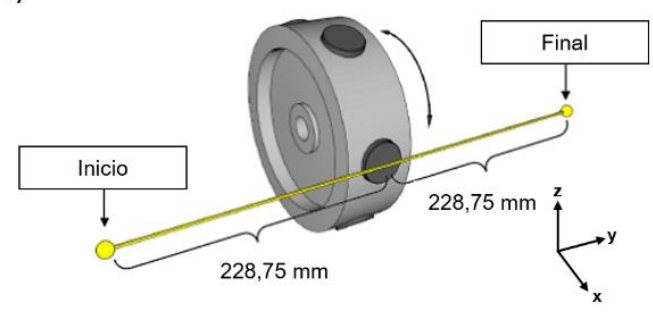

Figura 3.14. Tipo de portamuestras y ciclo realizado por la antorcha de plasma. a) y b) Materiales de aporte pulverulentos, c) y d) Materiales de aporte líquidos

\subsubsection{Condiciones de proyección para cada material de aporte}

\subsubsection{Polvos de vidrio bioactivo 4555}

Todas las fracciones de polvo de vidrio bioactivo $45 \mathrm{~S} 5$ se han inyectado en la pluma de plasma externamente de forma radial, con un inyector de $2 \mathrm{~mm}$ de diámetro, situado a $6 \mathrm{~mm}$ de la pluma de plasma y con un ángulo de $90^{\circ}$. En la tabla 3.10 se detalla el resto de los parámetros utilizados.

Se ha utilizado para los parámetros de proyección valores estándar obtenidos de la bibliografía relativa a proyección térmica por plasma. Como puede apreciarse, por un lado, todos los parámetros se mantienen constantes con el fin de estudiar el efecto del tamaño de partícula en la microestructura del recubrimiento, mientras que, por otra parte, para la fracción de polvo más fina (BGGS4) con fluidificante se emplean dos caudales de argón con el fin de estudiar el efecto de la energía y velocidad que reciben las partículas por parte de la pluma de plasma sobre el recubrimiento final. En todos los ensayos, se han realizado cinco pasadas o ciclos de deposición, es decir, el ciclo mostrado en la figura $3.14 \mathrm{~b}$ se ha realizado cinco veces. 
Tabla 3.10. Parámetros de proyección para la deposición de los polvos de vidrio bioactivo $45 \mathrm{~S} 5$

\begin{tabular}{cc}
\hline Parámetro & Valor \\
\hline Caudal de argón (slpm) & $25 / 38^{\star}$ \\
Caudal de hidrógeno (slpm) & 15 \\
Intensidad del arco eléctrico $(\mathrm{A})$ & 600 \\
Distancia de proyección $(\mathrm{mm})$ & 110 \\
Velocidad de la antorcha $(\mathrm{m} / \mathrm{s})$ & 1 \\
Incremento de altura $(\mathrm{mm})$ & 5 \\
Caudal de argón $(\mathrm{slpm})$ & 4 \\
Caudal másico de polvo $(\mathrm{g} / \mathrm{min})$ & 15 \\
\hline
\end{tabular}

*Únicamente con la fracción BGGS4 con fluidificante

\subsubsection{Suspensiones de partículas de vidrio bioactivo $45 S 5$}

Tras determinar el tipo y cantidad óptima de dispersante, se han depositado, tanto la suspensión resultante de la primera etapa de molienda (BG-Pul) como la resultante de la segunda (BG-Att). Debido a las diferencias en tamaño de partícula, para la suspensión BG-Pul se ha utilizado un inyector de 0,25 mm de diámetro mientras que la suspensión BG-Att se ha inyectado con uno de $0,20 \mathrm{~mm}$ de diámetro. Ambas suspensiones se han inyectado externamente de forma radial, situando el inyector a un ángulo de $75^{\circ}$ en contracorriente al flujo de la pluma de plasma y a una distancia de la pluma de $10 \mathrm{~mm}$. A continuación, se detallan el resto de los parámetros empleados, los cuales corresponden a condiciones estándar para depositar suspensiones y que ya han sido previamente optimizados en trabajos anteriores.

Como se observa en la tabla anterior, en este trabajo únicamente se ha realizado un estudio de la influencia de la distancia de proyección sobre la microestructura del recubrimiento manteniendo constantes el resto de los parámetros. Como se ha comentado anteriormente, tanto el portamuestras como la antorcha están en movimiento para asegurar la máxima refrigeración de los sustratos durante la proyección. Por tanto, durante un ciclo en el portamuestras rotatorio (Figura 3.14d) es imposible recubrir totalmente todos los sustratos. Para las velocidades utilizadas (seleccionadas tras varios ensayos con diferentes velocidades), es necesario llevar a cabo 91 veces el ciclo descrito en la figura 3.14d para asegurar el completo recubrimiento de todos los sustratos y que sean comparables a un ciclo del portamuestras estático. Puesto que con el portamuestras estático se han llevado a cado 5 ciclos, en la deposición de las suspensiones con el portamuestras rotatorio se han llevado a cabo 455 ciclos. 
Tabla 3.11. Parámetros de proyección para la deposición de las suspensiones de vidrio bioactivo $45 \mathrm{~S} 5$

\begin{tabular}{cc}
\hline Parámetro & Valor \\
\hline Caudal de argón (slpm) & 37 \\
Caudal de hidrógeno (slpm) & 8 \\
Intensidad del arco eléctrico (A) & 700 \\
Distancia de proyección (mm) & $60 / 65 / 70 / 75 / 80$ \\
Velocidad de la antorcha (m/s) & 1,25 \\
Velocidad rotación portamuestras (m/s) & 0,72 \\
Presión del depósito (bar) & 6 \\
Caudal volumétrico de suspensión (cm $3 / \mathrm{min})$ & $89(\mathrm{BG}-\mathrm{Pul}) / 19$ (BG-Att) \\
\hline
\end{tabular}

Además, para incrementar la adherencia de estos recubrimientos, previamente a la deposición de las suspensiones, se han llevado a cabo dos acciones. La primera es la deposición por APS de una capa de titania, como capa de anclaje, a partir de un polvo comercial de anatasa (Metco 102, Oerlikon Metco, Suiza) con una distribución de tamaños de partícula comprendida entre 10 y $55 \mu \mathrm{m}$. El polvo se ha inyectado externamente de manera radial, con un inyector de $1,8 \mathrm{~mm}$ de diámetro, situado a $6 \mathrm{~mm}$ de la pluma de plasma y con un ángulo de $90^{\circ}$. En la tabla 3.12 se detallan los valores utilizados para el resto de los parámetros.

La segunda acción ha sido precalentar los sustratos recubiertos con la capa de anclaje antes de depositar la capa de vidrio. Esta acción se ha llevado a cabo haciendo uso de la antorcha de plasma. Para ello, con el portamuestras girando, se ha situado la antorcha en una posición fija a $100 \mathrm{~mm}$ de distancia de los sustratos y se han precalentado hasta una temperatura entre 300-350 $\stackrel{\circ}{ } \mathrm{C}$.

Tabla 3.12. Parámetros de proyección para la deposición de la capa de anclaje de titania

\begin{tabular}{cc}
\hline Parámetro & Valor \\
\hline Caudal de argón (slpm) & 38 \\
Caudal de hidrógeno (slpm) & 14 \\
Intensidad del arco eléctrico $(\mathrm{A})$ & 600 \\
Distancia de proyección $(\mathrm{mm})$ & 120 \\
Velocidad de la antorcha $(\mathrm{m} / \mathrm{s})$ & 1 \\
Incremento de altura $(\mathrm{mm})$ & 4 \\
Número de ciclos & 2 \\
Caudal de argón $(\mathrm{s} / \mathrm{pm})$ & 4 \\
Caudal másico de polvo $(\mathrm{g} / \mathrm{min})$ & 45 \\
\hline
\end{tabular}

\subsubsection{Soluciones precursoras de vidrio bioactivo 4555}

Las distintas soluciones de precursores se han depositado también externamente de forma radial, con un inyector de $0,15 \mathrm{~mm}$ de diámetro, situándolo a un ángulo de $75^{\circ}$ en contracorriente al flujo de la pluma de plasma 
y a una distancia de la pluma de $10 \mathrm{~mm}$. Al igual que para las suspensiones, los sustratos también se han recubierto con una capa de anclaje de titania y precalentado hasta $300-350 \stackrel{\circ}{ }$. Asimismo, por cada proyección también se han llevado a cabo 455 ciclos. A continuación, se detallan los parámetros de proyección utilizados.

Puesto que los procesos que tienen lugar en el interior de la pluma de plasma al usar soluciones de precursores son muy complejos, en este trabajo se ha decidido hacer un barrido, tanto de caudales de argón, como de distancias de proyección, ya que estos parámetros influyen en gran medida en la microestructura del recubrimiento final. Las soluciones de precursores que contienen TEOS se han depositado con los parámetros descritos en la tabla 3.13, mientras que las soluciones que contienen partículas coloidales de $\mathrm{SiO}_{2}$ únicamente se han depositado para un caudal de argón de 25 slpm y distancias de proyección de 40 y $70 \mathrm{~mm}$.

Tabla 3.13. Parámetros de proyección para la deposición de las distintas soluciones de precursores de vidrio bioactivo $45 \mathrm{~S} 5$

\begin{tabular}{cc}
\hline Parámetro & Valor \\
\hline Caudal de argón (slpm) & $25 / 45$ \\
Caudal de hidrógeno (slpm) & 15 \\
Intensidad del arco eléctrico $(\mathrm{A})$ & 600 \\
Distancia de proyección $(\mathrm{mm})$ & $40 / 70 / 110$ \\
Velocidad de la antorcha (m/s) & 1,25 \\
Velocidad rotación portamuestras $(\mathrm{m} / \mathrm{s})$ & 0,72 \\
Presión del depósito (bar) & 6 \\
Caudal volumétrico de solución $\left(\mathrm{cm}^{3} / \mathrm{min}\right)$ & 33 \\
\hline
\end{tabular}

\subsection{Caracterización de los recubrimientos obtenidos}

\subsubsection{Caracterización microestructural}

Los recubrimientos obtenidos han sido caracterizados a nivel microestructural. Se ha observado y tomado micrografías primero de la superficie y después de la sección transversal de los recubrimientos mediante microscopía electrónica de barrido, utilizando los mismos parámetros de operación que en el caso de los polvos.

Para poder observar la sección transversal de los recubrimientos, ha sido necesario realizar una preparación metalográfica de éstos. En primer lugar, se ha cortado los recubrimientos mediante disco de diamante (M4D18, Struers, Dinamarca) en una cortadora automática (Secotom-10, Struers, Dinamarca). A continuación, los recubrimientos cortados se han embutido en frio mediante una resina de tipo epoxi (Kit Epofix, Struers, Dinamarca) y se ha dejado curar durante 24 horas para asegurar su completo endurecimiento. Finalmente, las muestras embutidas se han pulido en una pulidora automática (TegraPol-35, Struers, Dinamarca) utilizando diferentes paños (Struers, Dinamarca) tal y como se detalla en la tabla 3.14. 
Tabla 3.14. Descripción de los paños y tiempos de pulido utilizados en la preparación metalográfica de los distintos recubrimientos

\begin{tabular}{cccc}
\hline Paño de pulido & Abrasivo & $\begin{array}{c}\text { Tamaño de } \\
\text { grano }\end{array}$ & $\begin{array}{c}\text { Tiempo de } \\
\text { aplicación }\end{array}$ \\
\hline MD-Piano 220 & $\begin{array}{c}\text { Resina con } \\
\text { diamante }\end{array}$ & $68 \mu \mathrm{m}$ & 1 minuto \\
MD-Allegro & $\begin{array}{c}\text { Suspensión de } \\
\text { diamante }\end{array}$ & $15-6 \mu \mathrm{m}$ & 5 minutos \\
MD-Dur & $\begin{array}{c}\text { Suspensión de } \\
\text { diamante }\end{array}$ & $9-1 \mu \mathrm{m}$ & 5 minutos 30 \\
segundos
\end{tabular}

Tras el pulido, las muestras se han limpiado con agua destilada en baño de ultrasonidos y se han secado en estufa. Para cada recubrimiento, se ha tomado un mínimo de 20 micrografías diferentes en sección a 2000x aumentos y se han tratado mediante un software de análisis de imagen (Microlmage) para determinar tanto el espesor del recubrimiento como la porosidad, promediando los valores de las diferentes micrografías.

Además, puesto que en procesos sol-gel para síntesis de materiales multicomponente como el caso del vidrio bioactivo 45S5 es difícil obtener una distribución homogénea de los elementos por todo el material, mediante el EDX incorporado en el microscopio se ha realizado un mapa de la distribución de los elementos en la sección transversal de los recubrimientos obtenidos a partir de las soluciones que presentan mejor microestructura. Para ello, previamente, las muestras se han recubierto con una fina capa de carbono mediante evaporación y deposición a vacío y se han analizado en condiciones de alto vacío. Asimismo, también se ha determinado la presencia de fases cristalinas en los recubrimientos mediante análisis de su superficie por difracción de rayos $X$. Los parámetros de operación utilizados han sido los mismos que en el caso de los polvos.

\subsubsection{Adherencia de los recubrimientos}

La adherencia de los recubrimientos obtenidos a partir de materiales de aporte pulverulentos se ha determinado mediante tracción siguiendo la norma ASTMC633. Este ensayo consiste en pegar con un adhesivo específico dos sustratos iguales, uno de ellos incluyendo el recubrimiento objeto de estudio y el otro, 
únicamente granallado. El conjunto se ancla por ambos sustratos a un equipo universal de tracción (Instron 5889, Instron, Reino Unido) y se tracciona a velocidad constante. Cuando se produce la rotura o separación de ambos sustratos, se registra la carga de tracción a la que ha tenido lugar esta rotura (carga de tracción máxima) y se divide por la superficie de la cara recubierta, obteniendo así el valor de adherencia. Sin embargo, es esencial realizar una observación del lugar de la rotura, pues la rotura puede darse entre el recubrimiento y el sustrato original, dentro del mismo recubrimiento o en el mismo adhesivo (el ensayo se considera nulo en este último caso). En este trabajo, el ensayo de tracción se ha realizado a una velocidad constante de $1,67 \cdot 10^{-5} \mathrm{~m} / \mathrm{s}$, ensayando 3 muestras de cada recubrimiento y promediando los resultados.

Dado que los recubrimientos obtenidos a partir de materiales de aporte líquidos, especialmente a partir de soluciones, normalmente poseen espesores finos, no es posible emplear el ensayo de tracción según la norma ASTM-C633 para determinar la adherencia, puesto que no cumplen con el espesor mínimo requerido por esta norma. Por lo tanto, en este trabajo, se ha utilizado un ensayo de rayado para determinar la adhesión final de los recubrimientos [182]. Para ello se utilizó un equipo de rayado (Revetest, CSM Instrument, Alemania) equipado con un indentador Rockwell de diamante de forma cónica y de punta esférica con un radio de $0,2 \mathrm{~mm}$. Mediante este indentador, se han realizado rayas de $10 \mathrm{~mm}$ de longitud en cada recubrimiento ensayado, aumentando progresivamente la carga aplicada de 0 a $10 \mathrm{~N}$. Para evitar errores causados por la presencia de defectos específicos en la superficie, se hicieron tres rayas en cada recubrimiento. Antes y después del rayado, el indentador recorrió la superficie a ensayar aplicando una carga mínima, registrando así el perfil original de la superficie con el fin de detectar los cambios de profundidad experimentados por la zona rayada. Además, se utilizó un microscopio óptico acoplado al equipo de rayado, lo que permitió la caracterización visual de los cambios en el mecanismo de rayado tomando micrografías de las rayas realizadas en cada muestra. La carga crítica se determinó como la fuerza con la que la capa de anclaje comenzó a ser visible. La dureza al rayado también se ha determinado a partir de la ecuación 3.3 y se ha relacionado con la cohesión del recubrimiento.

$$
H S_{p}=\frac{k \cdot P}{w^{2}}(\text { ec. 3.3) }
$$

Donde $\mathrm{HS}_{\mathrm{p}}$ es la dureza al rayado (GPa), P es la fuerza correspondiente a la carga crítica (gramos de fuerza), $\mathrm{k}$ es una constante geométrica y cuyo valor es de 24,98, y w es la amplitud de la raya generada $(\mu \mathrm{m})$, en este trabajo se ha tomado como el ancho de la raya correspondiente a la carga crítica.

A modo de comparación, este ensayo también se ha utilizado para determinar la adherencia de los recubrimientos obtenidos a partir de polvos. 


\subsubsection{Superficie específica}

Tal y como se ha llevado a cabo para el caso de la fracción de polvo BGGS4, también se ha determinado la superficie específica para el recubrimiento resultante de está fracción. Para ello se ha utilizado el mismo equipo y los mismos parámetros.

Para poder realizar el ensayo, se ha sumergido el sustrato recubierto en $\mathrm{HCl}$ durante unas horas y a continuación, se ha despegado el recubrimiento del sustrato atacado. El recubrimiento desprendido se ha fragmentado en trozos, determinando su superficie específica.

\subsubsection{Estudio de la bioactividad}

Se ha estudiado la bioactividad de algunos de los recubrimientos depositados a partir de polvos y soluciones de precursores mediante inmersión en SBF. El procedimiento seguido, tanto de preparación de SBF, como de caracterización de las muestras, ha sido el mismo que en el caso del polvo de vidrio bioactivo salvo por dos diferencias, la cantidad de SBF utilizado por muestra y el tiempo de incubación.

Respecto al tiempo de incubación, los recubrimientos se han incubado hasta un máximo de 14 días, a diferencia del polvo el cual se ha incubado hasta 7 días.

La cantidad de SBF necesaria para la incubación de cada recubrimiento se ha determinado mediante la siguiente expresión:

$$
V_{S B F}=\frac{S_{c}}{10}(\text { ec. 3.4) }
$$

Donde $\mathrm{V}_{\mathrm{SBF}}$ es el volumen de $\mathrm{SBF}\left(\mathrm{cm}^{3}\right)$ y $\mathrm{S}_{\mathrm{c}}$ es el área de la muestra $\left(\mathrm{mm}^{2}\right)$, en este caso el recubrimiento de vidrio. Puesto que se ha recubierto la cara de un disco con un diámetro de $25 \mathrm{~mm}$, esto corresponde a un área de $490 \mathrm{~mm}^{2}$ y en consecuencia un volumen de $49 \mathrm{~cm}^{3}$ de SBF.

\subsubsection{Caracterización in-vitro}

\subsubsection{Tipo de células y cultivo celular}

Se ha evaluado la respuesta in-vitro del recubrimiento con mejor microestructura obtenido a partir de los polvos de vidrio bioactivo mediante osteoblastos humanos (MG-63, Sigma-Aldrich, USA). Para ello, el recubrimiento se ha cortado en pequeñas muestras cuadradas de aproximadamente $100 \mathrm{~mm}^{2}$ de superficie. A modo de comparación, también se han cortado y ensayado cuadrados de $100 \mathrm{~mm}^{2}$ de superficie de acero inoxidable AISI 304 sin recubrir. 
En primer lugar, se ha cultivado las células en atmosfera humidificada a $37^{\circ} \mathrm{C}$ con un $5 \%$ de $\mathrm{CO}_{2}$ en aire, empleando un medio de cultivo celular sintético (Dulbecco's modified eagle's culture medium o DMEM, Gibco, Alemania) el cual contiene un $10 \%$ de suero bovino (FCS, Sigma-Aldrich, USA) y un $1 \%$ de antibióticos (penicilina y estreptomicina). El cultivo celular se ha llevado a cabo durante aproximadamente una semana con el fin de obtener un número elevado de células con el que trabajar, cambiando el medio sintético cada 4872 horas.

De forma paralela al cultivo, se ha esterilizado todas las muestras (sustratos cortados con y sin recubrimiento) mediante un tratamiento térmico a $160{ }^{\circ} \mathrm{C}$ durante 2 horas en horno eléctrico. Una vez esterilizadas, se ha preincubado las muestras en medio de cultivo sintético (DMEM) en atmosfera humidificada a $37^{\circ} \mathrm{C}$ con un $10 \%$ de $\mathrm{CO}_{2}$ en aire durante 48 horas. La finalidad principal de la preincubación ha sido evitar un aumento excesivo del pH del medio de cultivo celular sintético tras adicionar las células, evitando así su muerte, especialmente en el caso de las muestras con recubrimiento de vidrio bioactivo, fenómeno del que se ha informado con frecuencia en la bibliografía $[183,184]$.

Una vez terminado el cultivo, se ha retirado el DMEM del frasco donde se ha llevado a cabo el cultivo, y se ha lavado las células con una solución salina tamponada con fósforo (PBS, Gybco, Alemania) y éstas se han despegado de las paredes mediante la adición de $3 \mathrm{~cm}^{3}$ de una mezcla de tripsina/EDTA (Gibco, Alemania). Seguidamente, se ha retirado la mezcla de tripsina/EDTA y se ha añadido al frasco $9 \mathrm{~cm}^{3}$ de DMEM a $37^{\circ} \mathrm{C}$ para cortar la reacción con la tripsina. A continuación, se ha extraído una pequeña alícuota de DMEM con células con el objetivo de determinar el número de células por unidad de volumen de medio de cultivo, y tras ello, se ha añadido DMEM nuevo a $37^{\circ} \mathrm{C}$ en el interior del frasco para diluir la concentración de células desde 340000 hasta 50000 células $/ \mathrm{cm}^{3}$.

Una vez alcanzada la concentración deseada de células, se ha introducido las muestras esterilizadas y preincubadas en microplacas con orificios de ensayo de $314 \mathrm{~mm}^{2}$ de área, y se han puesto en contacto con las células mediante la adición de $1 \mathrm{~cm}^{3}$ de DMEM conteniendo las células en cada orificio de ensayo. Como control, se rellenaron orificios sin muestra esterilizada. Finalmente, las microplacas conteniendo las muestras junto con las células se han incubado en atmosfera humidificada a $37^{\circ} \mathrm{C}$ con un $10 \%$ de $\mathrm{CO}_{2}$ en aire durante 24 horas.

\subsubsection{Adhesión y morfología de las células}

Tras las 24 horas de incubación, se ha procedido a estudiar la morfología y la adhesión de las células vivas. Por un lado, se ha utilizado la tinción con faloidina para evaluar, tanto la adherencia, como la morfología de las células, mientras que, por otro lado, se ha utilizado la tinción con Vybrant para contar el número de células vivas presentes sobre la superficie de las muestras. Además, todas 
las muestras que no se han utilizado para la tinción se han examinado mediante microscopía electrónica de barrido

En primer lugar, se retira el DMEM de todos los orificios de la microplaca (incluyendo los que no tienen muestra esterilizada) y estos orificios se limpian con cuidado usando PBS. Del total de muestras (con y sin recubrimiento) y orificios de control, se ha destinado 3 de cada tipo para la tinción con faloidina, 6 de cada tipo para tinción con Vybrant y el resto de las muestras para microscopía electrónica de barrido.

Para la tinción con faloidina, primero se ha fijado las células a la superficie de las muestras introduciendo una solución fijadora (FluoFix-PBS) en los orificios de la microplaca durante 15 minutos. Después, se ha vuelto a lavar los orificios con PBS y se ha permeabilizado las células introduciendo una solución tampón en los orificios durante 5 minutos. Seguidamente, se ha lavado los orificios con PBS y se han rellenado con una solución fluorescente de isotiocianato (Phalloidin, Sigma-Aldrich, USA) para colorear el citoesqueleto de las células. Para la tinción, se ha mantenido la microplaca durante 60 minutos en oscuridad. Una vez trascurrida la hora, se ha limpiado los orificios de nuevo con PBS y se han rellenado con una solución de 4',6-diamidino-2-fenilindol (Dapi, SigmaAldrich, USA) en PBS con una concentración de $1 \cdot 10^{-3} \mathrm{~cm}^{3}$ de Dapi por $1 \mathrm{~cm}^{3}$ de PBS. Esta solución se ha utilizado para colorear el núcleo de las células y se ha dejado en los orificios durante 5 minutos. Transcurrido este tiempo, se ha limpiado los orificios con PBS y se han rellenado con PBS nuevo para mantener las muestras conservadas en oscuridad a baja temperatura hasta el momento de la observación. La observación de las células se ha realizado mediante micrografías a diferentes aumentos $(5 x$ y $20 x)$ mediante un microscopio fluorescente (Axio Scope A1, Carl Zeiss, Alemania).

Para la tinción con Vybrant, se ha rellenado los orificios con una solución de tinte de membrana lipofílica (Vybrant, Thermo Fisher Scientific, USA) en DMEM, con una concentración de $4 \cdot 10^{-3} \mathrm{~cm}^{3}$ de Vybrant por $1 \mathrm{~cm}^{3}$ de DMEM, y se ha incubado la microplaca a $37^{\circ} \mathrm{C}$ durante 45 minutos. Transcurrido este tiempo, se ha limpiado los orificios con PBS y se ha fijado las células con la solución fijadora citada en el párrafo anterior, dejándola en los orificios durante 15 minutos. A continuación, tras lavar los orificios con PBS, se han vuelto a rellenar con la solución de Dapi citada en el párrafo anterior y se ha dejado durante 5 minutos. Transcurrido este tiempo, se ha limpiado los orificios con PBS y se han rellenado con PBS nuevo para mantener las muestras conservadas en oscuridad a baja temperatura hasta el momento de la observación. Por cada muestra se ha tomado 5 micrografías a 10x mediante el microscopio fluorescente citado en el párrafo anterior. A partir de estas micrografías, se ha contado el número de células con el software de análisis de imagen ImageJ. Los resultados obtenidos del conteo se han evaluado mediante un análisis de varianza unidireccional (ANOVA) con la prueba de Tukey, con un nivel estadístico de significación de 0,01 [183]. 
Finalmente, a las muestras que no se han coloreado se les ha añadido dos soluciones fijadoras diferentes (la primera conteniendo glutaraldehído + cacodilato de sodio y la segunda conteniendo glutaraldehído + cacodilato de sodio + paraformaldehído) durante 1 hora cada una. A continuación, se ha deshidratado todas las muestras mediante una serie de disoluciones de etanol de concentración variable desde $30 \%$ hasta $100 \%$. Para concluir, las muestras se han secado en un desecador y se han recubierto de carbono mediante evaporación y deposición a vacío para su observación en el microscopio electrónico. 


\section{RESULTADOS}



La exposición de los resultados obtenidos en el presente trabajo de tesis se lleva a cabo mediante la presentación de un compendio de diferentes publicaciones científicas en revistas indexadas de alto índice de impacto. A continuación, se detalla la relación de publicaciones recogidas en este trabajo en orden de presentación.

- Artículo 1

Autores: Eugeni Cañas, Mónica Vicent, Emilie Bannier, Pablo Carpio, María José Orts, Enrique Sánchez

Título: Effect of particle size on processing of bioactive glass powder for atmospheric plasma spraying

Revista: Journal of the European Ceramic Society

Volumen: $36 \quad$ Páginas: 837-845 Año: 2016

DOI: 10.1016/j.jeurceramsoc.2015.09.039

- Artículo 2

Autores: Eugeni Cañas, Alina Grünewald, Rainer Detsch, María José Orts, Enrique Sánchez, Aldo R. Boccaccini

Título: In vitro study of bioactive glass coatings obtained by atmospheric plasma spraying

Revista: Boletín de la Sociedad Española de Cerámica y Vidrio

Volumen:- Páginas:-- Año: 2020

DOI: 10.1016/j.bsecv.2020.06.004

- Artículo 3

Autores: Eugeni Cañas, Mónica Vicent, María José Orts, Rodrigo Moreno, Enrique Sánchez

Título: Bioactive glass suspensions preparation for suspension plasma spraying

Revista: Journal of the European Ceramic Society

Volumen: $36 \quad$ Páginas: 4281-4290 Año: 2016

DOI: 10.1016/j.jeurceramsoc.2016.06.011

- Artículo 4

Autores: Eugeni Cañas, Mónica Vicent, María José Orts, Enrique Sánchez

Título: Bioactive glass coatings by suspension plasma spraying from glycolether-based solvent feedstock

Revista: Surface \& Coatings Technology

Volumen: 318 Páginas: 190-197 Año: 2017

DOI: $10.1016 /$ j.surfcoat.2016.12.060 
- Artículo 5

Autores: Eugeni Cañas, Vicente Sanz, María José Orts, Enrique Sánchez

Título: Post-deposition heat treatment effect on microstructure of suspension plasma sprayed bioactive glass coatings

Revista: Surface \& Coatings Technology

Volumen: $371 \quad$ Páginas: 136-142

Año: 2019

DOI: 10.1016/j.surfcoat.2018.11.003

- Artículo 6

Autores: Eugeni Cañas, María José Orts, Aldo R. Boccaccini, Enrique Sánchez

Título: Solution Precursor Plasma Spraying (SPPS): A novel and simple process to obtain bioactive glass coatings

Revista: Materials Letters

Volumen: 223 Páginas: 198-202 Año: 2018

DOI: 10.1016/j.matlet.2018.04.031

- Artículo 7

Autores: Eugeni Cañas, María José Orts, Aldo R. Boccaccini, Enrique Sánchez

Título: Microstructural and in vitro characterization of $45 \mathrm{~S} 5$ bioactive glass coatings deposited by solution precursor plasma spraying (SPPS) Revista: Surface \& Coatings Technology

Volumen: 371 Páginas: 151-160 Año: 2019

DOI: 10.1016/j.surfcoat.2018.12.057

- Artículo 8

Autores: Eugeni Cañas, María Díaz, Carmen Alcázar, María José Orts, Rodrigo Moreno, Enrique Sánchez

Título: Comparison of different silica sources in the development of plasma sprayed $45 \mathrm{~S} 5$ bioactive glass coatings

Revista: Journal of Non-Crystalline Solids

Volumen: $544 \quad$ Páginas: 120164

Año: 2020

DOI: 10.1016/j.jnoncrysol.2020.120164 
Artículo 1 



\title{
Effect of particle size on processing of bioactive glass powder for atmospheric plasma spraying
}

\author{
Eugeni Cañas, Mónica Vicent, Emilie Bannier, Pablo Carpio, María José Orts, \\ Enrique Sánchez
}

Journal of the European Ceramic Society 36 (2016) 837-845

\section{http://dx.doi.org/10.1016/j.jeurceramsoc.2015.09.039}

Este trabajo aborda el estudio del efecto del tamaño partícula de un material de aporte pulverulento de composición similar a un vidrio bioactivo en el procesado y microestructura de recubrimientos obtenidos mediante proyección térmica por plasma atmosférico (APS). Se ha observado que la reducción del tamaño de partículas afecta negativamente a la fluidez del polvo. Además, el comportamiento térmico (pérdidas de peso, transiciones vítreas, cristalizaciones, etc.) también depende del tamaño de las partículas del polvo de vidrio.

No ha sido posible obtener un recubrimiento con las fracciones más gruesas (más de $200 \mu \mathrm{m}$ ) debido a su bajo grado de fusión en la pluma de plasma. Para las fracciones intermedias $(200-63 \mu \mathrm{m})$ se han obtenido recubrimientos, pero con una fusión de partículas insuficiente. Por el contrario, la fracción más fina $(<63 \mu \mathrm{m})$ necesitaba un fluidificante que permitiera transportar el material hasta la pluma de plasma. 

Journal of the European Ceramic Society 36 (2016) 837-845

\title{
Effect of particle size on processing of bioactive glass powder for atmospheric plasma spraying
}

\author{
E. Cañas*, M. Vicent, E. Bannier, P. Carpio, M.J. Orts, E. Sánchez \\ a Instituto de Tecnología Cerámica (ITC), Asociación de Investigación de las Industrias \\ Cerámicas (AICE), Universidad Jaume I, Castellón, Spain \\ * Corresponding author
}

\begin{abstract}
The work addresses the effect of the particle size of a bioactive glass feedstock on the processing and microstructure of the resulting coatings obtained by atmospheric plasma spraying (APS). It was observed that the reduction of particle size negatively affects the flowability of the powder. In addition the thermal behaviour (weight losses, glass transitions, crystallisations, etc) also depended on the particle size of the glass powder.

No coating was obtained with the coarser fractions (higher than $200 \mu \mathrm{m}$ ) due to their low melting degree in the plasma. For the intermediate fractions (200 to 63 $\mu \mathrm{m})$ coatings were obtained but insufficient particle melting was produced. On the contrary, the finest fraction $(<63 \mu \mathrm{m})$ needed a fluidiser which enabled the samples to be sprayed.
\end{abstract}

Keywords: Bioactive glass powders; Feedstock flowability; Feedstock thermal behaviour; Atmospheric plasma spraying; Bioactive glass coatings

\section{Introduction}

From the sixties there is an important need for bioactive materials to heal or replace damaged areas of the body, due to the ability of these materials to prevent fibrous encapsulation when compared with an inert implant. Bioactive materials include hydroxyapatite (HA) ceramics, glasses, glass-ceramics and surface-active composite materials [1,2]. The most studied of the above materials are glasses, known as bioactive glasses (BGs), because of their higher bioactivity index [3].

BGs are materials based on mixtures of oxides from the $\mathrm{SiO}_{2}-\mathrm{CaO}-\mathrm{MgO}-$ $\mathrm{Na}_{2} \mathrm{O}-\mathrm{K}_{2} \mathrm{O}-\mathrm{P}_{2} \mathrm{O}_{5}$ system. The first $\mathrm{BG}$, developed by L.L. Hench et al., was $45 \mathrm{~S} 5$ bioactive glass or Bioglass $\AA$, which consists of $45,0 \% \mathrm{SiO}_{2}, 24,5 \% \mathrm{CaO}$, $24,5 \% \mathrm{Na}_{2} \mathrm{O}$ and 6,0\% $\mathrm{P}_{2} \mathrm{O}_{5}$ (all percentages in wt\%) [4].

BGs preparation techniques include both melting (fusing and crushing) and solgel methods [5]. Employing the sol-gel technique, BGs exhibit more bioactivity than those obtained by melting in spite of having lower mechanical properties. 
BGs are the most promising materials for bone grafting in several clinical applications, such as orthopaedic, dental, maxillofacial and otolaryngological [6]. Nevertheless, BGs applications are limited due to their brittleness and poor mechanical properties. In order to solve these problems, BGs can be deposited onto a bioinert substrate to obtain a composite that improves its mechanical strength without changing its bioactivity [4].

There are many techniques to coat a substrate, usually metallic alloys, with BGs. These techniques can be enamelling, sol-gel method, electrophoretic deposition, laser cladding and thermal spraying techniques (plasma spraying and high-velocity oxy-fuel). Nonetheless the most employed technique to spray BGs, since 1980 , is thermal spraying, specifically atmospheric plasma spraying (APS) due to its low cost and industrial feasibility [1-4].

The literature shows many papers about optimisation of plasma spray conditions to obtain BG coatings by APS. Most of these papers also include the characterisation of the resulting coatings [7-12]. However, very few papers have dealt with the effect of the particle size of the bioactive glass feedstock on the processing and final microstructure of the obtained coatings. This aspect is of paramount importance when a glass powder feedstock must be fed into the plasma torch. Fine particle size is required for the powder to sufficiently melt and then adhere on the substrate during splat (melted particle) deposition in the APS process [13]. Moreover too fine particles dramatically impair powder flowability making it difficult or impossible the pneumatic transport of the powder from the container to the plasma torch. Besides the glass powder particle size strongly affects the liquid phase sintering of the as-deposited glass splats as well as the evolving of gas bubbles occurring during the rapid sintering of melted glass particles [14,15]. In other words, particle size of the BG feedstock is expected to drastically impact on the microstructure of the final coatings and therefore on their final properties.

Consequently, the present work aims at addressing the effect of the particle size of a given BG composition prepared by fusing and crushing on the flowability and thermal behaviour of the powder feedstock. The studied BG powder fractions were obtained from a frit by milling and sieving. Then the different BG powder fractions were sprayed onto metallic substrates by APS. The microstructure of the obtained coatings was examined. The final purpose of the research is to provide the necessary information to contribute to optimise the feeding of BG powder feedstocks in the APS process as well as the microstructure of the resulting coatings.

\section{Experimental}

\subsection{Feedstock preparation}

A mixture of analytical grade $\mathrm{SiO}_{2}, \mathrm{Ca}_{3}\left(\mathrm{PO}_{4}\right)_{2}, \mathrm{Na}_{2} \mathrm{CO}_{3}$ and $\mathrm{CaCO}_{3}$ was melted in the home-made rotary furnace showed in figure 1 , to get the frit. The mixture of raw materials was introduced into the furnace on the left side, whereas the 
melt was collected on the right side. The maximum temperature reached into the furnace was $1450^{\circ} \mathrm{C}$.

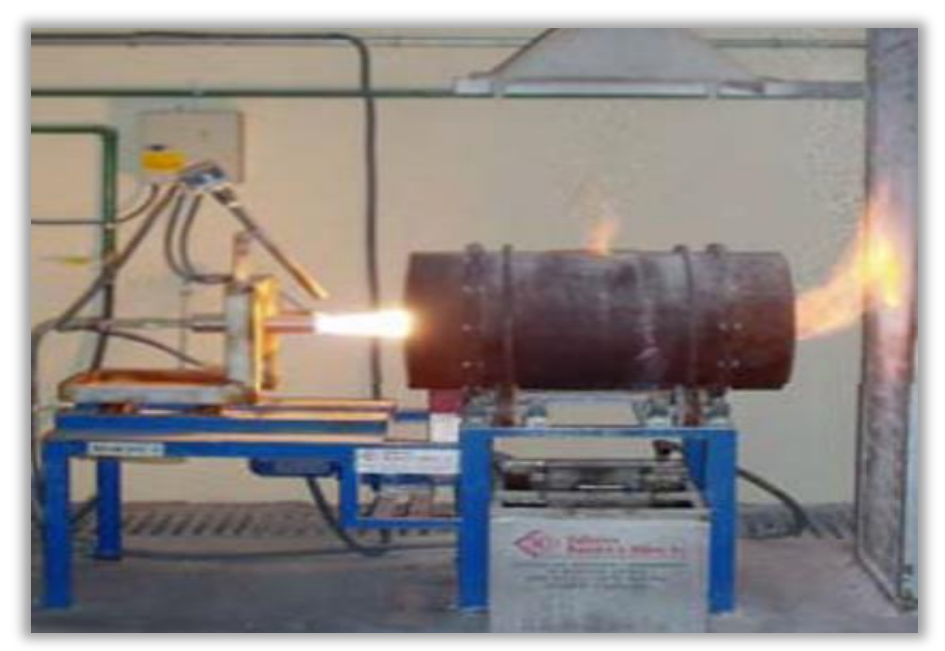

Figure 1 Rotatory furnace employed to obtain the frit

The melt was quenched into water and a BG frit was obtained. The chemical composition of the frit (Table 1) was determined by wavelength dispersive $\mathrm{X}-$ ray fluorescence spectrometry (AXIOS, PANalytical, The Netherlands). Table 1 shows the nominal and as-melted glass composition. As observed the frit composition is close to the nominal one. The frit was dry milled in a hammer mill. The milled powder was sieved to obtain different powder size fractions, which were conditioned and used as APS feedstocks. The different size fractions obtained are detailed in table 2. The morphology of both coarse and fine fractions, with the typical angular shape of a milled frit particle, can be observed in figure 2.

Table 1 Nominal and as-melted chemical composition of the frit

\begin{tabular}{ccccc}
\hline Composition (wt\%) & $\mathrm{SiO}_{2}$ & $\mathbf{P}_{2} \mathbf{O}_{5}$ & $\mathbf{C a O}$ & $\mathrm{Na}_{2} \mathbf{O}$ \\
\hline Nominal & 45,0 & 6,0 & 24,5 & 24,5 \\
As-melted & 47,6 & 5,3 & 23,1 & 24,0 \\
\hline
\end{tabular}

Table 2 Size fractions obtained from the BG powder

\begin{tabular}{cccccc}
\hline $\begin{array}{c}\text { Powder fraction } \\
\text { reference }\end{array}$ & BGGS & BGGS1* & BGGS2 & BGGS3 & BGGS4 \\
\hline $\begin{array}{c}\text { Particle size } \\
\text { distribution }(\mu \mathrm{m}) \\
\begin{array}{c}\text { Representative } \\
\text { size of each } \\
\text { fraction }(\mu \mathrm{m})\end{array}\end{array}$ & $700-200$ & $400-200$ & $200-100$ & $150-63$ & $<63$ \\
& * The percentage of BGGS1 fraction included in the BGGS fraction is 37,2 $\pm 0,8 \%$.
\end{tabular}



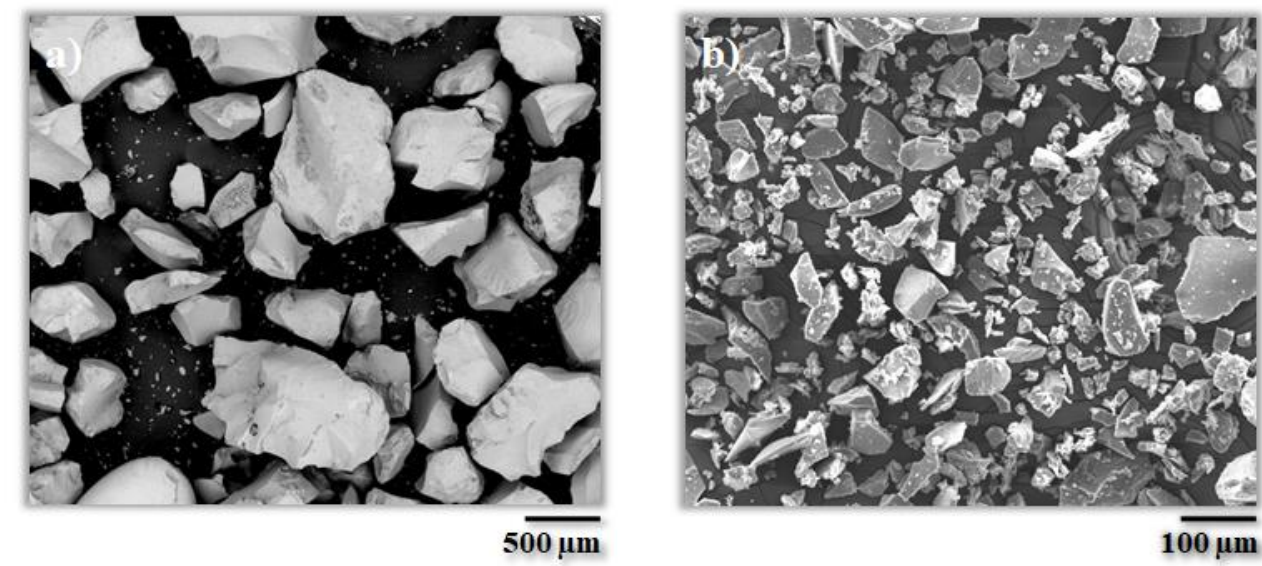

Figure 2 FEG-ESEM morphology of both (a) coarse (BGGS) and (b) fine (BGGS4) powder fractions

\subsection{Feedstock characterisation techniques}

The amorphous/crystalline character of the different size fractions was determined by X-ray diffraction (XRD) using a diffractometer (Advance diffractometer, Bruker Theta-Theta, Germany). The analysis was performed with Cu Ka radiation $(\lambda=1,54183 \AA$ ), generator settings of $30 \mathrm{kV}$ and $40 \mathrm{~mA}$ and data were collected in a $2 \theta$ range of $5-90^{\circ}$ with a step size of $0,02^{\circ}$ and a scanning speed of $0,5 \mathrm{~s} /$ step.

Flowability of the BG fractions was determined by means of two different methods, namely Hausner ratio $(H R)$ and angle of repose $\left(\alpha_{M}\right)$. Hausner ratio represents a method to estimate the flowability-cohesiveness of a given powder. Due to its simplicity HR has been extensively used to characterise APS feedstocks $[16,17]$. HR is defined as the quotient of the tapped density to the bulk (or poured) density of the powder. On the other hand to determine the angle of repose, a home-made device (Figure 3) was used which consisted in a powder holder coupled to an angle protractor. The holder filled with powder rotates until the powder falls. Then, the clock hand hitched to the holder indicates the angle of repose.

Due to the sensitivity of the BG powder to moisture, flowability tests of some fractions were also carried out with samples which had been left in contact with humid ambient in a climatic chamber in order to determine changes in flowability with adsorbed water [18]. The powder fraction was dried in an oven at $110^{\circ} \mathrm{C}$ and then cooled at room temperature in a desiccator. The dry powder was then introduced in the climatic chamber (WK3, Weiss Umwelttechnik, Germany) at $20{ }^{\circ} \mathrm{C}$ and $60 \%$ relative moisture and the adsorbed water was measured by weighing after $24 \mathrm{~h}$ inside the chamber so as to ensure that equilibrium was reached. These temperature and humidity conditions try to reproduce the typical conditions operating in the laboratory during plasma spray experiments. 


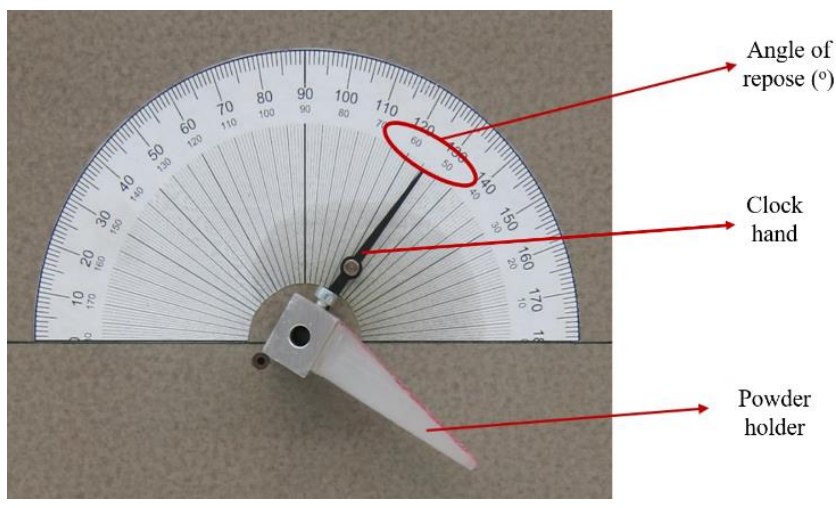

Figure 3 Device for the measurement of the angle of repose

The feedstocks thermal behaviour was investigated by simultaneous thermal analysis (DTA-TG) and heating microscopy. DTA-TG tests (TGA/SDTA 851e, Mettler Toledo, Switzerland) were carried out using a platinum crucible in air atmosphere, with a heating rate of $10 \stackrel{\circ}{\circ} / \mathrm{min}$ until a maximum temperature of $1200^{\circ} \mathrm{C}$. In order to complement these tests, a heating microscope (Misura 3, Expert Systems Solutions, Italy) was used and some characteristic temperatures for the powders were determined $[19,20]$. Cylindrical test samples of the powder fractions were prepared by pressing and, in the heating microscope, were subjected to a thermal cycle at a heating rate of $25^{\circ} \mathrm{C} / \mathrm{min}$ up to $1250^{\circ} \mathrm{C}$.

\subsection{Coating deposition and characterisation}

The different size fractions of the BG powder were sprayed onto metallic substrates by APS. Previously to deposition, the substrates (AISI type 304 stainless steel) were grit-blasted and cleaned. Grit-blasting was performed using black corundum with a pressure of 4.2 bar, and then the substrates were cleaned with ethanol. Surface roughness $\left(R_{a}\right)$ of grit-blasted and cleaned substrates was measured with a roughness tester (HOMMELWERKE T8000, Hommelwerke $\mathrm{GmbH}$, Germany). Roughness was 2,2 $\pm 0,1 \mu \mathrm{m}$.

The APS facility used comprises a plasma gun (F4-MB, Sulzer Metco, Germany) managed by a six axis robot (IRB 1400, ABB, Switzerland). In the plasma gun, the torch generation was accomplished using argon as primary plasma gas and hydrogen as secondary plasma gas. Spray conditions used were the same for all feedstocks as detailed in table 3. Powders were fed into the plasma torch by pneumatic transport employing argon as carrier gas.

The microstructure of the obtained coatings was observed in a field-emission gun environmental scanning electron microscope (FEG-ESEM) (QUANTA 200FEG, FEI Company, USA), and their amorphous/crystalline character was determined by XRD. 
Table 3 Plasma spray conditions used

\begin{tabular}{cc}
\hline Parameter & Value \\
\hline Argon flow rate $(\mathrm{s} / \mathrm{pm})$ & 25 \\
Hydrogen flow rate $(\mathrm{s} / \mathrm{pm})$ & 15 \\
Intensity $(\mathrm{A})$ & 600 \\
Plasma average enthalpy $(\mathrm{MJ} / \mathrm{kg})$ & $30-35$ \\
Spraying distance $(\mathrm{mm})$ & 110 \\
Spraying velocity $(\mathrm{m} / \mathrm{s})$ & 1 \\
Powder mass flow $(\mathrm{g} / \mathrm{min})$ & 15 \\
\hline
\end{tabular}

3. Results and discussion

\subsection{Effect of powder particle size on the feedstock flowability}

Figure 4a plots the results of HR tests for the different glass powder fractions. As expected HR increases (flowability decreases) as the particle size of the powder is reduced. This is because when the frictional forces between particles increase the difference between the tapped (vibrated) powder density and the as-poured powder density also tends to rise. Free-flowing powders display HR lower than 1,25 [21]. Thus, samples can be considered as free-flowing powders except those with particles smaller than $150 \mu \mathrm{m}$ (BGGS3 and BGGS4). In fact, when the particle size of the powder becomes increasingly smaller the adhesion forces between particles overcame the gravity forces, which predominate for coarse particles. Findings obtained with the other test (Figure $4 \mathrm{~b}$ ) ratify the effect of the particle size on flowability: the finer the particle size of the powder the higher the angle of repose is, i.e there is a clear flowability decrease as particle size is reduced. According to literature, for angles below $30^{\circ}$ powder has good flowability, angles comprising $30-45^{\circ}$ give some cohesiveness, angles between $45-55^{\circ}$ lead to cohesiveness and for angles higher than $55^{\circ}$ powder displays remarkable cohesiveness $[22,23]$. The correlation of the data obtained from both flowability measurement tests was plotted in figure 4c. As observed there are three different flowability zones in function of the HR and angle of repose. Coarse fractions (BGGS, BGGS1 and BGGS2) are in the good flowability zone in comparison with the fine fractions (BGGS3 and BGGS4) that are in the some cohesiveness zone. From the data acquired, it is then possible to obtain a good correlation between the two methods in both zones confirming the validity of these simple techniques to assess the flowability of powder feedstocks to be used in APS processes. 

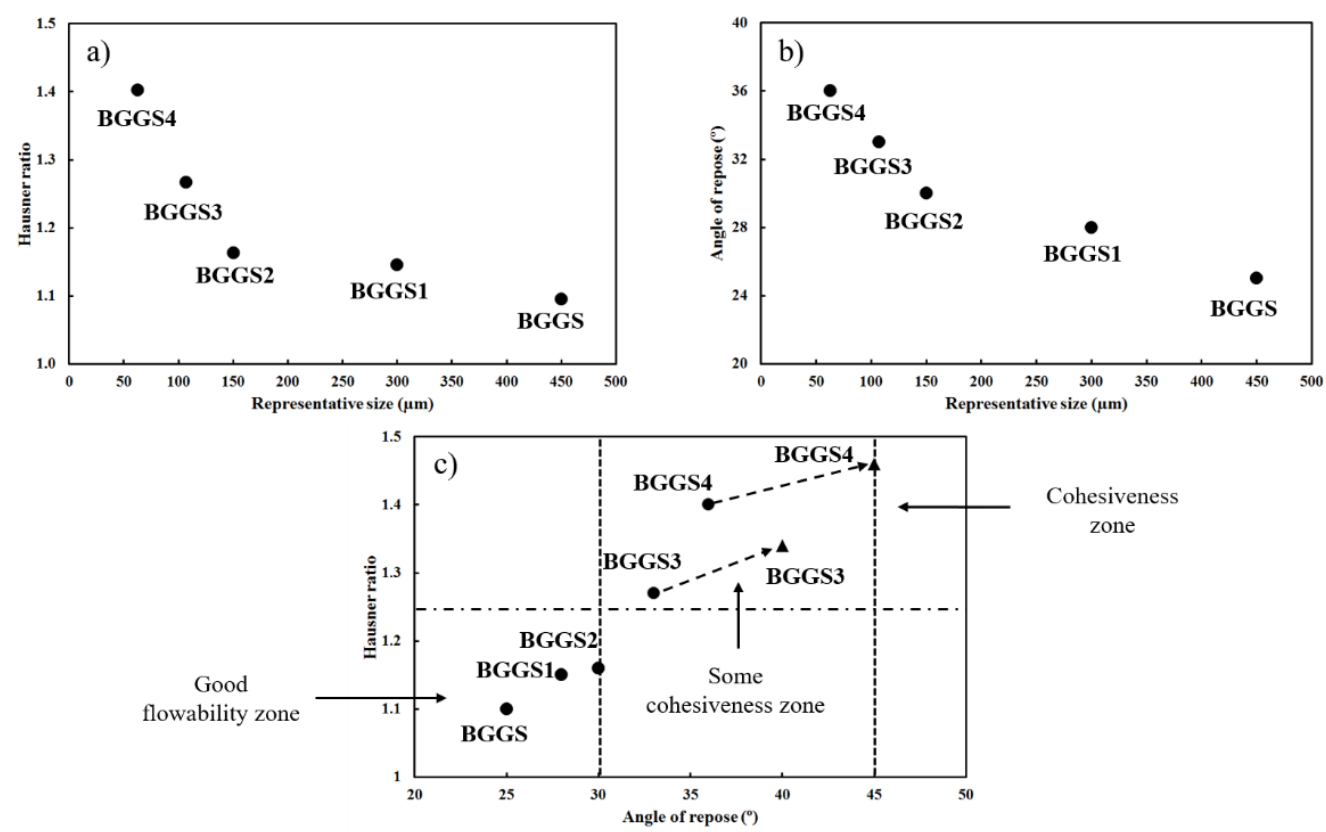

Figure 4 Flowability tests versus mean particle size of the tested glass powder fractions: (a) Hausner ratio, (b) Angle of repose and (c) Hausner ratio versus angle of repose for dry $(\bullet)$ and moist $(\Delta)$ powders

In addition flowability tests (HR and angle of repose) were also carried out with some samples which stayed inside the climatic chamber (at $20 \stackrel{\circ}{ } \mathrm{C}$ and $60 \%$ relative moisture) and for $24 \mathrm{~h}$ in order to allow the samples to adsorb their equilibrium moisture. The samples tested were BGGS3 and BGGS4, which corresponded to the smallest particle size fractions. Figure $4 \mathrm{c}$ collects the flowability findings (triangle dots) of these two samples. These data show a significant worsening of flowability (increasing of HR and angle of repose values) after a $24 \mathrm{~h}$ soaking time in the climatic chamber. This change in flowability can only be attributed to the fact that the bioactive glass powder samples are highly hygroscopic [18]. As expected, the amount of adsorbed water increases when particle size decreases, due to the increase of specific surface area. Adsorbed water on the powder surface markedly impairs the flowability of the samples, in particular of the finest powder due to the increasing of the adhesion forces associated with water [24]. As a consequence both samples shift to the cohesiveness zone in figure $4 \mathrm{c}$, specially the finest powder (BGGS4).

In an APS experiment, the powder feedstock can stay for some period of time (between 15-30 $\mathrm{min}$ ) in contact with room air inside the container of the plasma equipment before it is fed into the torch. That allows the powder to adsorb water. With the aim to assess the changes in water adsorbed with time and its effect on the flowability of the finest powder feedstock the water adsorbed inside the climatic chamber ( $20{ }^{\circ} \mathrm{C}, 60 \%$ relative moisture) as well as the angle of repose were monitored with time up to $8 \mathrm{~h}$. Figure 5 plots the variation of the adsorbed 
water and the angle of repose with the soaking time of the sample inside the climatic chamber.

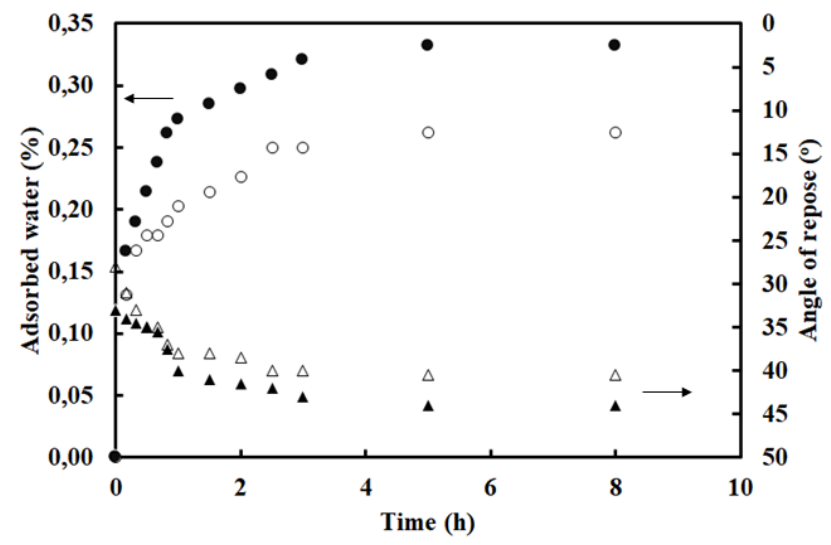

Figure 5 Variation of the adsorbed water and angle of repose of the finest powder fraction (BGGS4) with time exposure to $60 \%$ relative humidity air at $20{ }^{\circ} \mathrm{C}$. Bold points for sample without fluidiser and hollow points for sample with fluidiser

As it can be seen, there is a good parallelism between the amount of adsorbed water and the flowability of the powder. Thus as the water is adsorbed the flowability decreases being this decrease much more significant during the first hour of contact between the powder and the humid air. This is because the first layers of water dramatically increase the molecular adhesion forces by reducing particle surface asperities while the successive water layers become less efficient for this purpose [24]. The adsorbed water as well as the angle of repose seem to stabilise after $5 \mathrm{~h}$ of soaking time in the climatic chamber. From figure 5 it can be concluded that in 30 min the powder can adsorb more than $0,2 \%$ of water resulting in a significant increase of angle of repose from $33^{\circ}$ to $35,5^{\circ}$ and consequently in an impairing of flowability. In fact, the high cohesiveness rise observed in the BGSS4 sample after being in contact with room air for some time can block the feeding of this feedstock to the plasma plume.

\subsection{Effect of powder particle size on the thermal behaviour of the feedstock}

Figure 6 shows the XRD pattern of the BGGS fraction. The other powder fractions exhibited analogous patterns. As expected, this diffractogram corresponds to fully vitreous material. Thus, all fractions display amorphous structure without any devitrifying phase occurring during melting or crushing of the frit. Consequently, all BG powder fractions seem to be, at first, suitable to obtain bioactive glass coatings as reported elsewhere [25]. 


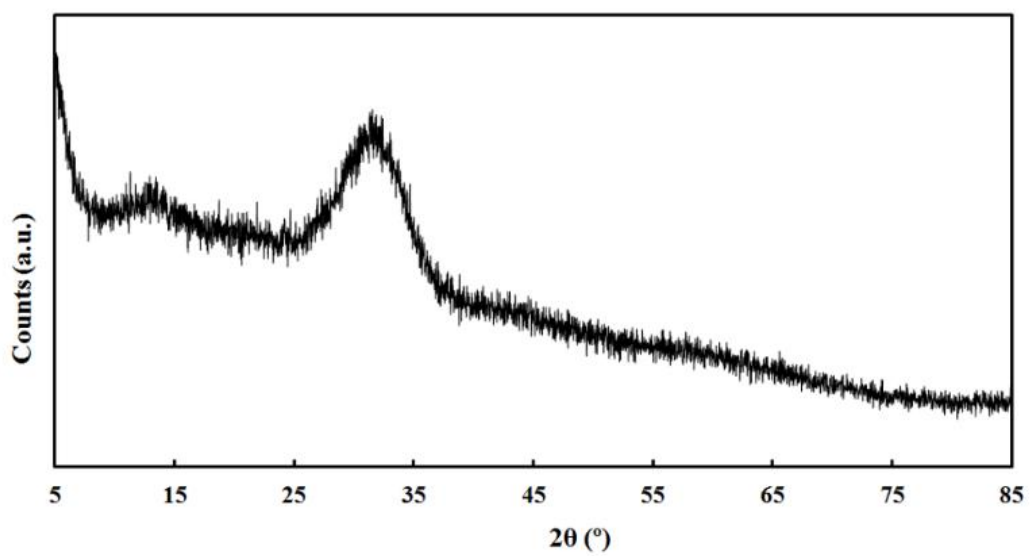

Figure 6 XRD pattern of BGGS powder fraction

The shrinkage-temperature diagram and the characteristic temperatures [20] obtained from heating microscope tests for BGGS, BGGS1, BGGS2 and BGGS3, are detailed in table 4 and figure 7, respectively.

No significant differences in the characteristic temperatures were observed except for the first shrinkage temperature $\left(T_{F S}\right)$. As it can be observed, the particle size defines when particles start sintering. Hence, the smaller the particle size, the lower the temperature at which shrinkage starts.

Table 4 Characteristic temperatures of BGGS, BGGS1, BGGS2 and BGGS3 fractions

\begin{tabular}{ccccc}
\hline Characteristic temperatures (을 & BGGS & BGGS1 & BGGS2 & BGGS3 \\
\hline First shrinkage $\left(\mathrm{T}_{\mathrm{FS}}\right)$ & 660 & 630 & 625 & 605 \\
Maximum shrinkage $\left(\mathrm{T}_{\mathrm{MS}}\right)$ & 730 & 710 & 700 & 690 \\
Softening point $\left(\mathrm{T}_{\mathrm{SP}}\right)$ & 1180 & 1170 & 1170 & 1170 \\
Half ball $\left(\mathrm{T}_{\mathrm{HB}}\right)$ & 1185 & 1180 & 1180 & 1175 \\
Flow point $\left(\mathrm{T}_{\mathrm{FP}}\right)$ & 1190 & 1185 & 1185 & 1180 \\
\hline
\end{tabular}

For all particle sizes, it can be observed that in the temperature range 700-1000 ${ }^{\circ} \mathrm{C}$ devitrification takes place and as a result sintering (shrinkage) stops. In order to identify the phases that crystallize, an amount of BG powder was heated on a ceramic substrate with a corundum layer to prevent the adhesion of both materials. The sample was heated at $25^{\circ} \mathrm{C} / \mathrm{min}$ to a maximum temperature of $800^{\circ} \mathrm{C}$, and the resulting material was quenched to avoid changes on cooling. XRD of this sample (Figure 8 ) shows a sodium calcium silicate phase with combeite structure $\left(\mathrm{Na}_{6} \mathrm{Ca}_{3} \mathrm{Si}_{6} \mathrm{O}_{18}\right)$ as major phase and of a sodium calcium phosphate phase with rhenanite structure $\left(\mathrm{NaCaPO}_{4}\right)$ as minor phase [26-28]. The corundum peak corresponds to the substrate used. From figure 7 it can be stated that particle size also influences the devitrification process. The smaller the particle size, the lower the temperature at which shrinkage stops as a consequence of the new formed crystals [29] as well as the lower the temperature at which sintering reinitiates. 


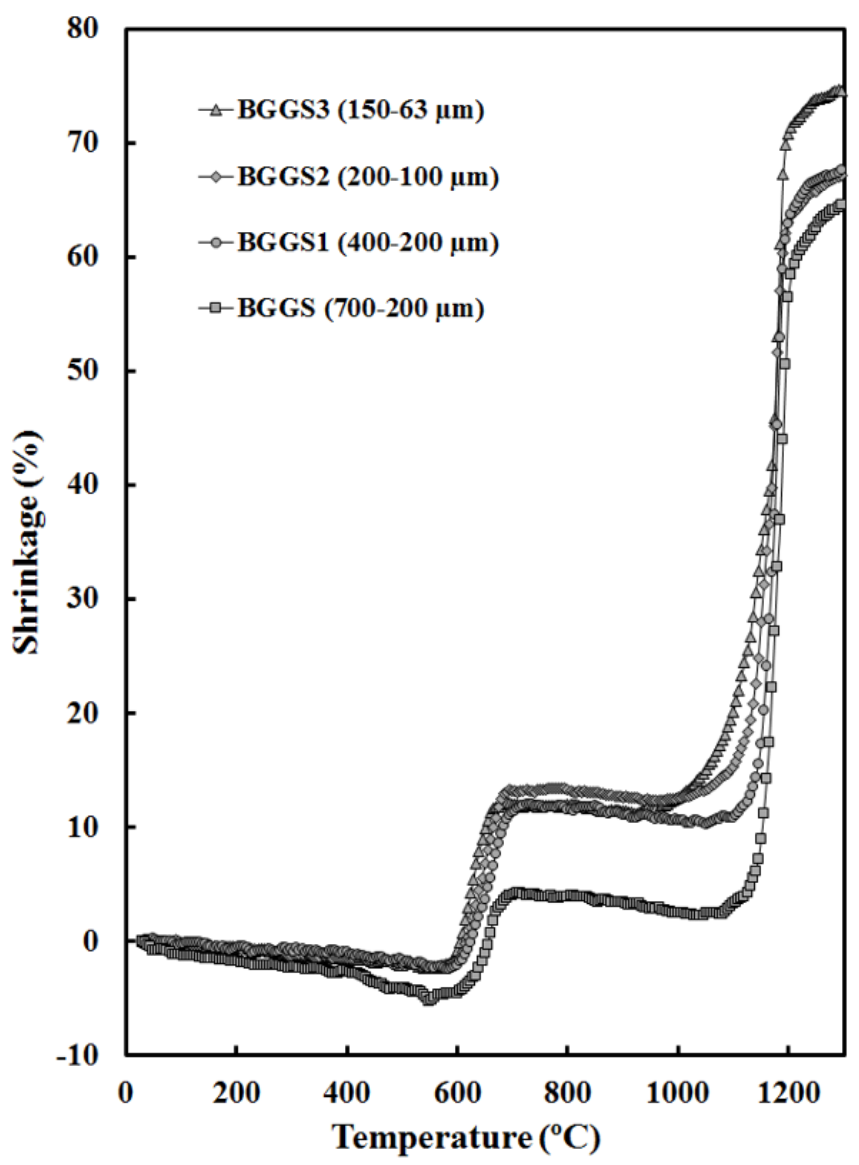

Figure 7 Shrinkage-temperature diagrams for BGGS, BGGS1, BGGS2 and BGGS3 powder fractions obtained in the heating microscope

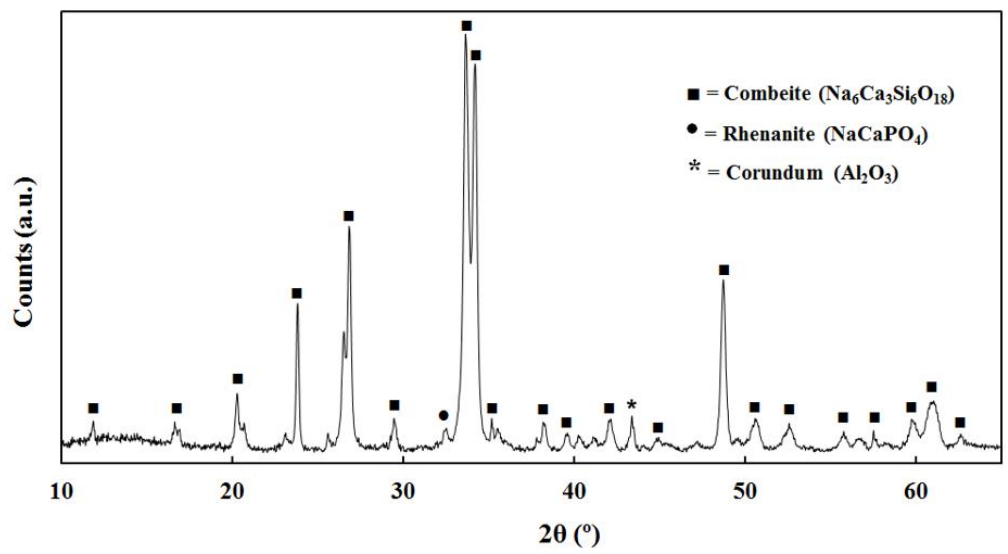

Figure 8 XRD pattern corresponding to the crystallised species at a peak temperature of $800 \stackrel{\circ}{\circ}$ 
The effect of particle size can be more easily observed in DTA/TG-DTG curves. Tests performed for BGGS and BGGS3 powder fractions are shown in figure 9. Curves are very similar; exothermic peaks start at lower temperature when the particle size is smaller. For the coarse fraction (BGGS), an endothermic effect corresponding to the elimination of the structural water $\left(T_{v}=180{ }^{\circ} \mathrm{C}\right)$ and another endothermic effect due to the glass transition $\left(T_{g 1}=520{ }^{\circ} \mathrm{C}\right)$ occur. These two endothermic peaks are followed by an exothermic peak due to the overlapping effect of the crystallisation of two different phases (combeite and rhenanite respectively), at $\mathrm{T}_{\mathrm{c} 1}=720 \stackrel{\circ}{\mathrm{C}}$ and $\mathrm{T}_{\mathrm{c} 2}=770 \stackrel{\circ}{\mathrm{C}}$ [26-28].

The formation of these crystalline phases is attributed to a glass phase separation that occurs after the glass transition. The process of glass phase separation is due to the high concentration of $\mathrm{Si}^{+4}$ and $\mathrm{P}^{+5}$ (high valence ions) into the starting glass [14,29]. These elements are glass network formers; hence, a rich silica phase and a rich phosphate phase are formed when temperature increases. Finally, melting occurs for a range of temperatures between $1000-1180^{\circ} \mathrm{C}$. In this temperature range there are two endothermic peaks $\left(\mathrm{T}_{\mathrm{m} 1}=1060^{\circ} \mathrm{C}\right.$ and $\left.\mathrm{T}_{\mathrm{m} 2}=1100^{\circ} \mathrm{C}\right)$ corresponding to the partial melting of the two crystalline phases formed. Besides, another endothermic peak is observed at a temperature of $\mathrm{T}_{\mathrm{g} 2}=840^{\circ} \mathrm{C}$ which is attributable to a second glass transition as reported elsewhere [26-28].

$\longrightarrow$ BGGS $(700-200 \mu \mathrm{m})$

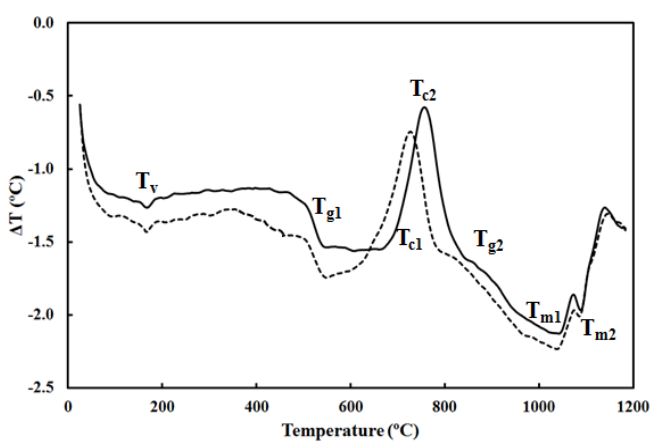

BGGS3 $(150-63 \mu \mathrm{m})$

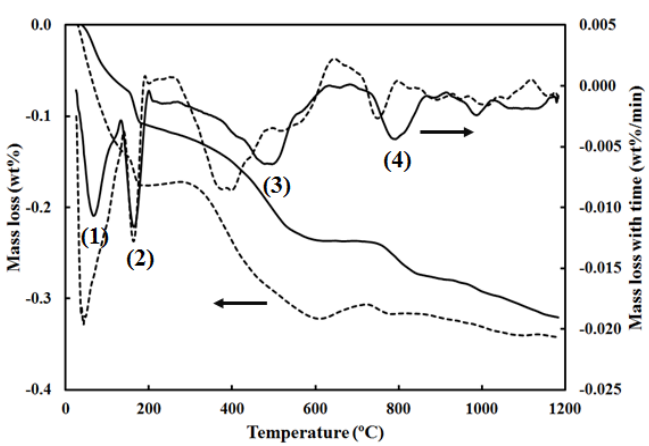

Figure 9 DTA/TG-DTG tests performed for the BGGS and BGGS3 powder fractions. Figure 9a: DTA tests. Figure 9b: TG/DTG tests.

In the case of the fine fraction (BGGS3), the effects mentioned also take place, but the crystallisation peak occurs at lower temperature.

The TG-DTG figures, in the case of the coarse fraction (BGGS), showed different weight losses. The first one (1) takes place at $80{ }^{\circ} \mathrm{C}$ and it is due to the evaporation of the free water. A second weight loss (2) occurs at $175 \stackrel{\circ}{\circ}$ because of the elimination of the structural water of the powder sample. In addition, a weight loss occurs (3) at $500{ }^{\circ} \mathrm{C}$ due to the elimination of the $-\mathrm{OH}$ groups and then, from $770 \stackrel{\circ}{\circ}$ onwards (4), the sample loses weight probably due to partial evaporation of $\mathrm{Na}_{2} \mathrm{O}$ [14,26-29]. For the fine fraction (BGGS3), 
the above effects also take place, but at lower temperatures. On comparing the obtained DTGs, the peak of free water elimination (1) is more marked for the BGGS3 glass due to its high moisture uptake ability (higher surface area). The DTA/TG-DTG tests for the remaining powder fractions are very similar.

\subsection{Microstructure of coatings obtained from the different glass powder fractions}

All the samples of glass powder fractions were used as APS feedstocks to obtain the corresponding coatings. Table 5 describes some characteristics of the obtained coatings.

FEG-ESEM micrographs are detailed in figure 10. Coarser fractions (BGGS and BGGS1) gave no rise to coatings. The particles of these fractions could not properly melt to adhere on the substrate due to their coarse size as well as to the extremely short soaking time into the plasma plume. On the other hand, when BGGS2 and BGGS3 fractions were sprayed, coatings were obtained.

Table 5 Characteristics of the obtained coatings

\begin{tabular}{|c|c|c|}
\hline Powder fraction & Coating & Observation \\
\hline BGGS & $\begin{array}{l}\text { No coating was } \\
\text { obtained }\end{array}$ & Particles cannot adhere \\
\hline BGGS1 & $\begin{array}{l}\text { No coating was } \\
\text { obtained }\end{array}$ & $\begin{array}{l}\text { Similar to BGGS } \\
\text { fraction }\end{array}$ \\
\hline BGGS2 & Coating was obtained & $\begin{array}{c}\text { cracked and porous } \\
\text { surface }\end{array}$ \\
\hline BGGS3 & Coating was obtained & $\begin{array}{l}\text { Similar to BGGS2 } \\
\text { fraction }\end{array}$ \\
\hline BGGS4 & $\begin{array}{l}\text { No coating was } \\
\text { obtained }\end{array}$ & No powder flowability \\
\hline
\end{tabular}
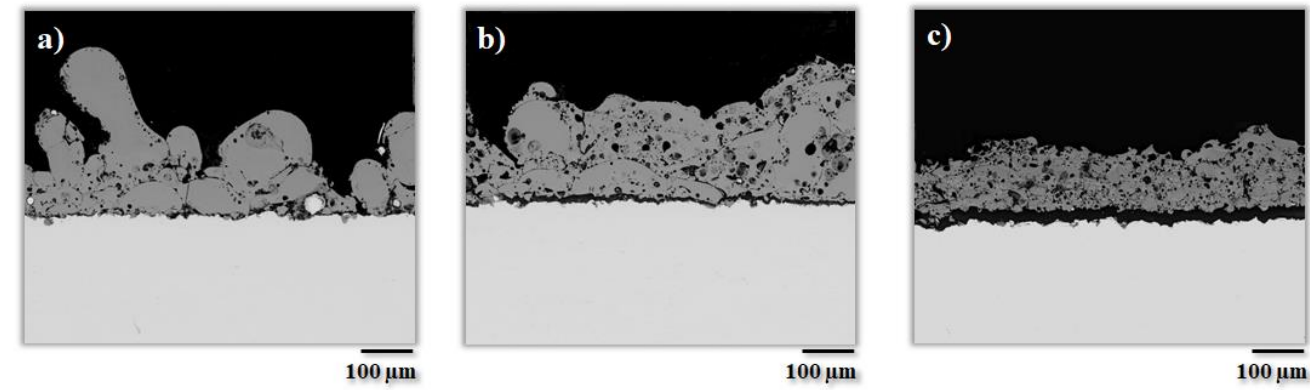

Figure 10 FEG-ESEM micrographs of the obtained coatings with (a) BGGS2, (b) BGGS3 and (c) BGGS4 (with $1 \mathrm{wt} \%$ fluidiser) powder fractions 
Figure 10 shows that the coatings display the typical splat-like microstructure of plasma sprayed coatings, with peak and valley surfaces and cracks and pores inside the splat matrix [30]. Even so, the coating from the BGGS3 fraction is less irregular than that obtained from the BGGS2 fraction as a consequence of the smaller particle size of sample BGGS3. Unlike other APS coatings obtained from highly refractory crystalline oxides such as alumina or zirconia, the liquid phase sintering occurring during the thermal treatment of glass powders gives rise to an abundance of round pores inside the coating. These findings confirm the results obtained by Cannillo et al. [10]. According to these researchers the round particles visible on the coating surface, especially in the BGGS2 coating, are the consequence of semi-melted particles in the plasma plume. Thus if the starting glass particle is too coarse the core of the particle, which is not melted, prevents the flattening of the particle, which preserves its sphere-like appearance.

For the finest particle size fraction (sample BGGS4) no coating was obtained either. This was due to its high ability of adsorbing water, which dramatically reduces the flowability of this powder preventing the feeding of the sample to the plasma by means of the pneumatic conveying system.

In order to solve the flowing problem of BGGS4, a fluidiser was added to the powder. The fluidiser used was hydrophobic fumed silica (Aerosil R812, Evonik Industries, Germany) with a mean particle size of $7 \cdot 10^{-3} \mu \mathrm{m}$ and a specific surface area of $260 \pm 30 \mathrm{~m}^{2} / \mathrm{g}$. This fluidiser was chosen from previous experience on flowability enhancement with other cohesive powders. A homemade high-intensity knife-type mixer was employed to mix the fluidiser with the fine powder. Several tests were performed and the best results were obtained for a mixing time of $5 \mathrm{~min}$ and a concentration of fluidiser in the powder of 1 wt\%. FEG-ESEM micrographs of the BGGS4 fraction with fluidiser are detailed in figure 11. Micrograph (a) shows the powder fraction mixed with fluidiser and micrograph (b) shows (at high magnification) the nanometric particles of fluidiser onto the surface of the glassy powder.
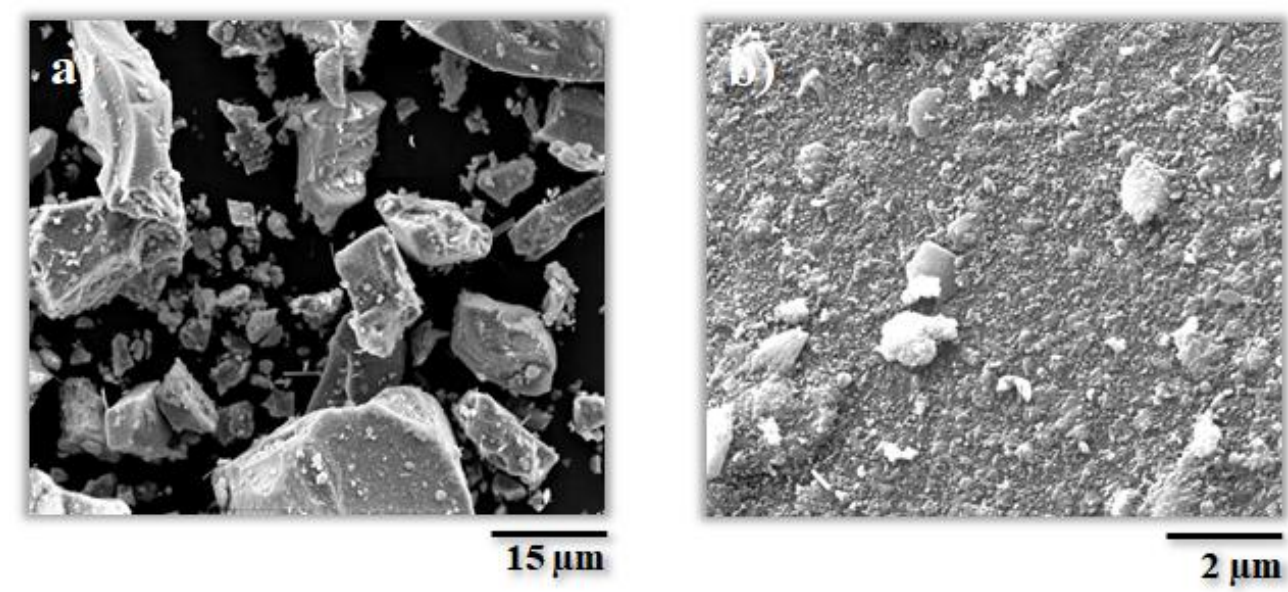

Figure 11 FEG-ESEM micrographs of the BGGS4 powder fraction with 1 wt $\%$ fluidiser 
In order to know if the use of the fluidiser could affect the water adsorption ability of the glass powder, moisture uptake with time and the angle of repose were determined for BGGS4 powder containing fluidiser in the same way as set out with the sample of BGGS4 fraction without fluidiser. Furthermore, Hausner ratio (HR) values of the BGGS4 powder fraction with and without fluidiser are shown in figure 5 and table 6 , respectively.

Table 6 Hausner ratio variation with fluidiser content for BGGS4 powder fraction

\begin{tabular}{ccc}
\hline Powder fraction & Fluidiser content (wt \%) & Hausner ratio (HR) \\
\hline \multirow{2}{*}{ BGGS4 } & $0 \%$ & $1,40 \pm 0,03$ \\
& $1 \%$ & $1,30 \pm 0,01$ \\
\hline
\end{tabular}

HR decreased when $1 \mathrm{wt} \%$ fluidizer was added to the BGGS4 powder, that is, powder flowability improved. On the other hand, as it can be seen in figure 5 (hollow circles), the maximum values of the moisture uptake and the angle of repose $\left(\alpha_{M}\right)$ of the powder also decreased when $1 \mathrm{wt} \%$ fluidiser was added, confirming the hydrophobic character of this additive. The reduction in water adsorption with time results in a parallel decrease of the angle of repose (hollow triangles), i.e. an improvement of flowability. Consequently, the powder with fluidiser could be led into the plasma plume, allowing to obtain a coating. The FEG-ESEM micrograph of this coating is shown in figure 10c. The microstructure is similar to that of the BGGS2 and BGGS3 coatings; but, in this case, the surface is much more regular as a consequence of the smaller particle size of the starting powder.

As the coatings showed no or little adherence to the substrate, they were XRD analysed. The obtained XRD patterns corresponded to amorphous materials, as depicted in figure 12 .

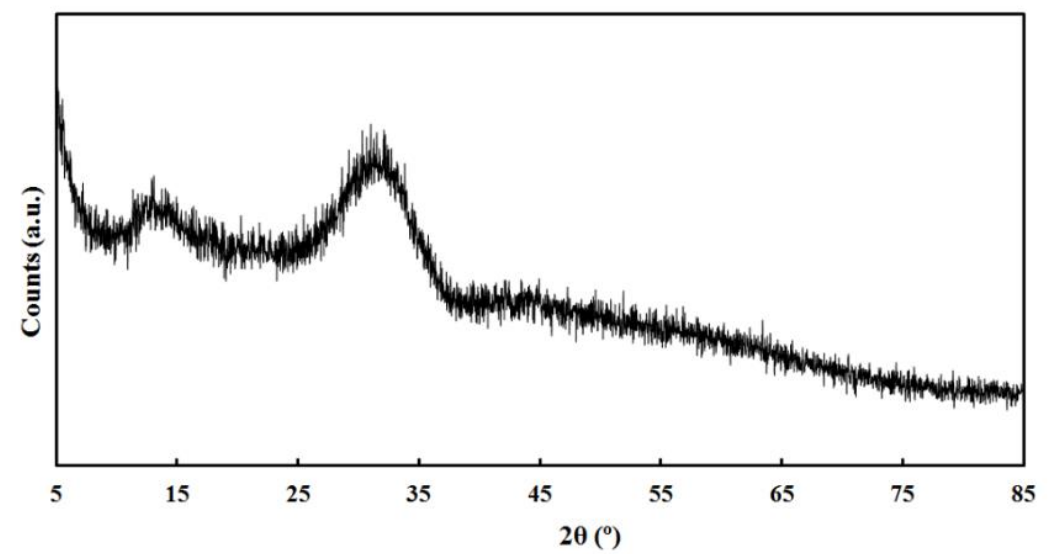

Figure 12 XRD pattern of the obtained coating starting from BGGS3 powder fraction

Hence, the amorphous structure of the feedstocks was preserved in the obtained coatings. These findings demonstrate that the crystalline phases that 
appear during the thermal treatment and started to melt at temperatures between $1000^{\circ} \mathrm{C}$ and $1100^{\circ} \mathrm{C}$ (Figure 9), completely melt in the plasma torch as a consequence of the extremely high temperatures reached (higher than $\left.10000^{\circ} \mathrm{C}\right)$. Thus, despite the effect of the particle size of the glass powder feedstock on the crystallisation phenomena the huge energy provided by the plasma ensures the melting of any of the crystalline phases newly formed when heating the glass. Besides, the rapid cooling that takes place after coating deposition impedes any devitrifying process, which can occur during the cooling of the melt for the powder feedstock.

\section{Conclusions}

Bioactive glass powder fractions with different particle size were prepared by melting, milling and sieving. The powders, used as feedstocks for APS, showed fully amorphous character as revealed by XRD analysis.

Thermal behaviour of the feedstocks was highly dependent on their particle size. All fractions underwent the same processes (weight losses, glass transitions, crystallisations, etc). However, the smaller the particle size the lower the temperature at which most of these processes took place.

The finest powder fraction showed highly hygroscopic behaviour, due to its higher specific surface area. Consequently, when this powder fraction adsorbs water from indoor air its flowability is seriously impaired.

With regard to the deposition of the powder fractions, at first coatings were only obtained from intermediate fractions BGGS2 (200-100 $\mu \mathrm{m})$ and BGGS3 (150$63 \mu \mathrm{m}$ ). Thus, when coarse fractions (BGGS and BGGS1) were sprayed, no coating was obtained due to the low melting degree of the larger powder particles as soaking time in the plasma plume is extremely low. The finest powder fraction (BGGS4) needed a hydrophobic fluidiser in order to improve its flowability and reduce its water adsorption ability. When $1 \mathrm{wt} \%$ of fluidiser was added it was possible to obtain a coating by APS. All the obtained coatings showed amorphous character which evidenced the melting of any crystalline phase that could appear during APS deposition. The microstructure of the obtained coatings corresponded to the typical splat-like matrix of APS coatings containing pores and cracks. Nevertheless the coarser the feedstock particle size the more irregular the coating surface was as a consequence of the insufficient particle melting which prevented the flattening of some particles when impacting on the substrate. The abundance of round pores in the microstructure is consequence of a liquid phase sintering mechanism operating during the thermal treatment of glassy particles.

Concerning the adherence between coatings and substrates, no consideration was made since the aim of this work was to determine the effect of the particle size. However, this is already under study by using a bond coat as well as testing different metallic substrates. 


\section{Acknowledgements}

Authors wish to acknowledge the University Jaume I of Castellon for the support in the RECUBIO project (P1-1B2013-69) and Fritta S.L. for the support in feedstock synthesis.

\section{References}

[1] J.A. Juhasz, S.M. Best, Bioactive ceramics: processing, structures and properties, J. Mater. Sci. 47 (2012) 610-624.

[2] P.N. De Aza, A.H. De Aza, P. Pena, S. De Aza, Bioactive glasses and glassceramics, Bol. Soc. Esp. Ceram. Vidr. 46 (2007) 45-55.

[3] J.A. Helsen, J. Proost, J. Schrooten, G. Timmermans, E. Brauns, J. Vanderstraeten, Glasses and bioglasses: synthesis and coatings, J. Eur. Ceram. Soc. 17 (1997) 147-152.

[4] A. Sola, D. Bellucci, V. Canillo, A. Cattini, Bioactive glass coatings: a review, Surf. Eng. 27 (2011) 560-573.

[5] V. López, M. Vicent, E. Bannier, E. Cañas, A.R. Boccaccini, L. Cordero, E. Sánchez, $45 \mathrm{~S} 5$ bioactive glass coating by atmospheric plasma spraying obtained from feedstocks prepared by different routes, J. Mater. Sci. 49 (2014) 7933-7942.

[6] V.J. Shirtliff, L.L. Hench, Bioactive material for tissue engineering, regeneration and repair, J. Mater. Sci. 38 (2003) 4697-4707.

[7] M. Monsalve, H. Ageorges, E. Lopez, F. Vargas, F. Bolivar, Bioactivity and mechanical properties of plasma-sprayed coatings of bioglass powders, Surf. Coat. Technol. 220 (2013) 60-66.

[8] G. Bolelli, D. Bellucci, V. Canillo, L. Lusvarghi, A. Sola, N. Stiegler, P. Müller, A. Killinger, R. Gadow, L. Altomare, L. De Nardo, Suspension thermal spraying of hydroxyapatite: Microstructure and in vitro behaviour, Mat. Sci. Eng. C 34 (2014) 287-303.

[9] T.M. Lee, E. Chang, B.C. Wang, C.Y. Yang, Characteristics of plasma-sprayed bioactive coatings on Ti-6Al-4V alloy: an in vitro study, Surf. Coat. Technol. 79 (1996) 170-177.

[10] V. Canillo, A. Sola, Different approaches to produce coatings with bioactive glasses: enamelling vs plasma spraying, J. Eur. Ceram. Soc. 30 (2010) 20312039.

[11] G. Goller, The effect of bond coat on mechanical properties of plasma sprayed bioglass-titanium coatings, Ceram. Int. 30 (2004) 351-355.

[12] E. Verné, M. Ferraris, A. Ventrella, L. Paracchini, A. Krajewski, A. Ravaglioli, Sintering and plasma spray deposition of bioactive glass-matrix composites for medical applications, J. Eur. Ceram. Soc. 18 (1998) 363-372. 
[13] J.R. Davis, Handbook of thermal spray technology, first ed., ASM International, The USA, 2004.

[14] J.M. Fernández Navarro, El vidrio (The glass), third ed., Consejo Superior de Investigaciones Cerámicas (CSIC), Spain, 2003.

[15] D. Alvarez-Estrada, Formación y eliminación de burbujas en vidriados cerámicos (Formation and removal of bubbles in ceramic glazes), IV Conference of Week Ceramic Studies of the Spanish Ceramic Society, Madrid, 1962, 511-526.

[16] M. Vicent, E. Bannier, R. Benavente, M.D. Salvador, T. Molina, R. Moreno, E. Sánchez, Influence of the feedstock characteristics on the microstructure and properties of $\mathrm{Al}_{2} \mathrm{O}_{3}-\mathrm{TiO}_{2}$ plasma-sprayed coatings, Surf. Coat. Technol. 220 (2013) 74-79.

[17] M. Vicent, E. Bannier, R. Moreno, M.D. Salvador, E. Sánchez, Atmospheric plasma spraying coatings from alumina-titania feedstock comprising bimodal particle size distributions, J. Eur. Ceram. Soc. 33 (2013) 3313-3324.

[18] A.C. Popa, V.M.F. Marques, G.E. Stan, M.A. Husanu, A.C. Galca, C. Ghica, D.U. Tulyaganov, A.F. Lemos, J.M.F. Ferreira, Nanomechanical characterization of bioglass films synthesized by magnetron sputtering, Thin Solid Films 553 (2014) 166-172.

[19] S. Mestre, E. Bou, P. Quereda, A. Barba, Using the hot stage microscope for estimating frit sealing temperature, Ceram. Forum Int. 78 (2001) 36-39.

[20] M.J. Pascual, L. Pascual, A. Durán, Determination of the viscosity-temperature curve for glasses on the basis of fixed viscosity points determined by hot stage microscopy, Phys. Chem. Glasses 42 (2001) 61-66.

[21] J.L. Amorós, A. Blasco, J.E. Enrique, F. Negre, Características de polvos cerámicos para prensado, Bol. Soc. Esp. Ceram. Vidr. 26 (1987) 31-37.

[22] D. Geldart, E.C. Abdullah, A. Hassanpour, L.C. Nwoke, I. Wouters, Characterization of powder flowability using measurement of angle of repose, China Part. 4 (2006) 104-107.

[23] A.C. Wong, Use of angle of repose and bulk densities for powder characterization and the prediction of minimum fluidization and minimum bubbling velocities, Chem. Eng. Sci. 57 (2002) 2635-2640.

[24] P.J. Sherrington, R. Oliver, Granulation, first ed., Heyden, London, 1981.

[25] O.P. Filho, G.P. LaTorre, L.L. Hench, Effect of crystallization on apatite-layer formation of bioactive glass 45S5, J. Biomed. Mater. Res. B 30 (1996) 509514.

[26] L. Lefebvre, J. Chevalier, L. Gremillard, R. Zenati, G. Thollet, D. BernacheAssolant, A. Govin, Structural transformations of bioactive glass $45 \mathrm{~S} 5$ with thermal treatments, Acta Mater. 55 (2007) 3305-3313.

[27] L. Lefebvre, L. Gremillard, J. Chevalier, R. Zenati, D. Bernache-Assolant, Sintering behaviour of $45 S 5$ bioactive glass, Acta Biomater. 4 (2008) 18941903. 
[28] O. Bretcanu, X. Chatzistavrou, K. Paraskevopoulos, R. Conradt, I. Thompson, A.R. Boccaccini, Sintering and crystallisation of 4555 Bioglass $^{\circledR}$ powder, J. Eur. Ceram. Soc. 29 (2009) 3299-3306.

[29] A.R. Boccaccini, Q. Chen, L. Lefebvre, L. Gremillard, J. Chevalier, Sintering, crystallisation and biodegradation behaviour of Bioglass ${ }^{\circledR}$-derived glassceramic, Faraday Discuss. 136 (2007) 27-44.

[30] L. Pawlowski, The science and engineering of thermal spray coatings, second ed., John Wiley and Sons, Great Britain, 2008. 
ARTículo 2 



\title{
In vitro study of bioactive glass coatings obtained by atmospheric plasma spraying
}

\author{
Eugeni Cañas, Alina Grünewald, Rainer Detsch, María José Orts, Enrique \\ Sánchez, Aldo R. Boccaccini
}

Boletín de la Sociedad Española de Cerámica y Vidrio (2020), In Press

\section{https://doi.org/10.1016/j.bsecv.2020.06.004}

Este trabajo aborda un estudio completo de la bioactividad de recubrimientos de vidrio bioactivo depositados mediante proyección térmica por plasma atmosférico. Se han caracterizado la microestructura, la adherencia, las fases cristalinas y la bioactividad de los recubrimientos obtenidos. También se ha estudiado la formación de hidroxiapatita carbonatada siguiendo un protocolo estándar y se ha evaluado la respuesta in vitro de los recubrimientos mediante su incubación con osteoblastos humanos (células MG-63).

Los recubrimientos obtenidos han mostrado una microestructura típica de recubrimientos de vidrio. Tras la inmersión en fluido biológico simulado, se ha comprobado que el recubrimiento es capaz de desarrollar una capa superficial de hidroxiapatita carbonatada, aunque la velocidad de aparición de esta capa es menor que la observada para el polvo de vidrio de partida. El ensayo de cultivo celular ha mostrado un crecimiento multidireccional de las células MG63, dando lugar a un buen contacto entre las células y la superficie del recubrimiento. Este estudio ha confirmado un efecto positivo de los recubrimientos en términos de bioactividad de la superficie y, lo que es más interesante, ha demostrado una adecuada interacción célula-material sobre la superficie del recubrimiento. 

Boletín de la Sociedad Española de Cerámica y Vidrio (2020), In Press

\title{
In vitro study of bioactive glass coatings obtained by atmospheric plasma spraying
}

\author{
E. Cañas ${ }^{a \star}$, A. Grünewald ${ }^{b}$, R. Detsch ${ }^{b}$, M.J. Orts ${ }^{a}$, E. Sánchez ${ }^{a}$, A.R. \\ Boccaccini ${ }^{\text {b* }}$ \\ a Instituto de Tecnología Cerámica (ITC), Universidad Jaume I, Castellón, Spain \\ b Institute of Biomaterials, University of Erlangen-Nuremberg, Erlangen, Germany \\ * Corresponding authors
}

\begin{abstract}
This research has addressed a complete study of the bioactivity of bioactive glass coatings obtained by atmospheric plasma spraying. The coatings have been characterised in terms of microstructure, adhesion, crystalline phases and bioactivity. Hydroxycarbonate apatite formation was also monitored following a standard protocol and the in-vitro cell response was evaluated by human osteoblast-like cells (MG-63 cells) incubation.

The obtained coatings shown a microstructure typical of glass coatings. A simulated body fluid test proved that coatings are capable of developing a surface layer of hydroxycarbonate apatite whereas the appearance of this phase takes place at a longer time than that observed for the powder feedstock. Cell-culture test showed multidirectional growth of MG-63 cells which promoted good contact between cells and the surface of the coating. This study has confirmed a positive effect of the coatings in terms of surface bioactivity and, more interestingly, it has proven an adequate cell-material interaction on the coating surface.
\end{abstract}

Keywords: Bioactive glass powder; Atmospheric plasma spraying; Bioactive glass coatings; Simulated Body Fluid; Cell culture test

\section{Introduction}

Atmospheric Plasma Spraying (APS) is a highly employed technique to produce coatings from powder feedstocks for a wide range of applications, such as biological coatings from hydroxyapatite feedstocks [1]. Moreover, with the development of bioactive glasses (BGs), this technique has also become promising for obtaining coatings from this type of materials [1-3]. The reasons for this growing interest in such coatings are: i) the glass coatings obtained preserve the amorphous structure that gives rise to a higher bioactivity than that of hydroxyapatite, without the need for any treatment after deposition, ii) easier control of coatings' morphology, thickness and structure, and hence of coatings' properties [1]. 
Thus, literature shows numerous recent works where thermal spray conditions have been optimized in order to obtain coatings with good mechanical (adhesion to the substrate) and functional properties (bioactivity). Many of these works use the Bioglass ${ }^{\circledR}$ composition developed by Hench et al. commonly called 45S5 [4,5]. However, other compositions derived from 45S5 Bioglass ${ }^{\circledR}$ have also been developed in order to modify the melting ability of the glass during thermal spraying or the final bioactivity of the glass coating [6-9].

Early studies on plasma sprayed BG coatings used glass powder obtained by means of the conventional technique of "melting and crushing". It has been shown that the projection was subordinated to the fluidity of the powder feedstock employed, which limited the possibility of feeding micron-sized powders of poor flowability [10]. For this reason, recent research was carried out using glass powder suspensions as plasma feedstock, which correspond to the technique known as Suspension Plasma Spraying (SPS) $[11,12]$. In this case, it is possible to use glass powder with a micron or even submicron particle size, although suspensions of non-aqueous nature must be used for this purpose to avoid glass leaching [13]. The use of liquid precursors of bioactive glass known as the Solution Precursor Plasma Spraying (SPPS) technique is a much more recent development [14]. Although the preparation of bioactive glasses by the sol-gel technique is quite common, the use of colloidal precursors in plasma spraying is a very recent approach [15-17]. This thermal spraying technique is especially interesting because it greatly simplifies the feedstock preparation process, as the preparation of the glass powder is not necessary, with the consequent savings of time and energy and increment of feedstock purity. Recently published results are promising regarding the microstructure and properties of the $B G$ coatings obtained $[18,19]$.

Previous research efforts have focused on the optimization of the feedstock characteristics, either solid or liquid, as well as on the spraying conditions in order to design an adequate microstructure in the final coating that allows coatings with a good adherence to the substrate as well as high bioactivity to be obtained. Although results are promising, BG coatings suffer poor adhesion while the bioactivity is quite acceptable. However, the determination of bioactivity has been carried out, in most cases only by means of simulated body fluid (SBF) tests [2,11,20,21], monitoring the formation of hydroxyapatite on the surface. Although a SBF test represents a simple and quick way of assessing coating bioactivity, a more completed in-vitro characterisation is necessary to address the ability of the coating to form bone tissues. To the best of our knowledge, very few works about cell tests on plasma-sprayed bioactive glass coatings have been performed [22-24]. Therefore, the capacity of cell-material response of this type of coatings as well as the relationship between coating microstructure and biological response are still scarcely understood.

From the foregoing, it is concluded that there is a need to carry out a more thorough evaluation of the cell biology response to bioactive glass coatings obtained by plasma spraying. Hence, this research has been carried out with the aim of: i) developing and characterising a bioactive glass coating by 
atmospheric plasma spraying from glass powder with an adequate microstructure and adherence to the substrate; ii) determining and monitoring its bioactivity over time by means of in-vitro SBF and cell culture tests; and iii) relating the biological response results with the microstructural characteristics of the resulting coating.

\section{Experimental}

\subsection{Bioactive glass powder feedstock preparation}

A powder feedstock of $45 \mathrm{~S} 5$ bioactive glass referred as $\mathrm{BG}$ sample was prepared by melting a mixture of analytical grade $\mathrm{SiO}_{2}, \mathrm{Ca}_{3} \mathrm{PO}_{4}, \mathrm{NaCO}_{3}$ and $\mathrm{CaCO}_{3}$ in a home-made rotatory furnace as shown in a previous works [10]. The resulting melt was then quenched in water obtaining the frit. The chemical composition of the frit determined by wavelength dispersive $\mathrm{X}$-ray fluorescence spectrometry (AXIOS, PANalytical, Netherlands) was (in wt\%): 47,6 $\mathrm{SiO}_{2}, 5,3$ $\mathrm{P}_{2} \mathrm{O}_{5}, 23,1 \mathrm{CaO}$ and $24,0 \mathrm{Na}_{2} \mathrm{O}$ which is very close to the nominal $45 \mathrm{~S} 5 \mathrm{BG}$ composition. The frit was subsequently processed according to the following steps: dry grinding in a hammer mill and sieving the resulting material to obtain a powder with a maximum particle size of $63 \mu \mathrm{m}$. Figure $\mathrm{S} 1$ of the Appendix/Supplementary information displays the morphology and the phase nature of the particles.

In order to enhance flowability of the glass powder feedstock, a hydrophobic fumed silica-based fluidiser (Aerosil R812, Evonik Industries, Germany) was added to the powder as previously reported [10]. The fluidiser was mixed with the fine powder by means of a high-intensity knife-type mixer. This fluidiser can be observed in the previous work [10], partially coating the glass particles.

\subsection{Bioactive glass coatings deposition and characterisation}

The next step was the deposition of the bioactive glass powder by Atmospheric Plasma Spraying (APS). In order to do so, a thermal spraying facility was used, whose details are reported in [10]. The spraying conditions employed are listed in table 1. Two different flow rates of argon were used; 25 slpm (standard litre per min) (BGC25 experiment) and $38 \mathrm{slpm}$ (BGC38 experiment). Comparing both conditions, the mixture with $25 \mathrm{slpm}$ argon is more energetic than the other one, as hydrogen is less diluted and consequently, after the ionization of the mixture, the plasma plume released possesses a higher enthalpy and, henceforth, a greater melting capacity for the particles [25].

Contrarywise the mixture of 38 slpm argon gives a higher momentum to the injected particles (particles at impact get more splashed) than the other mixture as both argon and total gas flow rates are greater. Moreover, the higher momentum results in less residence time of the particles inside the plasma plume and hence they arrive at the substrate less molten. AISI type 304 
stainless steel disks with $25 \mathrm{~mm}$ of diameter were used as substrates. Before the deposition of the coatings, the substrates were grit-blasted with black corundum and cleaned with ethanol, as reported in a previous work [10]. Only one face of the substrates was prepared and hence coated.

Table 1 Plasma spray conditions used to spray the coating

\begin{tabular}{cc}
\hline Spraying parameters & Bioactive glass coatings \\
\hline Argon flow rate $(\mathrm{s} / \mathrm{pm})$ & $25 / 38$ \\
Hydrogen flow rate $(\mathrm{s} / \mathrm{pm})$ & 15 \\
Intensity $(\mathrm{A})$ & 600 \\
Spraying distance $(\mathrm{mm})$ & 110 \\
Spraying velocity $(\mathrm{m} / \mathrm{s})$ & 1 \\
Powder mass flow $(\mathrm{g} / \mathrm{min})$ & 15 \\
Nozzle diameter $(\mathrm{mm})$ & 2 \\
\hline
\end{tabular}

The microstructure of the obtained coatings was observed in a field-emission gun environmental scanning electron microscope (FEG-ESEM) (QUANTA 200FEG, FEI Company, USA) using the backscattering electron detector signal under high vacuum conditions. Coating thickness and porosity were estimated by image analysis (Microlmage) at 2000x magnifications from FEG-ESEM pictures. 20 FEG-ESEM images were examined, and the findings averaged. Moreover, the nature of the coatings (amorphous or crystalline) was determined by X-ray diffraction (XRD; Advance diffractometer, Bruker Theta-theta, Germany). The XRD analysis was done using $\mathrm{Cu} \mathrm{Ka}$ radiation at a working power of $30 \mathrm{kV}$ and $40 \mathrm{~mA}$. In addition, a range of $2 \theta$ between $10^{\circ}-80^{\circ}$ was employed, with a step size of $0,02^{\circ}$ and a scanning speed of $0,5 \mathrm{~s} / \mathrm{step}$. Finally, the adhesion strength was determined by the pull-off method known as tensile adhesion test (TAT) following the ASTM-C633 standard. For this examination, 3 samples of each coating were tested using a universal testing machine (Instron 5889, Instron, UK). The test was carried out at a constant rate of crosshead travel of $1,67 \cdot 10^{-5} \mathrm{~m} / \mathrm{s}$, recording the tensile load at which the rupture of the coating occurred (maximum tensile load). From the recorded load, the adhesion of the coatings was determined, and the obtained results were averaged.

\subsection{SBF tests}

The bioreactivity of both the powder developed and the coatings was studied by immersing them in Simulated Body Fluid (SBF) following a standard protocol [26]. First, SBF was prepared following the method of Kokubo [27], and then the powders and coatings were soaked in SBF inside plastic vessels.

For the powders, a ratio of $1,5 \cdot 10^{-3} \mathrm{~g}$ of powder per $\mathrm{cm}^{3}$ of SBF was used. The vessels containing the powders were incubated inside a water bath at $36,5 \pm 0,5^{\circ} \mathrm{C}$ during $1 \mathrm{~h}$ and $1,2,5$ and 7 days. For each soaking time, 3 different aliquots of powder were used. 
In the case of the coatings, the amount of SBF needed was calculated by using the following relation:

$$
V_{S B F}=\frac{S_{C}}{10}(\text { eq. } 1)
$$

where $\mathrm{V}_{\mathrm{SBF}}$ is the volume in $\mathrm{cm}^{3}$ of $\mathrm{SBF}$ and $\mathrm{S}_{\mathrm{c}}$ is the area in $\mathrm{mm}^{2}$ of the sample (glass coating). As said before, substrates of $25 \mathrm{~mm}$ diameter were used, corresponding to a face area of $490 \mathrm{~mm}^{2}$, and hence $49 \mathrm{~cm}^{3}$ of SBF were used for each coating sample. The vessels containing the coated discs were incubated inside a water bath at $36,5 \pm 0,5^{\circ} \mathrm{C}$ during $1,2,5,7$ and 14 days. For each soaking time, 3 different coated discs were used, which were placed inside the vessel perpendicular to the bottom part.

Regardless of the type of sample (powder or coating), after each soaking time the $\mathrm{pH}$ of the SBF was measured. For comparison purposes, vessels filled with only SBF were incubated inside the water bath at $36,5 \pm 0,5^{\circ} \mathrm{C}$ during $1,2,5,7$ and 14 days as a control, and after each time the $\mathrm{pH}$ was also measured. Then, the sample object of study (powder and coating) was removed from the vessel, gently rinsed with distilled water and its surface morphology was observed by FEG-ESEM. In addition, the nucleation and growth of the hydroxycarbonate apatite (HCA) was followed by Fourier transform infrared spectroscopy (FTIR) (Nicolet 6700, Thermo Scientific, USA), energy-dispersive $\mathrm{X}$-ray microanalysis (EDX) (Genesis 7000 SUTW, EDAX, USA) and XRD. The samples for FEGESEM, were carbon coated by sputtering before inspection and the observation was done using the secondary electron detector signal under high vacuum conditions. FTIR was performed in absorbance mode, with a spectral resolution of $2 \mathrm{~cm}^{-1}$ from 1500 to $500 \mathrm{~cm}^{-1}$. EDX analysis was done at the same conditions as the FEG-ESEM observation and XRD using the parameters set out in the previous section.

\subsection{Cell culture}

For the cell culture study, human osteoblasts-like cells (MG-63, Sigma-Aldrich, USA) were chosen and cultured in Dulbecco's modified eagle's culture medium (DMEM, Gibco, Germany) in humidified atmosphere of $5 \% \mathrm{CO}_{2}$ in air at $37{ }^{\circ} \mathrm{C}$. The DMEM contained 10\% fetal calf serum (FCS, Sigma-Aldrich, USA) and $1 \%$ antibiotics (containing penicillin + streptomycin). The culture medium was changed every $48-72 \mathrm{~h}$.

The resulting coating from BGC25 experiment and uncoated AISI type 304 stainless steel were tested for the sake of comparison. Both type of samples (coated and uncoated) were cut into small squares with approximately $10 \mathrm{~mm}$ of side. Then, all samples were sterilized in electric furnace for $2 \mathrm{~h}$ at $160{ }^{\circ} \mathrm{C}$ and preincubated in DMEM at $37{ }^{\circ} \mathrm{C}$ in humidified atmosphere of $10 \% \mathrm{CO}_{2}$ in air for $48 \mathrm{~h}$. The main purpose of the preincubation was to avoid a high $\mathrm{pH}$ increase of the cell culture medium after seeding the cells to prevent their death, 
especially in the case of the bioactive glass coated samples, a phenomenon that has been reported frequently in literature [28,29].

After that, cell culture medium (ccm) or DMEM was removed from the culture flask and cells were washed with phosphate-buffered saline solution (PBS, Gibco, Germany) and detached from the same with $3 \mathrm{~cm}^{3}$ of trypsin/EDTA (Gibco, Germany). Then, $9 \mathrm{~cm}^{3}$ of DMEM at $37^{\circ} \mathrm{C}$ was added into the flask to inhibit the trypsin effect and a sample was taken to count the number of cells. Then, prewarmed ccm was used to dilute the cell suspension in order to achieve the desired amount of 50000 cells $/ \mathrm{cm}^{3}$.

Thereafter, the samples were placed inside untreated well plates of $314 \cdot \mathrm{mm}^{2}$ area and cells were seeded onto them. $1 \mathrm{~cm}^{3}$ of ccm containing cells was placed in each well. In addition, 9 wells without sample were seeded with DMEM containing cells as a control sample. Afterwards, the plates were incubated inside an incubator at $37{ }^{\circ} \mathrm{C}$ in a humidified atmosphere of $10 \% \mathrm{CO}_{2}$ in air for $24 \mathrm{~h}$. Finally, cells distribution, adhesion and morphology were analysed.

\subsubsection{Cell adhesion and morphology}

Phalloidin-staining was used for cell morphology and adhesion while Vibrantstaining was employed to count the number of cells on the samples.

For phalloiding-staining, first the $\mathrm{ccm}$ was removed and the samples were washed with PBS. Then, the cells were fixed to the samples with a fixing solution (FluoFix-PBS) for $15 \mathrm{~min}$, washed again and permeabilized with a permeabilization buffer for $5 \mathrm{~min}$. At that point, a fluorescein isothiocyanate solution (Phalloidin, Sigma-Aldrich, USA) was added to each well for detecting the cytoskeleton, and the plate was incubated for $1 \mathrm{~h}$ in dark. After washing again with PBS, a Dapi solution was prepared with a concentration of $1 \cdot 10^{-3} \mathrm{~cm}^{3}$ of 4',6-Diamidino-2-phenylindole, dihydrochloride (Dapi, Sigma-Aldrich, USA) per $1 \mathrm{~cm}^{3}$ of PBS and added into the wells for $5 \mathrm{~min}$ for observing nuclei. Finally, samples were washed with PBS and preserved in fresh PBS in the dark. For each sample, pictures were taken using a fluorescence microscope (Axio Scope A1, Carl Zeiss, Germany) at 5x and 20x magnifications.

Concerning the Vybrant-staining, the procedure was very similar to that used in the previous staining. The $\mathrm{ccm}$ was removed and the well plates were washed with PBS. Next, a mastermix solution, containing $4 \cdot 10^{-3} \mathrm{~cm}^{3}$ Dil cell solution (Vybrant, Thermo Fisher Scientific, USA) per $1 \mathrm{~cm}^{3}$ of $\mathrm{ccm}$, was added to each well and the plates were incubated for $45 \mathrm{~min}$ at $37^{\circ} \mathrm{C}$. Then, the solution was removed, the plates were washed with PBS and a fixing solution was put in the wells for $15 \mathrm{~min}$. After removing that solution, a Dapi solution was prepared again with a concentration of $1 \cdot 10^{-3} \mathrm{~cm}^{3}$ of Dapi per $1 \mathrm{~cm}^{3}$ of PBS and added into the wells for $5 \mathrm{~min}$. Finally, samples were washed with PBS and preserved in fresh PBS in the dark. For cell counting with Vybrant-staining, 6 bioactive glass coated samples, 6 AISI type 304 stainless steel samples and 6 wells without samples were used. For each sample, 5 micrographs at $10 x$ 
magnification were taken with fluorescent microscope and the number of cells was counted with ImageJ software. The results obtained from viable cells were also evaluated by one-way analysis of variance (ANOVA) with Tukey test with a significance statistical level of 0,01 , in order to assess the statistical significance of the results $[28,30]$.

\subsubsection{Scanning electron microscope examination}

The samples which were not used for the staining, were examined by scanning electron microscopy. After $24 \mathrm{~h}$ of incubation, $\mathrm{ccm}$ was removed from the wells and the samples were gently rinsed with PBS. Then, after adding two different fixing solutions (the first one containing glutaraldehyde + sodium cacodylate and the second one containing glutaraldehyde + sodium cacodylate + paraformaldehyde) for $1 \mathrm{~h}$ each, the samples were dehydrated with an ethanol series starting from a concentration of $30 \%$ until $100 \%$. Finally, the samples were put inside a critical point dryer, and after that they were carbon coated and observed by FEG-ESEM.

\section{Results and discussion}

\subsection{Coating's characterisation}

Surface and cross-section micrographs of the obtained coatings are displayed in figure 1.
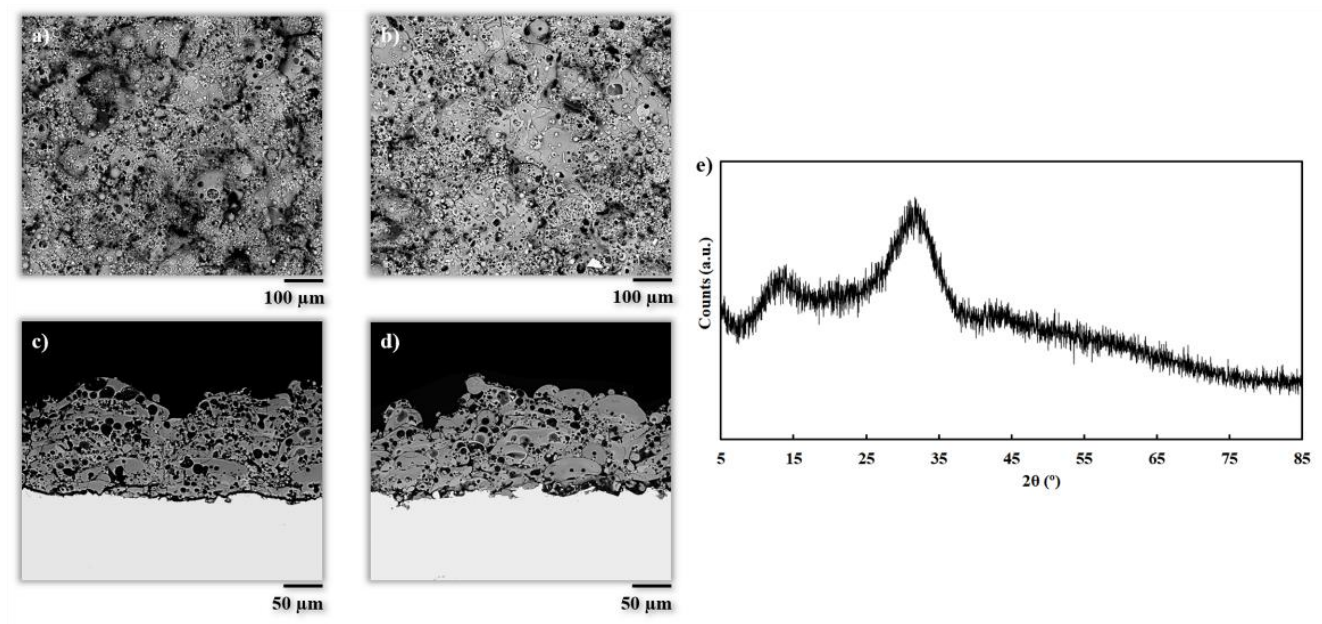

Figure 1. FEG-ESEM micrographs of the obtained coatings: a) surface and c) crosssection for the coating deposited with 38 slpm of argon, b) surface and d) cross-section for the coating deposited with $25 \mathrm{slpm}$ of argon, e) XRD pattern of the $25 \mathrm{slpm}$ argon deposited coating.

Typical APS coatings obtained from highly refractory crystalline ceramic oxides such as alumina or zirconia, result in microstructures composed of completely 
flatten splats. However, the obtained coatings in the present work exhibit a microstructure comprising partially deformed splats, and plenty of typically rounded pores from trapped gas as reported in previous investigations on plasma sprayed glass coatings $[7,11,12,31]$. This microstructure is associated to the melting behaviour of glass particles during the plasma deposition process, which is mainly influenced by the energy of the plasma plume. In both experiments, the particles achieved a semi-molten state with a rounded shape composed of an un-melted core surrounded by a molten glass layer. When these rounded particles impact onto the substrate, they remain attached to it due to this molten glass layer, but their flattening is prevented by the un-melted core. As it can be observed in figure 1, this effect is more visible to BGC38 coating (figures $1 \mathrm{a}$ and 1c) where a higher flow rate of argon was used. Therefore, as mentioned above, two effects took place simultaneously inside the plasma plume, that is hydrogen is more diluted resulting in a lower thermal conductivity through the plasma plume and lower residence time of the particle inside the plume. In contrast, for BGC25 coating, the higher thermal conductivity of the plasma plume combined with the higher residence time of the particles inside the plume, resulted in a thicker glass molten layer surrounding the core of the particles, giving rise to more flattened splats. These findings confirm previous results reported in the literature by Cannillo et al. [31]. According to these researchers, from the observation of these heterogeneous microstructures, low values of adhesion strength can be expected. Nevertheless, the rough surface of the coatings and their porosity could exert a positive influence, enhancing the bioactivity and osteoconductivity of the resulting coating $[32,33]$.

Table 2 shows some characteristics of the obtained coatings and their comparison with typical data for standard plasma spray coatings: deposition efficiency, thickness, porosity and adhesion strength $[34,35]$.

Table 2 Some characteristics of the obtained coatings compared with typical standard APS coating data $[34,35]$

\begin{tabular}{cccc}
\hline Characteristic & BGC25 & BGC38 & $\begin{array}{c}\text { Standard APS } \\
\text { coatings }\end{array}$ \\
\hline Deposition efficiency $(\%)$ & 90 & 83 & $90-95$ \\
Thickness $(\mu \mathrm{m})$ & $118,5 \pm 4,5$ & $100,0 \pm 4,5$ & $300-1500^{\mathrm{a}}$ \\
Porosity $(\%)$ & $26,5 \pm 3,0$ & $33,0 \pm 1,3$ & $7-10^{\mathrm{b}}$ \\
Tensile adhesion & $4,4 \pm 0,8$ & $2,3 \pm 1,0$ & $15-25^{\mathrm{c}}$ \\
strength $(\mathrm{MPa})$ & &
\end{tabular}

\footnotetext{
a Might be intentionally lower [34]

${ }^{b}$ Might be intentionally greater [34]

${ }^{c}$ Ceramic coatings with bond coat
}

Porosity for both coatings is higher than that observed to APS coatings as commented above. In addition, the differences in porosity between both 
coatings are also related to the microstructure. In fact, from figure 1 it can be appreciated that in the case of the BGC38 coating, the predominant type of pore is not rounded but with irregular, inter-splat shape due to the higher unflattened state of this coating. As said above, due to the lower melting of the glass particles, the particle's core remains unmelted preventing the particle to be totally flattened when they impact onto the substrate or the as-deposited coating. Therefore, they compact worse among themselves when stacking on the substrate to develop the coating giving rise the irregular pores. The deposition efficiency of the BGC38 and BGC25 coatings are in agreement with typical data of APS coatings; however, the thicknesses are in the lower range compared to APS layers. Although much higher thickness can be easily obtained by increasing the number of plasma torch passages, this is probably of scarce interest for biocoating application (100-150 $\mu \mathrm{m}$ maximum thickness) $[1,36,37]$. Again, the differences between the obtained coatings in both porosity and thickness are related to the melting state of the particles when impacting onto the substrate. Finally, regarding the adherence between the coatings and the substrate, lower adhesion values than some reported in the literature were obtained [38]. This fact could be due to using thinner substrates $(10 \mathrm{~mm})$ than the stablished by the ASTM-C633 standard (38 mm) [39]. Therefore, the substrates used in the present work are less ductile, causing a negative effect on the stress distribution inside the substrate during the tensile test. Even so, these values were found in good agreement with the other authors who tested similar probes [39]. Comparing both samples, the higher porosity of the BGC38 coating involves lower adhesion properties respect to the BGC25 coating. In any case, the final adhesion of the obtained coatings could be enhanced by using a common $\mathrm{TiO}_{2}$ bond coat, which has been proven as an efficient way of significantly increasing this adhesive strength [38].

Figure 1e shows the X-ray diffraction pattern of the BGC25 coating. As observed, the amorphous structure of the feedstocks (Figure S1) was fully preserved. The XRD pattern of the other coating was very similar. As reported elsewhere, extremely high cooling rates occurring during plasma spraying prevent glass splats from recrystallisation, resulting in a fully amorphous layer [40]. This high cooling rate represents another great advantage of plasma spray technique to obtain bioactive glass coatings as glass devitrification can then be easily avoided. As reported in literature, the preservation of this amorphous structure seems to be a key issue in order to enhance the bioactivity response [41].

\subsection{Powder and coating bioactivity by SBF test}

SBF test of the samples was done to analyse the bioreactivity of the bioactive glass powder feedstock and coatings, but only the BGC25 coating was tested. Although both coatings were completely amorphous and presented similar surface roughness, the BGC38 coating was rejected as it had less thickness and adhesion to the substrate, as well as a higher closed porosity resulting in a 
less cohesive microstructure due to the spraying parameters, as described above.

FTIR results from BG powder and BGC25 coating before and after soaking in SBF are presented in figure 2. Before soaking both samples in SBF, they displayed similar spectra (since the composition is the same), exhibiting Si-OSi stretching bands [42]. Nevertheless, as the samples were soaked and residence time inside SBF increases, the resulting FTIR spectra became different. Consequently, new absorption bands can be appreciated at $560 \mathrm{~cm}^{-1}$ and $605 \mathrm{~cm}^{-1}$, which correspond to $\mathrm{P}-\mathrm{O}$ bending from $\mathrm{PO}_{4}{ }^{3-}$ group, and at 1050 $\mathrm{cm}^{-1}$ corresponding to $\mathrm{P}-\mathrm{O}$ stretching $[40,43]$. Moreover, some bands at 800 $\mathrm{cm}^{-1}$ (Si-O non-bonding oxygen), and $1070 \mathrm{~cm}^{-1}$ and $1200 \mathrm{~cm}^{-1}$ (Si-O-Si stretching) can be appreciated [42]. Additionally, bands at $870 \mathrm{~cm}^{-1}$ and 1400 $\mathrm{cm}^{-1}$, characteristic of $\mathrm{CO}_{3}{ }^{2-}$ group, were also found, which are a clear sign of HCA formation mimicking bone like apatite since the formation of pure hydroxyapatite (HA) is unlikely in SBF [27].

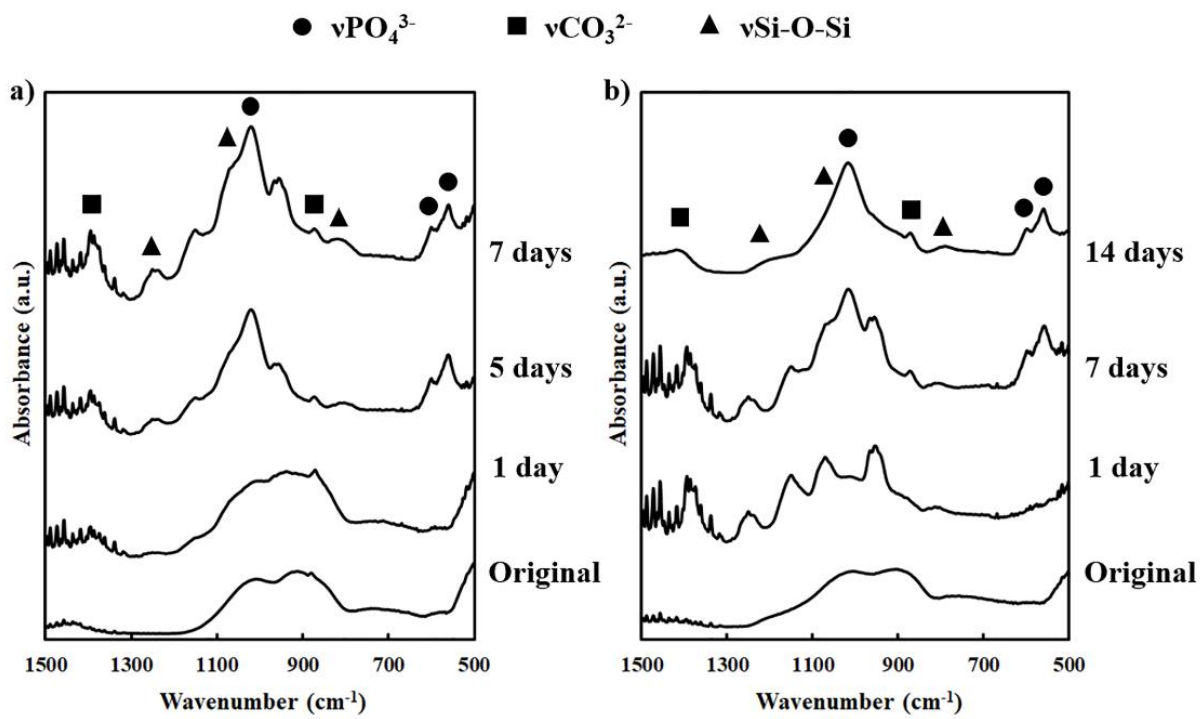

Figure 2. FTIR results before and after soaking in SBF at different times: a) for bioactive glass powder and b) for BGC25 coating.

Both types of samples display the same absorption bands. However, for the coating, the appearance of those bands takes place at a longer time than that observed for the bioactive glass powder feedstock. Absorption bands for the powder were fully evolved after 7 days in SBF while for the coating it took 14 days. This delay deals with the lower reactivity of the coating as a consequence of the sintering of the glass particles during plasma spraying at a high temperature. To confirm this result, the specific surface area of the powder feedstock and the coating were determined by BET (TriStar 3000, Micromeritics, The USA). For the BGC25 coating, due to its low adhesion, it was carefully detached [44,45], and then fragmented into pieces to carry out the 
measurement. The specific surface area was $0,47 \mathrm{~m}^{2} / \mathrm{g}$ for the powder and $0,0635 \mathrm{~m}^{2} / \mathrm{g}$ for the coating, which clearly explains the lower reactivity (available surface) of the coating in comparison with the powder feedstock.

Although the bands detected for both the powder and the coatings correspond to the presence of HCA, XRD was also performed to corroborate the FTIR results and confirm the phase nature of the crystals developed [26, 46]. The resulting patterns are shown in figure 3 , where only the characteristic peaks of $\mathrm{HCA}$ at $2 \theta$ of $26^{\circ}$ and $32^{\circ}$ can be seen [27].

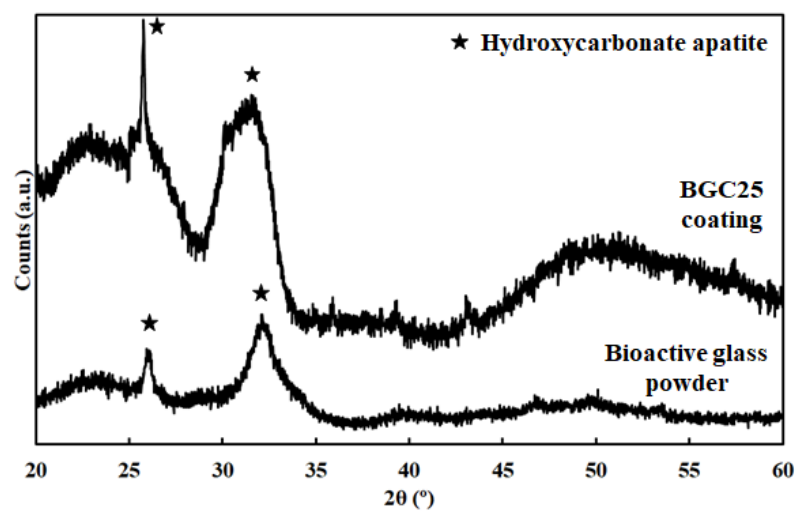

Figure 3. XRD patterns for the powder feedstock and the BGC25 coating samples after SBF immersion for 7 days and 14 days respectively.

These peaks become sharper at 7 days and 14 days for the powder feedstock and the BGC25 coating, respectively. Further confirmation of the impact of the surface reactivity on the kinetics of the HCA formation can be deduced when observing $\mathrm{pH}$ evolution during SBF test for both samples (bioactive glass powder and BGC25 coating) compared to the SBF without any sample. Figure 4 shows the $\mathrm{pH}$ increase of SBF containing both samples (powder and coating) as the test progresses as a consequence of the chemical interaction occurring between SBF and the glass surface [27].

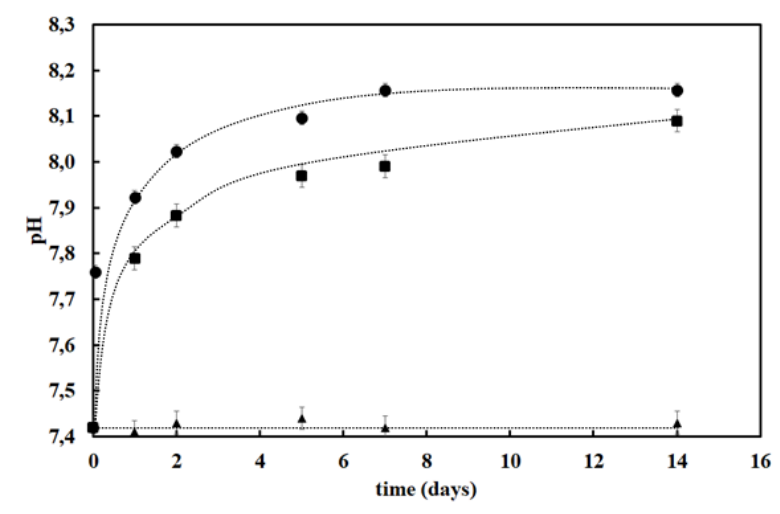

Figure 4. Evolution of SBF pH with immersion time for the bioactive glass powder (circle dots), the BGC25 coating (square dots) and SBF without any sample (triangle dots). 
More remarkable, starting with an initial $\mathrm{pH}$ value of 7,42 , bioactive glass powder shows a much faster $\mathrm{pH}$ increase during the first hours of immersion. As reported elsewhere, this first step in the SBF immersion test relates to cation (mainly $\mathrm{Na}^{+}$and $\mathrm{Ca}^{2+}$ ) release from the glass which takes place more rapidly for the bioactive glass powder sample compared to the coating due to its higher exposed surface area [47].

FEG-ESEM images of the HCA layer developed onto the powder and coating surfaces at different soaking times are displayed in figure 5 followed by their corresponding EDX analysis spectrum.
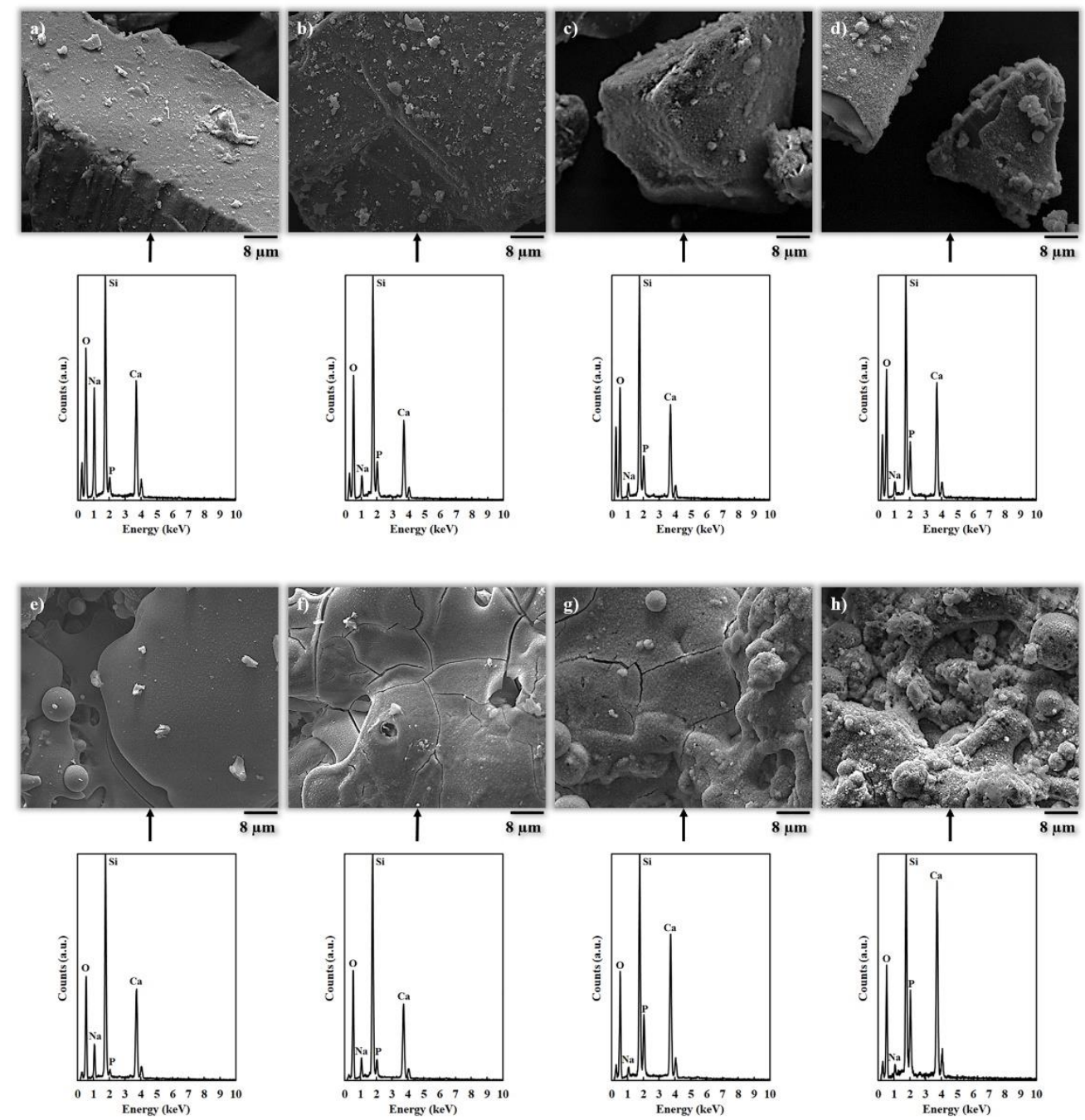

Figure 5. FEG-ESEM micrographs of the samples after different exposure time in SBF accompanied by their corresponding EDX analysis. From a) to d) bioactive glass powder before soaking and soaked for 1, 5 and 7 days, respectively. From e) to h) BGC25 coating before soaking and soaked for 1, 7 and 14 days, respectively. 
Powder micrographs (Figure $5 \mathrm{a}$ to $5 \mathrm{~d}$ ) show that HCA formation starts to be noticeable after at 1 day and fully developed after 7 days in SBF. For the coating (Figure $5 \mathrm{e}$ to $5 \mathrm{~h}$ ), HCA formation is observed after 7 days, which develops further covering the surface after 14 days. For both the powder and the BGC25 coating, the EDX spectra presented in figure 5 confirms the appreciations from FEG-ESEM micrographs. $P$ and $\mathrm{Ca}$ peaks grow as the immersion time increases, becoming fully developed after 7 days and 14 days exposure times for bioactive glass powder feedstock and BGC25 coating, respectively. Moreover, the intensity of the Na peak decreases as the soaking time increases confirming the cation exchange from the glass (powder or coating) to the SBF environment.

\subsection{Biological response}

The resulting $\mathrm{pH}$ variation of the medium (DMEM) in the three cases set out above (without sample, with AISI type 304 stainless steel uncoated sample and the BGC25 coating) is shown in figure 6.

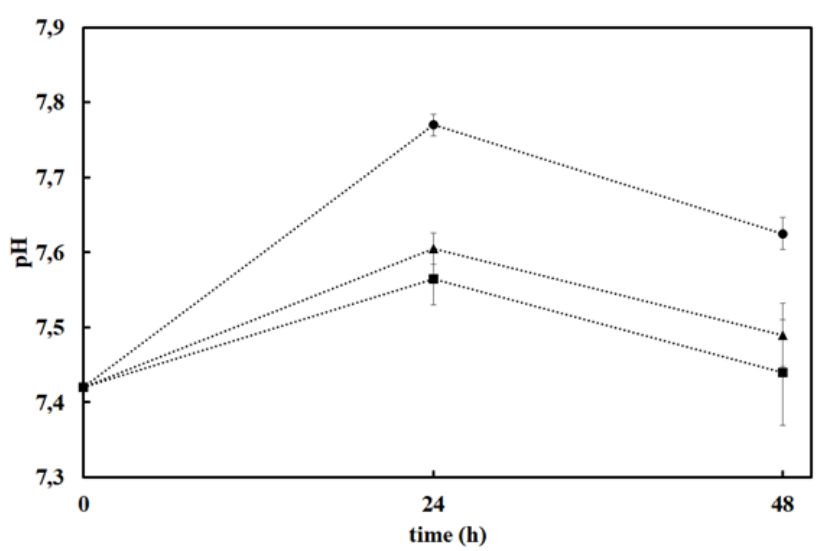

Figure 6. Medium pH variation during preincubation in $10 \% \mathrm{CO}_{2}$ humidified atmosphere. DMEM (square dots), AISI type 304 stainless steel + DMEM (triangle dots) and BG25C + DMEM (circle dots).

There is hardly any difference between the $\mathrm{pH}$ values of DMEM alone and that of AISI type 304 stainless steel compared to the sample coated with BG. Thus, when releasing cations $\left(\mathrm{Na}^{+}\right.$and $\left.\mathrm{Ca}^{2+}\right)$ into the medium, the $\mathrm{pH}$ values always grew. However, after $48 \mathrm{~h}$ the $\mathrm{pH}$ of the medium is lower than 7,7 in all cases, which makes it possible to seed the cells on the samples and their subsequent incubation.

After incubation, the adhesion, distribution and morphology of the cells in direct contact with the samples were assessed according to the procedures described in the experimental section. In figure 7, the cells are shown after phalloidinstaining at different magnifications. The cells are identified by fluorescent coloration, the cytoskeleton cell being red and the nuclei blue. From these 
micrographs, it is possible to appreciate a large concentration of cells well adhered and scattered on the surfaces of both samples (AISI type 304 stainless steel and BGC25 coating), which confirms their good biocompatibility. Nevertheless, different cell morphologies can be appreciated depending on the surface. The cells on the surface of the AISI type 304 stainless steel substrate display an elongated rhomboid shape very similar to that of the control cells, while for the BGC25 coating the cells present a star-shaped morphology with higher number of cytoplasmic extensions (enhancing the contact between cells and cells-surface). This different morphology could be caused by both the surface topography (rough surface) and the ion release from the glass coating which promotes the growth of the cells. Therefore, a higher cell proliferation is expected on the glass surface when compared to the metal surface.
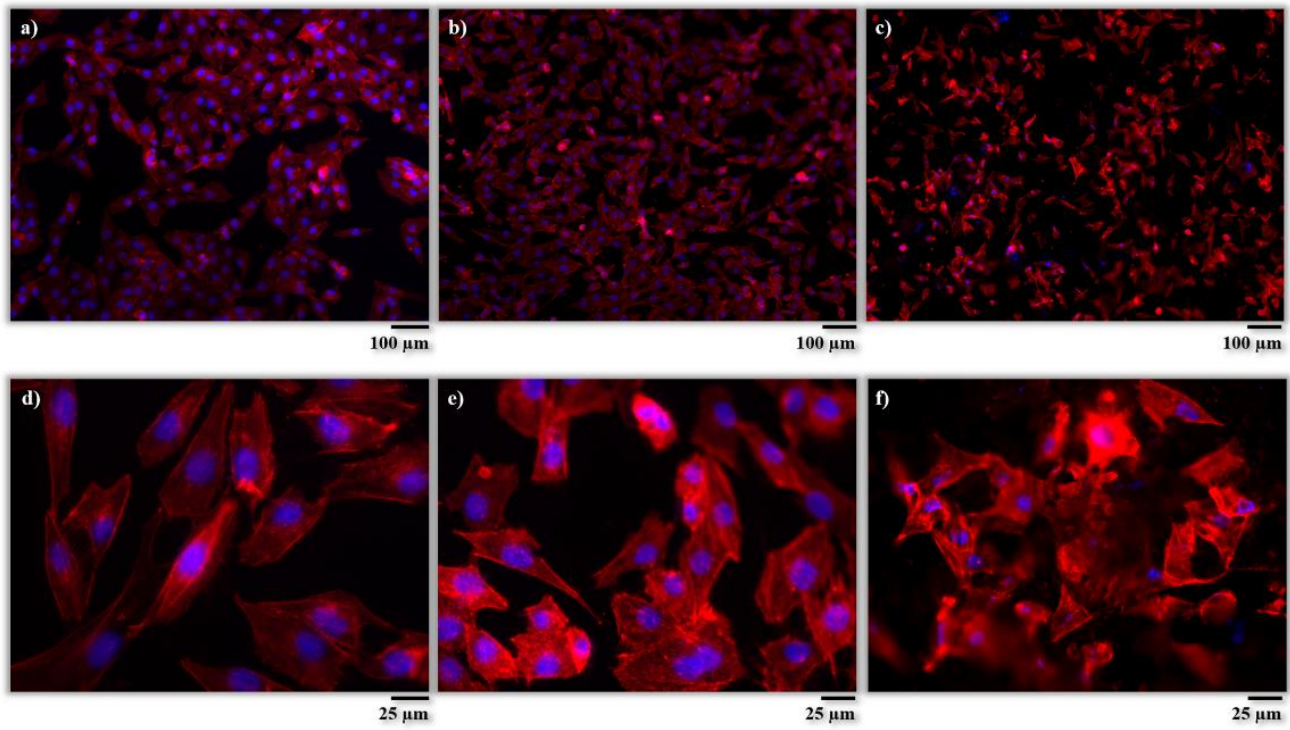

Figure 7. Fluorescent micrographs of MG-63 cells after phalloidin-staining in direct contact with the different surfaces. a) and d) well-plate without sample, b) and e) AISI type 304 stainless steel, c) and f) BGC25 coating.

The morphology was also checked by scanning electron microscopy (FEGESEM). As it can be seen in figure 8, the cell on the BG coating is spread in a multidirectional manner promoting contact between cells and the surface of the coating, as discussed above. Splat-structured morphology of the BG coating promotes the growth of cells and hence their attachment, in comparison with a non-structured (smooth) and impervious surface, as in the case of the metallic substrate $[48,49]$. 


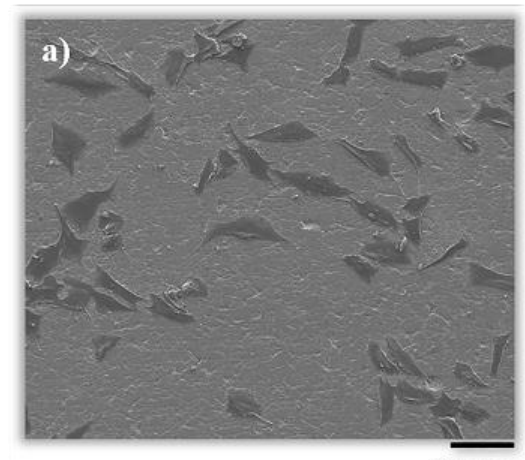

$80 \mu \mathrm{m}$

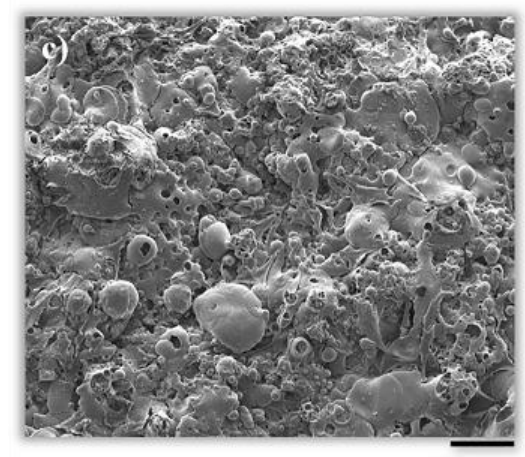

$80 \mu \mathrm{m}$
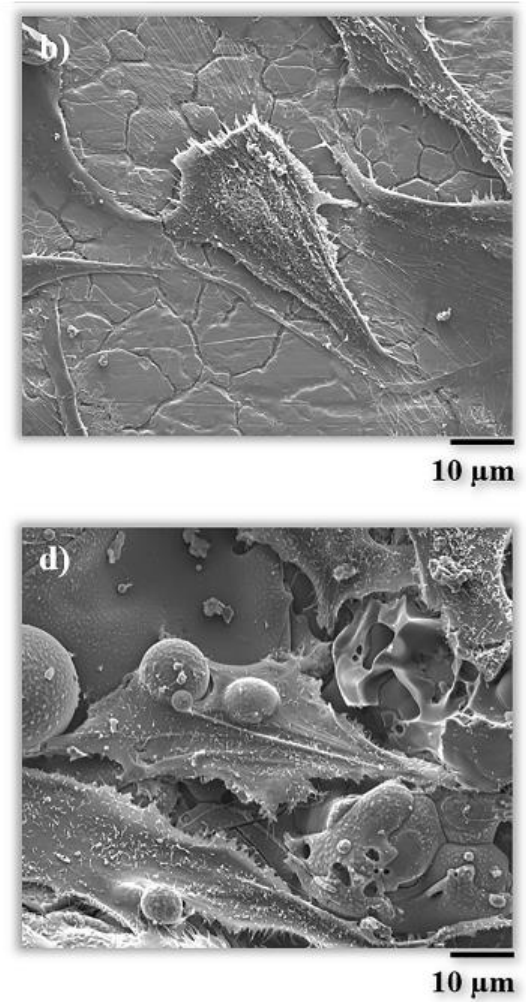

Figure 8. FEG-ESEM micrographs of MG-63 cells on the tested surfaces a) and b) AISI type 304 stainless steel, c) and d) BGC25 coating after 1 day of cultivation.

Regarding the number of cells, these results were quantitatively corroborated from micrographs obtained after Vybrant-staining (Figure 9) and are shown in figure 10. There is a large number of cells in contact with all the materials tested. In addition, it can also be observed that there are no significant differences between the amount of cells (cells $/ \mathrm{m}^{2}$ ) on the AISI type 304 stainless steel substrate and the BGC25 coating.
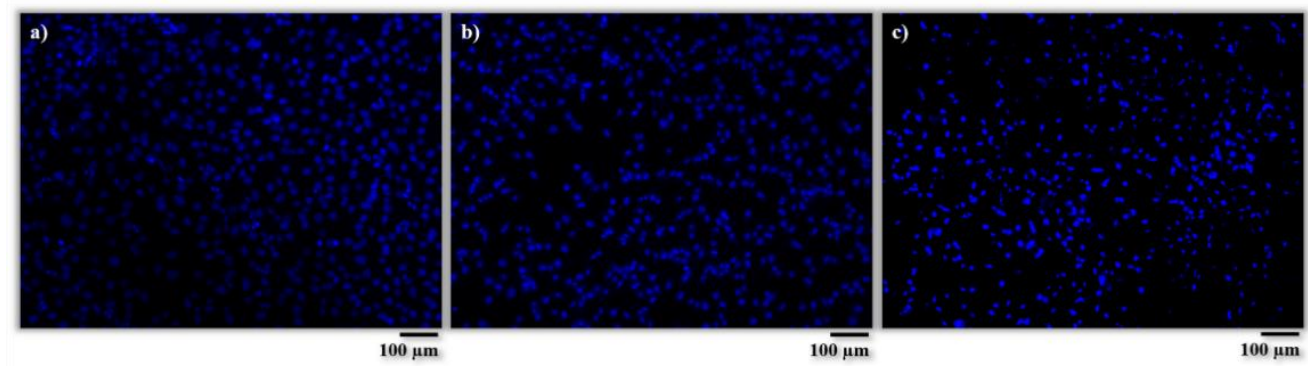

Figure 9. Fluorescent micrographs of MG-63 cell nucleus after Vybrant-staining in direct contact with the different surfaces a) well-plate without sample, b) AISI type 304 stainless steel, c) BGC25 coating. 


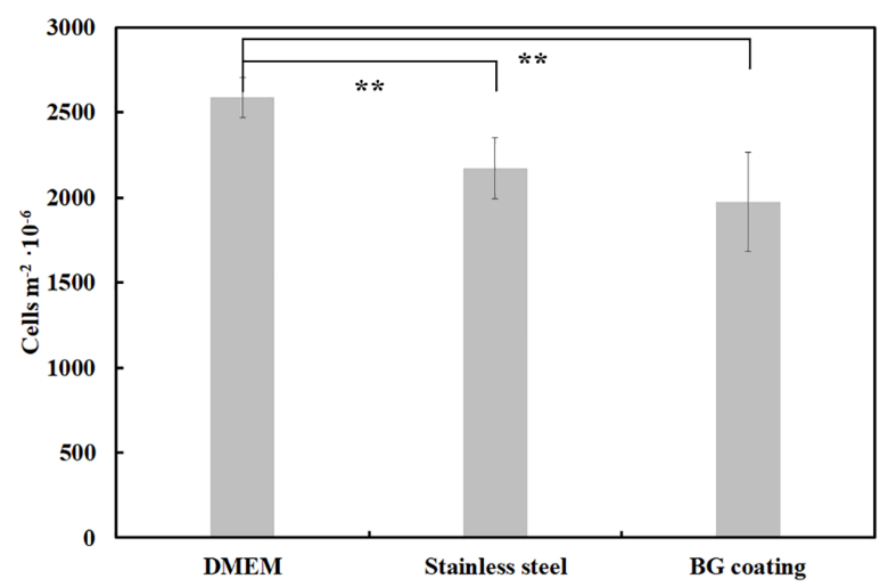

Figure 10. MG-63 cell amount (cells $/ \mathrm{m}^{2}$ ) on the well-plate, uncoated substrate and the bioactive glass coated substrate. Results expressed as mean with standard deviation. Statistically significant differences $(p<0,01)$ between means expressed with ${ }^{* *}$.

In summary, it can be concluded that there is a strong interaction between the tested surfaces and MG-63 osteoblasts-like cells, due to the high amount of living cells present on each surface after $24 \mathrm{~h}$ of incubation. Despite not finding significant differences in the number of cells $/ \mathrm{m}^{2}$ on each surface (AISI type 304 stainless steel substrate and the BGC25 coating), the BG coating presents multidirectional growth of the cells, which promotes contact between cells and the surface. Moreover, a higher proliferation rate of cells on the surface of the bioactive glass coating can be expected compared to that of the metal, as the surface roughness of the BGC25 coating and its open porosity are expected to promote ion exchange between the surface and the medium, which should positively affect cell behaviour [48]. However, in order to corroborate this statement, prolonged incubation times with primary human osteoblast cells should be applied to appreciate how evolve both coated and uncoated samples.

\section{Conclusions}

This research addressed a complete in-vitro study (immersion in SBF and cell culture) of a BG coating obtained by atmospheric plasma spraying technique. The following conclusions were inferred from the research.

Both coatings (BGC25 and BGC38) exhibited a microstructure composed of partially deformed splats plenty of rounded pores and considerable thickness. As previously reported, this microstructure evolves from glassy-nature feedstocks which rapidly sinter and cool during plasma spraying. The amorphous nature of the feedstock was preserved after deposition. High porosity of the coatings was observed, which can enhance its bioactivity.

Simulated body fluid test allowed to assess the precellular bioactivity of the coating. Bioactivity (formation of HCA) was monitored and verified by FTIR, 
FEG-ESEM, XRD and EDX and compared with that of the starting feedstock powder. All these tests confirmed the formation of the hydroxyapatite layer in the coating. However, the development rate of the HCA layer is slower on the coating surface than on the powder surface, due to the difference in the specific surface area.

Surface characteristics of the coating consisting of deformed splats and high roughness resulted in good interaction between coating surface and human osteoblasts-like cells. Despite the similar number of cells $/ \mathrm{m}^{2}$ on the BG coated and uncoated surfaces, multidirectional growth of cells were observed on the BG surface leading to a potentially superior biological response of the coating. With the aim to corroborate this statement, longer incubation times will be performed.

\section{Acknowledgements}

The authors of the present work thank Universitat Jaume I of Castellón for the support provided in funding action 3.1. of the Research Promotion Plan (PREDOC/2015/50) and the European Virtual Institute on Knowledge-based Multifunctional Materials ASBL (KMM-VIN) for the KMM-VIN Research Fellowship (calls 2016 and 2018).

\section{References}

[1] J.R. Jones, A.G. Clare, Bio-glasses, an introduction, first ed., John Wiley and Sons, Great Britain, 2012.

[2] T.M. Lee, E. Chang, B.C. Wang, C.Y. Yang, Characteristics of plasma-sprayed bioactive glass coatings on Ti-6A1-4V alloy: an in vitro study, Surf. Coat. Technol. 79 (1996) 170-177.

[3] T. Kitsugi, T. Nakamura, M. Oka, Y. Senaha, T. Goto, T. Shibuya, Bonebonding behavior of plasma-sprayed coatings of Bioglass $\AA$, AW-glass ceramic, and tricalcium phosphate on titanium alloy, J. Biomed. Mater. Res. 30 (1996) 261-269.

[4] J.R. Jones, Review of bioactive glass: From Hench to hybrids, Acta Biomater. 23 (2015) 53-82.

[5] A.R. Boccaccini, M. Erol, W.J. Stark, D. Mohn, Z. Hong, J.F. Mano, Polymer/bioactive glass nanocomposites for biomedical applications: A review, Compos. Sci. Technol. 70 (2010) 1764-1776.

[6] V. Cannillo, A. Sola, Potassium-based composition for a bioactive glass, Ceram. Int. 35 (2009) 3389-3393.

[7] A. Sola, D. Bellucci, V. Cannillo, A. Cattini, Bioactive glass coatings: a review, Surf. Eng. 27 (2011) 560-572. 
[8] F. Baino, E. Verne, Glass-based coatings on biomedical implants: a state-ofthe-art review, Biomed. Glasses 3 (2017) 1-17.

[9] A. Al-Noaman, S.C.F. Rawlinson, R.G. Hill, The role of $\mathrm{MgO}$ on thermal properties, structure and bioactivity of bioactive glass coating for dental implants, J. Non-Cryst. Sol. 358 (2012) 3019-3027.

[10] E. Cañas, M. Vicent, E. Bannier, P. Carpio, M.J. Orts, E. Sánchez, Effect of particle size on processing of bioactive glass powder for atmospheric plasma spraying, J. Eur. Ceram. Soc. 36 (2016) 837-845.

[11] A. Cattini, L. Latka, D. Bellucci, G. Bolelli, A. Sola, L. Lusvarghi, L. Pawlowski, V. Cannillo, Suspension plasma sprayed bioactive glass coatings: effects of processing on microstructure, mechanical properties and in-vitro behaviour, Surf. Coat. Technol. 220 (2013) 52-59.

[12] G. Bolelli, D. Bellucci, V. Cannillo, R. Gadow, A. Killinger, L. Lusvarghi, P. Müller, A. Sola, Comparison between suspension plasma sprayed and high velocity suspension flame sprayed bioactive coatings, Surf. Coat. Technol. 280 (2015) 232-249.

[13] S. Romeis, A. Hoppe, R. Detsch, A.R. Boccaccini, J. Schmidt, W. Peukert, Topdown processing of submicron 4555 Bioglass $\AA$ for enhanced in vitro bioactivity and biocompatibility, Proced. Eng. 102 (2015) 534-541.

[14] J. Henao, C.P. Salas, M. Monsalve, J.C. Castuera, O.B. Sanchez, Bio-active glass coatings manufactured by thermal spray: a status report, J. Mater. Res. Technol. 8 (2019) 4965-4984.

[15] T. Bhatia, A. Ozturk, L. Xie, E.H. Jordan, B.M. Cetegen, M. Gell, X. Ma, N.P. Padture, Mechanisms of ceramic coating deposition in solution-precursor plasma spray, J. Mater. Res. 17 (2002) 2363-2372.

[16] L. Xie, X. Ma. A. Ozturk, E.H. Jordan, N.P. Padture, B.M. Cetegen, D.T. Xiao, M. Gell, Processing parameter effects on solution precursor plasma spray process spray patterns, Surf. Coat. Technol. 183 (2004) 51-61.

[17] A. Mejias, R.T. Candidato Jr, L. Pawłowski. D. Chicot, Mechanical properties by instrumented indentation of solution precursor plasma sprayed hydroxyapatite coatings: Analysis of microstructural effect, Surf. Coat. Technol. 298 (2016) 93-102.

[18] E. Cañas, M.J. Orts, A.R. Boccaccini, E. Sánchez, Microstructural and in vitro characterization of $45 S 5$ bioactive glass coatings deposited by solution precursor plasma spraying (SPPS), Surf. Coat. Technol. 371 (2019) 151-160.

[19] Y. Xiao, L. Song, X. Liu, Y. Huang, T. Huang, J. Chen, Y. Wu, F. Wu, Bioactive Glass-Ceramic Coatings Synthesized by the Liquid Precursor Plasma Spraying Process, J. Therm. Spray Technol. 20 (2011) 560-568.

[20] X. Liu, C. Ding, Z. Wang, Apatite formed on the surface of plasma-sprayed wollastonite coating immersed in simulated body fluid, Biomater. 22 (2001) 2007-2012. 
[21] M.P. Ferraz, F.J. Monteiro, J.D. Santos, $\mathrm{CaO}-\mathrm{P}_{2} \mathrm{O}_{5}$ glass hydroxyapatite double-layer plasma-sprayed coating: In vitro bioactivity evaluation, J. Biomed. Mater. Res. 45 (1999) 376-383.

[22] C. Gabbi, A. Cacchioli, B. Locardi, E. Guadagnino, Bioactive glass coating: physicochemical aspects and biological findings, Biomater. 16 (1995) 515-520.

[23] A. Oliva, A. Salerno, B. Locardi, V. Riccio, F. Della Ragione, P. Iardino, V. Zappia, Behaviour of human osteoblasts cultured on bioactive glass coatings, Biomater. 19 (1998) 1019-1025.

[24] C. Wu, Y. Ramaswamy, X. Liu, G. Wang, H. Zreigat, Plasma-sprayed CaTiSiO ceramic coating on Ti-6Al-4V with excellent bonding strength, stability and cellular bioactivity, J. R. Soc. Interface 6 (2009) 159-168.

[25] V. López, M. Vicent, E. Bannier, E. Cañas, A.R. Boccaccini, L. Cordero, E. Sánchez, 45S5 bioactive glass coatings by atmospheric plasma spraying obtained from feedstocks prepared by different routes, J. Mater. Sci. 49 (2014) 7933-7942.

[26] A.L.B. Maçon, T.B. Kim, E.M. Valliant, K. Goetschius, R.K. Brow, D.E. Day, A. Hoppe, A.R. Boccaccini, I.Y. Kim, C. Ohtsuki, T. Kokubo, A. Osaka, M. ValletRegí, D. Arcos, L. Fraile, A.J. Salinas, A.V. Teixeira, Y. Vueva, R.M. Almeida, M. Miola, C. Vitale-Brovarone, E. Verné, W. Höland, J.R. Jones, A unified in vitro evaluation for apatite-forming ability of bioactive glasses and their variants, J. Mater. Sci. Mater. Med. 26 (2015) 115-124.

[27] T. Kokubo, H. Takadama, How useful is SBF in predicting in vivo bone bioactivity?, Biomater. 27 (2006) 2907-2915.

[28] J.J. Blaker, J.E. Gough, V. Maquet, I. Notingher, A.R. Boccaccini, In vitro evaluation of novel bioactive composited based on bioglass ${ }^{\circledR}$-filled polylactide foams for bone tissue engineering scaffolds, J. Biomed. Mater. Res. 67 (2003) $1401-1411$.

[29] C. Vitale-Brobarone, E. Verné, L. Robiglio, P. Appendino, F. Bassi, G. Martinasso, G. Muzio, R. Canuto, Development of glass-ceramic scaffolds for bone tissue engineering: Characterisation, proliferation of human osteoblasts and nodule formation, Acta Biomater. 3 (2007) 199-208.

[30] J. Ureña, S. Tsipas, A. Jimémez-Morales, E. Gordo, R. Detsch, A.R. Boccaccini, In-vitro study of the bioactivity and cytotoxicity response of $\mathrm{Ti}$ surfaces modified by $\mathrm{Nb}$ and Mo diffusion treatments, Surf. Coat. Technol. 335 (2018) 148-158.

[31] V. Canillo, A. Sola, Different approaches to produce coatings with bioactive glasses: enamelling vs plasma spraying, J. Eur. Ceram. Soc. 30 (2010) 20312039.

[32] M. Takemotoa, S. Fujibayashia, M. Neoa, J. Suzukib, T. Kokuboc, T. Nakamura, Mechanical properties and osteoconductivity of porous bioactive titanium, Biomater. 26 (2005) 6014-6023.

[33] K. Rezwan, Q.Z. Chen, J.J. Blaker, A.R. Boccaccini, Biodegradable and bioactive porous polymer/inorganic composite scaffolds for bone tissue engineering, Biomater. 27 (2006) 3413-3431. 
[34] L. Pawlowski, The science and engineering of thermal spray coatings, second ed., John Wiley and Sons, Great Britain, 2008.

[35] J.R. Davis, Handbook of thermal spray technology, first ed., ASM International, The USA, 2004.

[36] J.M. Gomez-Vega, E. Saiz, A.P. Tomsia, Glass-based coatings for titanium implant alloys, J. Biomed. Mater. Res. 46 (1999) 549-559.

[37] A. Pazo, E. Saiz, A.P. Tomsia, Silicate glass coatings on Ti-based implants, Acta Mater. 46 (1998) 2551-2558.

[38] G. Goller, The effect of bond coat on mechanical properties of plasma sprayed bioglass-titanium coatings, Ceram. Int. 30 (2004) 351-355.

[39] M. Monsalve, H. Ageorges, E. Lopez, F. Vargas, F. Bolivar, Bioactivity and mechanical properties of plasma-sprayed coatings of bioglass powders, Surf. Coat. Technol. 220 (2013) 60-66.

[40] G.M. Nelson, J.A. Nychka, A.G. McDonald, Flame Spray Deposition of Titanium Alloy-Bioactive Glass Composite Coatings, J. Therm. Spray Tech. 20 (2011) 1339-1351.

[41] O.P. Filho, G.P. La Torre, L.L. Hench, Effect of crystallization on apatite-layer formation of bioactive glass 45S5, J. Biomed. Mater. Res. B 30 (1996) 509514.

[42] A.A. El-Kheshen, F.A. Khaliafa, E.A. Saad, R.L. Elwan, Effect of Al2O3 addition on bioactivity, thermal and mechanical properties of some bioactive glasses, Ceram. Int. 34 (2008) 1667-1673.

[43] M. Mačković, A. Hoppe. R. Detsch, D. Mohn, W.J. Stark, E. Spiecker, A.R. Boccaccini, Bioactive glass (type 45S5) nanoparticles: in vitro reactivity on nanoscale and biocompatibility, J. Nanopart. Res. 14 (2012) 966.

[44] S. Paul, A. Cipitria, I.O. Golosnoy, L. Xie, M.R. Dorfman, T.W. Clyne, Effects of impurity content on the sintering characteristics of plasma-sprayed zirconia, J. Therm. Spray Technol. 16 (2007) 798-803.

[45] S. Paul, A. Cipitria, S.A. Tsipas, T.W. Clyne, Sintering characteristics of plasma sprayed zirconia coatings containing different stabilisers, Surf. Coat. Technol. 203 (2009) 1069-1074.

[46] H. Pirayesh, J.A. Nychka, Sol-gel synthesis of bioactive glass-ceramic 45S5 and its in vitro dissolution and mineralization behavior, J. Am. Ceram. Soc. 96 (2013) 1643-1650.

[47] M. Cerruti, D. Greenspan. K. Powers, Effect of $\mathrm{pH}$ and ionic strength on the reactivity of Bioglass ${ }^{\circledR}$ 45S5, Biomater. 26 (2005) 1665-1674.

[48] A. Itälä, H.O. Ylänen, J. Yrjans, T. Heino, T. Hentunen, M. Hupa, H.T. Aro1, Characterization of microrough bioactive glass surface: Surface reactions and osteoblast responses in vitro, J. Biomed. Mater. Res. 62 (2002) 404-411.

[49] R. Detsch, O. Guillon, L. Wondraczek, A.R. Boccaccini, Initial attatchment of rMSC and MG-63 cells on patterned bioglass ${ }^{\circledR}$ substrates, Adv. Eng. Mater. 14 (2012) B38-B44. 


\section{Appendix / supplementary information}

Figure S1a displays the typical angular shape of ground frit particles which were of fully amorphous nature (Figure S1b) as determined by X-ray diffraction (XRD) (Advance diffractometer, Bruker Theta-theta, Germany).
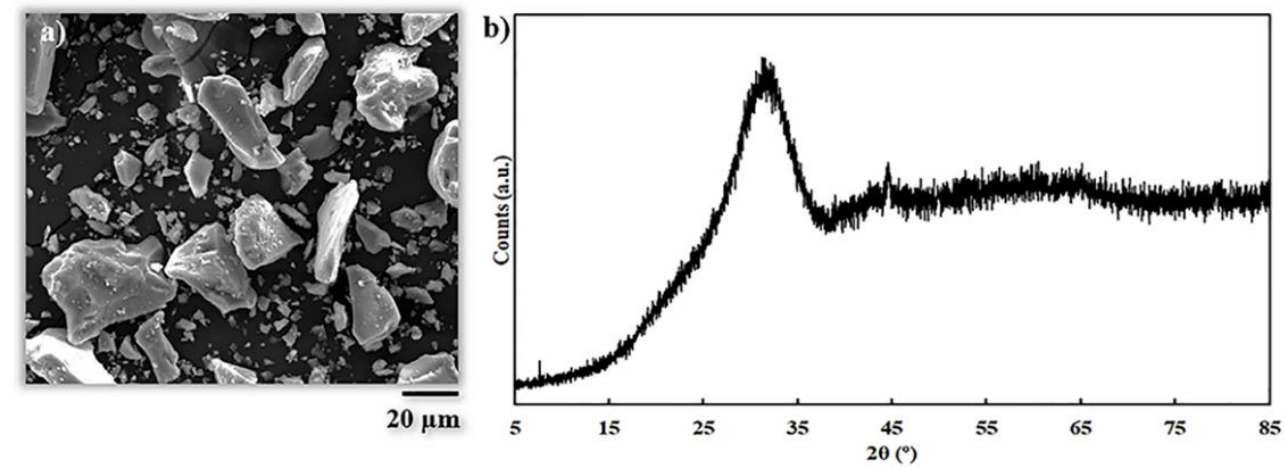

Figure S1. Particles morphology (a) and XRD spectrum (b) of the bioactive glass (45S5 BG) feedstock used. 

Artículo 3 



\title{
Bioactive glass suspensions preparation for suspension plasma spraying
}

\author{
Eugeni Cañas, Mónica Vicent, María José Orts, Rodrigo Moreno, Enrique \\ Sánchez
}

Journal of the European Ceramic Society 36 (2016) 4281-4290

\section{http://dx.doi.org/10.1016/j.jeurceramsoc.2016.06.011}

Este trabajo aborda la obtención de suspensiones estables de vidrio bioactivo para su empleo en proyección térmica por plasma. Para ello, se ha molturado en vía seca y tamizado un vidrio bioactivo para obtener un polvo con una distribución de tamaños de partícula por debajo de $63 \mu \mathrm{m}$. Se ha obtenido dos suspensiones con diferente distribución de tamaño de partícula $\left(D_{50}=8,3 \mu \mathrm{m}\right.$ y $D_{50}=2,2 \mu \mathrm{m}$ ) tras molturar en vía húmeda el polvo en un disolvente orgánico (dipropilenglicol metil eter) utilizando dos etapas de molienda diferentes. Las suspensiones obtenidas se han caracterizado y estabilizado para obtener materiales de aporte líquidos adecuados para ser utilizados en proyección térmica por plasma. El proceso de caracterización y estabilización se ha llevado a cabo mediante ensayos de sedimentación y caracterización reológica en ambas suspensiones empleando diferentes dispersantes.

Únicamente ha sido posible obtener recubrimientos con la suspensión con menor distribución de tamaños de partícula. Además, el empleo de una capa de anclaje de $\mathrm{TiO}_{2}$ ha dado lugar a una mejora en la eficiencia de deposición. Todos los recubrimientos obtenidos son totalmente amorfos. Además, presentan una microestructura compuesta por muchos poros redondos y aglomerados de vidrio que no han deformado totalmente al impactar contra el sustrato. 

Journal of the European Ceramic Society 36 (2016) 4281-4290

\title{
Bioactive glass suspensions preparation for suspension plasma spraying
}

\author{
E. Cañas ${ }^{a *}$, M. Vicent ${ }^{a}$, M.J. Orts ${ }^{a}$, R. Moreno ${ }^{b}$, E. Sánchez ${ }^{a}$ \\ a Instituto de Tecnología Cerámica (ITC), Universidad Jaume I, Castellón, Spain \\ b Instituto de Cerámica y Vidrio (ICV), Consejo Superior de Investigaciones Científicas \\ (CSIC), Universidad Autónoma de Madrid, Madrid, Spain
}

* Corresponding author

\begin{abstract}
A bioactive glass was dry-milled and sieved in order to obtain powders with particle size finer than $63 \mu \mathrm{m}$. Two suspensions, with different particle size distribution $\left(D_{50}=8,3 \mu \mathrm{m}\right.$ and $\left.D_{50}=2,2 \mu \mathrm{m}\right)$, were subsequently obtained from milling those powders in an organic solvent (dipropylene glycol methyl ether) by using two different grinding steps. The obtained suspensions were characterised and stabilised to produce adequate feedstocks to be used in suspension plasma spraying technique. For that purpose, sedimentation tests as well as rheological characterisation were carried out on both suspensions. Only the suspension feedstock containing the finest particle size, managed to produce a coating with suitable thickness and adherence on the substrate when a $\mathrm{TiO}_{2}$ bond coat was used. Besides $\mathrm{X}$-ray diffraction findings confirmed the amorphous nature of the obtained coatings. However, coating microstructure displayed many round, closed pores and surface observation revealed the presence of abundant non-deformed splats.
\end{abstract}

Keywords: Bioactive glass suspension; Rheology; Sedimentation; Suspension plasma spraying; Bioactive glass coating

\section{Introduction}

Nowadays, it is very usual to employ bioceramic materials to heal or replace damaged areas of the body, since these materials have an excellent biocompatibility with human body. Nevertheless, they are brittle materials with poor mechanical properties, therefore, their use in load-bearing applications is limited [1-5]. This constraint can largely be overcome by depositing these mate-rials onto metallic implants, obtaining a composite that combines good mechanical and biological properties [6]. There are several methods to deposit these materials, but the most common one is atmospheric plasma spraying (APS) due to its feasibility and the good bond between the coating and the substrate [7-10]. 
Crystalline calcium phosphate, like hydroxyapatite (HA), is the most employed bioceramic material to obtain bioactive coatings by APS, due to its similar composition to that of bones. Nevertheless, HA coatings require crystalline feedstocks of high purity, which increases the cost of the final product. Furthermore, during deposition by APS, HA tends to decompose partially resulting in coatings with a mixture of amorphous and crystalline zones, leading to a reduction of their bioactivity. Hence, to overcome this drawback in the development of biological coatings by APS, HA could be replaced by bioactive glasses (BGs), amorphous bioceramic materials which are prepared from a mixture of oxides such as $\mathrm{SiO}_{2}, \mathrm{CaO}, \mathrm{Na}_{2} \mathrm{O}, \mathrm{K}_{2} \mathrm{O}, \mathrm{MgO}$ and $\mathrm{P}_{2} \mathrm{O}_{5}$. The fabrication of sintered bioactive glasses is complex due to their tendency to crystallise during sintering, resulting in a delay of its bioactivity [11]. However, these materials could be obtained by two well-known techniques, namely the sol-gel method or the fusion and crushing procedure, i.e. the melting and subsequent quenching to obtain the glass powder [12,13]. Although HA and BG show good biocompatibility and have similar mechanical properties [1], bioactive glasses display higher bioactivity, resulting in less reaction time within the coating and the host tissue, and greater bonding between them $[1,2]$. Moreover, during the deposition by APS, bioactive glasses preserve their amorphous feature, which is necessary to obtain the desirable bioactivity of the BG coatings as reported in the literature [14-16]. Furthermore, their bioactivity is also affected by the $\mathrm{pH}$ of the medium as reported by Cerruti et al. [17]. Only at $\mathrm{pH} 8$ takes places the total reaction between bioactive glasses and surrounding tissues.

In the last few years, there has been a growing interest in the use of suspensions instead of powders as feedstock for plasma spraying. The liquid feedstock is fed into the plasma torch by injection or atomisation. This new technique is called suspension plasma spraying (SPS), and represents a solution to obtain fine microstructured coatings without handling very fine powders (with particle size lower than 5-10 $\mu \mathrm{m}$ ) which exhibit poor flowability to be plasma-sprayed [18]. Thus, the incorporation of these fine powders into stable suspensions that are subsequently fed into the plasma represents a feasible and interesting solution. Not less important, the use of a suspension instead of powder as a feedstock entails significant cost savings due to the simplification of the feedstock preparation and to the elimination of possible post-spray treatments [19]. Liquid feedstocks must exhibit very low viscosity to be injected into the plasma plume, as well as good physical and chemical stability, to evade the formation of agglomerates that can block the injector and impede a homogenous heating of the particles [19].

The SPS feedstocks could be prepared in both aqueous and organic medium, but not all organics are suitable for thermal spraying. The organic medium employed must accomplish some requirements such as adequate flash point or explosive limits in order to avoid accidents during spraying. Water and ethanol are the most employed liquids in SPS feedstocks preparation, each one showing advantages and disadvantages. When aqueous feedstock is employed, safer handling and storage are achieved but water vaporisation 
tends to cool the plasma plume, reducing the melting degree of the flying particles. On the other hand, when ethanol evaporates, an increment of the plasma plume temperature takes place, and consequently, the heat transmitted to the particles enhances particle melting. Nevertheless, employing an organic liquid makes it more dangerous the handling and storage in comparison with water, as mentioned by literature [20]. In the case of bioactive glass coatings obtained by SPS, the BG suspensions have to be prepared employing an organic medium instead of water, due to the chemical reaction (leaching) that occurs between the BG particles and water, which leads to a modification of the glass structure resulting in the gelling of the suspension [21].

Regardless the solvent used, BG feedstocks must be sufficiently stable for the suitable suspension conveying and spraying to occur. Stability means that particles in the suspensions must be well dispersed with little or no agglomeration trend during deposition. In fact, agglomerates can clog the nozzle hole as well as settle during suspension feeding giving rise to an inefficient or inadequate SPS process.

SPS of BG suspensions represents a very incipient research line in thermal spray literature. For this reason, very few papers on this topic are reported. In these papers, the preparation of the suspension feedstock does neither focus on the choice of a solvent (usually ethanol) nor on the solids content necessary for the SPS process to occur [22-24]. However, details about the colloidal or rheological behaviour of the suspension or time-stability (sedimentation trend) data of the SPS feedstock are rarely provided.

Consequently, the aim of the present work is to study and characterise the preparation process to produce stable bioactive glass suspensions from a BG powder. The final objective is to obtain suit-able non-aqueous suspension feedstocks for the SPS process. The working plan comprises two wet milling steps, since it is very difficult to reduce the particle size down to a few microns in just one step, employing an organic liquid as a milling and suspension medium. The organic solvent (dipropylene glycol methyl ether) was previously selected to accomplish with technical and safety requirements of the process. Both suspensions, obtained from each milling step, were rheologically characterised and sedimentation tests were also performed to determine their stability with time. Different dispersants were also tested to provide the desired sus-pension stabilisation.

Finally, both suspensions were sprayed on metallic substrates by SPS with the aim of knowing if they were suitable as feedstocks to obtain coatings, whose microstructure was examined by field-emission environmental scanning electron microscopy (FEG-ESEM) and their amorphous or crystalline feature was determined by $\mathrm{X}$-ray diffraction (XRD). 


\section{Experimental}

\subsection{Feedstocks preparation and characterisation}

In the present work, a bioactive glass with a composition of $47,6 \mathrm{SiO}_{2}, 5,3 \mathrm{P}_{2} \mathrm{O}_{5}$, $23,1 \mathrm{CaO}$ and $24,0 \quad \mathrm{Na}_{2} \mathrm{O}$ (in oxide wt\%) was obtained by melting and quenching, as previously reported [25]. Then, the glass was dry milled in a hammer mill and sieved to obtain a powder with a particle size lower than 63 $\mu \mathrm{m}$. The obtained powder was mixed with an organic liquid maintaining the solids content as 10 vol.\%. Dipropylene glycol methyl ether (Dowanol DPM, Dow Chemical, USA) was employed as organic suspension medium, since this environmental sound solvent provides good results as suspension medium when it is employed to prepare ceramic inks for digital printing. In table 1, are summarised the main characteristics of this medium in comparison with ethanol, a solvent commonly used in SPS process. It can be appreciated that the physical properties of both solvents (viscosity and surface tension) are quite similar, but Dowanol DPM has higher flash point than ethanol making handle, storage and transport of Dowanol suspensions safer and easier. On the other hand, the evaporation rate of Dowanol is lower than that of ethanol (higher vapour pressure and enthalpy of vaporisation). However, this constraint could be solved by increasing the solids content, resulting in a reduction of the amount of solvent to evaporate.

Table 1 Main properties of the organic medium employed compared with ethanol (obtained by suppliers)

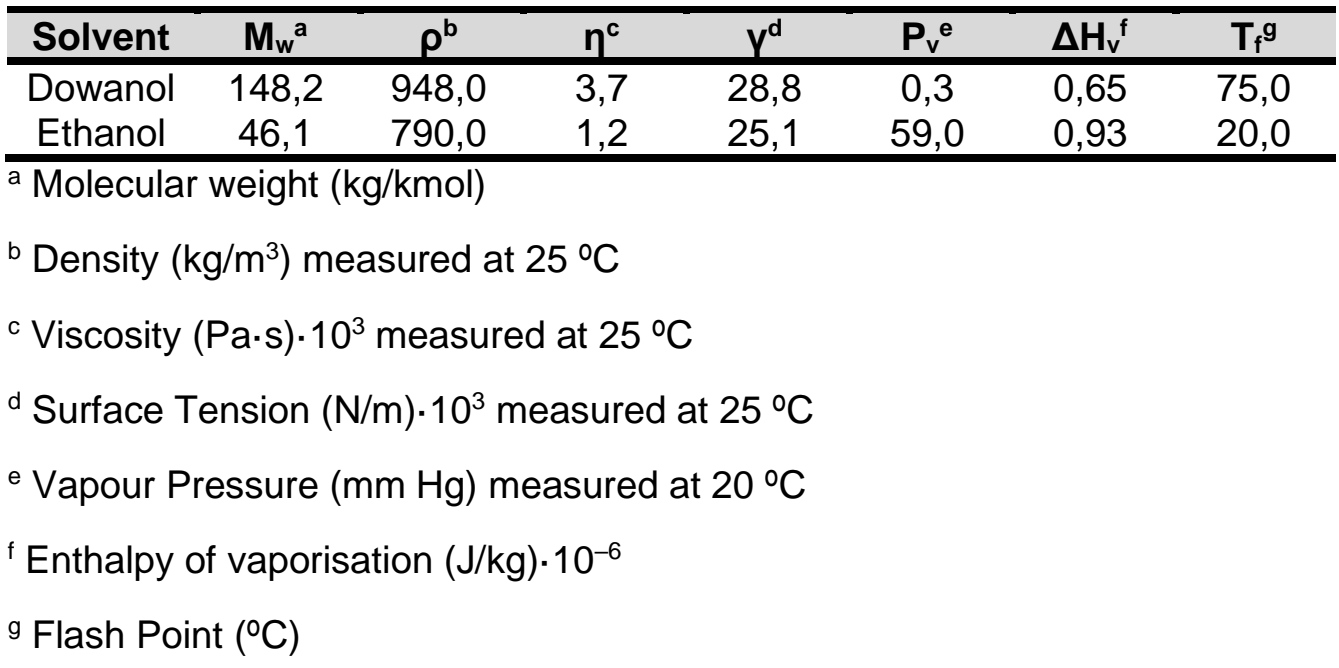

The resulting mixture was wet milled in a planetary mill (Pulverisette 5, Fritsch $\mathrm{GmbH}$, Germany) with alumina balls, to obtain a bioactive glass suspension (referred to as BG-Pul). The optimum milling time to achieve the finest particle size in the first milling step was determined by sedimentation in a test tube. For that purpose, various tests were carried out for different times, measuring for each time the volume of suspended solids in the test tube after one hour. When this volume remains constant, it means that finer particle size cannot be 
achieved with longer milling time. Moreover, density of the obtained suspension was determined by pycnometer, and the particle size distribution was measured by laser diffraction (Mastersizer 2000, Malvern Instruments, Great Britain).

Moreover, rheological and sedimentation tests were performed on the suspension with and without several selected dispersants, that were tested in different proportions in order to stabilise the suspension to prevent agglomeration and sedimentation. Based on previous research on the dispersion of non-aqueous, ceramic suspensions, the selected dispersants tested in this work were as follows [26]:

- A combination of monoesters and diesters with a carbon chain length of 15-25 units (Emphos PS21A, Witco Chemical, USA) referred to as Pho.

- An anionic polymeric dispersant (Hypermer KD7, Croma, UK) referred to as KD7.

- A triglyceride with three units of unsaturated fatty acid, specifically oleic acid (Glyceryl trioleate, Fluka, Germany) referred to as Triol.

- A solution of a block copolymer of high molecular weight (Disperbyk 190, Byk, Germany) referred to as D190.

The rheological study, performed at $25{ }^{\circ} \mathrm{C}$ using a double-cone and plate system, was done using a rheometer (Haake RS50, ThermoScientific, Germany). With this equipment the rate was controlled (CR) by loading the shear rate from 0 to $1000 \mathrm{~s}^{-1}$ in $5 \mathrm{~min}$, maintaining it at $1000 \mathrm{~s}^{-1}$ for $1 \mathrm{~min}$ and downloading it from 1000 to $0 \mathrm{~s}^{-1}$ in $5 \mathrm{~min}$.

Sedimentation tests, to determine the stability of the suspensions [27], were carried out in a multiple light scattering equipment (TurbiScan Classic MA2000, Formulaction, France), which can measure the variation with time of the amount of light backscattered by the suspended solids and the percentage of light transmitted by the liquid along the glass cell that contains the suspension. As a result, a family of curves (each one corresponding to a measurement of time) is obtained, which represents the percentage of light backscattered or transmitted as a function of glass cell height. All sedimentation tests were performed for one hour, taking data every five minutes. Figure 1 shows an example of stability test. On the left of that figure, an empty glass cell (Figure 1a) and filled with suspension (Figure 1b corresponds to the beginning of the test, Figure 1c after half an hour and Figure 1d after one hour) are shown. On the right, the theoretical curves obtained from the experiment are plotted. In figure $1 \mathrm{~b}$, the amount of light backscattered is the same along the entire cell; consequently, the obtained curve displays a straight profile. Nevertheless, as the solids settle (Figure 1c and d), the amount of light backscattered becomes higher on cell bottom, leading to a curve with peaks and valleys as shown by the theoretical curves. 

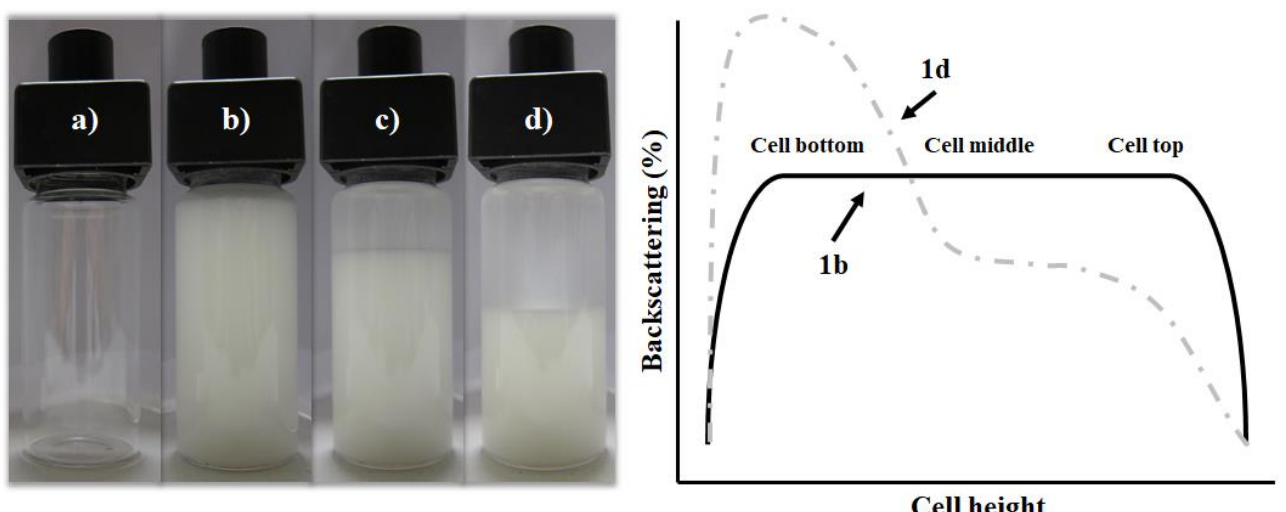

Figure 1 Left) Example of the glass cell employed in sedimentation tests. a: empty, b: full of suspension and ready for the test, c: with suspension after $0,5 \mathrm{~h}$ test and $\mathrm{d}$ : with suspension after $1 \mathrm{~h}$ test. Right) Theoretical sedimentation curves plotting the corresponding backscattering for pictures $1 \mathrm{~b}$ ) and 1d)

Then, the second wet milling step was performed on the BG-Pul suspension containing dispersant in order to reach finer particle size. The nature and amount of the dispersant used were chosen depending on the obtained results once the rheological studies and the sedimentation tests were finished. The milling was carried out with an attrition mill (Dispermat SL, VMA-Getzmann $\mathrm{GmbH}$, Germany) containing very small grinding zirconia balls of $0.8 \mathrm{~mm}$ mean size. A milling mixture of 10 vol.\% solids and 90 vol.\% Dowanol DPM was used. The obtained suspension (referred to as BG-Att) was characterised in the same way as the previous BG-Pul suspension (density, particle size distribution, rheological and sedimentation tests). Previously to characterisation, the optimum milling time was also determined. Nevertheless, this time cannot be assessed by sedimentation (as in the first milling step) since no distinction is possible between a turbid zone and a clear area due to the fine particle size of the ground suspension. Hence, particle size distribution was measured by laser diffraction for each milling time. Finally, particles morphology of the solid material in both suspensions was assessed by FEG-ESEM (QUANTA 200FEG, FEI Company, USA).

\subsection{Deposition and characterisation of the coatings}

Both types of suspensions (BG-Pul and BG-Att) were sprayed on metallic substrates by suspension plasma spraying (SPS). Coatings were deposited with a plasma torch (F4-MB, Sulzer Metco, Switzerland) managed by a six axes robot (IRB 1400, ABB, Switzerland) employing argon as primary plasma gas and hydrogen as secondary plasma gas. The substrates, which were made of AISI type 304 stainless steel, had disc shape with a diameter of $25 \mathrm{~mm}$. Prior to coatings deposition, substrates were grit-blasted using black corundum with a pressure of 4,2 bar and were cleaned with ethanol, being the obtained 
roughness $\left(R_{a}\right) 2,2 \pm 0,1 \mu \mathrm{m}$. This value was determined employing a roughness tester (HOMMEL-WERKE T8000, Hommelwerke GmbH, Germany). A TiO 2 powder was deposited by atmospheric plasma spraying (APS) from commercial anatase feedstock (Metco 102, Sulzer Metco, Switzerland), with particle size distribution between 10 and $55 \mu \mathrm{m}$, as bond coat to enhance coatings adhesion such as reported by literature $[23,28]$. Moreover, the substrates were preheated between $300-350^{\circ} \mathrm{C}$ to increase the adhesion too [29].

To deposit both suspensions, an injection system developed by the Instituto de Tecnología Cerámica (ITC) was coupled to the plasma torch [30]. The system is made up of two pressurised containers, which force the liquid to flow through an injector due to the pressure difference. A filter was placed into the injector to remove large agglomerates and possible contaminations that can clog the injector. The spraying conditions, based on literature data as well as on some previous research by the authors [22,31], are detailed in Table $2\left(\mathrm{TiO}_{2}\right.$ spraying parameters were given by the supplier).

Table 2 Plasma spray conditions used for each type of suspension feedstock as well as for the $\mathrm{TiO}_{2}$ powder bond coat

\begin{tabular}{cccc}
\hline Parameter & $\mathrm{TiO}_{2}$ bond coat & BG-Pul & BG-Att \\
\hline Argon flow rate $(\mathrm{slpm})$ & 38 & 37 & 37 \\
Hydrogen flow rate $(\mathrm{slpm})$ & 14 & 8 & 8 \\
Intensity $(\mathrm{A})$ & 600 & 700 & 700 \\
Spraying distance $(\mathrm{mm})$ & 120 & 80 & 80 \\
Spraying velocity $(\mathrm{m} / \mathrm{s})$ & 1,00 & 1,25 & 1,25 \\
Nozzle diameter $(\mathrm{mm})$ & 1,8 & - & - \\
Powder flow rate $(\mathrm{g} / \mathrm{min})$ & 45 & - & - \\
Injector diameter $(\mathrm{mm})$ & - & 0,25 & 0,20 \\
Suspension flow rate $\left(\mathrm{cm}^{3} / \mathrm{min}\right)$ & - & 89 & 19 \\
\hline
\end{tabular}

The spraying conditions were the same for both suspensions except the diameter of the injector, which was changed depending on the particle size distribution of the solid fraction in each suspension. Consequently, the suspension flow rates were different too. It should be noticed that these spraying conditions were not optimised since the optimising process was out of the scope of this paper. The amorphous/crystalline feature of the obtained coatings was assessed by XRD using a diffractometer (Advance diffractometer, Bruker Theta-Theta, Germany) and their microstructure was observed by FEG-ESEM.

\section{Results and discussion}

\subsection{First wet milling step (planetary mill)}

Figure 2 plots the results of sedimentation tests for the different milling times performed, measured as volume of suspended solids in a test tube, in order to determine the optimum milling time for this step. 


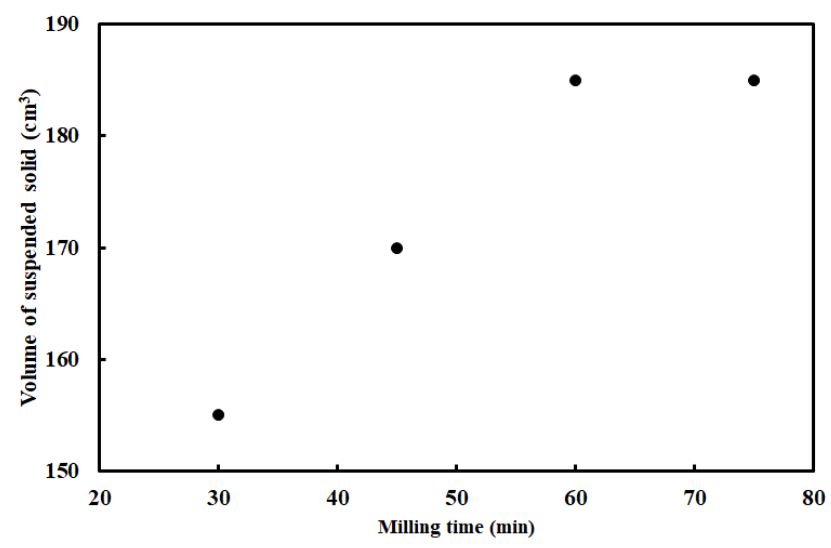

Figure 2 Variation of the suspended solids volume in sedimentation tests for different milling times (first milling step)

As expected, particle size decreases with the increment of milling time, resulting in a slower sedimentation rate and higher volume of suspended solids as a consequence of particle build-up in the suspension. Besides, after one milling hour the volume of suspended solids remains constant, thus finer particle size cannot be reached with this milling step. Therefore, this time is considered as the optimum time. The particle size distribution of the obtained suspension after one hour milling is plotted in figure 3 (continuous and dotted black curves for cumulative and frequency distributions respectively). In addition, particles morphology is shown in figure $4 a$.

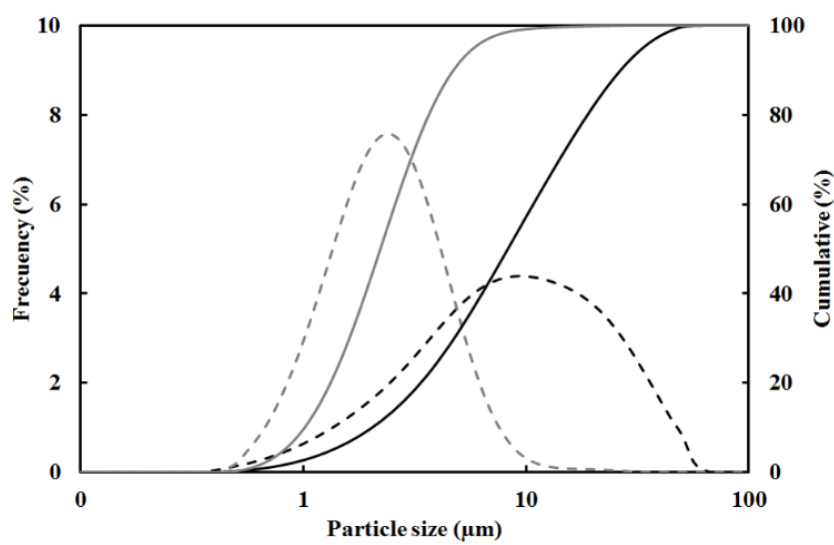

Figure 3 Particle size distributions for both types of suspensions. Continuous and dotted curves correspond to cumulative and frequency distributions respectively for $\mathrm{BG}-\mathrm{Pul}$ suspension after one hour milling (black) and BG-Att suspension after $3 \mathrm{~h}$ milling (grey) 

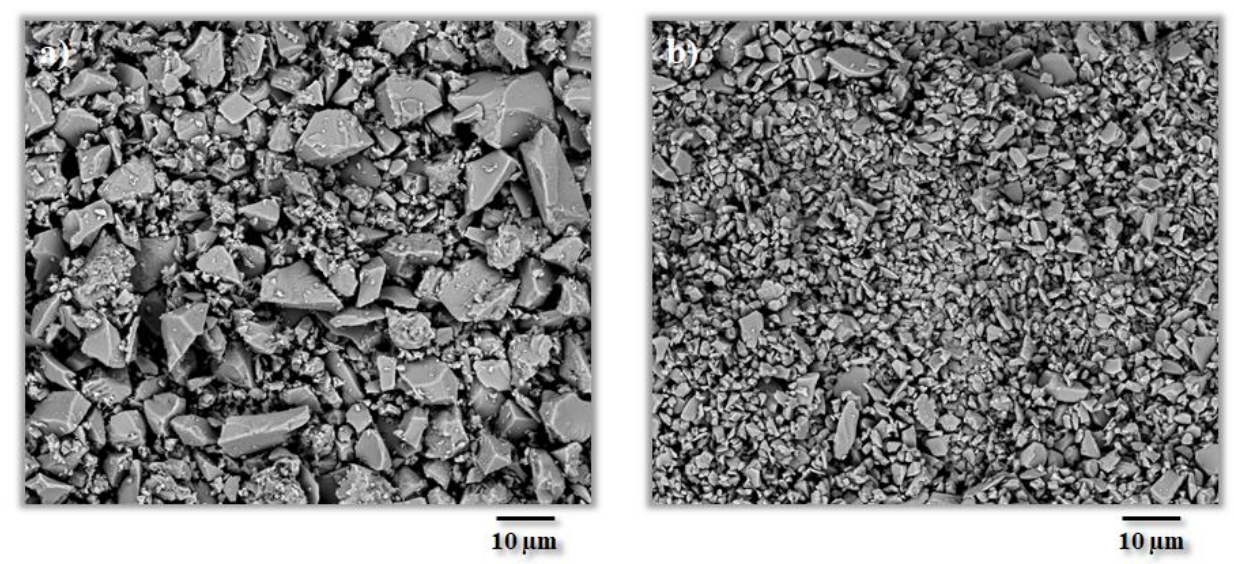

Figure 4 Particles morphology obtained after drying both suspensions. Figure 4a: BG-Pul suspension (first milling step). Figure 4b: BG-Att suspension (second milling step)

A wide monomodal particle size distribution was obtained with $D_{10}=2,0 \pm 0,3$ $\mu \mathrm{m}, \mathrm{D}_{50}=8,3 \pm 0,6 \mu \mathrm{m}$ and $\mathrm{D}_{90}=26,5 \pm 0,8 \mu \mathrm{m}$. This is a typical particle size distribution obtained in a planetary, laboratory ball mill. The width and average particle size of the distribution can also be observed in the SEM pictures of figure $4 \mathrm{a}$, where particles of different sizes are shown, being coarse particles (> $10 \mu \mathrm{m})$ quite predominant. In addition, all particles display the typical angular shape morphology of ground glass particles.

Finally, density of the resulting suspension was also determined, being 1075 $\mathrm{kg} / \mathrm{m}^{3}$. Concerning the stability of the BG-Pul suspension, the results obtained for the rheological tests are plotted in figure 5 as flow curve, which represent the shear stress as a function of the shear rate. This type of graph allows assessing the suspensions rheological behaviour in terms of viscosity, defined as the slope of the obtained curves, and the time dependence of flow behaviour (being thixotropy the most common case), which can also be obtained from this flow curve as the area closed between the uploading and downloading steps of the measurement [32].

In addition, table 3 sets out the values of thixotropy and viscosity measured at $900 \mathrm{~s}^{-1}$ shear rate in uploading step, of suspensions plotted in this figure. 


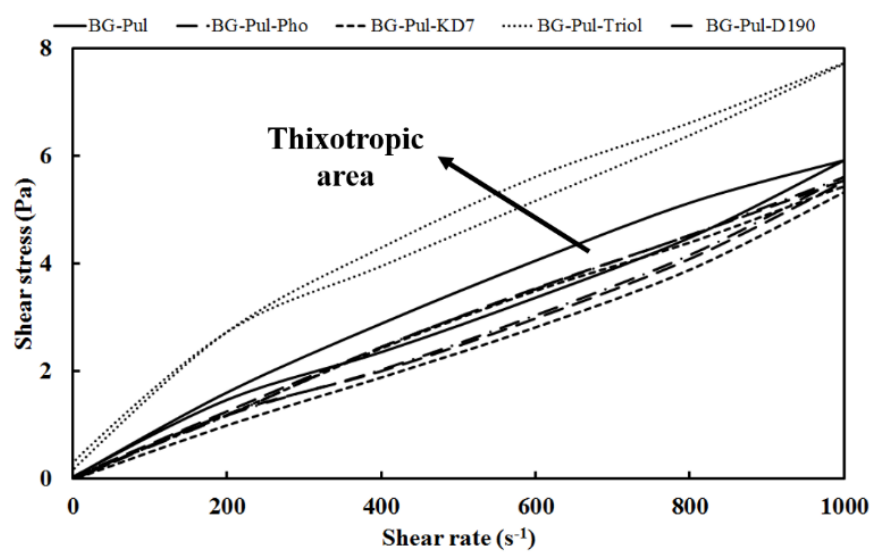

Figure 5 Flow curve for the BG-Pul suspension, with and without $0,5 \mathrm{wt} \%$ of the four tested dispersants, showing the thixotropic area

Table 3 Values of thixotropy and viscosity (measured at $900 \mathrm{~s}^{-1}$ shear rate in uploading step) of the BG-Pul suspensions with and without deflocculants, represented in figure 5

\begin{tabular}{ccc}
\hline Suspension & Thixotropic cycle $\left(\mathbf{P a} \cdot \mathbf{s}^{\mathbf{- 1}}\right)$ & Viscosity $(\mathbf{P a} \cdot \mathbf{s}) \cdot \mathbf{1 0}^{\mathbf{3}}$ \\
\hline BG-Pul & 373 & 6,0 \\
BG-Pul-Pho & 277 & 5,5 \\
BG-Pul-KD7 & 369 & 5,4 \\
BG-Pul-Triol & 193 & 7,9 \\
BG-Pul-D190 & 231 & 5,5 \\
\hline
\end{tabular}

It can be observed that, after the first milling step, the obtained suspension shows a pseudoplastic behaviour with a viscosity value of approximately $6 \cdot 10^{-3}$ $\mathrm{Pa} \cdot \mathrm{s}$ (measured at $900 \mathrm{~s}^{-1}$ shear rate In uploading step) as well as a visible thixotropic cycle of $373 \mathrm{~Pa} \cdot \mathrm{s}^{-1}$.This high thixotropy was consequence of the flocculated (structured) state of the suspension. This undesirable behaviour was tried to be changed by preparing mixtures of BG-Pul suspension with 0,5 wt\% (\% relative to solids content) of different (four) dispersing agents as set out in section 2.1. The flow curves obtained are also shown in figure 5. Higher amounts of dispersant were not used due to the difficulty, in some cases, of preparing homogeneous mixtures.

These flow curves demonstrate that the suspension maintains the pseudoplastic behaviour with the four different dispersant agents tested, but only Pho, KD7 and D190 dispersants reduced both viscosity and thixotropy, being this reduction minimal with regard to the suspension without dispersant (Table 3). Concerning the suspension in which Triol dispersant was used, a significant reduction of thixotropic cycle takes place, however, the viscosity increases with respect to the BG-Pul suspension (Figure 5 and Table 3). Since Triol is a non-ionic surfactant, it seems that the presence of charges is necessary to promote the required electrostatic repulsion to maintain stability and to overcome the strong tendency to settle. 
In brief, it can be stated that the addition of the non-ionic deflocculant (Triol) to the BG-Pul suspension does not provide the desired stability, since an increment of suspension viscosity takes place. A priori, only the addition of the ionic deflocculants (Pho, KD7 andD190) seem to do it (reduction of suspensions thixotropy and viscosity), but the reduction in viscosity is too low $\left(0,6 \cdot 10^{-3} \mathrm{~Pa} \cdot \mathrm{S}\right.$, as observed in table 3 ) to detect significant differences between suspensions containing these dispersants, and to determine the optimum dispersant agent which can stabilise the suspension. In addition, the tendency to settle is too high with all dispersant agents to preserve stability with time, so that sedimentation studies are necessary to determine the best dispersing conditions in terms of time stability [20].

Figure 6 represents the results of sedimentation tests for the BG-Pul suspension. This kind of plot shows the amount of light backscattered by the suspension into the cell as a function of time. At the beginning of the test (continuous black curve from figure 6a) the amount of light backscattered is the same in the three zones of the vessel since the material has not begun to settle. For stable suspensions, those values of backscattered light should not change with time (the initial curve should remain unchanged). On the contrary, when the suspension is not stable, particles settle during the test, and the amount of backscattered light increases at the bottom and in the middle (depending on the sedimentation rate) of the cell, but decreases at the top. This phenomenon is illustrated in Figure 6a, for the curves plotted in function of the sedimentation time, as a deformation of the initial curve leading to a peak or flat profile in the area corresponding to the cell bottom while this profile progressively branches for the rest of the cell (continuous grey curve from figure 6a). Therefore, from the analysis of the figure corresponding to the BG-Pul suspension, it can be deduced that this suspension is highly unstable, since the solid material rapidly settles with time.

The high sedimentation tendency of BG-Pul sample (Figure 6a) is a consequence of a low viscosity but highly structured (flocculated) suspension as set out above. Nevertheless, the addition of these four dispersants gave rise to dramatic changes in the evolution of the sedimentation curve profile. From the above figure, it can be stated that KD7 (Figure 6c) and D190 (Figure 6e) dispersants improved suspension stability, since the values of the backscattered light with time increased in the middle and the top of the cell. Moreover, the stability increment is much more significant for D190 sample. On contrary, dispersant Pho (Figure 6b) slightly retards the sedimentation with respect to the suspension without deflocculant (Figure 6a), and Triol sample (Figure 6d) does not improve stabilisation and cannot impede the fast sedimentation of the suspended solids. This behaviour can be observed in figure $6 \mathrm{~d}$ as the appearance of a flat curve at the zone corresponding to cell bottom, accompanied with a sharp drop of the backscattered light values from the cell top zone. With these tests the best dispersing conditions can be established in terms of sedimentation rate as no significant differences were found in the flow curves as reported above. 

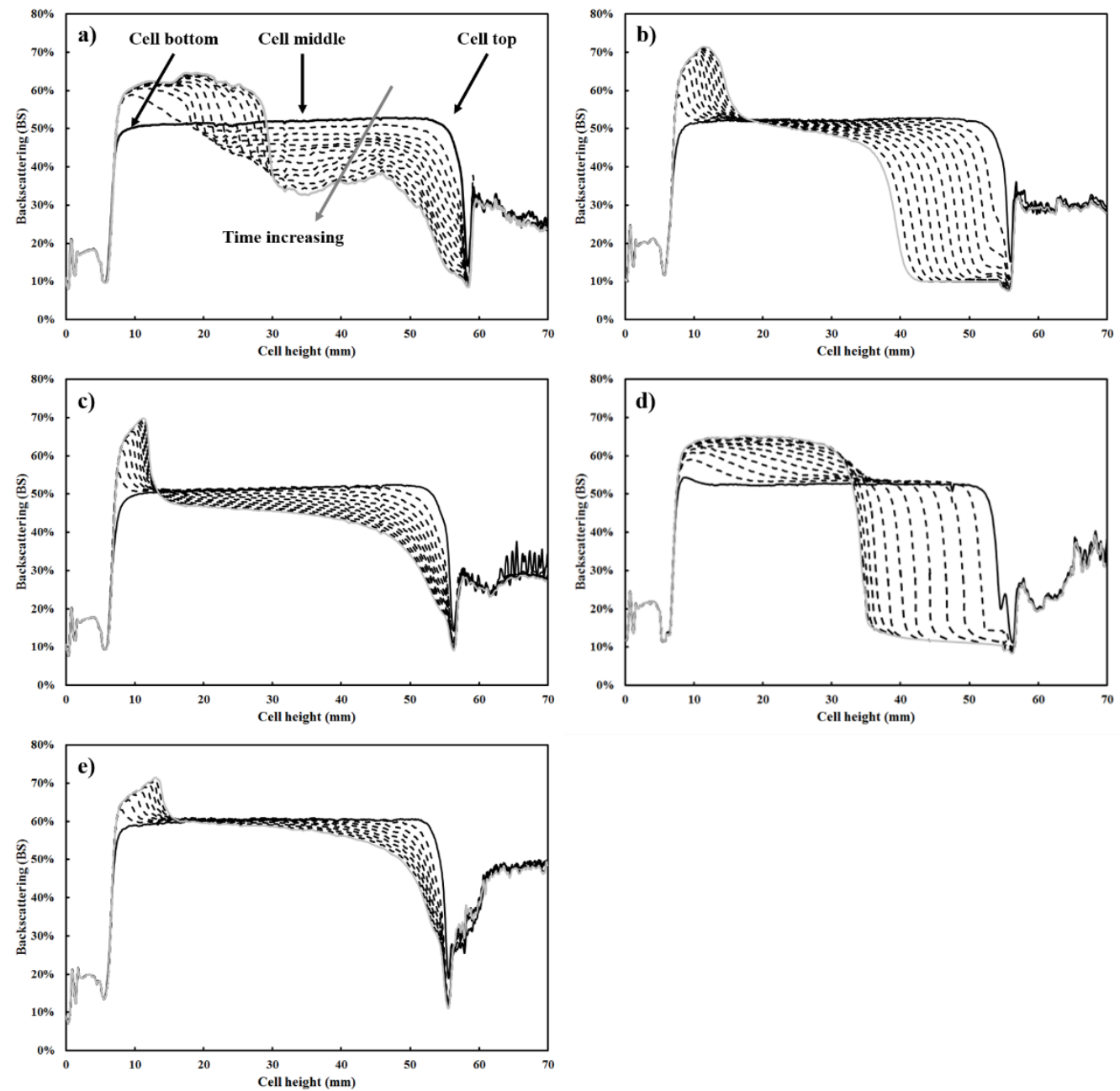

Figure 6 Results of the sedimentation test for the BG-Pul suspension without and with dispersant agents. Each curve from top to bottom represents the sedimentation profile monitored every five minutes during the sedimentation test until one hour. a) Without, b) Pho, c) KD7, d) Triol, e) D190

Consequently, taking into account the results obtained from the sedimentation tests, D190 was chosen as the optimum dispersant agent, as this additive reduces suspension viscosity and thixotropy as well as sedimentation tendency, giving rise to a stable suspension which can be used as SPS feedstock [19,20]. However, the particle size of the suspended solids $\left(D_{50}=8,3 \pm 0,6 \mu \mathrm{m}\right)$ can make it difficult the feeding of the suspension through the injection nozzle into the plasma torch. For this reason, a second milling step was addressed.

\subsection{Second wet milling step (attrition mill)}

As mentioned above a second wet milling step was implemented by grinding the BG-Pul-D190 suspension in an attrition mill. The obtained suspension was 
referred to as BG-Att-D190. Figure 7 plots the evolution of the characteristic particle diameters of the solids in suspension determined by laser diffraction as a function of milling time.

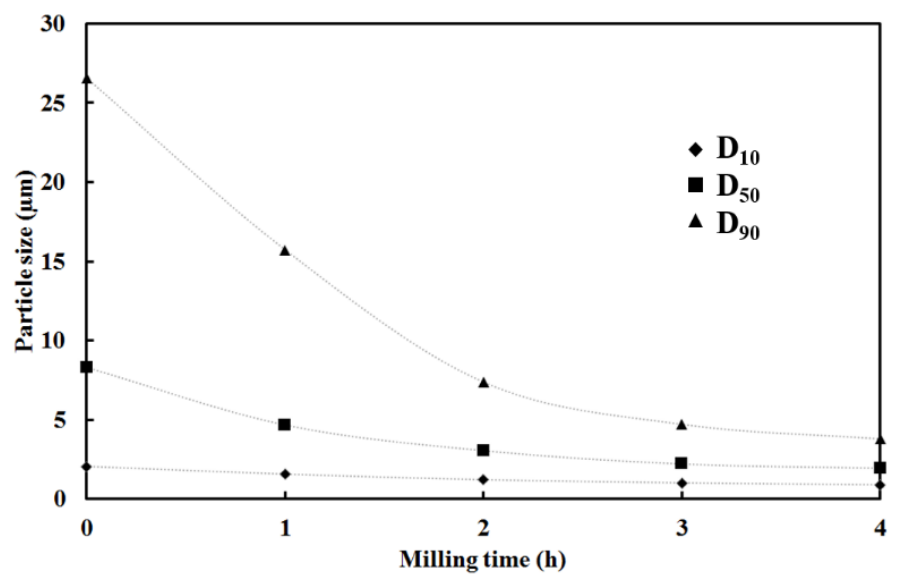

Figure 7 Particle size distributions of the BG-Att-D190 suspension in function of the milling time (three characteristic particle sizes of the distribution curve are shown)

It can be observed that fine particles $\left(D_{10}\right)$ hardly changed their size, while medium sizes $\left(D_{50}\right)$, reduced their initial size by factor 4 and coarse particles $\left(D_{90}\right)$ by factor 6 . In addition, this figure shows that after three hours of milling, the size of the particles hardly varies, hence this time was chosen as the optimum grinding time for the second milling step.

The particle size distribution of the obtained suspension (BG-Att-D190) after three hours milling is plotted in figure 3 (continuous sand dotted grey curves) and the particles morphology are shown in figure $4 \mathrm{~b}$. In addition, density was also determined being $1078 \mathrm{~kg} / \mathrm{m}^{3}$, very close to that of the BG-Pul suspension as expected.

Characteristic particle diameters of the BG-Att-D190 suspension after three hours milling (Figure 3 ) are: $D_{10}=1,0 \pm 0,1 \mu \mathrm{m}, D_{50}=2,2 \pm 0,1 \mu \mathrm{m}$ and $D_{90}=4,7$ $\pm 0,2 \mu \mathrm{m}$. It can be shown that the particle size distribution remains monomodal, but a narrowing effect occurs when compared with the BG-Pul distribution (Figure 3). In addition, particle size of the new suspension was significantly reduced. In reference to the morphology of the particles (Figure 4b) all of them also display the typical angular shape of ground glass particles. As evidenced by this figure, after the second milling step particles were finer and quite similar in shape.

To evaluate the effect of the second milling step on the stability of the BG-AttD190 suspension, the flow curve of this suspension was determined, and plotted with the curve corresponding to the BG-Pul-D190 suspension as shown in figure 8. 


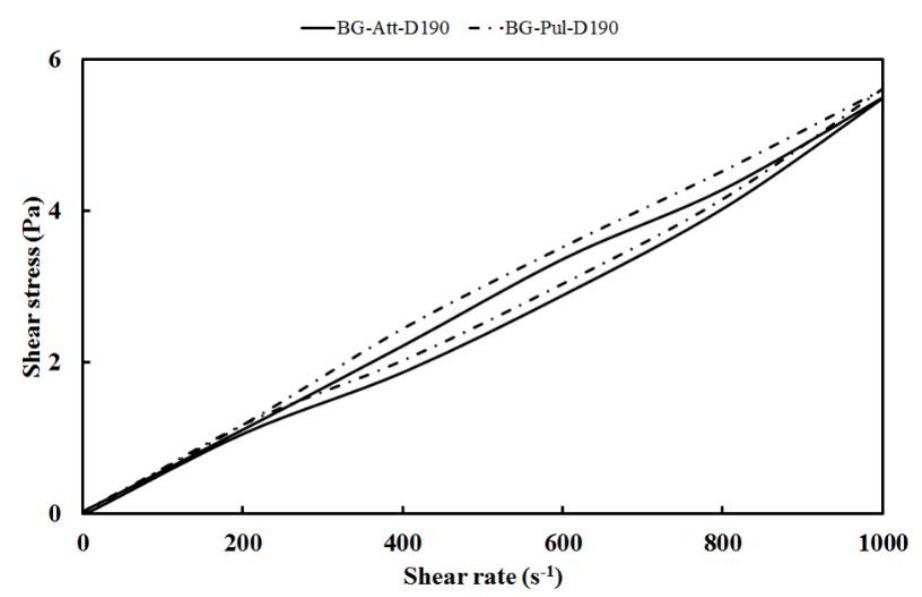

Figure 8 Flow curve for the BG-Att-D190 and BG-Pul-D190 suspensions

As it can be seen, this new suspension displays a pseudoplastic behaviour similar to that of the BG-Pul-D190 sample. Viscosity value (determined at 900 $\mathrm{s}^{-1}$ shear rate in uploading step) and thixotropy area were approximately $5,4 \cdot 10^{-3} \mathrm{~Pa} \cdot \mathrm{s}$ and $219 \mathrm{~Pa} \cdot \mathrm{s}^{-1}$ respectively. When compared with the data of the equivalent suspension (BG-Pul-D190) ground in the first milling step (Table 3), it can be stated that the dispersing efficiency of D190 additive is maintained through the second high-energy milling step. Nevertheless, the viscosity values are still too low to observe significant differences between both suspensions. Consequently, as in the first milling step, sedimentation tests are necessary to check the stability of the BG-Att-D190 suspension. The obtained results are shown in figure 9. In this figure, two sedimentation tests are shown, one test lasted one hour (Figure 9a) and the other one lasted $24 \mathrm{~h}$ (Figure 9b).
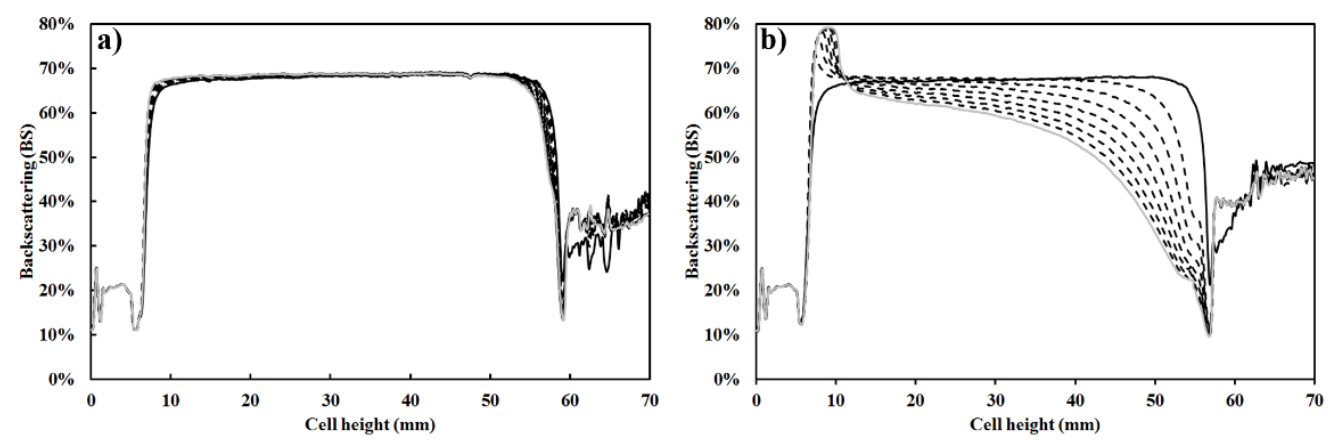

Figure 9 Results for the sedimentation test performed to the BG-Att-D190 suspension. a) After one hour, b) after $24 \mathrm{~h}$

As it could be expected, the presence of the dispersant agent influences the stability of the suspension as shown in figure 9a. Thus, after one hour practically no sedimentation occurs as deduced by the curves profile in this figure. However, sedimentation still occurs for longer times as it is demonstrated in 
figure $9 \mathrm{~b}$ (24 $\mathrm{h}$ test, taking measures every three hours) as the drop of the backscattered light values from the cell top zone after three hours test.

As a summary, the dispersant effect of D190 remains after the second milling step and it can be stated that although solids sedimentation takes place with time, the BG-Att-D190 suspension is quite stable (until $1 \mathrm{~h}$ ). As the suspension is easily redispersable, for longer periods of time, it would be enough to agitate the solids settled (zone of the curve shown in Figure 9b comprised between 5 and $12 \mathrm{~mm}$ of cell height) to disperse again the particles and to obtain a stable suspension for another hour.

\subsection{Coatings deposition and characterisation}

Suspensions obtained from each milling step were used as SPS feedstock. Both suspensions (BG-Pul and BG-Att) contained the dispersant D190 due to the positive effect shown by this additive, which managed to produce stable suspensions with an absence of sedimentation over one-hour period, as shown in figures $6 \mathrm{e}$ and $9 \mathrm{a}$. This time of stability was considered sufficient for the SPS process. In fact, the estimated time that the suspension stays in the SPS container and circuit for a real sample (not just a $25 \mathrm{~mm}$ disk) could be kept approximately lower than $1 \mathrm{~h}$, in function of type and dimensions of the sample (screw of a dental implant, hip prosthesis, etc). In these cases, the redispersion of the suspension by simple agitation would be the procedure to be followed as explained above.

The next step was the SPS deposition, which took place following the conditions described in table 2 , to prove that it is possible to obtain coatings from these suspensions (preliminary coatings). As mentioned above, a $\mathrm{TiO}_{2}$ bond coat previously deposited by APS from powder feedstock was also used. When BGPul-D190 suspension feedstock was used (regardless of the presence of bond coat), no coating was obtained due to nozzle clogging caused by the presence of coarse glass particles and most probably by the formation of large agglomerates of finer particles. Thus, coatings were only obtained when the high-energy milled suspension (BG-Att-D190) was employed without or with a previous $A P S \mathrm{TiO}_{2}$ bond layer, being preliminary coatings as mentioned above. Figure 10 displays the FEG-ESEM micrographs (section and surface) of the two coatings obtained from BG-Att-D190 suspension without and with the bond coat. 

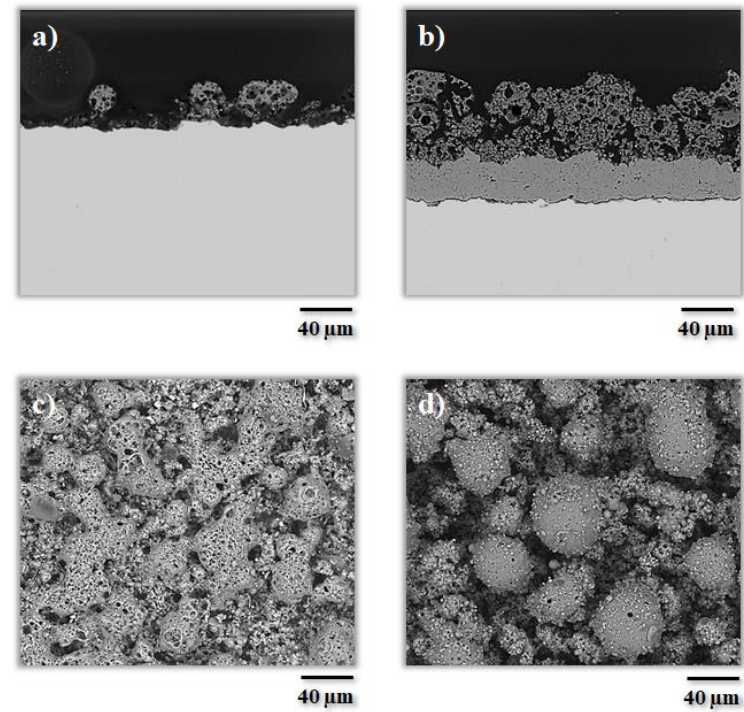

Figure 10 FEG-ESEM micrographs for coatings obtained with the BG-Att-D190 suspension. Figures 10a (surface) and 10c (section) without bond coat. Figures 10b (surface) and 10d (section) with bond coat

The coating showed in figure 10a (without bond coat), exhibits the typical cracked and porous microstructure of a glass coating [22]. Nevertheless, as it can be seen, its thickness is very thin ( $20 \mu \mathrm{m}$ approximately). When $\mathrm{TiO}_{2}$ bond coat was deposited before the glass layer, the obtained coating still shows the cracked and rounded porous microstructure of a glass coating, since the bond coat enhances coating adhesion but does not affect the coating microstructure $[23,33]$. However, the coating thickness significantly grows $(60 \mu \mathrm{m}$ approximately) with regard to the coating without bond coat $(20 \mu \mathrm{m})$. This unexpected finding can be due to the following causes: the spraying distance employed in coating deposition, the presence of a bond coat and the thermal conductivity values of the substrate (AISI type 304 stainless steel) and the bond coat $\left(\mathrm{TiO}_{2}\right)$. In both cases (with and without bond coat), due to the long spraying distance, most of the glass particles, which become agglomerated after the evaporation of the solvent, are melted and partially re-solidified during their flying along the plasma torch, reaching the substrate with insufficient temperature to be attached to the substrate [24]. Moreover, in the case of the coating without bond coat (Figure 10a), these agglomerates do not stick to the substrate due to the poor adherence between the ceramic top layer and the metallic substrate. On the other case (coating with bond coat), although the agglomerates have also melted and re-solidified, the presence of the bond coat enhances the adhesion between the glass coating and the substrate. In addition, since $\mathrm{TiO}_{2}$ has a low thermal conductivity than the substrate (AISI type 304 stainless steel), the heat was not released too quickly from the glass agglomerates when impacting, giving to a progressive heating of the system with each torch cycle and reaching a temperature higher than the glass 
transition temperature $\left(T_{g}=520 \stackrel{\circ}{\circ}\right)$ [25]. As a result, a viscous glass coating was formed, and therefore an increment of the deposition efficiency took place. At this point, all particles (including there-solidified ones) can easily stick to the coating [22-24].

These differences between both coatings can also be observed in the SEM pictures of coating surfaces (Figure 10c and d). In the case of the coating without bond coat (Figure 10c), a slightly irregular surface $\left(R_{a}=10,9 \pm 0,5 \mu \mathrm{m}\right)$ was developed due to the faster release of heat when glass particles impact, their inefficient deformation and their lowest adherence to the substrate. In the bond coated sample (Figure 10d), the increment in the deposition efficiency is evident, since the surface is more irregular $\left(R_{a}=12,0 \pm 0,4 \mu \mathrm{m}\right)$ than that of the other coating, with more material and plenty of large rounded glass agglomerates with a size of approximately tens of microns in diameter. However, this size is higher than that of the individual glass particles in the suspension. The formation of these coarse agglomerates is due to perturbations in the plasma torch, which reduce the perpendicular velocity component of the finest particles and increase the parallel velocity component of these particles before impacting onto the coating. As a consequence, the finest particles were deviated from their initial path and impact on the asperities (glass agglomerates) of the coating developed, forming a columnar structure namely the "cone shaped" structure [22,34], which is typical of some coatings obtained by SPS. As mentioned above, the coating keeps in a viscous state when these fine particles were deviated, therefore when they impact on the asperities, an increment of their size occurs. Regardless the different contributions which can play a role in the development of these coatings, findings evidence that the spraying conditions must be optimised in order to produce coatings that maintain this roughness (good bioactivity) with adequate mechanical properties (low internal porosity) [24]. A research with this purpose is already in progress. Finally, both coatings display an amorphous character, as demonstrated by the obtained XRD-patterns. Figure 11 shows the XRD-pattern, which corresponds to the BG-Att-D190 coating with a bond layer (the other coating, without a bond coat, shows a similar XRD-pattern). This finding indicates that the amorphous character of the feedstock used in suspensions preparation, was preserved. Hence, it can be stated that no crystalline phases were developed, due to the high temperatures reached in the plasma plume, which melt any possible crystalline phase, as well as to the fast cooling of the splats when impacting on the substrate preventing coating devitrification. Amorphous nature in the glass coating is a necessary factor to optimise the glass coating bioactivity as reported elsewhere [14-16]. Simulated Body Fluid (SBF) tests to confirm the bioactivity index of the obtained coatings will be presented in the coming research.

\section{Conclusions}

A bioactive glass powder, with amorphous character and micro-metric particle size, was obtained from a frit. This powder was mixed with dipropylene glycol 
methyl ether as liquid solvent in order to develop a new type of feedstock for suspension plasma spraying. The mixture was wet milled in a planetary mill, obtaining a bioactive glass suspension (BG-Pul) with an average particle size of $D_{50}=8,3 \pm 0,6 \mu \mathrm{m}$. Sedimentation of this suspension could be reduced by adding a dispersing agent. Nevertheless, this suspension feedstock could not be sprayed into the plasma torch owing to nozzle clogging produced by the large particle and agglomerate sizes contained in this suspension.

A second milling step was then performed, grinding the BG-Pul suspension containing a dispersant $(0,5 \mathrm{wt} \%$ of $\mathrm{D} 190, \%$ relative to solids content) in an attrition mill, obtaining a suspension (BG-Att) with much finer particle size $\left(D_{50}=2,2 \pm 0,1 \mu \mathrm{m}\right)$. The viscosity and thixotropic cycle of this suspension as well as the sedimentation rate become very low by means of this added, selected dispersant. Therefore, it can be stated that a stable suspension suitable for SPS process was obtained.

Thus, preliminary coatings were obtained with the BG-Att suspension (with and without bond layer). Microstructure was characterised by the presence of cracks and rounded pores. Nevertheless, when a $\mathrm{TiO}_{2}$ bond coat covered the substrate, coating's thickness was significantly increased respect to the coating without bond layer as a consequence of the increment of deposition efficiency due to the viscous state of the coating, as the bond coat prevents glass particles from fast heat release. However, the microstructure was not improved, thus their mechanical properties are expected to be poor. In addition, both coatings surfaces (with and without bond coat) were irregular and porous, in particular the surface of the coating with bond layer, which was made up of big rounded glass agglomerates forming the "cone shaped" structure. This structure gives rise to a high specific surface area which can be of interest for the enhancement of coating bioactivity.

The next milestone will be the deposition of bioactive coatings by SPS, with less internal porosity in order to enhance their mechanical properties, while maintaining or improving surface roughness to promote the reaction with biological fluids and sur-rounding tissues, reaching equilibrium between mechanical and biological properties. For that purpose, more research is in progress, regarding the optimisation of the spraying conditions in order to enhance particle melting and splat deformation, determining the adherence, hardness and bioactivity (SBF tests) of the new coatings in function of their microstructure features.

The results of this work allow us to conclude that the selected dispersing materials and conditions are adequate to prepare bioactive glass suspension feedstocks to be used in the development of bioactive coatings obtained by SPS process. 


\section{Acknowledgements}

The authors of this study thank Universitat Jaume I of Castellon for the support provided in funding the project RECUBIO (P1-1B2013-69).

\section{References}

[1] G. Goller, H. Demirkiran, F.N. Oktar, E. Demirkessen, Processing and characterization of bioglass reinforced hydroxyapatite composites, Ceram. Inter. 29 (2003) 721-724.

[2] L. Lefebvre, J. Chevalier, L. Gremillard, R. Zenati, G. Thollet, D. BernacheAssolant, A. Govin, Structural transformations of bioactive glass $45 \mathrm{~S} 5$ with thermal treatments, Acta Mater. 55 (2007) 3305-3313.

[3] M. Vallet-Regí, C.V. Ragel, A.J. Salinas, Glasses with medical applications, Eur. J. Inor. Chem. 2003 (2003) 1029-1042.

[4] J. Wilson, A. Yli-Urpo, R.P. Happonen, Bioactive glasses: Clinical applications, in: L.L. Hench, J. Wilson (eds.), An introduction to bioceramics, first ed., World Scientific, Singapore, 1993, pp. 63-74.

[5] T. Kokubo, Bioceramics and their clinical applications, first ed., CRC, The USA, 2008.

[6] J.R. Jones, Review of bioactive glass: From Hench to hybrids, Acta Biomater. 9 (2013) 4457-4486.

[7] S.J. Ding, Y.M. Su, C.P. Ju, J.H. Chern-Lin, Structure and immersion behaviour of plasma-sprayed apatite-matrix coatings, Biomater. 22 (2001) 833-845.

[8] Y.W. Gu, K.A. Khor, P. Cheang, In vitro studies of plasma-sprayed hydroxyapatite/Ti-6Al-4V composite coatings in simulated body fluid (SBF), Biomater. 24 (2003) 1603-1611.

[9] V. Cannillo, A. Sola, Different approaches to produce coatings with bioactive glasses: enamelling vs plasma spraying, J. Eur. Ceram. Soc. 30 (2010) 2031-2039.

[10] T.M. Lee, E. Chang, B.C. Wang, C.Y. Yang, Characteristics of plasma-sprayed bioactive glass coatings on Ti-6Al-4V alloy: an in vitro study, Surf. Coat. Technol. 79 (1996) 170-177.

[11] G.T. El-Bassyouni, H.H. Beherei, K.R. Mohamed, S.H. Kenawy, Fabrication and bioactivity behaviour of $\mathrm{HA} /$ bioactive glass composites in the presence of calcium hexaboride, Mater. Chem. Phys. 175 (2016) 92-99.

[12] P. Sepulveda, J.R. Jones, L.L. Hench, Characterization of melt-derived 45S5 and sol-gel-derived $58 \mathrm{~S}$ bioactive glasses, J. Biomed. Mater. Res. (Appl. Biomater.) 58 (2001) 734-740.

[13] A. Lucas-Girot, F.Z. Mezahi, M. Mami, H. Oudadesse, A. Harabi, M. Le Floch, Sol-gel synthesis of a new composition of bioactive glass in the quaternary 
system $\mathrm{SiO}_{2}-\mathrm{CaO}-\mathrm{Na}_{2} \mathrm{O}-\mathrm{P}_{2} \mathrm{O}_{5}$ : Comparison with the melting method, J. NonCryst. Solids 357 (2011) 3322-3327.

[14] J.A. Juhasz, S.M. Best, Bioactive ceramics: processing, structures and properties, J. Mater. Sci. 47 (2012) 610-624.

[15] J.A. Helsen, J. Proost, J. Schrooten, G. Timmermans, E. Brauns, J. Vanderstraeten, Glasses and bioglasses: synthesis and coatings, J. Eur. Ceram. Soc. 17 (1997) 147-152.

[16] P.N. De Aza, A.H. De Aza, P. Pena, S. De Aza, Bioactive glasses and glassceramics, Bol. Soc. Esp. Ceram. Vidr. 46 (2007) 45-55.

[17] M. Cerruti, D. Greenspan, K. Powers, Effect of $\mathrm{pH}$ and ionic strength on the reactivity of Bioglass ${ }^{\circledR} 45 S 5$, Biomater. 26 (2005) 1665-1674.

[18] J.R. Davis, Handbook of thermal spraying technology, first ed., ASM International, The USA, 2004.

[19] L. Pawlowski, The Science and Engineering of Thermal Spray Coatings, second edn., John Wiley \& Sons, Great Britain, 2008.

[20] R. Moreno, E. Bannier, Feedstocks suspensions and solutions, in: N. Espallargas (ed.), Future Development of Thermal Spray Coatings, Elsevier, Great Britain, 2015, pp. 51-80.

[21] S. Romeis, A. Hoppe, R. Detsch, A.R. Boccaccini, J. Schmidt, W. Peukert, Topdown processing of submicron 45S5 Bioglass ${ }^{\circledR}$ for enhanced in vitro bioactivity and biocompatibility, Proced. Eng. 102 (2015) 534-541.

[22] G. Bolelli, D. Bellucci, V. Cannillo, R. Gadow, A. Killinger, L. Lusvarghi, P. Müller, A. Sola, Comparison between Suspension Plasma Sprayed and High Velocity Suspension Flame Sprayed bioactive coatings, Surf. Coat. Technol. 280 (2015) 232-249.

[23] D. Bellucci, G. Bolelli, V. Cannillo, R. Gadow, A. Killinger, L. Lusvarghi , A. Sola, N. Stiegler, High velocity suspension flame sprayed (HVSFS) potassium-based bioactive glass coatings with and without $\mathrm{TiO}_{2}$ bond coat, Surf. Coat. Technol. 206 (2012) 3857-3868.

[24] A. Cattini, L. Latka, D. Bellucci, G. Bolelli, A. Sola, L. Lusvarghi, L. Pawlowski, V. Cannillo, Suspension plasma sprayed bioactive glass coatings: Effects of processing on microstructure, mechanical properties and in-vitro behaviour, Surf. Coat. Technol. 220 (2013) 52-59.

[25] E. Cañas, M. Vicent, E. Bannier, P. Carpio, M.J. Orts, E. Sánchez, Effect of particle size on processing of bioactive glass powder for atmospheric plasma spraying, J. Eur. Ceram. Soc. 36 (2016) 837-845.

[26] R. Moreno, The role of slip additives in tape-casting technology. I: Solvents and dispersants, Am. Ceram. Soc. Bull. 71 (1992) 1521-1531.

[27] O. Mengual, G. Meunier, I. Cayré, K. Puech, P. Snabre, Turbiscan MA 2000: multiple light scattering measurement for concentrated emulsion and suspension instability analysis, Talanta 50 (1999) 445-456. 
[28] A. Sola, D. Bellucci, V. Cannillo, A. Cattini, Bioactive glass coatings: a review, Surf. Eng. 27 (2011) 560-572.

[29] P. Fauchais, Understanding plasma spraying, J. Phys. D. Appl. Phys. 37 (2004) 86-108.

[30] M. Vicent, E. Bannier, P. Carpio, E. Rayón, R. Benavente, M.D. Salvador, E. Sánchez, Effect of the initial particle size distribution on the properties of suspension plasma sprayed $\mathrm{Al}_{2} \mathrm{O}_{3}-\mathrm{TiO}_{2}$ coatings, Surf. Coat. Technol. 268 (2015) 209-215.

[31] P. Carpio, E. Bannier, M.D. Salvador, A. Borrell, R. Moreno, E. Sánchez, Effect of particle size distribution of suspension feedstock on the microstructure and mechanical properties of suspension plasma spraying YSZ coatings, Surf. Coat. Technol. 268 (2015) 293-297.

[32] R. Moreno, Reología de suspensiones cerámicas (Ceramic suspensions rheology), first ed., Consejo Superior de Investigaciones Cerámicas (CSIC), Spain, 2005.

[33] G. Goller, The effect of bond coat on mechanical properties of plasma sprayed bioglass-titanium coatings, Ceram. Inter. 30 (2004) 351-355.

[34] K. VanEvery, M.J.M. Krane, R.W. Trice, H. Wang, W. Porter, M. Besser, D. Sordelet, J. Ilavsky, J. Almer, Column formation in suspension plasma-sprayed coatings and resultant thermal properties, J. Therm. Spray Technol. 20 (2011) 817-828. 

Artículo 4 



\title{
Bioactive glass coatings by suspension plasma spraying from glycolether-based solvent feedstock
}

\author{
Eugeni Cañas, Mónica Vicent, María José Orts, Enrique Sánchez
}

Surface \& Coatings Technology 318 (2017) 190-197

\section{http://dx.doi.org/10.1016/i.surfcoat.2016.12.060}

Los vidrios bioactivos están surgiendo como un sustituto de la hidroxiapatita en el desarrollo de recubrimientos bioactivos para aplicaciones biomédicas. La deposición de estos recubrimientos se lleva a cabo mediante una amplia gama de técnicas, siendo la proyección térmica por plasma atmosférico la más empleada. Sin embargo, apenas hay estudios acerca de la deposición de estos recubrimientos a partir suspensiones de vidrios bioactivos, por lo que resulta interesante más investigación en esta línea.

Así pues, este trabajo aborda un estudio sobre la deposición de recubrimientos de vidrio bioactivo a partir de suspensiones mediante proyección térmica por plasma. Para ello, se ha preparado una suspensión compuesta por partículas finas de vidrio utilizando dipropilenglicol metil éter como medio líquido, y se ha estabilizado mediante ensayos reológicos y de sedimentación. Al utilizarse un nuevo tipo de disolvente, se ha determinado su efecto en las propiedades de la pluma de plasma. Además, el comportamiento reológico de la suspensión se ha ajustado a un modelo de viscosidad simple.

La suspensión resultante se ha depositado sobre los sustratos metálicos mediante proyección térmica por plasma, empleando diferentes distancias de proyección. Todos los recubrimientos obtenidos han mostrado una adherencia y espesor similar. Sin embargo, tal y como se aprecia en las micrografías tanto en sección transversal como en superficie, la microestructura de los recubrimientos está muy influenciada por la distancia de proyección. De esta forma, se ha obtenido una relación entre la distancia de proyección y la microestructura de los recubrimientos. A pesar del efecto de la distancia, mediante difracción de rayos $X$ se ha confirmado que todos los recubrimientos son totalmente amorfos. 



\title{
Bioactive glass coatings by suspension plasma spraying from glycolether-based solvent feedstock
}

\author{
E. Cañas*, M. Vicent, M.J. Orts, E. Sánchez \\ a Instituto de Tecnología Cerámica (ITC), Asociación de Investigación de las Industrias \\ Cerámicas (AICE), Universidad Jaume I, Castellón, Spain \\ ${ }^{*}$ Corresponding author
}

\begin{abstract}
Bioactive glasses are emerging as a substitute of hydroxyapatite in the development of bioactive coatings for biomedical applications. The deposition of these coatings is carried out by a wide range of methods, being atmospheric plasma spraying the most employed technique. However, the research on the deposition of these coatings from suspension feedstocks by thermal spraying is still incipient, therefore more research about this topic is needed.

Thus, a bioactive glass suspension, composed of fine glass particles, was prepared and stabilised through rheological and sedimentation tests to be used as a feedstock in plasma spraying. The solvent used in the suspension preparation was dipropylene glycol methyl ether in order to develop a new type of bioactive suspension. Consequently, as a new type of solvent was used, its effect on the plasma torch properties was determined. On other hand, the rheological behaviour of the suspension feedstock was assessed by means of a simple viscosity model.

This suspension was deposited onto metallic substrates by plasma spraying, employing several spraying distances. All coatings displayed a suitable adherence and similar thickness. However, the microstructure of the obtained coatings is highly affected by the spraying distance as it can be seen in coatings surface and cross-section field emission gun environmental scanning electron microscopy examination. Thus, a relation between the spraying distance and coatings microstructure was found. On the other hand, X-ray diffraction confirmed the amorphous nature of the obtained coatings.
\end{abstract}

Keywords: Bioactive glass suspensions characterisation; Ability of heating factor; Suspension plasma spraying; Bioactive glass coatings

\section{Introduction}

Hydroxyapatite has been long used as bioactive coating for medical applications owing to the similarity of its composition with that of the bone tissue of the human body. However, a new bioceramic which displays the same bioactivity than hydroxyapatite but whose synthesis process is simpler has recently 
emerged. This is bioactive glass (BG), an amorphous material exhibiting a high index of bioactivity [1,2]. Numerous techniques such as electrophoretic deposition, sol-gel, enamelling, laser deposition or thermal spray techniques have been employed to obtain such coatings. However, thermal spray techniques and more specifically Atmospheric Plasma Spraying (APS) is the most used method due to the high temperatures reached in the plasma torch and the subsequent fast cooling of the deposited material so that the devitrification of the as-coated glass is inhibited [3,4].

In recent years, within the group of thermal spray techniques, Suspension Plasma Spraying (commonly known as SPS) has developed as a new method of coating deposition. SPS method is similar to APS with the difference that the material injected into the plasma torch is a suspension rather than a powdery material. One of the main advantages of SPS against APS process deals with the possibility of incorporating small particles (submicron- or even nano-sized) through the liquid [5]. Although there are numerous research groups depositing coatings from suspensions of different types of ceramic materials, mainly oxides, only few groups have started to work with bioactive glass particles, so that this research line is still incipient $[6,7]$.

On other hand, BG suspensions cannot be prepared in water due to its tendency to leach into this medium, resulting in gelation phenomena. For that reason, one of the challenges of the SPS feedstock preparation is to stabilise the glass particles together with the necessary additives (dispersant, thickener, suspending, etc.) in an organic solvent that is manageable and safe during thermal spraying. Although ethanol has been mostly used in BG suspensions preparation, our research group has very recently reported the use of an alternative solvent (dipropylene glycol methyl ether, hereafter DGME) which also accomplishes with technical and safety requirements of the process [8]. Thus, whereas the physical properties of both solvents (viscosity and surface tension) are quite similar, DGME displays higher flash point than ethanol making handle, storage and transport of suspensions containing this solvent safer and easier.

The literature reports many papers about optimisation of plasma spray conditions to obtain BG coatings by APS. Most of these papers also include the characterisation of the resulting coatings [9-14]. However, very limited numbers of papers have dealt with obtaining BG coatings by SPS technique. Regarding the microstructure of SPS coatings, this is strongly affected by the state of the particles when impact the substrate (or a deposited coating), and in turn, this state results directly from the mode of suspension injection [15]. With an external injection (atomization or continuous stream), coatings are generally finely grained. On the contrary, with an internal injection, coatings can be made up of large, well melted grains (axial injection) or may be comprised of two zones, a dense zone formed by well melted particles and an agglomerated zone made up of fine solid particles sintered between them (radial injection). Bolelli et al. and Cattini et al. have confirmed the last microstructures for SPS-BG coatings whereas at the same time these authors highlight the significant 
differences of SPS and APS coating microstructures $[6,16]$. Not least, these authors also point out that the SPS microstructure is very sensitive to the properties of the suspension feedstock (glass particle size, solids content, dispersion state...). As a result, the research on the suspension feedstock requirements to establish a suitable SPS process represents a matter of paramount importance.

In a recent paper with APS-BG coatings, the authors of the present work have shown that the abundance of round pores in the microstructure of these coatings is consequence of a liquid phase sintering mechanism operating during the thermal treatment of glassy particles [17]. For this reason, the SPS feedstock characteristics are expected to strongly affect the liquid phase sintering of the as-sprayed glass particles as well as on the evolving of gas bubbles occurring during the rapid sintering of melted glass particles. Nevertheless, the research on microstructure development in SPS-BG coatings as well as the relationships between suspension feedstock characteristics and coating microstructure and properties are still in a preliminary stage.

Otherwise, unlike conventional thermal spraying with dry feedstocks, in SPS the evaporation of the solvent tends to change the chemical composition of the plasma working gases giving rise to a modification of the transport properties of the plasma torch, which determine particle velocity and temperature. Hence, it is indispensable to address the effect caused in the plasma torch by the injected solvent in order to optimise the spraying parameters and achieve an energetic torch where the flying particles or agglomerates can properly melt.

Consequently, the aim of the present work is to contribute to better understanding of the development of the microstructure of SPS-BG coatings. In this research, a SPS feedstock of a given BG powder containing DGME as solvent will be used. This feedstock was prepared and stabilised in a previous research [8]. A viscosity model was also tested to accomplish with flow requirements of the feedstock suspension during the SPS operation. In addition, the effect of this solvent on the plasma torch was studied by calculating the ability of heating factor (AHF) and the degree of melting factor (DMF). Finally, during coatings deposition, spray distance was varied with the aim of developing different coating microstructures. Surface and cross-section microstructures of the obtained coatings were examined by field emission gun environmental scanning electron microscope (FEG-ESEM), and phase coating distribution was determined by $\mathrm{X}$-ray diffraction (XRD).

\section{Experimental}

\subsection{Synthesis and characterisation of the bioactive glass suspension}

Home-made bioactive glass powders were used to prepare the desired feedstock suspension. These powders showed the following characteristics: amorphous character, particle size lower than $63 \mu \mathrm{m}$ and an oxide composition (in wt\%) of $47,6 \mathrm{SiO}_{2}, 5,3 \mathrm{P}_{2} \mathrm{O}_{5}, 23,1 \mathrm{CaO}$ and $24,0 \mathrm{Na}_{2} \mathrm{O}$. This glass powder 
was obtained by the melting and quenching method [17]. To prepare the suspension, the glass powders were mixed with DGME solvent (Dowanol DPM, Dow Chemical, USA) with a proportion of 10 vol.\% of solids and 90 vol. $\%$ of solvent, employing $0,5 \mathrm{wt} \%$ (relative to solids content) of D190 (Disperbyk-190, Byk, Germany) as a dispersant agent to stabilise the suspension. The reasons for the choice of DGME as feedstock solvent as well as the comparison between this solvent and ethanol (the solvent commonly used in SPS) in terms of physical properties and handling and safety requirements are detailed in a previous work [8]. The mixture was wet-milled several times in order to reach finer particle sizes, following the procedure described in the above paper [8] and obtaining a bioactive glass suspension (referred to as BGS) which was used as feedstock in the SPS process.

From the obtained suspension (BGS), viscosity and thixotropy were determined through a rheological characterisation. For that purpose, a rheometer (Haake RS50, Thermo Scientific, Germany) which controls the rate (CR) was used operating at $25^{\circ} \mathrm{C}$ and using a double-cone and plate system. The assay carried out to determine both viscosity and thixotropy, consists in loading the shear rate from 0 to $1000 \mathrm{~s}^{-1}$ in $5 \mathrm{~min}$, maintaining the shear rate at $1000 \mathrm{~s}^{-1}$ during $1 \mathrm{~min}$ and downloading it from 1000 to $0 \mathrm{~s}^{-1}$ in $5 \mathrm{~min}$. Moreover, the stability with time of the obtained suspension was assessed by sedimentation test [18]. This test was carried out in a multiple light scattering equipment (TurbiScan Classic MA2000, Formulaction, France) which is able to measure the amount of light backscattered or transmitted by the suspension in function of time. For that aim, one test was performed for $1 \mathrm{~h}$, a second test for $15 \mathrm{~h}$ and another test for $24 \mathrm{~h}$.

On the other hand, density of the BGS was determined using a pycnometer, particle size distribution was measured by laser diffraction (Mastersizer 2000, Malvern Instruments, Great Britain) and morphology of the suspension solid material was assessed by FEG-ESEM (QUANTA 200FEG, FEI Company, USA) after drying in an oven (110 $\left.{ }^{\circ} \mathrm{C}\right)$ a sample of the BGS.

\subsection{Plasma plume transport properties}

In a system consisting of a particle inside a plasma (assuming unique temperature for either the solid or the plasma) the heat transferred from the plasma to the particle could be described by the following expression (equation 1) [19-21].

$$
\pi d_{p}^{2} h\left(T_{g}-T_{p}\right)+h_{r}\left(T_{g}\right)=\frac{1}{6} \pi \rho_{p} c_{p} d_{p}^{3} \frac{d T_{p}}{d t}+\pi d_{p}^{2} \varepsilon_{p} \sigma T_{p}^{4} \text { (eq. 1) }
$$

Where $d_{p}$ is the particle diameter $(m), h$ is the convection heat transfer coefficient $\left(\mathrm{W} / \mathrm{m}^{2} \cdot \mathrm{K}\right), \mathrm{T}_{g}$ is the plasma temperature $(\mathrm{K}), \mathrm{T}_{\mathrm{p}}$ is the particle temperature $(K), h_{r}$ is the radiative heat transfer coefficient $\left(W / m^{2} \cdot K\right), \rho_{p}$ is the 
particle density $\left(\mathrm{kg} / \mathrm{m}^{3}\right), \mathrm{c}_{\mathrm{p}}$ is the particle specific heat $(\mathrm{J} / \mathrm{K} \cdot \mathrm{kg}), \varepsilon_{\mathrm{p}}$ is the particle radiative emission coefficient and $\sigma$ is the Stefan-Bolzmann constant.

Considering the assumptions made by Pawlowski [19], equation 1 can be written as follows:

$$
A H F=\frac{L\left(T_{g}-T_{p}\right)^{2}\left(\left\langle\lambda_{g}\right\rangle\right)^{2}}{\left\langle\eta_{g}\right\rangle v_{g}}=\frac{H_{m}^{2} d_{p}^{2}\left\langle\rho_{p}\right\rangle}{16}=D M F
$$

Where $L$ is the length of the high temperature zone of the plasma $(m),\left\langle\lambda_{g}\right\rangle$ is the plasma average thermal conductivity $(\mathrm{W} / \mathrm{m} \cdot \mathrm{K}),\left\langle\eta_{\mathrm{g}}\right\rangle$ is the plasma average dynamic viscosity $(\mathrm{kg} / \mathrm{m} \cdot \mathrm{s}), v_{\mathrm{g}}$ is the plasma velocity of the high temperature zone $(\mathrm{m} / \mathrm{s})$ and $H_{m}$ is the particle fusion enthalpy $(\mathrm{J} / \mathrm{kg})$.

In equation 2, the left-hand side contains all variables related to the plasma torch and its transport properties being this side known as the ability of heating factor (AHF), whereas the right-hand side contains all variables related to the particle and is known as the difficulty of melting factor (DMF). Therefore, a particle with a diameter $d_{p}$ will be melted if AHF > DMF.

In the present work, since a new solvent different from the commonly used (ethanol) was employed to develop the suspensions, the effect of that solvent on the torch properties has been determined. For that purpose, a modified ability of heating factor $\left(\mathrm{AHF}_{\mathrm{m}}\right)$ was calculated $[20,21]$, which only depends of the transport properties, i.e. average thermal conductivity $\left(\left\langle\lambda_{g}\right\rangle\right)$ which affects the heat and momentum transfer (particles temperature and velocity) and dynamic viscosity $\left(\left\langle\eta_{g}\right\rangle\right)$ which only affects the momentum transfer (particles velocity). Thus, the left-hand side of equation 2 can be written as follows:

$$
\frac{1}{\left(T_{g}-T_{p}\right)} \sqrt{\frac{A H F v_{g}}{L}}=\frac{\left\langle\lambda_{g}\right\rangle}{\sqrt{\left\langle\eta_{g}\right\rangle}}=A H F_{m} \text { (eq. 3) }
$$

Moreover, the AHF and DMF were also calculated from equation 2.

\subsection{Suspension deposition and coatings characterisation}

The development of the bioactive coatings was done employing a thermal spraying facility, comprised by a plasma torch (F4-MB, Oerlikon Metco, Switzerland) coupled to a six axes robot (IRB 1400, ABB, Switzerland). The feeding system, a continuous-stream external injector, was adapted to spray suspensions by mechanical injection assisted by air pressure with a maximum pressure of 6 bar. More details about the SPS equipment have been reported in previous works [22,23]. 
The substrates employed to obtain the bioactive coatings were discs with a diameter of $25 \mathrm{~mm}$ made of AISI type 304 stainless steel, which were gritblasted using black corundum with a pressure of 4,2 bar and were cleaned with ethanol prior to the deposition of the bioceramic layer. Thus, substrates with a roughness value $\left(R_{a}\right)$ of $2,2 \pm 0,1 \mu \mathrm{m}$ were obtained, being this value measured in a roughness tester (HOMMELWERKE T8000, Hommelwerke $\mathrm{GmbH}$, Germany). In addition, before coatings deposition, all substrates were coated with a bond coat to enhance the adherence of the final coating. This layer was deposited from anatase feedstocks (Metco 102, Oerlikon Metco, Switzerland) with a particle size distribution between 10 and $55 \mu \mathrm{m}$ by atmospheric plasma spraying (APS) and using the spraying parameters given by the supplier (Table 1).

Finally, bioactive coatings were deposited with the facility described above, preheating the substrates coated with the bond coat between $300{ }^{\circ} \mathrm{C}$ and 350 ${ }^{\circ} \mathrm{C}$ (to further increase the adherence of the glass coatings). The plasma working gases used were a mixture of argon as primary gas and hydrogen as secondary gas. The spraying conditions utilised in this work are detailed in table 1 , and as it can be observed, several (five) spraying distances were tested in order to develop coatings with different microstructure. On the other hand, as the sample holder is a rotational device and the torch is only moved along the $y$ axis, the velocities of the plasma torch and the sampler holder as well as the runs performed by the torch (understood as the round travel performed by the torch along the y axis) were adjusted in order to complete 5 torch passages with a scan step of $5 \mathrm{~mm}$ per passage.

Table 1 Plasma spraying parameters used

\begin{tabular}{ccc}
\hline Spraying parameters & $\begin{array}{c}\mathrm{TiO}_{2} \text { bond coat } \\
\text { (APS) }\end{array}$ & $\begin{array}{c}\text { Bioactive glass top layer } \\
\text { (SPS) }\end{array}$ \\
\hline Argon flow rate (slpm) & 38 & 37 \\
Hydrogen flow rate (slpm) & 14 & 8 \\
Intensity (A) & 600 & 700 \\
Spraying distance $(\mathrm{mm})$ & 120 & $60 / 65 / 70 / 75 / 80$ \\
Spraying velocity $(\mathrm{m} / \mathrm{s})$ & 1 & 1,25 \\
Scan step $(\mathrm{mm})$ & 4 & 5 \\
Number of torch passages & 2 & $5(455$ runs $)$ \\
Nozzle diameter (mm) & 1,8 & - \\
Powder flow rate (g/min) & 45 & - \\
Sample holder velocity & - & 0,72 \\
(m/s) & - & 0,20 \\
Injector diameter (mm) & - & 19 \\
BGS flow rate (cm $3 / \mathrm{min})$ & - & 10 \\
BGS solids content (vol.\%) & & \\
\hline
\end{tabular}

Regarding the characterisation, all coatings were XRD analysed using a diffractometer (Advance diffractometer, Bruker Theta-theta, Germany) to 
determine their nature (amorphous or crystalline), and were observed in both surface and section by FEG-ESEM to examine the microstructure obtained for each coating in function of the spraying distance.

\section{Results and discussion}

\subsection{Bioactive glass suspension}

The BGS, with a density of $1077 \mathrm{~kg} / \mathrm{m}^{3}$, presents a narrow monomodal particle size distribution (continuous grey curves of figure 1a), with a $D_{50}$ of $2,2 \mu \mathrm{m}$. In addition, all glass particles display quite similar angular-shape (Figure 1b) which corresponds to the typical morphology of milled frit particles.

Thixotropy and viscosity of the BGS were estimated from the flow curve (Figure 2) obtained from the rheological test. In the range of shear rates tested (from 1 to $1000 \mathrm{~s}^{-1}$ ) the suspension shows a pseudoplastic behaviour, with a low thixotropic cycle of $258 \mathrm{~Pa} \cdot \mathrm{s}^{-1}$ and a low average viscosity value of $5,6 \cdot 10^{-3}$ $\mathrm{Pa} \cdot \mathrm{s}$ (measured at $500 \mathrm{~s}^{-1}$ in uploading step), being a priori suitable for the injection into the plasma plume (low viscosity requirement as well as little variation with time).
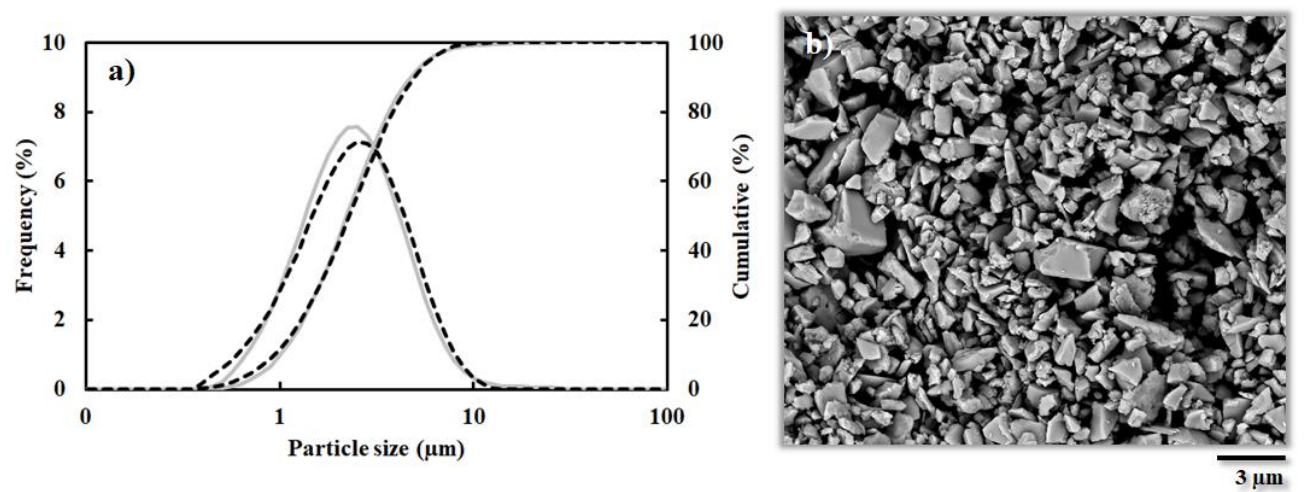

Figure 1. Characteristics of suspension particles. a) Particle size distribution (continuous grey curves correspond to the starting suspension and dotted black curves correspond to the aged suspension after 21 days); b) Particles morphology of the starting BGS 


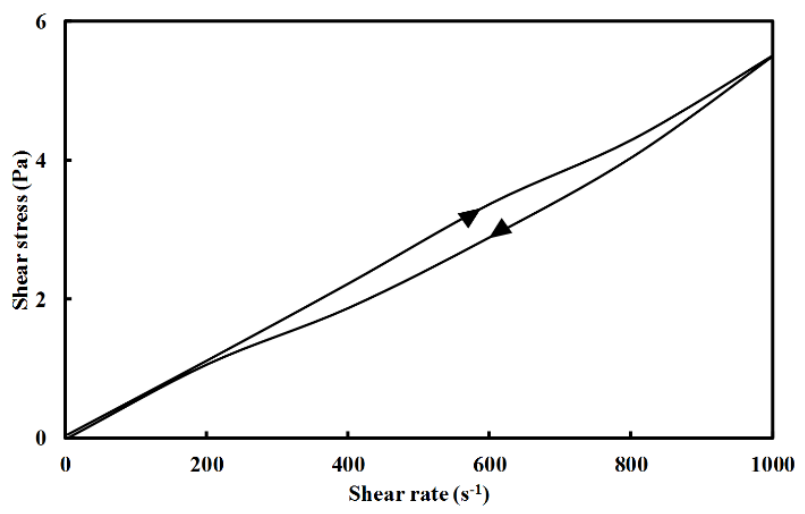

Figure 2. Flow curve of the BGS

To determine the real viscosity of the BGS at different points of the plasma spraying facility (stored at hopper, pumped within the pipes and injected to the torch through the injector), the experimental data from the obtained viscosity curve were adjusted to the Cross model. Unlike other models, this model allows to predict viscosity values for both low and high shear rates [24]. The model equation reads as follows:

$$
\frac{\eta_{o}-\eta}{\eta-\eta_{\infty}}=(K \cdot \dot{\gamma})^{m} \text { (eq. 4) }
$$

Where $\eta$ is the suspension viscosity $(\mathrm{Pa} \cdot \mathrm{s})$ at a given shear rate $\mathrm{Y}\left(\mathrm{s}^{-1}\right), \eta_{\mathrm{o}}(\mathrm{Pa} \cdot \mathrm{s})$ and $\eta_{\infty}(\mathrm{Pa} \cdot \mathrm{s})$ are the viscosity limit values extrapolated to cero and infinite velocity respectively, and $\mathrm{K}(\mathrm{s})$ and $\mathrm{m}$ (dimensionless) are fit constants. The parameters used for the adjustment are displayed in table 2, and figure 3 exposes the adjustment of the experimental values with the Cross model. As it can be observed these values fit well to the theoretical model. Only a little deviation from the model occurs at high shear rates in the downloading step due to the thixotropy, which causes a reduction in viscosity when the shear rate decreases.

Then, the rheological behaviour of the BGS was assessed at different points of the plasma equipment from the model for the shear rate of each point. The results are showed in table 3 and the viscosity of each point is highlighted in figure 3 with a triangle dot. As expected the suspension exhibits high viscosity during its storage since no shear is acting; nevertheless, during transport and injection, a dramatic decrease of the suspension viscosity occurs due to the increment of the shear rate, which is consequence of the little diameter of the pipe and the injector. In addition, the viscosity in the injector is even slightly lower than the average viscosity obtained from the rheological test. This low viscosity as well as a little variation of viscosity with time (low thixotropy) are key requirements for the suspension feedstock in a SPS process as reported elsewhere [25]. 
Table 2. Parameters of the Cross model for the BGS

\begin{tabular}{ccccc}
\hline $\boldsymbol{\eta}_{\text {o }}(\mathrm{Pa} \cdot \mathbf{s}) \cdot \mathbf{1 0}^{3}$ & $\boldsymbol{\eta}_{\infty}(\mathrm{Pa} \cdot \mathbf{s}) \cdot \mathbf{1 0}^{3}$ & $\mathbf{K}(\mathbf{s})$ & $\mathbf{m}$ & $\mathbf{R}^{\mathbf{2}}$ \\
\hline 84,8 & 5,4 & 2,4 & 1,1 & 0,98 \\
\hline
\end{tabular}

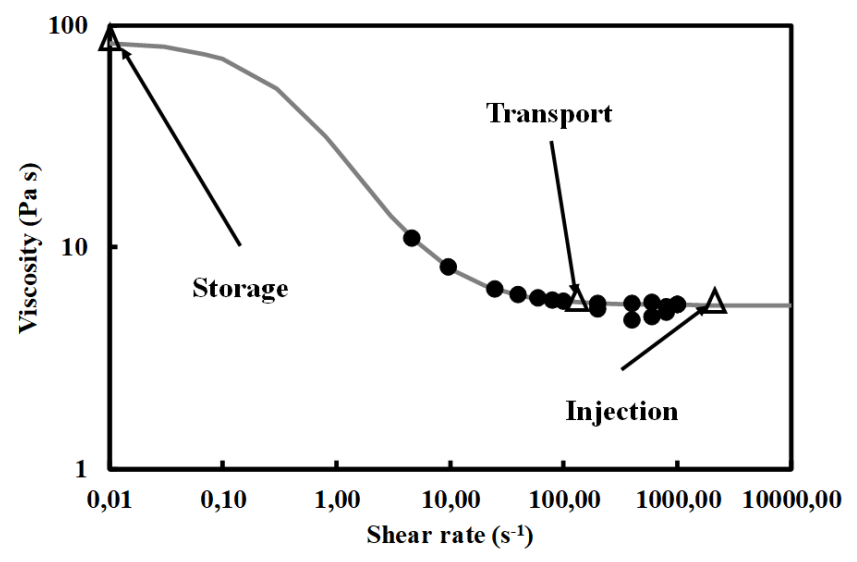

Figure 3. Adjustment of the Cross model. Circle points correspond to the experimental values, continuous line correspond to the theoretical values and triangle dots correspond to suspension viscosity at different points of the plasma facility

Table 3. Viscosity of the BGS at different points of the plasma spraying facility obtained from the Cross model

\begin{tabular}{cccc}
\hline Operation & Diameter $(\mathbf{m m})$ & $\begin{array}{c}\text { Shear rate } \\
\left(\mathbf{s}^{-1}\right)\end{array}$ & $\begin{array}{c}\text { Viscosity } \\
(\mathbf{P a} \cdot \mathbf{s}) \cdot \mathbf{1 0}^{\mathbf{3}}\end{array}$ \\
\hline Suspension storage & Hopper $=\infty$ & 0 & 84,8 \\
Suspension transport & Pipe $=5$ & 127 & 5,6 \\
Suspension injection & Injector $=0,2$ & 50955 & 5,4 \\
\hline
\end{tabular}

Otherwise, figure 4 sets out the results of the sedimentation tests. As previously reported, sedimentation tests in a multiple light scattering equipment allow to determine the stability of the suspensions [18]. As a result of the test, a few curves are obtained, which represents the percentage of light backscattered or transmitted as a function of glass cell height. Thus, for one hour the suspension is quite stable since no sedimentation occurs as figure 4a shows. However, for 15 and $24 \mathrm{~h}$, the sedimentation of coarse particles takes place as it can be seen in figures $4 \mathrm{~b}$ and $4 \mathrm{c}$. 

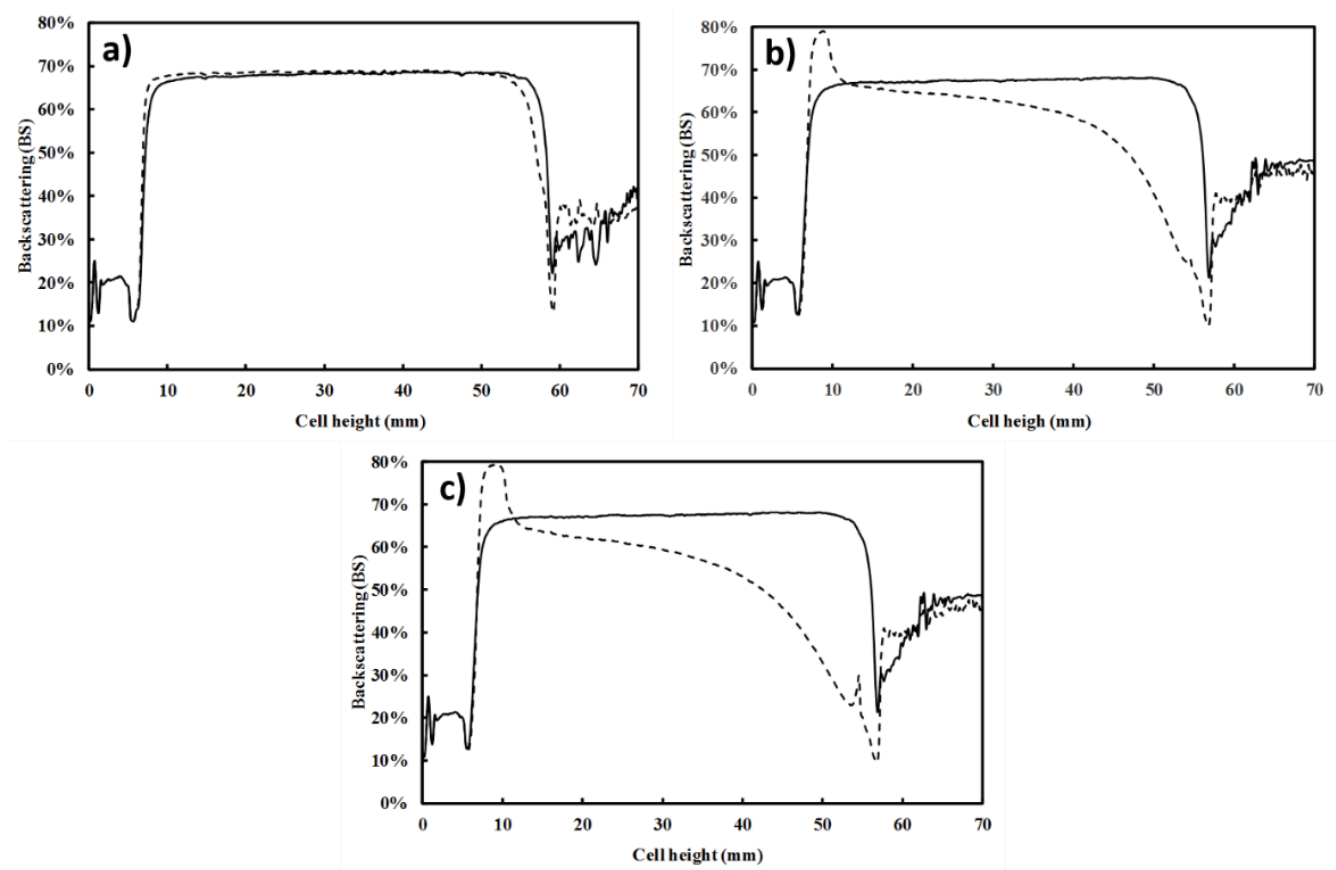

Figure 4. Sedimentation curves for the BGS. Continuous curves correspond to the beginning of the test and dotted curves correspond to the final of the assay. a) Test lasted until $1 \mathrm{~h}$; b) Test lasted until $15 \mathrm{~h}$; c) Test lasted until $24 \mathrm{~h}$

One way to solve this drawback is to redisperse de settled particles by a simple agitation. The particle size distribution of the BGS (aged during 21 days) after the redispersion is represented in figure 1 a (dotted black curves), and as it can be seen both particle size distributions are virtually equal. Moreover, the redispersed suspension has a $D_{50}$ of $2,3 \mu \mathrm{m}$, very close to that of the starting suspension ( $D_{50}$ of $\left.2,2 \mu \mathrm{m}\right)$. Concerning an industrial case, the estimated time that the suspension stays in the SPS container and circuit for a real sample could be lower than $1 \mathrm{~h}$, in function of type and dimensions of the sample (screw of a dental implant, hip prosthesis, etc). In these cases, the redispersion of the suspension by simple agitation would be a good procedure to be followed.

\subsection{Effect of solvent injection in the plasma torch properties}

From the spraying parameters used (Table 1) the average dynamic viscosity and thermal conductivity were calculated from $25^{\circ} \mathrm{C}$ until the plasma high temperature $T_{g}=9790^{\circ} \mathrm{C}$, by means of the free software Jet\&Poudres [26]. The calculations were done, employing the free software T\&TWinner [27,28] for the plasma gases as well as for the mixture of plasma gases and the evaporated solvent of the suspension (DGME). Furthermore, and for comparison purpose, these calculations were also done for the mixture of plasma gases and ethanol at the same spraying conditions. Then, from the average dynamic viscosity and 
thermal conductivity, the modified ability of heating factor was calculated by equation 3 and the results are showed in table 4.

Table 4. Average dynamic viscosity, average thermal conductivity and modified ability of heating factor for the plasma plume with and without solvents

\begin{tabular}{|c|c|c|c|}
\hline Plasma plume & $\begin{array}{c}<n g> \\
(\mathrm{kg} / \mathrm{m} \cdot \mathrm{s}) \cdot 10^{4}\end{array}$ & $\begin{array}{c}<\lambda g> \\
(W / m \cdot K)\end{array}$ & $\begin{array}{c}\text { AHFm } \\
\left(\mathrm{J} / \mathrm{K} \cdot[\mathrm{kg} \cdot \mathrm{m} \cdot \mathrm{s}]^{0,5}\right)\end{array}$ \\
\hline $\begin{array}{c}\mathrm{Ar}+\mathrm{H}_{2} \\
\mathrm{Ar}+\mathrm{H}_{2}+\mathrm{DGME} \text { (90 vol.\%) } \\
\mathrm{Ar}+\mathrm{H}_{2}+\text { Ethanol (90 vol.\%) }\end{array}$ & $\begin{array}{l}1,49 \\
1,32 \\
1,31\end{array}$ & $\begin{array}{l}0,72 \\
1,25 \\
1,42\end{array}$ & $\begin{array}{c}58,8 \\
109,0 \\
124,0\end{array}$ \\
\hline
\end{tabular}

From the results, it can be stablished that the injection of a solvent (indistinctly the type of solvent) into the plasma torch, reduces the torch viscosity and increases its thermal conductivity, resulting in an increment of the ability of heating factor. However, there are differences between the solvents (minimal differences), since high thermal conductivity and therefore high modified ability of heating factor were obtained for ethanol due to its lower molecular weight and its high ability to evaporate easily. Even so, it is evident the positive effect of the DGME into the transport properties, since the AHFm is increased almost twice with regard the AHFm of the torch.

Moreover, the AHF and the DMF factors were calculated by equation 2 for the mixture of plasma gases with the injection of the BGS, where the length and velocity of the high temperature zone of plasma were also obtained from the free software Jet\&Poudres. The results are showed in table 5, where it can be seen the effect observed above, since the injection of the BGS into the plasma torch increases the ability of the working gases to melt solid particles. Otherwise, the AHF of these gases, with and without DGME, is higher than the DMF ensuring a priori the complete melting of the particles.

Table 5. AHF and DMF values for the spraying conditions employed

\begin{tabular}{ccc}
\hline Plasma torch & AHF $\left(\mathbf{J}^{2} / \mathbf{k g} \cdot \mathbf{m}\right) \cdot 10^{6}$ & DMF $\left(\mathbf{J}^{2} / \mathbf{k g} \cdot \mathbf{m}\right) \cdot \mathbf{1 0}^{\mathbf{3}}$ \\
\hline $\mathrm{Ar}+\mathrm{H}_{2}$ & 2,28 & 4,42 \\
$\mathrm{Ar}+\mathrm{H}_{2}+\mathrm{DGME}(90$ vol.\%) & 7,78 & 4,42 \\
\hline
\end{tabular}

\subsection{Bioactive glass coatings}

Once a stable feedstock suspension was obtained, it was deposited by SPS under the spraying conditions displayed in table 1. Figure 5 shows the micrographs (both surface and cross-section) of the obtained coatings at the five spraying distances tested.

All coatings exhibit a similar porous and cracked microstructure with analogous thickness. Moreover, despite using a continuous-stream external injector to inject the suspension into the plasma jet as well as a new solvent, the obtained microstructure for all coatings is characterised by two zones (similar to the microstructure of coatings deposited with internal radial injection) $[6,15,16]$, i.e. 
a first layer made up of fine rounded drops partially sintered between them, and a top zone formed by agglomerated and melted particles which results in dense and flat areas. The formation of this first layer of fine rounded sintered particles, which is composed by the fine particles of the suspension feedstock since they are likely to re-solidify during their flight, takes place during the first torch runs, displaying a similar aspect for the five coatings as it can be seen in the crosssection micrographs at higher magnification from figure 5 (figures $5 c, 5 f, 5 i, 5 l$ and 50).

From this point, since the 455 runs (Table 1) are made in succession leaving no time for the samples to cool, a progressive heating of the system occurs with each torch run resulting in a coating temperature higher than the glass transition temperature $\left(\mathrm{T}_{\mathrm{g}}=520^{\circ} \mathrm{C}\right)$. Consequently, a viscous glass coating is formed onto the first glass layer deposited, on which all particles can easily stick, resulting in the top zone of the coating.

On the other hand, the microstructure of this top zone is highly influenced by the spraying distance employed [16], as it can be seen in surface and crosssection micrographs showed in figure 5 . For micrographs $5 a$ (surface) and $5 b$ (section), which correspond to a spraying distance of $60 \mathrm{~mm}$, the top zone is made up of coarse porous glass agglomerates with an angular shape, which manifest a deficiency in particle melting due to the short residence time into the plasma torch. With respect to the spraying distance of $65 \mathrm{~mm}$, micrographs $5 \mathrm{~d}$ (surface) and $5 e$ (section), the top zone is pretty similar to that of the shorter spraying distance $(60 \mathrm{~mm})$ however the agglomerates display more rounded corners. In the case of the longer spraying distance of $70 \mathrm{~mm}$, micrographs $5 \mathrm{~g}$ (surface) and $5 \mathrm{~h}$ (section), the top zone is made up of glass droplets fully melted and crushed, which evidence that the residence time into the plasma torch for this distance is enough to completely melt the agglomerates. From this point, increasing the spraying distance $(75 \mathrm{~mm})$, micrographs $5 \mathrm{j}$ (surface) and $5 \mathrm{k}$ (section), results in a top zone composed of totally rounded agglomerates, which exhibit a completely melt of the glass droplets accompanied by a resolidification stage due to the high residence time into the cold zones of the plasma torch. Consequently, the re-solidified agglomerates can be attached to the viscous glass layer but cannot coalesce between them. The same occurs for a longer distance $(80 \mathrm{~mm})$ as it can be seen in micrographs $5 \mathrm{~m}$ (surface) and $5 \mathrm{n}$ (section). However, the rounded agglomerates of this coating are smaller than those of the shorter distance $(75 \mathrm{~mm})$ because they are not so crushed, since the longer distance gives rise to a higher degree of solidification, and therefore lower ability to deform when agglomerates impact on the substrate. 

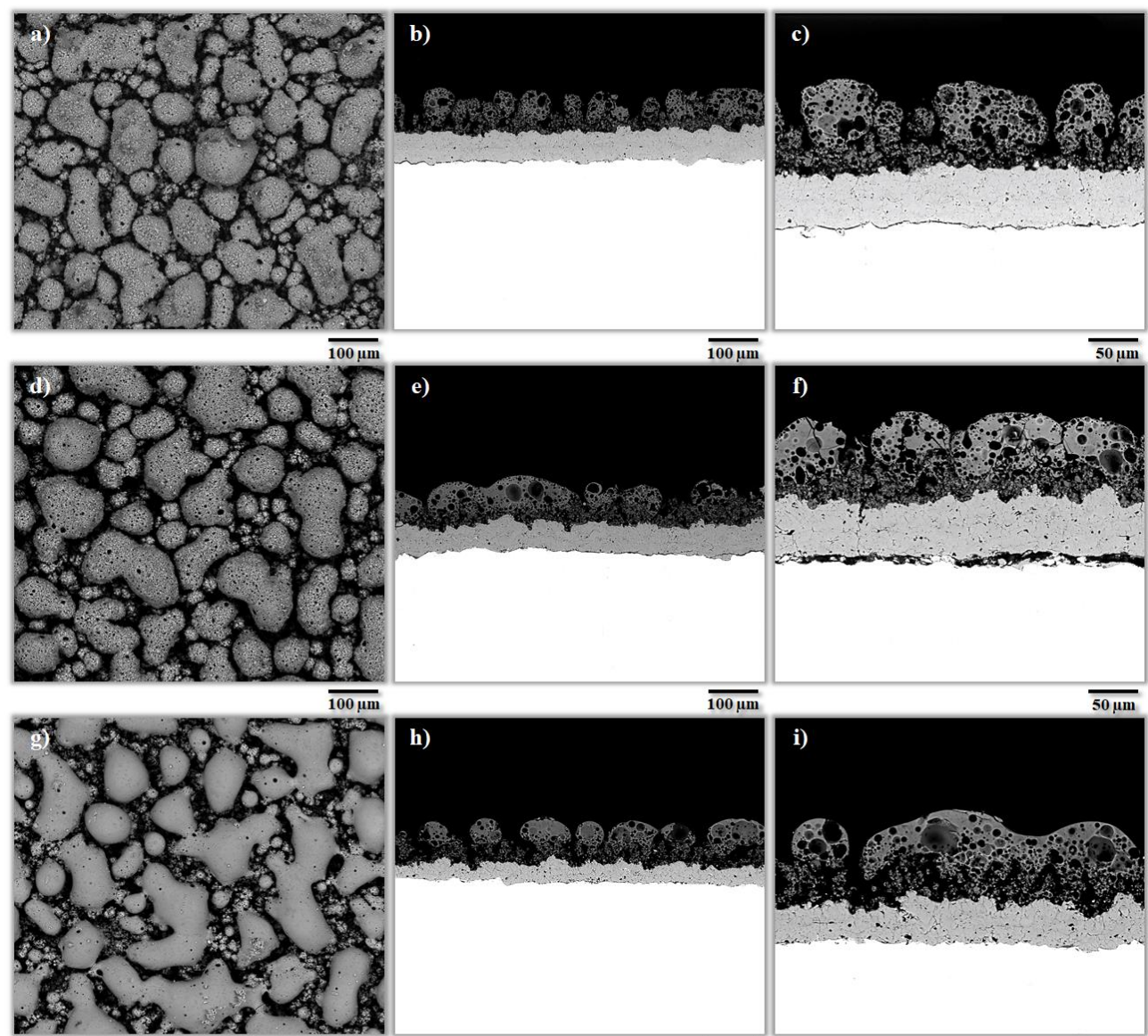

h)
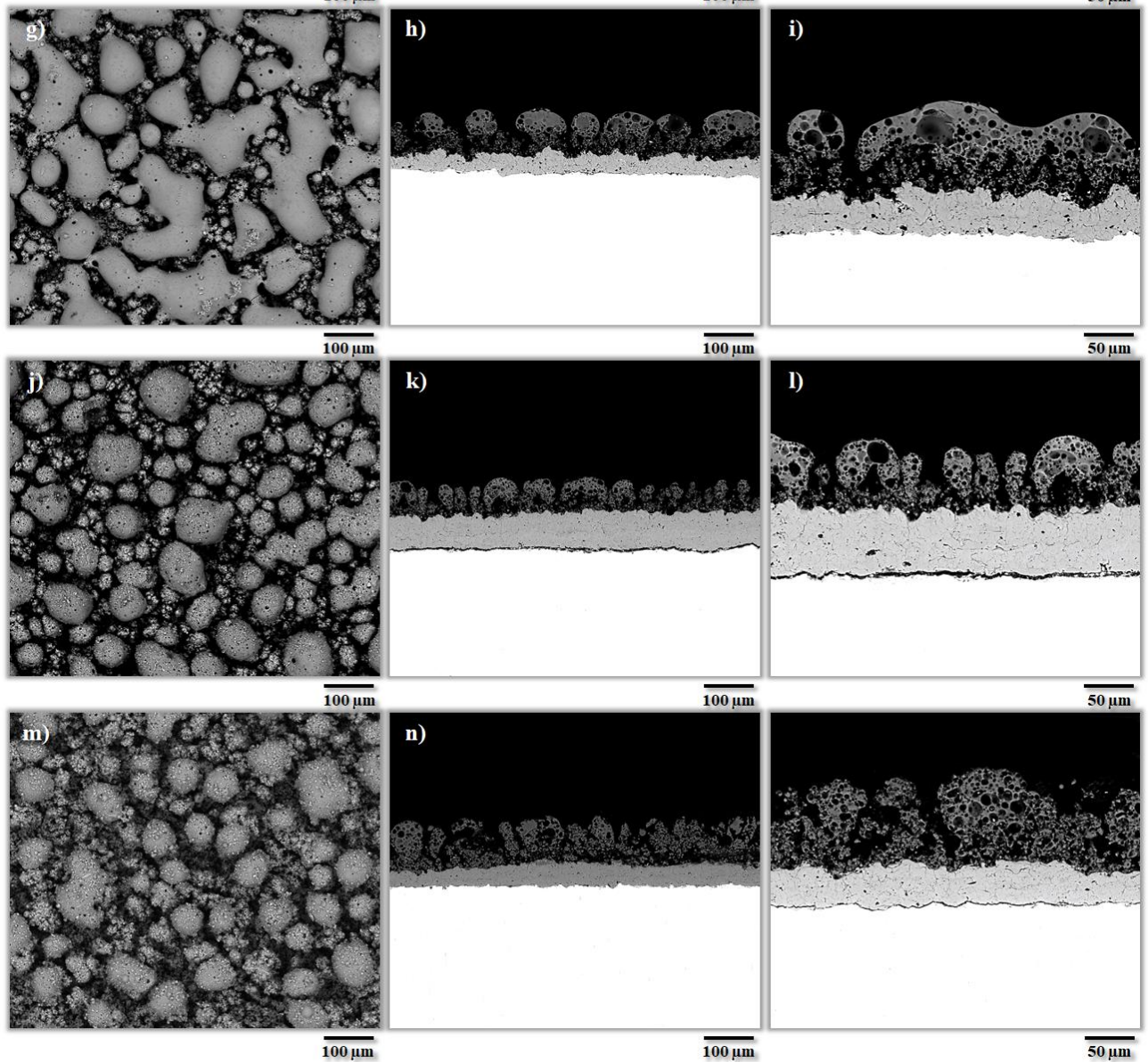

Figure 5. Coatings micrographs deposited under different spraying distances. a) surface and b) section for $60 \mathrm{~mm}$; d) surface and e) section for $65 \mathrm{~mm}$; g) surface and $\mathrm{h}$ ) section for $70 \mathrm{~mm}$; j) surface and $\mathrm{k}$ ) section for $75 \mathrm{~mm}$; m) surface and $\mathrm{n}$ ) section for $80 \mathrm{~mm}$. Micrograph (c), f), i), l) and o) correspond to coatings cross-section for spraying distances of $60,65,70,75$ and $80 \mathrm{~mm}$ respectively at higher magnification 
Moreover, the differences between coatings top zones can be easily observed in figure 6 , where the surface of coatings obtained for 60,70 and $80 \mathrm{~mm}$ spraying distances are showed at higher magnification.

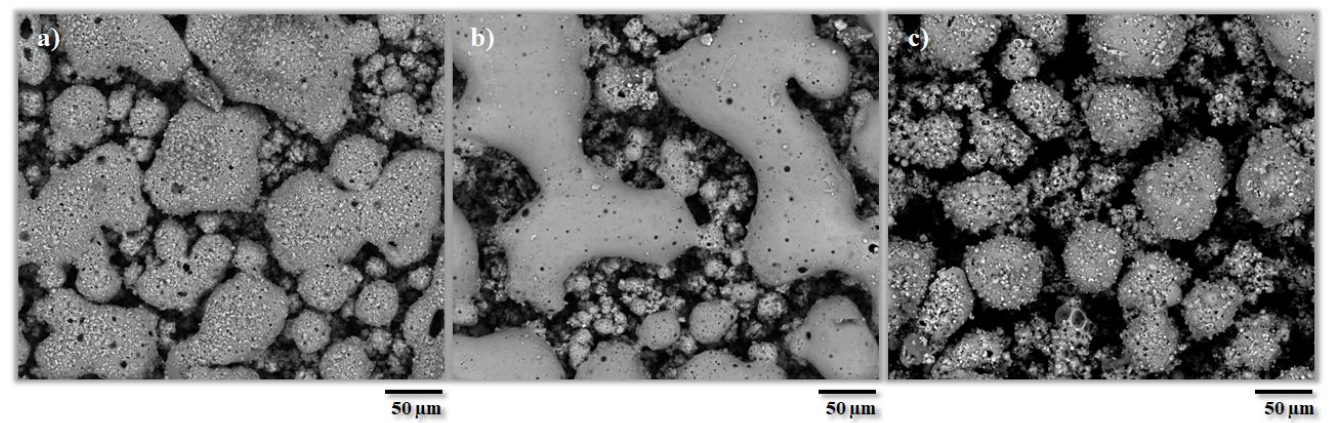

Figure 6. Surface micrographs at higher magnification. a) Spraying distance of $60 \mathrm{~mm}$; b) Spraying distance of $70 \mathrm{~mm}$; c) Spraying distance of $80 \mathrm{~mm}$

To sum up, all coatings display a microstructure with the same first layer, but a different top zone in function of the spraying distance is shown. Besides, all coatings present a "cone shaped" or columnar microstructure due to two factors: the utilisation of radial injection with an injector of high diameter as well as a low concentrated suspension prepared with a low surface tension solvent $[8,29]$. Both factors facilitate the growth of this kind of structure.

Consequently, it is clear that the most promising spraying distance for the spraying conditions employed in this research corresponds to $70 \mathrm{~mm}$. Furthermore, a relation between coatings microstructure and the spraying distance was found, since there is a maximum point concerning this variable. Hence below this distance, agglomerates do not sufficiently melt but above it agglomerates melt and partially re-solidify (Figures 5 and 6). However, mechanical and biological tests are needed in order to assess the final properties of the coatings, and thus, determine which is the best coating. For that purpose, a research including adhesion and in vitro tests are already in progress.

Finally, all coatings were analysed by XRD and the spectra of the coatings deposited for distances of 60,70 and $80 \mathrm{~mm}$ are presented in figure 7 (the other two coatings show similar patterns). From the diffractograms showed in this figure it can be seen that all coatings preserve the amorphous nature of the starting feedstock, allowing them to develop its bioactivity [30]. In addition, the obtained microstructure for all coatings, with high specific surface area will acts as "trabecular-like" structure increasing the reaction with biological fluid [31]. However, as mentioned above, biological tests are needed in order to confirm these statements and to determine the bioactivity of the obtained coatings. 


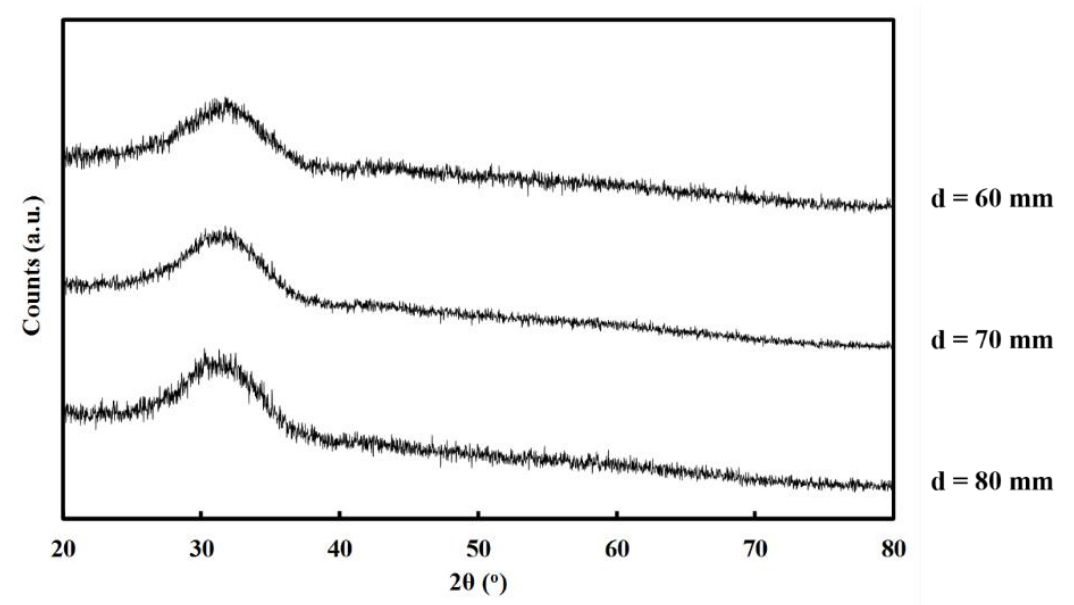

Figure 7. XRD spectra for the bioactive coatings deposited for a distance of 60,70 and 80 $\mathrm{mm}$

\section{Conclusions}

A bioactive glass suspension was obtained for its use as a feedstock in a SPS process. The suspension average viscosity was very low, allowing suspension injection into the plasma torch without any difficulty. In addition, the obtained suspension is quite stable, since for one hour no sedimentation occurs, however, for longer periods of time, a little amount of settled solid was formed, which could be suspended again by a simple agitation. Moreover, the viscosity of the feedstock suspension was fitted to the Cross model, obtaining a reasonably good adjustment. Through this model, it can be seen that the real viscosity of the suspension when is injected through the injector nozzle is lower than the average suspension viscosity, therefore the requirement of low viscosity imposed to suspension feedstock employed in SPS is met.

The effect of the new suspension solvent (DGME) onto the plasma torch properties was analysed. The positive effect for the plasma spraying process when this solvent is used has been proved, since the thermal conductivity and therefore the AHF parameter were increased almost twice.

Finally, bioactive coatings were obtained through the deposition of the feedstock suspension by SPS, employing different spraying distances. All coatings showed similar porous and cracked microstructure, made up of two different zones, as reported in the literature for the SPS process. However, a clear relation between the spraying distance and the microstructure of the obtained coating can be appreciated since for the shorter spraying distances (60 and 65 $\mathrm{mm}$ ) the agglomerates formed in the top layer partially melt showing an angular shape, due to the shorter residence time into the plasma torch. On the contrary, for the rest of the spraying distances $(70,75$ and $80 \mathrm{~mm})$, the residence time was enough to completely melt the particles. Furthermore, for the distances of 75 and $80 \mathrm{~mm}$, the residence time is so high that the particles melt and partially solidify before the impact on the substrate. Thus, the most promising spraying 
distance for the conditions used in this research is $70 \mathrm{~mm}$. Nevertheless, more research is already in progress (mechanical and biological tests) in order to determine which coating shows the best performance. On the other hand, all coatings showed amorphous nature, one of the requirements to develop their bioactivity when in contact with biological fluids.

\section{Acknowledgements}

The authors of the present work thank Universitat Jaume I of Castellón the support provided in funding RECUBIO project (P1-1B2013-69) and action 3.1. of the Research Promotion Plan (PREDOC/2015/50) as well as Prof. Rodrigo Moreno (ICV-CSIC, Madrid, Spain) for his kindly contribution in the rheological characterisation.

\section{References}

[1] L. Lefebvre, L. Gremillard, J. Chevalier, R. Zenati, D. Bernache-Assolant, Sintering behaviour of $45 S 5$ bioactive glass, Acta Biomater. 4 (2008) 18941903.

[2] G. Goller, H. Demirkiran, F.N. Oktar, E. Demirkessen, Processing and characterization of bioglass reinforced hydroxyapatite composites, Ceram. Inter. 29 (2003) 721-724.

[3] A. Sola, D. Bellucci, V. Cannillo, A. Cattini, Bioactive glass coatings: a review, Surf. Eng. 27 (2011) 560-573.

[4] G. Bolelli, V. Canillo, L. Lusvarghi, T. Manfredini, C. Siligardi, C. Bartuli, A. Loreto, T. Valente, Plasma-sprayed glass-ceramic coatings on ceramic tiles: microstructure, chemical resistance and mechanical properties, J. Eur. Ceram. Soc. 25 (2005) 1835-1853.

[5] P. Fauchais, M. Vardelle, A. Vardelle, S. Goutier, What do we know, what are the current limitations of suspension plasma spraying?, J. Therm. Spray Technol. 24 (2015) 1120-1129.

[6] G. Bolelli, D. Bellucci, V. Cannillo, R. Gadow, A. Killinger, L. Lusvarghi, P. Müller, A. Sola, Comparison between suspension plasma sprayed and high velocity suspension flame sprayed bioactive coatings, Surf. Coat. Technol. 280 (2015) 232-249.

[7] D. Bellucci, G. Bolelli, V. Cannillo, R. Gadow, A. Killinger, L. Lusvarghi, A. Sola, N. Stiegler, High velocity suspension flame sprayed (HVSFS) potassium-based bioactive glass coatings with and without $\mathrm{TiO}_{2}$ bond coat, Surf. Coat. Technol. 206 (2012) 3857-3868.

[8] E. Cañas, M. Vicent, M.J. Orts, R. Moreno, E. Sánchez, Bioactive glass suspensions preparation for suspension plasma spraying, J. Eur. Ceram. Soc. 36 (2016) 4281-4290 
[9] M. Monsalve, H. Ageorges, E. Lopez, F. Vargas, F. Bolivar, Bioactivity and mechanical properties of plasma-sprayed coatings of bioglass powders, Surf. Coat. Technol. 220 (2013) 60-66.

[10] X. Chen, M. Zang, X. Pu, G. Yin, X. Liao, Z. Huang, Y. Yao, Characteristics of heat-treated plasma-sprayed $\mathrm{CaO}-\mathrm{MgO}_{-} \mathrm{SiO}_{2}-$ based bioactive glassceramics coatings on Ti-6Al-4V alloy, Surf. Coat. Technol. 25 (2014) 97-103.

[11] T.M. Lee, E. Chang, B.C. Wang, C.Y. Yang, Characteristics of plasma-sprayed bioactive coatings on Ti-6Al-4V alloy: an in vitro study, Surf. Coat. Technol. 79 (1996) 170-177.

[12] V. Cannillo, A. Sola, Different approaches to produce coatings with bioactive glasses: enamelling vs plasma spraying, J. Eur. Ceram. Soc. 30 (2010) 20312039.

[13] G. Goller, The effect of bond coat on mechanical properties of plasma sprayed bioglass-titanium coatings, Ceram. Int. 30 (2004) 351-355.

[14] E. Verné, M. Ferraris, A. Ventrella, L. Paracchini, A. Krajewski, A. Ravaglioli, Sintering and plasma spray deposition of bioactive glass-matrix composites for medical applications, J. Eur. Ceram. Soc. 18 (1998) 363-372.

[15] L. Latka, S.B. Goryachev, S. Kozerski, L. Pawlowski, Sintering of fine particles in suspension plasma sprayed coatings, Mater. 3 (2010) 3845-3866.

[16] A. Cattini, L. Latka, D. Bellucci, G. Bolelli, A. Sola, L. Lusvarghi, L. Pawlowski, V. Cannillo, Suspension plasma sprayed bioactive glass coatings: effects of processing on microstructure, mechanical properties and in-vitro behaviour, Surf. Coat. Technol. 220 (2013) 52-59.

[17] E. Cañas, M. Vicent, E. Bannier, P. Carpio, M.J. Orts, E. Sánchez, Effect of particle size on processing of bioactive glass powder for atmospheric plasma spraying, J. Eur. Ceram. Soc. 36 (2016) 837-845.

[18] O. Mengual, G. Meunier, I. Cayré, K. Puech, P. Snabre, Turbiscan MA 2000: multiple light scattering measurement for concentrated emulsion and suspension instability analysis, Talanta 50 (1999) 445-456.

[19] L. Pawlowski, The science and engineering of thermal spray coatings, second ed., John Wiley and Sons, Great Britain, 2008.

[20] B. Pateyron, N. Calve, L. Pawlowski, Influence of water and ethanol on transport properties of the jets used in suspension plasma spraying, Surf. Coat. Technol. 220 (2013) 257-260.

[21] R.T. Candidato, B. Pateyron, A. Denoirjean, L. Pawlowski, Modification of thermal transport properties of $\mathrm{Ar}-\mathrm{H}_{2}$ working gases by calcium-phosphate precursors used for solution plasma spraying of HA coatings, ITSC 2016 conference, Shanghai, China.

[22] M. Vicent, E. Bannier, P. Carpio, E. Rayón, R. Benavente, M.D. Salvador, E. Sánchez, Effect of the initial particle size distribution on the properties of suspension plasma sprayed $\mathrm{Al}_{2} \mathrm{O}_{3}-\mathrm{TiO}_{2}$ coatings, Surf. Coat. Technol. 268 (2015) 209-215. 
[23] P. Carpio, E. Bannier, M.D. Salvador, A. Borrell, R. Moreno, E. Sánchez, Effect of particle size distribution of suspension feedstock on the microstructure and mechanical properties of suspension plasma spraying YSZ coatings, Surf. Coat. Technol. 268 (2015) 293-297.

[24] R. Moreno, Reología de suspensiones cerámicas (Ceramic suspensions rheology), first ed., Consejo Superior de Investigaciones Cerámicas (CSIC), Spain, 2005.

[25] R. Moreno, E. Bannier, Feedstocks suspensions and solutions, in: N. Espallargas (Ed.), Future development of thermal spray coatings, Elsevier, Great Britain, 2015, pp. 51-80.

[26] “Jet\&Poudres”, http://iets.poudres.free.fr.

[27] B. Pateyron, "T\&TWinner", http://ttwinner.free.fr.

[28] B. Pateyron, G. Delluc, N. Calve, T\&TWinner, la chimie et les propriétés de transports en ligne, dans l'intervalle de $300 \mathrm{~K}$ à $20000 \mathrm{~K}$ (T\&TWinner, the chemistry of on-line transport properties in interval of $300 \mathrm{~K}$ to $20000 \mathrm{~K}$ ), Mec. Indust. 6 (2005) 651-654.

[29] P. Sokolowski, S. Kozerski, L. Pawlowski, A. Ambroziak, The key process parameters influencing formation of columnar microstructure in suspension plasma sprayed zirconia coatings, Surf. Coat. Technol. 260 (2014) 97-106.

[30] O.P. Filho, G.P. LaTorre, L.L. Hench, Effect of crystallization on apatite-layer formation of bioactive glass 45S5, J. Biomed. Mater. Res. B 30 (1996) 509514.

[31] A. Cattini, D. Bellucci, A. Sola, L. Pawlowski, V. Cannillo, Functional bioactive glass topcoats on hydroxyapatite coatings: Analysis of microstructure and invitro bioactivity, Surf. Coat. Technol. 240 (2014) 110-117. 
Artículo 5 



\title{
Post-deposition heat treatment effect on microstructure of suspension plasma sprayed bioactive glass coatings
}

\author{
Eugeni Cañas, Vicente Sanz, María José Orts, Enrique Sánchez
}

Surface \& Coatings Technology 371 (2019) 136-142

\section{https://doi.org/10.1016/j.surfcoat.2018.11.003}

Este trabajo aborda un método simple y fácil para mejorar la microestructura de recubrimientos de vidrio bioactivo obtenidos mediante proyección térmica por plasma a partir de suspensiones. En base a investigaciones previas del grupo de los autores, se ha depositado un recubrimiento de vidrio bioactivo mediante proyección térmica por plasma, utilizando condiciones de proyección optimizadas, a partir de una suspensión estable.

Tras la caracterización microestructural, los recubrimientos se han sometido a un tratamiento térmico hasta temperaturas máximas de 400,500 y $600{ }^{\circ} \mathrm{C}$. Estas temperaturas se han elegido de acuerdo con la curva de contracción del vidrio de trabajo obtenida mediante microscopio de calefacción. Los resultados muestran una mejora de la microestructura de los recubrimientos (reducción tanto de la porosidad como del espesor y aumento de la adherencia) después de un tratamiento térmico a $500{ }^{\circ} \mathrm{C}$ con respecto al recubrimiento original. Sin embargo, para una temperatura de $400{ }^{\circ} \mathrm{C}$ la microestructura no se altera (la porosidad, el espesor y la adherencia son los mismos que los de la muestra original) mientras que a $600{ }^{\circ} \mathrm{C}$ el recubrimiento se separa totalmente del sustrato. 



\title{
Post-deposition heat treatment effect on microstructure of suspension plasma sprayed bioactive glass coatings
}

\author{
E. Cañas*, V. Sanz, M.J. Orts, E. Sánchez \\ a Instituto de Tecnología Cerámica (ITC), Universidad Jaume I, Castellón, Spain \\ * Corresponding author
}

\begin{abstract}
This research addresses a simple and easy method to improve the microstructure of suspension plasma sprayed bioactive glass coatings. Based on previous research of the group, a SPS bioactive glass coating was deposited under optimised variables employing a stable suspension feedstock.

After the microstructural characterisation, the coatings were subjected to a heat treatment at 400,500 and $600^{\circ} \mathrm{C}$ peak temperatures. These temperatures have been chosen according to the shrinkage curve of the working glass which results from a hot stage microscope. Results show an improvement of the coatings microstructure (reduction in both porosity and thickness and increment of the adhesion) after a heat treatment at $500{ }^{\circ} \mathrm{C}$ with respect to the original coating. However, for a temperature of $400 \stackrel{\circ}{\mathrm{C}}$ the coating microstructure is not altered (porosity, thickness and adherence are the same as those of the original sample) while at $600{ }^{\circ} \mathrm{C}$ the entire coating is completely delaminated.
\end{abstract}

Keywords: Bioactive glass suspensions; Hot stage microscopy; Suspension plasma spraying; Bioactive glass coatings; Post-deposition treatment

\section{Introduction}

Plasma spraying represents a technique with great potential to obtain bioactive glass (BG) coatings since it allows the in-situ deposition of the coating while preserving the amorphous nature of the feedstock. For that reason, some research groups have started to work on this technique to obtain and optimise the properties of BG coatings from powders [1-4]. But, as in other feedstocks [5-8], the deposition of particle suspensions employing Suspension Plasma Spraying (SPS) could also provide some advantages in comparison with powder feedstocks. Once the glass suspension has been obtained, the atomisation of the same into the plasma torch is not different from other feedstocks deposited by the SPS process [9-11]. However, during deposition of glass suspensions, care must be taken with the temperature of the substrate surface, since if a high surface temperature is not reached before depositing the coating, melted glass particles develop rapid sintering and cool without splashing when impacting the substrate leading to a first glass layer formed by 
small spherical glass drops connected between them and high inner porosity [12-14]. After 1-2 spraying passages, the glass layer already deposited, retains more heat from the torch, reaching high surface temperatures (higher than the glass transition temperature) and giving rise to a glass coating with a viscous top layer [15]. From that point, two phenomena take place at the same time. On the one hand, the deposition rate is increased since all arriving particles, including the re-solidified ones can be easily stacked to the deposited coating. On the other hand, due to stagnation flow of plasma gases, the arriving particles are deflected parallel to the coating surface, resulting in a mainly columnar coating growth mechanism which gives rise to the formation of a top layer made up of large, melted glass agglomerates with a very high number of closed and spherical pores due to gas entrapment because of the viscous flow sintering of the glass $[13,15,16]$. Therefore, a layered and columnar coating is achieved, with very porous microstructure which negatively affects the coating adhesion.

Fortunately, a simple post-spray treatment can provide great benefits for the BG coatings microstructure together with an enhancement of their adhesion [2]. Post-spray treatments have been widely used in the last decades in order to improve thermal sprayed coatings and increase their final quality. There are several post-treatments depending on both the type of coating material and the final application [17-19]. Typical post-deposition treatments are listed below:

- Heat treatment, which could be taken by different ways (electromagnetic heating by laser, microwave or spark plasma sintering; furnace treatment and combustion flame treatment).

- Impregnation, on which a liquid sealant is used to fill the open porosity by capillarity and then solidifies. Sometimes, a heat treatment is required to homogenize the microstructure.

- Finishing, in order to achieve the desired roughness (by polishing) and dimension (by grinding) based on the final application.

For the case of bioactive glass coatings, taking into account that they are brittle materials and a very carefully temperature control should be taken to avoid undesired crystallisation, a furnace heat treatment appears to be the suitable method to improve the bioactive glass coatings microstructure since the entire coating is heated in a homogeneous way and the temperature is perfectly controlled. In addition, employing a furnace makes it possible to work with very low temperatures (close to the glass transition temperature). Just care must be paid in order to control the thermal expansion of both the coating and the substrate, as the latter is also heated inside the furnace, and to avoid the formation of undesired crystalline phases.

Thus, the paper highlights the benefits of post-deposition heat treatment for bioactive glass coatings microstructure and properties contributing to the feasibility of the SPS process to produce good quality coatings. 


\section{Experimental}

\subsection{Bioactive glass suspension feedstock}

For the present work, a bioactive glass suspension feedstock was used, that has been already prepared, stabilised and characterised by the authors in previous works $[12,13]$. Basically, a bioactive glass with an oxide composition (in wt\%) $47,6 \mathrm{SiO}_{2}, 5,3 \mathrm{P}_{2} \mathrm{O}_{5}, 23,2 \mathrm{CaO}$ and $24,0 \mathrm{Na}_{2} \mathrm{O}$ was obtained by melting at $1450{ }^{\circ} \mathrm{C}$ the corresponding raw materials mixture and quenching into water, and the resulting frit particles were used to prepare an organic based glass suspension, as described before [12,13], resulting in a suspension with a solids concentration of $10 \mathrm{vol} . \%$ and a narrow particle size distribution with a mean size of $D_{50}=2,2 \mu \mathrm{m}$.

In those previous works, it was shown that the bioactive glass suspension feedstock exhibited an adequate rheological behaviour to be used as feedstock for SPS. The viscosity curve (Figure 1) showed a pseudoplastic behaviour and low viscosity values when shear was acting which makes it suitable for transport and injection $\left(5,6 \cdot 10^{-3}\right.$ and $5,4 \cdot 10^{-3} \mathrm{~Pa} \cdot \mathrm{s}$ at a shear rate of 127 and $51000 \mathrm{~s}^{-1}$ respectively) into the plasma torch.

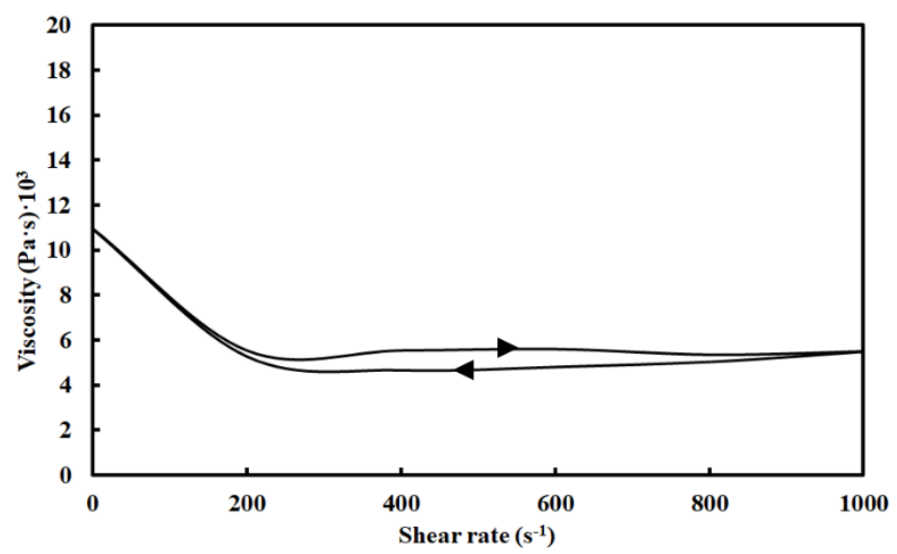

Figure 1. Viscosity curve of the suspension feedstock

Besides, no significant variation of viscosity with time (thixotropy) was observed. Concerning the stability, it was shown that for one hour there was no variation in the light transmitted or reflected (as shown in figure 2), therefore no sedimentation occurred.

However, from 15 to $24 \mathrm{~h}$, an increase of the light reflected in the lower part of the cell $(0-5 \mathrm{~mm})$ can be seen with a decrease in the backscattered light in the upper part (35-40 $\mathrm{mm}$ ) due to the sedimentation of coarse glass particles, while the fine particles remain suspended. But this drawback can be solved as authors demonstrated [13]. After 21 days of suspension storage, it was possible to re-disperse it only by simple agitation. The particle size distribution of the 
suspension after 21 days was measured, and there were no differences between the as-prepared and the re-dispersed suspensions particle sizes.
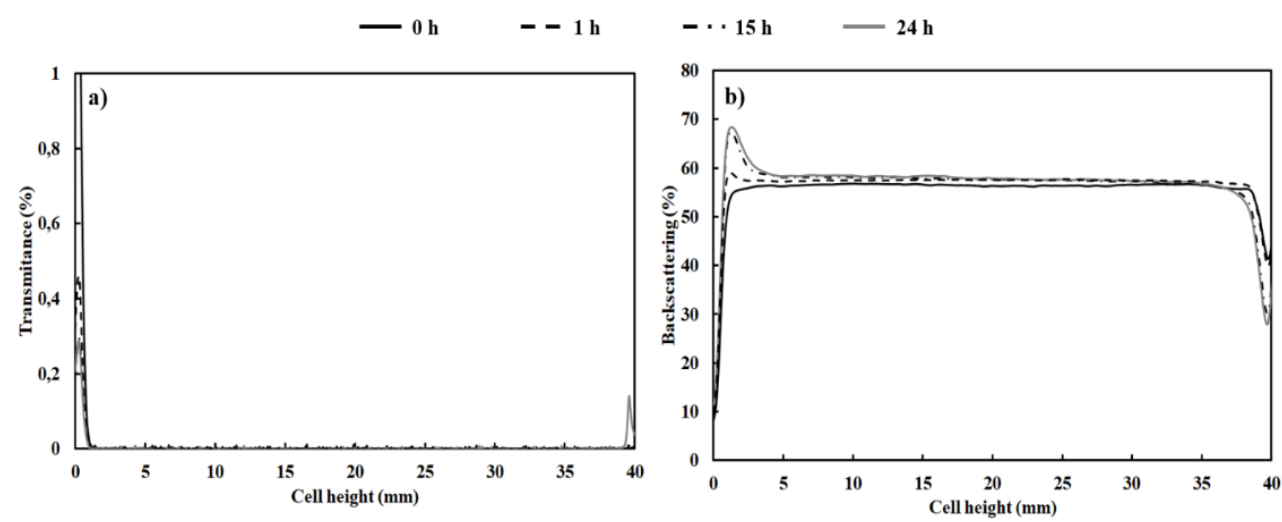

Figure 2. Stability of the suspension. a) Transmittance and b) Backscattering

\subsection{Sintering treatment of the suspension powders}

In the present work, a thermal characterisation of the feedstock was also performed in order to assess the behaviour of the home-made bioactive glass powders contained in the suspension at high temperatures and, after coatings deposition, to plan their heat treatment to improve coatings microstructure. For that reason, the sintering curve (variation in shrinkage with temperature) of the glass particles was determined by hot stage microscopy (HSM) (MISURA 3, Expert System Solutions, Italy) at a heating rate of $25^{\circ} \mathrm{C} / \mathrm{min}$, in air atmosphere. The HSM is the combination of a heating stage (hot stage) with a sample holder coupled with a light microscope and a system that allows to record the changes in shape and geometry of a sample with temperature when submitted to a thermal cycle. A cylindrical test piece was prepared by pressing the powder obtained after the solvent was removed from the glass suspension and was introduced into the microscope and subjected to the selected heating rate up to the melting of the powder.

\subsection{Coating deposition and characterisation}

The bioactive glass suspension feedstock was sprayed onto metallic substrates by SPS. Although SPS coatings from the same feedstock were already deposited by authors in previous works [12,13], for the present article new coatings were sprayed and characterised with the aim of reproducing the targeted microstructure to be optimised by the subsequent post-spraying process. Previously to deposition, the substrates (AISI type 304 stainless steel) were grit-blasted and cleaned. Grit-blasting was performed using black corundum with a pressure of 4,2 bar, and then the substrates were cleaned with ethanol. Roughness $\left(R_{a}\right)$ of grit-blasted and cleaned substrates was measured employing a roughness measurement equipment (HOMMELWERKE T8000, 
Jenoptik $A G$, France). The obtained $R_{a}$ value was $2,2 \pm 0,1 \mu \mathrm{m}$. To enhance the adherence of the final glass coating, substrates were first coated with a bond coat that was deposited from anatase feedstocks (Metco 102, Oerlikon Metco, Switzerland) with a particle size distribution between 10 and $55 \mu \mathrm{m}$ by atmospheric plasma spraying (APS) and using the spraying parameters given by the supplier (Table 1).

Table 1 Plasma spraying parameters used

\begin{tabular}{ccc}
\hline Spraying parameters & $\begin{array}{c}\mathrm{TiO}_{2} \text { bond coat } \\
\text { (APS) }\end{array}$ & $\begin{array}{c}\text { Bioactive glass top layer } \\
\text { (SPS) }\end{array}$ \\
\hline Argon flow rate $(\mathrm{slpm})$ & 38 & 37 \\
Hydrogen flow rate $(\mathrm{slpm})$ & 14 & 8 \\
Intensity $(\mathrm{A})$ & 600 & 700 \\
Spraying distance $(\mathrm{mm})$ & 120 & 70 \\
Spraying velocity $(\mathrm{m} / \mathrm{s})$ & 1,00 & 1,25 \\
\hline
\end{tabular}

The APS facility used comprises a plasma gun (F4-MB, Oerlikon Metco, Switzerland) managed by a six-axis robot (IRB 1400, ABB, Switzerland). In the gun, the plasma generation was accomplished using argon as primary gas and hydrogen as secondary gas. Details about the SPS equipment have been reported in previous works $[20,21]$.

Finally, bioactive coatings were deposited with the facility described above, preheating the bond coated substrates between $300^{\circ} \mathrm{C}$ and $350^{\circ} \mathrm{C}$. The plasma working gases used were a mixture of argon as primary gas and hydrogen as secondary gas. The spraying conditions utilised in this work are detailed in table 1.

Then, coatings were subjected to a post-treatment in an electric furnace to improve their microstructure. For that purpose, coatings were heated with a rate of $25^{\circ} \mathrm{C} / \mathrm{min}$ (the same used in the HSM step) from room temperature until a maximum temperature, which is selected according to the results of the hotstage microscope test of the feedstock powder as mentioned in the previous section. Once the maximum temperature was reached, it was kept for 30 min and finally the coatings were allowed to cool free in the furnace. Higher dwell times at maximum temperature were discarded since the coating started to present some delaminate.

Polished cross-sections of the coatings, as-sprayed and post-treated, were prepared and subsequently observed in a field-emission gun environmental scanning electron microscope (FEG-ESEM) (QUANTA 200FEG, FEl Company, USA), and their amorphous/crystalline character was determined by X-ray diffraction (XRD) (Advance diffractometer, Bruker Theta-theta, Germany).

On the other hand, coatings thickness and porosity were estimated by image analysis (Microlmage) at 2000x magnifications from FEG-ESEM pictures following a procedure set out elsewhere [22]. In addition, with aim of confirm the 
success of the heat treatment, the relative interfacial toughness $\left(\mathrm{K}_{c}\right)$ was determined in order to qualify the adhesion of the as-sprayed coating and those treated at $400^{\circ} \mathrm{C}$ and $500^{\circ} \mathrm{C}$. This test was done by Vickers indentation (Hardness tester M1C010, Emco-Test, Austria) on the polished cross-sections of the coatings at the interface between the bond coat and the glass coat [2326], performing 10 indentations of $5 \mathrm{~N}$ per coating with a diamond pyramid indenter. After each indentation, the half-length of the diagonal and the total length of the cracks (from the centre of the indentation until the end of the crack) generated at the interface were measured and used to calculate a relative interfacial toughness by means of Evan and Wilshaw model [24-26].

\section{Results and discussion}

\subsection{Thermal behaviour of suspension powders}

Figure 3 corresponds to the sintering curve of the bioactive glass powder obtained with the hot-stage microscope. This technique allows not only qualitative observations but also quantitative sintering studies [27-30]. The characteristic points or temperatures at which the test piece acquires certain geometries are showed in the same figure. Those characteristic temperatures were first defined by Scholze [31], and then Pascual et al. [32,33], comparing the calculated viscosities of the abovementioned characteristic temperatures with experimental values obtained with a high temperature viscometer.

The sintering curve shows four temperature ranges. From room temperature up to about $500{ }^{\circ} \mathrm{C}$ thermal expansion controls the size of the test piece and shrinkage slightly decreases. At $500{ }^{\circ} \mathrm{C}$ glass sintering starts. At this temperature glass viscosity is low enough to allow densification and shrinkage to occur. In the temperature range $650-900{ }^{\circ} \mathrm{C}$ a plateau is observed due to devitrification [4, 34]. Crystal formation increases viscosity and sintering stops. Two main phases are formed: a sodium calcium silicate and a sodium calcium phosphate $[4,35,36]$. At $900^{\circ} \mathrm{C}$ sintering restarts and shrinkage slowly starts up to $1050^{\circ} \mathrm{C}$. At this point, it can be appreciated the expansion of the cylindrical sample, which contrasts to the literature [4,34-36]. This unusual effect is caused by the entrapped air, which is hardly released to the ambient during the heat treatment due to the very fine porosity associated with the fine glass particle size. However, after all the air is removed, the shrinkage restarts again and takes place very fast until viscosity is low enough for the test piece to lose its original cylindrical shape. The temperatures at which shrinkage starts and stops slightly vary depending on the starting particle size of the glass in the test piece [4], and on the heating rate [30].

This curve is important as it allows to define temperatures at which the glass can be treated to be annealed or to modify the topography of a glass coated substrate. 

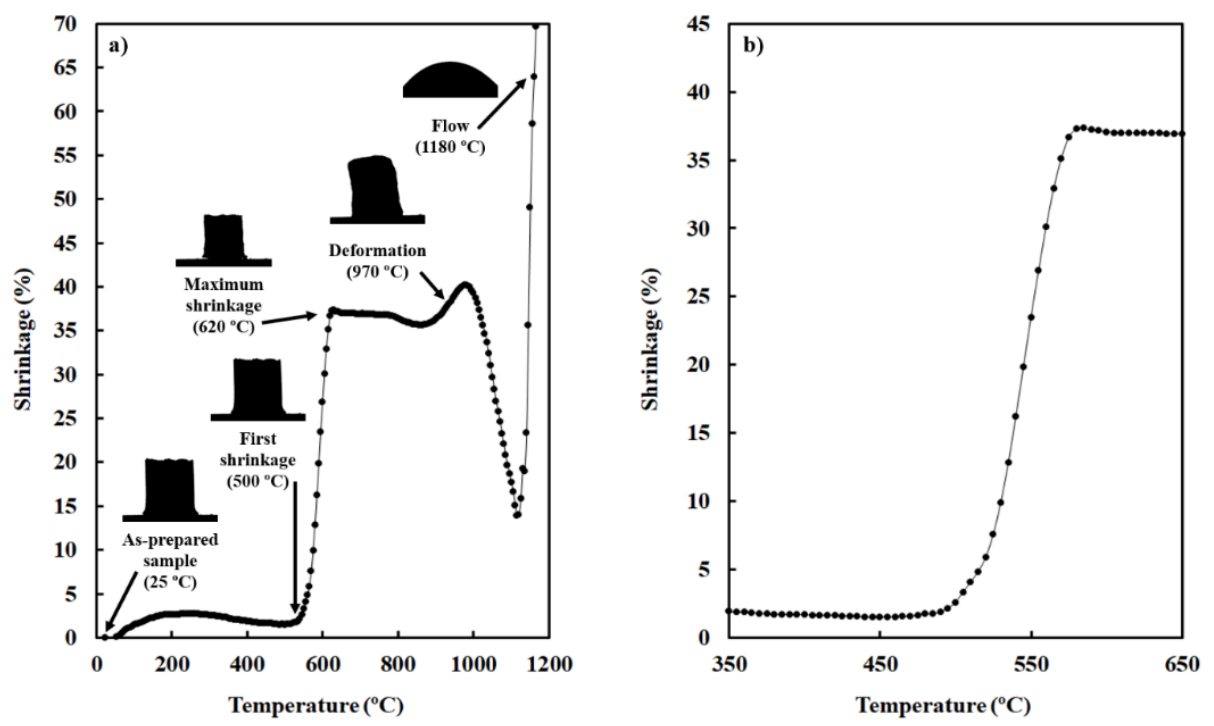

Figure 3. a) Sintering curve of the BG suspension powder from the HSM with the image of the test piece at each characteristic temperature and b) Diagram expansion for the temperature range comprised between $350-650 \stackrel{\circ}{ } \mathrm{C}$.

\subsection{Bioactive glass coatings}

The suspension prepared was used to obtain coatings by SPS with the spraying parameters detailed in table 1, which were optimised in an experiment grid described in a previous paper [13]. The microstructure of the coatings has been also thoroughly described in that previous research [13], and revealed two different zones, as can be seen in Figure 4, where each zone has been delimited.
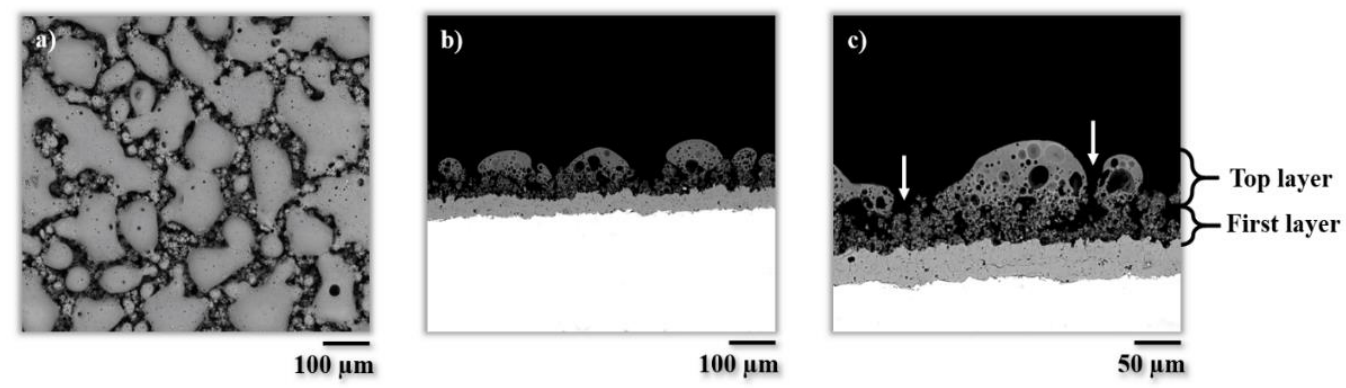

Figure 4. Microstructure of the as-sprayed coating before the heat treatment. a) Surface, b) cross-section and c) cross-section at higher magnification showing the two different zones of the coating

The inner part of the coating, just above the bond-coat, was a highly porous continuous layer of $35 \mu \mathrm{m}$ built by an assembly of fine droplets partially sintered 
with high open porosity (marked with white arrows). The external part of the coating had a completely different appearance as it consisted of dispersed and densified areas whose cross-section indicates that a higher degree of densification than that of the inner part of the coating has been achieved. This can be due to the fact that when spraying the last glass droplets impinge onto a hotter surface than that of the first ones. However, the coating microstructure is not optimal as it would have been convenient to have a more regular surface, uniformly covered by densified areas, instead of isolated dense areas over a highly porous layer, that probably weakly bonds to the substrate.

A first approach to improve the microstructure of the coatings was to modify the spraying conditions and to highly preheat the bond coated substrate but no significant changes were observed within the operational range of those parameters in the APS facility used.

\subsection{Post-spray heat treatment}

According to the literature [2] a post-deposition heat treatment could be needed when the microstructure of the coating is highly porous or not adequate. In order to do so, the thermal schedule must be carefully designed so that the coatings porosity could be reduced avoiding crystallization and without altering the substrate.

A decrease in porosity could be only accomplished if a considerable amount of liquid phase is formed. There are two temperature ranges in which liquid phase develops as stated in the sintering curve obtained with the hot-stage microscope (figure 3). The first one goes from $500{ }^{\circ} \mathrm{C}$ to $620{ }^{\circ} \mathrm{C}$ and corresponds to the rapid increase of shrinkage up to the plateau where sintering stops due to crystallization. The onset of the second temperature range in which liquid phase develops and another step of shrinkage occurs begins at about 900 ${ }^{\circ} \mathrm{C}$. Nevertheless, this last temperature range was discarded as it was too high to be withstood by the substrate.

The coatings were thermally treated at three temperatures around the first sintering step: 400,500 and $600^{\circ} \mathrm{C}$, following the firing cycle set out in section 2.3. Coatings deposition and characterisation.

The coating treated at $600{ }^{\circ} \mathrm{C}$ was detached from the substrate probably due to a thermal mismatch between substrate and coating. Thus, this temperature was found to be too high for the substrate used and no higher temperatures were tried.

Figure 5 shows the polished cross-sections of the coatings treated at $400{ }^{\circ} \mathrm{C}$ and $500{ }^{\circ} \mathrm{C}$. The microstructure of the $400^{\circ} \mathrm{C}$ treated coating shows no difference with the microstructure of the original coating (Figure 4): a porous layer near the substrate and isolated glass areas over this layer. Nevertheless, the coating treated at $500{ }^{\circ} \mathrm{C}$ showed an improved microstructure compared to 
the original one. The porous layer was densified, and the coating has become a homogeneous layer over the substrate.

Percentage of porosity and mean thickness of the coatings were determined by image analysis coupled to the scanning electron microscope, and results are shown in figure 6 . As it can be seen the coating treated at $400{ }^{\circ} \mathrm{C}$ has the same porosity, thickness and adherence than the original one. For the $500^{\circ} \mathrm{C}$ treated coating, percentage of porosity and mean thickness decrease due to sintering during the heat treatment.
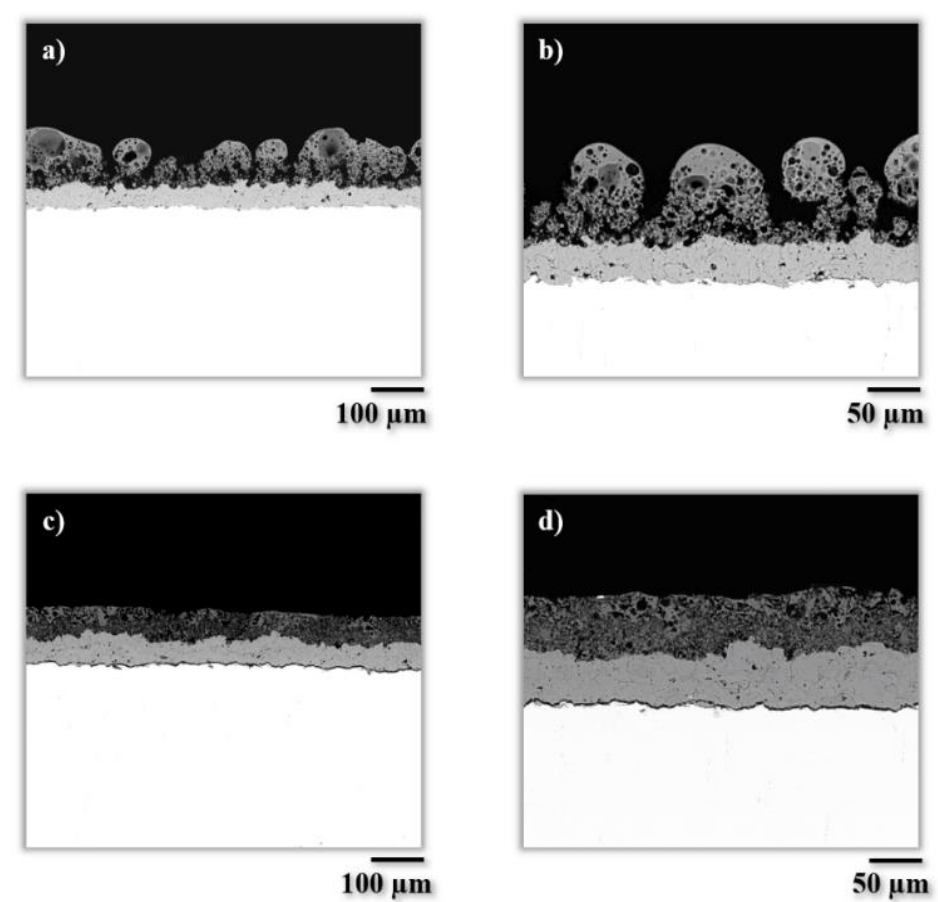

Figure 5. Cross-sections of the coating after the heat treatment. a) and b) coating treated

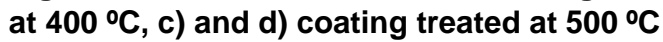



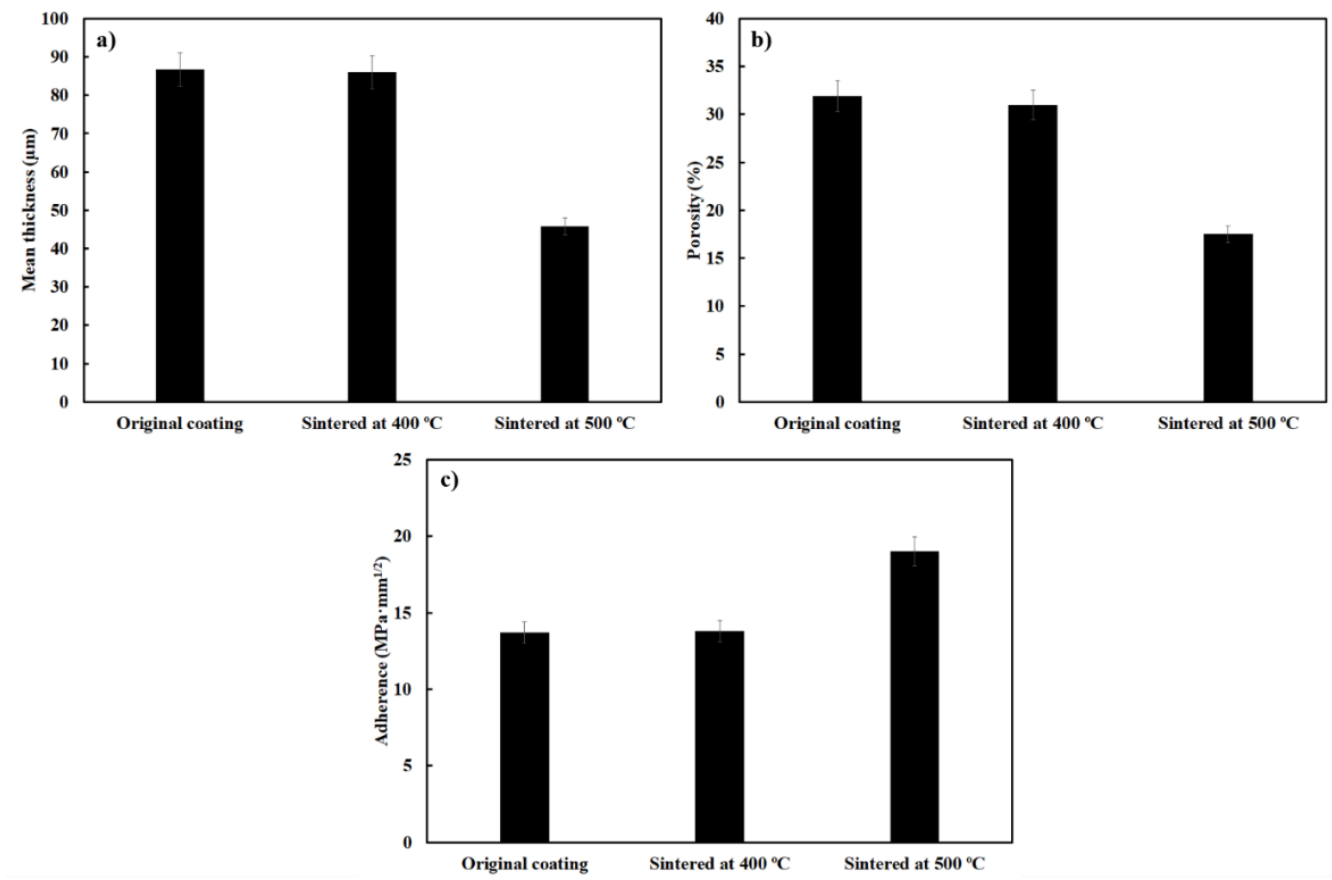

Figure 6. a) Mean thickness, b) porosity and c) adherence of the as-sprayed coating and the coatings treated at 400 and $500{ }^{\circ} \mathrm{C}$

Figure 6 also includes the relative interfacial toughness values determined by means of Evans and Wilshaw model from Vickers indentations. The common procedure consists in applying several indentations at different loads, to estimate a critical load from which the toughness is calculated [23]. Nevertheless, due to the low quality of glass microstructure as well as the poor mechanical resistance of glass layer the calculation of this parameter has been carried out by using only one load of $5 \mathrm{~N}$ (following the procedure described in section 2.3. Coatings deposition and characterisation), in which visible cracks through the glass layer-bond coat interface could be monitored. Similar procedure has been also followed in previous research [24, 25]. It can be appreciated that; an increment of the interfacial toughness takes place for the $500{ }^{\circ} \mathrm{C}$ treated coating with regard to the as-sprayed coating and that treated at $400{ }^{\circ} \mathrm{C}$, since a more homogeneous coating microstructure is achieved at $500{ }^{\circ} \mathrm{C}$ due to the liquid phase developed.

In addition, two examples of the indentation traces for the as-sprayed coating and that treated at $500{ }^{\circ} \mathrm{C}$ are presented in figure 7 . 

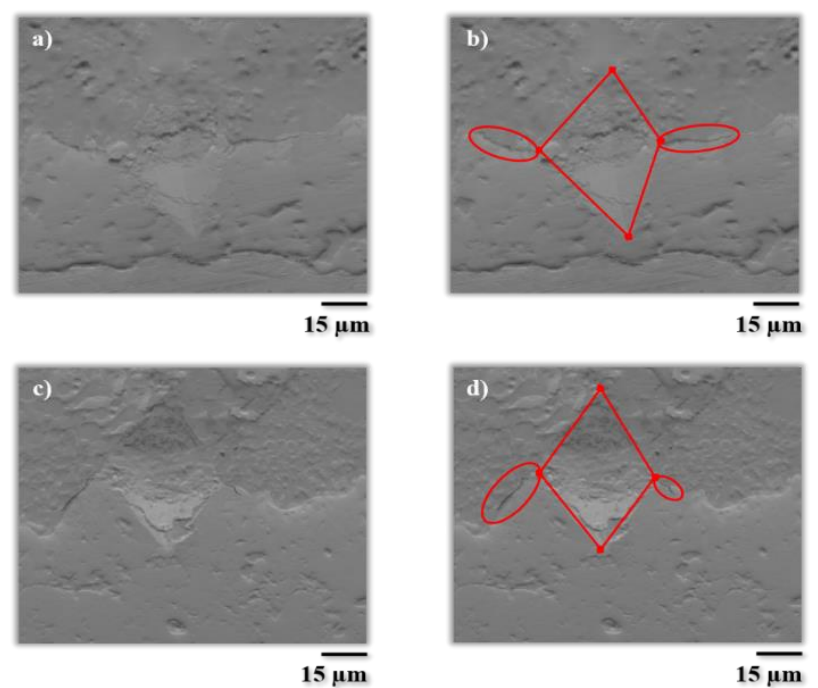

Figure 7. Coatings micrographs (BS detector: A-B mode) showing the interfacial indentations. a), b) As-sprayed coating and c), d) Treated at $500{ }^{\circ} \mathrm{C}$

For better understanding, in figures $7 \mathrm{~b}$ and $7 \mathrm{~d}$ both indenter trace and crack were surrounded in red. As demonstrated in figure 6, the coating treated at 500 ${ }^{\circ} \mathrm{C}$ shows higher fracture toughness, and this is supported by figure $7 \mathrm{c}$, at which a lower penetration of the indenter and shorter interfacial cracks can be appreciated, while for the as-sprayed coating, a greater penetration of the indenter can be appreciated, and longer and wider cracks, which confirms the low adherence of this coating. Nevertheless, in both cases there is a little deviation of the indenter from the bond coat to the glass coat, due to the difference in hardness of both layers.

Finally, figure 8 shows the XRD pattern of the original coating and the posttreated one at $500^{\circ} \mathrm{C}$. Both patterns correspond to fully amorphous materials. Thus, the post-treatment at $500 \stackrel{\circ}{\mathrm{C}}$ preserves the amorphous structure without any devitrifying phase occurring during the firing schedule.

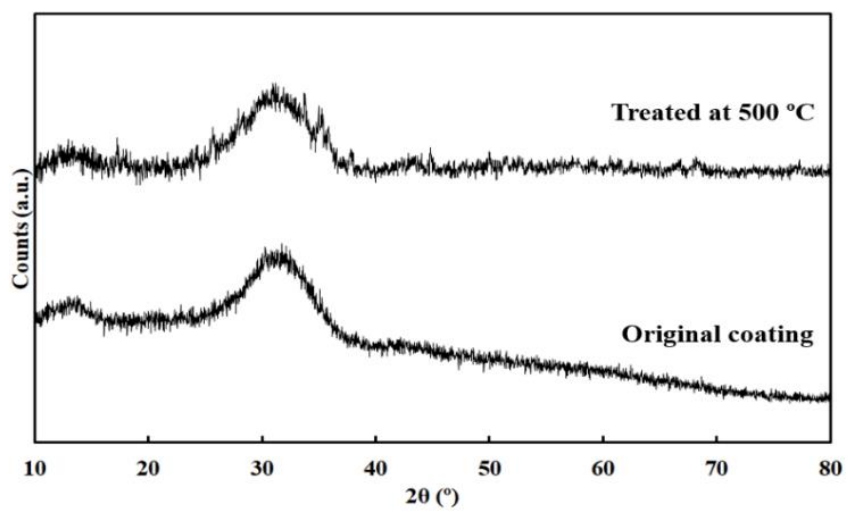

Figure 8. XRD patterns of the as-sprayed coating [13] and the coating treated at $500{ }^{\circ} \mathrm{C}$ 


\section{Conclusions}

A bioactive glass suspension was prepared to be used as a feedstock in a SPS process. The rheological behaviour of this suspension was adequate and showed low viscosity values when shear was acting. The stability of the suspension was assessed as no sedimentation was detected for $15 \mathrm{~h}$. Both characteristics made the suspension suitable for transport and injection into the plasma torch.

Bioactive coatings were obtained through the deposition of the feedstock suspension by SPS, based on previous research. The coatings were amorphous and showed a porous and cracked microstructure, made up of two different zones, as reported elsewhere. Even for the most suitable spraying conditions, the resulting coating was highly porous and irregular. In order to improve the microstructure of the coatings thermal post-treatments were designed according to the sintering curve of the powder feedstock obtained in a hot-stage microscope. The aim of the post treatment was to generate enough liquid phase to partially sinter the glass coating without developing crystalline phases and without altering the substrate.

Heat treatment at a peak temperature of $500{ }^{\circ} \mathrm{C}$ significantly improved the microstructure partially sintering the coating, homogenizing its thickness and improving adherence. XRD confirmed that the amorphous nature of the coating was preserved during the thermal treatment.

By carefully designing the firing schedule, according to the shrinkage curve obtained with a heating microscope, it is possible to improve the microstructure of a bioactive glass coating without neither changing its amorphous nature nor altering the substrate.

\section{Acknowledgements}

The authors of the present work thank Universitat Jaume I of Castellón the support provided in funding RECUBIO project (P1-1B2013-69) and action 3.1. of the Research Promotion Plan (PREDOC/2015/50) as well as Prof. Rodrigo Moreno (ICV-CSIC, Madrid, Spain) for his kindly contribution in the rheological characterisation.

\section{References}

[1] G. Goller, The effect of bond coat on mechanical properties of plasma sprayed bioglass-titanium coatings, Ceram. Int. 30 (2004) 351-355.

[2] V. Cannillo, A. Sola, Different approaches to produce coatings with bioactive glasses: Enamelling vs plasma spraying, J. Eur. Ceram. Soc. 30 (2010) 20312039. 
[3] M. Monsalve, H. Ageorges, E. Lopez, F. Vargas, F. Bolivar, Bioactivity and mechanical properties of plasma-sprayed coatings of bioglass powders, Surf. Coat. Technol. 220 (2013) 60-66.

[4] E. Cañas, M. Vicent, E. Bannier, P. Carpio, M.J. Orts, E. Sánchez, Effect of particle size on processing of bioactive glass powder for atmospheric plasma spraying, J. Eur. Ceram. Soc. 36 (2016) 837-845.

[5] C. Monterrubio-Badillo, H. Ageorges, T. Chartier, J.F. Coudert, P. Fauchais, Preparation of $\mathrm{LaMnO}_{3}$ perovskite thin films by suspension plasma spraying for SOFC cathodes, Surf. Coat. Technol. 200 (2006) 3743-3756.

[6] F.L. Toma, G. Bertrand, S. Begin, C. Meunier, O. Barres, D. Klein, C. Coddet, Microstructure and environmental functionalities of $\mathrm{TiO}_{2}-$ supported photocatalysts obtained by suspension plasma spraying, App. Catal. B: Environ. 68 (2006) 74-84.

[7] H. Kassner, R. Siegert, D. Hathiramani, R. Vassen, D. Stoever, Application of suspension plasma spraying (SPS) for manufacture of ceramic coatings, J. Therm. Spray Technol. 17 (2008) 115-123.

[8] A. Killinger, R. Gadow, G. Mauer, A. Guignard, R. Vassen, D. Stöver, Review of new developments in suspension and solution precursor thermal spray processes, J. Therm. Spray Technol. 20 (2011) 677-695.

[9] J. Fazilleau, C. Delbos, V. Rat, J.F. Coudert, P. Fauchais, B. Pateyron, Phenomena involved in suspension plasma spraying part 1: suspension injection and behaviour, Plasma Chem. Plasma Process. 26 (2006) 371-391.

[10] L. Pawlowski, Suspension and solution thermal spray coatings, Surf. Coat. Technol. 203 (2009) 2807-2829.

[11] P. Sokolowski, S. Kozerski, L. Pawlowski, A. Ambroziak, The key process parameters influencing formation of columnar microstructure in suspension plasma sprayed zirconia coatings, Surf. Coat. Technol. 260 (2014) 97-106.

[12] E. Cañas, M. Vicent. M.J. Orts, R. Moreno. E. Sánchez, Bioactive glass suspensions preparation for suspension plasma spraying, J. Eur. Ceram. Soc. 36 (2016) 4281-4290.

[13] E. Cañas, M. Vicent, M.J. Orts, E. Sánchez, Bioactive glass coatings by suspension plasma spraying from glycolether-based solvent feedstock, Surf. Coat. Technol. 318 (2017) 190-197.

[14] A. Cattini, L. Latka, D. Bellucci, G. Bolelli, A. Sola, L. Lusvarghi, L. Pawlowski, V. Cannillo, Suspension plasma sprayed bioactive glass coatings: Effects of processing on microstructure, mechanical properties and in-vitro behaviour, Surf. Coat. Technol. 220 (2013) 52-59.

[15] G. Bolelli, D. Bellucci, V. Cannillo, R. Gadow, A. Killinger, L. Lusvarghi, P. Müller, A. Sola, Comparison between suspension plasma sprayed and high velocity suspension flame sprayed bioactive coatings, Surf. Coat. Technol. 280 (2015) 232-249.

[16] D. Bellucci, G. Bolelli, V. Cannillo, R. Gadow, A. Killinger, L. Lusvarghi, A. Sola, N. Stiegler, High velocity suspension flame sprayed (HVSFS) potassium-based 
bioactive glass coatings with and without $\mathrm{TiO}_{2}$ bond coat, Surf. Coat. Technol. 206 (2012) 3857-3868.

[17] L. Pawlowski, The science and engineering of thermal spray coatings, second ed., John Wiley and Sons, Great Britain, 2008.

[18] Y. Yang, K.H. Kim, J.L. Ong, A review on calcium phosphate coatings produced using a sputtering process-an alternative to plasma spraying, Biomater. 26 (2005) 327-337.

[19] H. Pokhmurska, B. Wielage, T. Lampke, T. Grund, M. Student, N. Chervinska, Post-treatment of thermal spray coatings on magnesium, Surf. Coat. Technol. 202 (2008) 4515-4524.

[20] M. Vicent, E. Bannier, P. Carpio, E. Rayón, R. Benavente, M.D. Salvador, E. Sánchez, Effect of the initial particle size distribution on the properties of suspension plasma sprayed $\mathrm{Al}_{2} \mathrm{O}_{3}-\mathrm{TiO}_{2}$ coatings, Surf. Coat. Technol. 268 (2015) 209-215.

[21] P. Carpio, E. Bannier, M.D. Salvador, A. Borrell, R. Moreno, E. Sánchez, Effect of particle size distribution of suspension feedstock on the microstructure and mechanical properties of suspension plasma spraying YSZ coatings, Surf. Coat. Technol. 268 (2015) 293-297.

[22] V. Carnicer, M.J. Orts, R. Moreno, E. Sánchez, Microstructure assessment of suspension plasma spraying coatings from multicomponent submicronic $\mathrm{Y}-$ TZP $/ \mathrm{Al}_{2} \mathrm{O}_{3} / \mathrm{SiC}$ particles, Ceram. Int. 44 (2018) 12014-12020.

[23] G. Marot, J. Lesage, Ph. Démarécaux, M. Hadad, St. Siegmann, M.H. Staia, Interfacial indentation and shear tests to determine the adhesion of thermal spray coatings, Surf. Coat. Technol. 201 (2006) 2080-2085.

[24] A.N. Khan, J. Lu, H. Liao, Heat treatment of thermal barrier coatings, Mat. Eng. A 359 (2003) 129-136.

[25] S.A. Sadeghi-Fadaki, K. Zangeneh-Madar, Z. Valefi, The adhesion strength and indentation toughness of plasma-sprayed yttria stabilized zirconia coatings, Surf. Coat. Technol, 204 (2010) 2136-2141.

[26] A.G. Evans, T.R. Wilshaw, Quasi-static solid particle damage in brittle solidsI. Observations, analysis and implications, Acta Metall. 24 (1976) 939-956.

[27] A.R. Bocaccini, B. Hamman. Review: In situ high-temperature optical microscopy. J. Mater. Sci. 34 (1999) 5419- 5436.

[28] C. Siligardi, M.C. D’Arrigo, C. Leonelli, Sintering behaviour of glass-ceramic frits, Am. Ceram. Soc. Bull. 79 (2000) 88- 92.

[29] C. Lara, M.J. Pascual, M.O. Prado, A. Durán, Sintering of glasses in the system $\mathrm{RO}-\mathrm{Al}_{2} \mathrm{O}_{3}-\mathrm{BaO}-\mathrm{SiO}_{2}(\mathrm{R}=\mathrm{Ca}, \mathrm{Mg}, \mathrm{Zn})$ studied by hot-stage microscopy, Solid State Ion. 170 (2004) 201-208.

[30] O. Bretcanu, X. Chatzistavrou, K. Paraskevopoulos, R. Conradt, I. Thompson, A.R. Boccaccini, Sintering and crystallisation of $45 S 5$ Bioglass ${ }^{\circledR}$ powder, J. Eur. Ceram. Soc. 29 (2009) 3299-3306. 
[31] H. Scholze, Influence of viscosity and surface tension on Hot Stage Microscopy measurements on glasses, Ber. Dtsch. Keram. Ges. 391 (1962) 63-68

[32] M.J. Pascual, L. Pascual, A. Duran, Determination of the viscosity-temperature curve for glasses on the basis of fixed viscosity points determined by hot stage microscopy, Phys. Chem. Glasses 42 (2001) 61-66.

[33] M.J. Pascual, A. Durán, M.O. Prado, A new method for determining fixed viscosity point of glasses, Phys. Chem. Glasses 46 (2005) 512-520.

[34] J.R. Jones, A.G. Clare, Bio-glasses, an introduction, first ed., John Wiley and Sons, Great Britain, 2012.

[35] L. Lefebvre, L. Gremillard, J. Chevalier, R. Zenati, D. Bernache-Assolant, Sintering behaviour of 45 S5 bioactive glass, Acta Biomater. 4 (2008) 18941903.

[36] N.A. Zarifah, W.F. Lim, K.A. Matori, H.A.A. Sidek, Z.A. Wahab, N. Zainuddin, M.A. Salleh, B.N. Fadilah, A.N. Fauzana, An elucidating study on physical and structural properties of $45 \mathrm{~S} 5$ glass at different sintering temperatures. J. NonCrystal. Solid. 412 (2015) 24-29. 

ARTículo 6 



\title{
Solution precursor plasma spraying (SPPS): A novel and simple process to obtain bioactive glass coatings
}

\author{
Eugeni Cañas, María José Orts, Aldo R. Boccaccini, Enrique Sánchez
}

Materials Letters 223 (2018) 198-202

\section{https://doi.org/10.1016/j.matlet.2018.04.031}

Este trabajo aborda el uso de una técnica emergente de proyección por plasma conocida como proyección térmica por plasma a partir de soluciones (SPPS) para obtener recubrimientos de vidrio bioactivo. En esta técnica, el material de aporte para la proyección es una solución de precursores en lugar de un material pulverulento o una suspensión.

La composición estudiada ha sido la del vidrio 45S5. Se han obtenido recubrimientos modificando la composición del material de aporte (presencia o no de catalizador), la entalpía de la pluma de plasma y la distancia de proyección. El mejor recubrimiento se ha obtenido al utilizar catalizador (ácido nítrico a una concentración $0,2 \mathrm{M}$ ), depositando el material de aporte bajo condiciones de alta energía y una distancia de proyección corta.

Además, mediante inmersión en fluido biológico simulado se ha comprobado la buena bioactividad del recubrimiento debido al efecto de la porosidad interconectada que presenta. 



\title{
Solution precursor plasma spraying (SPPS): A novel and simple process to obtain bioactive glass coatings
}

\author{
E. Cañas ${ }^{a *}$, M.J. Orts ${ }^{a}$, A.R. Boccaccini ${ }^{b}$, E. Sánchez ${ }^{a}$ \\ a Instituto de Tecnología Cerámica (ITC), Universidad Jaume I, Castellón, Spain \\ b Institute of Biomaterials, University of Erlangen-Nuremberg, Erlangen, Germany \\ * Corresponding author
}

\begin{abstract}
This research addresses the use of an emerging plasma spray technique known as SPPS (Solution Precursor Plasma Spraying) to obtain bioactive glass coatings. In SPPS, the feedstock is a sol precursor of the bioactive glass instead of glass particles. Precursor feedstock composition (presence or not of acid catalyst), plasma torch enthalpy and spraying distance of the spraying process have been varied to produce bioactive glass coatings of nominally $45 \mathrm{~S} 5$ composition. A good quality coating was obtained when catalyst $(0,2 \mathrm{M}$ acid nitric) was used in the precursor and the plasma spraying took place with shorter spraying distance and higher plasma enthalpy. Bioactivity in Simulated Body Fluid test was confirmed and an effect of the coating interconnected porosity to enhance bioactivity was observed.
\end{abstract}

Keywords: Bioceramics; Solution feedstock; Solution precursor plasma spraying; Bioactive glass coating; Simulated body fluid; Microstructure

\section{Introduction}

Bioactive glasses are considered promising materials to be used as coatings onto metallic substrates in load-bearing applications due to their high bioactivity $[1,2]$. Among different application techniques, thermal spraying shows significant advantages; in particular, the fact that the deposition and consolidation of the coating occur simultaneously without the need of a sintering treatment. There have been some previous attempts to obtain bioactive glass coatings starting with glass particle feedstocks by different thermal spray techniques. Although coating bioactivity has been proven, the uncompleted sintering of glass particles during the spraying deposition gives rise to a highly porous microstructure poorly adhered to the substrate $[3,4]$. More recently, researchers have tried to use the suspension plasma spraying (SPS) process in which a glass particle suspension is fed into the plasma torch instead of a powder feedstock [5]. Although finer glass particles can be fed with a suspension, similar microstructures to those obtained from powder feedstocks are still produced $[5,6]$. In addition, regardless the use of a powder or particle 
suspension as feedstock, glass particles have to be produced by the fusing and crushing process which implies a series of laborious preparation steps such as melting, quenching, grinding, sieving, etc., which can introduce contaminants in the final feedstock.

Nowadays, the use of precursor solutions instead of traditional thermal spraying feedstocks (powders and suspensions) is gaining great interest in the thermal spray community due to the unique properties obtained, i.e thinner and nanostructured coatings with denser and more homogeneous microstructures [7]. In addition, the use of precursor solutions allows to obtain high purity feedstocks, avoiding possible contamination from feedstock preparation steps. In the family of thermal spraying techniques, there is a process known as SPPS (Solution Precursor Plasma Spraying) which has been extensively reported for varied materials (zirconia or hydroxyapatite, among others) but it has hardly been investigated with glass precursors [7]. In a previous research, authors have considered the production of bioactive glass coating by SPPS and SPS processes [8]. However, highly crystallized glass-ceramic coatings were obtained when a fixed sol precursor feedstock was used at given plasma spray conditions. The study presented in this letter has focused, for the first time, on the development of fully amorphous, bioactive glass coatings by varying feedstock composition as well as plasma spray variables in an SPPS process.

\section{Experimental}

\subsection{Solution feedstocks}

Bioactive glass of $45 \mathrm{~S} 5$ composition $\left(\mathrm{SiO}_{2} 45,0 \%, \mathrm{Na}_{2} \mathrm{O} 24,5 \%, \mathrm{CaO} 24,5 \%\right.$ and $\mathrm{P}_{2} \mathrm{O}_{5} 6,0 \%$, in wt.\%) was selected. Tetraethyl orthosilicate $\left(\mathrm{C}_{8} \mathrm{H}_{20} \mathrm{O}_{4} \mathrm{Si}\right.$ synthesis grade, Merck, Germany) or TEOS, triethyl phosphate $\left(\mathrm{C}_{6} \mathrm{H}_{15} \mathrm{O}_{4} \mathrm{P}\right.$ synthesis grade, Merck, Germany) or TEP, calcium nitrate $\left(\mathrm{Ca}\left(\mathrm{NO}_{3}\right)_{2} \cdot 4 \mathrm{H}_{2} \mathrm{O}\right.$ $>99 \%$, Sigma-Aldrich, USA), and sodium nitrate $\left(\mathrm{NaNO}_{3}>99 \%\right.$, VWR Chemicals, USA) were used as the precursors for $\mathrm{SiO}_{2}, \mathrm{P}_{2} \mathrm{O}_{5}, \mathrm{CaO}$, and $\mathrm{Na}_{2} \mathrm{O}$, respectively.

The sol precursor was prepared in aqueous media at a concentration of $4 \mathrm{M}$ with $0,2 \mathrm{M}$ nitric acid ( $\mathrm{HNO}_{3}$ Tritripur, Merck, Germany) as catalyst. A precursor without catalyst was also prepared. Higher amounts of catalyst were not used because it would shorten the gelation time. First, TEOS and deionized water were mixed under magnetic stirring, with a molar ratio of TEOS to water of 1:18, and the necessary amount of $\mathrm{HNO}_{3}$ (if required) was slowly added to the solution, keeping stirring until solution clarification. Then, TEP was added to the solution under stirring 30 min later, and then calcium and sodium nitrates after another $30 \mathrm{~min}$. The solution was kept stirring for an additional hour and the resulting sol was then aged overnight at room temperature before being used as feedstock. 


\subsection{Coating deposition and characterisation}

Coating deposition was carried out in a thermal spraying facility comprised by a plasma torch (F4-MB, Oerlikon Metco, Switzerland) coupled to a six axes robot (IRB 1400, ABB, Switzerland) and a home-made liquid feeding system operated by mechanical injection. More details about this facility have been reported elsewhere [9].

The substrates employed were discs with a diameter of $25 \mathrm{~mm}$ made of AISI type 304 stainless steel, which were grit-blasted using black corundum and then cleaned with ethanol prior to the deposition. In addition, all substrates were coated by powder plasma spraying with $\mathrm{TiO}_{2}$ bond coat (Metco 102, Oerlikon Metco, Switzerland) to enhance top coat adherence (Table 1). Finally, precursor glass coatings were deposited by SPPS on preheated, bond coated substrates $\left(300-350^{\circ} \mathrm{C}\right)$ to further adherence enhancement. Argon was used as primary plasma gas and hydrogen as secondary. The spraying conditions employed are detailed in table 1 . The following spraying conditions were varied: solution feedstock (with and without catalyst), ratio of plasma gases $\left(\mathrm{Ar} / \mathrm{H}_{2}\right)$ giving rise to different torch enthalpy and spraying distance. Modification of these three variables led to an 8 experiments grid.

Table 1. Spraying conditions for bond and top coats for the 8 experiments carried out

\begin{tabular}{ccc}
\cline { 2 - 3 } & $\begin{array}{c}\text { Bond coat } \\
\left(\mathrm{TiO}_{2}\right)\end{array}$ & $\begin{array}{c}\text { Bioactive glass } \\
\text { coating }\end{array}$ \\
\hline Argon flow rate (slpm) & 38 & $25 / 45$ \\
Hydrogen flow rate $(\mathrm{slpm})$ & 14 & 15 \\
Intensity $(\mathrm{A})$ & 600 & 600 \\
Spraying distance $(\mathrm{mm})$ & 120 & $70 / 110$ \\
Number of torch scans & 2 & 5 \\
Spraying velocity $(\mathrm{m} / \mathrm{s})$ & 1,00 & 1,25 \\
Injector diameter $(\mathrm{mm})$ & 1,80 & 0,15 \\
Powder flow rate $(\mathrm{g} / \mathrm{min})$ & 45 & - \\
Solution flow rate $\left(\mathrm{cm}^{3} / \mathrm{min}\right)$ & - & 33 \\
\hline
\end{tabular}

Coatings were analysed by X-ray diffraction (XRD) using a diffractometer (Advance diffractometer, Bruker Theta-theta, Germany) and were observed in both surface and cross-section by field emission gun environmental scanning electron microscopy (FEG-ESEM) (Quanta 200FEG, FEI Company, USA). Moreover, the coatings were immersed in Simulated Body Fluid (SBF) to investigate their bioactive character according to a standard protocol [10], employing soaking times ranging from 1 to 7 days. 


\section{Results and discussion}

In figure 1, for experiments 1 to 4 (without catalyst), only small discontinuous regions covered by bioactive glass particles with very poor attachment to the substrate were obtained. Hence, without adding catalyst, the sol-gel process and consequently the glass network forming hardly occur in the plasma torch. For this reason, a continuous coating layer is not obtained. This finding contrast with other SPPS processes in which no catalyst was used and coating layers could still be formed [11].

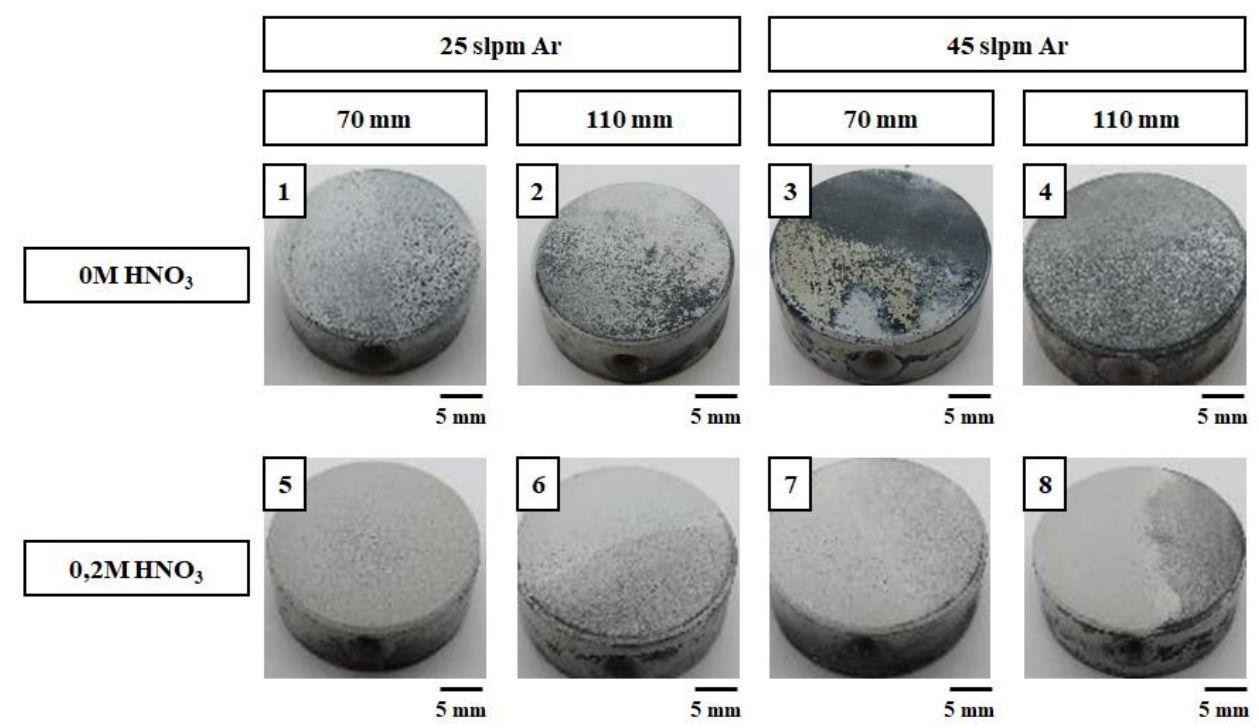

Figure 1. Macroscopic views of the coatings obtained from the eight deposition experiments

On the contrary, experiments 5 to 8 (with catalyst) succeeded in obtaining rather uniform coatings although the quality of the surfaces was very different. Thus, trials 5 and 7 led to better quality surfaces because of the shorter spraying distances used. As reported elsewhere [5], shorter spraying distances give rise to hotter substrates during deposition which allows glass molten particles to adhere onto the substrate. Finally, the best quality layer was obtained in experiment 5 which combines shorter spraying distance and higher plasma torch enthalpy. As expected, higher energy during deposition in an SPPS process contributes to the development of the different physical processes occurring from the solution feeding into the plasma torch to the final glass molten particle deposition, i.e. evaporation, gelation, pyrolysis, sintering and melting of glass particles [11]. In addition, as the spraying distance and torch power are key factors to provide precursors with enough time to develop all the necessary chemical reactions to form the desired material, the solution with $0,2 \mathrm{M}$ of nitric acid was sprayed using the same parameters employed in experiment 5, collecting in-flight particles before impacting onto the substrate and determining their composition by $\mathrm{X}$-ray fluorescence (XRF). From the 
above, it was found that the maximum deviation in composition was $0,5 \mathrm{wt} \%$ regarding the nominal one, so the obtained coating has a composition very close to that.

Figure 2 displays the surface and cross-section micrographs of the best quality coating obtained (sample 5). It can be observed that a thin layer of a quite homogeneous coating was produced with an average thickness of $35 \mu \mathrm{m}$. Interconnected porosity (marked $P$ ) associated to thermal spray processes is also observable giving rise to a high inner surface area. Nevertheless, this specific surface area can be a favourable feature for bioactivity, as reported in the literature for bioactive glasses [10,12]. From the coating surface study, a "two-zones microstructure" common in SPS can be appreciated with a cauliflower-like surface, which results from the high concentration of the solution feedstock [13].
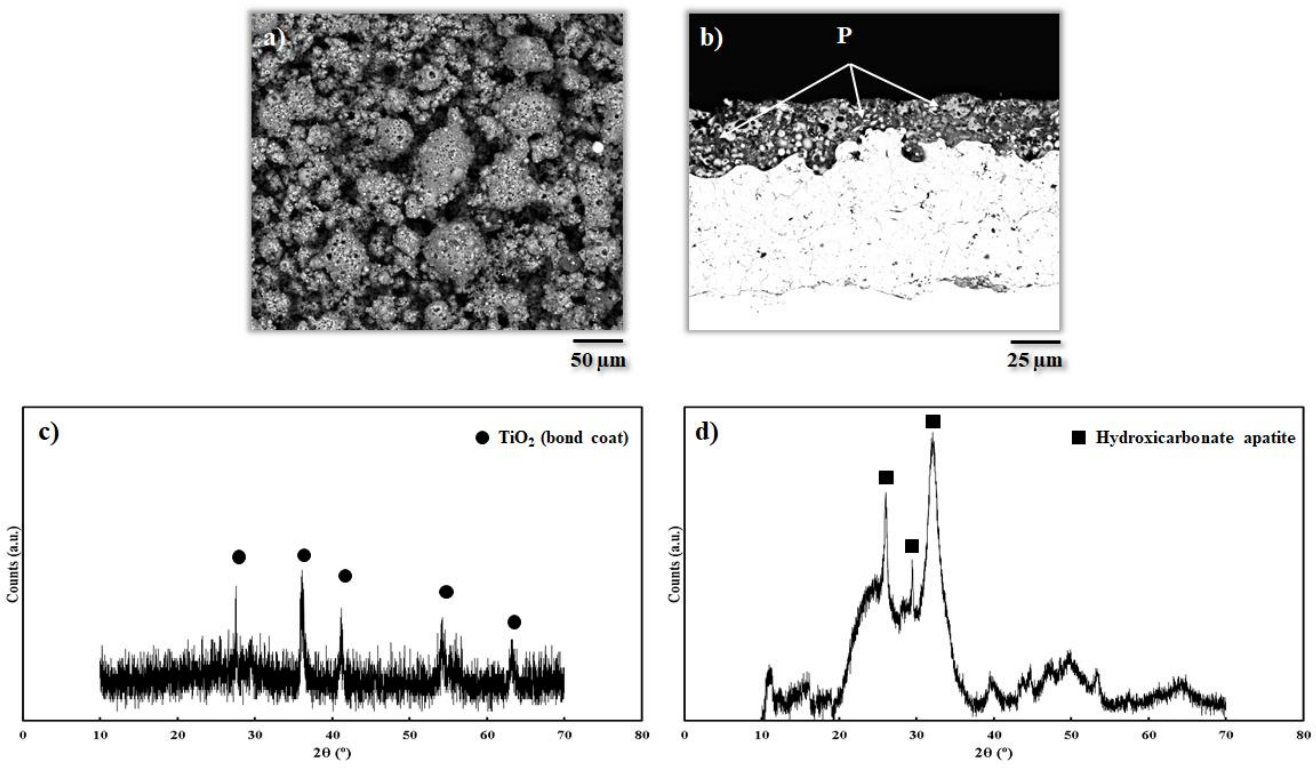

Figure 2. Surface (a) and cross-section (b) micrographs of the coating obtained from sample 5. The XRD pattern is also displayed (c). For the sake of comparison the XRD pattern of the coating after 7 days in SBF is also included (d).

Instead of atomising, the solution was radially injected into the torch with a continuous stream, resulting in droplet fragmentation when they make contact with the plasma torch and solvent evaporation rapidly occurs. This step is followed by a shell formation on the drops surface and the breaking of that shell due to an increment of the vapor pressure inside the drop. Thus, part of the shells and spherical particles tend to combine in-flight resulting in the cauliflower-like agglomerates on the coating surface. In the same figure, the XRD pattern of the coating is included. As observed, the coating shows a fully amorphous nature which indicates that the glass network was formed, and no crystallisation took place during deposition and cooling. Only few peaks, corresponding to the $\mathrm{TiO}_{2}$ bond coat, are observed. This finding contrasts with 
the results obtained by $Y$. Xiao et al. [8], who attributed the high degree of crystallisation in the coating to an inhibited droplet breakup due to high viscosity gel which resulted in insufficient melting of the glass droplets. Nevertheless, in that research long spraying distances and low energy plasma were used for the deposition of the feedstock.

Figure 3 shows the micrographs corresponding to the coating from experiment 5 immersed in SBF. Figures $3 a$ and $3 b$ show this coating before and after 7 days of immersion, respectively, and hydroxycarbonate apatite (HCA) layer was identified throughout the coating (Figure $3 \mathrm{~b}$ ) following the standard protocol by energy dispersive $X$-ray (EDX) and XRD [10]. Moreover, from this figure, a different reaction behaviour in function of the coating zone can be appreciated.

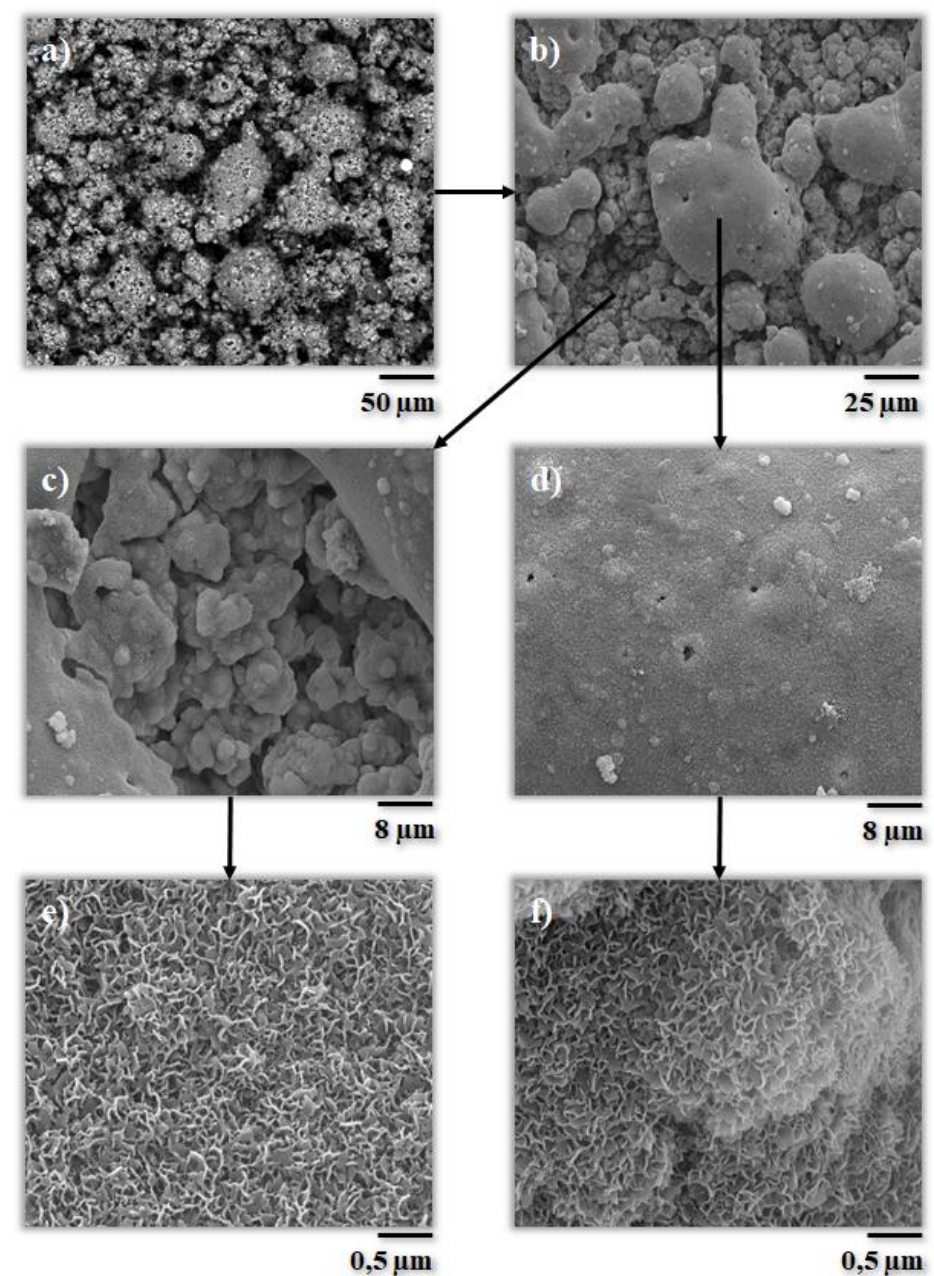

Figure 3. Micrographs of the coating from the experiment 5 after 7 days of immersion in SBF. a) Coating before immersion; b) Coating after 7 days in SBF; c) Inner zone of the immersed coating; d) Top zone of the immersed coating; e) HCA crystals of the inner zone; f) HCA crystals of the top zone 
As anticipated above, interconnected porosity favours bioactivity of bioactive glass surfaces, therefore the inner surface (Figure 3c) is "more reacted" than the cauliflower-like splats of the top zone (Figure 3d). Besides, in both cases (Figures $3 e$ and $3 f$ ), it is possible to appreciate at very high magnifications the typical HCA flake-like crystals, as reported also in literature [14]. In addition, in figure 2d, a XRD pattern corresponding to the "best" coating (sample 5) after 7 days of immersion in SBF is also included. As compared with the one corresponding to the non-immersed coating, a new crystalline phase started to appear due to the interaction of the coating surface with SBF. As expected, the peaks correspond to hydroxycarbonate apatite. Indeed, it is well known that in SBF the glass surface develops a silica rich layer after ion exchange, on which $\mathrm{Ca}$ and $\mathrm{P}$ ions precipitate forming the HCA layer [10].

From the obtained results, it can be concluded that a well adhered coating was obtained with a suitable bioactivity, being this property highly influenced by the microstructure features of the coating. Therefore, this fact should be considered in the design of SPPS bioactive glass coatings.

\section{Conclusions}

The SPPS process has been employed to obtain bioactive glass coatings from a sol precursor of the $45 \mathrm{~S} 5$ bioactive glass composition. A good quality coating has been obtained, which exhibits high surface area and the formation of a HCA layer, when immersed in SBF for 1 week, confirming the bioactivity of this coating.

Based on these results, it can be concluded that SPPS represents a suitable method to produce bioactive glass coatings in a simple way, avoiding the timeconsuming steps related to the preparation of glass particles. In addition, the use of a solution precursor can facilitate the incorporation of new doping elements to the feedstock composition, which could lead to bioactive glass coatings with biologically active ions. Consequently, these facts open new research opportunities concerning feedstock design and microstructure optimization in the SPPS process to expand the medical applications of bioactive glass coatings.

\section{Acknowledgements}

Authors thank Universitat Jaume I of Castellon for the support provided by funding its Research Promotion Plan (ref. PREDOC/2015/50) and The European Virtual Institute on Knowledge-based Multifunctional Materials AISBL (KMM-VIN) for the KMM-VIN Research Fellowship (call 2016). 


\section{References}

[1] A. Sola, D. Bellucci, V. Cannillo, A. Cattini, Bioactive glass coatings: a review, Surf. Eng. 27 (2011) 560-572.

[2] F. Baino, F. Verné, Glass-based coatings on biomedical implants: a state-ofthe-art review, Biomed Glasses 3 (2017) 1-17.

[3] E. Cañas, M. Vicent, E. Bannier, P. Carpio, M.J. Orts, E. Sánchez, Effect of particle size on processing of bioactive glass powder for atmospheric plasma spraying, J. Eur. Ceram. Soc. 36 (2016) 837-845.

[4] G. Bolelli, D. Bellucci, V. Cannillo, R. Gadow, A. Killinger, L. Lusvarghi, P. Müller, A. Sola, Comparison between suspension plasma sprayed and high velocity suspension flame sprayed bioactive coatings, Surf. Coat. Technol. 280 (2015) 232-249.

[5] A. Cattini, L. Latka, D. Bellucci, A. Sola, L. Lusvarghi, L. Pawlowski, V. Cannillo, Suspension plasma sprayed bioactive glass coatings: Effects of processing on microstructure, mechanical properties and in-vitro behaviour, Surf. Coat. Technol. 220 (2013) 52-59.

[6] E. Cañas, M. Vicent, M.J. Orts, E. Sánchez, Bioactive glass coatings by suspension plasma spraying from glycolether-based solvent feedstock, Surf. Coat. Technol. 318 (2017) 190-197.

[7] A. Killinger, R. Gadow, G. Mauer, A. Guignard, R. Vassen, D. Stöver, Review of new developments in suspension and solution precursor thermal spray processes, J. Therm. Spray Technol. 20 (2011) 677-695.

[8] Y. Xiao, L. Song, X. Liu, Y. Huang, J. Chen, Y. Wu, F. Wu, Bioactive glassceramic coatings synthesized by the liquid precursor plasma spraying process, J. Therm. Spray Technol. 20 (2011) 560-568.

[9] M. Vicent, E. Bannier, P. Carpio, E. Rayón, R. Benavente, M.D. Salvador, E. Sánchez, Effect of the initial particle size distribution on the properties of suspension plasma sprayed $\mathrm{Al}_{2} \mathrm{O}_{3}-\mathrm{TiO}_{2}$ coatings, Surf. Coat. Technol. 268 (2015) 209-215.

[10] A.L.B. Maçon, T.B. Kim, E.M. Valliant, K. Goetschius, R.K. Brow, D.E. Day, A. Hoppe, A.R. Boccaccini, I.Y. Kim, C. Ohtsuki, T. Kokubo, A. Osaka, M. ValletRegí, D. Arcos, L. Fraile, A.J. Salinas, A.V. Teixeira, Y. Vueva, R.M. Almeida, M. Miola, C. Vitale-Brovarone, E. Verné, W. Höland, J.R. Jones, A unified in vitro evaluation for apatite-forming ability of bioactive glasses and their variants, J. Mater. Sci. Mater. Med. 26 (2015) 115-124.

[11] M. Gell, E.H. Jordan, M. Teicholz, B.M. Cetegen, N.P. Padture, L. Xie, D. Chen, X. Ma, J. Roth, Thermal barrier coatings made by the solution precursor plasma spray process, J. Therm. Spray Technol. 17 (2008) 124-135.

[12] F. Westhauser, F. Ciraldo, P. Balasubramanian, A.S. Senger, G. Schmidmaier, A. Moghaddam, A.R. Boccaccini, Micro-computed-tomography-guided analysis of in vitro structural modifications in two types of $45 S 5$ bioactive glass based scaffolds, Mater. 10 (2017) 1341-1354. 
[13] R.T. Candidato, P. Sokolowski, L. Pawlowski, G. Lecomte-Nata, C. Constantinescu, A. Denoirjean, Development of hydroxyapatite coatings by solution precursor plasma spray process and their microstructural characterization, Surf. Coat. Technol. 318 (2017) 39-49.

[14] S.L. Esteban, E. Saiz, S. Fujino, T. Oku, K. Suganuma, A.P. Tomsia, Bioactive glass coatings for orthopaedic metallic implants, J. Eur. Ceram. Soc. 23 (2003) 2921-2930. 

ARTículo 7 



\title{
Microstructural and in vitro characterization of $45 \mathrm{~S} 5$ bioactive glass coatings deposited by solution precursor plasma spraying (SPPS)
}

\author{
Eugeni Cañas, María José Orts, Aldo R. Boccaccini, Enrique Sánchez
}

Surface \& Coatings Technology 371 (2019) 151-160

https://doi.org/10.1016/i.surfcoat.2018.12.057

\begin{abstract}
El presente trabajo se ha centrado en el desarrollo de recubrimientos de vidrio bioactivos mediante proyección térmica por plasma a partir de soluciones de precursores. Los precursores de $\mathrm{SiO}_{2}, \mathrm{CaO}, \mathrm{Na}_{2} \mathrm{O}$ y $\mathrm{P}_{2} \mathrm{O}_{5}$ se han mezclado en agua destilada para preparar soluciones concentradas con una composición similar al vidrio bioactivo $45 \mathrm{~S} 5$.
\end{abstract}

Las soluciones se han caracterizado reológicamente para evaluar su estabilidad con el tiempo y se han depositado sobre acero inoxidable AISI 304 para desarrollar recubrimientos bajo diferentes parámetros de proyección. El efecto de estos parámetros sobre la microestructura de los recubrimientos se ha estudiado mediante microscopía electrónica de barrido. Con el fin de completar la caracterización microestructural, los recubrimientos también han sido analizados por difracción de rayos $\mathrm{X}$ y ensayo de rayado. Además, se ha determinado la bioactividad de los recubrimientos mediante inmersión en un fluido biológico simulado.

El estudio ha demostrado que el uso de distancias de proyección cortas y caudal volumétrico de argón da lugar a la microestructura típica derivada del uso de materiales de aporte líquidos, además de producirse cierta cristalización en el recubrimiento, asociada a la distancia de proyección utilizada. El ensayo de rayado ha revelado que el recubrimiento posee buenas propiedades mecánicas en comparación con recubrimientos similares obtenidos mediante otras técnicas de proyección de plasma. Además, tal y como se ha demostrado mediante microscopía electrónica de barrido, difracción de rayos $\mathrm{X}$ y espectroscopía de infrarrojos por transformada de Fourier, el recubrimiento obtenido es capaz de desarrollar una capa de hidroxiapatita carbonatada al entrar en contacto con el fluido biológico simulado. 



\title{
Microstructural and in vitro characterization of $45 \mathrm{~S} 5$ bioactive glass coatings deposited by solution precursor plasma spraying (SPPS)
}

\author{
E. Cañas ${ }^{a \star}$, M.J. Orts ${ }^{a}$, A.R. Boccaccini ${ }^{b}$, E. Sánchez ${ }^{a}$ \\ a Instituto de Tecnología Cerámica (ITC), Universidad Jaume I, Castellón, Spain \\ b Institute of Biomaterials, University of Erlangen-Nuremberg, Erlangen, Germany \\ * Corresponding author
}

\begin{abstract}
The present work focused on the development of bioactive glass coatings employing Solution Precursor Plasma Spraying. Precursors of $\mathrm{SiO}_{2}, \mathrm{CaO}, \mathrm{Na}_{2} \mathrm{O}$ and $\mathrm{P}_{2} \mathrm{O}_{5}$ were mixed in distilled water to prepare concentrated solutions with a composition close to the $45 \mathrm{~S} 5$ bioactive glass.
\end{abstract}

Solutions were rheologically characterised to assess their stability with time and deposited onto AISI type 304 stainless steel to develop coatings under different parameters related to the thermal spraying technique. The effect of these parameters on coatings microstructure was studied by scanning electron microscopy. Coatings were also analysed by $\mathrm{X}$-ray diffraction and scratch test to complete the microstructural characterization. Moreover, coatings bioactivity was evaluated by immersing them in Simulated Body Fluid.

The study showed that using short spraying distances and low argon flow rates, gave rise to the typical microstructure derived from liquid feedstocks whereas some crystallization associated to the long spray distance used occurred. Scratch test revealed that the resulting coating possessed good mechanical properties when compared with similar coatings obtained by other plasma spraying techniques. Moreover, the obtained coating could develop an hydroxycarbonate apatite layer when in contact with Simulated Body Fluid as demonstrated by scanning electron microscopy, X-ray diffraction and Fourier transform infrared spectroscopy.

Keywords: Bioactive glass solution; Solution stability; Solution precursor plasma spraying; Scratch test; In vitro test

\section{Introduction}

Bioactive materials were developed as an improvement with regard to the bioinert materials typically used in the field of medicine [1,2]. The most studied bioactive material, which has been used for long time, is hydroxyapatite. This biomaterial is employed in a wide range of medical applications [3-5]. 
Not long ago, Prof. Hench discovered by accident a glass material composed of a silicate network incorporating sodium, calcium and phosphorus (45,0\% $\mathrm{SiO}_{2}, 24,5 \% \mathrm{CaO}, 24,5 \% \mathrm{Na}_{2} \mathrm{O}$ and $6,0 \% \mathrm{P}_{2} \mathrm{O}_{5}$, in wt\%) [6,7]. This glass, known as Bioglass ${ }^{\circledR}$ or $45 \mathrm{~S} 5$ bioactive glass, has proved to be more bioactive and to possess better osseointegration than hydroxyapatite [8,9], so that it can be used in different clinical treatments such as periodontal disease, bone regeneration or in middle ear surgery [7,10-12]. In addition, the US Food and Drug Administration (FDA) approves its employment in medical applications [7].

The main disadvantage of this material is its brittleness, which limits its utilisation in load-bearing applications $[13,14]$. To solve this problem, researchers started to develop the deposition of bioactive glass onto metallic substrates developing a composite layer which combines good mechanical properties with high bioactivity. Different techniques have been studied to deposit this type of coatings, i.e. enamelling, glazing, magnetron sputtering and pulsed laser deposition [15-19]. Among all these techniques, plasma spraying is the most employed method due to the high deposition rate, the good control of the substrate degradation (compared to the other deposition techniques) and the possibility of controlling the morphology, thickness and structure of the coating, and therefore its properties [15]. In addition, plasma spraying gives the chance of easily producing dense coatings which are suitable to be scaled-up for implantable devices.

Typically, plasma sprayed coatings have been deposited using glass powder. These powders can be obtained either by the melting and quenching method or by the sol-gel method accompanied by subsequent thermal treatment [20, 21]. Literature shows that bioactive glass coatings from powder feedstocks with good bioactivity can be deposited by plasma spraying. However, the coatings exhibited a cracked, highly porous microstructure with poor adhesion to the substrate [20, 22].

Recently, the employment of liquid feedstocks such as suspensions and solutions instead of powder feedstocks has received great interest in the thermal spray community for different materials, due to the unique coating properties achieved, whereas thinner $(40-50 \mu \mathrm{m})$ submicron- to nano-sized coatings could be easily produced [23-27]. For the case of bioactive glass coatings, its deposition from suspension feedstocks has been recently addressed. Thus, reported findings showed that final coatings displayed similar microstructures to those obtained from powder feedstocks [8, 28, 29]. On the contrary, the utilisation of solution feedstocks in the development of glass coatings has been hardly investigated while significant advantages can be obtained. On the one hand, thinner and nanostructured coatings with a more homogeneous microstructure can be engineered. On the other hand, using solutions allows to work with pure feedstocks comparing to powders and suspensions, since the preparation of both feedstocks implies a series of laborious steps which can often introduce some contaminants in the working material. 
In a previous work, the authors presented a preliminary study on the possibility of obtaining bioactive coatings using solution precursor plasma spraying (SPPS) [30]. Therefore, this current work aims to complete the previous research by determining the stability of the solution feedstocks as well as analysing their thermal behaviour inside the plasma torch. In addition, the effect of the employed spraying parameters on the morphology of the coatings was investigated. A mechanical characterization by scratch technique was carried out on bioactive glass coatings obtained by plasma spray for the first time. Finally, a complete study of the coatings' bioactivity was developed for long soaking times.

\section{Experimental}

\subsection{Preparation of the solution feedstock}

Following the previous work [30], bioactive glass 45S5 was selected as the working composition. Solutions were prepared with a precursor concentration of $4 \mathrm{M}$ ( 4 moles of precursors per litre of solution), using water as a solvent. The reactants listed below were used to synthesise the solution feedstock:

- Tetraethyl orthosilicate or TEOS $\left(\mathrm{C}_{8} \mathrm{H}_{20} \mathrm{O}_{4} \mathrm{Si}\right.$ synthesis grade, Merck, Germany) as a source of $\mathrm{SiO}_{2}$.

- Triethyl phosphate or TEP $\left(\mathrm{C}_{6} \mathrm{H}_{15} \mathrm{O}_{4} \mathrm{P}\right.$ synthesis grade, Merck, Germany) as a source of $\mathrm{P}_{2} \mathrm{O}_{5}$.

- Calcium nitrate $\left(\mathrm{Ca}\left(\mathrm{NO}_{3}\right)_{2} \cdot 4 \mathrm{H}_{2} \mathrm{O}>99 \%\right.$, VWR Chemicals, USA) as a source of $\mathrm{CaO}$.

- Sodium nitrate $\left(\mathrm{NaNO}_{3}>99 \%\right.$, Sigma-Aldrich, USA) as a source of $\mathrm{Na}_{2} \mathrm{O}$.

Those precursors were chosen basing on literature related to the development of $45 S 5$ bioactive glass employing the sol-gel method [31-33]. Nevertheless, both alkoxides (TEOS and TEP) are not miscible in water, therefore it is necessary to add a catalyst in order to hydrolyse them [30]. Although there are different types of catalysts for that purpose, nitric acid is the most used one [3234]. Higher amounts of catalyst drastically increase the gelation velocity of the sol. However, it is well known that the higher the nitric acid concentration, the lower the glass particle size [31]. Consequently, if the amount of catalyst is varied in the solution feedstock, glass particles with different sizes will be formed inside the plasma torch. For that reason, in the present work, the concentration of nitric acid $\left(\mathrm{HNO}_{3}\right.$, Tritripur, Merck, Germany) used in the solution feedstocks was $1,0,5$ and $0,2 \mathrm{M}$ (where the latter is the same as in the previous study [30]). The concentrations of catalyst are in moles of nitric acid per litre of water. The solution without catalyst was discarded since in the previous work [30] no coating was obtained when this feedstock was used. 
The procedure followed to prepare the feedstocks was the one used in the preliminary work [30], and involved mixing the distilled water and nitric acid to achieve an acidic dissolution. Then, TEOS was slowly added to the dissolution under magnetic stirring with a molar ratio water to TEOS of 18. After that, the mixture was kept in agitation during $30 \mathrm{~min}$ until full clarification. The amount of the remaining reactants was deduced from $45 \mathrm{~S} 5$ glass composition by stoichiometry. TEP was added in the same way as the TEOS, keeping the mixture under stirring for another $30 \mathrm{~min}$. Finally, calcium and sodium nitrates were added to the mixture under stirring, keeping the agitation for an additional hour. Finally, the solution feedstocks were kept at a temperature of $5 \stackrel{\circ}{ } \mathrm{C}$ inside a sealed container, unlike how it was done previously [30], where the solutions stayed at room temperature overnight, since the stability of the sols could be highly improved by cooling them [35].

\subsection{Characterisation of the feedstock}

Once all the solution feedstocks were synthesised, their chemical compositions were determined by wavelength dispersive $X$-ray fluorescence spectrometry (XRF) (AXIOS, PANalytical, The Netherlands). To carry out this test, a powder sample was obtained from each solution feedstock by drying the solution in a stove at $100^{\circ} \mathrm{C}$ and subsequent thermal treatment in an electric furnace at 700 ${ }^{\circ} \mathrm{C}$. Then, the resulting powder was dry milled and fused into beads for XRF using a Panalytical PERL' $X 3$ bead maker. Chemical composition was assessed in the above mentioned XRF spectrometer provided with a Rh anode tube. Certified reference materials were used to guarantee the measurement traceability.

On the other hand, the thermal behaviour of the developed sols was examined by both differential thermal analysis and thermo-gravimetric analysis (DTA-TG) in order to understand the processes which occurred to the feedstocks during the spraying [36]. DTA-TG tests were done in a thermal analyser (TGA/SDTA 851e, Mettler Toledo, Switzerland) putting each solution sample without drying it inside a platinum crucible and heating the material from room temperature up to a maximum temperature of $1200^{\circ} \mathrm{C}$ in air, employing a heating rate of 10 ${ }^{\circ} \mathrm{C} / \mathrm{min}$.

In addition, as different amounts of catalyst were used, the stability with time (or the gelation time) of each feedstock was assessed through a rheological characterisation at different times using a rheometer (CVO 120, Bohlin Instruments, Great Britain) which controlled the shear rate (CR). The test was carried out at room temperature $\left(25^{\circ} \mathrm{C}\right)$ using a double-gap system in which the shear rate was loaded from 0 to $500 \mathrm{~s}^{-1}$ in $5 \mathrm{~min}$, maintained at $500 \mathrm{~s}^{-1}$ for $1 \mathrm{~min}$ and downloaded from 500 to $0 \mathrm{~s}^{-1}$ in $5 \mathrm{~min}$. 


\subsection{Coatings deposition}

The bioactive glass coatings were deposited by solution precursor plasma spraying (SPPS). The thermal spraying facility comprised a mono-cathode plasma torch (F4-MB, Oerlikon Metco, Switzerland), coupled to a six-axis robot (IRB 1400, ABB, Switzerland). Argon was used as primary plasma gas and hydrogen as secondary plasma gas. The torch was connected to a home-made liquid feeding system, which injected the liquid feedstock in a radial way by mechanical injection. Details about the facility have been reported in previous works [37, 38].

The glass coatings were sprayed onto AISI type 304 stainless steel discs with a diameter of $25 \mathrm{~mm}$. Before coatings deposition, the substrates were gritblasted using black corundum with a pressure of 4,2 bar and cleaned with ethanol in an ultrasonic bath. The roughness $\left(R_{a}\right)$ of the substrates after the grit-blasting step was measured employing a roughness measurement equipment (Hommelwerke T8000, Jenoptik AG, France), obtaining a $R_{a}$ value of 2,2 $\pm 0,1 \mu \mathrm{m}$. In addition, prior to glass coating deposition, a bond coat was sprayed from anatase feedstock (Metco 102, Oerlikon Metco, Switzerland) with a particle size distribution ranging from 10 to $55 \mu \mathrm{m}$ by atmospheric plasma spraying (APS), with the aim of enhancing the top coating adhesion [39]. The parameters used to deposit the bond coat, given by the supplier, are showed in table 1.

Table 1 Plasma spraying parameters used

\begin{tabular}{ccc}
\hline Spraying parameters & $\begin{array}{c}\mathrm{TiO}_{2} \text { bond coat } \\
\text { (APS) }\end{array}$ & $\begin{array}{c}\text { Bioactive glass top coat } \\
\text { (SPPS) }\end{array}$ \\
\hline Argon flow rate (slpm) & 38 & $25 / 45$ \\
Hydrogen flow rate $(\mathrm{slpm})$ & 14 & 15 \\
Intensity $(\mathrm{A})$ & 600 & 600 \\
Spraying distance $(\mathrm{mm})$ & 120 & $70 / 110$ \\
Spraying velocity $(\mathrm{m} / \mathrm{s})$ & 1,00 & 1,25 \\
Feed rate & $45 \mathrm{~g} / \mathrm{min}$ & $33 \mathrm{~cm}^{3} / \mathrm{min}$ \\
\hline
\end{tabular}

Finally, the solution feedstocks were deposited employing the facility described above, and preheating the substrates between $300^{\circ} \mathrm{C}$ and $350^{\circ} \mathrm{C}$. The spraying conditions utilised in this work are also detailed in table 1 , which correspond to that used in the previous work [30]. As it can be seen, two different spraying distances and argon flow rates (giving rise to different plasma torch energy) were used, in order to find the optimal parameters for the deposition. The variation of these two variables was since they strongly affect the final microstructure of the coating as previously reported [40, 41]. 


\subsection{Coatings characterisation}

In order to evaluate the effect of the spraying parameters on the morphology of the coatings, the coatings were metallographically prepared by cutting and polishing. Surfaces and polished cross-sections of the coatings were observed in a field-emission gun environmental scanning electron microscope (FEGESEM) (QUANTA 200FEG, FEl Company, USA) with the backscattered electron detector signal.

Moreover, the nature of the phases (amorphous or crystalline) of the assprayed coatings was determined by X-ray diffraction (XRD) (Theta-theta D8 Advance diffractometer, Bruker, Germany) over a range of $2 \theta$ between $10^{\circ}$ and $80^{\circ}$, with the difference that the detector used (VANTEC-1) had higher resolution than that used in [30].

On the other hand, the adhesion of the coatings has been evaluated. Since coatings from liquid feedstocks, specially from solutions, typically showed thin thicknesses, it is not possible to employ the normalized tensile test (ASTMC633) to determine this property. Therefore, in this work, the scratch test was chosen in order to determine the final coatings adhesion [42]. For that purpose, a scratch tester (Revetest, CSM Instrument, Germany) equipped with a conical diamond Rockwell indenter of spherical tip with a radius of $200 \mu \mathrm{m}$ was used. Scratches of $1 \mathrm{~cm}$ length were made in each sample tested, progressively increasing the load applied from 0 to $10 \mathrm{~N}$. To avoid errors caused by the presence of specific defects on the sample surface, three scratches were made on each sample. Before and after scratching, the indenter went through the tested area applying a minimum load and registering the original profile of the surface, with the aim of detecting changes in depth experienced by the scratched area. In addition, an optical microscope was coupled to the equipment, which allowed the visual characterisation of the changes in the scratching mechanism by taking micrographs of the scratches made in each sample. The critical load was determined as the force at which the bond coating started to be visible. The scratch hardness was also determined from equation 1 and related to the cohesion of the coating.

$$
H S_{P}=\frac{k \cdot P}{w^{2}}(\text { eq. 1) }
$$

where $\mathrm{HS}_{\mathrm{P}}$ is the scratch hardness (GPa), $\mathrm{P}$ is the applied force (grams-force), $\mathrm{k}$ is a geometrical constant (24.98) and $\mathrm{w}$ is the scratch width $(\mu \mathrm{m})$.

\subsection{In vitro test}

In vitro test of the coatings was performed following a standard protocol of soaking in Simulated Body Fluid (SBF) [43]. 
First, the needed amount of SBF was prepared following the method of Professor Kokubo [44]. Then, the coatings were soaked in SBF inside a plastic vessel, using a fix volume of SBF determined by equation 2 .

$$
V_{S B F}=\frac{S_{C}}{10}(\text { eq. 2) }
$$

where $\mathrm{V}_{\mathrm{SBF}}$ is the volume of SBF (in $\mathrm{cm}^{3}$ ) and $\mathrm{Sc}$ is the area of the glass coating $\left(\mathrm{mm}^{2}\right)$. For the present study, as disks substrates with $25 \mathrm{~mm}$ diameter were used, coatings with an area of $490 \mathrm{~mm}^{2}$ were obtained, and hence $49 \mathrm{~cm}^{3}$ of SBF were used for each coating sample. Sometimes, hydroxycarbonate apatite (HCA) can precipitate in the SBF and be deposited on the surface of the coating, giving rise to fake results [44]. To avoid that, in this test the samples were placed inside the vessel in such a way that the coating was perpendicular to the bottom surface of the container. The vessels containing the coatings in SBF were placed inside a water bath at $36,5 \pm 0,5 \stackrel{\circ}{ } \mathrm{C}$. Coatings were tested for 1,7 and 14 days. After each soaking time, the $\mathrm{pH}$ of the SBF was measured and the coated sample was removed from the vessel and gently washed with distilled water. After that, the as-soaked coatings were coated with a very thin platinum layer in order to observe their surface morphology by FEG-ESEM using the secondary electron detector signal.

In addition, the nucleation and growth of HCA was monitored for each soaking time. For that purpose, the chemical composition of the surface of the assoaked coatings was determined by an energy-dispersive $X$-ray microanalysis instrument (Genesis 7000 SUTW, EDAX, USA) coupled to the FEG-ESEM. $\mathrm{XRD}$, over a range of $2 \theta$ between $10^{\circ}$ and $80^{\circ}$, and Fourier transform infrared spectroscopy (FTIR) (Nicolet 6700, Thermo Scientific, USA) in absorbance mode with a spectral resolution of $2 \mathrm{~cm}^{-1}$ from 1500 to $500 \mathrm{~cm}^{-1}$ were also carried out.

\section{Results and discussion}

\subsection{Bioactive glass solutions characterisation}

The obtained solution feedstocks showed a composition very close to that of the $45 \mathrm{~S} 5$ bioactive glass (Table 2). No significant differences between the solutions containing different amount of catalyst were found since all of them were made from the same amount of each precursor. 
Table 2. Solution feedstock composition

\begin{tabular}{ccccc}
\hline Oxide (wt\%) & $\mathrm{SiO}_{2}$ & $\mathrm{CaO}$ & $\mathrm{Na}_{2} \mathrm{O}$ & $\mathbf{P}_{2} \mathrm{O}_{5}$ \\
\hline $\begin{array}{c}\text { Nominal } \\
\text { 45S5 glass }\end{array}$ & 45,0 & 24,5 & 24,5 & 6,0 \\
$\begin{array}{c}\text { Solution } \\
\text { feedstock }\end{array}$ & 46,0 & 23,3 & 25,5 & 5,3 \\
\hline
\end{tabular}

Concerning the DTA-TG analysis, the results are represented in figure 1. It can be seen that the three feedstocks displayed a similar behaviour, since the same amount of precursors was used in the preparation of each sol as explained above.
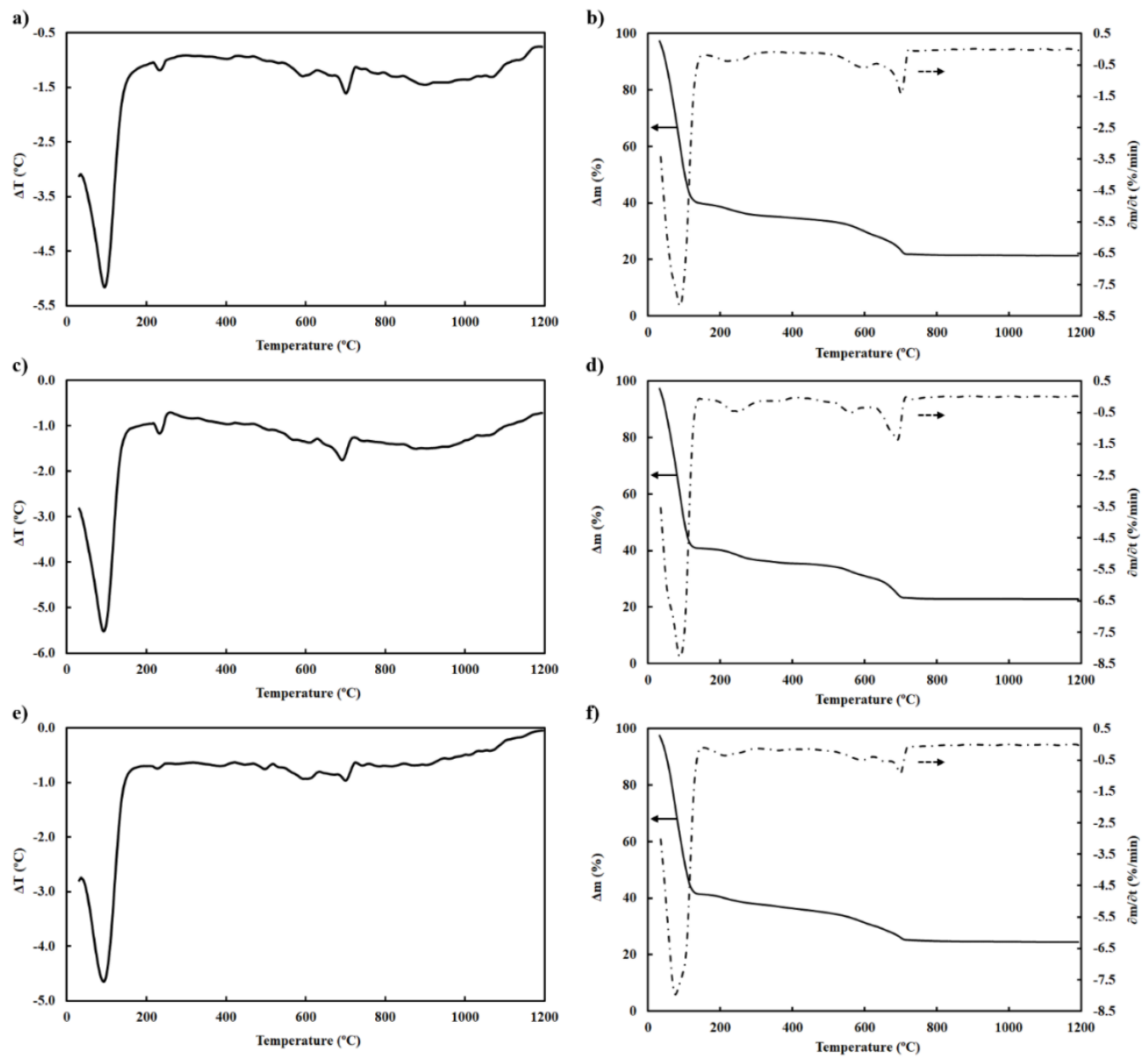

Figure 1. DTA-TG/DTG curves of each solution feedstock. a) DTA for the $0,2 \mathrm{M}$ sol. b) TG/DTG for the $0,2 \mathrm{M}$ sol. c) DTA for the $0,5 \mathrm{M}$ sol. d) TG/DTG for the $0,5 \mathrm{M}$ sol. e) DTA for the $1 \mathrm{M}$ sol. $f$ ) TG/DTG for the $1 \mathrm{M}$ sol

The same endothermic and exothermic peaks were observed in all cases, which suited well with those reported in the literature [33]. At $100^{\circ} \mathrm{C}$ there was an endothermic peak which corresponds to the water removal. This stage was 
accompanied by a $60 \%$ weight loss (as the TGA graphs show). Then, at about $235^{\circ} \mathrm{C}$ there was another endothermic peak which could correspond to the elimination of more water, resulting from condensation of precursors and catalyst. In all cases, the weight loss was around $5 \%$. After that, in the range of 600-800 $\stackrel{\circ}{ } \mathrm{C}$, both endothermic and exothermic peaks could be found. Moreover, two endothermic peaks (600 and $700{ }^{\circ} \mathrm{C}$ approx.) are visible, which correspond to the elimination of nitrates from the sodium and calcium precursors, and one exothermic peak ( $750^{\circ} \mathrm{C}$ approx.) is visible, which might be attributed to glass crystallization. These steps are accompanied by $15 \%$ weight loss. An $80 \%$ weight loss was observed in the entire performed cycle for all the feedstocks.

The flow curves of the three solution feedstocks are shown in figure 2. Each curve corresponds to a solution with a different concentration of catalyst, and all of them were determined immediately after the preparation of each feedstock. As the catalyst content increases the viscosity of the feedstocks also augments, but in general all feedstocks display very low viscosity (quotient between the shear stress and the shear rate). On the other hand, all curves present a slope change for a shear rate between 150 and $200 \mathrm{~s}^{-1}$. It is well known that solution precursors show a newtonian liquid behaviour, but in this case the resulting curves display a slight shear-thickening behaviour. This apparent anomaly, which is usually observed in sol-gel solutions with low viscosity, is caused by a slippage effect [45].

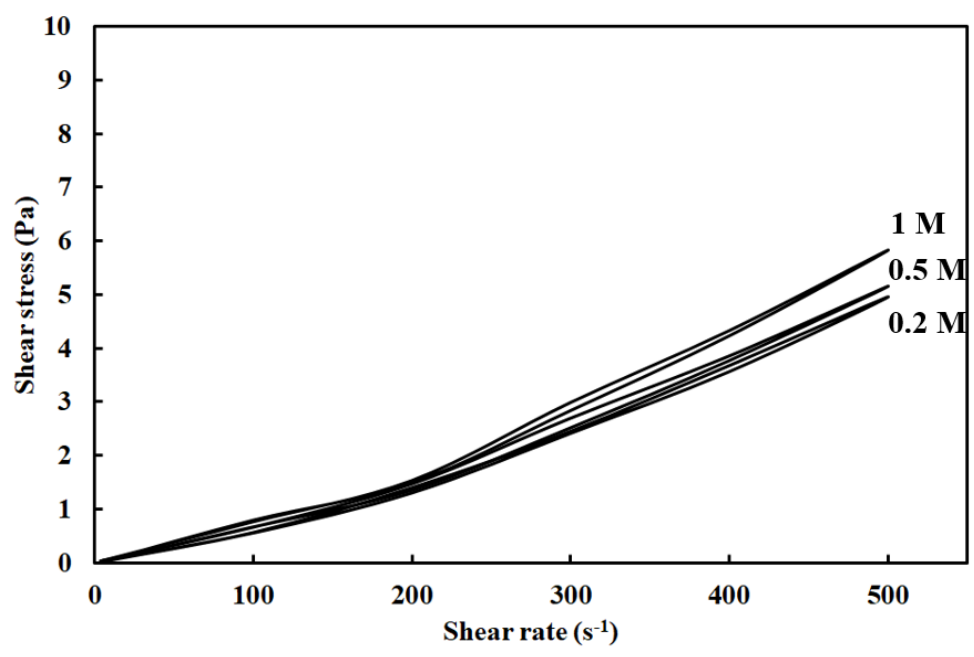

Figure 2. Flow curve of the solution feedstocks with different amounts of catalyst

Apart from this, a priori all feedstocks were appropriate to be sprayed since they showed a similar and proper thermal behaviour in the plasma torch leading to melted glass. In addition, solutions were suitable to be transported through the plasma facility pipes and subsequently injected into the plasma torch since they had low viscosity at high shear rates. 
However, if a further study of feedstock solution viscosity (at $500 \mathrm{~s}^{-1}$ shear rate) was carried out over time, it could be appreciated that not all feedstocks are appropriate to SPPS process, as shown in figure 3. As expected, higher amounts of catalyst gave rise to high gelation velocity. Thus, only in ten hours, the solution with $1 \mathrm{M}$ nitric acid showed a dramatic increase of viscosity, which proved that the solution had completely gelled leading to a densified gel. The $0,5 \mathrm{M}$ catalyst solution presented a similar behaviour to that of the $1 \mathrm{M}$ solution. It took more time to this feedstock to become a densified gel, but after 1 day the nucleation of gel agglomerates began inside the feedstock, which could clog the nozzle. In contrast, the solution with 0,2M nitric acid showed a different behaviour. As it can be seen in figure 3, the gelation process took place very drastically, although it needed between 7 and 9 days to occur. Results obtained from these tests revealed the high stability of $0,2 \mathrm{M}$ catalyst solution, while the solutions prepared with 1 and $0,5 \mathrm{M}$ of catalyst possessed very low stability with time.

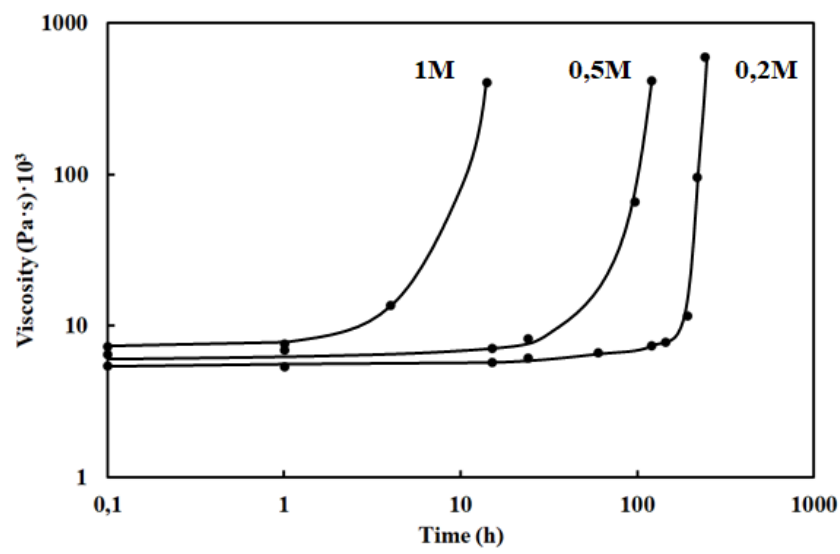

Figure 3. Stability with time (gelation time) for each solution based on their viscosity values

\subsection{Microstructural characterisation of bioactive glass coatings}

Due to the very low stability presented by the solution feedstocks with a catalyst concentration of 1 and $0,5 \mathrm{M}$, as seen in the previous section, these were discarded in order to avoid clogging of both the pipes and the injector. Only the solution with $0,2 \mathrm{M}$ of catalyst was sprayed using the parameters of table 1 . Combinations of spraying distance and argon flow rate resulted in an experimental grid composed of 4 different tests as showed in table 3.

Table 3. Experiment grid resulting from the combination of each modified parameter

\begin{tabular}{ccc}
\hline $\begin{array}{c}\text { Number of } \\
\text { experiment }\end{array}$ & $\begin{array}{c}\text { Spraying distance } \\
(\mathbf{m m})\end{array}$ & $\begin{array}{c}\text { Argon flow rate } \\
(\mathbf{s l p m})\end{array}$ \\
\hline 1 & 70 & 25 \\
2 & 110 & 25 \\
3 & 70 & 45 \\
4 & 110 & 45 \\
\hline
\end{tabular}


The surface micrographs of the obtained coatings from the $0,2 \mathrm{M}$ catalyst solution feedstock (runs 1 to 4 ) are showed in figure 4 at different magnifications.
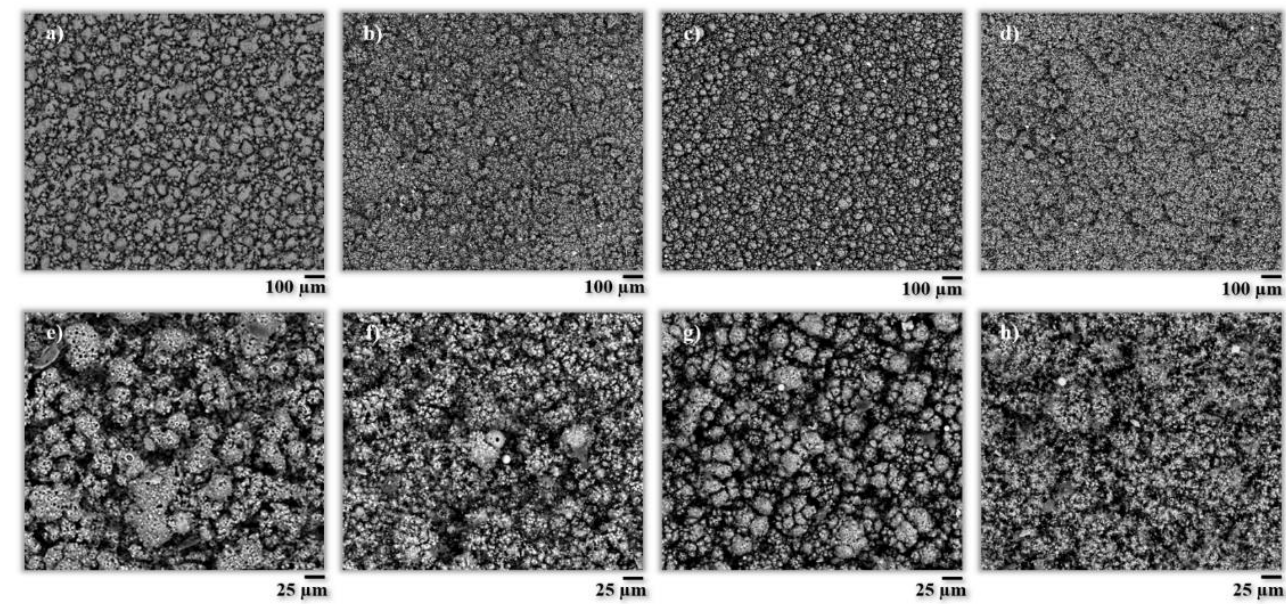

Figure 4. Surface micrographs of coatings deposited with the solution containing $0,2 \mathrm{M}$ of catalyst. a) and e) run 1. b) and f) run 2. c) and g) run 3 . d) and h) run 4

All experiments led to uniform coating surfaces, but the morphology of each surface was completely different because of both the spraying distance and the argon flow rate used. Coating from experiment 4 (Figures $4 \mathrm{~d}$ and $4 \mathrm{~h}$ ), i.e. high spraying distance and low argon flow rate, displayed the worst microstructure of the 4 tests carried out with the $0,2 \mathrm{M}$ catalyst feedstock. The whole coating was composed of very fine rounded glass particles loosely connected with each other, similar to the "powdery deposits" named by L. Xie et al. [46], and poorly attached to the substrate since they were easily removed from it. Coating deposited employing the parameters of test 2 (Figures $4 \mathrm{~b}$ and $4 \mathrm{f}$ ), i.e. high spraying distance and high argon flow rate, presented a similar microstructure than that of the 4-test coating, but the employment of higher enthalpy gave rise to the formation of some isolated glass agglomerates. Even so, most of the coating was formed by powdery deposits, resulting in a coating with an impaired adhesion.

Contrary to those tests (experiments 2 and 4), conditions operated in experiments 1 (Figure $4 \mathrm{a}$ and $4 \mathrm{e}$ ) and 3 (Figures $4 \mathrm{c}$ and $4 \mathrm{~g}$ ), i.e. short spraying distance and two different argon flow rates, led to good coatings featured by denser and more homogeneous surfaces showing the two-zones microstructure typical of liquid feedstock deposition, i.e. a first layer of fine glass rounded drops followed by a top layer of larger glass agglomerates. This type of microstructure was developed due to the high precursor concentration of the employed feedstock [36]. Although both experiments were carried out under the same spraying distance, the glass agglomerates of the top zone were highly influenced by the plasma energy which varied in function of the argon flow rate. 
For the coating of run 1, these agglomerates were coarser and appeared more melted, splashed and cohesive due to the greater amount of energy received from the plasma plume throughout the deposition process. For the run 3 , the agglomerates looked smaller and more isolated than those of experiment 1 . In addition, their morphology was much rounded, evidencing the low melting and splashing degree of the agglomerates and probably their poor adhesion to the substrate. To summarize, four different coatings were deposited employing the solution containing $0,2 \mathrm{M}$ of nitric acid. It was found that, regardless the argon flow rate employed, higher spraying distances resulted in coatings made up of powdery deposits without adhesion to the coating, while for shorter spraying distances an energetic plasma plume derived from the use of low rates of argon, led to well adhered coatings comprising quite molten and splashed particles.

In fact, cross-section characterisation was only successfully accomplished for the coating deposited under parameters of run 1, since it was the only coating that presented a minimal adhesion to remain on the substrate after the metallographic preparation step. The resulting micrographs are presented in figure 5 at different magnifications.

As observed, the resulting coating displayed a dense and homogeneous microstructure with and average thickness of approximately $35 \mu \mathrm{m}$ consisting of very fine re-solidified spherical glass drops entrapped in a molten glass matrix. In addition, the coating showed an open and interconnected porosity, which could improve the reaction ability of the coating with biological fluids, since the surface area is expected to be high.

On the other hand, XRD analysis of this coating (experiment 1 ) is presented in figure 6 . In the preliminary work done by the authors [30], the XRD pattern revealed not only a predominant amorphous phase, but also a succession of peaks corresponding to the anatase layer sprayed as bond coat.
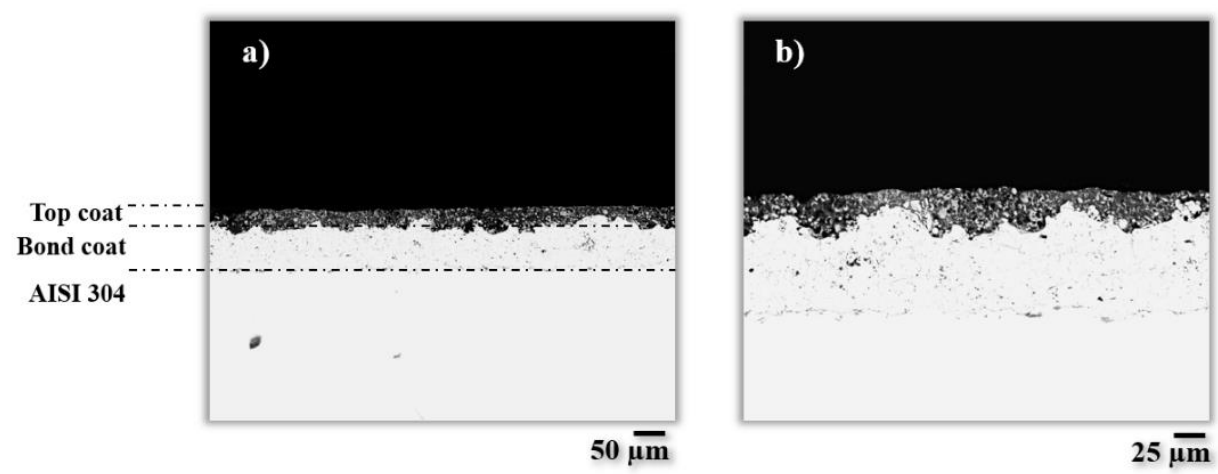

Figure 5. Cross-section micrographs of the unique adhered coating (run 1) 


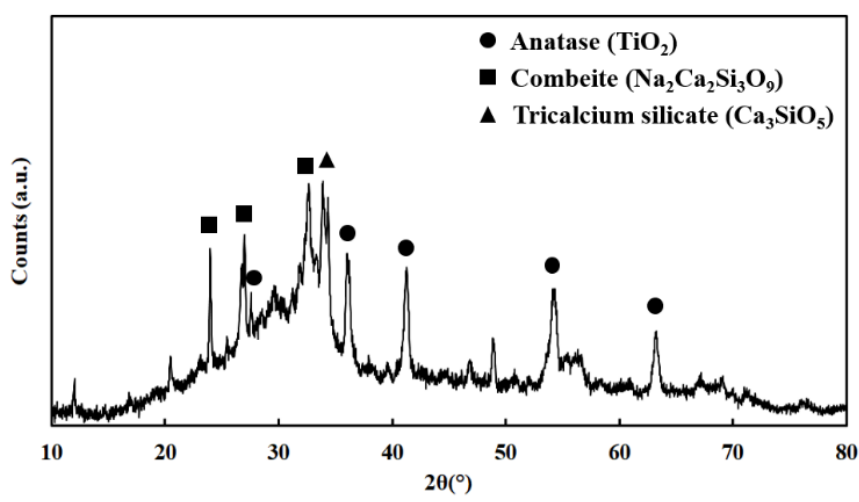

Figure 6. XRD pattern of the as-sprayed coating (run 1)

Nevertheless, as a new X-ray detector with higher resolution was used, under these new conditions the XRD pattern also displayed crystalline peaks corresponding to combeite. This material is a sodium and calcium silicate which crystallises from the $45 \mathrm{~S} 5$ bioactive glass [20]. The formation of this crystalline phase may be due to the long spraying distance utilised, which allowed some of the glass molten drops that fly in the peripheral area of the torch to re-solidify and crystallise before impacting to the substrate giving rise to the formation of crystalline spheres $[47,48]$. Then, these spheres were trapped by the softer or melted drops. In addition, the XRD pattern also exhibited one peak corresponding to tricalcium silicate $\left(\mathrm{Ca}_{3} \mathrm{SiO}_{5}\right)$, which resulted from the reaction between 3 moles of calcium oxide with 1 mole of silicon dioxide. The presence of these crystalline phases could reduce the bioreactivity of the developed coating.

\subsection{Scratch test results}

Scratch test was carried out on the resulting coating from run 1, following the procedure described in section 2.4. For the sake of comparison, the test was also done on 45S5 bioactive glass coatings deposited by atmospheric plasma spraying (APS) and suspension plasma spraying (SPS). The APS coating was the one called BGGS4 from ref. [20], but sprayed onto $\mathrm{TiO}_{2}$ bond coating. The SPS coating was the one shown in ref. [8], sprayed under $70 \mathrm{~mm}$ spraying distance. The three coatings were deposited using the same number of torch passages, that is 5 . The obtained mechanical parameters (critical load and scratch hardness) are shown in table 4.

For the SPS and SPPS coatings, the scratch hardness was calculated with the critical load while for the APS coating this parameter was determined with the maximum applied force. Figure 7 shows an optical micrograph of one scratch performed in the tested coatings. An example of the penetration depth curve is plotted in figure 8. 
Table 4. Mechanical properties of plasma sprayed bioactive glass coatings

\begin{tabular}{|c|c|c|}
\hline Tested coating & Critical load, $\mathrm{L}_{c}(\mathrm{~N})$ & $\mathrm{HS}_{\mathrm{P}}(\mathrm{GPa})$ \\
\hline $\begin{array}{c}\text { Atmospheric plasma } \\
\text { spraying }\end{array}$ & 10 & 0,64 \\
\hline $\begin{array}{c}\text { Suspension plasma } \\
\text { spraying }\end{array}$ & 1 & 0,06 \\
\hline $\begin{array}{l}\text { Solution precursor } \\
\text { plasma spraying }\end{array}$ & 5 & 1,27 \\
\hline
\end{tabular}

For the SPS and SPPS coatings, the scratch hardness was calculated with the critical load while for the APS coating this parameter was determined with the maximum applied force. Figure 7 shows an optical micrograph of one scratch performed in the tested coatings. An example of the penetration depth curve is plotted in figure 8 .

a)

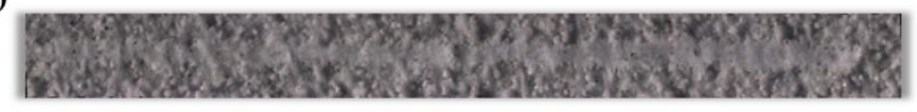

b)
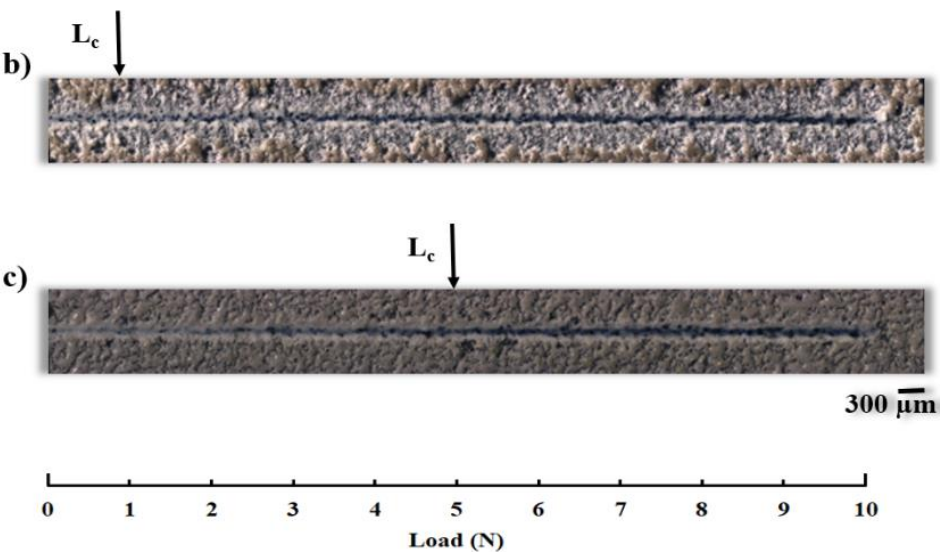

Figure 7. Example of the scratches performed on the coatings. a) Atmospheric plasma sprayed coating (from [20]). b) Suspension plasma sprayed coating (from [8]). c) Solution precursor plasma sprayed coating (from run 1)

The APS coating showed a critical load $\left(L_{c}\right)$ higher than the maximum force applied $(10 \mathrm{~N})$, therefore it is not possible to visualize the bond coating probably due to the great thickness of this coating. In addition, it can be seen in figure $8 \mathrm{a}$ that the penetration of the tip is quite deep, owing to the higher thickness. Therefore, the adhesion of this coating could not be as good as would be expected. Moreover, the scratch hardness value lies between those of the SPS and SPPS samples, since this coating presents a microstructure containing numerous closed pores which reduce the contact between splats [20], impairing 
the cohesion of the coating. The deeper penetration of the tip into the coating as well as the large width of the scratch shown in figure 7a confirm the poor cohesion of this coating. Moreover, as appreciated in this figure the splats have been ripped off and dragged by the tip.
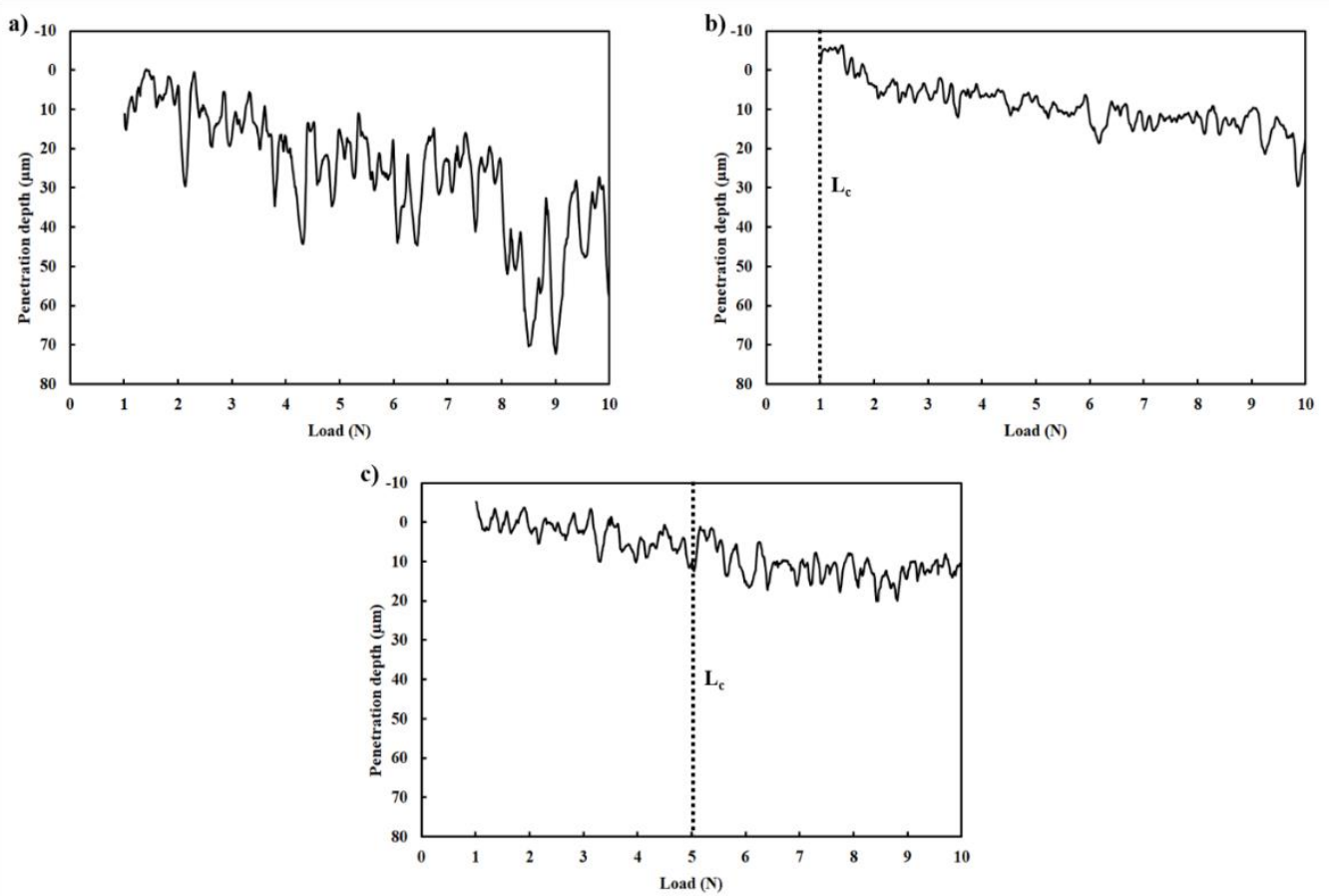

Figure 8. Penetration depth curve of the scratches performed in each coating. a) Atmospheric plasma sprayed coating (from [20]). b) Suspension plasma sprayed coating (from [8]). c) Solution precursor plasma sprayed coating (from run 1)

Concerning the SPS coating, this coating presents the worst adhesion and cohesion behaviour of all coatings investigated. The critical load $\left(L_{c}\right)$ and the scratch hardness are very low. Although the penetration depth of the tip appears quite regular, the scratch width is very high (higher than that of the APS coating). In figure $7 \mathrm{~b}$ it can be seen that tearing and delamination of the coating occurred around the scratch, and the coating is dragged until the end of the tip travel, similarly as in the APS coating, but to a larger extent. This behaviour is due to the microstructure of the coating; as reported in the previous study [8], the coating is composed of two layers, a first one of fine and rounded glass drops sintered between them and a top layer made up of coarse glass agglomerates poorly attached to the first layer, being these agglomerates the ones that were delaminated and dragged.

On the contrary, despite the intermediate value of the critical load $\left(L_{c}\right)$ which demonstrated a regular adhesion, the SPPS coating deposited in the present work showed the best cohesive mode, as deduced by its highest scratch hardness shown in table 4. In fact, from figure 7c, it can be observed that the scratch width is much narrower than those performed on the other coatings. In 
addition, as it can be seen in Figure 8c, the penetration path of the tip is regular and homogeneous. It can be concluded that the coating obtained from run 1 of the present work possessed good structural integrity when compared with its APS and SPS coating counterparts.

\subsection{In vitro test results}

The in vitro test was performed on the coating from experiment 1 since this coating showed enough adherence to the substrate to be characterized. The variation of the SBF pH in function of the soaking time is showed in figure 9.

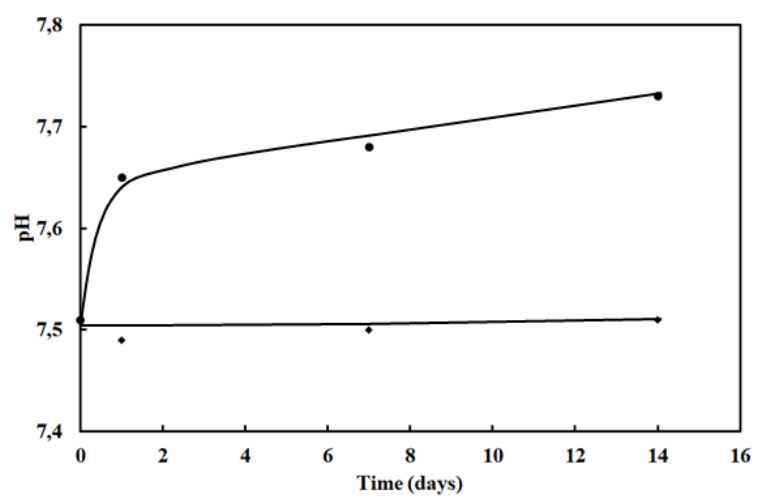

Figure 9. pH of the SBF (diamond dots) and SBF containing the coatings (circle dots) for each soaking time

A control sample (only SBF without coating) was also checked. Although the $\mathrm{pH}$ of the control sample remained constant over time, the $\mathrm{pH}$ of the SBF sample containing the coating underwent a significant increase, so that a reaction occurred between the incubating medium and the glass coating [43]. This increment in $\mathrm{pH}$ was very marked during the first day of incubation, becoming more progressive through the next 2 weeks of incubation. However, the final $\mathrm{pH}$ reached was low, evidencing that the crystalline phases founded in the coating negatively affected its bioreactivity.

Then, the reaction between the coating and the SBF was confirmed by SEM. Figure 10 shows surface micrographs from SEM observation. For each soaking time, a global surface micrograph was presented followed by one of each zone of the coating (first layer and top agglomerated layer) at higher magnifications.

Figure 10a shows the coating after 1 day of immersion in SBF, where the large agglomerates of the top layer seemed to have started to dissolve in the reaction medium, as they look smaller than those showed in figure 4a being this fact part of the steps which took place during the soaking test. At higher magnification (Figures 10b and 10c), in the coating soaked for 1 day it could be observed that the first layer of the coating had reacted and had been covered with HCA, while the agglomerates of the upper layer, even though they were partially dissolved, 
hardly showed presence of HCA, only isolated areas of the surface of these agglomerates appeared reacted.
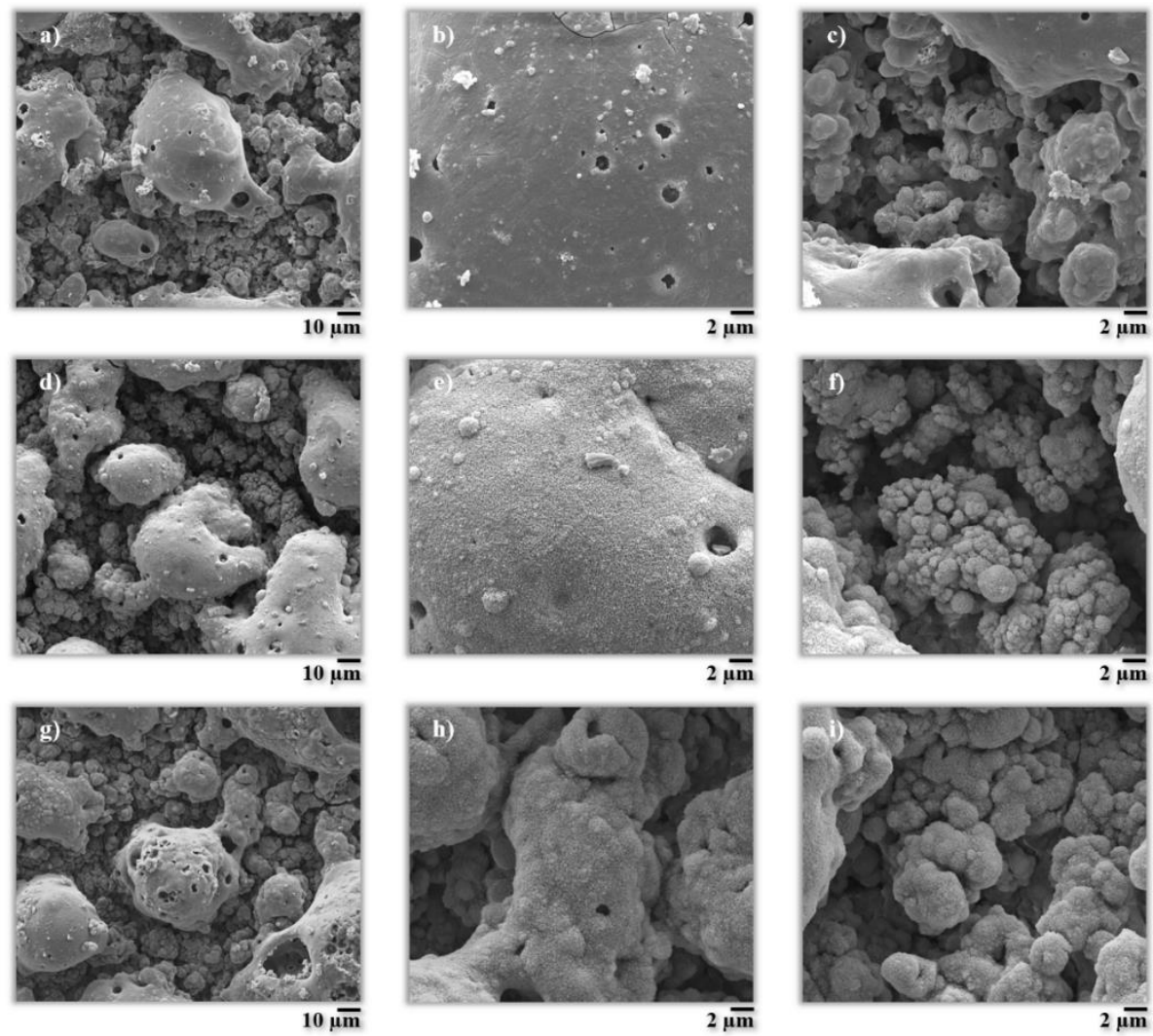

Figure 10. Surface micrographs of the soaked coatings. a), b) and c) 1 day of immersion. e), f) and $g$ ) corresponds to 7 days of immersion. $h$ ), i) and j) for 14 days

This difference in the reaction rate deals basically with the different sizes between the agglomerates and the fine glass particles of the first layer, which displayed a much higher surface area. For 7 days, it can be seen how the agglomerates in the top layer became more dissolved (Figure 10d), as well as they showed a continuous layer of HCA (Figure 10e) and the first layer of glass was totally reacted and fully covered with this material (Figure 10f). Finally, after 14 days in SBF, no further dissolution of the glass took place (Figure 10g), since the surface appearance was similar to that of the coating immersed for 7 days. However, for 14 days in SBF, both zones of the coating (the top zone and the first glass layer) appeared completely reacted and covered with HCA (Figures $10 \mathrm{~h}$ and $10 \mathrm{i})$. Even so, the first layer was always more reacted than the agglomerates.

The aforementioned behaviour was confirmed by EDX analysis. As it can be seen in figure $11 \mathrm{a}$, the intensity of the $\mathrm{P}$ and $\mathrm{Ca}$ peaks corresponds to $45 \mathrm{~S} 5$ bioactive glass. However, with higher soaking times (Figures 11b, 11c and 11d), 
the $\mathrm{P}$ and Ca peak intensities increased, which evidenced the formation of HCA. In addition, the peak intensity of $\mathrm{Si}$ was reduced as the immersion time increased, which can be attributed to an increase in the amount of HCA developed on the surface of the coating.
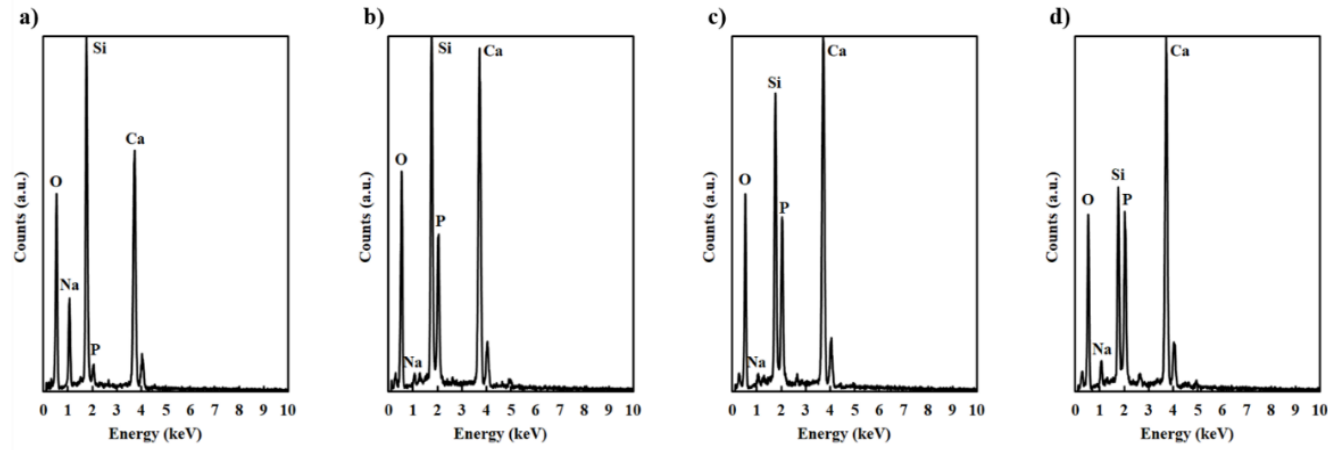

Figure 11. EDX patterns of the sprayed coating. a) As-sprayed. b) 1 day of immersion in SBF. c) 7 days of immersion in SBF. d) 14 days of immersion in SBF

On the other hand, FTIR analysis of the coatings was performed, and FTIR spectra for 1, 7 and 14 days of immersion are displayed in figure 12. In the spectra, absorption bands of $\mathrm{PO}_{4}{ }^{3-}$ at 560 and $605 \mathrm{~cm}^{-1}$, which correspond to $\mathrm{P}-\mathrm{O}$ bending, and at $1050 \mathrm{~cm}^{-1}$ associated to $\mathrm{P}-\mathrm{O}$ stretching can be appreciated. These peaks can be easily distinguished at 7 days and their intensity grows at 14 days. Other absorption bands were identified, two corresponding to carbonate group or $\mathrm{CO}_{3}^{2-}$ (at 870 and $1400 \mathrm{~cm}^{-1}$ ) and one at $800 \mathrm{~cm}^{-1}$ which relates to $\mathrm{Si}-\mathrm{O}$ stretching. Although the $\mathrm{P}-\mathrm{O}$ bands at 560 and $605 \mathrm{~cm}^{-1}$ are used to corroborate the presence of HA or HCA [33], they were not characteristic of both materials, they just indicated the presence of orthophosphate lattices [43].

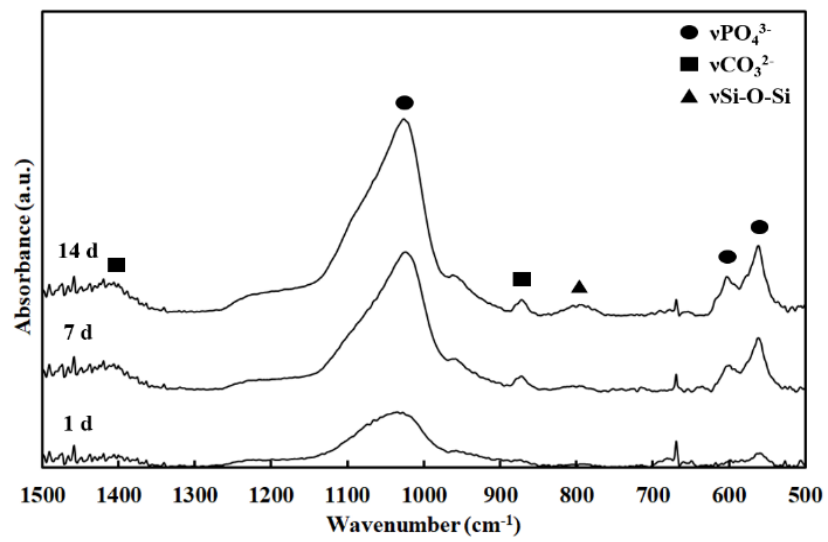

Figure 12. FTIR of the coatings after being soaked for 1, 7 and 14 days 
Therefore, the presence of HCA was assessed by XRD (Figure 13). The resulting patterns confirmed the nucleation and growing of HCA on the coatings surface, showing sharp peaks at $2 \theta$ of 26 and 32 degrees just for 1 immersion day.

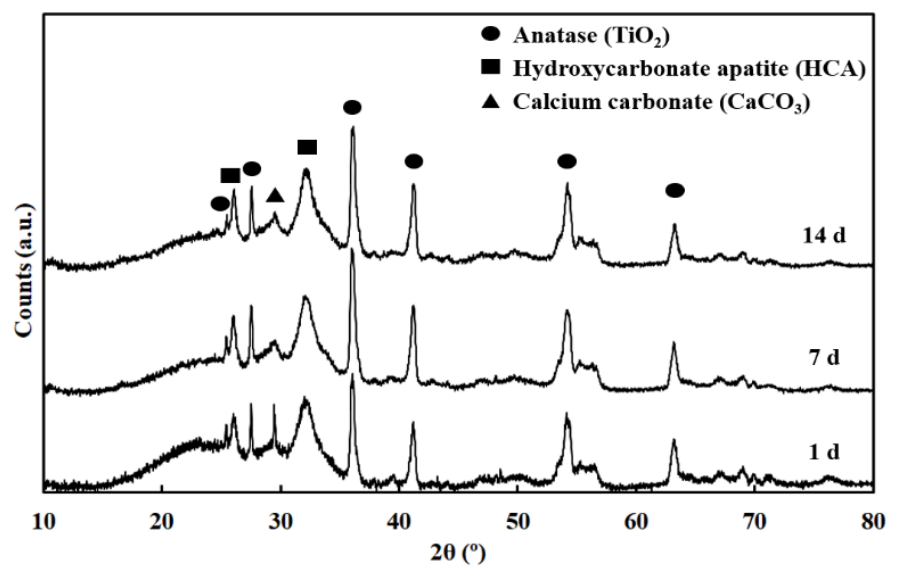

Figure 13. XRD patterns of the coatings immersed in SBF after 1, 7 and 14 days

These peaks were preserved for 7 and 14 days, while the crystalline phases (combeite and tricalcium silicate) disappeared as the incubation time increased. Moreover, the dissolution of the glass agglomerates observed from SEM surface micrographs could be also demonstrated by observing the XRD patterns, since by increasing the incubation time, a decrease in the intensity of the amorphous phase (between $2 \theta$ of 15 and 25 degrees) as well as an increase in intensity of the peaks corresponding to anatase (related to the bond coat as set out above) occurred. The main peak of calcium carbonate was also detected in the XRD patterns, but this compound precipitated from the SBF on the surface of the coating since the incubation medium was saturated [44], and its intensity decreased as the soaking time increased.

\section{Conclusions}

Bioactive glass solution feedstocks were developed with different amounts of catalyst to hydrolyse the alkoxides. As-prepared, all feedstock solutions were suitable to be injected into the plasma torch as they had low viscosity at higher shear rates. In addition, their thermal behaviour made them suitable to obtain bioactive glass coatings. However, higher amount of catalyst resulted in a nonstable feedstock over time because the solution gelation quickly occurred.

The sol containing $0,2 \mathrm{M}$ of catalyst was the only one that allowed to deposit a coating. Different coatings were deposited from this feedstock under two spraying distances and argon flow rates, observing that both variables exerted a great effect on the final coating microstructure. The best quality coating was developed under the shorter spraying distance and the higher argon flow rate. 
The as-sprayed coating revealed a dense and homogeneous microstructure composed of two zones typical of liquid feedstocks (a first layer of fine drops and a top layer of glass agglomerates) exhibiting a very high surface area. Scratch tests was carried in comparison with APS and SPS coating counterparts. The findings showed that SPPS coating possessed good mechanical (adhesion and cohesion) performance. In vitro test of this coating confirmed its good bioactivity. In addition, it was observed that the ability of the coating to react with the biological fluid was highly influenced by the microstructure.

Based on the obtained results, it can be concluded that is possible to deposit bioactive glass coatings by SPPS with a dense microstructure, good adhesion and suitability to react with biological fluids. However, more work is already in progress with the aim of further improvement of feedstock stability, the coating adherence as well as of eliminating the crystalline phase formation of. Moreover, doping elements will be also introduced in order to improve the biological response of the developed coatings.

\section{Acknowledgements}

The authors of the present work thank Universitat Jaume I of Castellón the support provided in funding action 3.1. of the Research Promotion Plan (PREDOC/2015/50) and The European Virtual Institute on Knowledge-based Multifunctional Materials ASBL (KMM-VIN) for the KMM-VIN Research Fellowship (call 2016).

\section{References}

[1] J.A. Juhasz, S.M. Best, Bioactive ceramics: processing, structures and properties, J. Mater. Sci. 47 (2012) 610-624.

[2] V.J. Shirtliff, L.L. Hench, Bioactive materials for tissue engineering, regeneration and repair, J. Mater. Sci. 38 (2003) 4697-4707.

[3] M. Akao, H. Aoki, K. Kato, Mechanical properties of sintered hydroxyapatite for prosthetic applications, J. Mater. Sci. 16 (1981) 809-812.

[4] K.A. Hiller, W. Buchalla, I. Grillmeier, C. Neubauer, G. Schmalz, In vitro effects of hydroxyapatite containing toothpastes on dentin permeability after multiple applications and ageing, Sci. Rep. 8 (2018) 4888-4900.

[5] D.M. Devine, E. Hoctor, J.S. Hayes, E. Sheehan, C.H. Evans, Extended release of proteins following encapsulation in hydroxyapatite/chitosan composite scaffolds for bone tissue engineering applications, Mat. Sci. Eng. C 84 (2018) 281-289.

[6] J.R. Jones, Review of bioactive glass: From Hench to hybrids, Acta Biomater. 23 (2015) 53-82. 
[7] A.R. Boccaccini, M. Erol, W.J. Stark, D. Mohn, Z. Hong, J.F. Mano, Polymer/bioactive glass nanocomposites for biomedical applications: A review, Compos. Sci. Technol. 70 (2010) 1764-1776.

[8] E. Cañas, M. Vicent, M.J. Orts, E. Sánchez, Bioactive glass coatings by suspension plasma spraying from glycolether-based solvent feedstock, Surf. Coat. Technol. 318 (2017) 190-197.

[9] J.A. Helsen, J. Proost, J. Schrooten, G. Timmermans, E. Brauns, J. Vanderstraeten, Glasses and bioglasses: synthesis and coatings, J. Eur. Ceram. Soc. 17 (1997) 147-152.

[10] P. Stoor, E. Söderling, J.I. Salonen, Antibacterial effects of a bioactive glass paste on oral microorganisms, Acta Odont. Scan. 56 (1998) 161-165.

[11] A.A. Gorustovich, C. Perio, J.A. Roether, A.R. Boccaccini, Effect of bioactive glasses on angiogenesis: a review of in vitro and in vivo evidences, Tissue Eng. B 16 (2010) 199-207.

[12] W. Cao, L. Hench, Bioactive materials, Ceram. Inter. 22 (1996) 493-507.

[13] A. Sola, D. Bellucci, V. Cannillo, A. Cattini, Bioactive glass coatings: a review, Surf. Eng. 27 (2011) 560-572.

[14] F. Baino, E. Verne, Glass-based coatings on biomedical implants: a state-ofthe-art review, Biomed. Glasses 3 (2017) 1-17.

[15] J.R. Jones, A.G. Clare, Bio-glasses, an introduction, first ed., John Wiley and Sons, Great Britain, 2012.

[16] V. Cannillo, A. Sola, Different approaches to produce coatings with bioactive glasses: Enamelling vs plasma spraying, J. Eur. Ceram. Soc. 30 (2010) 20312039.

[17] V. Cannillo, A. Sola, Potassium-based composition for a bioactive glass, Ceram. Inter. 35 (2009) 3389-3393.

[18] C.C. Mardare, A.I. Mardare, J.R.F. Fernandes, E. Joanni, S.C.A. Pina, M.H.V. Fernandes, R.N. Correia, Deposition of bioactive glass-ceramic thin-films by RF magnetron sputtering, J. Eur. Ceram. Soc. 23 (2003) 1027-1030.

[19] P. González, J. Serra, S. Liste, S. Chiussi, B. León, M.P. Amor, J.M. Fernández, A.R.A. López, F.M.V. Feria, New biomorphic SiC ceramics coated with bioactive glass for biomedical applications, Biomater. 24 (2003) 4827-4832.

[20] E. Cañas, M. Vicent, E. Bannier, P. Carpio, M.J. Orts, E. Sánchez, Effect of particle size on processing of bioactive glass powder for atmospheric plasma spraying, J. Eur. Ceram. Soc. 36 (2016) 837-845.

[21] J. Zhong, D.C. Greenspan, Processing and properties of sol-gel bioactive glasses, J. Biomed. Mater. Res. Appl. Biomater. 53 (2000) 694-701.

[22] M. Monsalve, H. Ageorges, E. Lopez, F. Vargas, F. Bolivar, Bioactivity and mechanical properties of plasma-sprayed coatings of bioglass powders, Surf. Coat. Technol. 220 (2013) 60-66. 
[23] A. Killinger, R. Gadow, G. Mauer, A. Guignard, R. Vassen, D. Stöver, Review of new developments in suspension and solution precursor thermal spray processes, J. Therm. Spray Technol. 20 (2011) 677-695.

[24] I. Rocnakova, K. Slamecka, E.B. Montufar, M. Remesova, L. Dyckova, A. Brinek, D. Jech, K Dvorak, L. Celko, J. Kaiser, Deposition of hydroxyapatite and tricalcium phosphate coatings by suspension plasma spraying: effects of torch speed, J. Eur. Ceram. Soc. 38 (2018) 5489-5496.

[25] X. Ma, P. Ruggiero, Practical Aspects of Suspension Plasma Spray for Thermal Barrier Coatings on Potential Gas Turbine Components, J. Therm. Spray Technol. 27 (2018) 591-602.

[26] O.P. Solonenko, Y. Ando, H. Nishiyama, D. Kindole, A.V. Smirnov, A.A. Golovin, S. Uehara, T. Nakajima, Synthesis of thick photocatalytic titania surface layers by solution plasma spraying and subsequent treatment by pulsed laminar plasma jet, Surf. Coat. Technol. 333 (2018) 39-51.

[27] P. Xu, L. Pershin, J. Mostaghimi, T.W. Coyle, Efficient one-step fabrication of ceramic superhydrophobic coatings by solution precursor plasma spray, Mat. Lett. 211 (2018) 24-27.

[28] G. Bolelli, D. Bellucci, V. Cannillo, R. Gadow, A. Killinger, L. Lusvarghi, P. Müller, A. Sola, Comparison between suspension plasma sprayed and high velocity suspension flame sprayed bioactive coatings, Surf. Coat. Technol. 280 (2015) 232-249.

[29] A. Cattini, L. Latka, D. Bellucci, G. Bolelli, A. Sola, L. Lusvarghi, L. Pawlowski, V. Cannillo, Suspension plasma sprayed bioactive glass coatings: effects of processing on microstructure, mechanical properties and in-vitro behaviour, Surf. Coat. Technol. 220 (2013) 52-59.

[30] E. Cañas, M.J. Orts, A.R. Boccaccini, E. Sánchez, Solution Precursor Plasma Spraying (SPPS): A novel and simple process to obtain bioactive glass coatings, Mat. Lett. 223 (2018) 198-202.

[31] Q.Z. Chen, Y. Li, L.Y. Jin, J.M.W. Quinn, P.A. Komesaroff, A new sol-gel process for producing $\mathrm{Na2O}-$ containing bioactive glass ceramics, Acta Biomater. 6 (2010) 4143-4153.

[32] J. Faure, R. Drevet, A. Lamelle, N.B. Jaber, A. Tara, H. El Btaouri, H. Benhayoune, A new sol-gel synthesis of $45 S 5$ bioactive glass using an organic acid as catalyst, Mater. Sci. Eng. C 47 (2015) 407-412.

[33] H. Pirayesh, J.A. Nychka, Sol-gel synthesis of bioactive glass-ceramic 45S5 and its in vitro dissolution and mineralization behavior, J. Am. Ceram. Soc. 96 (2013) 1643-1650.

[34] C.J. Brinker, G.W. Scherer, Sol-gel science. The physics and chemistry of solgel processing, first ed., Academic Press, The USA,1990.

[35] Y. Castro, A. Durán, R. Moreno, B. Ferrari, Thick sol-gel coatings produced by electrophoretic deposition, Adv. Mater. 14 (2002) 505-508.

[36] R.T. Candidato, P. Sokolowski, L. Pawlowski, G. Lecomte-Nana, C. Constantinescu, A. Denoirjean, Development of hydroxyapatite coatings by 
solution precursor plasma spray process and their microstructural characterization, Surf. Coat. Technol. 318 (2017) 39-49.

[37] M. Vicent, E. Bannier, P. Carpio, E. Rayón, R. Benavente, M.D. Salvador, E. Sánchez, Effect of the initial particle size distribution on the properties of suspension plasma sprayed $\mathrm{Al}_{2} \mathrm{O}_{3}-\mathrm{TiO}_{2}$ coatings, Surf. Coat. Technol. 268 (2015) 209-215.

[38] P. Carpio, E. Bannier, M.D. Salvador, A. Borrell, R. Moreno, E. Sánchez, Effect of particle size distribution of suspension feedstock on the microstructure and mechanical properties of suspension plasma spraying YSZ coatings, Surf. Coat. Technol. 268 (2015) 293-297.

[39] G. Goller, The effect of bond coat on mechanical properties of plasma sprayed bioglass-titanium coatings, Ceram. Int. 30 (2004) 351-355.

[40] R.T. Candidato, P. Sokolowski, L. Pawlowski, A. Denoirjean, Preliminary study of hydroxyapatite coatings synthesis using solution precursor plasma spraying, Surf. Coat. Technol. 277 (2015) 242-250.

[41] M. Khan, N. Hu, L. Zhenhua, Y. Wang, Z. Yi, Influence of solution-precursor plasma spray (SPPS) processing parameters on the mechanical and thermodynamic properties of 8YSZ, Ceram. Inter. 44 (2018) 7794-7798.

[42] R. Jaworski, L. Pawlowski, F. Roudet, S. Kozerski, F. Petit, Characterization of mechanical properties of suspension plasma sprayed $\mathrm{TiO}_{2}$ coatings using scratch test, Surf. Coat. Technol. 202 (2008) 2644-2653.

[43] A.L.B. Maçon, T.B. Kim, E.M. Valliant, K. Goetschius, R.K. Brow, D.E. Day, A. Hoppe, A.R. Boccaccini, I.Y. Kim, C. Ohtsuki, T. Kokubo, A. Osaka, M. ValletRegí, D. Arcos, L. Fraile, A.J. Salinas, A.V. Teixeira, Y. Vueva, R.M. Almeida, M. Miola, C. Vitale-Brovarone, E. Verné, W. Höland, J.R. Jones, A unified in vitro evaluation for apatite-forming ability of bioactive glasses and their variants, J. Mater. Sci. Mater. Med. 26 (2015) 115-124.

[44] T. Kokubo, H. Takadama, How useful is SBF in predicting in vivo bone bioactivity?, Biomater. 27 (2006) 2907-2915.

[45] V. Carnicer, C. Alcazar, E. Sánchez, R. Moreno, Aqueous suspension processing of multicomponent submicronic $\mathrm{Y}-\mathrm{TZP} / \mathrm{Al}_{2} \mathrm{O}_{3} / \mathrm{SiC}$ particles for suspension plasma spraying, J. Eur. Ceram. Soc. 38 (2018) 2430-2439.

[46] L. Xie, X. Ma, A. Ozturk, E.H. Jordan, N.P. Padture, B.M. Cetegen, D.T. Xiao, M. Gell, Processing parameter effects on solution precursor plasma spray process spray patterns, Surf. Coat. Technol. 183 (2004) 51-61.

[47] M. Gell, E.H. Jordan, M. Teicholz, B.M. Cetegen, N.P. Padture, L. Xie, D. Chen, X. Ma, J. Roth, Thermal Barrier Coatings Made by the Solution Precursor Plasma Spray Process, J. Therm. Spray Technol. 17 (2008) 124-135.

[48] Z. Yu, H. Moussa, M. Liu, R. Schneider, M. Moliere, H. Liao, Solution precursor plasma spray process as an alternative rapid one-step route for the development of hierarchical $\mathrm{ZnO}$ films for improved photocatalytic degradation, Ceram. Inter. 44 (2018) 2085-2092. 

ARTículo 8 



\title{
Comparison of different silica sources in the development of plasma sprayed 4555 bioactive glass coatings
}

\author{
Eugeni Cañas, María Díaz, Carmen Alcázar, María José Orts, Rodrigo \\ Moreno, Enrique Sánchez
}

Journal of Non-Crystalline Solids 544 (2020) 120164

\section{https://doi.org/10.1016/j.jnoncrysol.2020.120164}

\begin{abstract}
Este trabajo aborda la deposición de recubrimientos de vidrio bioactivo de composición similar al vidrio $45 S 5$ mediante proyección térmica por plasma a partir de materiales de aporte líquidos. $\mathrm{El} \mathrm{SiO}_{2}$ necesario para obtener la composición deseada se ha aportado mediante ortosilicato de tetraetilo (precursor típico de $\mathrm{SiO}_{2}$ en la obtención de vidrios por el método sol-gel), suspensiones de sílice coloidal y mezcla de ambos materiales.
\end{abstract}

Los materiales de aporte sintetizados se han caracterizado mediante estudios reológicos y de sedimentación. A continuación, los materiales de aporte se han depositado sobre sustratos metálicos bajo dos distancia de proyección diferentes, y los recubrimientos resultantes se han caracterizado desde un punto de vista microestructural y se ha analizado la presencia de fases cristalinas.

Se ha comprobado que todos los materiales sintetizados muestran una composición similar a la del vidrio 45S5, y presentan una viscosidad y estabilidad adecuadas para su empleo el proyección térmica por plasma. Se ha observado un efecto importante de la fuente de $\mathrm{SiO}_{2}$ en la microestructura resultante. Además, indistintamente de la fuente empleada, la microestructura mejora notablemente al reducir la distancia de proyección. 

Journal of Non-Crystalline Solids 544 (2020) 120164

\title{
Comparison of different silica sources in the development of plasma sprayed $45 \mathrm{~S} 5$ bioactive glass coatings
}

\author{
E. Cañas ${ }^{a \star}$, M. Díaz ${ }^{b}$, C. Alcázar ${ }^{b}$, M.J. Orts ${ }^{a}$, R. Moreno ${ }^{b}$, E. Sánchez ${ }^{a}$ \\ a Instituto de Tecnología Cerámica (ITC), Universidad Jaume I, Castellón, Spain \\ b Instituto de Cerámica y Vidrio (ICV), Consejo Superior de Investigaciones Científicas \\ (CSIC), Universidad Autónoma de Madrid, Madrid, Spain
}

* Corresponding author

\begin{abstract}
45S5 bioactive glass coatings were deposited by plasma spraying from liquid feedstocks. In these feedstocks, the $\mathrm{SiO}_{2}$ needed to achieve the $45 \mathrm{~S} 5$ bioactive glass composition has been provided either as tetraethyl orthosilicate (typical precursor of glasses by sol-gel), or as colloidal silica suspension or mixtures of both sources. The synthesised materials were analysed in terms of rheology and sedimentation tests, and subsequently deposited onto metallic substrates under two different spraying distances. The resulting coatings were characterised on the basis of microstructure and phase nature.

All feedstocks developed preserved the composition of the $45 S 5$ bioactive glass and showed adequate viscosity and stability to be transported and injected into the plasma plume. However, different coating microstructures were achieved when using tetraethyl orthosilicate or colloidal silica suspensions. Besides, regardless the source of silica an improvement of the coatings microstructure and phase nature have also been observed when the spraying distance was significantly reduced.
\end{abstract}

Keywords: $45 S 5$ bioactive glass; Plasma spraying; Silica; Glass suspension; Glass solution; Coating microstructure

\section{Introduction}

The 4555 bioactive glass or Bioglass ${ }^{\circledR}$, discovered by Prof. Hench, was the first bioactive material capable of developing new bone tissue when in contact with it [1]. $45 S 5$ glass is basically a soda-lime glass including some phosphorous with the following composition $45,0 \% \mathrm{SiO}_{2}, 24,5 \% \mathrm{CaO}, 24,5 \% \mathrm{Na}_{2} \mathrm{O}$ and $6,0 \%$ $\mathrm{P}_{2} \mathrm{O}_{5}$, in wt\% $[2,3]$. Nevertheless, from the discovery of this glass until now, a lot of research has been performed proposing modified compositions of this material depending on the synthesis method or the final application [4-9]. Consequently, nowadays there is a growing family of bioactive glasses based on mixtures of glass former and modifier oxides such as $\mathrm{SiO}_{2}-\mathrm{CaO}-\mathrm{MgO}-$ $\mathrm{Na}_{2} \mathrm{O}-\mathrm{K}_{2} \mathrm{O}-\mathrm{ZnO}-\mathrm{B}_{2} \mathrm{O}_{5}-\mathrm{P}_{2} \mathrm{O}_{5}$. 
Among all the emerging applications of these materials in the field of medicine, one of them is the utilisation of bioactive glasses as a prosthesis coating being plasma spraying the most common method employed for that purpose $[1,10,11]$. Up to now, the study and deposition of plasma sprayed bioactive glass coatings were done using powder and suspension feedstocks through Atmospheric Plasma Spraying (APS) and Suspension Plasma Spraying (SPS) processes respectively. These glass powder feedstocks were usually obtained either by the melting and quenching method or by sol-gel $[12,13]$, and then directly used in the form of powder or suspended in an organic medium when their particle size is lower than $10 \mu \mathrm{m}$ in order to preserve some stability. Typical organic media employed are ethanol or glycols [14-16], since bioactive glasses tend to react with water (leaching) leading to a cation exchange and consequently modifying their final composition [17].

Nevertheless, precursor solutions have started to be used as a feedstock in the field of plasma spraying, method referred as Solution Precursor Plasma Spraying (SPPS) $[18,19]$. The utilisation of this method allows an easier exploration of different material compositions as well as the deposition of advanced coatings (thinner and nanostructured) with a homogeneous and dense microstructure [20,21]. These aspects can provide significant advantages to obtain suitable coatings from bioactive glasses. In addition, SPPS permits to work with purer feedstocks since further powder or suspension elaboration steps which can introduce impurities or contaminants, such as milling, are removed and also allows the use of water as a solvent, since there is no problem of leaching from the precursors unlike the bioactive glass powders, resulting in feedstocks which are safer and easier to handle. SPPS has been used to deposit coatings from a wide variety of materials for different applications such as thermal barrier coatings [22-24], solid fuel cells [25,26], photocatalytic coatings [27,28] or biocoatings [29-33].

During the last years, authors of the present work also started to address the deposition of $45 \mathrm{~S} 5$ bioactive glass coatings from liquid feedstocks (suspension and solution of precursors) $[16,33]$. Despite the presence of crystalline phases, promising results were obtained when using SPPS, since the coating displayed good microstructure with higher adhesion [33]. Moreover, the SPPS bioactive glass coating showed a positive reaction when immersed in Simulated Body Fluid (SBF) [33].

As mentioned in the literature, the processes related to the material formation and deposition that take place inside the plasma plume once the solution feedstock is injected are complex (droplets evaporation and break up, gelation, precipitation, pyrolysis, sintering, melting, crystallisation) and not wellunderstood [22-24,34]. Therefore, the aim of the present work is to simplify the deposition mechanisms that take place in the plasma plume based on a new feedstock approach in which tetraethyl orthosilicate (TEOS), a metallic alkoxide usually employed as a precursor of $\mathrm{SiO}_{2}$, was partially or even totally replaced by colloidal silica suspensions. In that way, after feedstock injection into the plasma plume, only the liquid media must evaporate and then the colloidal silica 
particles can melt, react with the other diluted alkoxide and salts and act as a nucleus of glass formation. The developed feedstock materials were characterised in terms of viscosity and stability and deposited by plasma spraying. Then, all coatings were analysed by scanning electron microscopy and X-ray diffraction with the aim of assessing the possible effect of TEOS replacement on coatings microstructure. For the sake of comparison, the bioactive glass solution from previous work [33], without colloidal silica, was also prepared, characterised and sprayed.

\section{Experimental}

\subsection{Feedstocks preparation}

45S5 bioactive glass was used as target composition of feedstocks. Starting from previous work [33], an aqueous-based solution was prepared employing tetraethyl orthosilicate (TEOS) $\left(\mathrm{C}_{8} \mathrm{H}_{20} \mathrm{O}_{4} \mathrm{Si}\right.$ synthesis grade, Merck, Germany), triethyl phosphate (TEP) $\left(\mathrm{C}_{6} \mathrm{H}_{15} \mathrm{O}_{4} \mathrm{P}\right.$ synthesis grade, Merck, Germany), calcium nitrate $\left(\mathrm{Ca}\left(\mathrm{NO}_{3}\right)_{2} \cdot 4 \mathrm{H}_{2} \mathrm{O}>99 \%\right.$, VWR Chemicals, USA) and sodium nitrate $\left(\mathrm{NaNO}_{3}>99 \%\right.$, Sigma-Aldrich, USA) as precursors of $\mathrm{SiO}_{2}, \mathrm{P}_{2} \mathrm{O}_{5}, \mathrm{CaO}$ and $\mathrm{Na}_{2} \mathrm{O}$ respectively. First, nitric acid (Tritripur, Merck, Germany) was mixed with water resulting in an acidic solution with a concentration of $0,2 \mathrm{M}$ to hydrolyse TEOS and TEP. Then, TEOS was added drop by drop to the acidic solution under magnetic stirring at $500 \mathrm{rpm}$ and, after the addition of the whole reagent, the mixture was kept in agitation for half an hour until its total clarification. Next, TEP was added in the same way as TEOS (drop by drop, stirring at $500 \mathrm{rpm}$ and a mixture time of $30 \mathrm{~min}$ ). Finally, both salts were gradually added to the solution. The procedure was the same for the two salts and involved the addition of the reagent to the solution under magnetic stirring at $700 \mathrm{rpm}$ and after that, the resulting mixture was kept under agitation for $1 \mathrm{~h}$ to ensure complete dissolution of the reagent. Following this procedure, first calcium nitrate was added and then sodium nitrate. To achieve the $45 \mathrm{~S} 5$ glass composition, the amount of TEOS was determined based on a molar ratio water to TEOS of 18, and for the rest of reagents, their amounts were determined from the glass composition by stoichiometry. The resulting solution (referred as GS), with a total concentration of precursor of $4 \mathrm{M}$, was kept inside a sealed glass container at a temperature of $5^{\circ} \mathrm{C}$ [35].

After the synthesis of GS, different liquid feedstocks were prepared by replacing partially $(50 \%)$ or totally (100\%) TEOS by colloidal silica suspensions. For the replacement, two commercial suspensions were used, which are described below.

- Levasil CT17 PDL (AkzoNobel, USA), colloidal silica aqueous-based suspension, with a solids content of $30 \mathrm{wt} \%$ and stabilised at a pH of 3 .

- Ludox TM-40 (Sigma-Aldrich, USA), colloidal silica aqueous-based suspension, with a solids content of $40 \mathrm{wt} \%$ and stabilised at a pH of 9 . 
The procedure followed for feedstocks preparation was the same as for the GS with the difference that in all cases the colloidal silica suspensions were added at the final step of the procedure and not at the beginning as TEOS. Moreover, these feedstocks were also kept at low temperature $\left(5^{\circ} \mathrm{C}\right)$ inside a sealed glass container. Table 1 shows the references for the new feedstocks prepared.

Table 1. References of the new developed feedstocks

\begin{tabular}{c|cccc}
\hline $\begin{array}{c}\text { Feedstock } \\
\text { reference } \\
\text { Silica }\end{array}$ & LE05 & LU05 & LE1 & LU1 \\
Levasil & Ludox- & Levasil & Ludox- \\
$\begin{array}{c}\text { Degree of } \\
\text { substitution }\end{array}$ & CT17 & TM40 & CT17 & TM40 \\
Feedstock pH & 1,15 & $50 \%$ & $100 \%$ & $100 \%$ \\
\hline
\end{tabular}

\subsection{Characterisation of the developed feedstocks}

The chemical composition of the developed materials was determined. For that purpose, a sample of each feedstock was dried in a stove at $100{ }^{\circ} \mathrm{C}$ and the resulting powder was sintered at $700 \stackrel{\circ}{ } \mathrm{C}$. After sintering, each sample was dry milled and fused into bead; and their chemical composition was assessed by wavelength dispersive X-ray fluorescence spectrometry (XRF) (AXIOS, PANalytical, The Netherlands) with a $\mathrm{Rh}$ anode tube and certified reference materials.

When spraying liquid feedstocks, two different requirements must be fulfilled [36]:

- The feedstock must have low viscosity to make it possible its transport through the pipes and its injection into the plasma plume.

- The feedstock must have good physical and chemical stability to preserve the properties and characteristics of the material and hence to avoid the modification of coating properties with time.

For that reason, the stability of all feedstocks was assessed through a rheological study. This study, performed at $25^{\circ} \mathrm{C}$ by using a double-cone and plate system, was done in a rheometer (Haake RS50, Thermo Scientific, Germany) which controlled the shear rate (CR) from 0 to $1000 \mathrm{~s}^{-1}$ in $5 \mathrm{~min}$, maintaining it at $1000 \mathrm{~s}^{-1}$ for $1 \mathrm{~min}$ and downloading it from 1000 to $0 \mathrm{~s}^{-1}$ in 5 min. Since colloidal silica suspensions were introduced in the feedstocks, two new tests were carried out in order to complete the assessment of feedstocks stability. On the one hand, the variation of the zeta potential with $\mathrm{pH}$ was determined for these commercial suspensions. For that purpose, aliquots of each suspension were first diluted in potassium chloride $(\mathrm{KCl}) 0,01 \mathrm{M}$ and then the $\mathrm{pH}$ of each diluted aliquot was adjusted with hydrochloric acid $(\mathrm{HCl})$ and potassium hydroxide $(\mathrm{KOH})$. Finally, the zeta potential for each $\mathrm{pH}$ value was determined in a dynamic light scattering (Zetasizer NanoZS, Malvern, Great 
Britain). On the other hand, sedimentation tests were performed to those feedstocks containing the colloidal silica after its preparation. The tests were carried out in a multiple light scattering equipment (TurbiScan Classic MA2000, Formulaction, France), taking data during one hour of measurement.

\subsection{Deposition and characterisation of coatings}

Once the liquid feedstocks were prepared and characterised, the next step was their deposition by plasma spraying. The facility used to deposit the coatings comprised a single cathode plasma torch (F4-MB, Sulzer Metco, Switzerland) which is coupled to a six-axis robot (IRB 1400, ABB, Switzerland) for movement control. With the aim of injecting the liquid feedstocks, a home-made injection system is also attached to the plasma gun. This system is composed of two pressurised containers, which force the liquid to flow through an injector due to a pressure difference, injecting the liquid feedstock in a radial way to the plasma plume. A filter was placed into the injector to remove large agglomerates and possible contaminations that can clog the injector. Details about this facility can be found in published works $[37,38]$.

In order to deposit the coatings, AISI type 304 stainless steel substrates disk shaped with a diameter of $25 \mathrm{~mm}$ were used. The substrate preparation comprised a sand-blasting first step with black corundum at a pressure of 4,2 bar and a second step of cleaning with ethanol in an ultrasonic bath. After that, roughness of the substrates was measured with a roughness tester (HOMMELWERKE T8000, Hommelwerke $\mathrm{GmbH}$, Germany) being the obtained roughness $\left(R_{a}\right) 2,2 \pm 0,1 \mu \mathrm{m}$.

Concerning the spraying of the feedstocks, the parameters used are shown in table 2. Basically, these parameters are the same as described in previous research [33]. The only difference deals with the spraying distances employed. As shown in the previous research, the spraying distance has a great effect on the resulting microstructure of the coatings, giving rise to better coatings for a lower distance (higher adhesion to the substrate). Therefore, in the present work, the smallest distance was maintained $(70 \mathrm{~mm})$ and a shorter one $(40 \mathrm{~mm})$ was tested in order to study different microstructures and check if an improvement of the coatings' microstructure took place.

Furthermore, before feedstocks deposition, a bond coat of $\mathrm{TiO}_{2}$ powder was deposited by atmospheric plasma spraying (APS) from commercial anatase powder (Metco 102, Oerlikon Metco, Switzerland), with particle size distribution between 10-55 $\mu \mathrm{m}$ to enhance the glass top coating adhesion $[39,40]$. The spraying conditions used were given by the supplier and are also shown in table 2. As it can be seen, the spraying distance is longer than that used for the liquid feedstocks, in order to completely melt the powder particles. Moreover, the bond coated substrates were preheated between $300-350{ }^{\circ} \mathrm{C}$ in order to further improve adhesion [41]. 
Table 2. Plasma spray conditions used for the deposition of the $\mathrm{TiO}_{2}$ powder bond coat and each glass feedstock

\begin{tabular}{ccc}
\hline Parameter & $\begin{array}{c}\mathrm{TiO}_{2} \text { bond coat } \\
\text { (powder) }\end{array}$ & $\begin{array}{c}\text { 45S5 liquid } \\
\text { feedstocks }\end{array}$ \\
\hline Argon flow rate $(\mathrm{slpm})$ & 38 & 25 \\
Hydrogen flow rate $(\mathrm{slpm})$ & 14 & 15 \\
Intensity $(\mathrm{A})$ & 600 & 600 \\
Spraying distance $(\mathrm{mm})$ & 120 & $40 / 70$ \\
Spraying velocity $(\mathrm{m} / \mathrm{s})$ & 1,00 & 1,25 \\
Number of torch scans & 2 & 5 \\
Nozzle diameter $(\mathrm{mm})$ & 1,8 & - \\
Powder flow rate $(\mathrm{g} / \mathrm{min})$ & 45 & - \\
Injector diameter $(\mathrm{mm})$ & - & 0,15 \\
Liquid feedstock flow rate $\left(\mathrm{cm}^{3} / \mathrm{min}\right)$ & - & 33 \\
\hline
\end{tabular}

Finally, the coatings deposited from the different liquid feedstocks were examined and compared by field emission gun environmental scanning electron microscope (FEG-ESEM) (QUANTA 200FEG, FEI Company, USA). First, surface micrographs were taken and then the coatings were cut and metallographically prepared to observe their cross-section. For the latter, each coating was carefully cut with a diamond-coated and water-cooled disk (M4D18, Struers, Denmark) in an automatic cutting machine (Secotom-10, Struers, Denmark) and mounted with epoxy resin (Kit Epofix, Struers, Denmark) $[42,43]$. Then, the mounted samples were polished with a polishing machine (TegraPol-35, Struers, Denmark) using different clothes with their corresponding abrasive slurry (Struers, Denmark) and different times as shown below in table 3 .

Table 3. Consumables used for the polishing step, supplied by Struers

\begin{tabular}{cccc}
\hline Clothes & Abrasive slurry & Grit size & Application time \\
\hline MD-Piano 220 & $\begin{array}{c}\text { Resin bonded } \\
\text { diamond* }\end{array}$ & $68 \mu \mathrm{m}$ & $1 \mathrm{~min}$ \\
MD-Allegro & Diamond & $15-6 \mu \mathrm{m}$ & $5 \mathrm{~min}$ \\
MD-Dur & Diamond & $9-1 \mu \mathrm{m}$ & $5,5 \mathrm{~min}$ \\
MD-Mol & Diamond & $<3 \mu \mathrm{m}$ & $5,5 \mathrm{~min}$ \\
MD-Nap & Diamond & $<1 \mu \mathrm{m}$ & $6 \mathrm{~min}$ \\
\hline
\end{tabular}

${ }^{*}$ Abrasive incorporated in the cloth. Water-cooled

At the end, the samples were cleaned in an ultrasonic bath with distilled water and dried in an oven at $80{ }^{\circ} \mathrm{C}$ for $2 \mathrm{~h}$.

Furthermore, the distribution of elements of the bioactive glass composition ( $\mathrm{Si}$, $\mathrm{Ca}, \mathrm{Na}$ and $\mathrm{P}$ ) was studied by means of energy-dispersive $\mathrm{X}$-ray microanalysis (EDS) coupled to an electronic microscope (Quattro S, ThermoFisher Scientific, The USA). The polished cross-section samples used to obtain the micrographs 
were carbon coated by sputtering, placed inside the microscope and an X-ray mapping of elements was done under high vacuum conditions.

Finally, the amorphous/crystalline nature of the obtained coatings was assessed by X-ray diffraction (XRD) using a diffractometer (Advance diffractometer, Bruker Theta-Theta, Germany) with $\mathrm{Cu} \mathrm{Ka}$ radiation and performing the measurement over a range of $2 \theta$ between $10^{\circ}$ and $80^{\circ}$.

\section{Results and discussion}

\subsection{Feedstocks composition and stability}

The composition of the feedstocks resulting from their chemical analyses is shown in table 4 together with the composition of the nominal $45 S 5$ bioactive glass.

Table 4. Solution feedstocks composition

\begin{tabular}{ccccc}
\hline Composition (wt\%) & $\mathrm{SiO}_{2}$ & $\mathbf{C a O}$ & $\mathrm{Na}_{2} \mathrm{O}$ & $\mathbf{P}_{2} \mathbf{O}_{5}$ \\
\hline 45S5 glass & 45,0 & 24,5 & 24,5 & 6,0 \\
Glass solution [33] & 46,0 & 23,3 & 25,5 & 5,3 \\
Levasil substitution* & 49,6 & 21,6 & 24,1 & 4,8 \\
Ludox substitution* & 44,5 & 23,7 & 26,4 & 5,5 \\
\hline
\end{tabular}

${ }^{*}$ Average between the composition of feedstocks with partial and total replacement

As explained in previous work [33], the composition of the bioactive glass solution was very close to that of the nominal glass. In addition, using both colloidal silica suspensions (Levasil CT17 and Ludox TM-40), indistinctly of the degree of substitution the composition of the resulting new feedstocks remains very similar to the reference composition. The next step was the assessment of feedstocks stability. In first place the colloidal stability of silica suspensions as a function of $\mathrm{pH}$ was studied through zeta potential measurements. Figure 1 shows the evolution of zeta potential with $\mathrm{pH}$ for both colloidal suspensions (Levasil CT17 PDL in figure 1a and Ludox TM-40 in figure 1b).
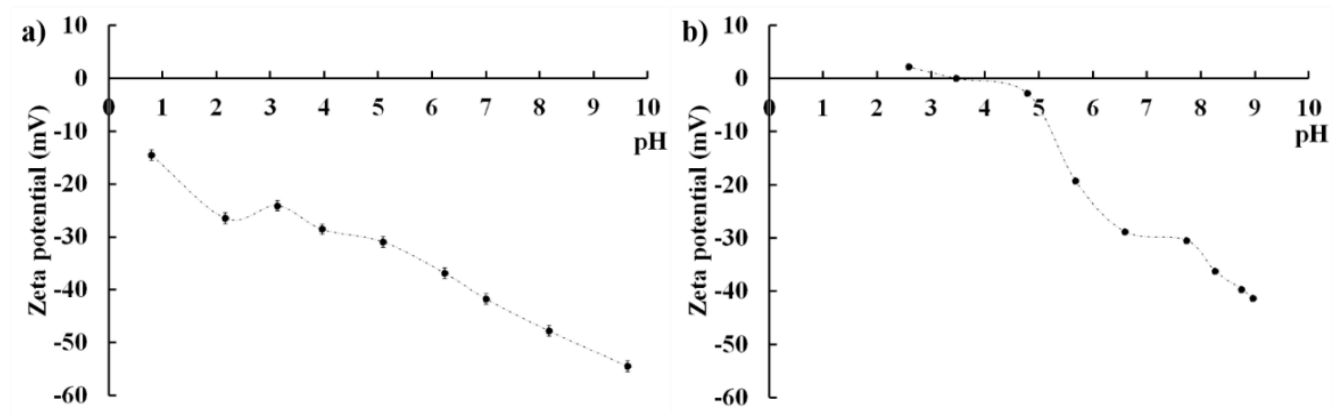

Figure 1. Zeta potential of colloidal silica suspensions as a function of pH. a) Levasil CT17 PDL and b) Ludox TM-40 
For both suspensions, it can be seen that the more basic the medium the higher the particle charge (in absolute value) and thus, the higher the repulsion between particles. In the case of the Levasil suspension, stabilized at acidic $\mathrm{pH}$ $(\approx 3)$ with a surface charge of $-24 \mathrm{mV}$, it can be observed that when moving to basic $\mathrm{pH}$ this charge tends to become more negative, increasing the particle surface charge (in absolute value) in a progressive way. However, in the case of Ludox suspension, stabilized at basic $\mathrm{pH}(\approx 9)$ with a surface charge of -41 $\mathrm{mV}$, the increment in surface charge is more marked when moving to basic $\mathrm{pH}$ from acidic $\mathrm{pH}$. In addition, for acid $\mathrm{pH}$, particles are positively charged. Therefore, there is an isoelectric point (a pH value at which there is no charge on particles surface) at $\mathrm{pH}$ between 3 and 4 .

Figure 2 displays the flow curves for the five different feedstocks.
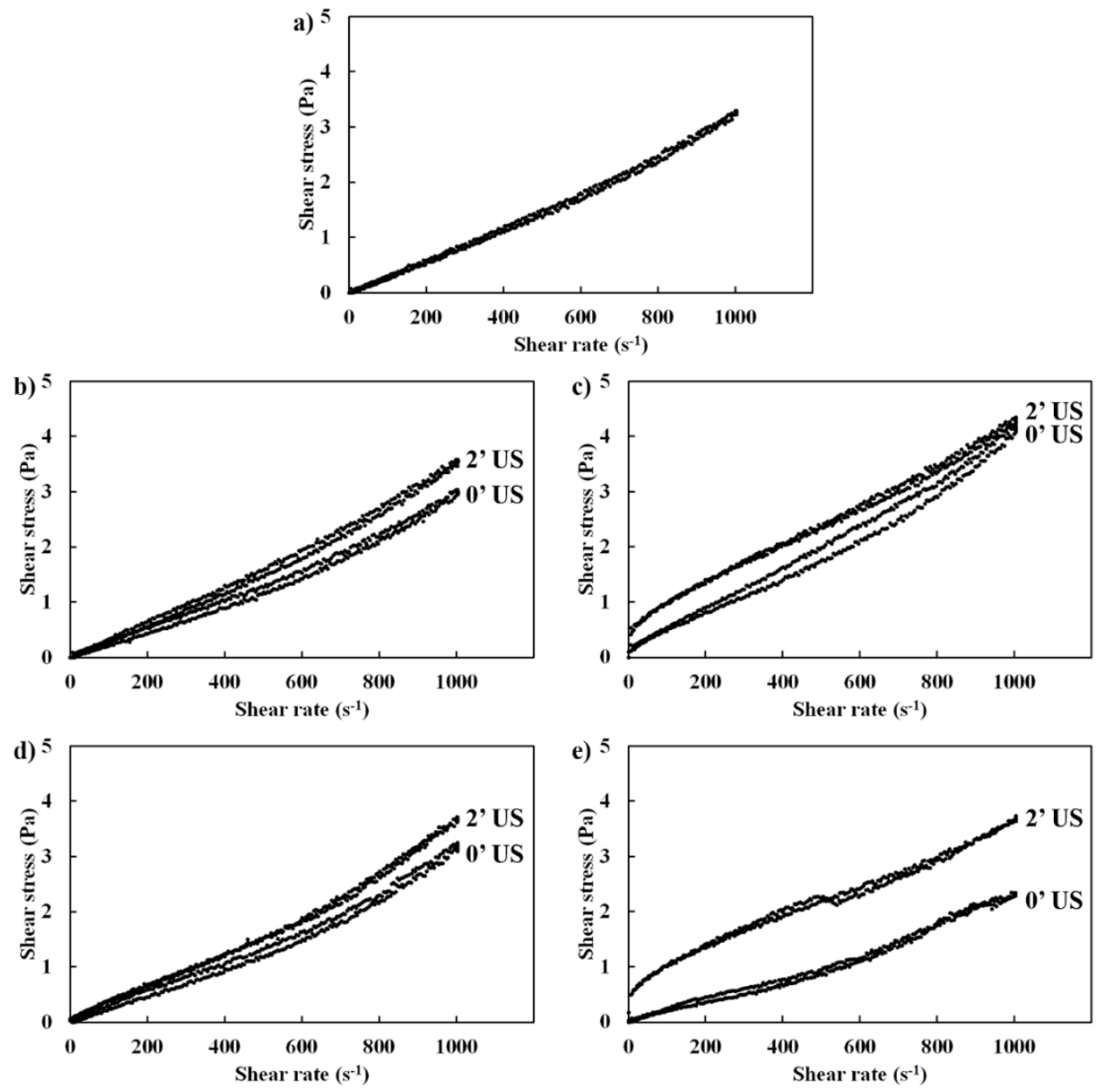

Figure 2. Flow curves of the developed feedstocks. a) GS feedstock, b) flow curves of LE05 before and after ultra-sonication, c) flow curves of LE1 before and after ultra-sonication, d) flow curves of LU05 before and after ultra-sonication and e) flow curves of LU1 before and after ultra-sonication 
From figure $2 \mathrm{a}$ (corresponding to the GS feedstock), it can be observed that this feedstock possessed a Newtonian behaviour, which is characteristic of sol-gel solutions and diluted suspensions and had a very low viscosity $\left(3,5 \cdot 10^{-3} \mathrm{~Pa} \cdot \mathrm{s}\right)$, which makes it suitable to be transported and injected into the plasma plume $[36,44]$. Moreover, thixotropy is not appreciated in figure $2 a$, that is a mismatch between the uploading and downloading resulting curves which is associated to changes in the material structure or a spatial rearrangement of particles in the direction of the applied flow, since the material is totally liquid without solid particles.

Concerning the substitution with Levasil CT17 suspension, the flow curves of the as-prepared LE05 and LE1 without ultra-sonication (0' US) are shown in figures $2 b$ and $2 c$ respectively. In both cases the Newtonian behaviour was preserved, and there is no thixotropy despite the introduction of solid particles in the feedstock. The differences between curves from the uploading and downloading steps are due to the error of the measurement device. Viscosity values for both feedstocks are $3 \cdot 10^{-3} \mathrm{~Pa} \cdot \mathrm{s}$ for LE05 and $4 \cdot 10^{-3} \mathrm{~Pa} \cdot \mathrm{s}$ for LE1, which are very similar to that of the bioactive glass solution. Regarding the rheological behaviour, it is possible to appreciate a slight increment of the shear stress at higher shear rates, which is due to a slippage effect caused by the low viscosity of the sample close to the edge of the measuring range.

However, as the colloidal silica contained in Levasil CT17 were dispersed at $\mathrm{pH}$ of $\approx 3$ and the resulting feedstocks (LE05 and LE1) had a pH lower than 2, there was a reduction of the surface charge of these colloidal particles. From figure $1 \mathrm{a}$, for a pH between 1 and 2 surface charges vary from $-10 \mathrm{mV}$ to $-15 \mathrm{mV}$ approximately. There is not enough charge to avoid particles interaction, and therefore, the colloidal silica particles were destabilised when added to the mixture due to the reduction of $\mathrm{pH}$, resulting in the formation and settling of agglomerates of particles.

This fact was also observed in the sedimentation tests results, which are displayed in table 5 as a maximum percentage of transmitted light after one hour of test along the cell as a function of the testing cell height. Since the analysed sample occupied a cell height from 5 to $65 \mathrm{~mm}$ approximately, three intervals or cell zones have been defined as shown in table 5 .

Table 5. Maximum percentage of transmitted light along the vessel in function of the test vessel height for the feedstocks before and after ultra-sonication

\begin{tabular}{|c|c|c|c|c|c|c|c|c|}
\hline \multirow[b]{2}{*}{ Cell test } & \multicolumn{2}{|c|}{ LE05 } & \multicolumn{2}{|c|}{ LE1 } & \multicolumn{2}{|c|}{ LU05 } & \multicolumn{2}{|c|}{ LU1 } \\
\hline & $\begin{array}{l}0^{\prime} \\
\text { US }\end{array}$ & $\begin{array}{l}2^{\prime} \\
\text { US }\end{array}$ & $\begin{array}{l}0^{\prime} \\
\text { US }\end{array}$ & $\begin{array}{l}2 ' \\
\text { US }\end{array}$ & $\begin{array}{l}0^{\prime} \\
\text { US }\end{array}$ & $\begin{array}{l}2 ' \\
\text { US }\end{array}$ & $\begin{array}{l}0^{\prime} \\
\text { US }\end{array}$ & $\begin{array}{l}2^{\prime} \\
\text { US }\end{array}$ \\
\hline $\begin{array}{c}\text { Bottom } \\
(5-25 \mathrm{~mm})\end{array}$ & $0 \%$ & $0 \%$ & $0 \%$ & $0 \%$ & $0 \%$ & $0 \%$ & $0 \%$ & $0 \%$ \\
\hline $\begin{array}{c}\text { Middle } \\
(25-45 \mathrm{~mm})\end{array}$ & $1 \%$ & $1 \%$ & $1 \%$ & $0 \%$ & $65 \%$ & $0 \%$ & $85 \%$ & $1 \%$ \\
\hline $\begin{array}{c}\text { Top } \\
(45-65 \mathrm{~mm})\end{array}$ & $30 \%$ & $1 \%$ & $62 \%$ & $2 \%$ & $80 \%$ & $1 \%$ & $90 \%$ & $13 \%$ \\
\hline
\end{tabular}


From this table, after one hour of test it can be observed in the case of LE05 that at the top of the test cell there is a $30 \%$ of transmitted light, which demonstrated that a significant sedimentation of the initially suspended colloidal particles took place and clearer sedimentation front is detected. Indeed, the higher the amount of colloidal particles added, the higher the destabilisation and, consequently, the higher the settling, as shown in table 5 for LE1 feedstock. From this table it can be observed that the maximum percentage of transmitted light at the top zone of the test cell is $62 \%$ for the LE1 feedstock. Of course, in the other zones of both feedstocks there was no transmitted light since all the settled solid concentrated in these zones.

To overcome this inconvenience, both feedstocks were subjected to ultrasonication (UP400S, Hielscher Ultrasonics, Germany) in order to break down the agglomerates generated due to the destabilisation of the colloidal particles $[45,46]$. After two minutes of ultra-sonication, it is possible to confirm that without a significant increase of the feedstocks' viscosity $\left(3,5 \cdot 10^{-3} \mathrm{~Pa} \cdot \mathrm{s}\right.$ for LE05 and $4,2 \cdot 10^{-3} \mathrm{~Pa} \cdot \mathrm{s}$ for LE1) as shown in figures $2 \mathrm{~b}$ and $2 \mathrm{c}$ (curves labelled with 2'US), the agglomerates were broken, and the primary colloidal particles were re-dispersed again. This little differences in viscosity with regard to the feedstocks before ultra-sonication is due to the presence of well-dispersed particles which are opposing greater flow resistance. Regarding the settling, sedimentation tests were done again to both feedstocks after two minutes of ultra-sonication and results are shown in table 5. Comparing these measurements with the previous ones, it can be affirmed that the destabilisation of the colloidal particles was successfully overcome for both feedstocks (LE05 and LE1) since for the tested period (60 min) there was no sedimentation observed as transmittance remains at $1 \%$ and $2 \%$ at the top cell for LE05 and LE1 feedstocks respectively.

Concerning the employment of Ludox TM-40, the flow curves of the asprepared LU05 and LU1 are shown in figures $2 \mathrm{~d}$ and $2 \mathrm{e}$ respectively (0' US). In both cases the Newtonian behaviour was preserved, and slight increment of the shear stress at higher shear rates can be also appreciated as in the Levasil CT17 utilisation. There was no significant difference in viscosity between the GS, LE05, LE1 and the LU05 $\left(3 \cdot 10^{-3} \mathrm{~Pa} \cdot \mathrm{s}\right)$. Contrary to that, the viscosity for LU1 was lower $\left(2 \cdot 10^{-3} \mathrm{~Pa} \cdot \mathrm{s}\right)$ than for the other feedstocks developed. Again, this is due to the destabilisation of the colloidal particles which, in the case of Ludox TM-40, is much more marked than in the case of the Levasil. In figure $1 \mathrm{~b}$, it was shown that silica particles in Ludox $\mathrm{TM}-40$ were stabilised at $\mathrm{pH} \approx 9$, and the surface charge of the particles was dramatically reduced when the $\mathrm{pH}$ was moved from basic to acid values. Unlike the Levasil silica suspension, when the total substitution was carried out with Ludox silica suspension, there was a significant change of $\mathrm{pH}$ for the particles (from 9 to 1 approximately) during which the surface charge of the particles is significantly reduced, even going through the isoelectric point (Figure 1b) where there is no charge on the surface of the particles. Therefore, the formation of an agglomerated structure took place, which immediately settled. Because of this, during the rheological measurements, almost all the particles settled at the bottom and the sample 
moved by the rotor had a much lower solids content so that there was hardly any solid material that opposed resistance to the flow. Therefore, the measurement provided an apparent lower viscosity due to the very fast sedimentation of particles.

This circumstance can be easily observed when the sedimentation test was done. Results of these tests are also shown in table 5 . In both cases, the destabilisation can be clearly observed, being much more marked (as mentioned above) when the substitution was complete, since after $60 \mathrm{~min}$ of test, there was a maximum percentage of light transmittance of almost $90 \%$ along the top and the middle zones of the cell test. In fact, by this time, it was already possible to distinguish two clearly differentiated zones in the feedstock.

Due to the success in overcoming that drawback in LE05 and LE1, the other feedstocks (LU05 and LU1) were homogenised by ultra-sonication for 2 min, and as in the previous case (Levasil CT17), promising results were obtained. Both feedstocks were stabilised, and the colloidal particles were re-dispersed again. The viscosity of LU05 and LU1 did not pointedly increased $\left(3,9 \cdot 10^{-3} \mathrm{~Pa} \cdot \mathrm{s}\right.$ and $4,1 \cdot 10^{-3} \mathrm{~Pa} \cdot \mathrm{s}$ respectively). Finally, sedimentation tests were done again to both feedstocks after two minutes of ultra-sonication and the results are included in table 5. As shown in this table, for the testing period $(60 \mathrm{~min})$ the feedstocks remained stable without particle settling. Only after one hour, a transmittance of $13 \%$ can be observed in the top zone of the cell test for the LU1. However, when comparing these results with those obtained before ultrasonication, after the great destabilisation of the material the outcome obtained after ultra-sounds can be considered as a promising result.

Finally, a further study of feedstocks stability over time was carried out. Each feedstock was rheologically tested at different times from its preparation and the viscosity value was taken the resulting curves. The obtained results are displayed in figure 3. As in the previously mentioned work [33], the bioactive glass solution feedstock (Figure 3a) has a stable viscosity value for 7 days, with no signs of gelation during this time. However, after the seventh day this feedstock started to gel, a process that drastically took place as reflected by the strong increase in the viscosity value of this solution between 7 and 9 days. Concerning the feedstocks with mixture of TEOS and colloidal silica suspensions, presented a similar behaviour than that of the original solution. It was expected that the lower the amount of TEOS (responsible of feedstock gelation) the higher the stability with time, but as it can be seen in figures $3 \mathrm{~b}$ and 3c (LE05 and LU05 respectively) the gelation process took place earlier. After five days, both feedstocks started to gel in a progressive way. Despite the enhancement of colloids destabilization shown by ultra-sonication, this step had a negative effect on the feedstocks containing TEOS. When the ultrasonication has been carried out, although the feedstocks were cooled in icewater bath, a considerable increase in the temperature of the feedstock took place and consequently, the gelation process was accelerated due to the presence of TEOS in the solution. Regarding the LE1 and LU1 feedstocks, since TEOS was completely replaced by colloidal silica particles in both feedstocks, 
regardless of the ultra-sonication, there was no precursor that could cause the gelation of the feedstock. In figures $3 d$ and $3 e$ (LE1 and LU1 respectively) it can be seen that after 35 days from the preparation of both feedstocks they remained completely liquid and the viscosity kept constant.
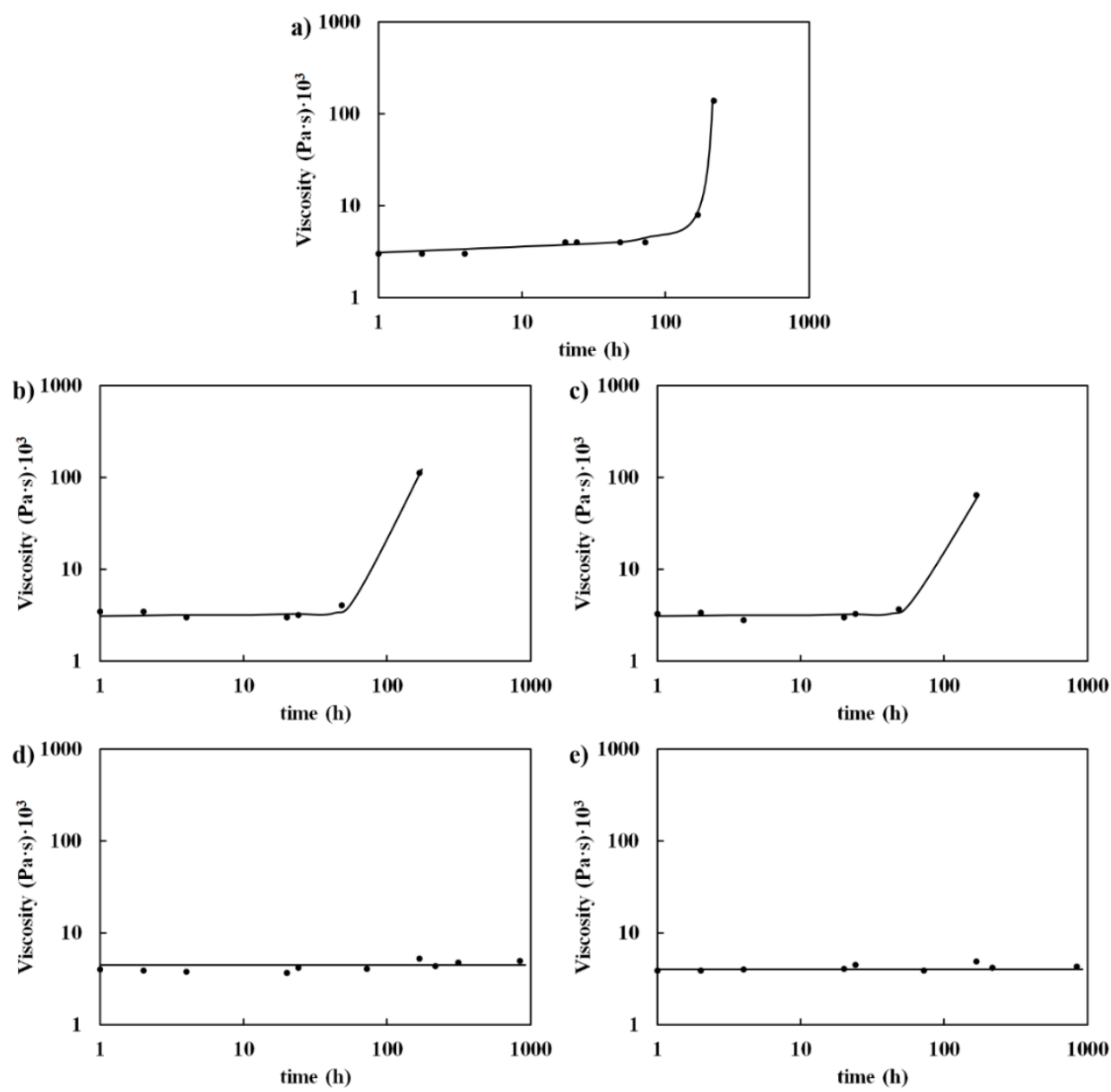

Figure 3. Stability of feedstocks with time after ultra-sonication. a) GS, b) LE05, c) LU05, d) LE1 and e) LU1

\subsection{Microstructural characterisation of the coatings}

The studied feedstocks were deposited by plasma spraying, as described above. Since different spraying distances were chosen and there were 5 different feedstocks, only the compositions with only precursor or colloidal silica (GS, LE1 and LU1) were sprayed in order to discriminate the effect of each silica source on the microstructure. The resulting micrographs are shown in figures 4 (surface micrographs) and 5 (cross-section micrographs) at different magnifications. 

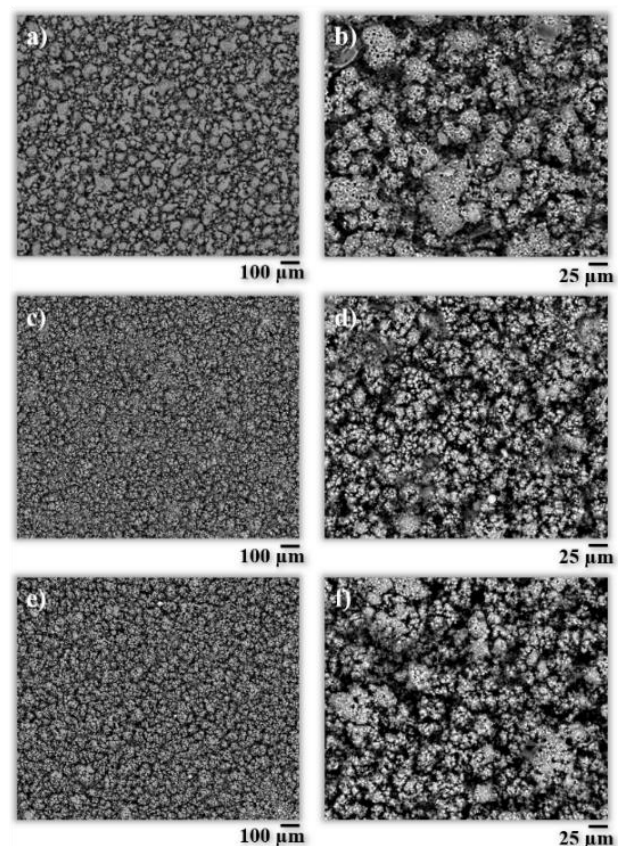
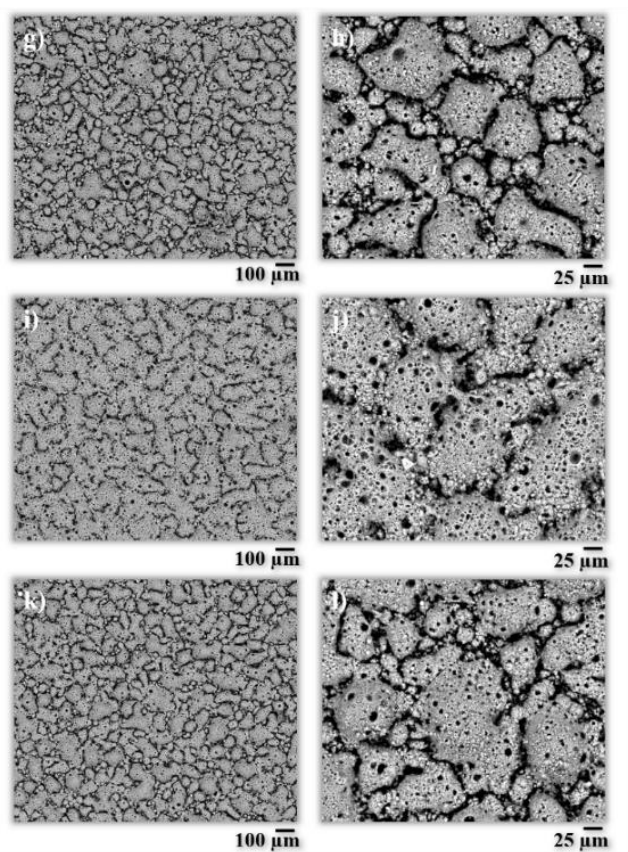

Figure 4. Surface micrographs of the deposited coatings. At $70 \mathrm{~mm}$ spraying distance: a) and b) GS coating (from [33]), c) and d) LE1 coating, e) and f) LU1 coating. At $40 \mathrm{~mm}$ spraying distance: $g$ ) and $h$ ) GS coating, i) and j) LE1 coating, $k$ ) and I) LU1 coating

From the surface examination of the obtained coatings, it can be observed that each one is completely uniform or superficially homogeneous, composed of agglomerates and deep valleys, as already found in literature about coatings deposition from liquid precursors [33,47-49]. However, a clear effect of both the spraying distance used and the presence of TEOS or colloidal silica particles can be seen in the final microstructure. The coating deposited from the original solution at $70 \mathrm{~mm}$ of spraying distance (figures $4 \mathrm{a}$ and $4 \mathrm{~b}$ ) [33], presented the two-zones microstructure typical of liquid feedstock deposition as explained, i.e. a first layer of fine glass rounded drops followed by a top layer of glass agglomerates [33,47-49], due to the high precursor concentration in the feedstock [49]. In fact, it is possible to appreciate some rounded and molten glass agglomerates on the top surface, which keep cohesive among them. Contrarily, the coatings deposited from LE1 (figures 4c and 4d) and LU1 (figures $4 \mathrm{e}$ and $4 \mathrm{f}$ ) showed a surface mainly covered by small rounded glass particles that were not splatted with scarce adhesion to the substrate. There is also the presence of molten glass agglomerates, but in comparison with the coating obtained from the GS, the number of these agglomerates is very low, and they appear dispersed and isolated.

Since the spraying parameters (gases flow rates, spraying distance, arc intensity, etc.) used in the deposition of these three coatings were the same, the difference in microstructure of the coatings from silica particles with respect to the coating deposited from the bioactive glass solution can be attributed to 
velocity of glass formation and the difference in particle size of the glass formed inside the plasma plume. In the case of the bioactive glass solution, the hydrolysis and condensation of the TEOS was necessary in order to obtain the $\mathrm{SiO}_{2}$ (the glass network former) by the use of a catalyst agent, therefore glass formation will take some time. In addition, in the present study nitric acid was chosen as catalyst [33]. As reported in the literature, the concentration of this catalyst affects the final particle size obtained, so that the higher the catalyst concentration, the smaller the particle size [50,51]. In fact, Chen et al. observed that for $1 \mathrm{M}$ concentration of nitric acid, the resulting distribution of bioactive glass particle sizes ranged from 1 to $5 \mu \mathrm{m}$, and by reducing this concentration the size distribution became wider and reached higher sizes [50]. Therefore, when using a concentration of $0,2 \mathrm{M}$ of nitric acid, the formation of micron-sized bioactive glass particles is expected, contrary to the case of the feedstock where $\mathrm{SiO}_{2}$ is already in the form of particle. In these feedstocks, it is expected that the formation of glass inside the plasma plume take place earlier than for the bioactive glass solution, since the silicon dioxide is already formed as a particle. In addition, the size of the glass drops developed will be finer since silica particles possessed colloidal size.

Hence, when GS was sprayed at $70 \mathrm{~mm}$ spraying distance, the formation of bioactive glass particles took place, with a particle size enough to melt before impacting onto the substrate. However, when LE1 and LU1 were sprayed at 70 $\mathrm{mm}$ spraying distance, as the particle size is lower than those from GS, a resolidification of the molten drops occurred before their impact onto the substrate, resulting in a microstructure similar to that reported in [22], where "powdery" deposits were found in the coatings.

When the spraying distance was reduced from 70 to $40 \mathrm{~mm}$, a significant improvement of coatings microstructure was reached. In addition, the difference in particle sizes described above also influenced the microstructure obtained by using this shorter spraying distance. Surface micrographs for coatings deposited from GS are shown in figures $4 \mathrm{~g}$ and $4 \mathrm{~h}$, from LE1 in figures $4 \mathrm{i}$ and $4 \mathrm{j}$, and for LU1 in figures $4 \mathrm{k}$ and $4 \mathrm{l}$. For the shorter spraying distance, the three coatings exhibited a surface covered again by molten glass agglomerates onto a first layer of fine glass particles partially splashed and sintered between them. However, in all cases these agglomerates are larger than those observed for coatings obtained with $70 \mathrm{~mm}$ spraying distance. Due to the shorter spraying distance, the glass particles not only receive energy from the plasma plume during its flight, but also once deposited after each gun passage. As described in a previous work about suspension plasma sprayed bioactive glass coatings [16], the as-deposited glass layers are heated and softened allowing more material to adhere leading to these surface agglomerates. On the other hand, coatings obtained from LE1 and LU1 feedstocks, presented surface agglomerates more splashed and connected among them resulting in denser coatings. In opposition, it can be observed that in the case of the coating obtained from the GS feedstock, the agglomerates are more rounded (without getting splashed at all) and separated between them. Again, this is an effect 
derived from the difference in size of the glass particles formed inside the plasma plume and the present colloidal ones from the novel solutions.

Regarding cross-section characterisation, apart from the coating deposited in the previous work (from GS at $70 \mathrm{~mm}$ spraying distance), it was only possible to examine the coatings deposited at $40 \mathrm{~mm}$ spraying distance from the three feedstocks. As seen above, the poor adhesion of the coatings deposited from LE1 and LU1 at $70 \mathrm{~mm}$ spraying distance due to their characteristic "powdery" microstructure gave rise to their total elimination during the cutting and metallographic preparation steps. The resulting cross-section micrographs of the analysed coatings are shown in figure 5 at different magnifications.
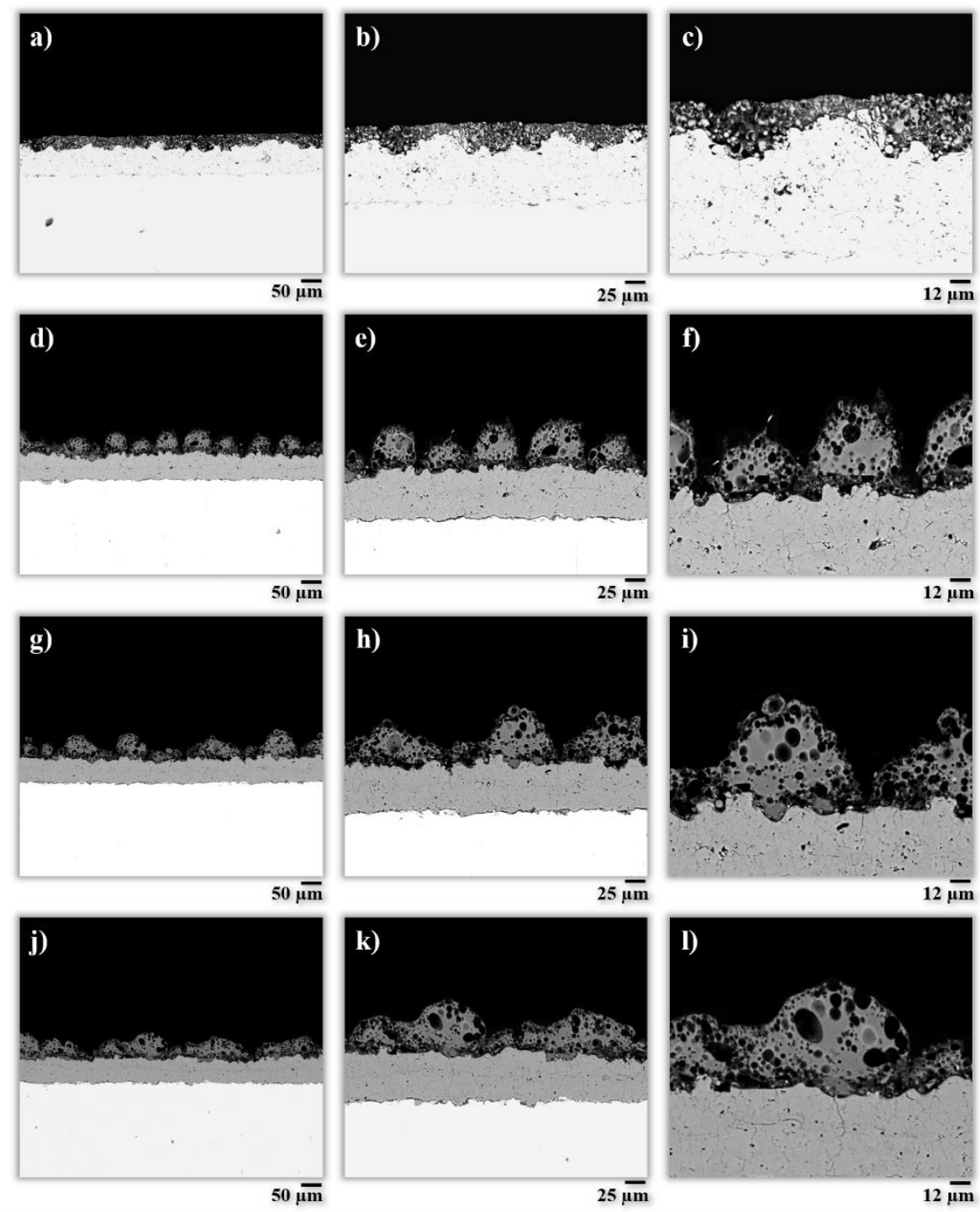

Figure 5. Cross-section micrographs of the deposited coatings. At $70 \mathrm{~mm}$ spraying distance: a), b) and c) GS coating (from [33]). At $40 \mathrm{~mm}$ spraying distance: d), e) and f) GS coating, g), h) and i) LE1 coating, j), k) and I) LU1 coating 
When the original solution was sprayed at $70 \mathrm{~mm}$ distance, a homogeneous coating was obtained with a thickness of approximately $35 \mu \mathrm{m}$ composed of small re-solidified spherical glass drops inside a molten glass matrix as described in [33]. Nevertheless, by reducing the spraying distance the obtained coatings were thicker (approximately $65 \mu \mathrm{m}$ ) than the original one, and their microstructure was substantially enhanced as explained above (surface micrographs explanation). From figures $5 d, 5 e$ and $5 f$, it is possible to appreciate that coating from GS feedstock deposited at $40 \mathrm{~mm}$ spraying distance is composed of a first layer of fine glass drops followed by a top layer of large and rounded glass agglomerates which are separated between them. Concerning the coatings deposited from the feedstocks LE1 and LU1 (figures $5 \mathrm{~g}$ to $5 \mathrm{I}$ ), these displayed a denser and more compact microstructure than that of the coating from the GS feedstock, with higher top glass agglomerates, which appeared more splashed and connected between them, making the coatings more regular and homogeneous. In the three cases, an open interconnected porosity was maintained from the coating deposited from the GS feedstock at $70 \mathrm{~mm}$ spraying distance, which can be beneficial for the interaction with biological fluids in the potential application of the bioactive coatings.

Concerning the distribution of the bioactive glass composition elements in the coating, X-ray mapping results for the four coatings shown in figure 5, are displayed in figure 6 .

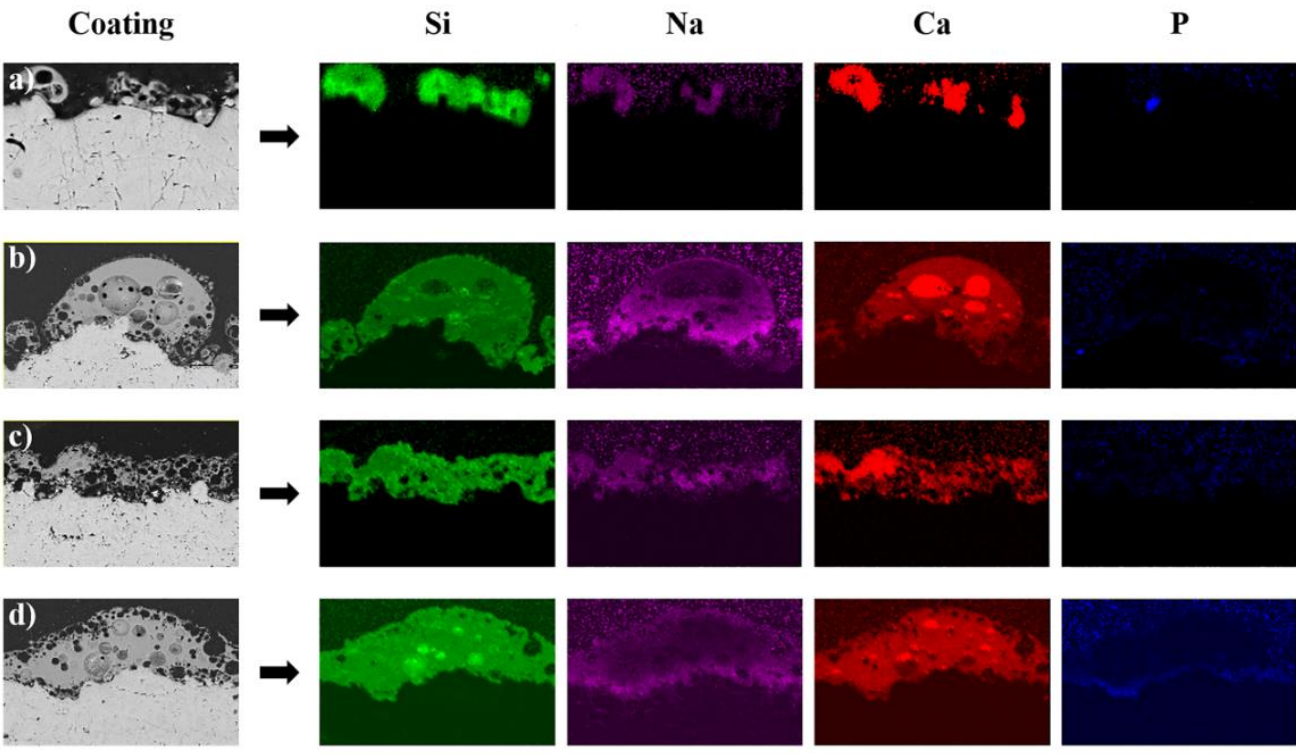

Figure 6. X-ray mapping of the deposited coatings. At $70 \mathrm{~mm}$ spraying distance: a) GS coating. At $40 \mathrm{~mm}$ spraying distance: b) GS coating, c) LE1 coating, d) LU1 coating

Regardless of the silica source and the spraying distance used, the four elements which compose the $45 \mathrm{~S} 5$ glass are present in all coatings. As it can be seen, the distribution of the four elements is quite homogeneous in all 
coatings, whereas low intensity signal for phosphorous was also observed. This lack of signal could be due to the relatively low content along with a partial volatilisation of this element during the deposition process, resulting in phosphorous gas trapped in the coating contributing to form the completely rounded inner pores [52]. However, this possible deficiency of phosphorous in the coating does not avoid the development of an hydroxycarbonate apatite layer (HCA), as demonstrated in the previous work [33]. Nevertheless, it could negatively affect the rate of HCA nucleation and growth [52], which should be confirmed with further experimentation.

Finally, the XRD patterns of the six deposited coatings are displayed in figure 7. For a spraying distance of $70 \mathrm{~mm}$, indistinctly of the feedstock used, the patterns shown crystalline peaks of different compounds as in the previous work.
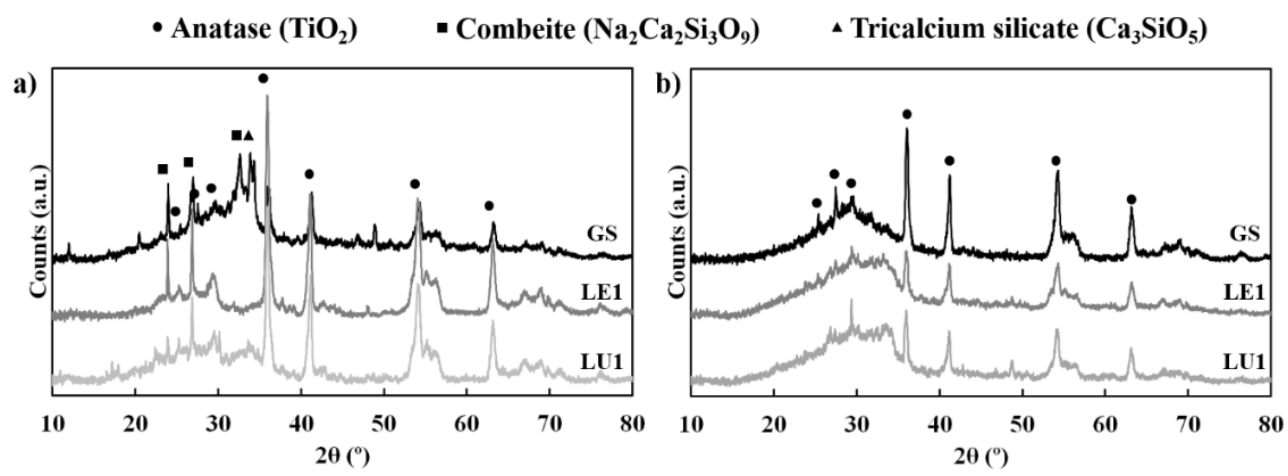

Figure 7. XRD patterns of the sprayed coatings. a) At $70 \mathrm{~mm}$ spraying distance for GS (from [33]), LE1 and LU1 coatings. b) At $40 \mathrm{~mm}$ spraying distance for GS, LE1 and LU1 coatings

Since coatings were very thin, the beam of electrons from the XRD were able to reach the bond coat and hence peaks of anatase appeared in the XRD pattern. The intensity of these peaks was higher for the coatings deposited from feedstocks containing the colloidal silica particles, since the re-solidification of the glass drops impaired their adhesion to the substrate, resulting in thinner coatings than that deposited from the GS feedstock. The other peaks correspond to the crystalline phases of combeite $\left(\mathrm{Na}_{2} \mathrm{Ca}_{2} \mathrm{Si}_{3} \mathrm{O}_{9}\right)$ and tricalcium silicate $\left(\mathrm{Ca}_{3} \mathrm{SiO}_{5}\right)$, which formation is due to the re-solidification of the glass drops inside the plasma plume because of the long spraying distance [33]. In fact, as described above, the re-solidification process is higher for the LE1 and LU1 feedstocks, resulting again in higher intensity crystalline peaks of combeite. For these three coatings (GS, LE1 and LU1), the developed crystallinity could be harmful for their bioactivity, since the onset time of HCA formation because of the reaction between the glass coating and the biological media increases with the crystallinity $[53,54]$.

Reducing the spraying distance from 70 to $40 \mathrm{~mm}$ prevented the glass drops inside the plasma plume from crystallization and thus, phase nature of all 
coatings was changed from almost crystalline to amorphous. Therefore, despite the partial vaporisation of $\mathrm{P}$, the onset time of HCA formation will be shorter compared to coatings deposited under $70 \mathrm{~mm}$ spraying distance. Moreover, as in the previous spraying distance, the thickness of the coatings is not enough to prevent the electron beam from reaching the bond coat layer, since there was the presence of crystalline peaks of anatase in all coatings. However, compared to the previous spraying distance, coatings deposited from liquid feedstocks with colloidal silica particles at $40 \mathrm{~mm}$ spraying distance show less intense anatase peaks since they are denser and homogeneous, as explained above, than that deposited from the GS feedstock, whose agglomerates are more rounded and isolated.

\section{Conclusions}

Different liquid feedstocks were developed for the deposition of plasma sprayed $45 S 5$ bioactive glass coatings employing TEOS, colloidal silica suspensions and mixtures of both as a source of silicon dioxide.

Colloidal silica suspensions can be a suitable material to replace TEOS in the development of $45 \mathrm{~S} 5$ bioactive glass solutions for plasma spraying, since the resulting feedstocks possessed adequate properties to be transported and injected into the plasma plume.

Compared to the original solution, the fast formation of glass particles inside the plasma plume related to the utilisation of this colloidal silica containing feedstocks, allows only the formation of well-adhered coatings at very short spraying distances.

The microstructure of the coatings at short spraying distance results better for the feedstocks containing colloidal silica particles since it is more homogeneous and more splashed, compared to the microstructure of the coating deposited from the original solution, which is mostly composed of big glass agglomerates. However, in all cases, there was no effect of the type of feedstock in the phase nature of the coatings and the distribution of the elements of the glass composition, which were homogeneously distributed in the coatings.

More research should be done in order to assess both the mechanical properties and the bioactivity of the developed coatings and analyse the effect of the lower amount of phosphorous on these properties. In addition, new research related with the mixtures of both sources is in progress with the aim of adjusting the feedstock $\mathrm{pH}$ before the addition of the colloidal particles to avoid the particles destabilisation and the ultra-sonication step since it caused the premature gelation of the feedstock. 


\section{Acknowledgements}

This work was supported by Universitat Jaume I (PREDOC/2015/50) and the Spanish Ministry of Economy, Industry and Competitiveness and European Regional Development Fund (MAT2015-67586-C3-R). Authors thank Dr. Encarna Blasco (ITC, Castellón, Spain) for her kindly contribution in the EDS mapping analysis step.

\section{References}

[1] J.R. Jones, A.G. Clare, Bio-glasses, an introduction, first ed., John Wiley and Sons, Great Britain, 2012.

[2] L.L. Hench, The story of Bioglass ${ }^{\circledR}$, J. Mater. Sci. Mater. Med. 17 (2006) 967978.

[3] M.N. Rahaman, D.E. Day, B.S. Bal, Q. Fu, S.B. Jung, L.F. Bonewald, A.P. Tomsia, Bioactive glass in tissue engineering, Acta Biomater. 7 (2011) 23552373.

[4] R. Li, A.E. Clark, L.L. Hench, An investigation of bioactive glass powders by sol-gel processing, J. Appl. Biomater. 2 (1991) 231-239.

[5] J. Zhong, D.C. Greenspan, Processing and properties of sol-gel bioactive glasses, J. Biomed. Mater. Res. 53 (2000) 694-701.

[6] J. Ning, A. Yao, D. Wang, W. Huang, H. Fu. X. Liu, X. Jiang, X. Zhang, Synthesis and in vitro bioactivity of a borate-based bioglass, Mater. Lett. 61 (2007) 5223-5226.

[7] A. Balamurugan, G. Balossier, S. Kannan, J. Michel, A.H.S. Rebelo, J.M.F. Ferreira, Development and in vitro characterization of sol-gel derived $\mathrm{CaO}-$ $\mathrm{P}_{2} \mathrm{O}_{5}-\mathrm{SiO}_{2}-\mathrm{ZnO}$ bioglass, Acta Biomater. 3 (2007) 255-262.

[8] V. Cannillo, A. Sola, Potassium-based composition for a bioactive glass, Ceram. Int. 35 (2009) 3389-3393.

[9] A. Moghanian, A. Sedghi, A. Ghorbanoghli, E. Salari, The effect of magnesium content on in vitro bioactivity, biological behavior and antibacterial activity of sol-gel derived 58S bioactive glass, Ceram. Int. 44 (2018) 9422-9432.

[10] J. Henao, C. Poblano-Salas, M. Monsalve, J. Corona-Castuera, O. BarceinasSánchez, Bio-active glass coatings manufactured by thermal spray: A status report, J. Mater. Res. Technol. 8 (2019) 4965-4984.

[11] Y. Liu, H. Li, B.T. Zhang, Chapter 9-Nanostructured ceramic coating biomaterials, in: G.J. Yang, X. Suo (Eds.), Advanced nanomaterials and coatings by thermal spray: Multi-dimensional design of micro-nano thermal spray coatings, Elsevier Inc., Oxford, 2019, pp. 291-311.

[12] J.P. Nayak, S. Kumar, J. Bera, Sol-gel synthesis of bioglass-ceramics using rice husk ash as a source for silica and its characterization, J. Non-cryst. Sol. 356 (2010) 1447-1451. 
[13] R. Ravarian, F. Moztarzadeh, M.S. Hashjin, S.M. Rabiee, P. Khoshakhlagh, M. Tahriri, Synthesis, characterization and bioactivity investigation of bioglass/hydroxyapatite composite, Ceram. Int. 36 (2010) 291-297.

[14] A. Cattini, D. Bellucci, A. Sola, L. Pawlowski, V. Cannillo, Suspension plasma spraying of optimised functionally graded coatings of bioactive glass/hydroxyapatite, Surf. Coat. Technol. 236 (2013) 118-126.

[15] D. Stojanovic, B. Jokic, Dj. Veljovic, R. Petrovic, P.S. Uskokovic. Dj. Janackovic, Bioactive glass-apatite composite coating for titanium implant synthesized by electrophoretic deposition, J. Eur. Ceram. Soc. 27 (2007) 15951599.

[16] E. Cañas, M. Vicent, M.J. Orts, E. Sánchez, Bioactive glass coatings by suspension plasma spraying from glycolether-based solvent feedstock, Surf. Coat. Technol. 318 (2017) 190-197.

[17] S. Romeis, A. Hoppe, R. Detsch, A.R. Boccaccini, J. Schmidt, W. Peukert, Topdown processing of submicron 45S5 Bioglass ${ }^{\circledR}$ for enhanced in vitro bioactivity and biocompatibility, Proced. Eng. 102 (2015) 534-541.

[18] P. Fauchais, M. Vardelle, S. Goutier, A. Vardelle, Key challenges and opportunities in suspension and solution plasma spraying, Plasma Chem. Plasma Process. 35 (2015) 511-525.

[19] P. Fauchais, A. Vardelle, Innovative and emerging processes in plasma spraying: From micro- to nano-structured coatings, J. Phys. D Appl. Phys. 44 (2011) 194011.

[20] E.H. Jordan, C. Jiang, M. Gell, The solution precursor plasma spray (SPPS) process: A review with energy considerations, J. Therm. Spray Technol. 24 (2015) 1153-1165.

[21] A. Killinger, R. Gadow, G. Mauher, A. Guignard, R. Va, D. Stöver, Review of New Developments in suspension and solution precursor thermal spray processes, J. Therm. Spray Technol. 20 (2011) 677-695.

[22] L. Xie, X. Ma, A. Ozturk, E.H. Jordan. N.P. Padture, B.M. Cetegen, D.T. Xiao, M. Gell. Processing parameter effects on solution precursor plasma spray process spray patterns, Surf. Coat. Technol. 183 (2004) 51-61.

[23] E.H. Jordan, L. Xie, M. Gell, N.P. Padture, B. Cetegen, A. Ozturk, X. Ma, J. Roth, T.D. Xiao, P.E. Bryant, Superior thermal barrier coatings using solution precursor plasma spray, J. Therm. Spray Technol. 13 (2004) 57-65.

[24] M. Gell, E.H. Jordan, M. Telcholz, B.M. Cetegen, N.P. Padture, L. Xie, D. Chen, $X$. Ma, J. Roth, Thermal barrier coatings made by the solution precursor plasma spray process, J. Therm. Spray Technol. 17 (2008) 124-135.

[25] Y. Wang, T.W. Coyle, Solution precursor plasma spray of nickel-yittia stabilized zirconia anodes for solid oxide fuel cell application, J. Therm. Spray. Technol. 16 (2007) 898-904.

[26] P. Michaux, G. Montavon, A. Grimaud, A. Denoirjean, P. Fauchais, Elaboration of Porous NiO/8YSZ layers by several SPS and SPPS routes, J. Therm. Spray Technol. 19 (2010) 317-327. 
[27] R. Dom, G. Sivakumar, N.Y. Hebalkar, S.V. Joshi, P.H. Borse, Deposition of nanostructured photocatalytic zinc ferrite films using solution precursor plasma spraying, Mater. Res. Bull. 47 (2012) 562-570.

[28] Z. Yu, H. Moussa, M. Liu, R. Schneider, M. Moliere, H. Liao, Solution precursor plasma spray process as an alternative rapid one-step route for the development of hierarchical $\mathrm{ZnO}$ films for improved photocatalytic degradation, Ceram. Int. 44 (2018) 2085-2092.

[29] T.W. Coyle, E. Garcia, Z. Zhang, L. Gan, Plasma spray deposition of hydroxyapatite coatings from sol precursors, Mater. Sci. Forum 539-543 (2007) 1128-1133.

[30] R.T. Candidato, P. Sokołowski, L. Łatka, S. Kozerski, L. Pawłowski, A. Denoirjean, Plasma spraying of hydroxyapatite coatings using powder, suspension and solution feedstocks, Weld. Tech. Rev. 87 (2015) 64-71.

[31] R.T. Candidato, C. Thouzellier, L. Pawlowski, Evaluation of the in-vitro behavior of nanostructured hydroxyapatite and zinc doped hydroxyapatite coatings obtained using solution precursor plasma spraying, J. Biomed. Mater. Res. Appl. Biomater. 106 (2018) 2101-2108.

[32] Y. Xiao, L. Song, X. Liu, Y. Huang, J. Chen, Y. Wu, F. Wu, Bioactive glassceramic coatings synthesized by the liquid precursor plasma spraying process, J. Therm. Spray Technol. 20 (2011) 560-568.

[33] E. Cañas, M.J. Orts, A.R. Boccaccini, E. Sánchez, Microstructural and in vitro characterization of $45 \mathrm{~S} 5$ bioactive glass coatings deposited by solution precursor plasma spraying (SPPS), Surf. Coat. Technol. 371 (2019) 151-160.

[34] L. Xie, X. Ma, E.H. Jordan, N.P. Padture, D.T. Xiao, M. Gell, Identification of coating deposition mechanisms in the solution-precursor plasma-spray process using model spray experiments, Mater. Sci. Eng. A 362 (2003) 204212.

[35] Y. Castro, A. Durán, R. Moreno, B. Ferrari, Thick sol-gel coatings produced by electrophoretic deposition, Adv. Mater., 14 (2002), pp. 505-508.

[36] R. Moreno, E. Bannier, Feedstocks suspensions and solutions, in: N. Espallargas (Ed.), Future development of thermal spray coatings, Elsevier, Great Britain, 2015, pp. 51-80.

[37] M. Vicent, E. Bannier, P. Carpio, E. Rayón, R. Benavente, M.D. Salvador, E. Sánchez, Effect of the initial particle size distribution on the properties of suspension plasma sprayed $\mathrm{Al}_{2} \mathrm{O}_{3}-\mathrm{TiO}_{2}$ coatings, Surf. Coat. Technol. 268 (2015) 209-215.

[38] P. Carpio, E. Bannier, M.D. Salvador, A. Borrell, R. Moreno, E. Sánchez, Effect of particle size distribution of suspension feedstock on the microstructure and mechanical properties of suspension plasma spraying YSZ coatings, Surf. Coat. Technol. 268 (2015) 293-297.

[39] D. Bellucci, G. Bolelli, V. Cannillo, R. Gadow, A. Killinger, L. Lusvarghi, A. Sola, N. Stiegler, High velocity suspension flame sprayed (HVSFS) potassium-based bioactive glass coatings with and without $\mathrm{TiO}_{2}$ bond coat, Surf. Coat. Technol. 206 (2012) 3857-3868. 
[40] A. Sola, D. Bellucci, V. Cannillo, A. Cattini, Bioactive glass coatings: a review, Surf. Eng. 27 (2011) 560-572.

[41] P. Fauchais, Understanding plasma spraying, J. Phys. D. Appl. Phys. 37 (2004) 86-108.

[42] M.F. Smith, D.T. McGuffin, J.A. Henfling, W.J. Lenling, A comparison of techniques for the metallographic preparation of thermal sprayed samples, J. Therm. Spray Technol. 2 (1993) 287-294.

[43] J.F. Li, H.L. Liao, C.X. Ding, C. Coddet, Optimizing the plasma spray process parameters of yttria stabilized zirconia coatings using a uniform design of experiments, J. Mater. Process. Technol. 160 (2005) 34-42.

[44] A. Guignard, Development of thermal spray processes with liquid feedstocks, Schriften des Forschungszentrums Jülich Reihe Energie \& Umwelt / Energy \& Environment, Jülich, Germany 2012, http://www.fz-juelich.de/zb/juwel.

[45] M. Vicent, E. Sánchez, A. Moreno, R. Moreno, Preparation of high solids content nano-titania suspensions to obtain spray-dried nanostructured powders for atmospheric plasma spraying, J. Eur. Ceram. Soc. 32 (2012) 185194.

[46] M. Vicent, E. Sánchez, G. Mallol, R. Moreno, Study of colloidal behaviour and rheology of $\mathrm{Al}_{2} \mathrm{O}_{3}-\mathrm{TiO}_{2}$ nanosuspensions to obtain free-flowing spray-dried granules for atmospheric plasma spraying, Ceram. Int. 39 (2013) 8103-8111.

[47] G. Bolelli, D. Bellucci, V. Cannillo, R. Gadow, A. Killinger, L. Lusvarghi, P. Müller, A. Sola, Comparison between suspension plasma sprayed and high velocity suspension flame sprayed bioactive coatings, Surf. Coat. Technol. 280 (2015) 232-249.

[48] L. Latka, S.B. Goryachev, S. Kozerski, L. Pawlowski, Sintering of fine particles in suspension plasma sprayed coatings, Mater. 3 (2010) 3845-3866.

[49] R.T. Candidato, P. Sokolowski, L. Pawlowski, G. Lecomte-Nana, C. Constantinescu, A. Denoirjean, Development of hydroxyapatite coatings by solution precursor plasma spray process and their microstructural characterization, Surf. Coat. Technol. 318 (2017) 39-49.

[50] Q.Z. Chen, Y. Li, L.Y. Jin, J.M.W. Quinn, P.A. Komesaroff, A new sol-gel process for producing $\mathrm{Na2O}-$ containing bioactive glass ceramics, Acta Biomater. 6 (2010) 4143-4153.

[51] B. Lei, X. Chen, Y.H. Koh, Effects of acidic catalysts on the microstructure and biological property of sol-gel bioactive glass microspheres, J. Sol-Gel Sci. Technol. 58 (2011) 656-663.

[52] O. Rojas, M. Prudent, M.E. López, F. Vargas, H. Ageorges, Influence of atmospheric plasma spraying parameters on porosity formation in coatings manufactured from $45 S 5$ bioglass powder, J. Therm. Spray. Technol. 29 (2020) 185-198.

[53] O.P. Filho, G.P. La Torre, L.L. Hench, Effect of crystallisation on apatite-layer formation of bioactive glass 45S5, J. Biomed. Mater. Res. 30 (1996) 509-514. 
[54] D.C. Clupper, J.J. Mecholsky Jr, G.P. La Torre, D.C. Greenspan, Bioactivity of tape cast and sintered bioactive glass-ceramic in simulated body fluid, Biomater. 23 (2002) 2599-2606. 

5. DISCUSIÓN DE RESULTADOS 

Tras exponer las distintas publicaciones con los resultados obtenidos, a continuación se lleva a cabo la discusión de los resultados más relevantes relativos a la adecuación de los diferentes materiales de aporte sintetizados y su efecto en la microestructura de los recubrimientos obtenidos, y, en consecuencia, en las propiedades mecánicas y bioactividad de éstos.

\subsection{Adecuación de los polvos de vidrio bioactivo}

Tal y como se ha mostrado en el artículo 1, se han estudiado diferentes polvos de vidrio bioactivo. Independientemente del tamaño de partícula, la composición de todos los polvos obtenidos es muy similar a la del vidrio bioactivo 45S5. Además, estos polvos son completamente amorfos (no hay presencia de fases cristalinas) y presentan una morfología angulosa. Se aprecia asimismo un efecto notorio del tamaño de partícula tanto en la fluidez como en el comportamiento frente a la temperatura de estos polvos.

Por un lado, las tres fracciones de polvo más gruesas (BGGS, BGGS1 y BGGS2) muestran una fluidez excelente, mientras que las dos más finas (BGGS3 y BGGS4) muestran cierta cohesión, lo que reduce su fluidez. Esto es debido no solo a su tamaño sino también al carácter higroscópico de estos materiales, pues se ha comprobado que tienen una elevada tendencia a captar agua del ambiente, sobre todo la fracción más fina debido a su elevada superficie específica. Aun así, mediante la adición del fluidificante se ha conseguido no solo mejorar la fluidez del material sino también reducir la cantidad de agua ambiente adsorbida sobre el material.

Por otro lado, respecto al comportamiento frente a la temperatura, todas las fracciones de polvo estudiadas sufren las mismas transformaciones fisicoquímicas. Sin embargo, la temperatura a la cual se dan estas transformaciones está condicionada al tamaño de partícula, pues cuando más fino es el material estas transformaciones ocurren a menor temperatura.

Lo expuesto anteriormente, se ve reflejado durante el proceso de obtención de los recubrimientos. Para los parámetros de proyección estudiados, en el caso de las fracciones más gruesas y con una distribución de tamaños de partícula ancha (BGGS y BGGS1), las partículas no llegan a fundir lo suficiente como para adherirse al sustrato y formar un recubrimiento. En cuanto a las fracciones BGGS2 y BGGS3, aunque las partículas son capaces de adherirse al sustrato, su fusión es únicamente superficial, por lo que el núcleo queda sólido e impide la deformación de la partícula al impactar contra el sustrato, resultando un recubrimiento con una microestructura demasiado porosa y heterogénea. Únicamente es posible obtener un buen recubrimiento si se utiliza la fracción más fina (BGGS4) con fluidificante.

Asimismo, está fracción fina (BGGS4) ha demostrado tener una gran bioactividad, puesto que, como se ha mostrado en el artículo 2, tras solo 1 día de inmersión en fluido biológico simulado (SBF) es posible apreciar la aparición de hidroxiapatita carbonatada (HCA). 


\subsection{Adecuación de las suspensiones de vidrio bioactivo}

Como segundo material de aporte se han utilizado suspensiones de vidrio bioactivo en un medio orgánico.

El medio orgánico empleado para preparar las suspensiones ha resultado ser adecuado, puesto que aumenta la energía de la pluma de plasma (ability of heating factor (AHF) superior al valor correspondiente a la pluma por si misma). Asimismo, mediante molturación en molino planetario es posible reducir el tamaño de partícula de la fracción de polvo BGGS4 hasta casi la mitad ( $\mathrm{d}_{90}=$ $27 \mu \mathrm{m}$ ), obteniendo una suspensión de partículas (BG-Pul) de muy baja viscosidad. Sin embargo, la suspensión presenta una elevada tixotropía y es muy inestable frente al tiempo (elevada sedimentación tras 5 minutos desde su preparación). Tras estudiar varios dispersantes, se ha visto que el Disperbyk 190 es el que mejores resultados ofrece y aumenta la estabilidad de la suspensión con el tiempo si bien no se reduce prácticamente la viscosidad de la suspensión. Aunque las partículas de la suspensión empiezan a sedimentar tras 10 minutos desde su preparación, este proceso de sedimentación es más lento y no es posible apreciar claramente una zona de líquido clarificado y una zona con polvo sedimentado, ya que gracias al dispersante hay una mayor repulsión entre partículas, lo que evita que éstas se aglomeren y formen una estructura que sedimenta rápidamente como en el caso de la suspensión sin dispersante.

Tabla 5.1. Propiedades de las suspensiones obtenidas sin y con Disperbyk 190

\begin{tabular}{cccc}
\hline Suspensión & $\begin{array}{c}\text { Viscosidad }^{\text {a }} \\
(\mathbf{P a} \cdot \mathbf{s}) \cdot \mathbf{1 0}^{\mathbf{3}}\end{array}$ & $\begin{array}{c}\text { Tixotropía } \\
\left(\mathbf{P a} \cdot \mathbf{s}^{-1}\right)\end{array}$ & $\begin{array}{c}\text { Estabilidad } \\
(\mathbf{m i n})\end{array}$ \\
\hline BG-Pul & 6,0 & 373 & 5 \\
BG-Pul-D190 & 5,5 & 231 & 10 \\
BG-Att-D190 & 5,4 & 219 & 60 \\
\hline
\end{tabular}

a Determinada a una velocidad de cizalla de $900 \mathrm{~s}^{-1}$

b Tiempo al que comienza la sedimentación

Aun así, el tamaño de partícula es demasiado elevado para utilizar esta suspensión en SPS, ya que se obturan los inyectores debido a las partículas más gruesas. Por tanto, queda justificado utilizar una segunda etapa de molienda en molino de atrición.

Tras la molienda de atrición, no se reduce la viscosidad de la suspensión y apenas se reduce la tixotropía. Sin embargo, al alcanzar un tamaño medio de partícula de $1 \mu \mathrm{m}$ y un tamaño máximo de $5 \mu \mathrm{m}$, no solo es posible depositar esta suspensión mediante SPS, sino que la estabilidad frente al tiempo mejora notablemente. Como se observa en la tabla anterior, la sedimentación de las partículas no es notable hasta pasados 60 minutos desde la preparación de la suspensión. Además, tal y como se muestra en el artículo 4, es posible dispersar de nuevo las partículas sedimentadas simplemente mediante agitación mecánica. 


\subsection{Adecuación de las soluciones de precursores de vidrio bioactivo}

El tercer material de aporte estudiado son soluciones de precursores, utilizando diferentes fuentes de $\mathrm{SiO}_{2}$.

Por un lado, empleando ortosilicato de tetraetilo (TEOS) como fuente de $\mathrm{SiO}_{2}$, se ha estudiado el efecto de la concentración de catalizador $\left(\mathrm{HNO}_{3}\right)$. Como se detalla en los artículos 6 y 7, independiente de la concentración de catalizador empleada, el vidrio que se deriva de las soluciones sintetizadas presenta una composición muy similar a la del vidrio 45S5, siendo su composición más aproximada que la del polvo sintetizado en este trabajo de tesis por fusión y enfriamiento brusco.

Todas las soluciones se comportan igual frente a la temperatura, experimentando las mismas transformaciones fisicoquímicas a las mismas temperaturas. Además, inmediatamente tras su síntesis, todas ellas presentan una baja viscosidad. Sin embargo, únicamente la solución con una concentración 0,2M de ácido, muestra una buena estabilidad frente al tiempo (7-9 días), resultando la más apta para su uso en SPPS. Para concentraciones elevadas, las soluciones presentan una baja estabilidad, pues se aprecian grandes aglomerados de gel a partir de 1 hora en el caso de una concentración $1 \mathrm{M}$ y de 12 horas para una concentración $0,5 \mathrm{M}$, gelificando totalmente tras 10 horas y 4 días, respectivamente. En el caso de no utilizar catalizador, se evita el incremento de viscosidad del material de aporte ya que el material no gelifica debido a que los reactivos orgánicos y el agua permanecen separados en dos fases claramente diferenciadas. Esto impide la formación de vidrio dentro de la pluma de plasma y por tanto la formación de recubrimiento.

Por otro lado, como se muestra en el artículo 8, manteniendo la concentración de catalizador $(0,2 \mathrm{M})$ se ha estudiado la sustitución del TEOS por partículas coloidales de $\mathrm{SiO}_{2}$. El vidrio derivado de estas nuevas soluciones sigue presentando una composición similar a la del vidrio $45 \mathrm{~S} 5$ y todas estas soluciones tras su preparación muestran una baja viscosidad.

El bajo pH de la solución provoca la desestabilización de las partículas coloidales resultando en su sedimentación inmediata. Este inconveniente se subsana mediante redispersión por ultrasonidos. No obstante, el calor aportado por la sonda durante la sonicación acelera el proceso de gelificación del TEOS para la solución en la que se ha sustituido un $50 \%$ del TEOS por partículas coloidales de $\mathrm{SiO}_{2}$, lo que se traduce en una estabilidad frente al tiempo menor que la solución original. A falta de estudiar otro modo de redispersión de partículas que no incluya ultrasonidos, solo las soluciones con un $100 \%$ de sustitución del TEOS presentan buena estabilidad para ser empleadas en SPPS, puesto que, como era de esperar, la ausencia de TEOS implica la no gelificación del material de aporte. 


\subsection{Efecto del material de aporte en la microestructura resultante}

Como se ha mostrado en los diferentes trabajos publicados, independientemente del material de aporte utilizado, todos los recubrimientos obtenidos presentan cierta porosidad, con poros completamente esféricos. Esta geometría de los poros es debida a la presencia de gas atrapado tanto entre splats como dentro de éstos, como consecuencia, tanto de la volatilización de $\mathrm{Na}$ y $\mathrm{P}$, como de aire atrapado en el momento del impacto y solidificación del material depositado. Sin embargo, el hecho de utilizar un material de aporte sólido o líquido afecta considerablemente a la microestructura resultante.

En el caso de utilizar un material de aporte en polvo (fracción BGGS4 con fluidificante), para los parámetros de proyección estudiados se obtienen recubrimientos con una microestructura laminar y compacta, es decir, el recubrimiento está compuesto por un apilamiento homogéneo de splats a lo largo de toda la superficie recubierta.

Por el contrario, en el caso de utilizar suspensiones y soluciones como materiales de aporte (BG-Att-D190 y soluciones con 0,2M de catalizador y diferentes fuentes de $\mathrm{SiO}_{2}$ ), los recubrimientos están compuestos por dos zonas, una primera capa compuesta por partículas esféricas de vidrio muy finas, parcialmente sinterizadas entre ellas, a partir de la cual se desarrolla una segunda capa de aglomerados de vidrio con una microestructura columnar. Como se ha descrito los artículos 3 y 4 , la formación de esta primera capa tiene lugar durante las primeras pasadas de la pluma sobre los sustratos, estando formada por las partículas que, tras fundir durante el vuelo en la pluma de plasma, resolidifican parcialmente antes del impacto. A continuación, conforme progresa el proceso de proyección, el recubrimiento depositado va recibiendo de forma continua energía de la pluma de plasma, evitando que las nuevas partículas que impactan se enfríen totalmente y mantengan un estado viscoso. En consecuencia, debido a este estado viscoso, la adhesión de nuevas partículas se incrementa, dándose incluso la adhesión de partículas totalmente resolidificadas provenientes de la zona periférica de la pluma de plasma. EI resultado es la formación de la segunda capa de vidrio en forma columnar.

En el caso de los recubrimientos SPPS, puesto que se ha utilizado un inyector de menor tamaño que en SPS, una vez ha penetrado la corriente de material en la pluma de plasma y se ha fragmentado en gotas, el tamaño de éstas es menor para la soluciones que para las suspensiones y, en consecuencia, los aglomerados que conforman la microestructura columnar tienen un volumen menor en recubrimientos SPPS.

Estas diferencias microestructurales son debidas al tamaño de partícula, pues el paso de un material de aporte pulverulento a uno líquido (suspensión o solución) conlleva una gran reducción en el tamaño de partícula, y a su vez, esta reducción del tamaño de partícula conlleva diferencias en las trayectorias seguidas por las partículas tal y como se ilustra en la figura 5.1. 


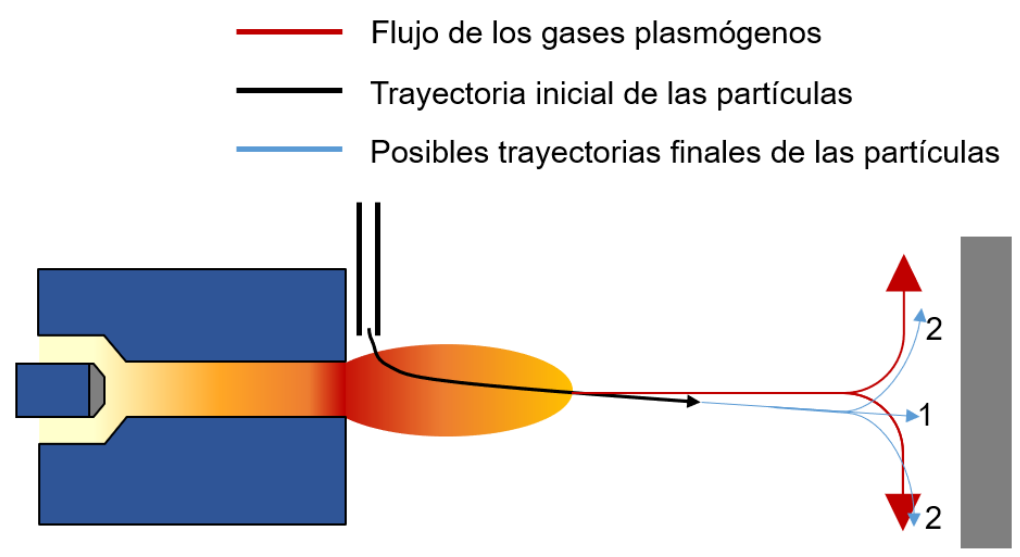

Figura 5.1. Trayectoria de las partículas en la pluma de plasma en función del tamaño de partícula

En proyección térmica por plasma, la velocidad de una partícula en el interior de la pluma de plasma se puede desglosar en dos componentes, la componente normal o perpendicular al sustrato y la componente paralela al sustrato. Para partículas con tamaños superiores a 5-10 $\mu \mathrm{m}$ predomina la componente normal frente a la paralela, por lo que las partículas seguirían la trayectoria 1 descrita en la figura 5.1. Por el contrario, en el caso de las partículas inferiores a $5 \mu \mathrm{m}$, es la componente paralela la que predomina, por lo que prevalecen las fuerzas de arrastre sobre las gravitacionales, tal y como se comenta en la introducción, de forma que el impacto no se produce de forma perpendicular al sustrato, sino que la corriente gaseosa resultante de la pluma de plasma arrastra las partículas de forma paralela al sustrato y éstas impactan sobre las asperezas del mismo (trayectoria 2), especialmente las partículas que vuelan por la periferia de la pluma, ya que su velocidad es mucho menor que las que vuelan por el centro de la pluma, siendo más susceptibles de ser arrastradas por los gases al llegar al sustrato. En base a esto, en el caso de depositar el polvo de vidrio bioactivo, prácticamente la totalidad de las partículas siguen la trayectoria 1, apilándose unas sobre otras. Sin embargo, en el caso de los materiales líquidos, las partículas siguen la trayectoria 2, dando lugar a la formación de la microestructura columnar puesto que el crecimiento del recubrimiento no se produce de forma uniforme, sino que lo hace a partir de las asperezas del soporte.

También se ha comprobado que el tamaño de partícula del material depositado, el cual es función del tipo de material de aporte, está relacionado con la distancia de proyección. En el caso del polvo, únicamente se ha estudiado una distancia de proyección fija de $100 \mathrm{~mm}$ (artículos 1 y 2), la cual se ha escogido en base a la bibliografía de recubrimientos de APS de diferentes materiales cerámicos, donde se establece como una distancia bastante efectiva. Respecto a la suspensión (artículos 3 y 4), para las condiciones de proyección estudiadas, se ha comprobado que la mejor distancia de proyección es $70 \mathrm{~mm}$, por encima de ésta los aglomerados de vidrio de la segunda capa del 
recubrimiento muestran una morfología totalmente esférica resultante de la fusión y resolidificación de las partículas antes de ser atrapadas por el recubrimiento, mientras que a distancias inferiores, estos aglomerados presentan una morfología irregular y angulosa debido a que las partículas no han fundido completamente durante el vuelo en la pluma de plasma. En el caso de las soluciones, independientemente de la fuente de $\mathrm{SiO}_{2}$, la mejor distancia de proyección corresponde a $40 \mathrm{~mm}$ (artículos 6, 7 y 8). Al utilizar TEOS, también es posible obtener recubrimientos a distancias menores o iguales a 70 $\mathrm{mm}$, aunque estos recubrimientos presentan diferentes fases cristalinas. Al utilizar partículas coloidales como fuente de $\mathrm{SiO}_{2}$, no es posible obtener recubrimientos a distancias muy por encima de $40 \mathrm{~mm}$, puesto que las partículas de vidrio formadas funden y resolidifican totalmente antes de impactar, dando lugar a un recubrimiento formado por esferas de vidrio aglomeradas sin adherencia al sustrato.

En resumen, conforme se muestra en la figura 5.2, para las condiciones de proyección y los materiales de aporte utilizados en este trabajo de tesis, el cambio de material pulverulento a suspensión, y de suspensión a solución equivale a la reducción del tamaño de partícula del material de trabajo tal y como se ha comentado anteriormente, resultando en una disminución de la distancia óptima de proyección para obtener un buen recubrimiento para cada tipo de material de aporte.
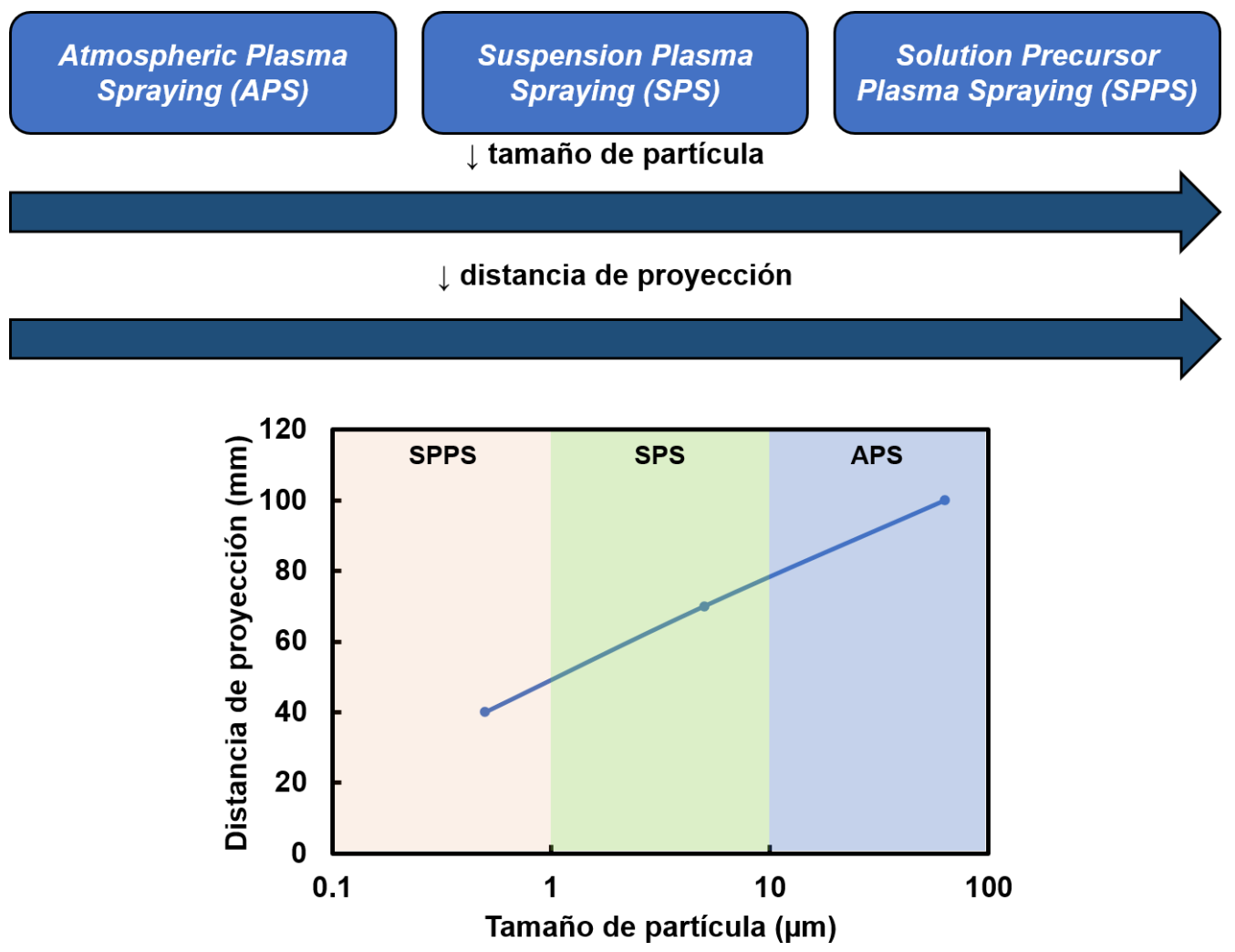

Figura 5.2. Relación entre el tamaño de partícula del material de aporte y la distancia de proyección utilizada 
Otro aspecto importante es el empleo de una capa de anclaje. Para las condiciones de proyección estudiadas en este trabajo de tesis, se ha comprobado que, a diferencia del polvo, al utilizar materiales de aporte líquidos la presencia de esta capa de anclaje, no solo mejora la adherencia del recubrimiento final, sino que aumenta la eficiencia de deposición (artículo 3). Como la capa de anclaje presenta menor conductividad térmica que el sustrato, el recubrimiento depositado de vidrio retiene más el calor proveniente de la antorcha de plasma, alcanzando un estado viscoso, resultando en un aumento de la eficiencia de deposición tal y como se ha comentado en párrafos anteriores.

Finalmente, modificando básicamente la distancia de proyección y la energía de la antorcha de plasma, se ha logrado obtener recubrimientos totalmente amorfos para los tres tipos de materiales de aporte estudiados.

\subsection{Efecto del material de aporte en las propiedades mecánicas y biológicas del recubrimiento.}

Debido a que la microestructura resultante del recubrimiento está muy influenciada por el tipo de material de aporte utilizado, tal y como se ha visto en el apartado anterior, esta influencia afecta también a las propiedades de los recubrimientos resultantes. En este trabajo, se ha comparado la adherencia de los recubrimientos como propiedad mecánica y la formación de una capa de hidroxiapatita carbonatada (HCA) tras inmersión en SBF como indicador de la bioactividad.

En primer lugar, se ha estudiado la adherencia (artículo 7). Para este estudio, se ha utilizado el recubrimiento depositado a partir de la fracción de polvo BGGS4 del artículo 1, el recubrimiento obtenido a partir de la suspensión BGAtt-D190 a $70 \mathrm{~mm}$ de distancia de proyección del artículo 4 y el recubrimiento derivado de la solución con TEOS y $0,2 \mathrm{M}$ de catalizador, depositado bajo una distancia de proyección de $70 \mathrm{~mm}$ y 25-15 slpm de argón e hidrógeno respectivamente (artículo 6). Con fines comparativos, para este ensayo, se ha realizado de nuevo la deposición del recubrimiento por APS, depositando el vidrio en polvo sobre la misma capa de anclaje que se ha utilizado para los otros dos recubrimientos.

Tras llevar a cabo los ensayos de rayado, en base a los resultados de carga crítica y dureza o resistencia al rayado, el recubrimiento depositado por SPPS es el que presenta un mejor rendimiento mecánico (mejor adhesión y cohesión) que los otros dos recubrimientos. El recubrimiento obtenido por SPS es el que peores resultados muestra, debido al gran espesor de la primera capa de partículas esféricas que reduce en gran medida la adherencia y cohesión del recubrimiento. Respecto al recubrimiento obtenido por APS, puede decirse que el rendimiento mecánico de este recubrimiento se encuentra entre el correspondiente a los recubrimientos depositados por SPPS y SPS. A pesar de presentar el mayor valor de carga crítica, la gran anchura del rayado (como en 
el recubrimiento SPS) y la gran penetración del indentador confirman la baja cohesión de este recubrimiento.

Por otro lado, se ha estudiado la formación de una capa de HCA tras inmersión en SBF. En este estudio se han utilizado los recubrimientos por APS y SPPS utilizados también en el estudio de la adherencia (artículos 2 y 7 ).

Ambos recubrimientos reaccionan positivamente con el SBF, tal y como confirman las micrografías MEB y los espectros de DRX y FTIR, desarrollando una capa de HCA sobre su superficie, que empieza a ser visible a partir del séptimo día de incubación en ambos casos. Sin embargo, a pesar de la presencia de fases cristalinas, el recubrimiento depositado por SPPS presenta un mayor grado de reacción debido a las diferencias microestructurales entre este recubrimiento y el depositado por APS.

Como se ha visto anteriormente, los recubrimientos obtenidos al depositar materiales de aporte líquidos presentan una microestructura columnar, resultando en una superficie específica mayor que la conseguida en el recubrimiento obtenido por APS, por lo que hay mayor cantidad de vidrio reaccionando e intercambiando iones con el SBF y por tanto la capa de HCA formada sobre el recubrimiento de SPPS es más gruesa. Esto queda reflejado en los espectros EDX para cada recubrimiento. Como se aprecia en el artículo 2, aunque los picos de $\mathrm{Ca}$ y $\mathrm{P}$ aumentan su intensidad a los 7 y 14 días, el pico más intenso siempre corresponde al Si. Por el contrario, tal y como puede verse en el artículo 7, los picos de Ca y $\mathrm{P}$ no solo son más intensos a los 7 y 14 días, sino que el pico de Ca llega a ser el pico de mayor intensidad para ambos tiempos de inmersión.

Asimismo, la reacción con el SBF en el propio recubrimiento obtenido por SPPS, también está influenciada por la microestructura, donde las partículas esféricas de vidrio de la primera capa son más reactivas que los aglomerados de vidrio que conforman la segunda capa.

Finalmente, también ha sido posible completar la caracterización in-vitro del recubrimiento obtenido por APS mediante la incubación con osteoblastos. Aunque únicamente ha sido posible llevar a cabo la incubación durante 1 día, se han obtenido resultados prometedores. Tras 1 día de incubación con osteoblastos humanos, el número de células vivas por $\mathrm{m}^{2}$ de recubrimiento es bastante elevado y muy similar a la muestra de control. Además, se ha observado un crecimiento multidireccional de las células en la superficie del recubrimiento estudiado, lo que conlleva una buena respuesta biológica por parte de éste. 


\section{Conclusiones}



En base a todo el estudio realizado y los resultados derivados del mismo, se obtienen las conclusiones detalladas a continuación:

> La proyección térmica por plasma atmosférico ha sido validada como técnica adecuada para la obtención de recubrimientos bioactivos a partir de polvos, suspensiones y soluciones de precursores.

$>\mathrm{Ha}$ sido posible obtener diferentes materiales de aporte con una composición similar a la del vidrio bioactivo 45S5, y adecuados para su uso en proyección térmica por plasma.

- Se ha comprobado que, a pesar de tener que utilizar un fluidificante, cuando el material de aporte es pulverulento, se obtienen mejores resultados para fracciones de polvo de tamaño de partícula pequeño $(<63 \mu \mathrm{m})$.

- Respecto a las suspensiones, es necesario varias etapas de molienda junto con un dispersante con el fin de obtener un material con viscosidad mínima, alta estabilidad frente al tiempo, tamaño de partícula fino y susceptible de proyectarse por SPS.

- En el caso de las soluciones, es necesario añadir catalizador para hidrolizar los alcóxidos, aunque una cantidad elevada acelera en exceso la gelificación impidiendo que pueda proyectarse este material. La sustitución del TEOS (precursor de $\mathrm{SiO}_{2}$ ) por partículas coloidales de $\mathrm{SiO}_{2}$ ha resultado ser una solución viable, tanto para simplificar los procesos que tienen lugar en la pluma de plasma, como para evitar la gelificación del material de aporte.

Para las condiciones de proyección estudiadas, el uso de materiales de aporte pulverulentos da lugar a un recubrimiento con una microestructura laminar, con un apilamiento homogéneo de splats. Por el contrario, el empleo de materiales de aporte líquidos da lugar a recubrimientos con una microestructura columnar compuesta por dos capas.

- Al utilizar un material pulverulento, además de la porosidad, la presencia de partículas parcialmente fundidas afecta negativamente a la cohesión del recubrimiento.

- El uso de suspensiones da como resultado recubrimientos con mala adherencia y cohesión, debido al excesivo espesor de la primera capa que conforma la microestructura.

- El empleo de soluciones de precursores permite obtener recubrimientos con buena adherencia y cohesión.

Para las condiciones de proyección estudiadas, es posible apreciar una clara relación entre el tamaño de partícula del material empleado 
(depende el tipo de material de aporte) y la distancia de proyección a la que se depositan dichos materiales de aporte para obtener buenos recubrimientos.

$>$ Es posible obtener recubrimientos totalmente amorfos con todos los materiales de aporte utilizados.

$>$ La microestructura resultante de los recubrimientos obtenidos con cada tipo de material de aporte afecta notablemente a la reacción de dichos recubrimientos con SBF.

- El grado de reacción de los recubrimientos preparados a partir de materiales líquidos es mayor al de los recubrimientos obtenidos a partir de polvos, debido a la mayor superficie específica resultante de la microestructura columnar.

- En el caso de recubrimientos obtenidos a partir de materiales líquidos, se aprecia diferentes zonas de reacción.

- En los ensayos realizados con osteoblastos humanos se ha comprobado que, para tiempos de incubación de un día, el recubrimiento derivado de la deposición de polvo fomenta el crecimiento de este tipo de células sobre su superficie. 


\section{Conclusions}



Based on the entire study carried out and the results derived from it, the conclusions detailed below have been obtained:

> Atmospheric plasma spraying has been validated as a suitable technique for obtaining bioactive coatings from powders, suspensions and precursor solutions.

$>$ It has been possible to obtain different feedstock materials, with a composition similar to that of the bioactive glass $45 \mathrm{~S} 5$, which are suitable to be used in plasma spraying.

- It has been proven that, despite the use of a fluidizing agent, when a powder feedstock is used better results are obtained for fine powder fractions $(<63 \mu \mathrm{m})$.

- Regarding the suspensions, several grinding stages are necessary together with a dispersant to obtain a material with minimum viscosity, high stability against time, fine particle size and suitable to be used in SPS.

- Concerning the solutions, it is necessary to add catalyst to hydrolyse the alkoxides, although a high quantity accelerates the gelation excessively, preventing the use of this material. The replacement of TEOS $\left(\mathrm{SiO}_{2}\right.$ precursor) by colloidal particles of $\mathrm{SiO}_{2}$ has proved to be a viable solution both to simplify the processes that take place in the plasma plume and to avoid the gelation of the solution feedstock.

For the spraying conditions studied, the use of powder feedstocks results in a coating with lamellar microstructure, with a homogeneous stacking of splats. In contrast, the use of liquid feedstocks results in coatings with a columnar microstructure consisting of two layers.

- When using a powdery material, in addition to the porosity, the presence of partially molten particles negatively affects the cohesion of the coating.

- The use of suspensions results in coatings with the worst adhesion and cohesion, due to the excessive thickness of the first layer that forms the microstructure.

- The use of precursor solutions results in coatings with good adhesion and cohesion.

For the spraying conditions tested, it is possible to appreciate a clear relationship between the particle size of the material used (depending on the type of feedstock) and the spraying distance at which the best coatings are obtained. 
$>$ It is possible to obtain completely amorphous coatings for all the feedstocks used.

$>$ The resulting microstructure from the utilisation of each type of feedstock, significantly affects the reaction of the coatings with the SBF.

- The reaction rate of coatings from liquid feedstocks is greater than that of coatings obtained from powders, due to the greater specific surface area resulting from the columnar microstructure.

- In the case of coatings from liquid materials, different reaction zones can be seen.

$>$ Tests with human osteoblasts have shown that, for one-day incubation time, the coating derived from powder deposition promotes the growth of this type of cells on its surface. 


\section{TRABAJO FUTURO}



Una vez estudiada la posibilidad de obtener recubrimientos de vidrio bioactivo mediante proyección térmica por plasma a partir de polvos, suspensiones y soluciones de precursores, y analizar el efecto de estos materiales en la microestructura y propiedades de los recubrimientos resultantes, el presente trabajo de tesis puede completarse mediante el desarrollo de varias líneas de investigación.

$>$ La primera línea de investigación consiste en concluir la caracterización mecánica e in-vitro (inmersión en SBF y cultivo celular) de los recubrimientos obtenidos por SPPS para una distancia de proyección de $40 \mathrm{~mm}$, tanto a partir de la solución original como las soluciones con $100 \%$ de sustitución del TEOS. Tal y como se ha demostrado en el presente trabajo de tesis, el recubrimiento depositado por SPPS a partir de la solución original a $70 \mathrm{~mm}$ de distancia de proyección ha resultado ser más reactivo tras su inmersión en SBF que el recubrimiento depositado a partir de polvo, a la vez que su adherencia ha resultado ser mejor. Por ello, tras la mejora microestructural de los recubrimientos SPPS derivada de reducir la distancia de proyección, resultaría interesante completar la caracterización mecánica e in-vitro de estos recubrimientos y de esta forma cerrar el trabajo de esta tesis.

$>$ La segunda línea de investigación aborda el estudio de composiciones de vidrio bioactivo distintas a la del vidrio 45S5 (estudiada en el presente trabajo de tesis). Debido a la facilidad que ofrece el empleo de soluciones de precursores para modificar la composición de trabajo, es posible abordar, de forma simultánea, el estudio de diferentes composiciones de vidrio bioactivo en base silicio. Los recubrimientos para cada composición se depositarán por SPPS tanto a partir de soluciones con TEOS como a partir de soluciones con partículas coloidales. Por ello, también será necesario un buen procesado coloidal de estos últimos materiales para solucionar el problema de la desestabilización de las partículas. Además, debido a la facilidad de modificar la composición, esta línea también aborda la inclusión de elementos metálicos dopantes, tales como plata o zinc, en las soluciones sintetizadas, dotando al recubrimiento de una nueva funcionalidad (carácter biocida y osteoconductividad).

$>$ La tercera línea de investigación está orientada a utilizar otros sistemas de proyección térmica por plasma. Todas aquellas soluciones de una determinada composición y con o sin inclusión de elementos metálicos dopantes que den mejores resultados, se depositarán mediante antorchas de plasma multicátodo, sistemas capaces de aportar mayor energía y velocidad a las partículas durante el vuelo en la pluma de plasma que la aportada por la pistola monocátodo usada en este trabajo de tesis, dando lugar a recubrimientos más densos y compactos. 



\section{DIFUSIÓN DE RESULTADOS}



Debido al carácter novedoso de la investigación realizada en este trabajo, se ha llevado a cabo una amplia difusión de los resultados obtenidos. Además de la relación de artículos mostrada en la presente tesis, se han elaborado otras publicaciones científicas y se ha participado en un gran número de congresos y jornadas tanto de carácter nacional como internacional.

\subsection{Publicaciones científicas}

Autores: Verónica López, Mónica Vicent, Emilie Bannier, Eugeni Cañas, Aldo R. Boccaccini, Luís Cordero, Enrique Sánchez

Título: $45 S 5$ bioactive glass coatings by atmospheric plasma spraying obtained from feedstocks prepared by different routes

Revista: Journal of Materials Science

Volumen: 49 Páginas: 7933-7942 Año: 2014

DOI: $10.1007 / \mathrm{s} 10853-014-8519-2$

Autores: Eugeni Cañas, Óscar Iván Rojas, María José Orts, Hélène Ageorges, Enrique Sánchez

Título: Effect of feedstock and plasma gun on the microstructure and bioactivity of plasma sprayed bioactive glass coatings

Revista: Surface \& Coatings Technology

Volumen: $406 \quad$ Páginas: 126704

Año: 2021

DOI: $10.1016 /$ j.surfcoat.2020.126704

\subsection{Participación en congresos y jornadas}

Autores: Eugeni Cañas, Mónica Vicent, Emilie Bannier, María José Orts, Enrique Sánchez

Título: Recubrimientos de vidrio bioactivo obtenidos mediante proyección térmica por plasma atmosférico a partir de polvos con distinto tamaño de partícula

Tipo de contribución: Póster

Congreso: LIV Congreso de la Sociedad Española de Cerámica y Vidrio (SECV 2014)

Lugar: Badajoz (España)

Fecha: 19-22 Noviembre 2014 
Autores: Eugeni Cañas, Mónica Vicent, Emilie Bannier, María José Orts, Enrique Sánchez

Título: Bioactive glass powder preparation for atmospheric plasma spraying Tipo de contribución: Ponencia oral

Congreso: XIV International Conference of the European Ceramic Society (ECERS 2015)

Lugar:Toledo (España) Fecha: 21-25 Junio 2015

Autores: Eugeni Cañas, Mónica Vicent, Emilie Bannier, María José Orts, Enrique Sánchez

Título: Effect of particle size of bioactive glass feedstocks on atmospheric plasma spraying coatings

Tipo de contribución: Ponencia oral

Congreso: European Congress and Exhibition on Advanced Materials and Processes (EUROMAT 2015)

Lugar: Varsovia (Polonia)

Fecha: 20-24 Septiembre 2015

Autores: Eugeni Cañas, Mónica Vicent, María José Orts, Rodrigo Moreno, Enrique Sánchez

Título: Preparation of bioactive glass feedstocks for suspension plasma spraying

Tipo de contribución: Ponencia oral

Congreso: 7èmes Rencontres Internationales sur la Projection Thermique (RIPT 2015)

Lugar: Limoges (Francia)

Fecha: 9-11 Diciembre 2015

Autores: Eugeni Cañas, Mónica Vicent, María José Orts, Enrique Sánchez Título: New applications of ceramic frits: bioactive glasses

Tipo de contribución: Póster

Congreso: Congreso Mundial de la Calidad del Azulejo y Pavimento Cerámico (QUALICER 2016)

Lugar: Castellón (España)

Fecha: 8-9 Febrero 2016 
Autores: Eugeni Cañas, Mónica Vicent, María José Orts, Rodrigo Moreno, Enrique Sánchez

Título: Suspension plasma spraying to obtain bioactive glass coatings

Tipo de contribución: Ponencia oral

Congreso: $13^{\text {th }}$ International Conference on Ceramic Processing Science (ICCPS 2016)

Lugar: Nara (Japón) Fecha: 8-11 Mayo 2016

Autores: Eugeni Cañas, Mónica Vicent, María José Orts. Enrique Sánchez Título: Evaluación de la adherencia de recubrimientos bioactivos obtenidos mediante proyección térmica por plasma atmosférico

Tipo de contribución: Ponencia oral (Ponente)

Congreso: XIV Congreso Nacional de Materiales (CNMat 2016)

Lugar: Gijón (España)

Fecha: 8-10 Junio 2016

Autores: Eugeni Cañas, Mónica Vicent, María José Orts, Rodrigo Moreno, Enrique Sánchez

Título: Preparación y caracterización de suspensiones de vidrios bioactivos para proyección térmica

Tipo de contribución: Ponencia oral (Ponente)

Congreso: V Jornadas de Jóvenes Investigadores ICV (VJJI 2016)

Lugar: Madrid (España) Fecha: 5 Julio 2016

Autores: Eugeni Cañas, Mónica Vicent, María José Orts, Enrique Sánchez Título: Atmospheric plasma sprayed bioactive glass coatings: effect of spraying conditions on coatings adhesion

Tipo de contribución: Ponencia oral (Ponente)

Congreso: Sixth International Conference on Shaping of Advanced Ceramics (Shaping 2016)

Lugar: Montpellier (Francia) Fecha: 18-20 Julio 2016 
Autores: Eugeni Cañas, Mónica Vicent, María José Orts, Enrique Sánchez Título: Efecto de los parámetros de proyección sobre la adherencia de recubrimientos bioactivos depositados mediante proyección térmica por plasma atmosférico

Tipo de contribución: Ponencia oral (Ponente)

Congreso: I Jornadas de Jóvenes Investigadores ITC (IJJI 2017)

Lugar: Castellón (España)

Fecha: 8 Marzo 2017

Autores: Eugeni Cañas, Mónica Vicent, María José Orts, Enrique Sánchez Título: Sintering treatment after deposition of suspension plasma sprayed bioactive glass coatings

Tipo de contribución: Ponencia oral (Ponente)

Congreso: International Thermal Spray Conference and Exposition (ITSC 2017)

Lugar: Düsseldorf (Alemania)

Fecha: $7-9$ Junio 2017

Autores: Enrique Sánchez, Eugeni Cañas, Víctor Carnicer

Título: Suspension plasma spraying: the meeting point for ceramic processing and plasma spraying technique

Tipo de contribución: Ponencia oral invitada

Congreso: $15^{\text {th }}$ Conference and Exhibition of the European Ceramic Society (ECERS 2017)

Lugar: Budapest (Hungría)

Fecha: 9-13 Julio 2017

Autores: Eugeni Cañas, Mónica Vicent, María José Orts, Enrique Sánchez Título: Adhesion assessment of bioactive coatings deposited by atmospheric plasma spraying

Tipo de contribución: Póster

Congreso: $15^{\text {th }}$ Conference and Exhibition of the European Ceramic Society (ECERS 2017)

Lugar: Budapest (Hungría)

Fecha: 9-13 Julio 2017 
Autores: Eugeni Cañas, Mónica Vicent, María José Orts, Aldo R. Boccaccini, Enrique Sánchez

Título: Comparison of plasma-sprayed bioactive coatings deposited from different feedstocks

Tipo de contribución: Ponencia oral (Ponente), premiada con "Best Oral Presentation Award in Area F: Biomaterials and Healthcare"

Congreso: European Congress and Exhibition on Advanced Materials and Processes (EUROMAT 2017)

Lugar: Salónica (Grecia)

Fecha: 17-22 Septiembre 2017

Autores: Enrique Sánchez, Eugeni Cañas

Título: Suspension plasma spraying to obtain bioactive glass coatings. Postdeposition treatment needed?

Tipo de contribución: Ponencia oral invitada

Congreso: 8èmes Rencontres Internationales sur la Projection Thermique (RIPT 2017)

Lugar:Limoges (Francia) $\quad$ Fecha: 6-8 Diciembre 2017

Autores: Eugeni Cañas, Hakima Belkadi, María José Orts, Enrique Sánchez Título: Effect of feedstock and thermal spraying variables on the performance of solution precursor plasma sprayed bioactive glass coatings

Tipo de contribución: Ponencia oral (Ponente), premiada con "Best Oral Presentation Award"

Congreso: 8èmes Rencontres Internationales sur la Projection Thermique (RIPT 2017)

Lugar: Limoges (Francia) $\quad$ Fecha: 6-8 Diciembre 2017

Autores: Eugeni Cañas, María José Orts, Enrique Sánchez

Título: 45S5 bioactive glass coatings developed by solution precursor plasma spraying (SPPS)

Tipo de contribución: Ponencia oral invitada (Ponente)

Congreso: XV Congreso Nacional de Materiales (CNMat 2018)

Lugar: Salamanca (España) $\quad$ Fecha: 4-6 Julio 2018 
Autores: Davide Borghi, Eugeni Cañas, María José Orts, Luca Lusvarghi, Enrique Sánchez

Título: Precursor concentration and stand-off distance effect on solution precursor plasma sprayed 45S5 bioactive glass coatings

Tipo de contribución: Ponencia oral (Ponente)

Congreso: LVI Congreso de la Sociedad Española de Cerámica y Vidrio (SECV 2018)

Lugar:Barcelona (España) Fecha: 8-10 Octubre 2018

Autores: Eugeni Cañas, María José Orts, Hélène Ageorges, Enrique Sánchez Título: Plasma sprayed bioactive glass coatings deposited with two different plasma torches

Tipo de contribución: Ponencia oral

Congreso: XVI Conference and Exhibition of the European Ceramic Society (ECERS 2019)

Lugar:Turín (Italia) Fecha: 16-20 Junio 2019

Autores: Eugeni Cañas, María José Orts, Enrique Sánchez, Aldo R. Boccaccini Título: Bioactivity study of plasma sprayed 45S5 bioactive glass coatings from solid and liquid feedstocks

Tipo de contribución: Póster

Congreso: Workshop for Young Researchers in Ceramics and Glasses for Medical Applications (YouCGMed 2019)

Lugar: Madrid (Spain)

Fecha: 10-11 Octubre 2019

Autores: Eugeni Cañas, María José Orts, Hélène Ageorges, Enrique Sánchez Título: Effect of feedstock and plasma gun on deposition of bioactive glass coatings

Tipo de contribución: Ponencia oral (Ponente)

Congreso: 9èmes Rencontres Internationales sur la Projection Thermique (RIPT 2019)

Lugar: Jülich (Alemania) Fecha: 11-13 Diciembre 2019 
Autores: Davide Borghi, Eugeni Cañas, Stefania Morelli, Veronica Testa, Giovanni Bolelli, Luca Lusvarghi, María José Orts, Enrique Sánchez

Título: Microstructure and bioactivity of solution precursor plasma sprayed $45 \mathrm{~S} 5$ glass coatings from feedstocks with different concentration

Tipo de contribución: Ponencia oral (Ponente)

Congreso: 9èmes Rencontres Internationales sur la Projection Thermique (RIPT 2019)

Lugar: Jülich (Alemania) $\quad$ Fecha: 11-13 Diciembre 2019 

9. ANEXOS 

En esta sección se adjunta todas las autorizaciones, por parte de los coautores hacia el doctorando, para la utilización de las publicaciones conjuntas como parte de esta tesis doctoral. Asimismo, se comprometen a no utilizar estas publicaciones como parte de otro trabajo de tesis. 


\section{UNIVERSITAT
JAUME I \\ Escola de Doctorat · ED}

Dr. Emilie Bannier como coautora doy mi autorización a Eugeni Cañas Recacha para la presentación de las siguientes publicaciones como parte de su tesis doctoral.

Relación de publicaciones:

- E. Cañas, M. Vicent, E. Bannier, P. Carpio, M.J. Orts, E. Sánchez, Effect of particle size on processing of bioactive glass powder for atmospheric plasma spraying, J. Eur. Ceram. Soc. 36 (2016) 837-845, DOI: 10.1016/j.jeurceramsoc.2015.09.039

También renuncio a poder utilizar estas publicaciones como parte de otra tesis doctoral.

Y para que conste, firmo este documento.

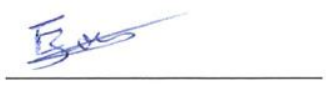

Dr. Emilie Bannier

Castellón de la Plana, 06 de Junio de 2019

Tot això, atenent a l'article 23 de la Normativa dels Estudis de Doctorat, regulats pel RD 99/2011, a la Universitat Jaume I (Aprovada pel Consell de Govern núm. 19 de 26 de Gener de 2012, modificada pe Consell de Govern núm. 29 de 27 de Novembre de 2012 i amb posterior modificació pel Consell de Govern núm. 37 de 25 de Juliol de 2013):

"(...)

d'ajustar-se, en la mesura que siga possible, a l'estructura següent: Introducció / objectius - Un capitol per article incorporat - Discussió general dels resultats - Conclusions. -Acceptació dels coautors que el doctorand presenta el treball com a tesi i renúncia expressa d'aquests a presentar-lo com a part d'una 


\section{UNIVERSITAT \\ Escola de Doctorat $\cdot$ ED}

Dr. Vicente Sanz Solana como coautor doy mi autorización a Eugeni Cañas Recacha para la presentación de las siguientes publicaciones como parte de su tesis doctoral.

Relación de publicaciones:

- E. Cañas, V. Sanz, M.J. Orts, E. Sánchez, Post-deposition hea treatment effect on microstructure of suspension plasma sprayed bioactive glass coatings, Surf. Coat. Technol. 371 (2019) 136-142, DOI: 10.1016/j.surfcoat.2018.11.003

También renuncio a poder utilizar estas publicaciones como parte de otra tesis doctoral.

Y para que conste, firmo este documento.

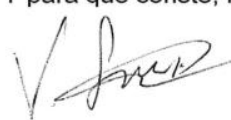

Dr. Vicente Sanz Solana

Castellón de la Plana, 06 de Junio de 2019

Tot això, atenent a l'article 23 de la Normativa dels Estudis de Doctorat, regulats pel RD 99/2011, a la Universitat Jaume I (Aprovada pel Consell de Govern núm. 19 de 26 de Gener de 2012, modificada pe Consell de Govern núm. 29 de 27 de Novembre de $2012 \mathrm{i}$ amb posterior modificació pel Consell de Govern núm. 37 de 25 de Juliol de 2013):

"(...) "Aquelles tesis doctorals que opten per la incorporació d'articles (compendi de publicacions) han

d'ajustar-se, en la mesura que siga possible, a l'estructura següent: Introducció / objectius - Un capítol per article incorporat - Discussió general dels resultats - Conclusions. - Acceplació dels coautors que el doctorand presenta el treball com a tesi i renuncia expressa d'aquests a presentar-lo com a part d'una 


\section{UNIVERSITAT \\ Escola de Doctorat · ED}

Dr. Mónica Vicent Cabedo como coautora doy mi autorización a Eugeni Cañas Recacha para la presentación de las siguientes publicaciones como parte de su tesis doctoral.

Relación de publicaciones:

- E. Cañas, M. Vicent, E. Bannier, P. Carpio, M.J. Orts, E. Sánchez Effect of particle size on processing of bioactive glass powder for atmospheric plasma spraying, J. Eur. Ceram. Soc. 36 (2016) 837-845, DOI: 10.1016/j.jeurceramsoc.2015.09.039

- E. Cañas, M. Vicent, M.J. Orts, R. Moreno, E. Sánchez, Bioactive glass suspensions preparation for suspension plasma spraying J. Eur. Ceram. Soc. 36 (2016) 4281-4290, DOI: 10.1016/j.jeurceramsoc.2016.06.011

- E. Cañas, M. Vicent, M.J. Orts, E. Sánchez, Bioactive glass coatings by suspension plasma spraying from glycolether-based solvent

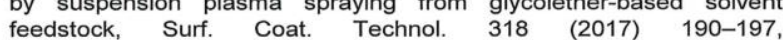
DOI: 10.1016/j.surfcoat.2016.12.060

También renuncio a poder utilizar estas publicaciones como parte de otra tesis doctoral

Y para que conste, firmo este documento

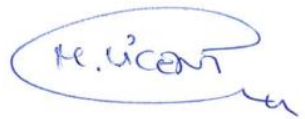

Dr. Mónica Vicent Cabedo

Castellón de la Plana, 06 de Junio de 2019

Tot això, atenent a l'article 23 de la Normativa dels Estudis de Doctorat, regulats pel RD 99/2011, a la Universitat Jaume I (Aprovada pel Consell de Govern núm. 19 de 26 de Gener de 2012, modificada pe Consell de Govern núm. 29 de 27 de Novembre de 2012 i amb posterior modificació pel Consell de Govern núm. 37 de 25 de Juliol de 2013):

"(...)

d'ajustar-se, en la mesura que siga possible, a l'estructura següent: Introducció / objectius - Un capitol per article incorporat - Discussio general dels resultats - Conclusions. -Acceptacio dels coautors que er altra tesi doctoral. 


\section{UNIVERSITAT}

Escola de Doctorat · ED

Dr. Pablo Carpio Cobo como coautor doy mi autorización a Eugeni Cañas Recacha para la presentación de las siguientes publicaciones como parte de su tesis doctoral.

Relación de publicaciones:

- E. Cañas, M. Vicent, E. Bannier, P. Carpio, M.J. Orts, E. Sánchez, Effect of particle size on processing of bioactive glass powder for atmospheric plasma spraying, J. Eur. Ceram. Soc. 36 (2016) 837-845, DOI: 10.1016/j.jeurceramsoc.2015.09.039 También renuncio a poder utilizar estas publicaciones como parte de otra
tesis doctoral.

Y para que conste, firmo este documento.

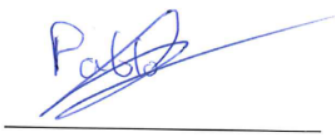

Dr. Pablo Carpio Cobo

Valencia, 11 de junio de 2019

Tot aixó, atenent a l'article 23 de la Normativa dels Estudis de Doctorat, regulats pel RD 99/2011, a la Universitat Jaume I (Aprovada pel Consell de Govern núm. 19 de 26 de Gener de 2012, modificada pe Govern núm. 37 de 25 de 29 de 27 de Novembre de $2012 \mathrm{i}$ amb posterior modificació pel Consell de "(....

"Aquelles tesis doctorals que opten per la incorporació d'articles (compendi de publicacions) han

d'ajustar-se, en la mesura que siga possible, a l'estructura següent: Introducció / objectius - Un capito per article incorporat - Discussió general dels resultats - Conclusions. -Acceptació dels coautors que el altra tesi doctoral ". 


\section{UNIVERSITAT \\ JAUME I}

Escola de Doctorat $\cdot$ ED

Maria Díaz Fernández como coautora doy mi autorización a Eugen Cañas Recacha para la presentación de las siguientes publicaciones como parte de su tesis doctoral.

Relación de publicaciones:

- E. Cañas, M. Díaz, C. Alcázar, M.J. Orts, R. Moreno, E. Sánchez, Comparison of different silica sources in the development of plasma sprayed 45 S5 bioactive glass coatings, J. Non-Cryst. Sol. 544 (2020) 120164, DOI: 10.1016/j.jnoncrysol.2020.120164

También renuncio a poder utilizar estas publicaciones como parte de otra tesis doctoral.

Y para que conste, firmo este documento.

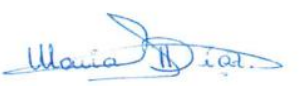

Maria Díaz Fernández

Madrid, 30 de Junio de 2020

of aixó atenent a l'article 23 de la Normativa dels Estudis de Doctorat regulats pel RD 99/2011. a la Universitat Jaume ) (Aprovada pel Consell de Govern num. 19 de 26 de Gener de 2012, modificada pel Consell de Govern núm. 29 de 27 de Novembre de 2012 i amb posterior modificacio pel Consell de Sovern núm. 37 de 25 de Juliol de 2013)

"Aquelles lesis doctorals que opten per la incorporació d'articles (compendi de publicacions) han

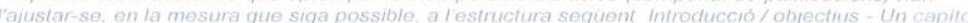

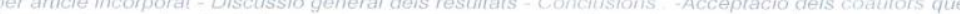
toctorand presenta el treball com a tesi I renuncra expressa d'aquests a presentar-to com a part d'una altra tesi doctoral 


\section{UNIVERSITAT}

Escola de Doctorat · ED

Carmen Alcázar Rodrigo como coautora doy mi autorización a Eugeni Cañas Recacha para la presentación de las siguientes publicaciones como parte de su tesis doctoral.

Relación de publicaciones:

- E. Cañas, M. Díaz, C. Alcázar, M.J. Orts, R. Moreno, E. Sánchez, Comparison of different silica sources in the development of plasma sprayed $45 S 5$ bioactive glass coatings, J. Non-Cryst. Sol. 544 (2020) 120164, DOI: 10.1016/j.jnoncrysol.2020.120164

También renuncio a poder utilizar estas publicaciones como parte de otra tesis doctoral.

Y para que conste, firmo este documento.

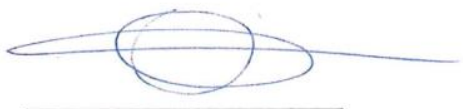

Carmen Alcázar Rodrigo

Madrid, 30 de Junio de 2020 Tot aixó, atenent a l'article 23 de la Normativa dels Estudis de Doctorat, regulats pel RD 99/2011, a la Universitat Jaume I (Aprovada pel Consell de Govern núm. 19 de 26 de Gener de 2012, modificada pel Govern num 37 de 25 de Juliot de 2013):

$(1)$

"Aquelles tesis doctorals que opten per la incorporació d'articles (compendi de publicacions) han d'austar-se en la mesura que siga possible a l'estructura següent: Introducció / objectius - Un capitol per articte incomprat - Discussió general dels resullats - Conclusions. Acceptació dels coautors que doctorand presenta el treball com a tesi i renúncia expressa d'aquests a presentar-lo com a part d'una altra tesi doctoral. 


\section{UNIVERSITAT \\ Escola de Doctorat · ED}

Dr. Rodrigo Moreno Botella como coautor doy mi autorización a Eugeni Cañas Recacha para la presentación de las siguientes publicaciones como parte de su tesis doctoral.

Relación de publicaciones:

- E. Cañas, M. Vicent, M.J. Orts, R. Moreno, E. Sánchez, Bioactive glass suspensions preparation for suspension plasma spraying, J. Eur. Ceram. Soc. 36 (2016) 4281-4290

10.1016/j.jeurceramsoc.2016.06.011

- E. Cañas, M. Díaz, C. Alcázar, M.J. Orts, R. Moreno, E. Sánchez, Comparison of different silica sources in the development of plasma sprayed 45 S 5 bioactive glass coatings, J. Non-Cryst. Sol. 544 (2020) 120164, DOI: 10.1016/j.jnoncrysol.2020.120164

También renuncio a poder utilizar estas publicaciones como parte de otra tesis doctoral.

Y para que conste, firmo este documento.

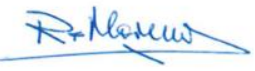

Dr. Rodrigo Moreno Botella

Madrid, 30 de Junio de 2020

Tot això, atenent a l'article 23 de la Normativa dels Estudis de Doctorat, regulats pel RD 99/2011, a la Universitat Jaume I (Aprovada pel Consell de Govern núm. 19 de 26 de Gener de 2012, modificada pel Consell de Govern num. 29 de 27 de Novenbre de 2012 i amb posterior modificací pei Consell de Govern num. 37 de 25 de Juliol de 2013): "(...)

"Aquelles tesis doctorals que opten per la incorporació d'articles (compendi de publicacions) han d'ajustar-se, en la mesura que siga possible, a l'estructura següent: Introduccio / objectius - Un capitol per article incorporat - Discussió general dels resultats - Conclusions. Acceptació dels coautors que doctorand presenta el treball com a tesi i renúncia expressa d'aquests a presentar-lo com a part d'una altra tesi doctoral. 


\section{UNIVERSITAT}

Escola de Doctorat · ED

Ms. Alina Grünewald as co-author I authorise Eugeni Cafias Recacha to include the publications listed below in his doctoral thesis.

List of publications:

- E Cañas, A Grünewald, R. Detsch, M.J. Orts, E. Sánchez, A.R. Boccaccini, In vitro study of bioactive glass coatings obtained by atmospheric plasma spraying, Bol. Soc. Esp. Ceram. Vidr. (2020) In Press, DOI: 10.1016/j.bsecv.2020.06.004

In addition, I waive the right to use those articles as part of any other doctoral thesis.

Signed,

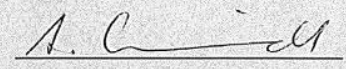

Ms. Alina Grünewald

Erlangen, Nov 12, 202

In accordance with article 23 of the Regulation of Doctoral Studies, regulated by RD 99/2011, at the Universitat Jaume I (Approved by the Governing Council No. 19 of January 26, 2012, modified by the Governing Council no. 29 of N A "Those doctoral theses that sut for the anendment by the Governing Council No. 37 of July 25, 2013): (....) those doctoral theses that opt for the incorporation of articles (compendium of publications) must include the PhD thesis" 


\section{UNIVERSITAT}

Escola de Doctorat . ED

Dr.-Ing. Rainer Detsch as co-author I authorise Eugeni Cañas Recacha to include the publications listed below in his doctoral thesis.

List of publications:

- E. Cañas, A. Grünewald, R. Detsch, M.J. Orts, E. Sánchez, A.R. Boccaccini, In vitro study of bioactive glass coatings obtained by atmospheric plasma spraying. Bol. Soc. Esp. Ceram. Vidr. (2020) In Press, DOI: 10.1016/j.bsecv.2020.06.004

In addition, I waive the right to use those articles as part of any other doctoral thesis.

Signed,

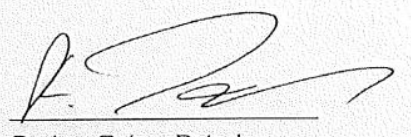

Dr.-Ing. Rainer Detsch

Erlangen, November, 11, 2020

In accordance with article 23 of the Regulation of Doctoral Studies, regulated by RD 99/2011, at the Universita Joume I (Approved by the Governing Council No. 19 of January 26, 2012, modified by the Governing Council no. 29 of November 27, 2012 and subsequent amendment by the Governing Council No. 37 of July 25, 2013): "(..) "Those doctoral theses that opt for the incorporation of articles (compendium of publications) must include the acceptance of the co-authors of the publications that have waived the right to present them as a part of another PhD thesis"

Mit CamScanner qescannt 


\section{UNIVERSITAT \\ Escola de Doctorat · ED}

Prof. Dr.-Ing. habil. Aldo R. Boccaccini as co-author I authorise Eugeni Canas Recacha to include the publications listed below in his doctoral thesis.

List of publications:

- E. Cañas, M.J. Orts, A.R. Boccaccini, E. Sánchez, Solution Precursor Plasma Spraying (SPPS): A novel and simple process to obtain bioactive glass coatings, Mater. Lett. 223 (2018) 198-202, DOI: 10.1016/j.matlet.2018.04.031

- E. Cañas, M.J. Orts, A.R. Boccaccini, E. Sánchez, Microstructural and in vitro characterization of $45 \mathrm{~S} 5$ bioactive glass coatings deposited by solution precursor plasma spraying (SPPS), Surf. Coat. Technol. 371 (2019) 151-160, DOI: 10.1016/j.surfcoat.2018.12.057

- E. Cañas, A. Grünewald, R. Detsch, M.J. Orts, E. Sánchez, A.R. Boccaccini, In vitro study of bioactive glass coatings obtained by atmospheric plasma spraying, Bol. Soc. Esp. Ceram. Vidr. (2020) In Press, DOI: 10.1016/j.bsecv.2020.06.004

In addition, I waive the right to use those articles as part of any other doctoral thesis.

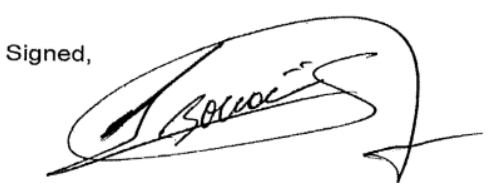

Prof. Dr.-Ing. habil. Aldo R. Boccaccin

Erlangen, Month Day, Year

$$
\text { November, } 2020
$$

In accordance with article 23 of the Regulation of Doctoral Studies, regulated by RD 99/2011, at the Universitat Jaume I (Approved by the Governing Council No. 19 of January 26, 2012, modified by the Governing Council 29 of November 27,2012 and subsequent amendment by the Governing Council No. 37 of July 25, 2013):" no. "Those doctoral theses that opt for the incorporation of articles (compendium of publications) must inc:"(..) acceptance of the co-authors of the publications that have waived the right to present them as a part of ane PhD thesis" 


\section{UNIVERSITAT}

Escola de Doctorat $\cdot$ ED

Dr. María José Orts Tarí como coautora doy mi autorización a Eugeni Cañas Recacha para la presentación de las siguientes publicaciones como parte de su tesis doctoral.

Relación de publicaciones:

- E. Cañas, M. Vicent, E. Bannier, P. Carpio, M.J. Orts, E. Sánchez, Effect of particle size on processing of bioactive glass powder for atmospheric plasma spraying, J. Eur. Ceram. Soc. 36 (2016) 837-845 DOI: 10.1016/j.jeurceramsoc.2015.09.039

- E. Cañas, M. Vicent, M.J. Orts, R. Moreno, E. Sánchez, Bioactive glass suspensions preparation for suspension plasma spraying, J. Eur. Ceram. Soc. $36 \quad$ (2016) 4281-4290, DOI: 10.1016/j.jeurceramsoc.2016.06.011

- E. Cañas, M. Vicent, M.J. Orts, E. Sánchez, Bioactive glass coating by suspension plasma spraying from glycolether-based solven feedstock, Surf. Coat. Technol. 318 (2017) 190-197, DOI: 10.1016/j.surfcoat.2016.12.060

También renuncio a poder utilizar estas publicaciones como parte de otra tesis doctoral.

Y para que conste, firmo este documento.

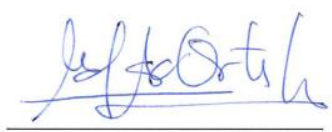

Dr. María José Orts Tarí

Castellón de la Plana, 12 de noviembre de 2020 Tot això, atenent a l'article 23 de la Normativa dels Estudis de Doctorat, regulats pel RD 99/2011, a la Universitat Jame (Aprova pel Conselle Govern núm. 19 de 26 de Gener de 2012, modificada $p$ 37 de 25 de Juliol de 2013): "(...)

"Aquelles tesis doctorals que opten per la incorporació d'articles (compendi de publicacions) han d'ajustar-se en la mesura que siga possible, a l'estructura següent: Introducció / objectius - Un capitol per article incorporat - Discussió general dels resultats - Conclusions. Acceptació dels coautors que doctorand presenta el treball com a tesi i renúncia expressa d'aquests a presentar-lo com a part d'una altra tesi doctoral. 


\section{UNIVERSITAT}

Escola de Doctorat · ED

Dr. María José Orts Tarí como coautora doy mi autorización a Eugeni Cañas Recacha para la presentación de las siguientes publicaciones como parte de su tesis doctoral.

Relación de publicaciones:

- E. Cañas, M.J. Orts, A.R. Boccaccini, E. Sánchez, Solution Precursor Plasma Spraying (SPPS): A novel and simple process to obtain bioactive glass coatings, Mater. Lett. 223 (2018) 198-202, DOI: 10.1016/j.matlet.2018.04.031

- E. Cañas, V. Sanz, M.J. Orts, E. Sánchez, Post-deposition hea treatment effect on microstructure of suspension plasma sprayed bioactive glass coatings, Surf. Coat. Technol. 371 (2019) 136-142, DOI: 10.1016/j.surfcoat.2018.11.003

- E. Cañas, M.J. Orts, A.R. Boccaccini, E. Sánchez, Microstructural and in vitro characterization of $45 \mathrm{~S} 5$ bioactive glass coatings deposited by solution precursor plasma spraying (SPPS), Surf. Coat. Technol. 371 (2019) 151-160, DOI: 10.1016/j.surfcoat.2018.12.057

También renuncio a poder utilizar estas publicaciones como parte de otra tesis doctoral.

Y para que conste, firmo este documento.

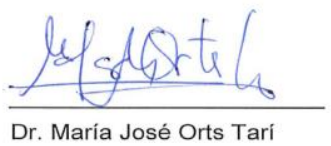

Castellón de la Plana, 12 de noviembre de 2020 Tot això, atenent a l'article 23 de la Normativa dels Estudis de Doctorat, regulats pel RD 99/2011, a la
Universitat Jaume I (Aprovada pel Consell de Govern núm. 19 de 26 de Gener de 2012, modificada pel Consell de Govern núm. 29 de 27 de Novembre de $2012 \mathrm{i}$ amb posterior modificació pel Consell de Govern núm. 37 de 25 de Juliol de 2013):

Gover
"(...)
"Aqueth

"(...) d'ajustar-se, en la mesura que siga possible, a l'estructura següent: Introducció / objectius - Un capitol per article incorporat - Discussió general dels resultats - Conclusions doctorand presenta el treball com a tesi i renúncia expressa d'aquests a presentar-lo com a part d'un altra tesi doctoral. 


\section{UNIVERSITAT}

Escola de Doctorat · ED

Dr. María José Orts Tarí como coautora doy mi autorización a Eugeni Cañas Recacha para la presentación de las siguientes publicaciones como parte de su tesis doctoral.

Relación de publicaciones:

- E Cañas, M. Díaz, C Alcázar, M.J. Orts, R. Moreno, E. Sánchez, Comparison of different silica sources in the development of plasma sprayed $45 \mathrm{~S} 5$ bioactive glass coatings, J. Non-Cryst. Sol. 544 (2020) 120164, DOI: 10.1016/j.jnoncrysol.2020.120164

- E. Cañas, A. Grünewald, R. Detsch, M.J. Orts, E. Sánchez, A.R. Boccaccini, In vitro study of bioactive glass coatings obtained by atmospheric plasma spraying, Bol. Soc. Esp. Ceram. Vidr. (2020) In Press, DOI: 10.1016/j.bsecv.2020.06.004

También renuncio a poder utilizar estas publicaciones como parte de otra tesis doctoral.

Y para que conste, firmo este documento.

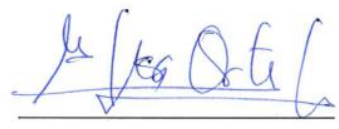

Dr. María José Orts Tarí

Castellón de la Plana, 12 de noviembre de 2020 Tot això, atenent a l'article 23 de la Normativa dels Estudis de Doctorat, regulats pel RD 99/2011, a la Universitat Jaun (Aprovada pel Con Govern núm. 37 de 25 de Juliol de 2013):

"(...)

"Aquelles tesis doctorals que opten per la incorporació d'articles (compendi de publicacions) han d'ajustar-se en la mesura que siga possible, a l'estructura següent: Introducció / objectius - Un capitol per article incorporat - Discussió general dels resultats - Conclusions. Acceptació dels coautors que doctorand presenta el treball com a tesi i renúncia expressa d'aquests a presentar-lo com a part d'una altra tesi doctoral. 


\section{UNIVERSITAT}

Escola de Doctorat · ED

Dr. Enrique Sánchez Vilches como coautor doy mi autorización a Eugeni Cañas Recacha para la presentación de las siguientes publicaciones como parte de su tesis doctoral.

Relación de publicaciones:

- E. Cañas, M. Vicent, E. Bannier, P. Carpio, M.J. Orts, E. Sánchez, Effect of particle size on processing of bioactive glass powder for atmospheric plasma spraying, J. Eur. Ceram. Soc. 36 (2016) 837-845 DOI: 10.1016/j.jeurceramsoc.2015.09.039

- E. Cañas, M. Vicent, M.J. Orts, R. Moreno, E. Sánchez, Bioactive glass suspensions preparation for suspension plasma spraying, J. Eur. Ceram. Soc. 36 (2016) 4281-4290, DOI: 10.1016/j.jeurceramsoc. 2016.06.011

- E. Cañas, M. Vicent, M.J. Orts, E. Sánchez, Bioactive glass coatings by suspension plasma spraying from glycolether-based solvent feedstock, Surf. Coat. Technol. 318 (2017) 190-197, DOI: 10.1016/j.surfcoat.2016.12.060

También renuncio a poder utilizar estas publicaciones como parte de otra tesis doctoral.

Y para que conste, firmo este documento.

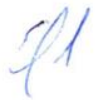

Dr. Enrique Sánchez Vilches

Castellón de la Plana, 12 de noviembre de 2020

Tot això, atenent a l'article 23 de la Normativa dels Estudis de Doctorat, regulats pel RD 99/2011, a la Universitat Jaume I (Aprovada pel Consell de Govern núm. 19 de 26 de Gener de 2012, modificada pel Consell de Govern núm. 29 de 27 de Novembre de 2012 i amb posterior modificació pel Consell de Govern núm. 37 de 25 de Juliol de 2013):

"(...)

"Aquelles tesis doctorals que opten per la incorporació d'articles (compendi de publicacions) han d'ajustar-se en la mesura que siga possible, a l'estructura següent: Introducció / objectius - Un capitol per article incorporat - Discussió general dels resultats - Conclusions. -Acceptació dels coautors que doctorand presenta el treball com a tesi i renúncia expressa d'aquests a presentar-lo com a part d'una altra tesi doctoral. 


\section{UNIVERSITAT}

Escola de Doctorat $\cdot$ ED

Dr. Enrique Sánchez Vilches como coautor doy mi autorización a Eugeni Cañas Recacha para la presentación de las siguientes publicaciones como parte de su tesis doctoral.

Relación de publicaciones:

- E. Cañas, M.J Orts, A.R. Boccaccini, E Sánchez, Solution Precursor Plasma Spraying (SPPS): A novel and simple process to obtain bioactive glass coatings, Mater. Lett. 223 (2018) 198-202 DOI: 10.1016/j.matlet.2018.04.031

- E. Cañas, V. Sanz, M.J. Orts, E. Sánchez, Post-deposition hea treatment effect on microstructure of suspension plasma sprayed bioactive glass coatings, Surf. Coat. Technol. 371 (2019) 136-142 DOI: 10.1016/j.surfcoat.2018.11.003

- E. Cañas, M.J. Orts, A.R. Boccaccini, E. Sánchez, Microstructural and in vitro characterization of $45 \mathrm{~S} 5$ bioactive glass coatings deposited by solution precursor plasma spraying (SPPS), Surf. Coat. Technol. 371 (2019) 151-160, DOI: 10.1016/j.surfcoat.2018.12.057

También renuncio a poder utilizar estas publicaciones como parte de otra tesis doctoral.

Y para que conste, firmo este documento.

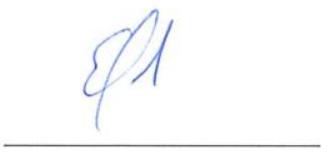

Dr. Enrique Sánchez Vilches

Castellón de la Plana, 12 de noviembre de 2020

Tot això, atenent a l'article 23 de la Normativa dels Estudis de Doctorat, regulats pel RD 99/2011, a la Universitat Jaume I (Aprovada pel Consell de Govern núm. 19 de 26 de Gener de 2012, modificada pe Consell de Govern núm. 37 de 25 de Juliol de 2013): "(...)

"Aquelles tesis doctorals que opten per la incorporació d'articles (compendi de publicacions) han d'ajustar-se en la mesura que siga possible a l'estructura següent: Introducció / objectius - Un capítol per article incorporat - Discussió general dels resultats - Conclusions. Acceptació dels coautors que doctorand presenta el treball com a tesi i renúncia expressa d'aquests a presentar-lo com a part d'una altra tesi doctoral." 


\section{UNIVERSITAT}

Escola de Doctorat · ED

Dr. Enrique Sánchez Vilches como coautor doy mi autorización a Eugeni Cañas Recacha para la presentación de las siguientes publicaciones como parte de su tesis doctoral.

Relación de publicaciones:

- E. Cañas, M. Díaz, C. Alcázar, M.J. Orts, R. Moreno, E. Sánchez, Comparison of different silica sources in the development of plasma sprayed $45 \mathrm{~S} 5$ bioactive glass coatings, J. Non-Cryst. Sol. 544 (2020) 120164, DOI: 10.1016/j.jnoncrysol.2020.120164

- E. Cañas, A. Grünewald, R. Detsch, M.J. Orts, E. Sánchez, A.R. Boccaccini, In vitro study of bioactive glass coatings obtained by atmospheric plasma spraying, Bol. Soc. Esp. Ceram. Vidr. (2020) In Press, DOI: 10.1016/j.bsecv.2020.06.004

También renuncio a poder utilizar estas publicaciones como parte de otra tesis doctoral.

Y para que conste, firmo este documento.

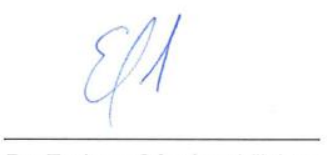

Dr. Enrique Sánchez Vilches

Castellón de la Plana, 12 de noviembre de 2020 Tot això, atenent a l'article 23 de la Normativa dels Estudis de Doctorat, regulats pel RD 99/2011, a la
Universitat Jaume I (Aprovada pel Consell de Govern núm. 19 de 26 de Gener de 2012, modificada pel Consell de Govern núm. 29 de 27 de Novembre de 2012 i amb posterior modificació pel Consell de Govern núm. 37 de 25 de Juliol de 2013):

"(...)

"Aquelles tesis doctorals que opten per la incorporació d'articles (compendi de publicacions) han d'ajustar-se, en la mesura que siga possible, a l'estructura següent: Introducció / objectius - Un capíto per article incorporat - Discussió general dels resultats - Conclusions -Acceptació dels coautors que doctorand presenta el treball com a tesi i renúncia expressa d'aquests a presentar-lo com a part d'un altra tesi doctoral. 



\section{Bibliografía}



[1] S.V. Dorozhkin, Bioceramics of calcium orthophosphates, Biomater. 31 (2010) 1465-1485.

[2] L.L. Hench, Bioceramics, J. Am. Ceram. Soc. 81 (1998) 1705-1728.

[3] R.H. Doremus, Bioceramics: review, J. Mater. Sci. 27 (1992) 285-297.

[4] J. Park, Bioceramics. Properties, characterizations and applications, first ed., Springer, The USA, 2008.

[5] V.A. Dubok, Bioceramics-yesterday, today, tomorrow, Powder Metall. Metal Ceram. 39 (2000) 381-394.

[6] S.M. Best, A.E. Porter, E.S. Thian, J. Huang, Bioceramics: past, present and for the future, J. Eur. Ceram. Soc. 28 (2008) 1319-1327.

[7] D. Arcos, M. Vallet-Regí, Bioceramics for drug delivery, Acta Mater. 61 (2013) 890-911.

[8] J.F. Shackelford, Bioceramics, first ed., Gordon and Breach Science Publishers, The Netherlands, 2005.

[9] L.L. Hench, Bioceramics: from concept to clinic, J. Am. Ceram. Soc. 74 (1991) 1487-1510.

[10] L.L. Hench, An introduction to bioceramics, second ed., Imperial College Press, Great Britain, 2013.

[11] T. Kokubo, Bioceramics and their clinical applications, first ed., Woodhead Publishing, Great Britain, 2008.

[12] A. Ravaglioli, A. Krajewski, Bioceramics: materials, properties and applications, second ed., Springer Science+Business Media, Great Britain, 1992.

[13] División de recubrimientos biomédicos de la empresa APS Materials Inc.: https://apsmaterials.com/biomedical/hydroxyapatite-coating/

[14] K. Gurbinder, Bioactive glasses-Potential biomaterials for future therapy, first ed., Springer Nature, Switzerland, 2017.

[15] L.L. Hench, The story of Bioglass $\AA$, J. Mater. Sci. Mater. Med. 17 (2006) 967-978.

[16] J.A. Juhasz, S.M. Best, Bioactive ceramics: processing, structures and properties, J. Mater. Sci. 47 (2012) 610-624.

[17] J.R. Jones, A.G. Clare, Bio-glasses, an introduction, first ed., John Wiley and Sons, Great Britain, 2012.

[18] M. Brink, T. Turunen, R. Happonen, A. Yli-Urpo, Compositional dependence of bioactivity of glasses in the system $\mathrm{Na}_{2} \mathrm{O}-\mathrm{K}_{2} \mathrm{O}-\mathrm{MgO}-$ $\mathrm{CaO}-\mathrm{B}_{2} \mathrm{O}_{3}-\mathrm{P}_{2} \mathrm{O}_{5}-\mathrm{SiO}_{2}$, J. Biomed. Mater. Res. 37 (1997) 114-121. 
[19] A. Lucas-Girot, F.Z. Mezahi, M. Mami, H. Oudadesse, A. Harabi, M.L. Floch, Sol-gel synthesis of a new composition of bioactive glass in the quaternary system $\mathrm{SiO}_{2}-\mathrm{CaO}-\mathrm{Na}_{2} \mathrm{O}-\mathrm{P}_{2} \mathrm{O}_{5}$ comparison with melting method, J. Non-Cryst. Solids 357 (2011) 3322-3327.

[20] P. Sepulveda, J.R. Jones, L.L. Hench, Characterization of melt-derived $45 \mathrm{~S} 5$ and sol-gel derived 58S bioactive glasses, J. Biomed. Mater. Res. 58 (2001) 734-740.

[21] P. Sepulveda, J.R. Jones, L.L. Hench, In vitro dissolution of meltderived 45S5 and sol-gel derived 58S bioactive glasses, J. Biomed. Mater. Res. 61 (2002) 301-311.

[22] Y. Zhou, H. Li, K. Lin, W. Zhai, W. Gu, J. Chang, Effect of heat treatment on the properties of $\mathrm{SiO}_{2}-\mathrm{CaO}-\mathrm{MgO}-\mathrm{P}_{2} \mathrm{O}_{5}$ bioactive glasses, J. Mater. Sci. Mater. Med. 23 (2012) 2101-2108.

[23] A. Saboori, M. Rabiee, F. Moztarzadeh, M. Sheikhi, M. Tahriri, M. Karimi, Synthesis, characterization and in vitro bioactivity of sol-gel derived $\mathrm{SiO}_{2}-\mathrm{CaO}-\mathrm{P}_{2} \mathrm{O}_{5}-\mathrm{MgO}$ bioglass, Mater. Sci. Eng. C 29 (2009) 335-340.

[24] Q.Z. Chen, Y. Li, L.Y. Jin, J.M.W. Quinn, P.A. Komesaroff, A new solgel process for producing $\mathrm{Na}_{2} \mathrm{O}-$ containing bioactive glass ceramic, Acta Biomater. 6 (2010) 4143-4153.

[25] J. Ma, C.Z. Chen, D.G. Wang, X.G. Meng, J.Z. Shi, Influence of the sintering temperature on the structural feature and bioactivity of sol-gel derived $\mathrm{SiO}_{2}-\mathrm{CaO}-\mathrm{P}_{2} \mathrm{O}_{5}$ bioglass, Ceram. Inter. 36 (2010) 1911-1916.

[26] H. Pirayesh, J.A. Nychka, Sol-gel synthesis of bioactive glass-ceramic $45 \mathrm{~S} 5$ and its in vitro dissolution and mineralization behaviour, J. Am. Ceram. Soc. 96 (2013) 1643-1650.

[27] O. Bretcanu, X. Chatzistavrou, K. Paraskevopoulos, R. Conradt, I. Thompson, A.R. Boccaccini, Sintering and crystallisation of 4555 Bioglass ${ }^{\circledR}$ powder, J. Eur. Ceram. Soc. 29 (2009) 3299-3306.

[28] A.R. Boccaccini, Q. Chen, L. Lefebvre, L. Gremillard, J. Chevalier, Sintering, crystallisation and biodegradation behaviour of Bioglass ${ }^{\circledR}-$ derived glass-ceramic, Faraday Discuss. 136 (2007) 27-44.

[29] Q.Z. Chen, K. Rezwan, V. Françon, D. Armitage, S.N. Nazhat, F.H. Jones, A.R. Boccaccini, Surface functionalization of Bioglass ${ }^{\circledR}-$ derived porous scaffolds, Acta Biomater. 3 (2007) 551-562.

[30] J.M. Fernández Navarro, El vidrio (The glass), third ed., Consejo Superior de Investigaciones Cerámicas (CSIC), Spain, 2003.

[31] K.E. Wallace, R.G. Hill, J.T. Pembroke, C.J. Brown, P.V. Hatton, Influence of sodium oxide content on bioactive glass properties, J. Mater. Sci. Mater. Med. 10 (1999) 697-701. 
[32] M.D. O'Donnell, S.J. Watts, R.G. Hill, R.V. Law, The effect of phosphate content on the bioactivity of soda-lime-phosphosilicate glasses, J. Mater. Sci. Mater. Med. 20 (2009) 1611-1618.

[33] D.S. Brauer, N. Karpukhina, M.D. O'Donnell, R.V. Law, R.G. Hill, Fluoride-containing bioactive glasses: effect of glass design and structure on degradation, $\mathrm{pH}$ and apatite formation in simulated body fluid, Acta Biomater. 6 (2010) 3275-3282.

[34] J.F. Shackelford, R.H. Doremus, Ceramic and glass materials: structure, properties and processing, first ed., Springer Science+Business Media, The USA, 2008.

[35] V.J. Shirtliff, L.L. Hench, Bioactive material for tissue engineering, regeneration and repair, J. Mater. Sci. 38 (2003) 4697-4707.

[36] V. Cannillo, A. Sola, Potassium-based composition for a bioactive glass, Ceram. Inter. 5 (2009) 3389-3393.

[37] D. Bellucci, V. Cannillo, G. Ciardelli, P. Gentile, A. Sola, Potassium based bioactive glass for bone tissue engineering, Ceram. Inter. 36 (2010) 2449-2453.

[38] D. Bellucci, V. Cannillo, A. Sola, A new potassium-based bioactive glass: sintering behaviour and possible applications for bioceramic scaffolds, Ceram. Inter. 37 (2011) 145-157.

[39] R. Li, A.E. Clarck, L.L. Hench, An investigation of bioactive glass powders by sol-gel processing, J. Appl. Biomater. 2 (1991) 231-239.

[40] J. Zhong, D.C. Greenspan, Processing and properties of sol-gel bioactive glasses, J. Biomed. Mater. Res. 53 (2000) 694-701.

[41] J.R. Jones, Review of bioactive glasses: from Hench to hybrids, Acta Biomater. 9 (2013) 4457-4486.

[42] P. Balasubramanian, T. Büttner, V.M. Pacheco, A.R. Boccaccini, Boroncontaining bioactive glasses in bone and soft tissue engineering, J. Eur. Ceram. Soc. 38 (2018) 855-869.

[43] J. Ning, A. Yao, D. Wang, W. Huang, H. Fu, X. Liu, X. Jiang, X. Zhang, Synthesis and in vitro bioactivity of a borate-based bioglass, Mater. Lett. 61 (2007) 5223-5226.

[44] A. Balamurugan, G. Balossier, S. Kannan, J. Michel, A.H.S. Rebelo, J.M.F. Ferreira, Development and in vitro characterization of sol-gel derived $\mathrm{CaO}-\mathrm{P}_{2} \mathrm{O}_{5}-\mathrm{SiO}_{2}-\mathrm{ZnO}$ bioglass, Acta Biomater. 3 (2007) 255262.

[45] A. Moghanian, A. Sedghi, A. Ghorbanoghli, E. Salari, The effect of magnesium content on in vitro bioactivity, biological behavior and 
antibacterial activity of sol-gel derived $58 \mathrm{~S}$ bioactive glass, Ceram. Inter. 44 (2018) 9422-9432.

[46] G.S. Lázaro, S.C. Santos, C.X. Resende, E.A. dos Santos, Individual and combined effects of the elements $\mathrm{Zn}, \mathrm{Mg}$ and $\mathrm{Sr}$ on the surface reactivity of a $\mathrm{SiO}_{2} \cdot \mathrm{CaO} \cdot \mathrm{Na}_{2} \mathrm{O} \cdot \mathrm{P}_{2} \mathrm{O}_{5}$ bioglass system, J. Non-Cryst. Sol. 386 (2014) 19-28.

[47] D. Bellucci, V. Cannillo, A novel bioactive glass containing strontium and magnesium with ultra-high crystallization temperature, Mater. Lett. 213 (2018) 67-70.

[48] F. Sharifianjazi, N. Parvin, M. Tahriri, Synthesis and characteristics of sol-gel bioactive $\mathrm{SiO}_{2}-\mathrm{P}_{2} \mathrm{O}_{5}-\mathrm{CaO}-\mathrm{Ag}_{2} \mathrm{O}$ glasses, J. Non-Cryst. Sol. 476 (2017) 108-113.

[49] A. Vulpoi, L. Baia, S. Simon, V. Simon, Silver effect on the structure of $\mathrm{SiO}_{2}-\mathrm{CaO}-\mathrm{P}_{2} \mathrm{O}_{5}$ ternary system, Mater. Sci. Eng. C, 32 (2012) 178-183.

[50] A. Hoppe, R. Meszaros, C. Stähli, S. Romeis, J. Schmidt, W. Peukert, B. Marelli, S.N. Nazhat, L. Wondraczek, J. Lao, E. Jallot, A.R. Boccaccini, In vitro reactivity of $\mathrm{Cu}$ doped $45 \mathrm{~S} 5$ Bioglass ${ }^{\circledR}$ derived scaffolds for bone tissue engineering, J. Mater. Chem. B, 1 (2013) 56595674.

[51] C. Stähli, M. James-Bhasin, A. Hoppe, A.R. Boccaccini, S.N. Nazhat, Effect of ion release from Cu-doped 45S5 Bioglass ${ }^{\circledR}$ on 3D endothelial cell morphogenesis, Acta Biomater. 19 (2015) 15-22.

[52] W. Cao, L.L. Hench, Bioactive materials, Ceram. Inter. 22 (1996) 493 507.

[53] F. Baino, G. Novajra, V. Miguez-Pacheco, A.R. Boccaccini, C. VitaleBrovarone, Bioactive glasses: Special applications outside the skeletal system, J. Non-Cryst. Sol. 432 (2016) 15-30.

[54] V. Miguez-Pacheco, L.L. Hench, A.R. Boccaccini, Bioactive glasses beyond bone and teeth: emerging applications in contact with soft tissues, Acta Biomater. 13 (2015) 1-15.

[55] L. Sun, C.C. Berndt, K.A. Gross, A. Kucuk, Material fundamentals and clinical performance of plasma-sprayed hydroxyapatite coatings: A review, J. Biomed. Mater. Res. 58 (2001) 570-592.

[56] P. Cheang, K.A. Khor, Addressing processing problems associated with plasma spraying of hydroxyapatite coatings, Biomater. 17 (1996) 537544.

[57] G. Goller, H. Demirkiran, F.N. Oktar, E. Demirkessen, Processing and characterization of bioglass reinforced hydroxyapatite composites, Ceram. Inter. 29 (2003) 721-724. 
[58] L. Lefebvre, J. Chevalier, L. Gremillard, R. Zenati, G. Thollet, D. Bernache-Assolant, A. Govin, Structural transformations of bioactive glass 45S5 with thermal treatments, Acta Mater. 55 (2007) 3305-3313.

[59] P.N. De Aza, A.H. De Aza, P. Pena, S. De Aza, Bioactive glasses and glass-ceramics, Bol. Soc. Esp. Ceram. Vidr. 46 (2007) 45-55.

[60] P. Fauchais, A. Vardelle, B. Dussoubs, Quo vadis thermal spraying?, J. Therm. Spray Technol. 10 (2001) 44-66.

[61] J.R. Davis, Handbook of thermal spray technology, first ed., ASM International, The USA, 2004.

[62] L. Pawlowski, The science and engineering of thermal spray coatings, second ed., John Wiley and Sons, Great Britain, 2008.

[63] R.W. Smith, R. Knight, Thermal spraying I: Powder consolidation-From coating to forming, J. Miner. Metal. Mater. Soc. 49 (1995) 32-39.

[64] K.N. Strafford, Surface Engineering: Processes and Applications, first ed., CRC Press, Australia, 1994.

[65] M. Vicent, E. Bannier, R. Moreno, M.D. Salvador, E. Sánchez, Atmospheric plasma spraying coatings from alumina-titania feedstock comprising bimodal particle size distributions, J. Eur. Ceram. Soc. 33 (2013) 3313-3324.

[66] K. Patel, C.S. Doyle, D. Yonekura, B.J. James, Effect of surface roughness parameters on thermally sprayed PEEK coatings, Surf. Coat. Technol. 204 (2010) 3567-3572.

[67] R.S. Lima, A. Kucuk, P.Berndt, Evaluation of microhardness and elastic modulus of thermally sprayed nanostructured zirconia coatings, Surf. Coat. Technol. 135 (2001) 166-172.

[68] M. Mellali, A. Grimaud, A.C. Leger, P. Fauchais, J. Lu, Alumina grit blasting parameters for surface preparation in the plasma spraying operation, J. Therm. Spray Technol. 6 (1997) 217-227.

[69] R.S.C. Paredes, S.C. Amico, A.S.C.M. d'Oliveira, The effect of roughness and pre-heating of the substrate on the morphology of aluminium coatings deposited by thermal spraying, Surf. Coat. Technol. 200 (2006) 3049-3045.

[70] C.C. Berndt, G.N. Haddad, A.J.D. Farmer, K.A. Gross, Thermal spraying for bioceramic applications, Mater. Forum 14 (1990) 161-173.

[71] C.R.C. Lima, J.M. Guilemany, Adhesion improvements of Thermal Barrier Coatings with HVOF thermally sprayed bond coats, Surf. Coat. Technol. 201 (2007) 4694-4701. 
[72] H. Kurzweg, R.B. Heimann, T. Troczynski, M.L. Wayman, Development of plasma-sprayed bioceramic coatings with bondcoats based on titania and zirconia, Biomater. 19 (1998) 1507-1511.

[73] P.Cheang, K.A. Khor, L.L. Teoh, S.C. Tam, Pulsed laser treatment of plasma-sprayed hydroxyapatite coatings, Biomater. 17 (1996) 19011904.

[74] A.K. Sharma, R. Krishnamurthy, Microwave processing of sprayed alumina composite for enhanced performance, J. Eur. Ceram. Soc. 22 (2002) 2849-2860.

[75] J. Colmenares-Agudo, S. Zhao, C. Young, A. Orlov, The effects of thermal spray technique and post-deposition treatment on the photocatalytic activity of TiO2 coatings, Surf. Coat. Technol. 204 (2009) 423-427.

[76] R. González, M. Cadenas, R. Fernández, J.L. Cortizo, E. Rodríguez, Wear behaviour of flame sprayed NiCrBSi coating remelted by flame or by laser, Wear 262 (2007) 301-307.

[77] T. Troczynski, Q. Yang, G. John, Post-deposition treatment of zirconia thermal barrier coatings using sol-gel alumina, J. Therm. Spray. Technol. 8 (1999) 229-234.

[78] J.K.N. Murthy, D.S. Rao, B. Venkataraman, Effect of grinding on the erosion behaviour of a WC-Co-Cr coating deposited by HVOF and detonation gun spray processes, Wear, 249 (2001) 592-600.

[79] C. Wen, Surface coating and modification of metallic biomaterials, first ed., Woodhead Publishing, Great Britain, 2015.

[80] J. Colmenares-Angulo, R. Molz, D. Hawley, R.C. Seshadri, Thoriumfree versus thoriated plasma gun electrodes: statistical evaluation of coating properties, J. Therm. Spray Technol. 25 (2016) 622-630.

[81] P. Fauchais, Understanding plasma spraying, J. Phys. D Appl. Phys. 37 (2004) R86-R108

[82] R. Hui, Z. Wang, O. Kesler, L. Rose, J. Jankovic, S. Yick, R. Maric, D. Gosh, Thermal plasma spraying for SOFCs: Applications, potential advantages, and challenges, J. Power Sources 170 (2007) 308-323.

[83] E. Pfender, Fundamental studies associated with the plasma spray process, Surf. Coat. Technol. 34 (1988) 1-14.

[84] M.I. Boulos, Thermal plasma processing, IEEE Trans. Plasma Sci. 19 (1991) 1078-1089.

[85] División de alimentadores de polvo para proyección por plasma de la empresa Oerlikon Metco: https://www.oerlikon.com/metco/en/products- 
services/coating-equipment/thermal-spray/feeders/feeders-plasma/ (Última consulta en Junio de 2019).

[86] División de alimentadores de polvo para proyección por plasma de la empresa Flame Spray Technologies: https://www.fst.nl/systems/auxiliary-equipment/powder-feeders-forthermal-spray-applications/ (Última consulta en Junio de 2019).

[87] División de alimentadores de polvo para proyección por plasma de la empresa Medicoat: http://www.medicoat.com/thermal-spraysystems/powder-feeder/ (Última consulta en Junio de 2019).

[88] División de alimentadores de polvo para proyección por plasma de la empresa GTV: https://www.gtv-mbh.com/_old/gtv-mbhenglisch/www.gtv-mbh.de/cms/front_content2242.html?idcat=60 (Última consulta en Junio de 2019).

[89] División de alimentadores de polvo para proyección por plasma de la empresa Thermal Spray Depot: http://www.thermalspraydepot.com/2010/04/20/thermal-spraypowder-feeders/ (Última consulta en Junio de 2019).

[90] V. Pershin, M. Lufitha, S. Chandra, J. Mostaghimi, Effect of substrate temperature on adhesion strength of plasma-sprayed nickel coatings, J. Therm. Spray Technol. 12 (2003) 370-376.

[91] A. Vaidya, T. Streibl, L. Li, S. Sampath, O. Kovarik, R. Greenlaw, An integrated study of thermal spray process-structure-property correlations: A case study for plasma sprayed molybdenum coatings, Mater. Sci. Eng. A 403 (2005) 191-204.

[92] H. Li, S. Costil, H.L. Liao, C.J. Li, M. Planche, C. Coddet, Effects of surface conditions on the flattening behavior of plasma sprayed $\mathrm{Cu}$ splats, Surf. Coat. Technol. 200 (2006) 5435-5446.

[93] Z. Zeng, S. Kuroda, H. Era, Comparison of oxidation behavior of $\mathrm{Ni}-$ $20 \mathrm{Cr}$ alloy and $\mathrm{Ni}-$ base self-fluxing alloy during air plasma spraying, Surf. Coat. Technol. 204 (2009) 69-77.

[94] F. Otsubo, H. Era, K. Kishitake, Structure and phases in nickel-base self-fluxing alloy coating containing high chromium and boron, J. Therm. Spray Technol. 9 (2000) 107-113.

[95] G. Bolelli, V. Cannillo, L. Lusvarghi, T. Manfredini, Wear behaviour of thermally sprayed ceramic oxide coatings, Wear 261 (2006) 1298-1315.

[96] A. Kulkarni, Z. Wang, T. Nakamura, S. Sampath, A. Goland, H. Herman, J. Allen, J. Ilavsky, G. Long, J. Frahm, R.W. Steinbrech, Comprehensive microstructural characterization and predictive property modeling of plasma-sprayed zirconia coatings, Acta Mater. 51 (2003) 2457-2475. 
[97] R. Vassen, G. Kerkhoff, D. Stöver, Development of a micromechanical life prediction model for plasma sprayed thermal barrier coatings, 303 (2001) 100-109.

[98] X. Zheng, M. Huang, C. Ding, Bond strength of plasma-sprayed hydroxyapatite/Ti composite coatings, Biomater. 21 (2000) 841-849.

[99] J. Yang, Y. Zhang, Z. Zhao, Y. An, H. Zhou, J. Chen, G. Hou, Tribological behaviors of plasma sprayed $\mathrm{CuAl} / \mathrm{Ni}$-graphite composite coating, Tribol. Int. 90 (2015) 96-103.

[100] J. Mateos, J.M. Cuetos, E. Fernández, R. Vijande, Tribological behaviour of plasma-sprayed WC coatings with and without laser remelting, Wear 239 (2000) 274-281.

[101] M. Tului, B. Giambi, S. Lionetti, G. Pulci, F. Sarasini, T. Valente, Silicon carbide based plasma sprayed coatings, Surf. Coat. Technol. 207 (2012) 182-189.

[102] Y. Zhang, J. Li, J. Huang, C. Ding, Mechanical and tribological properties of plasma-sprayed $\mathrm{Cr} 3 \mathrm{C} 2-\mathrm{NiCr}$, WC-Co, and $\mathrm{Cr} 2 \mathrm{O} 3$ coatings, J. Therm. Spray Technol. 7 (1998) 242-246.

[103] C. Bartuli, R.W. Smith, E. Shtessel, SHS powders for thermal spray applications, Ceram. Inter. 23 (1997) 61-68.

[104] X.Q. Cao, R. Vassen, S. Schwartz, W. Jungen, F. Tietz, D. Stöever, Spray-drying of ceramics for plasma-spray coating, J. Eur. Ceram. Soc. 20 (2000) 2433-2439.

[105] M. Vardelle, A. Vardelle, P. Fauchais, K.I. Li, B. Dussoubs, N.J. Themelis, Controlling particle injection in plasma spraying, J. Therm. Spray Technol. 10 (2001) 267-284.

[106] A. Vardelle, P. Fauchais, B. Dussoubs, N.J. Themelis, Heat generation and particle injection in a thermal plasma torch, Plasm. Chem. Plasm. Process.18 (1998) 551-574.

[107] M. Vardelle, A. Vardelle, P. Fauchais, Spray parameters and particle behavior relationships during plasma spraying, J. Therm. Spray. Technol, 2 (1993) 79-91.

[108] H.B. Xiong, L.L. Zheng, S. Sampath, R.L. Williamson, J.R. Fincke, Three-dimensional simulation of plasma spray: effects of carrier gas flow and particle injection on plasma jet and entrained particle behaviour, Inter. J. Heat Mass Transf. 47 (2004) 5189-5200.

[109] Y.P. Wang, V. Prasad, G.X. Wang, S. Sampath, J.R. Fincke, Model and powder particle heating, melting, resolidification, and evaporation in plasma spraying processes, J. Heat Transf. 121(1999) 691-699. 
[110] A. Kucuk, R.S. Lima, C.C. Berndt, Influence of plasma spray parameters on in-flight characteristics of $\mathrm{ZrO} 2-8 \mathrm{wt} \%$ Y2O3 ceramic particles, J. Am. Ceram. Soc. 84 (2001) 685-692.

[111] A. Kucuk, R.S. Lima, C.C. Berndt, Influence of plasma spray parameters on formation and morphology of $\mathrm{ZrO} 2-8 \mathrm{wt} \%$ Y2O3 deposits, J. Am. Ceram. Soc. 84 (2001) 693-700.

[112] T. Zhang, D.T. Gawne, B. Liu, Computer modelling of the influence of process parameters on the heating and acceleration of particles during plasma spraying, Surf. Coat. Technol. 132 (2000) 233-243.

[113] L. Zhao, K. Bobzin, F. Ernst, J. Zwick, E. Lugscheider, Study on the influence of plasma spray processes and spray parameters on the structure and crystallinity of hydroxylapatite coatings, Mater. Sci. Eng. Technol. 37 (2006) 516-520.

[114] C.H. Quek, K.A. Khor, P. Cheang, Influence of processing parameters in the plasma spraying of hydroxyapatite/Ti-6Al-4V composite coatings, J. Mater. Process. Technol. 89-90 (1999) 550-555.

[115] D.R. Mash, N.E. Weare, D.L. Walker, Process variables in plasma-jet spraying, 13 (1961) 473-478.

[116] M. Friis, C. Persson, J. Wigren, Influence of particle in-flight characteristics on the microstructure of atmospheric plasma sprayed yttria stabilized ZrO2, Surf. Coat. Technol. 141 (2001) 115-127.

[117] J.L. Sui, M.S. Li, Y.P. Lu, Y.Q. Bai, The effect of plasma spraying power on the structure and mechanical properties of hydroxyapatite deposited onto carbon/carbon composites, Surf. Coat. Technol. 190 (2005) 287292.

[118] D. Apelian, M. Paliwal, R.W. Smith, W.F. Schilling, Melting and solidification in plasma spray deposition-phenomenological review, J. Inter. Metal. Rev. 28 (1983) 271-294.

[119] V. Rat, J.F. Coudert, A simplified analytical model for dc plasma spray torch: influence of gas properties and experimental conditions, J. Phys. D Appl. Phys. 39 (2006) 4799-4807.

[120] C.Y. Yang, B.C. Wang, E. Chang, J.D. Wu, The influences of plasma spraying parameters on the characteristics of hydroxyapatite coatings: a quantitative study, J. Mater. Sci. Mater. Med. 6 (1995) 249-257.

[121] M. Mellali, P. Fauchais, A. Grimaud, Influence of substrate roughness and temperature on the adhesion/cohesion of alumina coatings, Surf. Coat. Technol. 81 (1996) 275-286.

[122] M.F. Morks, Y. Tsunekawa, M. Okumiva, M.A. Shoeib, Splat morphology and microstructure of plasma sprayed cast iron with different preheat substrate temperatures, J. Therm. Spray Technol. 11 (2002) 226-232. 
[123] L. Bianchi, A. Grimaud, F. Blein, P. Lucchèse, P. Fauchais, Comparison of plasma-sprayed alumina coatings by RF and DC plasma spraying, J. Therm. Spray Technol. 4 (1995) 59-66.

[124] L. Bianchi, A.C. Leger, M. Vardelle, A. Vardelle, P. Fauchais, Splat formation and cooling of plasma-sprayed zirconia, Thin Solid Films 305 (1997) 35-47.

[125] C. Pierlot, L. Pawlowski, M. Bigan, P. Chagnon, Design of experiments in thermal spraying: a review, Surf. Coat. Technol. 202 (2008) 44834490.

[126] S. Dyshlovenko, L. Pawlowski, P.Roussel, D. Murano, A. Le Maguer, Relationship between plasma spray operational parameters and microstructure of hydroxyapatite coatings and powder particles sprayed into water, Surf. Coat. Technol. 200 (2006) 3845-3855.

[127] J.F. Li, H.L. Liao, C.X. Ding, C. Coddet, Optimizing the plasma spray process parameters of yttria stabilized zirconia coatings using a uniform design of experiments, J. Mater. Process. Technol. 160 (2005) 34-42.

[128] F. Azarmi, T.W. Coyle,J. Mostaghimi, Optimization of atmospheric plasma spray process parameters using a design of experiment for alloy 625 coatings, J. Therm. Spray. Technol. 17 (2008) 144-155.

[129] J.F. Li, H. Liao, B. Normand, C.Cordier, G. Maurin, J. Foct, C. Coddet, Uniform design method for optimization of process parameters of plasma sprayed TiN coatings, Surf. Coat. Technol. 176 (2003) 1-13.

[130] S. Dyshlovenko, C. Pierlot, L. Pawlowski, R. Tomaszek, P. Chagnon, Experimental design of plasma spraying and laser treatment of hydroxyapatite coatings, Surf. Coat. Technol. 201 (2006) 2054-2060.

[131] J. Vattulainen, E. Hämäläinen, R. Hernberg, P. Vuoristo, T. Mäntylä, Novel method for in-flight particle temperature and velocity measurements in plasma spraying using a single CCD camera, J. Therm. Spray Technol. 10 (2001) 94-104.

[132] J. Cizek, K.A. Khor, Z. Prochazka, Influence of spraying conditions on thermal and velocity properties of plasma sprayed hydroxyapatite, Mater. Sci. Eng. C 27 (2007) 340-344.

[133] A. Killinger, R. Gadow, G. Mauer, A. Guignard, R. Vassen, D. Stöver, Review of new developments in suspension and solution precursor thermal spray processes, J. Therm. Spray. Technol. 20 (2011) 677-695.

[134] L. Pawlowski, Finely grained nanometric and submicrometric coatings by thermal spraying: a review, Surf. Coat. Technol. 202 (2008) 43184328. 
[135] R. Moreno, E. Bannier, Feedstocks suspensions and solutions, in: N. Espallargas (Ed.), Future development of thermal spray coatings, Elsevier, Great Britain, 2015, pp. 51-80.

[136] J. Fazilleau, C. Delbos, V. Rat, J.F. Coudert, P. Fauchais, B. Pateyron, Phenomena involved in suspension plasma spraying part 1: suspension injection and behaviour, Plasma Chem. Plasma Process. 26 (2006) 371-391.

[137] C. Monterrubio-Badillo, H. Ageorges, T. Chartier, J.F. Coudert, P. Fauchais, Preparation of $\mathrm{LaMnO} 3$ perovskite thin films by suspension plasma spraying for SOFC cathodes, Surf. Coat. Technol. 200 (2006) 3743-3756.

[138] G. Bolelli, J. Rauch, V. Cannillo, A. Killinger, L. Lusvarghi, R. Gadow, Investigation of high-velocity suspension flame sprayed (HVSFS) glass coatings, Mater. Lett. 62 (2008) 2772-2775.

[139] M.N. Rahaman, Ceramic processing and sintering, second ed., Marcel Dekker Inc., The USA, 1995.

[140] L. Pawlowski, Suspension and solution thermal spray coatings, Surf. Coat. Technol. 203 (2009) 2807-2829.

[141] R. Moreno, Reología de suspensiones cerámicas (Ceramic suspensions rheology), first ed., Consejo Superior de Investigaciones Cerámicas (CSIC), Spain, 2005.

[142] A. Barba, V. Beltrán, C. Feliu, J. García, F. Ginés, E. Sánchez, V. Sanz, Materias primas para la fabricación de soportes de baldosas cerámicas (Raw materials for the manufacture of ceramic tiles), second ed., Instituto de Tecnología Cerámica (ITC), Spain, 2002.

[143] División de reómetros y viscosímetros de la empresa ThermoFisher Scientific:

https://www.thermofisher.com/search/browse/category/es/es/602505/M anufacturing+\%26+Processing+Instruments+\%26+Equipment\%2FRhe ometers+\%26+Viscometers (Última consulta en Junio de 2019).

[144] T. Molina, M. Vicent, E. Sánchez, R. Moreno, Dispersion and reaction sintering of alumina-titania mixtures, Mater. Res. Bull. 47 (2012) 24692474.

[145] R.J. Farris, Prediction of the viscosity of multimodal suspensions from unimodal viscosity data, Trans. Soc. Rheol. 12 (1968) 281-301.

[146] W. Fan, Y. Bay, Review of suspension and solution precursor plasma sprayed thermal barrier coatings, Ceram. Inter. 42 (2016) 14299-14312.

[147] P. Fauchais, R. Etchart-Salas, V. Rat, J.F. Coudert, N. Caron, K. Wittman-Ténèze, Parameters controlling liquid plasma spraying: 
solutions, sols or suspensions, J. Therm. Spray. Technol. 17 (2008) 3159.

[148] P. Fauchais, V. Rat, J.F. Coudert, R. Etchart-Salas, G. Montavon, Operating parameters for suspension and solution plasma-spray coatings, Surf. Coat. Technol. 202 (2008) 4309-4317.

[149] L. Latka, S.B. Goryachev, S. Kozerski, L. Pawlowski, Sintering of fine particles in suspension plasma sprayed coatings, Mater. 3 (2010) 38453866.

[150] K. VanEvery, M.J.M. Krane, R.W. Trice, H. Wang, W. Porter, M. Besser, D. Sordelet, J. llavsky, J. Almer, Column formation in suspension plasma-sprayed coatings and resultant thermal properties, J. Therm. Spray Technol. 20 (2011) 817-828.

[151] P. Fauchais, A. Joulia, S. Goutier, C. Chazelas, M. Vardelle, A. Vardelle, S. Rossignol, Suspension and solution plasma spraying, J. Phys. D Appl. Phys. 46 (2013) 224015.

[152] T. Bathia, A. Ozturk, L. Xie, E.H. Jordan, B.M. Cetegen, M. Gell, X. Ma, N.P. Padture, Mechanisms of ceramic coating deposition in solutionprecursor plasma spray, J. Mater. Res. 17 (2002) 2363-2372.

[153] E.H. Jordan, L. Xie, M. Gell, N.P. Padture, B. Cetegen, A. Ozturk, J. Roth, T.D. Xiao, P.E.C. Bryant, Superior thermal barrier coatings using solution precursor plasma spray, J. Therm. Spray Technol. 13 (2004) 57-65.

[154] M. Gell, E.H. Jordan, M. Teicholz, B.M. Cetegen, N.P. Padture, L. Xie, D. Chen, X. Ma, J. Roth, Thermal barrier coatings made by the solution precursor plasma spray process, J. Therm. Spray. Technol. 17 (2007) 124-135.

[155] L. Xie, X. Ma, E.H. Jordan, N.P. Padture, D.T. Xiao, M. Gell, Identification of coating deposition mechanisms in the solutionprecursor plasma-spray process using model spray experiments, Mater. Sci. Eng. A 362 (2003) 204-212.

[156] P. Sokolowski, S. Kozerski, L. Pawlowski, A. Ambroziak, The key process parameters influencing formation of columnar microstructure in suspension plasma sprayed zirconia coatings, Surf. Coat. Technol. 260 (2014) 97-106.

[157] B. Pateyron, N. Calve, L. Pawlowski, Influence of water and ethanol on transport properties of the jets used in suspension plasma spraying, Surf. Coat. Technol. 220 (2013) 257-260.

[158] R.T. Candidato, B. Pateyron, A. Denoirjean, L. Pawlowski, Modification of thermal transport properties of $\mathrm{Ar}-\mathrm{H}_{2}$ working gases by calcium- 
phosphate precursors used for solution plasma spraying of HA coatings, Presentend at ITSC 2016, Shanghai, P.R. China, May 10 - 12, 2016.

[159] E.P. Bertin, Introduction to X-ray Spectrometric Analysis, first ed., Springer Science and Business Media, The USA, 1978.

[160] D.J. Stokes, Principles and Practice of Variable Pressure/Environmental Scanning Electron Microscopy (VP-ESEM), first ed., John Wiley and Sons, United Kingdom, 2008.

[161] R. Jenkins, R.L. Snyder, Introduction to X-Ray Powder Diffractometry, first ed., John Wiley and Sons, The USA, 1996.

[162] B.D. Cullity, S.R. Stock, Elements of X-ray diffraction, third ed., Prentice Hall, The USA, 2001.

[163] M. Vicent, E. Bannier, R. Benavente, M.D. Salvador, T. Molina, R. Moreno, E. Sánchez, Influence of the feedstock characteristics on the microstructure and properties of $\mathrm{Al}_{2} \mathrm{O}_{3}-\mathrm{TiO}_{2}$ plasma-sprayed coatings, Surf. Coat. Technol. 220 (2013) 74-79.

[164] J.L. Amorós, A. Blasco, J.E. Enrique, F. Negre, Características de polvos cerámicos para prensado, Bol. Soc. Esp. Ceram. Vidr. 26 (1987) 31-37.

[165] D. Geldart, E.C. Abdullah, A. Hassanpour, L.C. Nwoke, I. Wouters, Characterization of powder flowability using measurement of angle of repose, China Part. 4 (2006) 104-107.

[166] A.C. Popa, V.M.F. Marques, G.E. Stan, M.A. Husanu, A.C. Galca, C. Ghica, D.U. Tulyaganov, A.F. Lemos, J.M.F. Ferreira, Nanomechanical characterization of bioglass films synthesized by magnetron sputtering, Thin Solid Films 553 (2014) 166-172.

[167] M.E. Brown, Handbook of Thermal Analysis and Calorimetry, first ed., Elsevier, The Netherlands, 1998.

[168] S. Mestre, E. Bou, P. Quereda, A. Barba, Using the hot stage microscope for estimating frit sealing temperature, Ceram. Forum Int. 78 (2001) 36-39.

[169] S.J. Gregg, K.S.W. Sing, Adsorption, surface area and porosity, second ed., Academic Press, London, 1982.

[170] A.L.B. Maçon, T.B. Kim, E.M. Valliant, K. Goetschius, R.K. Brow, D.E. Day, A. Hoppe, A.R. Boccaccini, I.Y. Kim, C. Ohtsuki, T. Kokubo, A. Osaka, M. Vallet-Regí, D. Arcos, L. Fraile, A.J. Salinas, A.V. Teixeira, Y. Vueva, R.M. Almeida, M. Miola, C. Vitale-Brovarone, E. Verné, W. Höland, J.R. Jones, A unified in vitro evaluation for apatite-forming ability of bioactive glasses and their variants, J. Mater. Sci. Mater. Med. 26 (2015) 115-124. 
[171] T. Kokubo, H. Takadama, How useful is SBF in predicting in vivo bone bioactivity?, Biomater. 27 (2006) 2907-2915.

[172] S.K. Sharma, D.S. Verma, L.U. Khan, S. Kumar, S.B. Khan, Handbook of Materials Characterization, first ed., Springer International Publishing, Switzerland, 2018.

[173] S. Romeis, A. Hoppe, R. Detsch, A.R. Boccaccini, J. Schmidt, W. Peukert, Top-down processing of submicron 45S5 Bioglass ${ }^{\circledR}$ for enhanced in vitro bioactivity and biocompatibility, Proced. Eng. 102 (2015) 534-541.

[174] R. Moreno, The role of slip additives in tape-casting technology. I: solvents and dispersants, Am. Ceram. Soc. Bull. 71 (1992) 1521-1531.

[175] H.G. Merkus, Particle Size Measurements: Fundamentals, Practice and Quality, first ed., Springer Science and Business, Switzerland, 2009.

[176] O. Mengual, G. Meunier, I. Cayré, K. Puech, P. Snabre, Turbiscan MA 2000: multiple light scattering measurement for concentrated emulsion and suspension instability analysis, Talanta 50 (1999) 445-456.

[177] Jet\&Poudres, http://iets.poudres.free.fr.

[178] B. Pateyron, T\&TWinner, http://ttwinner.free.fr.

[179] Q.Z. Chen, Y. Li, L.Y. Jin, J.M.W. Quinn, P.A. Komesaroff, A new solgel process for producing Na2O-containing bioactive glass ceramics, Acta Biomater. 6 (2010) 4143-4153.

[180] J. Faure, R. Drevet, A. Lamelle, N.B. Jaber, A. Tara, H. El Btaouri, H. Benhayoune, A new sol-gel synthesis of $45 \mathrm{~S} 5$ bioactive glass using an organic acid as catalyst, Mater. Sci. Eng. C 47 (2015) 407-412.

[181] H. Pirayesh, J.A. Nychka, Sol-gel synthesis of bioactive glass-ceramic $45 \mathrm{~S} 5$ and its in vitro dissolution and mineralization behavior, J. Am. Ceram. Soc. 96 (2013) 1643-1650.

[182] R. Jaworski, L. Pawlowski, F. Roudet, S. Kozerski, F. Petit, Characterization of mechanical properties of suspension plasma sprayed TiO2 coatings using scratch test, Surf. Coat. Technol. 202 (2008) 2644-2653.

[183] J.J. Blaker, J.E. Gough, V. Maquet, I. Notingher, A.R. Boccaccini, In vitro evaluation of novel bioactive composited based on bioglass $®$-filled polylactide foams for bone tissue engineering scaffolds, J. Biomed. Mater. Res. 67 (2003) 1401-1411.

[184] C. Vitale-Brobarone, E. Verné, L. Robiglio, P. Appendino, F. Bassi, G. Martinasso, G. Muzio, R. Canuto, Development of glass-ceramic scaffolds for bone tissue engineering: characterisation, proliferation of 
human osteoblasts and nodule formation, Acta Biomater. 3 (2007) 199208 